sebl-

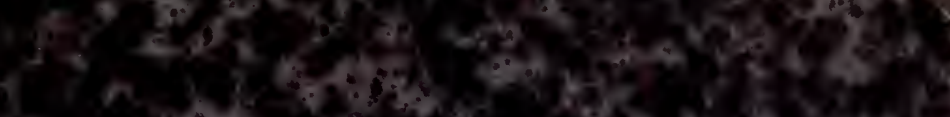

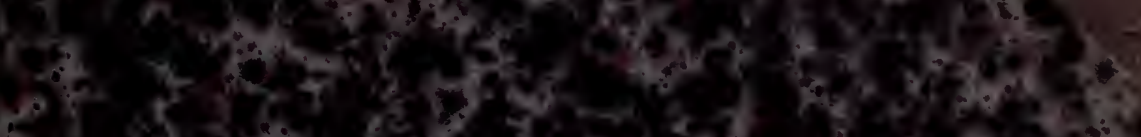

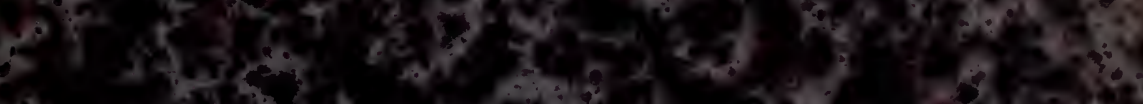
trets

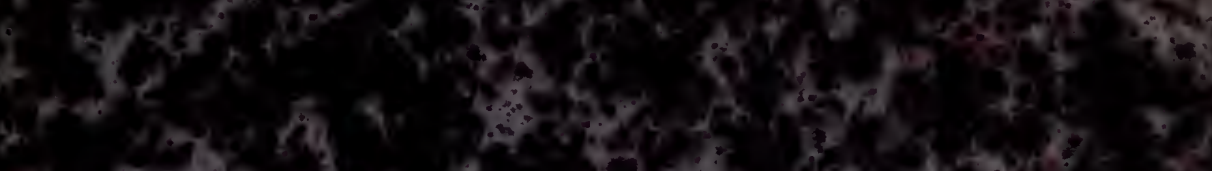
Sit

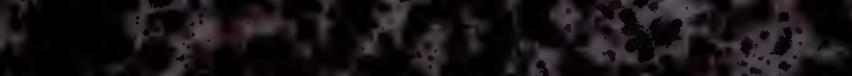

$5 x^{2} x^{2}+y^{3}, 3 x$

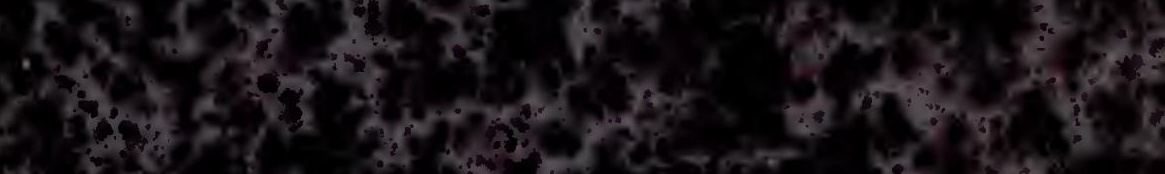

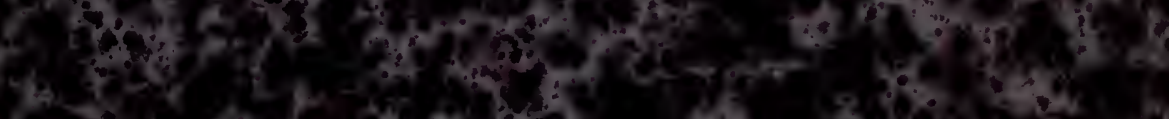

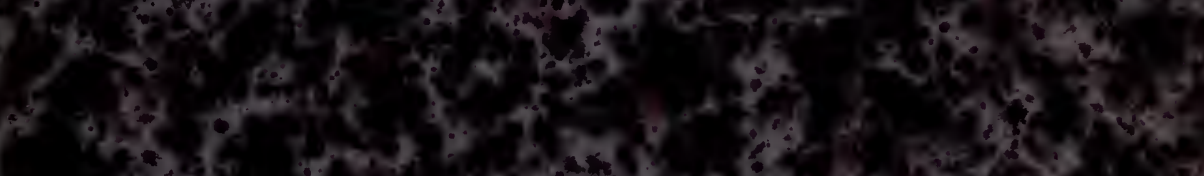
(1)

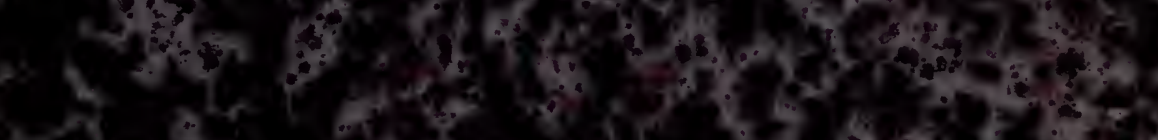

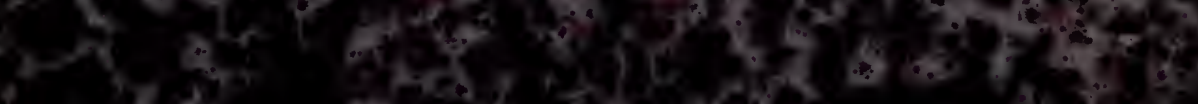

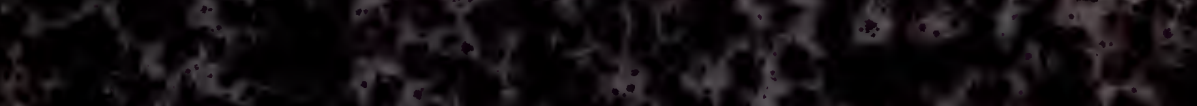

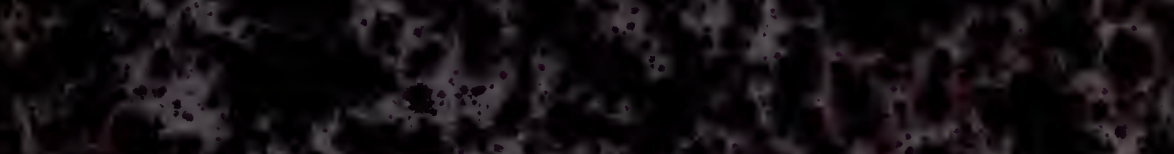

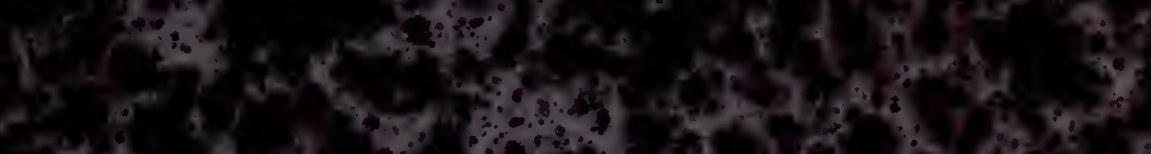

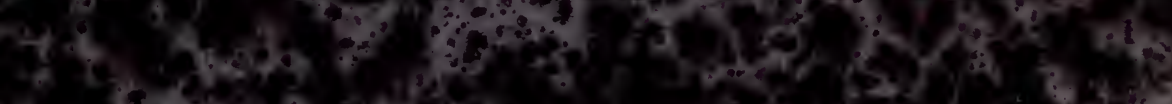

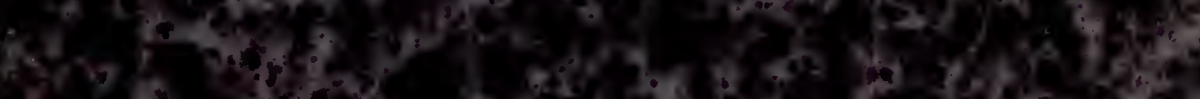

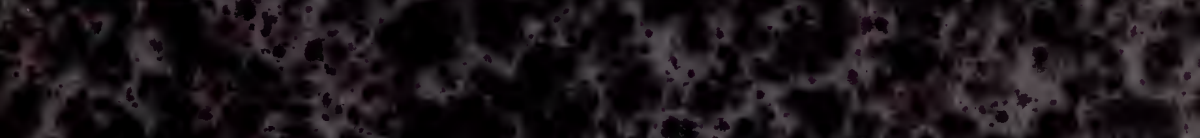

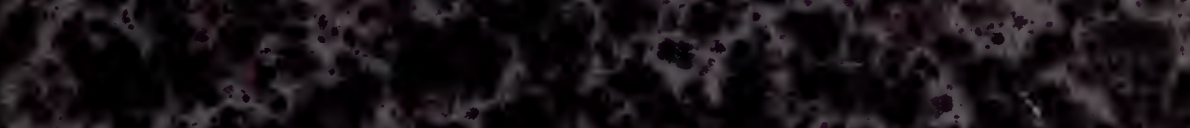

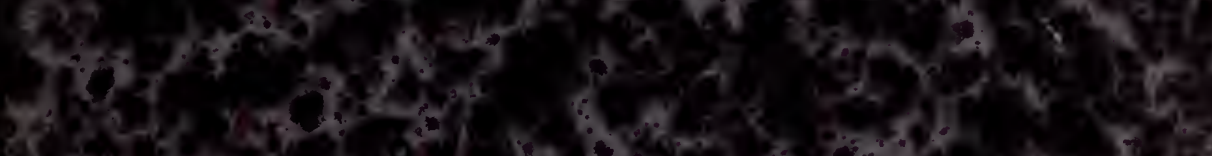

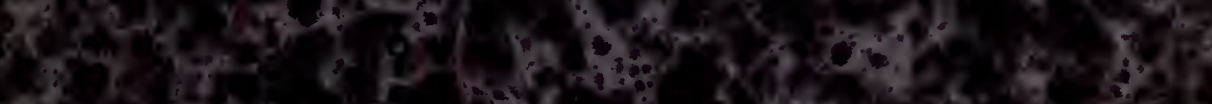

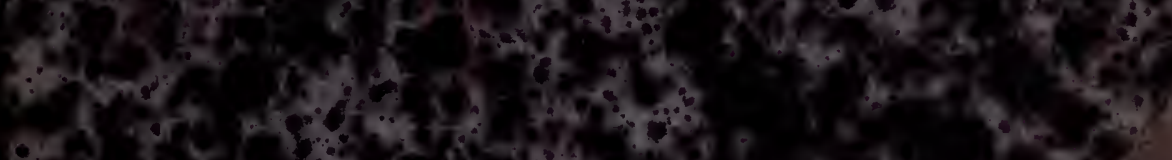

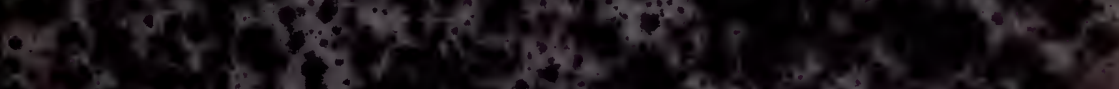
3.t.1. 20.2.

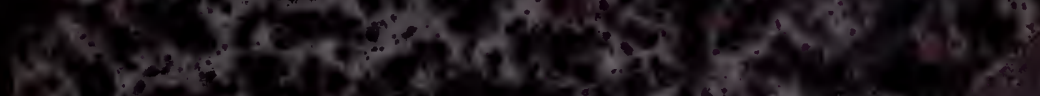





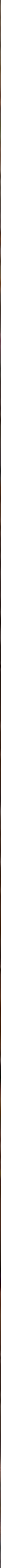





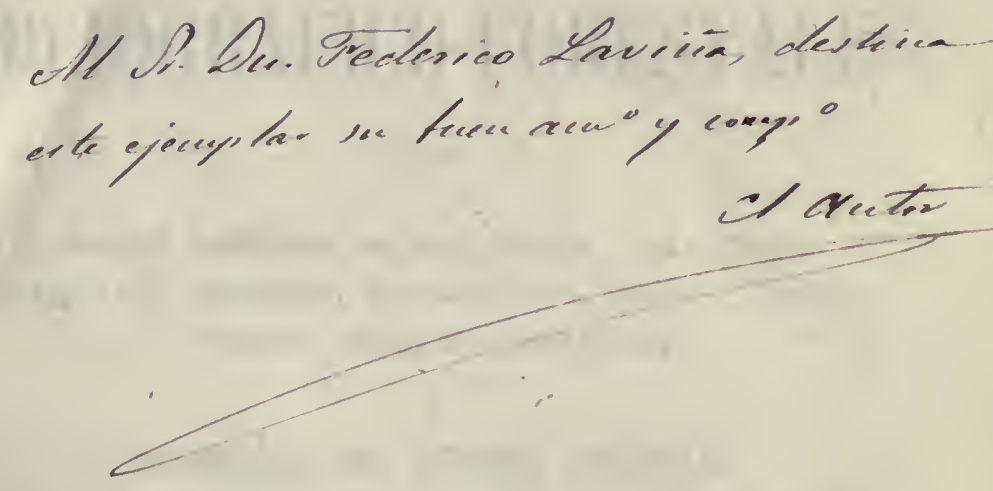
APUNTES BIBLIOGRÁFICO-FORESTALES. 



\section{APUNTES}

\section{BIBLIOGRAFICO-FORESTALES,}

6 SBA

BRETE RESÚMEN DE LOS LIBROS, FOLLETOS, Ártículos, MPRESOS, MANUsGritos, MAPAS, PlaNos, Y DEMÁS TRABAJOS ORIGINALES,

$\dot{0}$

TRADUCIDOS POR AUTORES ESPAÑOLES,

relativos á la CRIA, cultivo,

APROVECHANHFTo; ADNINISTRACION, LEgISLACION Y ECONOMiA DE LOS MONTES, arbolados, playtios, prádos, caza y pesca,

POR

\section{DON JOSÉ JORDANA Y MORERA,}

\section{INGENIERO DE MONTES.}

(No se ha puesto á la venta ningun ejemplar de esta obra.)

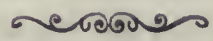

MADRID:

ESTABLECIMIENTOS TIPOGRAFICOS LE M. MIYUESA, Jualelo, 19 , y houda de Embajadores . 


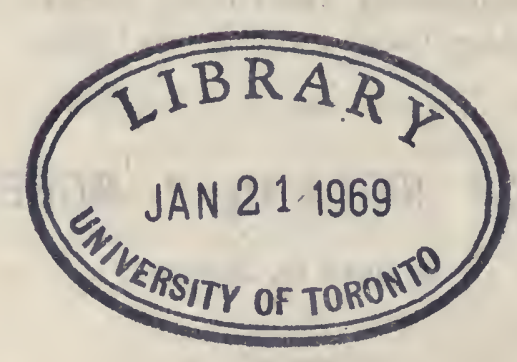

$$
\begin{aligned}
& z \\
& 5991 \\
& 374
\end{aligned}
$$


EXCMO. É ILMO. SR. D. BERNARDO DE LA TORRE ROJAS.

Mi querido y antiguo Director: Una pobre obrilla, que tal vez ni aun merezca este nombre, y que tan solo refleja sobre su oscuro autor el escaso mérito de las asíduas tareas á su preparacion dedicadas, es el trabajo que hoy tengo el honor de ofrecer á V., rogándole que lo acoja con su natural bondad.

Si los merecimientos hubiesen de tener siempre su justa recompensa, no sé en verdad como satisfaria el país la deuda con V. contraida al instituir en 1847 , con un desinterés, un celo y una fé de que apenas hay ejemplo, la primera y de cada dia mas floreciente Escuela forestal, que nació en Villaviciosa de Odon y revive hoy en San Lorenzo del Escorial, en donde su enérgica y patriótica voluntad creó el plantel vigoroso de los jóvenes Ingenieros que, mas tarde, haciéndose eco de sus doctrinas, difundieron por toda España la luz dasonómica, emulando dignamente á sus maestros de Tharand.

$Y$ si la nacion debe á $\mathrm{V}$. el homenaje de su admiracion y de su agradecimiento por haber fundado la Escuela de Ingenieros de montes, iqué no le deberán los escogidos para recibir la sávia de la nueva vida científica, encargados luego de propagarla cọn el doble carácter de facultativos y servidores del Estado?

Cúpome la suerte á mi, el mas oscuro de todos, de formar parte de esta falange, y, como á mis compañeros, la de inspirarme siempre en las doctas lecciones y severas máximas de moral con que alimentó $\mathrm{V}$. nuestros jóvenes corazones, calentados por el entusiasmo y por el paternal cariño que siempre nos ha dispensado.

Notorio es que los alumnos de Villaviciosa de Odon ayer, 
hoy los Ingenieros de montes españoles, buscando la expresion del profundo respeto $\mathrm{y}$ afecto que les inspira el nombre de $\mathrm{V}$. lo han trocado por el de padre, cuya sentida significacion solo V. es capaz de apreciar.

Hicieran y ofreciéranle grandes obras, y todo fuera poco en justa correspondencia de tantas mercedes.

Por esta causa, al poner en este momento en sus manos cl presente libro, lo hago como testimonio de mi eterno reconocimiento, significándolo mas, por ser el primero que traza mi inexperta pluma, y como tal fruto de los conocimientos científicos adquiridos bajo su direccion. Nobleza obliga.

No solo este, que como de primogenitura le correspondia, sino cuantos trabajos pueda moldear mi pobre entendimiento, son de $\mathrm{V}$. á quien, con el mayor respeto y veneracion

B. L. M .

\section{José Jordara y Alorera.}

Madrid 30 de Abril de 1873. 


\section{ADVERTENGIA PRELIMINAR.}

La importancia de la dasonomia y el interés que tiene el estudio de todas las cuestiones que con los montes se relacionan, es motivo bastante para justificar la necesidad que hay ya de una $B i$ bliografia forestal, en donde se encuentren reunidos todos los antecedentes que á este ramo del saber humano se contraen. Ni es menos interesante tambien esta recopilacion para seguir paso á paso el desarrollo de la ciencia y poder escribir oportunamente la historia de sus progresos y perfeccionamientos.

Mientras los montes no fueron considerados en sus relacinnes intrínsecas ni en sus elementos dasogénicos, y sí mas bien como un conjunto inconexo de indiriduos regetales aislados, no habia en verdad, fundamento racional para formar de su estudio un ramo independiente, ni cabia mas que adicionar esta materia á la agronomía, constituyendo una humilde seccion de arboricultura.

Mas tarde, cuando el espíritu sintético se apoderó de ellos y se estudiaron las leyes de su crecimiento, desarrollo y produccion, fundáronse las bases de la nueva ciencia, y hubo necesidad de segregarlos de aquel linaje de estudios entregándolos de lleno al dominio de la especulacion que determinú con reglas fijas, invariables y claras, la verdadera diferencia que existe entre el cultivo agrario y la produccion forestal.

A partir de estos tiempos, la literatura dasonómica, viviendo de su propio tecnicismo y girando en una esfera independiente, ha adquirido un vasto desarrollo multiplicando los libros y obras que de la dasonomía se ocupan, por mas que en España, nacida apenas á la vida forestal moderna, no haya llegado todavía á aquella admirable fecundidad de que tan justamente se envanecen los maestros de la docta Alemania.

El movimiento literario forestal sin embargo vá pronunciándose mas de cada dia en nuestra patria, pero, como sucede siempre 
que se trasplanta una ciencia, los primeros trabajos han sido lijeros, tímidos y de corta extension, sirviendo tan solo para preparar el camino á las obras maestras 'que mas adelante constituirán sin duda el verdadero tesoro dasonómico nacional.

Así y todo, los materiales no son escasos, y puesto que hasta el presente no parece que se haya escrito cosa alguna con carácter bibliográfico, bien pueden mis humildes Apuntes abrir la marcha, como remotos precursores de una Bibliogr a fia completa y acabada, cuyo trabajo está brindando sobre todo á nuestros sábios dasónomos, que tambien los tiene España en la ciencia de Cotta y Hundeshagen.

All'́, dados los adelantos que se han hecho en la materia, podrán encontrar los eruditos y estudiosos todos los datos que deben contener las obras de esta índole en donde el menos exigente tiene derecho á pedir que las noticias se presenten agrupadas por materias distinguidas por autores conocidos ó anónimos, separadas por publicaciones tipográticas $\delta$ manuscritas, reseñadas con designacion de ediciones, precios y bibliotecas donde se encuentren, adicionadas con notas biográficas de los escritores, expuestas con largos extractos de su contenido, y por último, completadas con juicios críticos, severos, imparciales y atinados.

Todo esto requiere un gran caudal de conocimientos, y no poco discernimiento y madurez. Falto de estas dotes, he preferido dejar el campo vírgen para mas entendidos exploradores, por cuyo motivo me he limitado tan solo á formar tres grupos de las noticias recogidas: el primero comprende las publicaciones de toda clase; el segundo las memorias y artículos contenidos en los periódicos y obras de materias diversas indicadas en el primero; y el tercero, los manuscritos y trabajos gráficos inéditos, sujetándolo todo al órden alfabético de títulos para ordenar de algun modo los escritos regis trados. El findice de autores que vá al final del trabajo facilita la investigacion. Esto es todo.

Me he visto precisado á dar cuenta de muchos tratados de agricultura, so pena de dejar incompleto el estudio, porque en la mayor parte de estas publicaciones hay una seccion dedicada al cultivo de los árboles silvestres ó de monte, que constituye mas ó menos imperfectamente una seccion especial de selvicultura, y este asunto. claro está, no podia pasarse por alto en. unos Apuntes forestales.

Motivos semejantes me han inducido á dar á conocer las publicaciones que tratan de prados naturales, caza, pesca, roturaciones, etc., en cuanto estos ramos se consideran como producto $\delta$ trabajo propio de los montes, y forman en todos los tratados dasonómicos una hijuela de mucho interés.

Jas inconexo parece á primera vista el admitir los trabajos refe- 
rentes á leyes agrarias y guardería rural, y sin embargo, no he creido oportuno desecharlos, porque sucede con estas publicaciones de carácter legislativo lo mismo que con algunas de carácter técnico, esto es, que, predominando en ellas á veces las consideraciones agronómicas, envuelven á la vez puntos de jurisdiccion forestal, constituyendo un todo difícil de separar. Todos saben que el escollo mas peligroso en bibliografía, es el de la determinacion de los límites de las ciencias ó materias.

Fn la breve indicacion del contenido de las publicaciones de que se dá cuenta, he procurado ceñirme á los puntos mas notables de cada trabajo con relacion al objeto y al mérito del mismo, valiéndome en muchos casos de algunas palabras ó frases del texto, con el fin de poner mas de relieve sus condiciones científicas y literarias.

No hay que decir que tratándose de publicaciones de índole forestal, la base de mis Apuntes debia buscarse forzosamente en el Diccionario de bibliografia agronómica del Ilmo. Sr. D. Braulio Anton Ramirez, de cuya obra queda hecho el mejor elogio con recordar que fué premiada por la Biblioteca nacional de Madrid. Reunidos en ella los estudios forestales de toda clase, era imposible dar un paso en mis Apuntes sin tropezar con las noticias del Diccionario, tan exactas y perfectas en la designacion de las obras, como cumplidas y extensas en la indicacion del contenido de las mismas. No me era dado, pues, hacer otra cosa que entresacar de allí los materiales de montes y constituir con ellos la base de mi trabajo. Así he procedido habiendo tenido repetidas ocasiones de comprobar la fidelidad con que se han consignado en la obra repetida, todas las indicaciones, extractos y referencias. Casi puede decirse que mis indicaciones se han circunscrito á las publicaciones posteriores á 1861 en cuyo año se terminó el Diccionario, sin que, á pesar de largos y repetidos rebuscos, haya podido encontrar mas que algunas obras escapadas á la diligencia del Sr. Anton Ramirez.

Tambien he utilizado los trabajos de D. Miguel Colmeiro contenidos en su apreciable monografía La Botánica y los Botánicos de la Peninsula hispano-lusitana, y los de los inteligentes ingenieros de minas D. Eugenio Maffei y D. Ramon Rua Figueroa, autores de la Bibliografia mineral hispano-americana que acaba de publicarse, cuya obra puede rivalizar indudablemente con las mejores de su clase.

Tocante á manuscritos y planos inéditos apenas si despues de los mencionados en el Diccionario, he citado alguno notable por su rareza ó curioso por alguna circunstancia especial, y confieso ingénuamente que en este género de tareas hubiera podido con facilidad 
apuntar muchos y apreciables trabajos, pues los hay abundantes en el ministerio de Fomento, en la Junta consultiva del Cuerpo de Ingenieros de montes y en la Escuela especial del ramo á donde no creo que me hubiera sido difícil penetrar. Al eludir esta tarea, me he dejado guiar tan solo" del respeto que merece todo trabajo oficial, que siguiendo el curso ordinario de los trámites administrativos, no lleva consigo su forzosa publicacion, pareciéndome que cuando de esto se trata, además de recabar la competente autorizacion superior, es menester tambien consultar la voluntad del que llevó á cabo el estudio.

Por lo demás, la ciencia ganaria mucho con que se diesen á luz los trabajos á que me refiero, y bien valdria la pena de someter esta tarea al exámen y clasificacion de personas doctas y peritas.

Volviendo á los Apuntes, debo hacer presente que no habiendo mas medio útil para dar á conocer el contenido de las obras periódicas, que el de reseñar separadamente los artículos ó puntos de que tratan, y siendo esto extensamente largo si se ha de hacer con todos los que contienen, he adoptado un temperamento medio por el cual dejo registrados aquellos trabajos que me parecen de mas importancia con relación á los diversos aspectos que presenta la materia forestal.

Una excepcion he hecho á favor de la Revista forestal, ECoNómica Y AGßícora, anotando casi todos los ąrtículos que contiene, excepcion que puede justificarse atendiendo á que este periódico es el primero y hasta huy único de su clase en tspana. Tambien he trasladado al lugar oportuno la mayor parte de los artículos de la Revista del Instituto agricola catalan de S'an Isidro, los del Botelin oficial del Ministerio de Fomento, y los de la Gaceta de Madrid, por el crédito que estas publicaciones disfrutan.

Aun cuando son muchas las bibliotecas, catálogos y bibliografías que he registrado, no pretendo seguramente haber llegado siquiera á coleccionar las publicaciones mas importantes, que en cuestiones bibliográficas, me lo ha enseñado la experiencia, es muy difícil poder decir la última palabra.

Trabajos de este género requieren mucha erudicion, largo espacio, constante diligencia, numerosas relaciones, tranquilidad de espíritu y tambien lıolgados recursos. Nada de esto me ha sobrado y por lo tanto nadie extrañe que, sin mas que mi buena voluntad, salgan estas páginas flojas y desaliñadas. Tan convencido estoy de lo mucho que les falta, que á encontrar otro nombre mas̀ humilde que el de Apuntes, con él las hubiera dado al público.

Debo una eficáz colaboracion á muchos de mis compañeros y a migos, que han contribuido con sus noticias á que este trabajo 
salga menos imperfecto. Don Pablo Gonzalez de la Peña me ha franqueado además su librería, rica y curiosa como pocas, en publicaciones forestales. Me complazco en consignar aquí el testimonio de mi gratitud por los buenos y desinteresados oficios con que han coadyurado todos á mis fines. Omito la designacion de nombres porque la lista sería muy larga, y si me permito citar el del joven, ilustrado y laborioso ingeniero de montes D. Eugenio Plá y Rave es porque su cooperacion ha sido de tal naturaleza que ha pasado con mucho exceso los límites de lo que la amistad y el amor á la ciencia podian exigir.

Concluyo recordando que el presente trabajo, y no me he de cansar de repetirlo, responde solo al deseo de abrir la primera senda para que otros la perfeccionen cumplidamente. Por mi parte he empleado ya en ello todas mis fuerzas. Quantum potui feci.

Madrid 30 de Abril de 1873. 

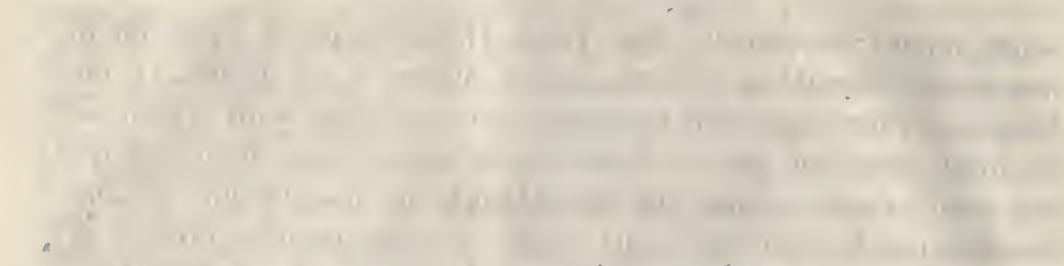

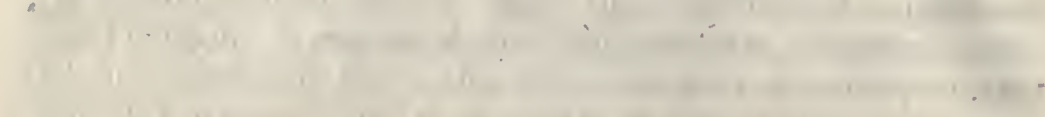

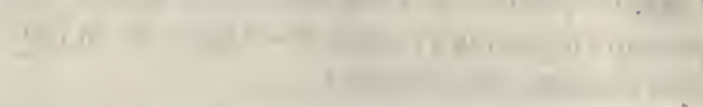

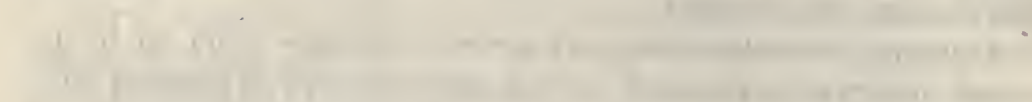

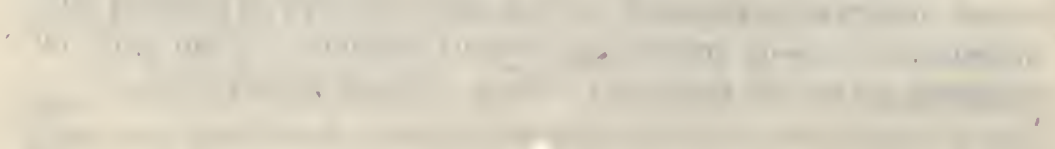

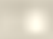

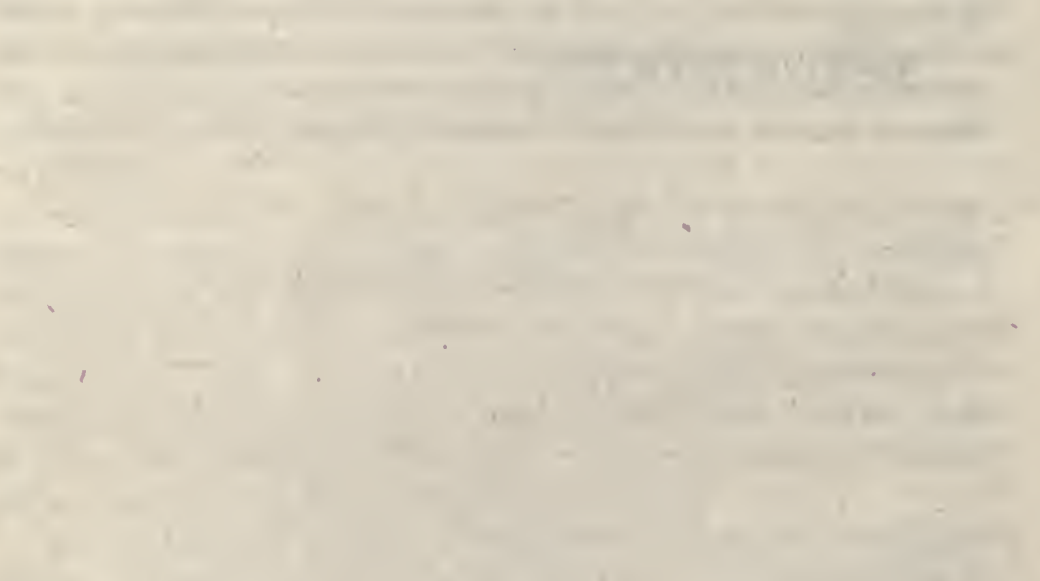

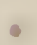




\section{PRIMER GRUPO.}

\section{PUBLICACIONES DE TODAS CLASES.}

\section{A (*).}

1. A las Cóntes.-Hoja de cuatro páginas: sin pié de imprenta.

La firman en Barcelona á 21 de Diciembre de 1872, los indivíduos de la Junta directiva de la Sociedad Fomento de la produccion nacional. Presidente D. P. Bosch y Labrús y secretarío D. Delmiro del Caral.

Es una exposicion en que, fundándose en la importancia económica y física de los montes, se suplica á las Córtes que no aprueben el proyecto de ley de montes presentado á las mismas por el señor ministro de Fomento con fecha 5 de Noviembre de 1872.

2. ABEJA (La). - Revista científica y literaria, principalmente extractada de los buenos escritores alemanes, por D. Antonio Bergnes de las Casas, catedrático de lengua griega en la facultad de Filosofía y Letras de la Universidad de Barcelona; D. Miguel Guitart y Buch, doctor en medicina; D. Antonio Sanchez Comendador, catedrático de Mineralogía y Zoología en la Facultad de Ciencias de dicha Universidad; D. Antonio Ráve, catedrático de Física en la facultad de Ciencias de idem, y D. Juan Font y Guitart.-Barcelona: 1858-1860, por J. Oliveres, seis cuadernos en fólio, á dos columnas, que forman en junto 250 páginas.

En la página 211, figura el artículo siguiente: $E l$ tronco de wn árbol es sw árbol genealógico; por E. Adolfo Roszmaeszler, traduccion de A. Bergnes de las Casas. Es un artículo de cortas dimensiones, en cuyo texto se intercala un grabado del tronco de un pino, que presenta las capas anuales. El autor flgura sostener una conversacion con diferentes árboles, y va explicando. por los anillos de los troncos, las edades, vicisitudes, y la buena o mala nutricion de cada uno.

(*) Imitando á los bibliófilos mas notables, el método seguido en estos A puntes para establecer el órden alfabélico de los títulos de las obras, consiste en considerar aisladamente las letras y las palabras, sin unirlas con las que les siguen. 
3. Acotamiento.-Por D. José María Royo y Murciano.-Madrid: 1862. Imprenta de la Revista de Legislacion á cargo de D. Julian Morales. $-4 .^{\circ}, 24$ páginas.

En este artículo, que se publicó bajo la forma de folleto, se analizan y discuten las condiciones en que la propiedad particular debe hallarse para que se pueda ejercitar el derecho consignado en lós decretos de las Córtes de 14 de Enero de 1812, 8 de Junio de 1813 y Real órden de 17 de Mayo de 1836, relativos á que todo el terreno de propiedad particular pueda ser acotado y cerrado aprovechando los dueños sus frutos como mejor les conviniese. Sienta por principio que las malas prácticas más $\delta$ ménos antiguns, á las que, contra lo establecido por las leyes, se les ha dado el nombre de uso 6 costumbre, no son titulos especiales de adquisicion respecto de los que el derecho tiene reconocidos, y por tanto, que en las tierras de su propiedad puede cada cual introducir en todos tiempos sus ganados ó los agenos, á prsar de cualquiera disposicion municipal que lo prohiba, excepto en el caso especial de los terrenos artigados, en los que los particulares que los cultivan solo tienen el derecho de aprovechamiento del suelo que se rompe y labra para sembrar, quemando el monte bajo, pero sin poder tocar los árboles ni hacer suya la propiedad, porque ellos, dice, son una detentacion precaria, que no impide al Estado ó al comun si fuera dueño de los baldíos, el derecho de disponer libremente de los mismos, subsistiendo tan solo dicha práctica por tolerancia.

4. ACta Adicional al tratado de límites celebrado entre España y Francia, el 2 de Diciembre de 1856, relativa á la pesca y navegacion en el Vidasoa.-4..$^{\circ}$ marquilla, 16 páginas á dos columnas.

Sin año ni punto de impresion. Es un regiamento formado por los delegados de las municipalidades ribereñas para la pesca en dicho rio, cuyo documento, fechado en Bayona el 31 de Marzo de 1859, consta de 33 artículos y 3 adicionales, y está escrito en ambos idiomas. Fijánse las épocas para las diferentes clases de pesca, las dimensiones que han de tener los pescados $\dot{y}$ mariscos para aprovecharlos ó devolverlos al agua, las redes, los instrumentos y métodos que son permitidos para no exterminar $\delta$ ahuyentar la pesca. la policia y vigilannia que debe ejercerse por un guarda de cada pais, y el modo de proceder, en fin, contra los infractores.

5. Actas y memohias de la Real Sociedad Económica de los Amigos del País de la provincia de Segovia.-Madrid, 1785-1793, por Antonio Espinosa. - 4. $.^{\circ}, 4$ tomos de 413, 406, 363 y 422 páginas.

Contiene en el tomo II una Memoria sobre qué especies de árboles producirá y convendrá mejor plantar en el término de dos leguas al contorno de la ciudad de Segooia, indicando los medios de conseguirlo; $y$ en el tomo IV un Discurso sobre el estado y decadencia de los montes y plantios y de su restauracion.

Puede.verse la reseña de estos trabajos en su lugar respectivo.

6. ACTOS DE visita y Mojonacion de los Pasos y Abrebaderos Reales, y Descansaderos de Gánados de lá Ciudad de Zaragoza, y 
sus Barrios el año 1705.-Por D. Gerónimo Anton y Sayas.-Zaragoza, 1705.-Fólio, 185 páginas :

No hace mencion de este libro, el Sr. Anton Ramirez en su Diccionario de bibliograf́́a agronómica. La indicacion la tomamos del tomo IV, pág. 183, de la Biblioteca nueva de los escritares aragoneses de D. Fólix de Latassa, el cual no expresa la imprenta donde se compuso la obra. "Tengo este volumen, dice, donde se describen exactamente los Territorios que se dicen."

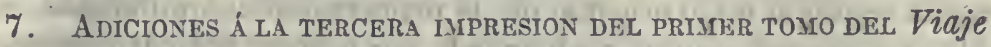
de España, de D. Antonio Ponz.-IIadrid por Ibarra, 1787.-8. menor, 34 páginas.

Contiene noticias sobre plantaciones 'hechas en Aranjuez y un Catálogo de los árboles y arbustos del jardin del Principe, en el Real Sitio de Aranjuez, etc., por D. Pablo Boutelou.

8. Agricultor ESPAÑol (Eł.).-Periódico de agricultura, selvicultura, horticultura, ganadería, economía rural é industrial, botánica, higiene, veterinaria, farmacia veterinaria, amena literatura, variedades y anuncios. Redactado por el corde de Rault y de Ramsault y D. Angel Fernandez de los Rios._Madrid: 1850, 1851: $4 .^{\circ}, 379$ páginas. Contiene diversos grabados, que representan instrumentos y animales, y una lámina iluminada (pág. 7,) con el fruto de la grosella ó uva espinosa.

Este volúmen es lo único que se publicó de dicho periódico. En 1851 se refundió en la Revista semanal (antes mensual,) de Agricultura, dirigida por D. Augusto de Burgos.

En las páginas 5,6 y 7 , contiene un artículo sobre Multiplicacion del olmo, y en la 225 otro sobre Poda en general de los que damos cuenta en el lugar correspondiente.

9. Agricultura espa ̃̃ola (T A $)$.- - Periódico andaluz de intereses materiales.-Sevilla: 1858-1861. -Imprenta de la Revista mercantil y.de la Agricultura española. -4 tomos á dos columnas y en fólio, el primero que dá principio el 8 de Julio de 1858 y concluye en 30 de Junio de 1859, tiene 688 páginas; el segundo desde 7 de Julio del mismo hasta 28 de Junio de 1860,641 páginas; el tercero desde 5 de Julio á fin de Diciembre de igual año, 312 páginas, y el cuarto hasta el 31 de Octubre de 1861, 704 páginas.

Contiene: tomo I Alimentacion de los animales domésticos; prados naturales y artificiales, por Tablada, páginas 135 y 308.-Enseñanza agronómica; Villaviciosa de Odon y Aranjuez; escuelas de Ingenieros de montes y de Ingenieros agronómos, por Tablada, página 246.-Excursion agronómica á la Rioja castellana y alavesa, por Tablada, página 283. Tomos II, III y IV.Guardia rural, páginas 537 y 519 del II, 93 del III y 289 del 1 V. Tomo IV.Envenenamientode los animales por los pastos (se cita entre otras plantas el 
enebro.) página 695. - Fomento del arbolado, página 390.-Tomo IV. Seccion de horticultura.-Abeto Douglas, página 537.-Arboles de ornato para parques, jardines y paseos públicos, página 475. - Falsa acácia monófila, página 393.-Madroño, página 421. -Nuevo erable con hojas de fresno, página 567. Tres especies de almendros, página 104.

Reseñamos en su lugar los titulados Aulaga, Esparto $(E l)$ y Montes.

10. Agricultura General de Gabriel Alonso de Herrera.-Corregida segun el texto original de la primera edicion publicada en 1513 por el mismo autor y adicionada por la Real Sociedad Económica Matritense.-Madrid: 1818-19, Imprenta Real. -4 tomos en $4 .^{\circ}$, de XXIV—544 páginas el primero, de 466 el segundo, de 655 el tercero, y de 361 el cuarto.

Adicionada por D. Antonio Sandalio de Arias, D. Claudio Boutelou, D. Simon de Rojas Clemente, D. José Elizondo, D. Mariano Lagasca, D. Francisco de Paula Martí, D. Francisco Martinez Robles y D. Agustin Pascual, padre del que lleva igual nombre hoy.

Segun las noticias adquiridas, se han hecho hasta el dia veintisiete ediciones de esta obra, dos en italiano y veinticinco en español desde 1813 hasta 1858.

Divídese en seis libros; el tercero trata de los árboles, su plantacion, poda é ingertos de las especies forestales siguientes: avellano, arrayan, álamo blanco, álamo negro, boj, castaño, endrino, ciprés, encina, fresno, laurel, enebro, sabina, acebuche, árbol del Paraiso, palma, palmito, pino, abeto, alerce, serbal, sáuce, mimbre, abedul, aliso, carpe, acácia, acebo, acer, ailanto, alaterno, aligustre, argan, catalpa, citiso, drago, durillo, haya, madroño, malagueta, plátano. raigon del Canadá, sangüeso,-- sófora del Japon, tamarindo, tejo, tilo, tulipanero y zumaque. El capítulo VI adicional del libro quinto, trata del cultivo de los prados naturales y artificiales, cuyo trabajo se debe á D. Francisco Antonio Martinez Robles, así como las adiciones al anterior á D. Antonio Sandalio de Arias y á D. Mariano Lagasca.

De la adicion al libro I, tomo $1 .^{\circ}$ sobre el cultivo y aprovechamiento de la barrilla, etc., damos cuenta en el lugar correspondiente.

11. Agricultura general y gobierno de la casa de campo, en que por extenso se trata de todos los bienes del campu, con los nuevos descubrimientos y métodos de cultivo para la multiplicacion de los granos; del aumento de la cria de ganados y de lo demás dependiente de una casa de campo; con el cultivo de prados naturales y artificiales, de los árboles de bosque y monte, de las viñas, de los olivares, de los morerales con la cria de la seda, y de otros frutos útiles muy singulares; $y$ con los tratados de huerta y de jardinería todo con especiales avisos é instrucciones. - Compuesta del Noble Agricultor de Monsieur Dupuy, de los autores que mejor han tratado de este arte y de otras varias observaciones particulares, con diversas estampas, por D. Joseph Antonio Valcárcel.-Valencia: 
1765-1795, pol los impresores J. E. Dolz, J. T. Lúcas Burguete y Cervera.-10 tomos $4 .^{\circ}, 400$ y 500 páginas próximamente cada uno.

En el cuarto volúmen trata de los árboles y daños que reciben por la atmósfera y los insectos, y en el décimo de la regaliza.

12. Agricultura samantina (La).- - Sus males y sus remedios. Memoria escrita por D. Antonio García Maceira, ingeniero de montes.-Salamanca: imprenta de Oliva y hermano.-4. ${ }^{\circ}, 49$ páginas.

Lámentase de la déspoblacion y roturaciones de muchos montes situadọs en regiones montañosas; encarece la utilidad de los arbolados forestales, y la de una guarderia instruida y bien organizada; indica los principales defectos de que adolece la legislacion penal vigente, y recomienda el fomento de los montes y la formacion de almácigas y viveros por partidos judiciales, de donde se podrian sacar las plantas necesarias para la repoblacion, distribuyéndose gratuitamente entre los pueblos de los respectivos distritos.

13. Agricultura valenciana (La). Revista quincenal de la Sociedad valenciana de Agricultura.-Valencia: 1864-1865, imprenta de La Opinion, á cargo de Josú Domenech. -3 tomos en $4 .^{\circ}$ de 500 páginas próximamente, con láminas y grabados.

Contiene los artículos titulados Moxtes (Los), Castaño $(E l)$ que indicamos en el lugar correspondiente.

14. Agrónomo (EL), ó sea Diccionario del agricultor. Encierra los conocimientos necesarios para cuidar y administrar bien las haciendas rurales, y conservar la salud, haciendo que la vida del campo sea deliciosa. Trata igualmente de las tierras destinadas á la siembra de los granos, de las viñas, de los prados, bosques, huertas, árboles frutales, flores, yerbas medicinales y otras usuales; las viltudes de las frutas y verduras y de varios árboles, y remedios para algunas enfermedades. Concluye con un índice de las voces contenidas en este Diccionario, con su significacion en catalan. Recopilado de varios autores españoles y extranjeros.-Barcelona: 1849, por la viuda de Mayor, $8 .^{\circ} 268$ páginas.

Se explican poco mas de doscientas roces. Las hay esencialmente forestalus, como abedul, acácia, acebo, etc.

15. AL Público.-Almería: Imprenta de Alvarez.-Hoja volante en fólio, una página.

La firman en Almería á 23 de Mayo de 1863 los Sres. D. Ramon Orozco, D. Felipe Barron y D. Antonio Hernandez, manifestando que demandan ante los tribunales al Sr. D. Ignacio Gomez de Salazar por las ofensas que les ha inferido con motivo de sus publicaciones acerca de los aprovechamientos de esparto en los montes de la provincia.

16. AL Público.-Almería: Imprenta de D. Mariano Alvarez.Hoja volante en fólio, una página. 
AL PÚBLICO. - ALGUNOS.

Suscrita en Almeria á 16 de Mayo de 1863, por los Sres. D. Ramon Orozco, D. Felipe Barron y D. Antonio Hernandez. Tiene por objeto, conocidos ya del público los dos folletos publicados por estos señores acerca de la cuestion del esparto, poner de manifiesto la certeza de sus observaciones, por medio de la reproduccion literal de la órden del Gobierno civil de la provincia que circunscribe el disfrute de aquella planta en los montes públicos al tiempo que media desde $10^{\circ}$ de Abril á 31 de Octubré de cada año, y la de un edicto del alcalde de Oña que manda cesar el aprovechamiento desde el dia 10 de Mayo del año corrien te de 1863, aplazándolo hasta primeros de Setiembre cuya determinacion ilegal parece que tambien habian tomado los alcaldes de Nijar, Gergal y otros pueblos.

17. AL público.-Almería: Imprenta de la Viuda de Cordero.Hoja volante en fólio, una página.

La suscriben en Almería á 9 de Junio de 1863, los Sres. D. Ramon Orozco, P. P. Ginés Orozco, Felipe Barron, Antonio Hernandez é Ignacio Gomez de Salazar, manifestando al público que, mediante una reunion de personas respetables convocadas por el señor Gobernador de la provincia, en ninguno de los escritos publicados acerca del aprovechamiento del esparto en los montes de aquella provincia, han tenido intencion de inferirsé la menor ofensa reciprocamente.

\section{AL PÚBLICo.-Hoja volante en $4 .^{\circ}$ una página.}

Autorizada en Soria á 18 de Diciernbre de 1868, por los ingenieros del distrito forestal de aquella provincia D. Manuel Solans, D. Rafael Breñosa y D. Alejandro Izquierdo. Estos funcionarios demuestran que al informar desfavorablemente la peticion del Ayuntamiento de Soria relativa á la corta de doce mil pinos verdes en los montes Grande y de Santa Inés, cuando el fuego acababa de aniquilar la enorme cifra de quince. millones de árboles de todas edades, han procedido con arreglo á los principios técnicos, y cumpliendo con el deber que tienen de velar por la conservacion de la riqueza forestal, protestando en su consecuencia del contenido de la exposicion elevada por la municipalidad al Exemo. Sr. Ministro de Hacienda, en li que se dice que la oflcina de montes es la rémora permanence de los Ayuntamientos, para que no rindan (los montes) los beneficios que de ellos se debian esperar.

19. Algunos DE LOS QUE HAN CRITICADo.....-Por D. Alfredo de Luis.-Hoja de tres páginas en folio, sin pié de imprenta.

Está fechada en Noviembre de 1872, y dirigida en forma de carta al Ministro de Fomento Excmo. Sr. D. Josć Echegaray. Se sabe que el autor ha hecho uso del seudónimo en esta carta que, con referencia al proyecto de ley de montes presentado á las Córtes por el mencionado Ministro, encierra una razonada crítica aflrmando que el Estado debe fijar y conservar la zona de montes exigida por las necesidad ss físicas y económicas de pais; que el Cuerpo de montes debe deslindar y tasar los prédios forestales enagenables; que los vecinos de los pueblos tienen un firme derecho de propiedad sobre los montes de comun aprovechamiento; que el reparto de tierras, conforme á las reglas que estáblece el proyecto, no es equitativo; y que 
este no dá garantía bastante para asegurar el cultivo agrario permanente de las párcelas que se entreguen á los vecinos de los pueblos cuyos sean los montes divididas.

Esta carta es la segunda de las tres que escribió el autor sobre la cuestión. Quedan registradas las dos restantes bajo las indicaciones siguientes: Mi aficion al estudio...-Si creyese que V. E...-Pueden verse en la Revista forestal, económica y agricola, tomo VI, página 46 en donde fueron copiadas.

20. Almanaque agrícola para el año DE 1861 , arreglado á las lunaciones, segun el meridiano de Murcia.-Murcia, 1861. por Francisco Bernabeu. $-8 .^{\circ}, 28$ páginas.

Parece que este almanaque es debido á D. José Musso y Fontes, propietario de Lorca, quien encontró la fórmula entre los manuscritos de su señor padre D. José Musso y Valiente. Este á su vez la obtuvo de los jesuitas. Asi lo dice el Sr. Ramirez en su Dic. de bibliog. agronom.

Señala las horas que corresponden al momento de tener las plantas ménos jugos acuosos, en las que conviene hacer las cortas, asi como determina tambien las horas en que dichus jugos son mas abundantes, signiflcándose así la conveniencia de hacer las incisiones 6 sangrías álos árboles, en este - espacio de tiempo, para obtener las resinas y gomas.

21. Almanaque ilustrado del labrador y del ganadero para el año de 1860. Verdadera agenda universal de las gentes del campo, por D. Domingo de la Vega y 0rtiz._Madrid, 1859, por D. José Casas y Diaz. $-8 .^{\circ}, 213$ páginas.

Explica mensualmente las operaciones del cultivo,'tratando á la vez de las pratenses y forestales.

22. Alto Aragon (EL). Periódico de Huesca.-Véase: Montes del Pirineo (Los).-Monte (El) y los monasterios de San Juan de la Peñ. - Escandalosas talas del Pirineo (Las). - Llamamos la atencion... etc.-Una aclaracion.-Avbolado. Sobre la necesidad de él. y sobre las talas de los montes del Pirineo.

23. AMENIDADEs, florestas y recreos de la provincia de la Vera alta y baja, en la Extremadura. Con un tratado de la retirada que muchos santos pontífices..... etc. Compuesto por D. Gabriel Azedo de la Berneza, natural de la villa de Xarandilla.-Con privilegio. En Madrid por Andrés García de la Iglesia: año de 1667.

Dice el Sr. Barrantes en su Catálogo razonado y critico de los libros, memorias y papeles, impresos y manuscritos que tratan de las provincias de Extremadura, que solo vió un ejemplar de este libro conservado en la librería del Sr. Gayangos. En la descripcion del arbolado menciona el autor los madroños, laureles, palmas, castaũos, cipreses, robles, loros, alisos, fresnos y álamos, leyéndose un poco más adelante lo siguiente: "Aquí los avellanos, los quejigos con su flor como de peral que nacen en las aberturas de los peñascos de los montes..." "Aquí los incorruptibles tejos de encendida y ma- 
ravillosa madera, por criarse al desembarazo de los cierzos más frios, acomodan tambien para esculturas, camas y escritorios."

24. Amrgo del País (EL). Periódico de la Sociedad Económica Matritense. Contiene sus juntas ordinarias y públicas y de sus secciones; sus memorias, proyectos, dictámenes é informes más interesantes, y los que acoja de las demás sociedades y corporaciones literarias del reino; artículos sobre industria, economía, beneficencia é instruccion pública, y noticias de utilidad general.-Madrid, 1844-1849, por I. Boix é imprenta del Colegio de Sordo-mudos.Siete tomos de 309 á 600 páginas; los seis primeros en $4 .^{\circ}$ mayor y á dos columnas; el sétimo en folio.

Los artículos de más interés forestal son: Sobre los montes de España.Bosques de Liébana.-Cultioo del pino maritimo en Sologne.-De las escuelas de ingenieros de montes (arboretos, rodales de estudio, viveros y herborizaciones, etc.).-Ejecucion práctica de la siembra (con relacion á los montes). Montes de España (sobre las causas de su decadencia)._-Necesidad de los pasios, y consideraciones generales sobre los prados naturales y artiftciales. Noticias del haya.-Guardia rural.

Publicó tambien los titulados: Código rural español.-Congreso agrícola de Bruselas,-Criaderos o planteles de árboles. - Instruccion práctica sobre la creacion de prados naturales, y una Memoria snbre el sistema más conveniente de selvicultura, que registramos en el sitio correspondiente.

25. Anales de ciencias naturales.-Véase: Anales de Historia natural.

26. Anales de Historia natural.-Madrid, 1799-1804.-Imprenta Real, siete tomos en $4 .^{\circ}$, de 300 á 400 páginas y 49 láminas.

Comenzaron á publicarsa en Octubre de 1799 por los Sres. D. Antonio José Cavanilles, D. Domingo García Fernandez y D. Cristiano Herrgen, repartiéndose.por cuadernos de 80 y 100 páginas. Los cineo tomos últimos se titularon Anales de Ciencias naturales.

Los artículos de interés forestal son los siguientes:

Tomo II.....-Monografia del género Tilo, por E. P. Ventenat.

" Obscrvaciones sobre algunos vegetales que producen resina elástica. Trata del cauchouc y del Castilla elástica, llamado asi porque D. Vicento Cervantes, catedrítico do botánica de Méjico, le dedicó á D. Juan del Castillo, quien falleció el año de 1793, pág. 214.

Tomo III....-Descripcion de varias especies nuevas de encina, por D. Luis Née.-Véase: Encina.

Tomo IV.....-Introduccion á la Ichtyologia oriental de España, por D. Ignacjo de $\mathbf{A s s o}$. guen:

En los Anales de Ciencias Naturales se encuentran los artículos que si-

Tomo IV....-Arboles y arbusios. Razon de las especies raras que se cul- 
tioan al aire libre en los gardines de Aranjwez, etc., por D. Claudio y D. Estéban Boutelou.

Tomo V.....-Discurso que D. Antonio Caranilles leyó en el Real Jardin Botánico de esta córte, el $10^{\circ}$ de Abril de 1802 , sobre la utilidad, multiplicacion y germinacion de las plantas, importancia de los bosques, etc.

9

Estraclo de la obra francesa titulada Historia de las encinas de la A mérica septentrional, por el licenciado Andrés Michaux.

De estos últimos damos cuenta en el lugar correspondiente.

27. Anales de la Sociedad Econónica Matriteńse.-Escudo de la Sociedad.-Madrid: Imp. del Colegio de Sordo-mudos y de ciegos, 1853-1861.-Nueve tomos en $4 .^{\circ}$ con paginacion subdividida por séries.

Damos cuenta en el lugar oportuno de la Memoria sobre el Origen é historia de los bienes de Propios, presentada por el sócio D. Julian Sainz Milanés, que vió la luz en dichos $A$ nales.

28. Anales de nuevos descubrimientos usuales y prácticos, ó memorias de economía industrial, rural y doméstica. Con real permiso. Barcelona, 1828-1829: Imp. de J. Torner. -Dos tomos $80^{\circ}$ mayor, con 6 láminas litografiadas, 148 págs. el 1. ${ }^{\circ}$ y 144 el 2.

En el primero se encuentran tratadas las materias siguientes: Advertencia para asegurar los injertos de pua.-Para preservar de la yodredumbre las maderas. En el segundo, puede verse el artículo, Del injerto en yerba.

No hemos visto indicada esta obra en el Diccionario de bibliografia agronómica del $\mathrm{Sr}$. Anton Ramirez.

29. AnUario adinistrativo y estadístico de la provincia de Madrid para el año de 1868. Redactado de órden del Excmo. Sr. Gobernador, por D. Francisco Javier de Bona, jefe de seccion de Estadística de primera clase, encargado de la de Madrid, secretario de la seccion de Estadística de la Junta general del ramo y de la Comision provincial, de la sociedad Económica Matritense, miembro. efectivo de la sociedad de Estadística de París, etc., etc. Publicado por acuerdo y á expensas de la Excma. Diputacion provincial.-Escudo de armas de la Diputacion provincial de Madrid: Oficina tipográfica del Hospicio, 1868 y 1869.-Un tomo, 4. , 726 págs.

Se ocupa de la clasificacion de los montes, terrenos, productos, obstáculos, plan de aprovechamiento, subastas, siniestros, deslindes, poblacion y régimen forestal. Hace elogios del ingeniero jefe del distrito forestal $D$. Mrnuel del Pozo, por su celo en la formacion y ejecucion de los planes de aprovechamiento.

30. ANUario estadístico DE España, correspondiente al año de 1858, publicado por la comision de Estadística general del reino.- 
Escudo de armas de Kispaña.-Madrid: Imprenta nacional, 1859, fólio, 710 págs.

Desde la pág. 93 á la 161 comprende la Reseña agricota, de la que hablamos en el lugar correspondiente, cọn el enunciado que sigue: Reseñas geográfica, geológica y agricola dz España.

31. Anuario estadístico de España, correspondiente á $1859 \mathrm{y}$ 1860, publicado por la comision de Estadística general del reino.Escudo de armas de España.-Madrid: Imprenta nacional, 1860, fólio, 598 págss.

En la parte destinada al Territorio, págs. 37 á 39, expresa el número de montes públicos que existen en cada provincia y su extension, y los montes exceptuados y enagenables, con distincion de los del Estado, de los pueblos y establecimientos públicos.

32. Anuario estadístico de España, publicado por la Direccion general de Estadística: 1866-67.-Madrid: Establecimiento tipográfico de M. Minuesa, 1870, fólio, 1.174 págs.

La seccion segunda ó de Montes, que es subdivision de las Industrias minera, forestal y pesquera, contiene desde la pág. 596 á la 616 ambas inclusive, ocho estados y tres resúmenes de los rendimientos en metálico y tasacion de los productos ordinarios, de uso vecinal, derribados por los vientos, incendiados y sustraidos fraudulentamente con inclusion de lo destruido, correspondientes al año forestal de 1866 á 1867 en los montes públicos de pino, roble $\delta$ haya, en los exceptuados de la desamortizacíon por ser de aprovechamiento comun ó estar destinados á dehesas boyales, y en los declarados enagenables.

33. ' AnUario Estadístico de España, publicado por la Junta general de Estadística, 1860: 1861.-Escudo de armas de España.Madrid: Imprenta nacional, 1862: 1863, fólio, 881 págs.

La seccion segunda ó de Monles, que es subdivision de las Industrias minera, forestal y pesquera, págs. 451 á 469 , contiene trece estados que expresan el resúmen general de la clasificaclon de montes públicos; los del Estádo, de los pueblos y establecimientos públicos exceptuados de la venta y enagenables; la clasificacion de los últimos con arreglo á la cabida aforada; la proporcion entre el territorio de cada provincia y el de los montes públicos; el término medio en hectáreas de la superficie que ocupa cada monte segun sus clases y las provincias respectivas; la extension superficial de los montes exceptuados de la venta, del Estado, de los pueblos y de los establecimientos públicos segun sus especies dominantes; la superficie que en cada provincia ocupan los montes de las cuatro especies que mas dominan en ellas entre los exceptuados por la clasiflcacion general; los rendimientos en metálico y tasacion de los productos consumidos en especie en todos los montes públicos durante el año 1860 , y el personal facultativo y subalterno del ramo de monles pagado con los fondos del Estado y de las provincias.

34. Anuario estadístico de España, publicado por la Junta ge- 
neral de Estadística, 1862: 1865.-Escudo de armas de España.Madrid: Imprenta nacional, 1866: 1867, fólio, 920 págs .

La seccion segunda ó de Montes, que es subdivision de las Industrias minera, forestal y pesquera, pág. 394 á 407 , contiene seis est zí os que expresan los rendimientos en metálico y tasacion de los prod uctos consumidos en especie durante los años 1861-1865, en los montes exceptuados de la desa mortizacion y en los declarados enagenables y no vendidos al terminar este período; un resúmen de los dos anteriores; otro de la produccion de los montes públicos exceptuados de la desamortizacion en los años 1861-1865; otro de igual clase para los montes públicos declarados enagenables y exceptuados en igual tiempo, y otro general de la produccion de las mismas fincas en los años 1861, 1862, 1863, 1864 y 1865.

35. Apuntes sobre el algarrobo $\mathrm{Y}$ su cultivo, por D. Peregrin Caruana y Martin, indivíduo de la Sociedad de Amigos del País de Valencia. - Valencia: imprenta de J. Ferrer de Orga, 1841. $4 .^{\circ}, 20$ páginas.

Describe la planta, el terreno á propósito para su vegetacion, los sistemas de multiplicacion, cultivo, poda, ingerto, recoleccion y conservacion del fruto. Dá además una noticia de las enfermedades propias del árbol, y delas utilidades y ventajas que produce, consignando que de los troncos viejos se hace carbon superior al del pino, asi como que de las ramas gruesas se hacen excelentes mangos de herramientas, siendo superior á todas las demás especies conocidas para cepillos de carpintesía. En la conclusion encarece el autor la conveniencia de que se escriba sobre el interesante punto de montes y plantíos.

36. ApUntes sobre el esparto, localidades donde se cria; métodos de beneficio y cultivos; usos generales á que se destina, y en particular su aplicacion á la industria del papel.-Por D. Eduardo Pardo y Moreno, ingreniero primero del Cuerpo de montes.-Madrid: imprenta de El Clamor, de D. D. Navarro, 1865.-Folleto en 4. ${ }^{\circ}$ de 91 páginas.

Trata de la descripcion de la planta; operaciones de arranque, época de la recoleccion; inconvenientes de hacer dos recolecciones en el mismo año; cultivo y aprovechamiento; quema de las atochas; exámen comparativo de estos métodos; plan de ordenacion; escarda ó limpia de la atocha; aplicaciones del esparto; embojo; atochadas, industrias diversas; fabricacion del papel; consideraciones sobre la industria del esparto; cálculo sobre el precio necesario del esparto; y bases para formular las condiciones con que se deben realizar los disfrutes sin daño del porvenir de los atochares.

37. APUNTES SOBRE EL SERVICIO DEL RAMIO DE MONTES, por el ingeniero D. Manuel del Valle.-Madrid: imprenta de Beltran y Viñas, $1859 .-4 .^{\circ}, 16$ páginas.

Lleva la fecha de Enero de 1859.

Se ocupa de las principales razones aducidas en pró y en contra de que 
los ingenieros se empleen en trabajos facultativos, y pateutíza la necesidad de modificar el servicio, á cuyo efecto presenta el cuadro de una nueva organizacion, cuyo planteamiento presupuesta en una suma poco mayor que la destinada entónces á la administracion referida.

38. Apuntes sobre los sistemas mas en uso en Francia para la conservacion y preparacion de las maderas que entran en la.construccion de sus vías férreas, por el comandante graduado de infantería D. Leopoldo Sheidnagel, capitan de ingenieros.-Madrid: imprenta del Memorial de Ingenieros, 1858.-4. ${ }^{\circ}, 7$ páginas.

Describe los procedimientos modernos mas aceptados, ó sean los de Boucherie, Pavne, Bethell y Perreau.

Esta publicacion no figura en el Diccionario de bibliografia agronómica del Ŝr. Anton Ramirez.

39. ApUntes $\mathrm{Y}$ Noticias sobre los sistemas conocidos para la conservacion de las maderas de construccion, por el comandante graduado de infantería D. Leopoldo Scheidnagel, capitan de Ingenieros.-Madrid: Imprenta del Memorial de Ingenieros, 1858.-4. ${ }^{\circ}, 24$ páginas.

Reseña los procedimientos mas aceptados, ó sean los de Kyan, Margary, Burnett, Payne, Bethell, Boucherie, Ondry, Apelt y Machabée.

Tampoco figura este folleto en el Diccionario de bibliografía agronómica del Șr. Anton Ramirez.

40. ARbolado público (EL); los hospitales y asilos provinciales; la instruccion agrícola; los bancos regionales; arbitrios muni- ' cipales que pueden establecerse para dar trabajo á los jornaleros; $\mathbf{y}$ algunas indicaciones sobre otros ramos de la administracion provincial y municipal, por R. M. Cañaveras, oficial de la clase de primeros del cuerpo de administracion civil.-Logroño: Imprenta y litog'rafía de F. Menchaca, 1869:-4. ${ }^{\circ}, 63$ págs.

Condena la plantacion en las vías públicas de árboles infructíferos ó poco adecuados al clima y terreno en donde se plantan, haciendo varios cálculos minuciosos para demostrar el gran producto que se obtendria si aquellas plantas diesen frutos de valor en el mercado. Sigue un proyecto del autor para fomentár el arbolado público cuyo objeto es entregar los terrenos municipales, menos los montes, á una asociacion de jóvenes en cada pueblo, encargados de la plantacion y fomento, distribuyéndose los productos en la adquisicion de plantas, semillas, herramientas, etc.

Al tratar de los bienes de Propios, manifiesta su opinion favorable á la idea de revertirlos al Estado asi como los del comun de vecinos.

41. Arboles de ribera.-Véase: Calendario para el agricultor y ganadero para 1862.

42. Arbolista PRÁctico (EL). Arte de cultivar toda clase de árboles, preparacion y division de todos ellos, de su multiplicacion, 
enfermedades é insectos, con la descripcion de todos los árboles de jardin y de monte; el cultivo de cada uno de ellos, y sus usos $y^{*}$ propiedades. Escrito segun los adelantos del dia y conforme á la práctica de los mas célebres arbolistas.-Madrid, 1844, por Romeral. $-8 .^{\circ}$

Es uno de los Manuales que bajo el nombre colectivo de Agricultura popular, se publicaron en aquella época. Los preceptos están tomados de los autores de mas nota.

43. Arboricultura ó sea cultivo de árboles y arbustos. Lecciones dadas en el Ateneo científico y literario de esta córte, por el profesor de dicho establecimiento D. Antonio Blanco Fernandez, doctor en medicina y cirugía, catedrático de cultivios especiales en la Escuela superior central de Ingenieros agrónomos, é individuo de varias corporaciones científicas nacionales y extranjeras.-Madrid, 1864.-Imprenta de D. L. Palacios.-Dos tomos en $4 .^{\circ}$ de 444 y 358 páginas, con grabados numerosos en el texto.

Trata de la organografia, fisiología, influencia de los agentes atmosféricos, duracion y muerte de los árboles, entrando despues en todo lo concerniente á su cultivo con toda la extension apetecible, á cuyo efecto hace la monografía cultural de cada especie, con aplicacion í los jardines, paseos, huertas, parques, etc. Concluye con unas nociones de aprovechamientos de montes y una recopilacion de la legislacion forestal española que puede inleresar á los propietarios.

Advierte el autor que ha utilizado las doctrinas que contiene la obra de Mr. Du Breuil sobre esta misma materia.

44. Argan (EL).-Véase: Direccion general de Estadistica, Agricullura, etc.

45. ARgos (EL).-Periódico político de Madrid.-Véase: Arbolado de la córte (El).-Arbolado de Madrid (El).-Reforma (La) de los Cuerpos de Ingenieros civiles.-Ventas de Balsain (Las).-Guarderia vural.

46. ARte de ballistería $\mathrm{x}$ Monteria, escrito con método para escusar la fatiga que ocasiona la ignorancia. Por Alonso Martinez de Espinar .-Madrid, 1664, en $4 .^{\circ}$

Se hizo una segunda edicion en Madrid el año 1761.

Consta de tres libros: el primero explica la ballestería y cetrería, con los pronósticos atmosféricos y el uso de armas, el segundo se refiere á la naturaleza de los animales montaraces y artificios para cazarlos; y el tereero está dedicado á la volatería y cria de perros.

Tambien trata del caballo, de una pelea de un toro, un leon y un tigre, y de las alimañas más comunes.

47. ARTE DE CAZAR, ó cazador instruido y experimentado con es- 
copeta y perros, á pié y á caballo. Contiene la enseñanza de traer el caballo; el reconocimiento de la escopeta, con la enseñanza de tirar; los tiempos de buscar la caza en sus comederos, con el tiempo de sus crias; el modo de enseñar y criar los perros perdigueros y perros maestros, con la enseñanza de hacer lazos para coger la caza mayor, $y$ varias reglas y curiosidades al perfecto conocimiento de este ejercicio. Su autor D. Juan Manuel de Arellano. Quinta edicion.-Madrid: 1807, por Vallin.-8. ${ }^{\circ}, 134$ págs. La primera edicion se hizo en Madrid el año 1788.

Las materias de que trata se dividen en 29 capitulos de corta extension.

48. AuISO DE CAÇADORES Y DE CAÇA, ordenado por el magnífico y muy insigne doctor Pero Nuñez de Avendaño: letrado del ilustrísimo Sr. D. Iñigo Lopez de Mendoza, tercero deste nombre: Duque del Infantado: dirigido á su illustrísima señoría.-Alcalá de Henares, MDxuIII, por Joan de Brocar. $-4 .^{\circ}$, III.-39 folios; letra gótica.

Despues de estudiar el origen y el derecho de la caza, trata de los cepos $y$ arınadijos que se pueden usar conforme á la pragmática de Burgos de 1514 . Explica la razon de prohibirse la caza en los dias de nieve, los casos en que el cazador debe respetar la propiedad agena y los en que incurre en pecado mortal ó infringe las leyes del reino, con otros puntos especiales.

49. Aviceptología (La) ó Manual completo de caza y pesca, dividido en tres tratados. El primero contiene ardides, trampas y estratagemas que se emplean para coger todo género de aves, con otro tratado sobre la crianza de los pájaros de jaula y canto. El segundo contiene la caza de montería ó caza mayor. El tercero de la pesca ó pescador práctico. Este tratado es el resultado de los conocimientos adquiridos por una larga y estudiada práctica. Obra útil para los aficionados á caza y pesca. Adornada con láminas intercaladas en el texto para su mejor inteligencia, estando al final el bando de caza y pesca. Por D. José María Tenorio.-Madrid, 1861: imprenta de José Cùesta, á cargo de Javier Rodriguez. - $8 .^{\circ}, 347$ páginas.

En opinion del Sr. Ramirez, Diccionario de bibliografia agronómica, la edicion no es tan moderna como aparece. "La Aviceptologia del Sr. Tenorin, dice, se imprinió por N. Llorenci el año de 1843 , precisamente en $8 .^{\circ}$, aunque conteniendo solo 342 págs. Posible es que en la edicion de 1861 no haya de nuevo más que la portada y los índices." 


\section{B.}

50. Bases establecidas por la diputacion general de Álava, PARA. PRECAVER LOS DAÑOS QUE ESTABAN EJECUTÁNDOSE EN LOS MONTES COMUNES, Y PARTICULARES DE LOS PUEBLOS.-Hoja sin pié de imprenta ni fecha.

Expedidas en Vitoria á 2 de Enero de 1815, por el Diputado general Don Francisco Urquijo de Iraben.

Contiene cinco bases, prohibiendo la corta y extraccion de árboles, la entrada del ganado cabrío en los montes, las roturaciones, y el abuso de celebrar ciertos festejos con cargo á los fondos comunes con ocasion de los aprovechamientos de árboles y leñas, á no ser que preceda el cumplimiento de determinados requisitos legales.

51. Bellezas de la naturaleza (las) ó descripcion de los árboles, plantas, cataratas, fuentes, volcanes, montes, minas, etc., los más considerables y extraordinarios del globo, por Mr. Antoine. Traducido del francés por D. Juan Mariano de Rementería y Fica.Madrid, 1832. Imprenta de D. E. Aguado.-8. ${ }^{\circ}, 260$ páginas.

En la conversacion primera trata de las producciones del reino vegetal hasta la página 49 .

No se hace mencion de este libro en el Diccionario de bibliografia agronómica, del Sr. Anton Ramirez, sin duda por no tener verdadero caracter agrario.

52. Bien DEL PAís (EL). Periódico de lá sociedad académica y recreativa de Figueras. Boletin de agricultura y conocimientos útiles.-Figueras, 1845-1848, por Gregorio Matas y de Bodallés.-Cuatro tomos en $4 .^{\circ}$ á dos columnas de 188, 190, 99 y 97 páginas.

Además de algunos artículos sobre árboles y guardia rural, publicó, entre los que pueden interesar á los que estudian liss cuestiones de montes uno titulado Observaciones sobre el alcornoque; explicacion del singular fenomeno de la reproduccion de su corteza. Tomo segundo, página 66.

53. Boletin de AGricultura, industria y CoMercio, por D. Augusto de Búrgos.-Madrid, $185 \% .-40^{\circ}$ mayor, 272 páginas á dos columnas.

Se encuentran en él los siguientes artículos: Arbolados públicos, causas de su deterioro y pérdida. Páginas 31,33 y 34.-Arboles; de su infuencia sobre la naturaleza del suelo. Página 55.-Guardia rural; sobre un interrogatorio del Gobierno para su reorganizacion. Páginas 41 y 42.-Olmo; de su multiplicacion. Páginas 19. - Plantaciones en canales y caminos, pagina 28. 
54. BOLETIN DE LA REVISTA FORESTAL ECONÓMICA Y AGRíCOLA.Legislacion y jurisprudencia forestal, ordenada y comentada por los vocales de la Junta consultiva del cuerpo de Ingenieros de montes, D. Pedro Bravo y D. Francisco Ramirez.-Madrid, 1868. Imprenta de El Universal. $-4 .^{\circ}$

Está en publicacion y llega á la página 480.

Comienza por la ley de montes de 24 de Mayo de 1863 y el reglamento de 17. de Mayo de 1865, dictado para su ejecucion, al cual acompaña dispuesta al pié de cada artículo respectivo, la legislacion anterior pertinente al caso. Se insertan tambien por órden cronológico, las decisiones y sentencias dictadas por el Consejo Real, (hoy Consejo de Estado), y por el Tribunal Supremo de Justicia, sobre asuntos que afectan más ó menos directamente á las cuestiones de montes.

55. Boletin enciclopédico de la Sociedad económica de Amigos del País (de Valencia), que contiene el extracto de sus sesiones ordinarias, extraordinarias y públicas; la descripcion de las exposiciones públicas que celebra de flores, de frutos y de industria, y la relacion de los premios, distinciones y recompensas que concede; los trabajos más importantes de sus comisiones de Educacion, Agricultura, Industria, Artes, Comercio y Ciencias exactas y naturales; el estado, mejoras y adelantos de las cátedras de Agricultura, de Aritmética, Geometría, Mecánica y 1)elineacion, y de Química aplicada á las Artes que están á su cargo, -y de las que puedan establecerse en adelante. Y la noticia del impulso y mejoras que recibe diariamente la educacion general y de los progresos y descubrimientos hechos en nuestro país y en el extranjero en todos los ramos de riqueza pública. Acompañado de un índice ó boletin bibliográfico de las mejores obras que se publican y reimprimen en España y fuera de ella.-Valencia, 1841-1870.-Imprentas de Lopez, Monfort y Rius. -16 tomos en $4 .^{\circ}$ de 200 á 500 páginas.

De nuestras indagaciones resulta que en la biblioteca de la Snciedad no existe la coleccion completa de esta publicacion, segun las activas diligencias que, á nuestro ruego, ha hecho el Ingeniero de montes D. Buenaventura Bachiller. Solo el Sr. Monfort, distinguido sỏcio de la Económica valenciana, posee todos los tomos del Boletin que se han dado á luz. La portada del tomo diez y siguientes dice: Boletin de la Sociedad económica de Amigos del Pais de Valencia. El tomo catorce corresponde á 1865 y el quince á 1870 , de modo que han trascurrido cinco años durante los cuales esta publicacion ha estado suspendida sin que conozcamos las causas.

Con el tomo diez correspondiente á los años 1857 y 1858 , se repartió por separado la Memoria sobre los árboles de monte ó bosque, de D. Vicente Tor losa y Cerdá, de la que nos ocupamos en el lugar respectivo.

Eń la coleccion de artículos de este Boletin, figuran los siguientes: Arbol del cielo ó Aylanto; de su introduccion en Valencia, de su crecimiento y multi- 
plicacion.-Destruccion de las orugas y otros insectos. - Arbol de Judea y sus utilidades: árbol del amor, algarrobo loco, propio para jardines y combustible.-Arbol del sebo, originario de la China.

Los titulados: Conservacion de maderas.-Aplicacion de las maderas para empedrados y pavimentos y Capullos y orugas de los pinos; posibilidad de utilizar los capullos para el' hilado, quedan registrados en el lugar que les corresponde.

56. Boletin General DE ventas DE Bienes Nacionales.-Véase: Tasacion de los montes y terrenos anejos (de las minas de Riotinto), con su Memoria y Estado.

5\%. Boletin oficial de la provincia de Jaen.-Véase: Regla. mento sobre la organizacion del servicio que deben prestar los empleados y la cooperacion eficaz de las autoridades locales para la prosperidad de los montes de la provincia de Jaen.

58. Bolemin OFICIAL de la PRovincia de Zaragoza.-Véase: Instruccion para el servicio publico de los montes de la provincia de Zaragoza.

59. Boletin óficial del Ministerio de Comercio, Instritccion y Obras públicas. Despues Bolelin oficial del Ministerio de Fomento.-Madrid, 1848-1865: en diversas imprentas, la primera de La Publicidad á cargo de M. Rivadeneyra; la última la oficina tipográfica del Hospicio. - Sesenta y cuatro tomos en $4 .^{\circ}$, hasta 29 de Junịo de 1865 en que cesó la publicacion de Real órden. Desde 1862 hasta 1865 salio por entregas semanales formando cada semestre un tomo de 342 á 500 págs. Anteriormente cada trimestre forma un tomo. La numeracion no es correlativa porque la publicacion se dividió en tres épocas: la primera comprende diez y seis tomos hasta el año 1851; la segunda cuarenta y dos con el nombre de Boletin oficial del Ministerio de Fomento hasta el segundo semestre de 1862 , en que separada la parte oficial de la que no tenia este carácter, se tituló Revista cientifica del Ministerio de Fomento, que comprende seis tomos.

Entre otros figuran en sus páginas los siguientes trabajos que anotamos en el lugar que les corresponde: Alternatioa de cosechas. - Animales dañinos. - Arroyo Bularque. - Arte de dirigir la 'sáoia. - Arbol del sebo (El).Guardia rural. Proyecto para establecerla. - Invento curioso.-Memoria sobre el estado de los ramos dependientes del Ministerio de Fomento en la provincia de las islas Baleares. -Memoria sobre las mejoras de la provincia de Jaen.-Memoria de reconocimiento de los montes de Sierra-Bullones.-Programa de los premios de la sociedad Económica de Amigos del pais de Asturias. - Recoleccion y conservacion de los productos. - Revista forestal.

60. Boletin oficial del Minisierio de Fomento. - Véase el que antecede. 
61. Bolsa (LA).-Periódico político de la tarde, defensor de los contribuyentes.-Véase: Montes de Cuenca.

62. Bosquejo DASOGRÁfico DE IA PRovincia DE Oviedo.-Véase: Junta general de Estadistica.

63. Bosquejo dasográfico dE LA PROvincia de SANTANDER.Véase: Junta general de Estadistica.

64. Bosques y Árboles huecos de VizCaya y GuipúzcoA.-Véase: Introduccion á la Historia natural, etc.

65. Breves indicaciones en defensa del derecho que sobre los montes denominados Claros corresponde al Sr. D. Segundo Colmenares.-Madrid: Impręnta de Rojas y Compañía, 1867.-4. ${ }^{\circ}, 8$ págs.

Sin firma. Fechado en Madrid á 4 de Junio de 1867. Los montes en cuestion, sitos en los términos de los puẻblos de Colmenar, Cardoso, Vado, Bocígano, Peralejo y Peñalva, provincia de Guadalajara, formaban parte de un mayorazgo en que sucedió el Sr. Duque de Hijar, quien los vendió en 1862 á D. Segundo Colmenares, segun indica el folleto, encaminado á probar que aquellos pueblos no tienen derecho al disfrute de los montes indicados, y que la demanda de amparo posesorio pedido al juzgado de Tamajon por el Sr. Colmenares, debe prosperar contra las providencias administrativas dictadas por el Gobernador civil acerca de este asunto.

66. Breves observaciones sobre la memoria que bajo el título, Suelo, clima, cultivo agrario y forestal de la provincia de Vizcaya, ha publicado el ingeniero de montes D. Lucas de Olazabal. Por D. Fernando Mieg, profesor de Historia natural en el Instituto de Bilbao. - Bilbao: Imprenta y litografía de D. Juan E. Delmás, MDCCCLVIII.-8. $.^{\circ}, 15$ págs.

Véase: Suelo, clima, cultioo agrario, etc. Las observaciones del Sr. Mieg se refieren princlpalmente á determinar las especies herbáceas, leñosas y arbóreas, no expresadas por el autor de la Memoria, ó designadas impropiamente respecto á sus nombres, habitacion, etc.

\section{O.}

67. CaCga (Libre de la). En el arch. de la Cor. de Arag. Curi. sig seccion I. Reg. Jolan. loc. Joan. If. 101. b. se lée esta carta: «La Reyna Darago Car cosf:» Del libre de la Caca que havets trames al senyor Rey li havets fet gran plaer segons ell vos escriu. E nos daquell é del acord dessus ditvos fem moltes gracies... Dada en Montçó ả sots nostre segell secretá XXVIII dies dabril del any MCCCXXXIX. Dirigitur Comiti Fuxensi. 
Copiamos textualmente esta indicacion de la seccion de Anonimos de las Memorias para ayudar á formar un diccionario critico de los escrilores catalanes, de D. Félix Torres Amat.

68. Calculos de cubicaciones de madera para el uso de comerciantes, propietarios, arquitectos, maestos de obras, capitanes de buques, empleados de aduanas y ferro-carriles, carpinteros, etc., etc. Por, José Gil y Montaña. Barcelona, 1858, imp. y lib. del Diario de Barcelona á cargo de F. Gabañach.-8. , Iv, 128 págs .

69. CALENdARIo del AGRICUltor Y GANAdERo PARA 1862, por Don Domingo de la Vega y Ortiz, ilustrado con 17 grabados y un bellísimo mapa descriptivo-ägrícola de España y Portugal.-Madrid: 1862.-C. Moro, librero, editor.-12, 310 págrs.

En la páy. 160 comienza un artículo denominado Arboles de ribera, dividido en tres partes, que tratan de la importancia y aprovechamiento de las indicadas plantas, del recogimiento de las aguas y reconstitucion climatérica, y del aprovechamiento y encauzamiento de los rios y corrientes perennales. En todas se encarece la utilidad de propagar el arbolado para la salubridad del país, para la aminoracion de las sequías, para asegurar las vertientes de los cursos fluviales, para aumentar los productos leñosos, y para otras aplicaciones de importancia. La Gaceta de Madrid, reprodujo este artículo en el número del 29 de Octubre de 1862.

De la preparacion de las maderas trata en las págs. 234, 235 y 236.

70. Calendario del selvicultor, ó manual de Silvicultura práctica, obra útil á los propietarios de bosques, y empleados en el ramo de montes. Por D. José María Paniagua, individuo correspon diente de la Academia de ciencias naturales de Madrid.-Zaragoza: 1846. Por Cristobal Yuste.-4. ${ }^{\circ}, 194$ págs.

Determina los trabajos de los doce meses del año, y se ocupa de los cortes, repoblacion, siembras, frutos, climas y terrenos, añadiendo un vocabulario ó definiciones de las principales voces que se emplean en la obra.

71. CAÑADA occidental de la provincia de Sória. Madrid: 1856, imp. de M. Minuesa. $-80^{\circ}$ mayor, 52 págs.

Este opúsculo, que no se menciona en el Diccionario de tibliografia agronómica del Sr. Anton Ramirez, se imprimió sin ponerlo á la venta.

72. Carbonera (La), finca propia del Excmo. Sr. Conde de Parcent.-Memoria descriptiva y tasacion oficial de la finca denominada $L a C a C^{2}$ bonera de la pertenencia del Excmo. Sr. Conde de Parcent.-Zaragoza: 1869. - Establecimiento tipográfico de Calisto Ariño. -4. ${ }^{\circ}$ menor, 20 págs. con un croquis en negro que representa la situacion de la finca, respecto de Zaragoza, Zuera, Tardienta, Gurrea, Luna y otros pueblos. 
Se describe en este opúsculo la extension total y parcial de la finca y se particulariza el sistema de explotacion mas adecuado para utilizar las maderas y carbones, y para cultivar ciertas porciones del fundo, calculándose minuciosamente los rendimientos en especie y dinero. Este trabajo está fechado en Zaragoza á 15 de Setiembre de 1869. Lleva estas iniciales: T. G. E.

Sigue la tasacion oficial de la finca practicada el dia 19 y siguientes del mes de Julio de $186 \%$, por el Ingeniero jefe del distrito forestal de Zaragoza D. José Jordana, y por D. José Valier, perito nombrado por el propietario, de la que se deduce que el prédio tiene unas 5.000 hectáreas cuya superficie, como suelo, se tasa en 250.000 escudos, y en 464.539 escudos 800 milésimas el vuelo de toda clase.

Del preámbulo que precede á este folleto se deduce que con fecha 15 de Enero de 1865 se publicó otro, que como el actual, tenia por objeto dar á conocer las condiciones naturales, agronómicas y forestales de la finca, añadiendo los sistemas de explotacion que pudieran ofrecer una realizacion más inmediata, todo con el fin de que estas noticias sirviesen de guia á los que deseasen interesarse en la venta en pública subasta del prédio en cuestion. No hemos podido ver ningun ejemplar de este trabajo.

73. Cartas eruditas y curiosas por las que en la mayor parte se continúa el designio de el Theatro crítico universal, impugnando $\delta$ reduciendo á dudosas varias opiniones comunes, dedicadas... (á varios personajes). Escritas por el muy ilustre Sr. D. Fr. Benito Gerónimo Feijóo y Montenegro, maestro general del órden de S. M. etc.-Madrid: 1781, por Blas Roman, impresor de la Real Acadeınia de derecho español y público.-Cinco tomos en $4 .^{\circ}$, de á 500 páginas próximamente.

El tomo $V$, carta $X$, contiene un escrito sobre los plantios y la necesidad que hay de ellos en España.

74. CARTAS SOBRE LA EXISTENCIA Y CONSERVACION DE LOS MONTES, dirigidas al Excmo. Sr. Ministro de Fomento por el Ilmo. Sr. D. Bernardino Nuñez de Arenas.-Madrid, 1854: Establecimiento tipográfico de D. F. de P. Mellado.-4. $.^{\circ}, 44$ págs.

Son tres cartas fechadas en 22 de Octubre, 4 y 7 de Noviembre de 1854, en Villaviciosa de Odon, domicilio de la escuela de Ingenieros de Montes, de la cual habia sido director el Sr. Nuñez Arenas. La primera carta prueba la inconveniencia de la venta de los montes de Propios; la segunda describe los esfuerzos que los ilustrados gobiernos de otros paises han hecho en pró de los montes, y la tercera reseña los defectos del scrvicio de montes. en su direccion y administracion.

75. Cartilla agrarta, ó sea la práctica de la agricultura y de la ganadería, segun los autores mas clásicos de estos tiempos, dispuesta por el coronel D. José Espinosa.-Madrid, 1822: Por L. Amarita. $-4 .^{\circ}, 416$ págss. 
Trata de la plantacion y cultivo de árboles, con la explicacion de los ingertos y de las podas, de las enfermedades mas comunes de los mismos y de los climas y terrenos que les convienen.

76. Cartilla agraria, ó sea Manual de Agricultuva teóricopráctica, escrito con arreglo á las prescripciones del Real decreto de 11 de Diciembre de 1848, por D. Augusto de Búrgos.-Madrid, 1851: Por M. Rivadeneyra. $-8 .^{\circ}, 177$ págs.

Dedica una seccion á la arboricultura.

77. Cartilla agraria, por D. Alejandro Oliván.-Madrid, 1856: Por la viuda de Búrgos. - 8., 63 págs.

Se ocupa de los pastos y de los árboles.

78. Cartilla de agricultura, por D. Ramon de Casanova, comisario régio de agricultura en la provincia de Barcelona.-Barcelona: Imprenta del Diario de Barcelona á cargo de Francisco Gabañach, $1857 .-4 .^{\circ}, 77$ págs.

Lamenta la escasez de -arbolado y encarece la importancia de sus productos maderables, dictando reglas para la cria y cultivo de las especies forestales mas importantes y comunes de nuestro pais, expontáneas y exóticas.

79. Cartilla de agricultura práctica, por D. Zoilo Espejo.Manila: Imprenta de Ramirez y Giraudier, 1869.-8.', 103 págs.

Trata muy lijeramente de las plantas industriales, textiles y tintóreas, y de los árboles de monte, dando nociones de su cultivo.

80. Cartilla de selvicultura, por D. Julian Diez de Andino, Ingeniero de montes.-Santander: Imprenta de la A beja montañesa, 1860. $-4 .^{\circ}, 54$ págs.

El autor la dedica á la Excma. Diputacion provincial de Santander en gratitud á sus esfuerzos por la prosperidad forestal.

Se ocupa con la detencion necesaria de la fijacion de dunas, terrenos pantanosos, preparacion del terreno para las siembras, de la eleccion de especie, de la adquisicion de la semilla, de la ejecucion de las siembras, de las plantaciones, de la reproduccion por division y multiplicacion, de los ingertos, de la conservacion del arbolado, de los gastos de repoblacion y de los instrumentos selvícolas.

81. Cartilla elemental de agricultura, acomodada á nuestro suelo y clima. Por D. Antonio Sandalio de Arias y Costa, jardinero mayor del Real convento de señoras de la Encarnacion de esta córte. Madrid, 1808: Por Gomez Fuentenebro y compañía.-8. 212 páginas.

En la segunda edicion, Madrid, 1833 , por L. Amarita, $8 .^{\circ}$, xv, -31 páginas y xul de índices, entre otras materias aumentadas figura una instruccion del arbolista. 
82. Cartilla elemental de agricultura, por D. Benito Ceferino Miranda Prieto, agrónomo examinado en el Real colegio de San Fernando de Madrid en el año de 1818.-Habana, 1850: Establecimiento tipográfico de Barcina.-4. ${ }^{\circ}, 173$ págs.

El cuarto capítulo trata de lo que debe saber el arbolista.

83. Cartilla forestal, para los sobreguardas y guardas encargados de la custodia y fomento de los montes públicos.-Contiene los artículos de la ley de 24 de Mayo de 1863, del reglamento de 17 de Mayo de 1865 dictado para la ejecucion de aquella y de las Ordenanzas generales de montes de 22 de Diciembre de 1833, cuyo tex to literal deben conocer aquellos funcionarios para el desempeño de su cometido, completado todo con el decreto lel Regente del reino de 28 de Agosto de 1869, relativo al personal subalterno del Cuerpo de montes, al que se acompaña el Reglamento correspondiente de igual fecha.-Cervera: Imprenta de Joaquin Solé, 1869.-4. 23 pág:s.

Reproduce toda la legislacion vigente relativa á aprovechamientos, denuncias, incendios, custodia, policía, etc., cuyo cumplimiento atañe al personal subalterno del ramo.

84. Cartilla práctica del tasador de propiedades del Estado, para el uso de los peritos agrimensores y prácticos de labranza, con objeto de que puedan tener conocimiento exacto del estado de sus derechos devengados, y de los que vayan cobrando y les queden por cobrar. Formada por el Oficial $1 .^{\circ}$ de la Administracion del ramo de la provincia de Albacete.-Albacete, 1860.-Imprenta de La Union. - 8. ${ }^{\circ}$ mayor, 104 páginas.

En la cubierta dice: "Compuesta por D. Saturnino Arce y Cortazar ."

La materia de esta obra, de la que no se hace mencion en el Diccionario de Bibliografia agronómica del Sr. Anton Ramirez, comprende, como es natural, todo clase de fincas forestales.

85. Cartilla rústica, ó sean principios de agriculturapráptica, sacados de las obras más recientes que se han publicado sobre este arte, y de las prácticas de algunos países más adelantados en ella.Obra escrita para optar al premio ofrecido por el Instituto agrícola catalan de San Isidro, segun el programa de $10^{\circ}$ de Noviembre de 1855 , y premiada con el accésit consistente en una medalla de cobre. Su autor D. Joaquin Salarich, licenciado en medicina y cirujía, sócio honorario del Instituto agrícola catalan de San Isidro, y miembro de rarias academias científicas. - Barcelona. Imprenta del Diario de Barcelona, á cargo de Francisco Gabañach, 1859.--4.', 281 páginas y grabados intercalados en el texto.

Dá cuenta do la accion benéfica que ejerce el arbolado sobre el clima y 
conservacion del terreno, indicando los medios de multiplicacion y trasplante. Se ocupa especialmente de la siembra, plantacion y poda de muchas especies forestales.

86. CASA RÚsTiCa DE 1840, ó nueva guía manual de todas las ciencias y artes pertenecientes á los habitantes del campo, propietarios, arrendadores, viñeros, hortelanos, ganaderos, etc. Obra á la par que útil, divertida, compuesta por los tratados de $\mathrm{D}^{6}$ Olivier de Serres, L'Abbé Rozier, Parmentier, Sonnini Chabert, Fromage, François de Neufchateau, Buc ${ }^{6} \mathrm{Hoz}$, Dandolo, Hubert, Verri, Mathieu de Dombasle, Soulange Bodin, Bourgelat, Lafosse, Flandrin, etc. Arreglada en todas sus partes, segun los conocimientos actuales, y en vista de las obras más recientes, así francesas como extranjeras, por una sociedad de agrónomos, médicos, veterinarios y químicos. Traducida al castellano por D. M. G. S., catedrático de lenguas y literatura en varios establecimientos.-Mradrid, 1842, por Omaña.Tres tomos en $4 .^{\circ}$, de 242,252 y 299 páginas y diversas láminas.

En el tomo Il trata, entre otras cosas, de la madera en general, y de los productos forestales y animales dañosos á los bosques, incluyendo una Disertacion sobre bosques, arbolados y plantios de D. Jose María de Nieva, de que damos cuenta en el lugar correspondiente. El tratado de la caza, está en el tomo III.

87. Castellar (EL) Y la pardina ie Miranda, ó sea la verdad y la mentira y Cubillos y sus impugnadores.-Por D. Francisco $\mathrm{Cu}$ billos Abellán.-Zaragoza, 1870. Establecimiento tipográfico de Calisto Ariño. - 4. ${ }^{\circ} 16$ págiuas.

Se ocupa del origen de aquellas dos fincas. Pobló y fortificó el Castellar en 1091 el Rey D. Sancho Ramirez, con objeto de espulsar de Zaragoza al rey moro, como lo consiguió en 1118. El señorio del castillo y villa lo dió á su hijo apellidado Luna, quien lo transfirió á sus sucesores, siendo el último D. Fadrique de Aragon, conde de este nombre. Continuando con razonamientos históricos y de derecho, deduce el autor que la finca pertenece al Estado, si bien con obligacion de devolver al actual poseedor conde de Villahermosa, la suma de 13.000 florines y 45.0 . 3 stellus jaqueses.

De la pardina de Miranda, asegura que fué donada en 1160 por D. Ramon de Berenguer, Príncipe de Aragon y conde de Barcelona, al Ilmo. y vencrable D. Pedro Tunez, Obispo de Zaragoza, para si y sus sucesores, de modo que labiendo pasado á ser propiedad del Estado los bienes del clero, y como. tales los del arzobispado de aquella ciudad, la finca debe declararse propiedad de la nacion.

88. Catalogo D' els peixos qú escrien, é peixquen en lo Mar de Valencia.-Por Márcos Antonio Orellana. Valencia, viuda de Martin Peris, 1802.-4..$^{\circ}$ cuatro hojas prels. y 10 páginas.

Indicado de este modo en el Catálogo de la Biblioteca de Salvá, tomo ll, página 409, núm. 2731. "Fuster dice, á pesar de conocer mucho á Orellana, 
ignoró que el segundo folleto, (esto es, el que aquí se indica), se hubiese impreso; y es más original habiéndolo sido en Valencia."

No figura este folleto en el Diccionario de bibliografia agronómica, del Sr. Anton Ramirez.

89. CAtálogo de ros peces que habitan ó frecuentan las costas de Cádiz y Huelva, con inclusion de los del rio Guadalquivir. Por el doctor D. Antonio Machado, licenciado en ciencias naturales, catedrático de zoologia y mineralogia, y decano de la facultad de filosofía de la universidad de Sevilla.-Sevilla, 185\%. Imprenta y librería española y extranjẹra.-4..$^{\circ}$ marquilla, 29 páginas.

No se limita el autor á presentar el catálogo, sino qué tambien se ocupa del modo de pescar y de los daños que causá á la cria el método del Bou.

90. Catálogo de los productos presentados en la Exposicion de agricultura, celebrada en Madrid el año 1857, precedido de algunos apuntes sobre la misma. (Tomado de la parte no oficial del Boletin de Fomento.) Escudo de armas de España. Madrid, Imprenta nacional, $1857 .-4 .^{\circ}, 740$ páginas.

Figuran todos los productos forestales, como maderas, leñas, carbones, jugos, cortezas, etc.

91. Catálogo ide los productos presentados por la Diputacion de Navarra en la Exposicion de Bayona.-Pamplona: Imprenta de Francisco Erasun y Rada.-Año 1864.-4. ${ }^{\circ}, 40$ páginas.

Dá cuenta de la coleccion de maderas de los montes del Estado y de los de particulares presentada á dicha exposicion, citando las localidades de donde procedian algunas especies, como el pinabete, el roble, el haya, el pino silvestre, la encina, el tejo, el olmo, el aliso, el abedul, el castaño, el acebo, el enebro y el fresno. Enumera los productos secundarios de la clase de carbones, cortezas y yesca.

92. Catálogo del establecimiento de floricultura y jardinería llamado Quinta de la Esperanza, junto al embarcadero del canal de Manzanares.-Madrid: Imprenta de Luis Beltran, 1861.-Fólio, 20 páginas.

Comprende gran número de especies forestales indígenas y exóticas. Las plantas están agrupadas por familias, indicándose los nombres vulgares, el precio y las condiciones del clima, suelo, humedad, etc., que requiere su cultivo.

En la cubierta exterior se lee: Quinta de la Esperanza.-Catálogo de las plantas cultivadas en el establecimiento de foricultura y jardineria de José Fernandez Iglesias, 1861 á 1862.

93. Catáloco Descriptivo de los objetos que contiene el Museo naval.-Tercera edicion corregida y aumentada.-Madrid: Impren ta de T. Fortanet, 18\%1.-4. ${ }^{\circ}, 213$ páginas.

La segunda sdicion se hizo en Madrid el año 1862, en la imprenta de Luis 
Beltran, comprendiendo 253 páginas en $4 .^{\circ} \mathrm{El}$ mencionado libro da cuenta de las abundantes y variadas colecciones de maderas de diversos países del globo que contiene el museo, $y_{2}$ de las muestras de otros productos forestales como cortezas, resinas, esparto, etc.

94. Catálogo general de la seccion española, publicado por la Comision régia de España.-Paris: Imprenta general de Ch. Lahure, 1867.-4. $.^{\circ}, 504$ páginas.

Se ocupa brevemente de los montes de España, pág. 84, en la reseña geográfico-estadística que precede al catálogo. Este abraza la parte relativa á los productos de beneficios é industrias forestales, desde la página 205 á la 216; lo referente á los productos de la caza y pesca, desde la página 216 á la 218 , y los artículos análogos de la isla de Cuba y Filipinas, en las páginas 416 , $417,448,449$ y 450 . Predominan las maderas sobre los demás productos.

95. Catálogo netódico y razonado de los mamíferos de Andalucía, clasificados segun el sistema del Dr. Enrique Schinz, por el doctor D. Antonio Machado y Nuñez, Catedrático y Decano de la Facultad de Ciencias de la Universidad de Sevilla.-Sevilla: Imprenta de Gironés y Orduña, $1869 .-4 .^{\circ}, 48$ páginas.

Indicà la habitacion de las especies comprendidas en el catálogo; y las describe con bastante extension, figurando entre estas el murciélago, el erizo, el zorro, el liron, etc. Lamenta la necesidad que tiene de trashumar el ganado de lana á causa de la roturacion de terrenos forestales.

96. CatÁlogo Y DEscripció D'ELs PaRdals dE L'Albufera dE Valencia, por Márcos Antonio Orellana.-Valencia, 1795.-4. , 16 páginas.

Así indicado en el Catálogo de la Biblioteca de Saloá, tomo II, pág. 409, número 2,730 .

En el Diccionario de bibliografia agronómica del Sr. Anton Ramirez, no aparece registrada esta publicacion.

97. CAtálogos DF montes públicos exceptuados de la desamortizacion, hechos por el Cuerpo de Ingenieros de Montes en cumplimiento de lo dispuesto por Real decreto de 22 de Enero de 1862, y Real órden de la misma fecha.

Provincia de Albacete......... 22 páginas.

Id. de Alicante........... 9 id.

Id. de Almería........... 4 id.

Id. de Avila............ 20 id.

Id. de Badajoz........... 4 id.

Id. de Baleares........... 4 id.

Id. de Barcelona.......... 6 id.

Id. de Búrgos........... 94 id.

Id. de Cáceres........... 16 id.

Id. de Cádiz........... 13 id. 


\begin{tabular}{|c|c|c|}
\hline rot & de Castellon de la Plana. & 13 \\
\hline Id. & de Córdoba............ & 4 \\
\hline Id. & de Gerona ............. & 6 \\
\hline Id. & de Granada............ & 8 \\
\hline Id. & de Guadalajara......... & 42 \\
\hline Id. & de Huelra............. & 10 \\
\hline Id. & de Huesca............ & 58 \\
\hline Id. & de Jaen................ & 24 \\
\hline Id. & de Logroño........... & 27 \\
\hline Id :" & de Lugo.............. & 4 \\
\hline Id. & de Madrid ............ & 34 \\
\hline Id. & de Málaga............. & 14 \\
\hline Id. & de Murcia $\ldots . . . \ldots \ldots$. & 19 \\
\hline Id. & de Navarra............ & 20 \\
\hline Id. & de Orense...$\ldots \ldots \ldots$. & 19 \\
\hline 'Id. & , de Segrovia............ & 30 \\
\hline Id . & de Soria....$\ldots \ldots \ldots$ & 37 \\
\hline Id. & de Tarragona.......... & 11 \\
\hline Id. & de Valladolid........... & 22 \\
\hline Id. & de Zamora............ & 54 \\
\hline Id. & de. Zaragoza .......... & 29 \\
\hline
\end{tabular}

Folletos en fólio impresos en la Imprenta nacional, en el año 1864 los veintiuno primeros, y en el año 1865 los diez restantes, todos con igual forma tipográfica, pudiéndose reunir en un solo volúmen.

Comprenden por provincias los montes del Estado, de los pueblos y de estabiecimientos públicos, con inảicacion del número de órden, términos municipales en donde radican los montes, nombres, pertenencia, confines, . especie arbórea dominante y cabila aforada en hectáreas de los mismos.

98. Catecisio de agricultura. Por D. Jaime Llansó, catedrático de dicha asignatura en la Casa-Lonja de Barcelona.-Barcelona, 1850, por Ramon Martin Indar._8. ${ }^{\circ}$, vil._-197 páginas.

Hay un capitulo que trata de las pomaradas y bosques.

99. Catecismo elemental de agricultura práctica, zootécnia, horticultura, jardinería, montes y plantíos; con una breve reseña de economía y administracion rural y un sencillo método de agrimensura y aforo de líquidos y áridos. Esscrito al alcance de los ninos, para que pueda servir de texto en la s escuelas de ambos sexos; por D. Juan Zóilo Fernandez y Perez, licenciado en farmácia, indivíduo de la Junta gencral de Agricultura y regente de química.- Madrid, Setiembre de 1856, por la viuda de Vazquez é hijos.- $-8 .^{\circ}, 140$ páginas y 3 láminas. 
Dedica algunas páginas á tratar de las dehesas y prados, arboricultura y selvicultura.

100. Cazador gallego'(EL), con escopeta y perro, por D. Froilán Troche y Zúñiga.-Santiago, 1837, por la viuda é hijos de Compañel.-8. $.^{\circ}, 301$ páginas.

Se ocupa de la caza de perdices, colornices, liebres, conejos, jabalíes, curzos, venados y gamos, lołos, zorros, chochas ó árceas, aguanetas ó becacines, $\mathrm{y}$ aves maritimas y acuátiles ó acuáticas.

Analiza tambien la legislacion del ramo, entendiendo que para ser buena una ley de caza, es menester que no se general, sino especial para cada provincia ó provincias análogas.

101. CAZADOR práctico (EL), ó arte de manejar la escopeta, con las reglas para cazar y precauciones que han de tenerse para evitar las desgracias que suelen acarrear los descuidos de los cazadores; aumentado con el arte de pescar.-Madrid, 1844, por Manuel Romeral.-8..$^{\circ} 108$ páginas.

Despues de lo relativo á las armas trata de la caza de pluma y de la mayor ó de pelo, comprendiendo la de los jabalíes, la de lus lobos por medio de trampas y cepos, y la de las zorras. Hay un capítulo destinado á la cria de perros perdigueros, y termina el tratado con el arte de pescar, explicando los arreos del pescador de caña y los cebos más convenientes.

102. Ć́Líbre (EL), pero escandaloso expediente entrè el Estado y Ayuntamiento de Juslibol y los duques de Villahermosa y conde del Real, hermanos, sobre usurpacion del monte Pardina de MiranDA, valuado en treinta millones de reales.-Por D. Francisco Cubillos Abellán.-Madrid, imprenta de Julian Peña, 1871.-Gran folio, 2 páginas.

Hoja fechada en Madrid á 18 de Julio de 1871.-Hace la historia de las vicisitudes porque lia pasado esta finca que considera de la pertenencia del Estado, como subrogado este en los derechos dominicales que la mitra arzobispal tenia sobre la finca, cuya propiedad disputan al presente el Ayun. tamiento de Juslibol por un lado y por otro los duques de Villahermosa con el apoyo de la Asociacion de ganaderos de Zaragoza. Expone los trámites así administrativos como judiciales que ha seguido esta cuestion, y fundado en 'la sentencia dictada por el juzgado de primera instancia, manifiesta que la administracion ha debido incautarse en el acto de la finca y proceder á la cobranza de los cánones y contribuciones, sometiendo á la accion de los tribunales de justicia al que directa ó indirectamente se hubiese opuesto á ello, incluso el Ayuntamiento de Zaragoza por haber secuestrado seis despachos de apremio, cuando la inhibicion debió ser general.

103. Ciprés (EL). Consideraciones sobre este árbol, por V. V.F. y L. Palma 1863, imprenta y librería de P. J. Gelabert.-4. ${ }^{\circ}, 16$ páginas.

La indicacion de este trabajo la hemos tomado del Boletin bibliográfico español, Núm. 10, del 13 Mayo 1863, pág. 114. 
104. Clamor público (EL). Periódico político de Madrid.-Véase: Estudios sobre el ramo de montes y arbolados de España.

105. ClasificaCion general DE y.os MONTES Públicos, hecha por el Cuerpo de Ingenieros del ramo, en cumplimiento de lo prescrito por Real decreto de 16 de Febrero de 1859 y Real órden de 17 del mismo mes, y aprobada por Real órden de 30 de Setiembre siguiente.-Escudo de armas de España.-Madrid.-Imprenta nacional.1859.-Fólio, sin paginacion seguida.

Al final tiene un estado que resume el trabajo anterior, expresando las provincias, poblacion, número de ayuntamientos, número de pueblos, superficie total de cada provincia, número total de montes y su superficie, montes enagenables del Estado, de los pueblos y de corporaciones civiles y su superficie, montes exceptuados de la venta cuya propicdad tiene el mismo carácter, superficie de estas fincas, y por último lós totales corres, pondientes en número de montes y en superficie.

Encabezan el libro las disposiciones dictadas para ejecutar la clasificacion indicándose los ingenieros que la llevaron á cabo en las provincias respectivas.

Para cada una de estas se expresan los partidos judiciales, ayuntamientos, pueblos, nombres de los montes, cabida aforada en lectáreas y las especies dominantes y subordinadas. Distribúyense como sigue:

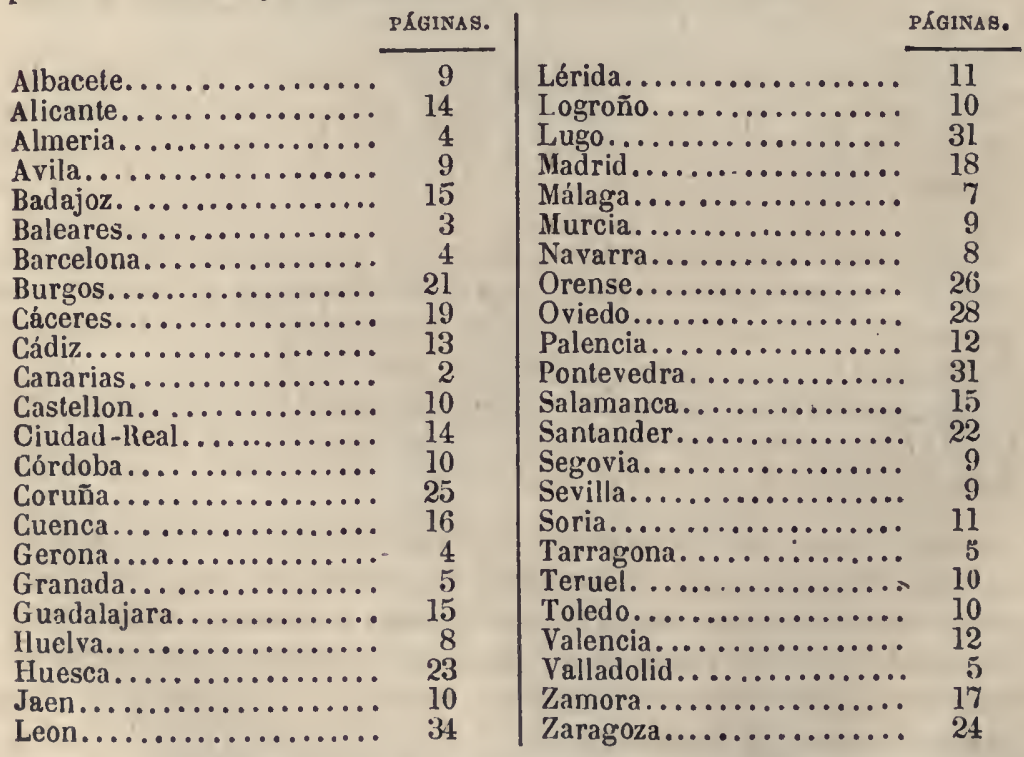

106. Coleccion de las reales Resolvciones, que expresan las gracias y franquicias concedidas á los roturadores de terrenos incultos y á los fundadores de nueras poblaciones y colonias.-Madrid, 1827?_Folio, 17 páginas. 
No dice el lugar ni el año de impresion.

En una circular de la Direccion general de Propios y arbitrios del reino, se hace inérito de la Real órden de 27 de Agosto de 1827 , relativa á la destruccion de la mancomunidad de pastos de cierlos montes de la provincia de Toledo, su division en suertes, con el cánon de un 2 por 100 para reducirlos á cultivo en dos años, y concesion á los adquirentes de las gracias y franquicias luechas á los roturadores de Sierra Morena, por virtud del Real decreto de 19 de Mayo de 1816; de la Bula de Su Santidad de 31 de Ostubre del mismo año, comunicada en Real cédula de 23 de Diciembre del siguiente, de la de 22 de Julio de 1819, del Real decreto de 31 de Mayo del mismo año, y de la concesion hecha en 1825 á D. Francisco Sanchez Gadeo.

Como complemento de instruccion, se insertan los capítulos L á LVIII de la ley $3 .{ }^{a}$, libro VII, título XXII de la Novisima Recopilacion, que forman parte de las disposiciones dictadas para colonizar Sierra Morena, y además, de otras varias, la de 1825 , por la que se promete á Gadeo la exencion de tributos por diez y seis años y el tílulo de Baron, si realiza el proyecto de fundar las poblaciones que se expresan.

107. COLECCION DE LEYES, DECRETOS Y DEMÁS DISPOSICIONES DE INTERÉS GENERAL, RELATIVAS AL SERVICIO ASí FACULTATIVO COMO ADMInistrativo Del Ramo DE montes, expedidas desde 22 de Diciembre de 1833 hasta 31 de Diciembre de 1868. - Madrid, imprenta del Colegio nacional de Sordo-mudos y de Ciegos, 1869.—4., 462 páginas.

Publicacion oficial hecha por el Ministerio de Fomento, en virtud de haqerse agotado la primera edicion. En esta se refunden en un solo volúmen, todas las disposiciones contenidas en la edicion de que damos cuenta en el número que sigue, admitiendo tan solo las que están vigentes, y descartando, por lo mismo, las que derogadas ó inaplicables, hacen confuso el manejo de estas colecciones legislativas. Se añaden las autorizaciones para procesar decisiones y sentencias del Consejo de Bstado, publicadas desde que rige el reglamento de 17 de Mayo de 1865̆, para la ejecucion de la ley de montes de 24 de Mayo de 1863, que ofrecen mayor interés.

La coleccion comienza con las Ordenanzas generales de montes de 22 de Diciembre de 1833. Tiene dos indices, uno cronológico y, otro alfabético, que hacen muy cómodo y rápido el manejo.

108. ColicCiON DE LEYES, REALES DECRETOS X DEMÁS DISPOSICIONES DE INTERÉS GENERAL, RELATIVAS AL SERVICIO ASí FACULTATIVO COMO ADMINISTRATIVO DEL RAMO DE MONTES, expedidas desde 22 de Diciembre de 1833 hasta 31 de Diciembre de 1868.--Escudo de armas de España. - Madrid: Imprenta nacional, 1859-1866.-4. ${ }^{\circ}$ Dos tomos de 483 y 292 páginas.

El segundo tomo comprende lo legislado desde el 17 de Marzo de 1859 , 31 de Diciembre de 1865.

Es publicacion dispuesta por el Ministerio de Fomento, que comienza en las Ordenanzas generales de montes de 22 de Diciembre de 1833 . Tiene dos in- 
dices, uno cronológico y otro alfabético, que hacen muy cómodo y rápido el manejo.

109. Coleccion de madras formada y dedicada á S. M. el emperador de lo: franceses, por el Sr. D. José María de Fivaller de Velaz, Ingeniero de montes.-Litografía de Roig.-4. ${ }^{\circ}$ mayor, 7 páginas sin iumeracion.

No hay fecha ni se indica el lugar de la publicacion, si bien se sabe que se hizo en Barcelona. Comprende este catálogo 234 especies leñosas, indicadas con sus nombres científicos y los vulgares en español y francés, añadiendo las noticias de las localidades en que se encuentran las mensionadas especies, y el sitio de su procedencia.

110. Coleccion de productos í instrumentos Forestales. (Indice).-Exposicion universal.-París, año de 1855.-Madrid: Im prenta de M. Rivadeneyra, 1855.

Es una hoja de gran tamaño impresa por órden del ministerio de Fomenlto, que contiene el catálogo de las maderas, carbones, ciscos, resinas, espartos, cortezas, corchos, instrumentos, plantas, maderas de Costa-Firme, y marcos de Madrid y de Cuenca, que figuraron en la Exposicion universal, coleccionadas por el cuerpo de Irgenieros de montes español.

111. Coleccion de productos forestales. (Indice).-Exposicion universal.-Lóndres, año de 1862.

Es una hoja de gran tamaño impresa de órden del Ministerio de Fomento, que contiene los nombres sistemáticos, los vulgares españoles y los vulgares ingleses, de las muestras de madera de 316 especies leñosas remitidas á aquel certamen por el cuerpo de Ingenieros de montes español. Se indican tambien las provincias de donde proceden los ejemplares.

112. Comision de la Flora forestal española.-Resúmen de los trabajos verificados por la misma durante los años de 1867 y 1868 . Madrid: Imprenta del Colegio nacional de Sordo-mudos y Ciegos, 1870. - En folio, 137 páginas y 7 láminas en negroque representan diferentes formas de hojas de especies del gémero Quercus.

Esta Memoria presentada por el Jefe de la comision el Inspector del cuerpo de montes, D. Máximo Laguna, se mandó imprimir por cuenta del Estado por órden de S: A. el Regente del Reino de 14 de Setiembre de 1869.

En el Itinerario describe las excursiones hechas por Andalucia, Valencia, Alicante, Logroño, Navarra, Iluesca, provincias Vascongadas y alguna otra. Sigue despues un catálogo metódico de las especies clasificadas por la comision, que llega al número de 369 , y concluye con unos Aquntes y observaciones sobre algunas familias y especies incluidas en el catálogo anterior de los géneros Abies, Pinus y Quercus.

113. Comision de la Flora formestal española.--Resúmen de los trabajos verifieados por la misma durante los años de 1869 y 1870 . Madrid: Tipografía del Colegio nacional de Sordo-mudos y Ciegos, 
1872. -En folio, 199 páginas y 13 láminas en negro que representan una Genista, y varias ramas y frutos de Quercus, Sorbus, Catha ó Celastrus, Myrtus y Rhamnus.

Presentada esta Memoria por el Inspector del cuerpo de montes D. Máximo Laguna, y mandada imprimir por euenta del Estado, por Real órden de 10 de Julio de 1871.

Comprente las Escursiones á las provincias de Extremadura, Toledo, Cuenca, Guadalajara, Zaragoza, (Moncayo), Santander, Astúrias, Navarra, provincias Vascongadas, Barcelona, Tarragona, Gerona, Lérida, Murcia, Alicante, Gålicia, Cádiz, sevilla, Huclva, Málaga y Granada. Sigue un catálogo metódico de las especies leñosas dicotiledóneas y monocotiledỏneas en número de 489, y unos Breves apuntes sobre el haya.

114. Compendo de Arboricultura, aplicado á las plantaciones en las carreteras, por el ingeniero jefe de 2." clase de caminos, canales y puertos, D. Luis Sainz y Gutierrez, comendador de número de la Real y distinguida órden de Isabel la Católica.-Jaen. 1871. Imprenta de los Sres. Rubio. - $4 .^{\circ} \mathrm{v}-222$ págrinas y 4 de índice,

El Ministerio de Fomento manifestó haber visto con agrado el trabajo. y lo recomendó á los Ingenieros jefes de provincia.

C'onsta el Compendio de nueve partes y un apéndice, distribuyéndose en elias las materias, del modo siguiente: Primera parte. Nociones elementales de organografia y fisiologia vegetal. - S'egunda parte. Establecimienlo y conservacion de un vivero.-Tercera parte. Propagacion de los árboles. - Cúarta parle. Trasplante definitivo. - Quinta parle. Aplicaciones diversas de las plantaciones. -Sesta parte. Poda y sus modificaciones.-Sétina parte. Enfermedades de los árboles y lesiones que pueden sufrir.-Oclava parle. Aninuales perjudiciales $y$ animales ütiles $\dot{a}$ los árboles. -Novena parte. Lijera descripcion de los principales árboles y arbustos que pueden colocarse en los paseos, parques, carreteras y setos vivos. Sigue un Apéndice, que contiene la explicacion del nuevo sistema de pesas y medidas.

115. Cuspendo de las leyes expedidas sobre la caza, nveramente defendida é ilvstrada, práctica, civil y criminal en la materia de Reales Bosques, y Sitios, y su expedicion en los Tribunales; Dedicale al Eminentmo. Señor Don Lvis Manuel Fernandez Portocarrero, Cardenal de la Santa Iglesia de Roma del título de Santa Sabina, Arçobispo de Toledo, Primado de las Españas, Chanciller Mayor de Castilla, del Consejo de Estado de Su Mag. Su avtor el lic. Don Ga:par de Bvjanda, Abogado de los Reales Consejos, y Cura pròpio de la Iglesia Parroquial de San Martin de la Villa de Ocaña. Con licencia, en Madrid: Por Francisco Sanz, Impressor del Reyno, y Portero de Cámara de Su Mag. Año de 1691.-4. ${ }^{\circ} 132 \mathrm{~h}$.

Indicada de este modo en el Ensayo de una Biblioteca española de libros raros y curiosos, de los Sres. Zarco del Valle y Sancho Rayon. 
Son unos comentarios bastante prolijos de las leyes expedidas sobre la caza, tanto en baldíos como en sitios reales, hasta la fecha en que escribio el autor.

116. Compendio de Valoracion de montes, por el Dr. Gustavo Heyer, director de la academia forestal de Munden, traducido del aleman por D. Francisco de P. Arrillaga, ingeniero de montes. profesor de la escuela especial del ramo.-Madrid, Imprenta nacional. $-4 .^{\circ} 123$ páginas.

Esta traduceion ha sido publieada por el Gobierno, prévios los favorables informes que respecto de ella, emitió la Junta de profesores de la escuela de Ingenieros de montes y la consultiva del ramo. "No existiendo obras de igual mérito, ni en francés ni en español, dice el Sr. Arrillaga, adopté para texto en la escuela la de lleyer que por su órden, su método, su concision y buena doctrina es la mas propia para satisfacer las exigeneias de la enseñanza."

Se divide en dos partes: la primera estudia lo relativo al valor, al interés, al cáleulo de intereses, las fórmulas para el eáleulo de los intereses compuestos y los ingresos y gastos; en la segunda se hacen ya las aplieaciones inmediatas de estos conocimientos á la determinacion de los valores del suelo y vuclo y despues á la del monte, eon inelusion de las rentas forestales Concluye la obra con tres tablas de factores para el cálculo de intereses compuestos.

117. Compendio del tratado del célebre Duhamel du Moxceat SOBRE SIĖMIBRAS Y PLANTíOS DE ÁRBOLES Y DE SU CULTIVo, ó medios de multiplicar y criar árboles; de plantarlos en espesillos y alamedas; de formar montes y bosques, y de conservar y restablecer los deteriorados. Ilustrado con notas por el Dr. D. Casimiro Gomez Ortega, indivíduo de varias academias literarias y sociedades económicas de dentro y fuera de España, y ảel Instituto Nacional de Francia. Madrid 1805, Imprenta Real.—8..$^{\circ}$ marquilla, 318 páginas.

Explica las eausas del atraso de las plantaciones en España, no obstante las eédulas protectoras del siglo XVI, que inserta literalmente. Consta la obra de seis libros: el $1 .^{\circ}$ versa sobre el terreno, exposicion y eleccion de las especies; el $2 .^{\circ}$ trata de la multiplicacion; el $3 .^{\circ}$ del cultivo de los arbolillos nuevos hasta la época de su trasplante en lugar permanente; el $4 .^{\circ} \mathrm{del}$ plantío de árboles criados en plantel y otras eausas concernientes al objeto; el $5 .^{\circ}$ de los bosques de grande extension y el $6 .^{\circ}$ de la conservacion y restauracion de los mismos.

118. CoMpendio sobre EL MOdo dE SEMbrar, plantar, CRIAR, POjJAR y CORTAR TODA ESPECIE DE ÁtrBOLES, con su descripcion y propiedades, para la conservacion y aumento de los montes y arbolados, y utilidad de los empleados en este ramo, y de los labradores y hacendados. Por D. Juan Bautista Golobardas, oficial quinto honorario del Ministerio de Marina, y teniente $y$ visitador de montes 
del corregimiento de Vich, provincia marina de Mataró, del departamento de Cartagena.-Barcelona, 1817, por Brusi.-8. 308 páginas.

Trata de los montes y árboles, de la sie mbra, trasplante, poda, conservacion, aumento y corta del arbolado y de los frutos, flores, hojas, cortezas y demás productos, insertando al final un índice alfa bético de los árboles de que se ocupa, poniendo los nombres en castellano, latin y catalán.

119. Compendios de las ACTAS DE La ReAl Sociedad ARAgonesa correspondientes á los años 1798-1804, formados mediante comision de la misma, por su secretario D. Diego de Torres.-Escudo de la Sociedad con el lema Florece fomentando.-Con licencia. En Zaragoza: en la imprenta de Mariano Miedes, impresor de la Reál Sociedad, los tomos $1 .^{\circ}, 2 .^{\circ}, 3 .^{\circ}, 4 .^{\circ}, 5^{\circ}$ y $7 .^{\circ}$, años 1799,1800 , $1801,1802,1803$ y 1805 , y en la oficina de Medardo Heras, el tomo $6 .^{\circ}$, año $1804.4 .^{\circ}, 100$ paginas próximamente cada tomo.

En el Diccionario de bibliografia agronómica del Sr. Anton Ramirez, no se dá cuenta más que del Compendio de 180u. D. Francisco Zapater y Gomez, ilustrado propietario de Zaragoza, y uno de los sócios á quienes debe más la Económica aragonesa, posee una coleccion completa de dichos Compendios, que ha examinado el jóven ingeniero de montes D. Patricio Bellido. Nosotros no tenemos noticia de que exista otra coleccion, si bien es fácil encontrar algun tomo suelto. De la publicacion de estos Compendios dió noticia D. Agustin Alcaide, secretario que fué de la Sociedad en su Discurso leido á la Real Sociedad Aragonesa de los A migos del Pais en la junta general de apertura que celebró el 13 de Enero de 1815, páginas 10 y 17, Zaragoza en la oficina de Andrés Sebaslian. $-4 .^{\circ}, 72$ páginas, del cual posee un ejemplar el laborioso bibliófilo y entendido abogado D. Pascual Savall y Dronda, en la actualidad residente en Madrid y censor que ha sido de aquella corporacion, al cual debemos muchas noticias y el exámen de varios libros muy curiosos que contiene su rica librería.

En el Compendio de 1798, página 9, se hace constar que en los montes de la villa de Sádaba hubo hasta la mitad de aquel siglo en la parte confinante con las Bárdenas Reales, bosques y madera abundante para las casas y edificios, aprovechándose aun en los últimos años, muchos pinos para casas pequeñas, pero que en el dia apenas se podia con mucho trabajo sacar leña para el consumo de la villa, la cual no habia cuidado de la conservacion de los montes y ménos de replantar y llevar á efecto las Reales órdenes de plantíos. Con este motivo, la Sociedad encarece la necesidad que la agricultura, las artes y manufacturas tienen de los montes, y lastimándose de su desolacion y ruina, trae á la memoria del público la conveniencia de cumplir las disposiciones sobre fomento del arbolado, y aconseja el reparto de premios á los que propaguen las plantaciones, recordando que por este medio se logró la plantacion de más de 24.000 árboles. Dá cuenta tambien de haber encargado al secretario la formacion de un papel que demuestre el estado deplorable de 
los bosques, é indique los medios que deban representarse á la piedad del Rey para evitar una decadencia tan universal.

En el Compendio de 1799, se dió cuenta de haber plantado el sócio D. Joaquin Garcés de Marcilla, más de 8.000 árboles en las márgenes del rio y parages eriales. Tambien se consigna haber a tjud icado la Sociedad un premio de $\mathbf{2 0}$ pesos á D. Joaquin Garay, vecino del lugar de Alloza, por haber plantado en las riberas de los rios y parajes eriales del corregimiento de Alcañiz y en el término de aquel lugar, gran número de árboles fresnos, álamos blancos y olmos en el invierno de 1798. Asimismo se dá cuenta de haber adjudicado el premió de 50 pesos y la patente de sócio al Dr. D. Manuel Normante, presbítero, rector párroco del lugar de Biniés, corregimiento de Cinco Villas, por la Memoria y descripcion que hizo de los pueblos de su partido, en la que se dá cuenta del clima, pastos, condiciones de los montes y otros puntos de interés forestal. En el inismo año la Sociedad aprobó el escrito formulado por el secretario con arreglo á la comision que se le dió en el anterior, para poner de manifiesto el fatal estado de los montes de todo el reino de Aragon, aprobando asímismo los medios que hizo presentes para la restauracion de aquella riqueza, y representando al efecto á la piedad del Rey.

En el Compendio de 1800, se dice haber logrado en varios años descripciones de los partidos de Zaragoza, Albarracin y Teruel, ofreciéndose un premio de 50 pesos al que describa parte de los pueblos del de Alcañiz, señalando el número de vecinos, estado actual de sus montes, cabida de sus pastos, etc.

En el Compendio de 1801, se ofrecen nuevos premios á los que acrediten haber plantado mayor número de árboles en las riberas de los rios y parajes eriales, y se dá cuenta de las grandes plantaciones llevadas á cabo por varios caballeros sócios, en propiedades situadas á orillas de los rios, preservándolas de los riesgos de las avenidas.

En el Compendio de 1802, se dá cuenta desde la página 61 en adelante, de los premios ofrecidos en aquel año por el ramo de agricultura, entre los que figura uno al que mejor trate de los pueblos del partido y corregimiento de Barbastro, comprendiendo la descripcion del clima, situacion, extension y cualidades del terreno, estado presente de sus montes, calidades de sus pastos y proporciones que ofrecen ó podrian ofrecer con mejor cultivo, para carbon, leña, maderas de construccion, etc. Asínismo se señalaron tres premios para los que acreditasen haber plantado mayor número de árboles. en las riberas de los rios y parajes eriales, con ta! que el número no bajase de 500 y estuviesen vivas y prendidas las plantas en la prima vera de 1803. Notificóse la adjudicacion de un premio á D. Joaquin Tramullas, vecino de Zaragoza, por haber plantado 600 lombardos, álamos y olmos, en montes y eriales; y otro á D. Ramon Barberán, vecino de Caspe, por haber plantado tambien en terrenos eriales de aquella villa, 1.100 árboles de álamos, olmos, chopos, sáuces y otros. Añade la Sociedad, que no cesará de fomentar el aumento de plantíos y la conservacion de los montes y arbolados, sobre cuyos asuntos habia hecho las más vivas representaciones á la Superioridad, en vista de la ruina general de los montes y bosques, y de la falta de leñas y maderas. 
En el Compendio de 1803 , se señala un premio de 50 pesos y patente de sócio sin contribucion, al que mejor describa los pueblos del partido y corrégimiento de Tarazona, indicando entre otras cosas, el estado de los montes, calidad de los pastos y proporcion que ofreceria el mejor cultivo de aquellos, para carbon, leña, maderas, etc. Tambien se ofrecieron tres premios de 25 pesos cada uno, al que acreditase haber plantado mayor número de árboles en las riberas de los rios y parajes eriales.

Por último, en el Compendio de 1804, se reprodujeron los premios ofrecidos elı el año anterior, y se dió cuenta de haber adjudicado uno de 25 pesos á D. Gerónimo García y Lopez, vecino de la villa de Ricla, por haber plantado en terrenos eriales. En este mismo Compendio, al dar cuenta de los exámenes generales de los alımnos de la escuela de agricultura sostenida por la Sociedad, se dice que D. Domingo Fernandez disertó sobre los bosques, modo de criarlos y medio seguro de extenderlos; estableciendo el derecho de propiedad á favor de sus cultivadores.

120. Concordia (LA).- - Revista moral, política y literaria.Véase: Sobre las ventajas del arbolado. - Sobre la siembra de las yemas de árboles, etc.

121. Conocimiento de LAS diez aves Menores de JaUla; su canto, enfermedad, cura y cria, y ahora de nuevo añadidas que el autọr le omitió. Compuesto por Juan Baptista Xamarro, residente en esta córte.-Madrid (sin año) por Gabriel del Barrio, impresor de la Real capilla de la Majestad.-8. ${ }^{\circ}, 92$ páginas con grabados.

Esta es la tercera de las ediciones hechas, datando la primera de 1601 y la segunda 'de 1671 . Ocúpase de los ruiseñores, pardillos, jilgueros, canarios, reyezuelos, calandrias, cardenales, ninchones, zorzales, verdecillos, luganos, verderones y solitarios. Es muy original la parte de la obra en que el autor valiéndose de voces breves repetidas, constituye una série de dicciones con las que por onomatopeya pretende imitar el canto de cada una de las indicadas aves.

Dice el Sr. Anton Ramirez, en su Diccionario de bibliografía agronómica, que entre los manuscritos de la Biblioteca nacional (L. 171) existe una copia bastante exacta de este curioso libro, sin nombre de autor.

122. Consideraciones sobre la venta de los bienes de Propios, por D. G. Marazuela Cortés.-Madrid, 1851, imprenta de Neira y Ducazcal. $-4 .^{\circ}, 30$ páginas.

La indicacion de este folleto, del cual nada se dice en el Diccionario de bibliografia agronómica del Sr. Anton Ramirez, la hemos tomado del Diccionario general de bibliografia española de D. Dionisio Hidalgo, tomo Il, página 83.

123. Constitucional (EL).-Periódico político de Madrid.-Véase: Nos place ver á muestros colegas, etc.-Pudièramos decir que en la cuestion de montes, etc. $-A$ las pocis horas de haber leido, 
etc.-El proyecto de ley de montes, etc.-Paseos y arbolados de' Madrid.

124. Consultor (EL) de los ayuntamientos y de los juzgados municipales. Periódico de administracion y de justicia municipal.

Este periódico cuya publicacion continúa, se dió al público por primera vez en 1852, bajo la direccion de D. Marcelo Martinez Alcubilla, con el título de El Consultor. En Julio de 1866 se encargó de la direccion D. Celestino Masy Abad, dandole el título de El Consultor de los Ayuntamientos, siendo de advertir que en 1860 , se denominaba ya $E l$ Consultor de Ayuntamientos. Por último, en 1870 se encargó de él su actual director y propietario D. Fermin Abella, designándole del modo que queda registrado más arriba.

Los números de cada año forman un tomo en fólio, constituyendo ya el número de veinte los publicados desde 1832 á 1872. E: número de páginas varía desde 350 á 500 . Hasta 1869 , se estampó en Madrid en la imprenta de El Consultor. Despues ha seguido estampándose en la imprenta de Enrique de la Riva, de la inisma villa.

Comprende esta publicacion los siguientes artículos que estractamos en el lugar correspondiente: Sobre la repoblacion del arbolado en la provincia de Burgos.-Osservaciones acerca de los (montes) de dominio parlicular y de los de Propios y comunes de los pueblos. - Fomento del arbolado.-Arbolado. Su poda, replantacion y fomento.-Biones de Propios y comunes. Consideraciones sobre la proposicion de ley presentada á las c'órtes para su reparto á censo entre los vecinos. - Observaciones acerca del 10 por 100 de sus productos (de los montes) con destino á su replantacion y fomento. - Conocimiento (Del) de los delitos y faltas por infracciones de las ordenanzas generales de los montes puiblicos. - Aprovechamientos comunales de pastos en favor de la ganaderia.Aprovechainientos comunes. - Propiedad rural. Expedientes de roturaciones arbitrarias. - Aprovechamientos comunales. -Montes. Proyecto de ley presentado á las Cortes.

125. Contemporáneo (EL).-Periódico político de Madrid.Véase: No queremos dejar pasar, etc.-El autor de los articulos sobre montes, etc.-Si prueba necesitásemos de que la ley de montes, etc.

126. Contestacion á la demanda interpuesta ante el Tribunal Supremo, por el letrado D. Francisco Pí y Margall, en nombre de varios ingenieros del Cuerpo Nacional de Montes, sobre revocacion de la Real órden de 6 de Setiembre de 1871, redactada por el letrado D. Víctor Navario, en nombre de los demandados. - Valencia, imprenta de Ferrer de Orga.-1873.—4. ${ }^{\circ}, 16$ páginas.

Este escrito está fechado en Valencia á 1. ${ }^{\circ}$ de Abril de 1873.

La Real órden que se cita en la portada es de 1872, y no de 1871 como allí se dice.

Comentando las disposiciones dictadas sobre el punto objeto de la cuestion, y con presencia de las que regulan la organizacion de la Escuela y 
Cuerpo de ingenieros del ramo, el letrado Navarro aboga por sus clientes, pidiendo la confirmacion de la Real órden de 6 de Setiembre de 1872 relativa á la colocacion, en la escala del Cuerpo, de los ingenieros á quienes dicno letrado defiende.

Véase lo expuesto en el registro del folleto titulado: Demanda interpuesta ante el Tribunal Supremo de Justicia, por el letrado D. Francisco Pi y Margall, en nombre de varios ingenieros del Cuerpo nacional de montes, sobre revocacion de la Real órden de 6 de Setiembre de 1872.

127. Contestacion á las observaciones publicadas por los Sres. D. Ramon Orozco, D. Felipe Barron y D. Antonio Hernandez, sobre aprovechamiento del esparto.-Almería, imprenta de la viuda de Cordero. - 1863.-4. ${ }^{\circ}, 13$ páginas.

Suscrito en Almeria á 29 de Abril de 1863 por D. Ignacio Gomez de Salazar.

Despues de refutar los principales argumentos de sus contrincantes, insiste en las conclusiones de la mocion que presentó en 12 de aquel mes y año á la Junta da Agricultura, Industria y Comercio, sobre la explotacion del esparto, la propiedad de algunos terrenos y el acotamiento de los que pertenecen ó son necesarios á la agricultura y ganadería.

128. Contestacion al escrito publicado por el Sr. D. Ignacio Gomez de Salazar, sobre aprovechamiento del esparto.-Almería, 1863.-Imprenta de D. Mariano Alvarez y Robles.-4. ${ }^{\circ}, 20$ páginas.

Se refiere al escrito que vió la luz pública en 29 de Abril de aquel año. Suscriben la presente contestacion, en Almeria á 4 de Mayo de 1863, los señores D. Ramon Orozco, D. Felipe Barron y D. Antonio Hernandez, refutando las aserciones del Sr. Salazar, é insistiendo en sus opiniones contrarias á las de dicho contrincante en lo que respecta á la propiedad, acotamiento de terrenos y disfrute del esparto en los montes de los pueblos.

129. Continuacion del Almacen de frutos literarios, ó semanario de obras inéditas. - Con Real permiso.-Madrid, imprenta de Repullés, 1818-1819. -8 tomos en $4 .^{\circ}$, de 288 páginas cada uno.

No hemos visto indicada esta publicacion en el Diccionario de bibliografia agronómica del $\mathrm{Sr}$. Anton Ramirez, siendo así que registra la titulada: Almacen de frutos lilerarios. En la que nos ocupa, encontramos los artículos siguientes, de que damos cuenta en el lugar que les corresponde: Descripcion de la isla de Pinos, etc.-Apuntaciones sobre los montes de Galicia y Astúrias.

130. Correspondencia (LA).-Diario de noticias publicado en Madrid.-Véase: Comunicado, por D. Mariano de la Paz Graells.

131. Crónica (La).-Periódico de Badajoz. - Véase: Un problema sobre montes.-Observaciones almosféricas, etc. 
132. Cuerpo de ingenieros de Montes.-Véase: Coleccion de troductos é instrumentos forestales. - Coleccion de productos foresales.-Modelo de uniforme.-Instruccion de entrada, etc.-Programa de las malerias, etc.

133. Cuerpo nacional de ingenieros de montes.-Véase: Cuerpo de ingenieros de Montes.

134. Cujestion sobre el dominio de los montes de Caravaca, pendiente entre el Estado y los particulares propietarios de los inismos.-M adrid, imprenta de C. Moliner y compañía.-1871.-4. ${ }^{\circ}$ 35 páginas.

Aparece suscrito en Caravaca á 19 de Setiembre de 1871 por los señores D. Antonio Blanc, D. Eugrenio Vallejo y D. Diego Sanchez Olmo, á nombre de la comision de propietarios.

Se hace una historia comentada del expediente posesorio, cuya resolucion pendia del ministerio de Fomento, por lo que toca á ciertos actos administrativos de formacion del catálogo de montes públicos, subasta de espartos y otros particulares. El objeto es probar que el Estado no tiene derecho alguno á los indicados montes, y que se debe dejar en quieta y pacífica posesion de ellos, á los que se dicen sus propietarios.

135. Cultivador (El).-Periódico de agricultura, horticultura, jardinería y economía rural, publicado bajo los auspicios de la M. I. Junta de Comercio de Barcelona, y dirigido por su catedrático de Agricultura práctica y botánica, D. Jáime Llansó.-Barcelona, 1848-1851, imprenta de J. M. de Bodallés, de R. M. Indar y de El Sol.-Cuatro tomos en $4 .^{\circ}$, de á 500 páginas próximamente á dos columnas.

Figuran entre sus articulos los siguientes: Alcornoques; de si es útil el trasplanlarlos. Se dan reglas para el trasplante de los expontáneos y de los procedentes de almáciga ó criadero. III. 81.-Criaderos de arbolados; necesidad de que se propaguen; exiracto de una Memoria escrita por D. José de Salvador, IV. 25.-Fresno; sus utilidades; se habla principalmente del aprovechamiento de sus hojas para forraje. II. 134.- Hojas de los árboles, cosecha y conservacion para alimento del ganado. I. 150.-Poda en general, de su origen, su objeto y opiniones de los que la creen contraria á la naturaleza. IV, 378 - Prados naturales; de su conservacion; 1.439.

Contiene además tres artículos titulados Almez, Bosques y Castaño, y una Memoria sobre los bosques y arbolados de España, que registramos en el lugar que les corresponde segun sus títulos.

136. Cultivo de Árboles.-Por A. de Herrera.-Madrid, 1773. $-8 .^{\circ}$, pergamino.

Así indicada en el Catálogo de los libros que se hallan de venta en la libreriade D. B.J. Hernandez, en las Cuatro-Calles de Toledo.-Madrid, imdrenta de Espinosa y compañia, 1850.-4. $0^{\circ}, 80$ páginas. 
En el Diccionario de bibliografia agronómica del Sr. Anton Ramirez nada se dice de este libro, al menos bajo el título con que lo damos á conocer. No seria extraño que la indicacion del Catálogo fuese defectuosa.

137. Cultivo DE LOS PRADOS NATURALES Y FORMACION DE LOS ARTIFICIALEs, con una reseña de las plantas más útiles para ellos, conforme á los adelantos de la época, y segun las doctrinas de los mejores agricultores nacionales y extranjeros, tales como Herrera, Arias, Soto, Rozier, Hanim, etc., por D. R. C. y S.-Madrid, 1859, por R. Campuzano.-8. $.^{\circ}, 63$, págs.

Se ocupa de lo concerniente á la materia, distinguiendo con minuciosidad los prados naturales de los artificiales. Añade una lista de las plantas dañosas.

138. Curso completo 6 diccionario universal de agricultura TEÓRICA-PRÁCTICA, económica y de medicina rural y veterinaria, escrito en francés por una Sociedad de agrónomos y ordenado por el abate Rozier, traducido al castellano por D. Juan Alvarez Guerra, individuo de la Sociedad económica de Madrid.-Madrid, 1797-1803, Imprenta Real. - 16 tomos en $4 .^{\circ}$ de más de 400 páginas cada uno. -Ilustrado con 138 láminas y cuatro estados.

En las Variedades de ciencias, literatura y artes, 1803, tomo I. pág. 36, se da una idea de la obra, y en el Memorial literario de los años 1801 y 1804 , tomo I, páginas 108 y 321; tomo III, páginas 42 y 237; tomo IV, página 131 , y tomo V, páginas 13 y 194 , se describen los artículos más notables de los tomos IX hasta el XVI, que es el último.

Despues se publicó una edicion económica titulada Nuevo Diccionario de Agricultura leórico-práctica y económica y de medicina doméstica y veterinaria, del abate Rozier.-Madrid, 1842-1815.--Imprenta de I. Boix, editor.13 tomos en $4 .^{\circ}$ con 143 láminas y una portada alegórica.

Es tal el desórden que se advierte en los índices para colocar las 143 láminas, que no hay medio de lograrlo sin un esquisito cuidado. D. Dionisio Hidalgo, en su Boletin bibliográfico, se toma la pena de hacer á este efecto una detenida y oportuna explicacion.

Se ocupa, entre otros asuntos de cierto interés forestal, de la descripcion, culivo, propiedades y aplicaciones del abedul, abeto, acácia, acebo, acebuche, álamo, arce, almez, alcornoque, alerce, lentisco, cornicabra, aliso, almendro, a vellano, castaño, carpe, cedro, chopo, encina, enebro, fresno, haya, pino, sabina, serval, taray y algunos otros vegetales leñosos.

139. Curso jJe Agricultúra pRáctica conforme à los últimos adelantamientos hechos en esta ciencia y á las mejores prácticas agrarias de Europa, por D. Agustin de Quinto.-Madrid, 1818, por Collado.-Dos tomos en $4 .^{\circ}, 340$ y 463 páginas y varias láminas.

En 18301 se hizo otra edicion en Madrid por J. Rodrigueż, dos tomos en $4 .^{\circ}$ con 299 y 375 páginas. En 1861 se reprodujo por la libreria Lopez en dos to- 
mos tambien de 300 y 376 páginas, con el título de Novisima guia de labrado res, etc. gerto.

El tomo segundo trata de los árboles en general y de la poda é in-

\section{D.}

140. Debate (Er).-Periódico político de Madrid.-Véase: Privilegios.-Proyecto de ley de montes (El).

141. Defensa del ayuntamento constitucional de San Martin DE Valdeiglesias, en los autos que sigue con doña María Ascension de Latorre é hijos, sobre la propiedad de la finca titulada: "La Magdalena,» por el licenciado D. Juan Antonio Corcuera, abogado de los tribunales nacionales y del ilustre colegio de esta córte.Madrid, 1865.-Imprenta de D. Pedro Montero.-Fólio, 36 páginas.

La defensa está fechada en Madrid á 20 de Diciembre de 1863. El prédio objeto del litigio comprendia doscientas sesenta fanegas con inonte de pino y jaras, valoradas en dos millones de reales.

142. Demanda interpuesta ante el Supremo Tribunal de JusTicia, por el letrado D. Francisco Pí y Margall en nombre de va_ rios ingenieros del cuerpo de montes sobre revocacion de la órden de S. A. de 23 de Marzo último.-Madrid: Imprenta de la Sociedad española de crédito comercial.-1870.-4. $0^{\circ}, 23$ páginas.

Fechada en Madrid á 22 de Agosto de 1870. Se pide la derogacion de la órden del Regente, lecha 23 de Marzo de 1870, por la que se declara que los recurrertes no han utilizado en tiempo oportuno los recursos que las leyes les concedian para pedir la expulsion del Cuerpo de los ingenieros señores D. Cláudio Boutelou y D. Antonio Campuzano. Se pide asimismo la anulacion del título de los referidos ingenieros, $\delta$ cuando menos, la rectificacion del escalafon del Cuerpo, poniendo á estos en el lugar que les corresponde por la numeracion de sus títulos.

143. Demanda interpuesta ante el Tribunal supremo de JusTicia por el letrado D. Francisco Pí y Margall ei nombre de varios ingenieros del cuerpo nacional de montes sobre revocacion de la Real órden de 6 de Setiembre de 1872.-Bar'celona: Im-prenta de Cayetano Campins (Gracia). 1873.-4. ${ }^{\circ}, 11$ páginas.

Fechada y suscrita en Madrid a 27 de Diciembre de 1872. Aboga, á nonıbre de los ingenieros D. Victoriano Deleyto, D. Eugenio Plá, D. Erǹesto Ruiz, D. Gerardo Conder, D. Eduardo Castellanos, D. Calisto Rodriguez y D. Cárlos Allué, pidiendo la revocacion de la Real órden de 6 de Setiembre de 1872 , por la que, modificando lo dispuesto en la de 11 de 0ctubre de 1871, se establece que los indicadosingenieros queden colocados encl escalafon de 
a clase de segundos, como fueron clasificados por la Junta de profesoros de la Escuela, ó sea alternando con los ingenieros D. Eduardo Serrano, D. Ricardo Cordoniu, D. José Deop, D. José Diaz Hoyuelos, D. Ramon Egozcue, D. Benigno Quiroga y D. Ramon del Hoyo. Solicita en su virtud la confirmacion de la segunda de aquellas Reales disposiciones, y el derecho, á favor de sus representados, á ser indemnizados de todos los perjuicios que por la Real órden de 6 de Setiembre se les hayan irrogado y puedan irrogárseles, inclusos en estos perjuicios las costas del juicio.

144. Demostracion de una Calumia y respuesta á varias murmuraciones con la historia de los hechos.-Promesa cumplida á los toledanos por D. Manuel María Herreros, su convecino. Toledo: Imprenta de Severiano Lopez Fando, 1862.-4. ${ }^{\circ}, 60$ páginas.

Trata de la marcha administrativa oficial del asunto rcferente á la division de los montes de Toledo, aboliendo la mancomunidad y disponiendo la asignacion de términos á los pueblos existentes en el territorio de dichos montes, con el establecimiento de enfiteusis sobre otros terrenos á calidad de reducirlos á cultivo en propiedad particular, caso que comprendia á los vecinos del antiguo lugar de Yébenes, barrio de Toledo.

145. Dertosense (EL).-Véase: Montes. Discordancia entre el periódico La Ley y El Derlosense sobre esta materia.

146. Descripcion de la Cañada leonesa, desde Valdeburon á Montemolin.-Madrid: 1856.--Imprenta de M. Minuesa. $-8 .^{\circ} .52$ páginas.

De este folleto y de los siguientes no se ha puesto ningun ejemplar á la venta. No se mencionan en el Diccionario de bibliografia agronómica del Sr. Anton Ramirez. Están indicados en el tomo II, pág. 247 del Diccionario general de bibliografia española de D. Dionisio Hidalgo.

147. Descripcion de la Cañada segoviana, desde Carabias al valle de la Alcudia.-Madrid: 1856.-Imprenta de M. Minuesa.8. ${ }^{\circ}$ mayor, 38 páginas.

148. Descripcion de la Cañada sortana, desde Yanguasal valle de la Alcudia. - Madrid: 1857.-Imprenta de M. Minuesa.-8. mayor, 40 páginas.

149. Descripcion é historia del Paraguay $\mathrm{Y}$ del Rio de la Plata.-Obra póstuma de D. Félix de Azara, brigadier de la Real Armada, y autor de las obras tituladas: «Apuntes para la historia de los cuadrúpedos y pájaros del Paraguay,» y de otras. La publicasu sobrino y herederi el Sr. D. Agustin de Azara, marqués de Nibbiano, caballero de la órden de Cárlos III, etc., etc., bajo la direccion de D. Basilio Sebastian Castellanos de Losada, caballero de las órdenes de Isabel la Católica y de San Genaro, Anticuario de la Bi- 
blioteca nacional, etc., etc., autor de varias obras literarias, de Is biografía de dicho autor con que concluye la obra, y de las notas que la ilustran.-Madrid: 1847.-Imprenta de Sanchiz.-2 tomos en $4 .^{\circ}$, de 347 y 288 páginas.

El capítulo VI, páginas š̉ á 79, está destinado á tratar de las plantas sil_ vestres. En él se dá noticia de la mayor parte de las especies vegetales que se encuentran en los montes, describiendo el estado general de estas y las cualidades de vegetacion, económicas é industriales de los árbøles y arbustos que en ellos viven.

150. Descripcion generax de Africa.-Por Luis del Mármol. Primera parte: Granada, por René Rabut, 1573.-Dos tomos en fólio; 294 fol. con 6 de principios, y 14 tablas el I, y el II 308 fol. con dos de principios. Segunda parte: Málaga, por René, 1599; un tomo fólio, 117 fól. con 2 de principios.

Contiene noticias sobre varias producciones de Africa, y se ocupa especialmente del Alerce, Callitris quadrivalvis. Vent., y del Erguen 6 Argan, Argania Sideroxylon. Rœm et Schult.

151. Descripcion histórica del Real Bosque y CASa de AranJuEz, dedicada al Rey Nuestro Señor por D. Juan Antonio Alvarez de Quindós y Bạena, criado de S. M. -De órden superior.-Madrid en la Imprenta Real.-Año de 1804.-8. 472 páginas.

Es interesante la relacion que en esta obra se hace de la dehesa y jardines de aquel Real Sitio.

No está indicado este libro en el Diccionario de bibliografia agronómica del Sr. Anton Ramirez.

152. Descripcion y RESISTENCIA DE LAS MAdERAS DE CONSTRUCCIoN de las Islas Filipinas, por el teniente coronel graduado, comandante del cuerpo de ingenieros del ejército, D. Nicolás Valdés. -Manila, imprenta de Ramirez y Gira udier, 1858.-4. ${ }^{\circ}, 30$ páginas.

Este trabajo, fechado en. Manila á 1. ${ }^{\circ}$ de Junio de 1856, está hecho con presencia de los de igual clase ejecutados anteriormente por el coronel de ingenieros D. Tomás Cortés en 1828, y por el coronel de artillería D. Juan Novella.

Comprende los nombres vulgares y específicos, la descripcion y las aplicaciones de la madera de 48 especies indigenas, expresando en cada una de ellas el peso especifico, la resistencia á la presion y tension ó sea coeliciente de cohesion, elasticidad máxima á que se deben someter en las construcciones, carga correspondiente á esta elasticidad, coeficiente 6 módulo de elasticidad, y resistencia á la torsion indicando el coeficiente de fractura en fuerza. absoluta y en las aplicaciones.

Al final va un cuadro que expresa el órden de preferencia que merecen 
las maderas antes indicadas, con arreglo á las diferentes resĩstencias y cualidades especiales.

No hemos visto registrado este folleto en el Diccionario de bibliografía agronómica del Sr. Anton Ramirez.

153. Despues DE Algunos DIAS, etc.-Almería, imprenta de la viuda de Cordero. - Hoja volante en $4 .^{\circ}$, una página.

Manifiesta al púbtico, su autor D. Ignacio Gomez de Salazar, con fecha 6 de Junio de 1863, que se ha enterado de otra hoja circulada por los señores Orozco, Barron y Hernandez contra su persona, con relacion á la polémica que viene sosteniendo con dichos señores acerca del aprovechamiento del esparto, la cual califica de inexacta, prometiéndose responder en todos los terrenos de los cargos que se le hacen.

154. Destructor DE LOS insectos (Ex). - Traduccion del francés. -Madrid, Romeral, $1844,8 .^{\circ}$

Citado así en el Bosquejo de bibliografia agricola de D: Agustin Pascual. No consta en el Diccionario de bibliografia agronómica del Sr. Anton Ramirez.

155. Diana (LA) ó arte de la caza,-Poema dedicado al Serenísimo Sr. D. Luis Antonio Jáime de Borbon, infante de las Españas etc. Por 1). Nicolás Fernandez de Moratin, criado de la Reina Madre, Nuestra Señora. Entre los Arcades de Roma, Flumisbo Thermo-, donciaco.-Madrid, 1765, oficina de Miguel Escribano.-8. ${ }^{\circ}$, xII-108 páginas sin numerar.

Es un poema de 438 estrofas divididas en cinco cantos: el $1 .^{\circ}$, que consta de 83 , trata de la antigüedad, orígen y excelencia de la caza; el $2 .^{\circ}$, de 69. sobre sus peligros y pertrechos necesarios, como instrumentos, animales, etc, y su enseñanza; el $3 .^{\circ}$, de 68 , sobre la cura de los caballos, pesquería y astro. logia, como necesaria á los cazadores; el $4 .^{\circ}$, de $\mathbf{7 4}$, sobre la volatería 0 caza de las aves; el $5 .^{\circ}$, de 81 , sobre la caza de las fieras, y su naturaleza, y el $6 .^{\circ}$, de 63, se titula Batida general.

156. Diario de avisos de Zaragoza. - Véase: Sobre montes.

157. Diario de Barcelona, de avisos y noticias.-Véase: Inundaciones (Las).-Desamortizacion forestal._Proyecto de ley de montes $(E l) .-M e d i o$ de aumentar las lluvias, etc.

158.-Diario De CÁdiz. - Véase: Ultimo atentado contra nuestra riqueza forestal.

159. Diario de las sesiones de Córtes. 1861.- Véase: Dictámen de la comision y roto particular, etc.

160. Diario de las sesiones de las juntas generaes de agriCultura.-Año de 1849.-Madrid, 1849, por M. de Rojas.-Fúlio, 171 páginas y 140 de apéndices, lista é índices. 
Entre las materias sujetas á la deliberacion del Congreso agrícola fígura' la siguiente: $\pi_{0}{ }^{2}$ Variaciones que convenga introducir en nuestra legislacion para el fomentode los montes y plantios. - Véase: Dictámen presentado á las Juntas generales de Agricultura de 1849.

161. Diario de Tarragona. - Véase: Lijeras consideraciones sobre la falta de lluvia, etc.-Agricultura $(L a)$ y los montes.

162. Diccionario de agricultura práctica y economía rural.Redactado bajo la direccion del Excmo. Sr. D. Agustin Estéban Co'llantes y D. Agustin Alfaro, por D. Augusto de Búrgoos, D. Agustin Pascual, D. José Hidalgo Tablada, D. Miguel Bosch, D. Nicolás Casas y Mendoza, D. José Echegaray, D. Balbino Cortés y otras especialidades._Madrid, 1851-1855, por L. García, A. Perez Dubrull, M. Minuesa y C. Armesto. - Siete tomos en $4 .^{\circ}$ mayor de á 600 páginas próximamente á dos columnas, y un atlas de 56 láminas que contienen más de 500 figuras.

La portada que se repartió en $185 \%$, al terminar la publícacion, se halla escrita en dichos términos; las que se dieron durante ésta, decian así: „Diccionario de agricultura práctica y economia rural, redactado bajo la direccion de D. Agustin Estéban Collantes y D. Agustin Alfaro, jefes superiores de Administracion civil, individuos de la Sociedad Económica Matritense y de otras corporaciones científicas y literarias."

Contiene la descripcion de casi todas las especies forestales y distintos artículos de carácter administrativo y legislativo. Descuellan las monografias dasonómicas del abedul, abeto ó pinabete, acácia, acebo, arce, álamo, alcornoque, alerce, almez, a vellano, encina, haya y pino, respecto de las cuales. Cespues de una abundante lista de las especies arbóreas del mismo género exóticas ó indigenas, se dan sus nombres vulgares y científicos y se describe la localidad, métodos de beneticio, cultivo, productos, enemigos, enfermedades y cuantas noticias se requieren para un completo conocimiento dasonómico.

Los artículós Baldios y Propios están desarrollados del modo más conveniente á la historia administrativa, legal y económica de esta clase de fincas.

Reune todos los antecedentes necesarios para el aprovechamiento y cultivo de yerbas y pastos el artículo Prados.

En los que se ocupan de las Leñas y Madera, se da á conocer la estructura anatómica, composicion química, cualidades y aplicaciones de estos productos, reseñarido los métodos de preparacion y conservacion.

El tratado de las cstepas, que no otra cosa es el artículo Sosar, compendia cuanto se ha escrito acerca de las de nuestro pais, con inclusion de los detenidos trabajos de Willkomm.

Tiene en él cabida la descripcion de las costas españolas bajo el aspecto climatológico y fitográfico, terminando con un numeroso catálogo m etódico de las planıas halófilas de la Península.

Por último, en el artículo Ciencia de montes se resume con el mayor méto- 
do y claridad toda la dasonomia, ocupándose de las cortas, métodos de beneficio, operaciones de aprovechamiento, pastos, yerbas,',brozas, ramoneo, frutos, cortezas, jugos, plantas menudas, caza, pesca y canteras, guarderia, siembras y plantaciones, entrando luego en la dasocracia, subdividida en reconocimiento, inventario y ordenacion, con otras divisiones de órden inferior, que omitimos por no hacer demasiado extenso este comentario.

El artículo destinado á la Escuela de montes, que sigue inmediatamente al anterior, dibuja á grandes rasgos la historia forestal, natural y técnica de España, y termina con una clara y minuciosa descripcion de aquel establecimiento.

163. DicCIONARIO DE DERicho AdMinistrativo ESPAÑor, para uso de los funcionarios dependientes de los ministerios de Gobernacion y Fornento, y de los Alcaldes y Ayuntamientos. Por D. Fernando Cos-Gayon y D. Emilio Cánovas del Castillo. -Madrid: 1860. Imprenta de los herederos de Vallejo. $-4 .^{\circ}, 992$ páginas.

Dá cuenta de todas las disposiciones vigentes en los ramos que abrazan aquellos dos ministerios. La materia forestal se encuentra en las siguientes indicaciones: Acotamientos, pág. 8; Agrónomo, pág. 23; Amojonamiento, página 58; Apeo, pág. 61; A provechamientos comunes, pág. 65̆; Aprovechamientos de montes, pág. 71; Arbolados, pág. 81: A spirantes á Ingenieros, pág. 104; A uxiliares agrimensores, pág. 113; Baldíos, pág. 142; Bellotera, pág. 158; Bienes del Estado, de Propios y comunes, pág. 183; Bosques, pág. 189; Clasifcacion general de montes, pág. 291; Comisarios de montes, pág. 302; Corchos, pág. 43̈4; Cortas y cortezas, pág. 45̆7; Cuerpo de Ingenieros de montes, página 461; Desamortizacion, pág. 978; Deseuajes y deslindes, pág. 477; Distritos forestales, pág. 489; Escuelas de Ingenieros, pág. b̆31; Ferrerias, página 562; Guardas de montes, pág. 640; Incendios de montes, pág. 661; Ingenieros de montes, pág. 672; Junta facultativa de montes, pág. 693; Montanera y montes, pág. 768; Plantios, pág. 791; Policia forestal, pág. 796; Propios, pág. 863; Realengos y baldios, pág. 897; Sicmbras y plantios, pág. 919; Tervenos incultos, baldios y realengos, pág. 9̋̈4; Aprovechamiento de monles, pág. 973; y Desamortizacion, pág. 978. Estos dos últimos puntos corresponden al A péndice.

164. Diccionario de materia merCantil, industrial Y agríColA, que contiene la indicacion, la descripcion y los usos de todas las mercancías, por D. José Oriol Ronquillo, licenciado en farmacia, subdelegado principal de sanidad de farmacia de Barcelona, encargado del primer distrito: sócio corresponsal de la nacional academia de medicina y cirugía y de la sociedad médica de emulacion, ex-primer perito químico del Excmo. Ayuntamiento con-titucional y ex-inspector de géneros medicinales de la misma ciudad, miembro correspondiente de la sociedad de farmacia de París.-Barcelona.-1851-1857.-4 tomos; los tres primeros en la imprenta de D. Agustin Sardá, y el último en la de José Tauló; de 640 á 725 páginas cada tomo. 
En las letras correspondientes se registran las descripciones de muchas especies arbóreas, así como las de los productos resinosos y sus deri. vados.

El Sr. Anton Ramirez, nada dice de esta obra, sin duda por no ser ex . clusivamente agricola, en su Diç̧ionario de Libliografía agronómica.

165. DicCionalio histórico de LAS ARTES DE LA PESCA NACioNAL. Por el Comisario Real de Guerra de Marina D. Antonio Sañez Reguart, sócio de mérito de la Real Sociedad de Amigos del País de Madrid y de San Lúcar de Barrameda.-Madrid, 17y1-1795, por la viuda de J. Ibarra. -5 tomos en fólio, de 416, 441, 453, 350 y 418 páginas con 347 láminas que representan muchos ardides é instrumentos de pescar.

Abraza el estudio de la pesca de los rios, lagunas, etc.

166. Dictámen piesentajio Á las juntas generales de agriCULTURA DE 1849, por su comision $\%$., sobre las variaciones que convenga introducir en nuestra legislacion para el fomento de los Montes y Plantíos.-Madrid, 1849, por M. Rojas.-4. ${ }^{\circ} 36$ páginas.

A juicio de la comision debe el Gobierno administrar directamente los montes del Estado; intervenir en la administracion de los de Propios y comunes, de corporaciones y establecimientos públicos; vigilar simplemente sobre los de particulares, y procurar la consolidacion de los que están proindiviso, así comola formacion de una estadistica forestal. En este trabajo se hace una exposicion de las vicisitudes porque los montes han pasado; de la ineficacia de las leyes dictadas para su conservacion y fomento, del régimen administrativo, de los medios de ejecutar las reformas y trabajos convenientes á la mejora de los montes, y de la parte contenciosa y penal del ramo.

Se reprodujo este dictá men en el Boletin oficial del Ministerio de Comercio, Instruccion y Obras priblicas.-1850.-Tomo X, pág. $33 ̈ 7$.

167. Direccion general de Agricultura, Industria y Conercro.-Escalafon del cuerpo de Ingenieros de Montes, en $1 .^{\circ}$ de Agosto de $1859,10^{\circ}$ de Enero de $1860,10^{\circ}$ de Enero de $1861,10^{\circ}$ de Lnero de $1862,1 .^{\circ}$ de Enero de $1863,1 .^{\circ}$ de Enero de $1864,1 .^{\circ}$ de Enero de $1865,10^{\circ}$ de Enero de $1866,10^{\circ}$ de Febrero de $1867,10^{\circ}$ de Enero de $1868,10^{\circ}$ de Marzo de 1869,2 de Julio de 1870 y 15 de Febrero de 1871.

Son otras tantas hojas en $4 .^{\circ} \sin$ firma, ni pié de imprenta. La de 2 de Julio de 1870, dice: Direccion general de obras priblicas, agricullura, industria y comercio, por estar reunidas entonces las dos direcciones antiguas de Obras públicas y Agricullura, etc.

168. Direccion general de Agricultura, industria $\Psi$ COMercio.-Véase: Eucalyptus globulus. 
169. Direccion general de Estadística, Agricultura, IndusTRIA Y COMERCIO. - El Argan.

Es una hoja suelta en $4 .^{\circ}$, sin fecha, circulada en 1872, con la indicacion de la Imprenta nacional, en la que se describe botánicamente el árbol y despues se dan curiosas noticias respecto á su historia, localidades donde vive, siembra, forma de la planta y aprovechamiento del fruto, explicándose minuciosamente el método empleado para extraer el aceite del mismo. Todas estas noticias son debidas al cónsul de España en Mogador, D. Salustiano Ponte, que las consignó en una Memoria, remitida al ministerio de Estado. Se insertó en la Gaceta de Madrid del 2 de Enero de 1872, y en El Fomento, tomo II, pág. 101, donde se dice haber redactado la indicada reseña é instruccion D. Pablo Gonzalez de la Peña. Tambien publicó estas noticias la Revista del. Instituto agricola catalan de San Isidro.-1872.-Tomo XXI, página 42.

170. Discurso político, RÚstico y LEGAL, sobre las labores, ganados y plantíos, en el cual se intentan persuadir los considerables beneficios que resultarán á esta Monarquía de la union y concordia de aquellos tres hermanos, etc...., compuesto por el doctor D. Vicente Calvo y Julian, noble de Aragon, abogado de los Reales Consejos, Presidente y Fiscal de la Academia de Abogados de Zaragoza, y opositor á Prebendas Doctorales, etc.-Con licencia. En Madrid. En la oficina de Antonio Marin. Aũo de 1770.-4. 116 páginas.

Estudia el medio de aumentar los plantios optando por el cerramiento para evitar los daños por los ganados y demás que suelen tener lugar en fincas abiertas.

171. Discurso pronunciado ante la Excelentísima Diputacion provincial de Gerona al dar cuenta sus comisionados del cargo con que se les honró, por D. Alberto de Quintana y Combis, y publicado por dicho señor.-Barcelona: Establecimiento tipográfico de Narciso Ramirez y compañía: 1867.-4. , 136 páginas.

Expone la conveniencia de que España se eleve á la altura á que Austria se colocó, bajo el punto de vista forestal, en la Exposicion universal de París de aquel año, á donde fué comisionado; recuerda con elogio los trabajos hechos en Valencia sobre la inundacion del Júcar por una comision de ingenicros de montes, y manifiesta el deseo de que se hagan otros análogos para la provincia de Gerona, sujeta con frecuencia á análogas calamidades; se declara partidario de una legislacion severa para los destructores de los montes; trata de los dunas, recomendando los trabajos hec hos por Bremontier en las landas de Burdeos, y hace una reseña de las aplicaciones que para estos casos puede tener el pino marítimo.

172. Discurso pronunciado por el Sr. D. Telesforo Montejo y Robledo, en la sesion celebrada por el Senado el dia 19 de Julio de 
1871, con motivo de su interpelacion sobre la venta de varios terrenos en los montes de Balsain.-Madrid: Imprenta de J. Antonio García.-Fólio, 7 páginas.

Denuncia los abusos cometidos con motivo de las ventas de aquellos terrenos, acerca de los cuales dá minuciosos pormenores, finca por finca, y escita al Gobierno para que los corrija y castigue, declarando además la nulidad de las ventas, y procurando que se reconozcan y respeten los derechos de la ciudad y tierra de Segovia, y los de su noble Junta de Linajes, á ciertos usos y productos de aquellos montes.

173. Discurso sobre los medios de connaturalizar y propagar en España los Cedros de la Habana y otros árboles, así de construccion como de maderas curiosas y frutales, por D. Antonio Parra.-Madrid: 1799, por la viuda de Ibarra.-8. ${ }^{\circ}, 36$ páginas.

Hace mérito de 287 árboles, 267 especies y 20 palmas. Comprende además la noticia de algunas maderas duras que existen en la isla de Cuba, explicando sus colores, los parajes donde se encuentran y las aplicaciones que tienen, empleándose para todos los casos la nomenclatura vulgar.

174. Discursos mercuriales.-Memorias sobre la agricultura, marina, comercio y artes liberales y mecánicas. Su autor D. Juan Enrique de Graef.-Madrid: 1755-1756; Imprenta de S. Ramirez, de Juan de San Miguel y herederos de Lorenzo Mojados.-Veinte números de á 80 páginas, que forman tres volúmenes en $8 .^{\circ}$ Los del primero llevan paginacion aislada; desde el segundo comíenza correlativa, y sigue en el tercero, formando hasta 1141 páginas: en junto ascienden á 1600 .

Entre sus artículos se ven los siguientes: Causa de helarse los árboles.$M e ́ d i c o$ de los árboles $(E l)$. - Método para sembrar y criar el pinabete. -Plantacion de árboles silvestres, y Memorias sobre el plantío de árboles. Todos ellos quedan registrados en el lugar que les corresponde segun sus titulos.

175. Discusion (LA).-Periódico democrático de Madrid.-Véase: Montes del Estado.

176. Disertacion sobre la NeCESidad de los bosques, arbolaDos Y Pi.Antíos para el mejoramiento de la agricultura y la que tienen de ellos las artes y manufacturas, el comercio, la economía doméstica, la salud pública y cuanto influye en el bien general de una nacion. Leida en la cátedra de Agricultura del Real Jardin Botánico de Madrid, el 17 de Agosto de 1818, por D. José María de Nieva.-Madrid, 1822, por M. Búrgos.-8., 24 páginas.

Este escrito está reproducido en la Casa rústica, tomo 11, pág. 210, y el autógrafo se encuentra en la Biblioteca agricola del Jardin Botánico de Madrid; es la tercera de las diversas disertaciones inéditas que forman un vo- 
lúmen. Tambien se copió en el tomo XIV, año 186ว, del Boletin de la So. ciedad económica de Amigos del Pais de Valencia.

Recuerda los esfuerzos hechos por los gobiernos de España, para fomen tar el arbolado, aduciendo datos de lo que sucede en otras naciones. Recomienda la plantacion de álamos, castaños de Indias, árboles del amor, acacias y otros en lus caminos, y hace presente que en los terrenos inmediatos á la costa se producian en otros tiempos excelentes viñedos.

17\%. Disertacion SOBRE LA PRÁCtiCa Y METOdOS DE INGERTAR, leida en la cátedra de Agricultura del Real Jardin Botánico de esta córte el 28 de Julio del presente año, por el capitan Fernando de la Serna.-Madrid: 1817, Imprenta que fué de García.-8. ${ }^{\circ}, 88$ pági nas, con dós láminas que contienen 15 figuras.

Describe los diferentes métodos de ingertar.

178. Disertacion sobre la utilidad de los Árboles.-Reimpresa en la ciudad de la Laguna á expensas de la Real Sociedad de Amigos del País. Año de 1832.-Con licencia.-En dicha ciudad por D. Juan Diaz Machado. $-4 .^{\circ}, 26$ páginas y dos de principios.

La Sociedad, en vista de la solidez de las reflexiones y del gran conocimiento de la cuestion que brilla en aquel trabajo, publicado en la Gaceta de Madrid, acord6 reimprimirlo como lo hizo en el presente folleto, al cual van unidas al final tres curiosas notas de aplicacion á las condiciones naturales de las islas Canarias. Tambien se publicó esta Disertacion en el Boletin of cial del Ministeric de Fomento. 1862. Tomo XLI, pág. 275, y en la Reoista de ugricultura práctica. 1861. Tomo X, pág. 311.

La doctrina del artículo de que se trata es completamente favorable á la escuela que defiende la influencia evidente que el arbolado ejerce sobre las condiciones climatéricas é higiénicas de un país, saneando la atmósfera, favoreciendo las lluvias y obrando como protector de las aguas corrientes y de los terrenos denudables. El autor atribuye las sequías de Murcia y otras comarcas á la falta de vegetacion forestal, y recon enda las repoblaciones arbóreas en los yermos y eriales de los alrededores de Madrid, provincia de Guadalajara y cuantas por su desnudez y esterilidad requieren mayor templanza en el clima que disfrutan.

La aceptacion que tuvo este trabajo habla muy alto en favor de su mérito.

179. Doce libros de agricultura (Los), que escribió en latin Lucio Junio Moderato Columela, traducidos al castellano por D. Juan María Alvarez de Sotomayor y Rubio.-Madrid, 1824, por Miguel de Búrgos.-Dos tomos en $4 .^{\circ}$; el primero de $\mathrm{xxIv} .-322$ páginas y el segundo de 229, y 52 más de índice.

La Sociedad Económica Matritense intentó publicar una edicion en latin, de la que se salvaron pocos ejemplares. La portada es como sigue: $L$. Juni Moderati Columelo. - De re rustica libri.-Matriti MDCCCXXXV11. Ex typographia Sordo-mulorum. 8. mayor, 241 páginas, 
Hay una traduccion hecha por D. Juan Perez Villaamil, de la cual se inprimió parte en la Imprenta Real por los años de 1815.

En el cuarto libro del I tomo, se trata de los ingertos, vides, mimbres, retamas, cañaverales, castaños y encinas.

180. Dos palabras más sobre la Memoria que bajo el título: Suelo, clima, cullivo agrario y forestal de Vizcaya, escribió el ingeniero de montes D. Lúcas de Olazabal, y contestacion á la réplica que ha dado á nuestras observaciones. Por D. Fernando Mieg, profesor de Historia natural en el Instituto de Bilbao.Bilbao, 1858, por la viuda de N. Delmás. $-4 .{ }^{\circ}, 31$ páginas.

véase: Suelo, clima, cullivo, etc.

\section{E.}

181. ECo DE ARAgon (EL).-Periódico político de Zaragoza.Véase: Aprovechamientos forestales. -Guarderia rural.-Monte. Rompesacos (El), de ?la villa de Luna.-Fomento y mejora de los montes públicos. - Pasos cabañales.

182. ECo DE LA GANADFRía (EL) y de la agricultura, publicado bajo los auspicios de la Asociacion general de ganaderos.-Madrid, 1860-1872, imprenta de Tomás Nuñez Amor, y el último tomo en la de Diego Valero.--Trece tomos, los dos primeros en fólio de 296 y 286 páginas, y los restantes de 188 á 570 , en $4 .^{\circ}$

Entre otros varios contiene los artículos siguientes: Tomo I.-Montes del Estado.-Tomo II y III.-Utilidad de los árboles.-Tomo IV. - Sicomoro (Del).-Tomo V.-Montes (Los).-Tomo VII.-Arboles resinosos. - Del cultivo de los pinos. - Haya (La). - El roble, - Tomo VIII. - Arboricultura. Lijera idea de los progresos realizados en el departamento de las landas francesas por medio del cultivo del pino maritimo.-Tomo XII. - Infuencia de los bosques en la produccion cereal. - Sequía ( $L a)$ y los árboles.

De todos ellos damos cuenta en el lugar correspondiente.

183. ECo dE LA Lex (EL) y LA España JuRídiCa.-Revista de jurisprudencia y legislacion, ciencias económicas, morales y políticas, administracion, notariado é instruccion pública, publicada bajo la direccion de D. José María Pantoja.-Miadrid, 1859-1861, imprenta de Miguel Arcas y Sanchez.-Tres tomos en fólio, á dos columnas.

Entre los colaboradores figuran los ingenieros de montes D. José y D. Ramon Jordana. Empezó en Abril de $\mathbf{1 8 5 9}$ con el título de $\boldsymbol{B l}$ Eco de la ley, periódico de jurisprudencia, administracion y notariado, y en 8 de Diciem- 
bre del mismo año se unió á La España juridica, adoptando el título puesto al principio.

Damos cuenta en el lugar que les corresponde, de los artículos siguientes: Legislacion forestal. - Desamortizacion forestal. - Vicisitudes de la propiedad forestal. - Bienes de corporaciones. - Montes (Los) ¿deben hallarse en poder de los particulares, de los pireblos ó del Estrdo? - Inconoenientes de la division de la propiedad en algunos montes de Extremadura. - Montes (De los) bajo su aspecto económico-administrativo.

184. Elementos de agricultura general.-Obra escrita para acompañar al dtlas de Agricultura elemental, por el Pbro. D. José M: Vila y Robles, profesor de esta asignatura en la Escuela normal superior de Tarragona.-Tarragona, imprenta del Diavio, 1865. $-8 .^{\circ}, 155$ páginas.

Trata sumariamente de la piscicul tura y árboles de bosque.

185. Elementos DE agricultura, que contienen los principios teóricos y prácticos de esta útil, agradable y honestísima ocupacion. Por D. Diego Carballo y Sampayo, caballero de Justicia en la Religion de San Juan.-Version española, por D. Joseph María Calderon de la Barca, de la misma Religion Hospitalaria.-Con licencia.-En Madrid en la Imprenta Real.-Año de 1795.-4. XxII-202 páginaś, con dos láminas á la 136.

Es traduccion del portugués, edicion publicada en Madrid el año 1790.

En el capitulo ll, trata de los prados naturales, dedicando desde la página 179 á la 188, á los bosques, plantas erráticas y fugitivas (higueras, nogales, almendros, etc., y cipreses, álamos, cedros, plátanos, etc.), y á algunos arbustos y plantas pequeñas útiles en la agricultura, como los mimbres, sauces, retamas, castaños y toxos.

186. Elementos de Agricultura. - Su autor D. Manuel Boedo y Cardois, cura párroco de San Vicente de Vigo, en la provincia de la Coruña.-Coruña, imprenta de Iguerreta.-1836.-4. ${ }^{\circ}, 262$ páginas.

Se ocupa lijeramente de árboles, plantaciones, poda, ingertos, acodos, estacas, prados y arbolados.

187. ENCIClopedia ModerNa.-Diccionario universal de literatura, ciencias, artes, agricultura, industria y comercio, publicada por Francisco de P. Mellado.-Madrid, 1851-1855; establecimiento tipográfico de Mellado.-37 tomos en $4 .^{\circ}$, á dos columnas. Los 34 primeros de texto de 500 á 700 páginas cada uno, ó sea doble número de columnas, que son las numeradas; los tres restantes forman un atlas de 402 láminas.

Se registran los articulos siguientes: Arboles. -Desmontes ó roturaciones. Encina.-Ingertos.-Montes.-Plantios.-Poda y Vivero.

188. ENSAYO ARITMÉTICO SOBRE EL VALOR DE LOS PLANTTíos,-MUrcia, 1856, por J. C. Palacios. $-4 .^{\circ}, 28$ páginas. 
Segun indicacion de D. Agustin Pascual, el autor de este opúsculo es el Sr. D. Alejo Molina y Saurin, vizconde de Huerta. Tiene por objeto aplicar el cálculo matemático al descubrimiento del valor de una plantacion cualquiera en fracciones, del que tendrán sus rendimientos capitalizados en la cima de su desarrollo, ó sea en el apogeo de su produccion. El cálculo se hace por especies de árboles ó arbustos, que necesitan para su completo desarrollo de uno á ciento cincuenta años; los problemas se resuelven con aplicacion de las tablas de logaritmos.

189. Ensayo de DEsCripCion geognóstica de la pRovincia de TeRukL.-Véase: Junta general de Estadistica.

190. Ensayo de la Socredad Bascongada de los Amigos del PAís.-Año 1766.-Dedicado al Rey N. Señor.-Con las licencias necesarias.-En Vitoria, por Tomás de Robles.-Año 1768.-8. $\mathrm{xxx}-360$ páginas.

Hemos extractado de esta publicacion el artículo que trata de la Plantacion de árboles, reseñado en el lugar correspondiente.

19I. ENSAYO DE UNA HISTORIA DE LOS PECES Y otras producciones marinas de la costa de Galicia, arreglado al sistema del caballero Cárlos Linneo. Con un tratado de las diversas Pescas y de las Redes y Aparejos con que se practican. Por D. Joseph Corhide, Académico honorario de la Historia, vecino de la Coruña.-Año de 1788.-En la oficina de Benito Cano.-8. $.^{\circ}, 263$ páginas.

El estudio monográfico, bastante completo á los fines de un conocimiento práctico, abraza tambien las clases de moluscos'y zoófitos. Termina con un indice de los nombres castellanos, con los correspondientes latinos de Linneo; otro de los gallegos con igual correspondencia; otro de nombres latinos de Linneo con sus equivalentes castellanos; otro de nombres de cosas de distintas lenguas y dialectos de que se habla en la obra; $y$ otro de los nornbres españoles y franceses contenidos en el tratado de pescas.

192. Ensayo de Zoología agrícola y forestal, ó sea Tratado de los animales útiles y perjudiciales á la agricultura, á los montes y al arbolado, por D. Antonio Blanco Fernandez, doctor en Medicina y Cirujía, Catedrático de Agricultura por oposicion desde 1835, Caballero de la Real Orden americana de Isabel la Católica, Profesor de Agricultura en el Ateneo de esta córte, é indivíduo de varias corporaciones científicas nacionales y extranjeras. Otra publicada bajo la proteccion del Gobierno de S. M. á propuesta del Real Consejo de Agricultura, Industria y Comercio.--Escudo de armas de España.Madrił, Imprenta Nacional.-1859.-4. , vill.-572 páginas, con 205 grabados intercalados en el texto.

Trata primero de los animales útiles al agricultor por sus costumbres y productos, y despues de los nocivos. Convienc conocer principalmente, por lo que toca á los montes, el capitulo IV de la segunda parte, páginas 361 
á 368 , que estudia los insectos nocivos á dichos prédios y á los arbolados, así como toda la parte de piscicultura, páginas 115 á 172 , correspondiente á la seccion $4 .^{2}$ de la primera parte.

193. Epoca (L.1).—Periódico político de Madrid.-Véase: A la España._Cuestion de montes._Las tardias jeremiadas..., etc.-Montes españoles (Los) bajo el punto de vista de su desamortizacion y administracion.-Anunque fuera del sitio destinado... etc.-En nuestro anterior articulo, etc.,-Continua El Reino atacando al Ministerio de Fomento en las cuestiones de montes... etc.-Filtros naturales.Arbolado en Espina (El).-Damos espresivas gracias,.. etc.-La frecuencia con que se repiten... etc.-Un triste vaticinio.-Parque (El), los jardines y paseos publicos de Madrid.-Del proyecto de ley de montes... etc.-Muy equivocado esta El Imparcial... etc.-Rogamos à la Direccion general de Agricultura..., elc.-De donde menos se piensa..., etc.

194. Escalas agrimensoras de fincas desamortizables para el uso de los peritos agrimensores y prácticos de labranza con título, autorizados para tasar fincas rústicas y urbanas, para el de los oficiales de propiedades encargados del negociado de peritos, para los comisionados de ventas y para los compradores de bienes nacionales.Formadas por el oficial $10^{\circ}$ de la Administracion del ramo en la provincia de Albacete.-Albacete, 1860, imprenta de La Union.$8 .^{\circ}, 88$ páginas.

El autor de esta obrita, que no menciona el Sr. Anton Ramirez en su Diccionario de bibliografia agronómica, es, segun expresa la cubierta, D. Saturnino Arce y Cortázar, adninistrador principal (cesante por retorma) de los ramos de Gobernacion.

La materia comprende tambien las fincas forestales.

195. Escuela ESPECIAL DEL CUERPO DE INGENiEROS DE MONTES.Lecciones de administracion forestal.-Apuntes de la clase.-Madrid, imprenta de T. Nuñez Amor, 1861.-4. ${ }^{\circ}, 44$ páginas.-Van unidos al mismo los Formularios de correspondencia oficial y particular para el uso de los Ingenieros de montes, de los que damos cuenta en el lugar correspondiente.

Tratan las Lecciones de los puntos siguientes: Nociones de la propiedad en general. Aplicaciones de la propiedad al dominio de los montes. De las servidumbres. El Estado debe tener á su favor la presuncion legal de propietario en los montes de dominio dudoso, mientras no se acredite lo contrario. Los litigios en materia de montes conviene seguirlos, siempre que sea posible, por la via administrativa, no solo para facilitar su curso, sino para asegurar su fallo. El Gobierno administra por derecho propio los montes del Estado. Dirige por conveniencia pública el servicio de los montes pertenecientes á los puebros y corporacionos. En los montes de particulares ejerce la policia conforme à las leyes 
y a los reglamentos locales. Conducta de los ingenleros en el servicio. Idea general sobre la organizacion del Gobierno de España y Gobierno de las Colonias.

196. España (La).-Periódico político de Madrid.-Véase: Estudios forestales. Coleccion de articulos, etc.-A un cuando nos habiamos propuesto... etc.-La premura de los trabajos periodisticos... elc. -Cumpliendo nuestro empeño... etc.-En uno de nuestros últimos nimeros... etc.-Entre todas las fórmulas parlamentarias... etc.Montes (Los).

197. España y la Argelia (La).-Noticia á propósito de la Exposicion internacional franco-española, por el Sr. Alfredo de Cés-Caupenne, caballero de la Legion de Honor, miembro del Consejo greneral de Constantina, comisario de la Argelia en la Exposicion de Bayona.-Argel, Typografía Bastide, 1864.-8. , 85 páginas.

Este opúsculo está escrito en francés y en español, siguiendo el testo á la par, $\delta$ sea las páginas de la izquierda á partir de la portada, en el primer idioma, y las de la derecha en el segundo.

La cubiert a dice: L'Espagne et l'Algerie, notice franco-espagnole. - La España y la Argelia, noticia franco española.

Sin dar más que una lijera idea de la historia y clima de España, así como de la poblacion que suele emigrar á Argel, describe, tambien brevemente, este pais, estudiando en párrafos distintos los principales productos y los elementos de su riqueza. De las maderas, alcornoques, encinas, oliros, pinos de Alepo y tuyas se ocupa en el párrafo XVII, página 39.

Presenta la estadistica superficial de los bosques, expone el sistema seguido en aquella colonia de ceder el Estado á los particulares á censo hasta por noventa años la explotacion de los alcornocales; encarece la bondad del corcho y sus aplicaciones; menciona tambien las concesínes de encinas hechas por diez y ocho años, y los arriendos de olivares considerados alli como bos ques.

Respecto á lós pinares de Alepo sujetos á arrendamiento, en una extension de $\mathbf{2 0 . 0 0 0}$ hectáreas próximamente, ensalza la bondad de la resina que producen, la cual considera superior á la del pino marítimo. Por último, de la tuya solo hace mérito por las cepas nudosas y veteadas que de ella obtiene la ebanisteria.

198. Espectáculo de la NATURALEza, ó conversaciones acerca de las particularidades de la historia natural que han parecido más á propósito para excitar una curiosidad útil, y formarles la razon á los jóvenes lectores. Escrito en el idioma francés por el abarl M. Pluche y traducido al castellano (cuarta edicion).-Madrid, 1785, imprenta de A. Sotos, B. Cano, Real, P. Marin y J. Otero.-16 tomos en $4 .^{\circ}$,de 300 á 400 páginas próximamente, y 200 láminas.

En el tomo III hay un tratado de la poda; en el IV se habla de las selvas 
y de la madera, y en el $\mathrm{V}$ de los pastos, las dehesas, fuentes, montañas y mar.

199. Esperanza (LA).-Periódico político de:Madrid.-Véase: Estos dias se ha estado discutiendo... . etc.

200. Esposicion aragonesa.-Reglamento para la esposicion y clasificacion de productos.-Zaragoza. Tipografía de Francisco Castro, impresor de la Real Sociedad, 1868. -4. $.^{\circ}, 38$ páginas.

En las páginas 27 y 28 están indicados los productos forestales, los relativos á caza y pesca, y lo concerniente al material para el cultivo de los montes y útiles de caza y pesca.

201.-Esposicion presentada al Excmo. Sr. Ministro de Fomento en defensa del libre uso y aprovechamiento de la propiedad forestal del dominio particular de la sierra de Segura, por D. Rafael de Castilla y Quirós.-Madrid, 1862, imprenta de las Escuelas Pias.-Fólio, 8 páginas.

Hizo mencion de este folleto, del cual no hemos podido ver ningun ejemplar, el Boletin bibliográfico español, núm. 9, del 1. ${ }^{\circ}$ də Mayo de 1863, página 98.

202. Exposicion univerisal DE 1867.--Véase: Exposicion universal de $186 \%$.

203. EstadístiCA DE LA PRODUCCION DE LOS MONTES PÚBLICOS EN LOS AÑoS DE 1861-1865, presentada al Excmo. Sr. Ministro de Fomento por la Direccion general de Agricultura, Industria y Comercio en Marzo de 1866.-Escudo de armas de España.-Madrid, imprenta del Colegio de Sordo-mudos y de ciegos, 1866.-Fólio, 119 páginas con un estado que contiene el «Resúmen general de la produccion de los montes públicos en los años forestales de 1861, 62, 63, 64 y 65.»

Está precedida de una Memoria analítica y comparativa, fechada en Madrid á 20 de Marzo de 1866, y firmada por el Director general, Ilmo. Sr. D. Félix García Gomez. Siguen los estados estadisticos que expresan los rendimientos en metálico y tasacion de los productos ordinarios, de usos vecinales, de árboles derribados por los vientos, de árboles ú otros productos incendiados $\delta$ aprovechados fraudulentamente, en los montes del Estado, de los nueblos y de establecimientos públicos, exceptuados de la desamortizacion por estar poblados de pino, roble ó haya, ó por estar destinados á dehesas boyales $\delta$ haber sido declarados de aprovechamiento comun, asi como los datos referentes á los montes enagenables. Hay estados-resúmenes por el quinquenio en cada uno de estos casos y resúmenes generales, especificándose los datos por provincias.

204. Exтracto del cuaderno de leyes y ordenanzas con que se gobierna esta M. N. y M. L. provincia de Alava, y diferentes pri- 
vilegios y cédulas de S. M. que van puestos en el índice.-En Vitoria, por Tomás de Robles y Navarro, año de 1761 .

Contiene el decreto de la Junta general de 19 de Abril de 1749 sobre conservacion de montes, la representacion hecha en la Junta general de 19 de Noviembre de 1750 por los procuradores de la hermandad de Salvatierra, Ayala, San Millan y Truraiz en queja de que los vecinos roturaban los montes; el decreto de la Junta general de 25 de Noviembre de 1730 sobre aprovechamiento y roza de egidos públicos, plantíos y aumento y conserva cion de los montes; y el decreto de la Junta general de 5 de Mayo de 1753, en que se declara que solo los vecinos pueden usar y disfrutar los montes comunes, con arreglo á las disposiciones vigentes.

En el Diccionario de billiografía agronómica del Sr. Anton Ramirez no se habla de esta publicacion.

205. Estudios forestales.-Coleccion de artículos publicados por La España sobre la organizacion y servicio facultativo del ramo de montes en Europá, y particularmente en el reino de Sajonia.Madrid, 1852, imprenta de Diaz y compañía.-Fólio, 38 páginas.

En la introduccion describe la Escuela de Ingenieros de montes de Villaviciosa de Odon, y desarrolla luego la materia en once artículos, demostrando la necesidad de un Cuerpo de Ingeníeros para el servicio de los montes del Estado, las condiciones económicas y técnicas de esta riqueza y su influencia en el clina y en la salubridad, dando una idea detallada de la organizacion del servicio forestal en el reino de Sajonia.

"Por la época de la publicacion de estos articulos, dice D. Braulio Anton Ramirez, en su Diccionario de bibliografia agronómica, pág. 154, por Ja materia, por el estilo y aun por la doctrina, es casi indudable que son debidos y la pluma de D. Agustin Pascual, quien hoy ocupa dignamente un puesto muy honroso en el Cuerpo de Ingenieros, y por cuya organizacion y prosperidad abogó entonces con tanta fé como fortuna.»

206. Estudios ForEstales.-Los montes en sus relaciones con las necesidades de los pueblos, por D. H. Ruiz Amado, ingeniero de montes.-Tarragona, imprenta de Puigrubí y Arís, $1870.4 .^{\circ}, 1401$ páginas.

Estí dividida en tres partes, y aun cuando la numeracion de las páginas es seguida, se ha puesto una portada en la segunda parte, con objeto de que quede dividida la obra en dos volúmenes, comprendiendo el primero hasta la página 771. En la portada del segundo volúmen se ha escrito despues del nombre del autor, lo siguiente: Jefe de primera clase del cuerpo de Ingenieros de montes. - Lobra premiada con la medalla de oro en la exposicion agricela celebrada en Barcelona en Seliembre y Octubre de 1872).-II. Parte segunda y tercera. No tiene más que un índice que vá al final de la obra.

El informe emitido por el Jurado calificador, terminaba así: "Esta obra revela conocimientos nada comunes de las ciencias que están en relacion con la dasonomia, dando una nueva prueba (el autor) con esta publicacion, 
de su reconocida inteligencia y saber, que no solo abarca las ciencias naturales, si que tambien las económicas y legislativas. Atendidas las consideraciones que preceden, la importancia del objeto de la obra, y la manera satisfactoria como lo ha realizado, creemos al autor de los Estudios forestales D. Hilarion Ruiz Amado, acreedor á la medalla de oro, correspondiente al apéndice de la seccion tercera del programa.»

Examina el autor con la extension necesaria los puntos siguientes: Los montes en sus relaciones con el aire y sus corrientes, con el suelo, con la temperatura del aire, con los hidrometéoros y distribucion de las aguas dentro $y$ sobre la tierra, y con las necesidades de los pueblos. - Los montes de la region forestal por su influencia en la fisica, ex la economia y en la moral de los pueblos, tienen grandisima importancia en la prosperidad de las naciones y constituyen una condicion indispensable de su existencia.-Principales condiciones de existencia y propiedades económicas de los montes.-Condiciones del individuo, del Estado, del municipio y de la provincia como propietarios y administradores de los montes. - Desamortizacion forestal. - Indicacion de los montes enagenados en España desde 1855 y durante el siglo xix en Prusia y Francia.-Sistema que, para realizar la desamortizacion, debiera seguirse en concepto del autor.-Administracion forestal.-Reseña histórica de la legislacion administratioa forestal desde el Furno-suzgo hasta el año corriente de 1872.-Discusion de las bases para la reforma de la Administracion.-Resimen $y$ conclusion.

207. Estudios Históricos sobre los giros y pastos comunes de Jerez de los Caballeros, por D. J. Cardenal.-Madrid, 1855.-8.

"Este folleto, dice el señor Barrantes en su Catálogo razonado y critico de los libros, memorias y papeles impresos y manuscritos, que tratan de las provincias de Extremadura, que primeramente se publicó en el periódico Las Novedades, contiene tambien curiosas noticias históricas de Jerez, pues el derecho comunal á que se refiere le ha sido concedido por varios monarcas en premio de servicios importantes, y en la época moderna ocasion de profundas alteraciones en el órden público, pues fácilmente se comprende que eso de pastar gratuitamente los ganados de los pobres en todas las dehesas del término, más se acerca á las peligrosas utópias del socialismo, que á las conveniencias y respetos de la legalidad."

No se menciona esta publ icacion en el Diccionario de bibliografia agronómica del Sr. Anton Ramirez.

208. Estudios QUE SOBRE LA AGRICUlturt en sus varias aplicaciones, ha hecho en la Exposicion universal de París el doctor D. Fernando Amor y Mayor, catedrático de Historia natural en el Instituto provincial de segunda enseñanza de Córdoba, académico de la suprimida de Esculapio y de la nacional agrícola, manufacturera y comercial de París, y miembro de la sociedad entomológica de Francia. Cornisionado por la Excma. Diputacion provincial de Córdoba. Se imprime á expensas de la misma Excma. Corporacion.- 
Córdoba, 1856, por F. García Tena.-Fólio, x. -243 páginas y 13 láminas.

Enumera entre otras plantas, algunos árboles de selva, cuyo cultivo cree conveniente introducir y propagar en la provincia.

209. Estudios REFERENTES Á LA AGRICULTURA Y zOOTECNIA, por D. Basilio de Chavarri. - Madrid, Imprenta y librería de D. Eusebio Aguado, $1865 .-4 .^{\circ}$ menor, 81 páginas.

Recuerda la conveniencia del cultivo de los baldíos y se ocupa del arbolado en lo relativo á su multiplicacion y aplicacion de sus productos para fomentar la riqueza nacional.

210. Estudios SOBRE EL PROYECTO JUROPEO DE LA UNION DE LOS TRES MARL's, Mediterráneo, Cantábrico y Atlántico, por el Eluro y el Duero, el canal Imperial y el de Castilla, ó sea pensamientos sobre navegacion interior oriental y septentrional de España, seguidos de una Memoria, en que se proponen algunos medios para el desarrollo de la agricultura de Aragon y de la España, considerada en los Monegros. Por el doctor D. Nicolás Malo, abogado del ilustre colegio de Zaragoza, del Gremio y claustro de la Universidad literaria de esta córte, etc., etc.-Madrid, 1850, por Aguirre y Compañía.8. ${ }^{\circ}, 230$ páginas y un mapa.

Respecto de los Monegros habla con extension de los riegos y plantios recomendando mucho la cria de montes para contrarestar las sequias y favorecer el cultivo de la vid, el olivo y otras plantas agrícolas.

211. Estudios SOizRe EL RAMO de MONTES Y ARBolados de España, insertos en El Clamor Público de 1845, seguidos de una recopilacion legislativa-forestal desde el Fuero-Juzgo hasta 31 de Diciembre de 1854 y de otros documentos curiosos é importantes. Por D. Juan de la Cruz Martinez, diputado á Córtes Constituyentes, licenciado en Jurisprudencia, abogado de las tribunales de la nacion, individuo correspondiente de la Real Academia de la Historia, de la Matritense de Jurisprudencia y Legislacion, y sócio de la de Amigos del País de Jaen.-Madrid, 1855, por J. Trujillo.-4. ${ }^{\circ}$, 126 páginas.

'Recopila las disposiciones forestales dictadas desde los tiempos más'remotos hasta la época presente; discurre acerca de los apeos, deslindes y amojonamientos, y se extiende en apreciaciones sobre la administracion y ordenacion del ramo, de sus ingenieros y empleados, y de la estadística forestal.

212. Estudios sobre las maderas. Su explotacion, clasificacion de las maderas segun su empleo, propiedades de las mismas despues de cortadas, y una Menoria histórica y teórica sobre su 
conservacion, por M. P. Jousselin, ingeniero civil. Traduccion y anotaciones de D. P. C. Espinosa, ingeniero de caminos.-Madrid, 1855.-En $4 .^{\circ}, 62$ páginas y una lámina.

Este opúsculo carece de portada. Tratados los asuntos que indica el título, comienza en la página 11 la traduccion de la Memoria de Mr. Jousselin que comprende los capítulos siguientes: $10^{\circ}$ Composicion fisica y quimica de las maderas, causas de destruccion, medios preservativos, corta de los árboles, inmersion en el agua dulce y sulada y apilamiento; $2{ }^{\circ}$ Procedimientos de conservacion, sustancias empleadas, enlucidos y pinturas, disolucion de sulfato de hierro, aceite de lino y sub-sulfato de hierro, agua de cal, sulfato de cal, aceites, grasas y breas, sublimado corrosivo y ácido de arsénico; $3 .^{\circ}$ A parato Bréant, idem Payne, procedimiento Pollak, idem Knab; $4 .^{\circ}$ Procedimiento del dortor Boucherie, aplicacion d la coloracion de las maderas, antiguos procedimientos de coloracion, procedimiento Renard-Perrin; $5 .^{\circ}$ Empleo de la creosota, procedimiento Perronet, Bourdon y de Fontenay, y estado de las maderas despues de la aplicacion de los diversos procedimientos de conservacion; 6. Objeto de la desecacion, antiguos procedimientos, procedimiento de la compañia inglesa de desecacion, idem de Bethel, idem de Mr. le Chatelier, nuevo pracedimiento de Mr. Bethel.

Siguen á la traduccion varias notas en que el Sr. Espinosa trata de las ventajas é inconvenientes de descortezar los árboles en pié; de la inmersion de las maderas en agua caliente; del almacenaje permanente, de la pintura y de la carbonizacion, etc.

213. Eucalyptus globulus.-Madrid: 1868. Imprenta del colegio de Sordo-mudos y de ciegros. $-4 .^{\circ}, 3$ páginas.

Es una hoja suelta publicada por la Direccion general de Agricultura, Industria y Comercio, que contiene la descripcion de la planta, la historia de su introduccion en Europa, las condiciones de sus productos y los métodos de siembra, plantacion y cultivo.

En uno de los primeros números del mes de Abril de 1872, de La Independencia española, periódico político de Madrid, se publicó tambien una descripcion de este árbol, indicándose las localidades españolas y extranjeras en donde ha sido introducido, y dando cuenta de sus cualidades terapéuticas é industriales.

El Consultor de los Ayuntamientos. Tomo XVI. 1868, pág. 136, publicó asímismo algunas noticias acerca de la siembra y cultivo de este árbol, tomando los datos de algunos Boletines oficiales.

Se ocupó tambien de este árbol, en el tomo II, pág. 299, El Fomento en un artículo titulado El Eucalyphus globulus y su uso terapéutico, traducido por D. Balbino Cortés en Argel á 26 de Marzo de 1872, del que con el mismo objeto dió á luz $L a$ Union farmacéutica de Francia en el Bulletin des $\nabla a-$ riations au 31 janoier 1872.

214. Europeo (EL).-Periódico de ciencias, artes y literatura, por los Sres. Cook, Aribau, L. Montegrgia, Lopez Soler y Galli-. 
Barcelona, 1823-1824. Por Torner. $-8 .^{\circ}$, dos tomos de 407 y 538 páginas.

En el número del 3 de Abril de 1824, página 11, se insertó un artículo poco importante titulado: Jardineria; de la belleza ideal de los bosques.

Contiene tambien otro sobre bosques, de que damos cuenta en el lugar respectivo.

215. Exámen de las encinas y demás árboles de la península QUE PRODUCEN BELlotas, con la designacion de los que se llaman mestos, por D. Miguel Colmeiro, doctor en ciencias, catedrático de botánica en la universidad de Sevilla, y D. Estéban Boutelou, ingeniero de montes, subinspector de los bosques reales.-Sevilla, 1854, imprenta de D. José M. Geofrin.-4. , 14 páginas.

Tiene por objeto disipar las dudas y acabar con la confusion que ha reinado respecto á las especies del género Quercus que viven expontáneas en España. Despues de un detenido juicio crítico de los trabajos de clasificacion hechos por algunos botánicos, reseña las indicadas especies con el nombre sistemático y vulgar, la d escripcion característica, localidades donde se encuentran, productos que rinden, especialmente los frutos, etc.

Se publicó tambien este folleto en el Boletin oficial del Ministerio de Fomento, 183\%.-Tomo X, páginas 38 y 82.

Tal vez por predominar en este escrito el carácter botánico, dejó de incluirlo en su Diccionario de bibliografía agronómica, el Sr. Anton Ramirez.

216: Excursion forestal por los imperios de Austria y Rusia, verificada de R. O. en el verano de 1864, por D. Máximo Laguna y Villanueva, ingeniero jefe de segunda clase del Cuerpo de montes y profesor en la escuela especial del mismo.-Impresa de Real órden.-Escudo de armas de España.-Madrid, imprenta del colegio de Sordo-mudos y de ciegos, 1866.-4.', 123 páginas.

Comienza por la Real órden del Ministerio de Fomento, fecha 30 de Mayo de 1864, por la que se dispuso que el Sr. Laguna llevase á cabo la excursion, dedicándose á estudiar el estado de la enseñanza, el de la administracion del ramo y el cultivo y aprovechamiento de las estepas.

La memoria trata de la enseñanza en Austria, en las escuelas y academias de Mariabrunn, Schmnitz, Weiswasser, Aussee y Kreuz, comparándolas con la de Villaviciosa en España, y proponiendo en ella útiles modificaciones. Estudia despues el servicio forestal del indicado imperio, Bohemia, Hungría y Sajonia, así como la enseñanza forestal de Rusia, su escuela práctica de Lissinow, las escuelas de las estepas y la administracion general del ramo.

217. EXPEDIENTE SOBRE EL REGIMEN Y ADMINISTRACION DE LOS montes de Segura de la Sierra y de su provincia.-Madrid, 1825, por Miguel de Búrgos.-4., 113 páginas.

Se imprimió en 1811 de órden del Gobierno intruso, y se dió á luz la presente edicion de órden superior por las interesantes noticias que cortiene 
sobre la sifuacion de los montes y la utilidad y aprovechamiento de las maderas para la construccion naval y usos económicos.

Comienza el expediente con una exposicion elevada al Rey el 23 de Enero de 1811, por el Ministro de Hacienda, haciendo ver la decadencia de la riqueza forestal, comprendida en 56 leguas cuadradas, en cuya extension se contaban por los años de 1783 á 90 , sobre 260 millones de árboles, y atribuyendo á la intervencion de los ministerios del Interior, Hacienda y Marina, el mal estado de la administracion. Sigue un extenso dictámen evacuado el 3 de Febrero por el ingeniero general de marina D. Tomás Muñoz; des pues una extensa é importante Memoria sobre la situacion geográfica y extension de la provincia de Segura de la Sierra, con los pueblos y rios que comprende, y sistema del gobierno y administracion de sus montes; á continuacion de esta Memoria, que consta de seis capítulos, divididos en 152 párrafos, fechada á 1. de Abril de 1811, y escrita por D. Juan Sans, insértase el oficio con que todos estos antecedentes se remitieron á informe de D. Martin Fernandez de Navarrete; y por último, desde la página 79 á la 113, con fecha 12 de Mayo del citado año 1811, las Reflexiones sobre los montes de Segura de la Sierra, etc., de dicho autor, que se publicaron tambien en edicion aparte, de cuyo opúsculo nos ocupamos en el lugar respectivo.

218. Experimextado Cazador (El), ó perfecto tirador, compuesto por D. J. M. G. N.-Madrid, 1750, por Azrrar.-8.', 125 páginas.

Hay otras ediciones posteriores. La quinta se publicó en Madrid el año de 1832.

Comprende la caza mayor y menor.

219. Exposició DE lo estad ACtUal DE L' AGricultura en la ISI.A de MenorCA, escrita arregladament á las observacions que ha reunid sobre la matexa D. Rafael Febrer y Alberti. Per D. Julio Soler.-Mahon, 1857, por J. Fabrequés y Pascual.-8. ${ }^{\circ}, 162$ páginas, y una lámina.

Escrita con arreglo á los preceptos de la gramática menorquina de D. Antonio Febrer y Alberti.

Entiende que importa mucho fomentar el plantío de árboles.

220. ExPOSICION ACERCA DE LA URGENCIA CON QUE DEBE ATENDIGRSE Á LA TOLIĆ́A $X$ REGIMEN DE LOS RIOS por los inmensos daños que están causando y mayores que amenazan. Elevada por el comisario régio de Agricultura de la provincia de Gerona (D. Narciso Fages de Romá), al Ilmó. Sr. Director general de Agricultura, y mandada circular de Real órden á los grobernadores de las provincias, para que, oyendo á las diputaciones y consejos provinciales, etc., etc., informen, á fin de poderse presentar á las Córtes á principios de 1851, el correspondiente proyecto de ley.-Figueras, 1850, por G. M. de Bodallés. $-4 .^{\circ}, 7$ páginas. 
Se insertó además esta exposicion en el tomo I, página 194 del periódico titulado La Granja.

Los males causados por los desbordamientos de los rios, provienen, segun el autor, de la destruccion del arbolado y de los descuajes de las vertientes, por lo cual, entre otras medidas, propone la plantacion en las orillas y la repoblacion de las vertientes de las cuencas.

221. Exposicton dirigida al CONGRESO de los diputados por D. Joaquin Reche, como gerente de la Sociedad Reche y compañía, sobre la compra de la dehesa llamada Nava-el-Rincon, sita en términos de Balsain, provincia de Segovia.-Madrid, imprenta de Manuel Minuesa, 1871.-4. ${ }^{\circ}, 22$ páginas.

Firma la exposicion en Madrid á 15 de Noviembre de 1871, D. Joaquin Reche. Hace la historia de la venta de la finca en cuestion y de los procedimientos oficiales que tuvieron lugar al efecto de comprobar la denuncia entablada por los ingenieros que tenian intervencion en los bosques del extinguido Real patrimonio, de cuyos antecedentes deduce la validez de la venta y la inexactitud de los abusos que dice, se suponian cometidos, insistiendo en que la dehesa no formaba parte de las masas conocidas con el nombre de pinares de Balsain. Con estos fundamentos, pide al Congreso que se sirva nombrar una comision especial para que, abriendo las informaciones que juzgue convenientes, pueda proponer las resoluciones oportunas sobre la gestion de los diversos Ministros y personas que han entendido en la venta é incidentes posteriores relativos á la finca Nava-el-Rincon, emitiendo sobre ellos el dictámen, y formulando las censuras que estime merecidas.

222. ExPOSICION QUE LOS COMPRADORES DE LAS DßHESAS Ó MATAS llamadas Nava-EL-Horno, Navaquemadilla, Nava-el-Paraiso, Plantío, Parque y NAVA-LA-LoA, sitas en términos de Balsain y de la Granja, dirigen al Congreso.-Madrid, imprenta de la viuda de Aguado é hijo, 1871.-4. $.^{\circ}, 27$ páginas.

Firman la exposicion en Madrid á 8 de Noviembre de 1871, D. Is idro y D. Pablo de Villota.

Despues de hacer la historia de la venta de dichas fincas y juzgar los actos oliciales y las apreciaciones facultativas de la comision encargada de comprobar sobre el terreno el grado de certeza de la denuncia que fué pre sentada al Ministerio de Hacienda, relativa á excesos en las cortas, extralimitaciones y otros particulares, suplican los exponentes al Congreso que nombre una comision de su seno que, abriendo las informaciones que estime oportunas sobre cuanto concierne á las enagenaciones de las fincas ó dehesas adquiridas por los recurrentes en términos de Balsain y" la Granja, yá los actos de los diversos Ministerios que con ellas tengan relacion, emita su dictámen y proponga las resoluciones que dentro de sus facultades, y respecto á cuantos hechos y personas sean censurables $\delta$ justiciables por excitacion de la Cámara, entienda procedentes.

223. Exposicion universal DI 1867.-Véase: Catálogo general 
de la seccion española, etc.-Discurso pronunciado ante lo Excelentisima diputacion provincial de Gerona, etc.

224. Exposicion univrsal. - Véase: Coleccion de productos é instrumentos forestales. - Coleccion de productos forestales.

225. Exposicion y proyecto sobre planteles, que al excelentísimo Sr. D. Martin de los Heros, intendente general de la Real Casa, presenta D. Mariano Sangüesa.-Madrid, 1856, por T. Fortanet. $-4 .^{\circ}, 58$ páginas.

El plan tiene por objeto fomentar el arbolado de las Reales posesiones.

226. Extractos de las juntas generales celebradas por la Real Sociedad Vascongada de los Amigos del País (en la ciudad de Vitoria y villas de Bilbao y Vergara, por los meses de Julio, Agosto y Setiembre) desde 1771 hasta 1793.-Madrid, por D. Antonio Sancha los tomos I y XV: Vitoria, por Tomás de Robles, desde el tomo II hasta el XI; Vitoria, por Gregorio Marcos de Robles y Revilla, los tomos XII, XIII y XIV; y Vitoria, por Baltasar de Mantelí, los ocho restantes. -23 tomos en $4 .^{\circ}$, de 85 á 284 páginas.

Al título sigue el emblema de las tres manos enlazadas con una cinta con la inscripcion vasca Irurac-bat (las tres son una). En el Extracto de 1773, el indicado emblema está encerrado en una medalla, cuyo reverso representa una corona de encina, sobre la cual se lee: Lau onari (las cuatro fuera mejor).

El Sr. Anton Ramirez en su Diccionario de bibliografia agronomica, página 162, solo dá cuenta del tomo de 1774: "Tenemos fundamento para creer añade, que publicó (la Sociedad) tres tomos en $4 .^{\circ}$, que abrazan la relacion de sus tareas desde 1774 á 1777. No los hemos visto, y la falta de evidencia nos abstiene de consignarlo como un hecho.» Hoy ya está fuera de duda que la coleccion consta de 23 tomos qne comienzan en 1771 y terminan en 1793, segun puede verse en la Bibliografia mineral hispano-americana, tomo II, página 346, que acaban de publicar los ilustrados ingenieros de minas Sres. Maffei y Rua Fizzueroa, los cuales, con una diligencia y un celo poco comunes, han logrado ver la única coleccion completa que tal vez exista en España y que obra en poder de un particular de Bilbao, pues la que conserva D. Sotero Mantelí, en Vitoria, segun dichos ingenieros, carece del tomo correspondiente á 1793 .

Por nuestra parte debemos á la amabilidad del Sr. Maffei, el liaber podido examinar los tomos de los años 1771, 1772, 1773, 1774, 1778, 1782 $1783,1781,1783,1786,1787,1788,1789,1790$ y 1792 , que son los que ha reunido á fuerza de mucha diligencia. De los tomos correspondientes á los años $1773,1776,1777,1779,1780,1781$ y 1791 , nos ha proporcionado cumplidos extractos el distinguido ingeniero de montes D. Juan José de Herran que ha examinado toda la coleccion en Vitoria, el cual añade, que el extracto de 1793 no se imprimió á consecuencia de los sucesos políticos de aquella época, asegurando que en las juntas del referido año, no se trató ningun 
asunto agronómico. Como los Sres. Maffei y Rua Figueroa, aseguran haberse publicado el extracto del repetido año, damos esta noticia, para que puedan hacer los aficionados sus investigaciones con mayor copia de datos. Tambien dice el Sr. Herran, que en los años 1769 y 1770 se suspendieron las juntas, por cuya razon los extractos comienzan desde el de 1771.

Extractamos de esta publicacion y damos cuenta de ellos en el lugar correspondiente, los arlículos siguientes: Arboles.-Cultivo del enebro.-Ingenieros civiles.-Observaciones acerca del carbon vegetal, etc.-Plantacion do árboles.-Plantaciones. - Premio nuevo.-Siembras de piñones.-Ventajas de usar el carbon de chopo en las ferrerias.-Viveros.

\section{H.}

227. Faro asturiáno (EL).-Véase: Castaños.-Robles.-Encinas, hayas, nogales y fresnos.

228. Fenix (EL).-Véase: Castaño (El).

229. Física de los Árboles.-Véase: Physica de los árboles.

230. Folleto sobre los bienes de Propios en la? parte relativa á su enagenacion, por D. Eugenio García de Gregorio-Madrid, 1851, Imprenta del Colegio de sordo-mudos. $-4 .^{\circ}$

Tomamos esta indicacion del Diccionario general de bibliografia española de D. Dionisio Hidalgo, tomo III, pág. 147.

Nada se dice de este trabajo en el Diccionario de bibliografia agronómica del Sr. Anton Ramirez.

231. Fomento de LA PROduCCion NÁcionál.-Revista semanal, órgano de la liga proteccionista. Publicada en Barcelona.-Véase: Proyecto de ley de montes.

232. Fomento (EL).-Periódico de Badajoz.-Véase: Nueva ley de montes $(\mathrm{La})$.

233. Fomento (EL).-Periódico de Búrgos.-Véase: Sobre la repoblacion del arbolado en la provincia de Bürgos.

234. Fomento (EL). - Revista semanal de intereses materiales.Madrid, 1871-72, Imprenta de los Sres. Rojas.-Dos tomos de 92 y 330 páginas en fólio.

Comenzó en 7 de Noviembre de 1871 y terminó el 7 de Junio de 1872.Contiene un articulo sobre el Esparto $(D e l)$, registrado en el lugar que le corresponde.

235. Formularios de CORRESPONDENCIA OFICIAL Y PARTiCULAR para el uso de los Ingenieros de montes.-Madrid, 1853, Establecimiento tipográfico-militar de Fermin Torrubia.-Un folleto en $4 .^{\circ}$ de 34 páginas. 
Contiene modelos de exposiciones á S. M., autoridades y jefes superiores; órdenes de superior á inferior y de inferior á superior; instrucciones; diario; resúmen mensual; traslado de órdenes; consultas; informes; partes sencillos; correspondencia familiar de toda clase; tratamientos, y formularios adicionales con aplicacion al servicio de los Ingenieros de montes empleados en las comisiones.

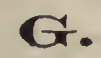

236. Gaceta De Madrid.-Madrid, 1661-1873, por los impresores Julian de Paredes en 1661; Bernardo de Villa-Diego en 1678; Ariztia en 1728 y por la Imprenta Real, primero en 1800 , y Nacional mas adelante hasta la época presente.

Sin contar varios artículos de que heruos dado cuenta al tratar de las publicaciones que primero los insertaron, dejamos extractados como contenidos en la presente publicacion, los que siguen: Arboles y plantas funerarias. -A ulaga.-Castaños, robles, encinas, hayas, nogales y fresnos-Carcoma.-Cul tivo del pino maritimo en Sologne. -Ingerto (Del).-Castaño $(E l)$.-Esparto $(E l)$. - Especies arbóreas que deben propagarse en España. - Estudios sobre la inundacion del Júcar. - Nolicias y observaciones sobre la isla de Ceilan, remitidas por el vicecónsul de España.-Selvicullura.-Sobre los trasplantes.Trasplantacion de los árboles crecidos.

237. GaCeta DEL Comercio.-Diario de Santander.-Véase: Montes.-De la conservacion de los montes por el Estado, etc.

238. Gaceta Econonista.-Periódico de Madrid.-Véase: Venta de los montes del Estado.

239. Gaceta indistrial (La).-Periódico de Madrid.-Véase: Ingenieros (Los).

240. Gobierno DE LA PROVINCIA DE ZARAGOZA:-Guardia rural. -Suplemento al núm. 52 del Boletin oficial de esta provincia, correspondiente al martes 31 de Marzo, de 1868. -Zaragoza, Imp. de Antonio Gallifa, 1868. -4. ${ }^{\circ}, 16$ págs .

Es una circular dirigida con fecha 31 de Marzo de 1868, á los Alcaldes de la provincia, por el Gobernador D. Antonio Candalija, en la que á fin de poner de relieve la importancia de la Guardia rural, dá á conocer las obligaciones mas esenciales de estt cuerpo, así como los abusos y faltas que pueden cometerse en cada uno de los ramos de policía rural, determinándolas con la debida separacion é indicando los artículos del Código penal $\delta$ del reglamento de la Guardia rural á que deben contraerse los actos punibles. Constituyen secciones especiales, los puntos que versan sobre montes, pastos y yerbas, paseos y arbolados, caza y pesca.

241. Gobierno de la provincia de Zaragoza.-Hoja en fólio, una página. 
Es una circular de 10 artículos expedida por el Gobernadar civil de la provincia de Zaragoza, D. Ignacio Mendez de Vigo, á 12 de Agosto de 1859, por la que dicta varias reglas referentes al trasporte de productos forestales, expedicion de guias, acotamientos, instruccion de expedientes de aprovechamiento, daños, instruccion de diligencias por disfrutes fraudulentos, etc.

242. Gobierno en las Fieras Y animales silvestres, por Valdecebro.-Barcelona, $1696,4^{\circ}$

Citada en un catálogo impreso en Madrid, año 1865, de lá biblioteca del Excmo. Sr. D. Pedro Caro y Sureda, Marqués de la Romana. No se indica en el Diccionario de bibliografia agronómica del Sr. Anton Ramírez.

243. Granja (LA). Revista de Agricultura y biblioteca rural; periódico de la sociedad de Agricultura del Ampurdan.-Figueras, 1850-1855.-Cinco volúmenes, $4 .^{\circ}$

Contiene un artículo titulado: Alcornoque; de su cultivo é ingerto, que registramos en lugar oportuno, asi como hacemos lo mismo, con la memoria; Exposicion de la urgencia con que debe atenderse á la policia y régimen de los rios, etc., que se insertó en esta Revista, si bien fué á la vez publicada aparte en forma de folleto.

244. Guadalete (EL). Periódico político y literario de Jerez.Véase: Algunas palabras sobre la imporlancia de los montes y arbolados.

245. Guadalquivir (El). Periódico liberal (Córdoba).-Véase: Enagenacion de la dehesa de la Jara (La).

246. Guarderia RURAL. - MEMoria y Proyecto para Establecer una nUeva guazdia rural en España.-Publicada en la Revista de Administracion del corriente año, por D. José Galofre.-Madrid, 1872. No indica la imprenta. $4 .^{\circ}$ mayor, 36 págs. y una lámina en negro con figuras que representan la situacion, formas perimétricas, division, agrupacion y servidumbres de vias pastoriles, de las fincas.

La portada interior dice: Memoria y proyecto para establecer una nueva Guarderia rural.-Dedicado al Excmo. Sr. Ministro de Fomento.

Firma la memoria su autor, en Madrid á 15 de Enero de 1872.

En la Revista de Administracion, año I, se encuentra en las páginas 37, 97, 129, 161 y 193 .

Estudia la influencia que las costumbres, la clase de propiedad, las servidumbres, la forma agrimétrica y otras causas, ejercen en la cuestion. Analiza las disposiciones anteriores y concluye formulando cuatro bases que encierran todo el plan de la organizacion, objeto del proyecto, reducido á la ampliacion del cuerpo de la Guardia civil, constituyendo un grupo destinado exclusivamente á la custodia de la propiedad rústica, cuyo presupuesto de gastos asciende á 16.820 .000 reales correspondientes á 8.880 guardas de campo segun los cálculos del proyectista. 


\section{H.}

247. Himno forestal del Cuerpo de ingenieros de montes, cantado por los alumnos de la Escuela en sus escursiones de 1848 (año de la fundacion).二Hoja sin pié de imprenta ni indicacion de autor.

Esta entusiasta composicion, debida indudablemente á alguno de los jóvenes alumnos de aquella Escuela, consta de tres partes: Coro general, Diana y Brindis.

248. Historia de la arquitectura de Jardines.-Véase: Memoria acerca del plan de una obra de arquitectura de jardines.

249. Historia de la Coirpañía de Jisus en la provincia deL Paraguay . - Por Pedro Lozano.-Madrid, 1754.-Dos tomos en fól.

En el libro segundo se indican algunas plantas de Chile, y en el libro quinto se mencionan los corpulentos alerces de Chilóe, especie denominada Libocedrus telrágona, Endl., y bien diferente de los árboles que en el antiguo mundo fueron designados con el nombre de Alerces.

250. Historia de la EConomía política de Aragon. Por D. Ignacio de Asso. Con licencia.-Zaragoza, por Francisco Magallon, 1798.-4. ${ }^{\circ}, 508$ págs.

Aunque algo dispersas, contiene esta obra curiosas noticias acerca del estado de los montes mas importantes del antiguo reino de Aragon. El autor lamenta la decadencia del arbolado forestal y le atribuye gran influencia en el clima. En la pág. 1 y̆ se lee lo siguiente: «El partido de Daroca y señaladamente el territorio de Paniza, Aladren, Segura y la Cuerla estuvo en otro tiempo muy bien provistò de carrascales, pinares y montes de leña: mas estos se hallan hoy en dia muy deteriorados, y amenazando su última ruina por la im- pericia de los carboneros, por el excesivo consumo de carbon que se hace en Zaragoza, y por la inobservancia de los Estatutos antiguos de la Comunidad renovados en 1686, que prescriben las mas acertadas reglas para el reparo y conservacion de los montes. En ellos está prevenido el tiempo de coger la bellota, y lo que se debia observar en los nuevos rompimientos. Se limita el permiso de hacer leña á los montes de Cerveruela, Vistabella, Luesma, Badules y algunos otros, exceptuando la loma del 0so, que permanecia vedada. Se declara asimismo por leña de mal corte la que se hace destrozando el pié y brazos principales del árbol ó descepando la raiz. Se prohibe hacer cortes en el plano de Cuerla, y en los pinares de Azuara, Segura, Herrera, Torrecilla, etc., y solo se permite quemar aliagas en los hornos de los alfareros. Por este resúmen se echarán de ver las admirables disposiciones que contienen dichas Ordenanzas en el importante asunto de la conservacion y restauro de los bosques." 
251. Historia física, política y natural de la isla de Cuba, por D. Ramon de la Sagra.-París, imprenta de Maulde y Renou. Mad., est. tipog. de D. Franc. de P. Mellado._1842.-1861.-Trece tomos en fólio mayor con planos, dibujos, estados, etc., de 135 á 376 págss.

El primer tomo trata lijeramente en la pág. 241 de los desmontes, añadiendo breves consideraciones acerca de las especies arbóreas destruidas y de la influencia que ejercen los montes en el clima del país. En el cap. 11 del tomo xuı se ocupa de la tendencia á la destruccion de la vegetacion arbórea, de los reglamentos antiguos de montes y bosques; de los vicios y defectos de que estos adolecen; de las reclamaciones hechas por ilustrados patricios; de los daños irreparables ya causados, y de la imprevisíon que domina respecto de la riqueza forestal.

252. Historia natural de Cayo Plinio Segundo. Traducida por el licenciado Gerónimo de Huerta, médico y familiar del Santo Oficio de la Inquisicion, y ampliada por el mismo con escolios y anotaciones en que aclara lo oscuro y dudoso, y añade lo no sabido hasta estos tiempos. Dedicada al Católico Rey de las Españas é Indias D. Felipe IV, nuestro señor.-Madrid, 1624-1629, por Luis Sanchez y por Juan Gonzalez.-Dos tomos en fólio, de xxvilı-907 y XVI-720 págs.

En el libro xv, págs. 61 á 80 , trata de los frutos de los pinos, castaños y varios frutales; en el xvı, págs. 81 á 166, de las bellotas de varios árboles silvestres y del uso de las cortezas, maderas y otros aprovechamientos; y en el xvir, págs. 117 á 156, bajo el epigrafe de Precios admirables de los árboles, comprende un tratado de los que mas bien son hechos por el arte, que nacidos, y dá reglas para la siembra, poda, curacion de enfermedades, etc.

253. Historia natural de la malagueta ó pimienta de Tavasco, y noticia de los usos, virtudes y exencion de derechos de esta saludable y gustosa especia, con la lámina del árbol. Escrita de órden del Rey por el doctor D. Casimiro Gomez Ortega, primer catedrático del Real Jardin Botánico y de las Reales Academias de la Historia, Médica, de la de Ciencias de Paris y de la Real Sociedad de Lóndres.-Madrid, 1780, por Joaquin Ibarra.-4. ${ }^{\circ}$ mayor, 34 págs.

Describe el árbol y las cualidades y usos de sus productos, advirtiendo que la madera es dura y á propósito para varias obras. Lo recomienda para la ornamentacion por ser siempre verde, y cree que se propagaria bien en Málaga y Valencia.

254. Historia y magia natural, ó ciencia de filosofía oculta, con nuevas noticias de los mas profundos misterios y secretos del universo visible, en que se trata de animales, peces, aves, plantas, flores, yerbas, paraiso, montes y valles. Por el P. Heruando Castri- 
llon.-Madrid, 1692, por García Infanzon, y 1723, por Sanz. 4. ${ }^{\circ}$ XII. - 324 págs. y xvr de índices.

En el tratado quinto se ocupa el autor de los campos, valles y bosques de la tierra y de las yerbas y árboles que se crian en ellos, pero lo hace sin interés, despues de tratar de cuestiones diversas.

255. Hoja Forestal. A La América.-Madrid, 1860.-Imprenta del Colegio de Sordo-mudos y de Ciegos. - 4 págs. en fólio.

Firmada en Madrid á 16 de Junio de 1860, por D. José Cortés.

Tiene por objeto rebatir la asercion de La A mérica en la cuestion de desamortizacion forestal, demostrando con cálculos científicos y con los resultados de prácticas experımentales auténticas, que aquel periódico al combatir la legislacion entonces vigente sobre la desamortizacion forestal, no logró hacer notar mas que la pureza de la doctrina en que ésta se apoya, puesta en práctica por los gobiernos de todas las naciones del continente, donde la ciencia ha llegado á mayor altura, dejando probado á la vez que el sistema desamortizador propuesto por La América carece de base y es de todo punto impracticable.

256. Hoja Forestal. A La Discusion.-Madrid, 1860.-Imprenta del Colegio de Sordo-mudos y de Ciegos. - 2 págs en fólio.

Es una hoja suelta que firma en Madrid á 12 de Enero de 1860, D. José Cortés. Tiene por objeto combatir las doctrinas sentadas por La Discusion relativas á la posesion de los montes y á la desamortizacion de los públicos. $\mathrm{El}$ autor establece que la conservacion de los montes es uno de los primeros intereses de la sociedad, y que no ofreciendo garantías bastantes para conseguir este fin el interés particular, corresponde al Estado desempeñar este servicio, adquiriendo la propiedad forestal.

\section{I.}

257. Iberia (LA).-Diario liberal de Madrid.-Véase: $A l$ escuchar el incesante clamor..., etc.-Proyecto de ley de montes.

258. InEA DE LA LEY AGRARIA ESPaÑola, por D. Manuel Sisternes y Feliu, Fiscal del Consejo de Cámara de S. M.-Valencia 1786, por B. Monfort. - $4 .^{\circ}$ mayor, 148 págs.

Los ejemplares de este trabajo, que se juzga estimable, escasean mucho.

259. Ilustracion Española y americana (La).-Periódico de Madrid.-Véase: Arboles en España (Los).

260. Ilustracion (LA).-Periódico universal.-Unico redactor y propietario D. Angel Fernandez de los Rios.-Madrid, 1849.1857. - Oficinas y establecimiento tipográfico del Semanario pintoresco y de la Ilustracion, á cargo de Alhambra.-Nueve tomos en 
fólio, á trés columnas, que tienen sobre 500 págs. á excepcion del primero, uno que consta de 352 , y el último de 272 ; todos ellos con profusion de grabados.

En el tomo I, pág. 143, hay un artículo dedicado al aprovechamiento de la acácia y á las aplicaciones de su madera; en lá pág. 176 otro, sobre los bosques de Francia, y en la pág. 338 otro sobre los árboles.

261. Imparcial (EL).-Diario de intereses morales y materiales, literatura, noticias y anuncios.-(Publicado en Zaragoza).-Véase: Montes, por $E$. Ft.

262. Imparcial (EL).-Periódico liberal de Madrid.-Véase: proyeclo sobre montes $(E l)$. - Proyecto de ley de montes.

263. Independencia española (La).-Diario liberal de la tarde, órgano del partido constitucional.-Publicado en Madrid.-Véase: Carta de Cachano Tejas..., etc.

264. Indice de la legislacion de todos los ramos de Gobernacion y Fomento desde $1 .^{\circ}$ de Enero de 1850 hasta 30 de Junio de 1866, por D. Antonio de Medina y Canaìs, secretario del Gobierno de la Coruña.-2. ${ }^{\mathrm{a}}$ edicion del índice publicado en 1864, corregida y aumentada con todas las disposiciones posteriores hasta el dia.-Coruña, Establecimiento tipográfico de Puga, 1866. -4. ${ }^{\circ}, 516$ púgrs.

Comprende disposiciones importantes sobre aprovechamientos, estadística, personal, etc., si bien todas las que contiene están expresadas por medio de brevísimos estractos.

265. Informe de la Sociedad Económica de Madrid al Real y Supremo Consejo de Castillà en el expediente de ley agraria, extendido por su indivíduo de número D. Melchor Gaspar de Jovellanos, á nombre de la junta encargada de su formacion, y con arreglo á sus opiniones.-Nueva edicion.-Madrid, 1820, por I. Sancha.-4. ${ }^{\circ}$, 235 págs.

Existe una edicion de 1795 hecha por el mismo Sancha, otra de 1814 hecha en Palña, y otra de 1834, en Madrid, por J. Palacios, habiéndose reproducido en las Memorias de la Sociedad Económica Matritense, y en las diversas ediciones de las obras de tan eminente escritor. Esta de 1820 es, sin embargo, la mas correcta, porque se hizo bajo los auspicios y direccion de la Sociedad Económica, respetando con la mayor escrupulosidad el original corregido por el mismo Jovellanos, para no reproducir las incorrecciones que se notan en las referidas Memorias y sobre todo en la edicion de Palma.

Entre los puntos que mas relacion guardan con la materia forestal, está el de los baldíos, tierras concejiles y montes públicos, que con lijeras excepciones entiende que se fomentarian pasando al dominio privado.

266. Ingolime de la Socieday Económica die Välexcia, al M. I. 
Sr. Gobernador civil de su provincia, sobre la urgencia y bases de una ley de policía y conservacion del régimen de los rios de la Península.-Valencia, 1850, por José Rius.-4. ․ 15 págs.

Se publicó tambien en el Boletin enciclopédico de la Sociedad económica de Amigos del pais de Valencia. Tomo vi.

Fué emitido este dictámen teniendo á la vista la Exposicion que sobre el mismo punto elevó al Gobierno en 1850 D. Narciso Fages de Romá, circulada á los Gobernadores para que oyesen sobre el particular á las corporaciones mas competentes.

La Económica valenciana opina que sería un golpe fatal para la agricultura el obligar, como pretende el Sr. Fages de Romá, á hacer plantaciones que defiendan las orillas y pueblen las vertientes, considerando bastante útil para el objeto de defender los rios, la aplicacion de la ley de expropiacion forzosa por causa de utilidad pública.

267. Ingenieros DE Montes.-Recuerdos de la fundacion.-Enero de 1866 . - Cuaderno autografiado de 22 págs.

Concluye con una nota autógrafa de su autor, el Excrno. é llmo. Sr. Don Bernardo de la Torre Rojas, fundador de la Escuela de Ingenieros de montes de Villaviciosa de Odon, en la que consigna su deseo de que se considere su contenido como parte de su testamento, recomendando el trabajo á los Ingenieros, para que lo conserven como una memoria de familia y como la última prueba que puede darles de su entrañable afecto. Está firmada en Villäviciosa de Odon á $10^{\circ}$ de Enero de 1866.

En el folleto se desenvuelve el sentido filosófico del lema que se adoptó en la fundacion de aquel establecimiento "Saber es hacer. El que no hace no sabe." Traza á grandes rasgos la historia de la creacion de la Escuela, y establece y comenta los puntos dominantes que sirvieron de norte para fundarla, en lo relativo á la condicion esencialmente práctica de los estudios, al espíritu de cuerpo, á la abnegacion personal, á la moralidad, á la disciplina y á otras circunstancias fundamentales en toda institucion facultativa destinada al servicio del Estado.

268. Instruccion de entrada (á la Escuela superior del Cuerpo de Ingenieros de montes), para los pretendientes á las plazas de alumnos, publicada en la Gaceta de 18 de Julio de 1858.-4. - - Hoja sin pié de imprenta.

Consta de diez artículos, y reproduce al final el tercero, once y doce del Real decreto de 16 de Marzo de 1859. Fechada en Villaviciosa de Odon á 12 do Julio de 1858 y suscrita por el Director B. de la Torre Rojas.

269. Instruccion para el cultivo del Pino marítimo ó de Burdeos, Pino piñonero ó de piñon comestible, Pino silvestre, Alfalfa, Nabos gordos ó gallegos, Remolachas, Zanahoria y Trébol, que por encargo de la primera-seccion de la Junta provincial de Agricultura, Industria y Comercio de Santander, ha formado el vocal nato de la misma D. José Ezquerra, Ingeniero jefe de segunda clase del 
cuerpo de Montes. $4 .^{\circ}, 15$ págs. - Carece de fecha y pié de imprenta.

Tiene por objeto esta instruccion fomentar en la provincia el cultivo de aquellas plantas, con objeto de desarrollar la riqueza forestal y pecuaria.

2\%. InSTRUCCION PARA EL PUEBLo.-Cien tratados sobre los conocimientos mas indispensables. Otra enteramente nueva, con grabados intercalados en el texto, por diferentes autores.-Madrid, 1851-1853, por Mellado. -Dos tomos en $4 .^{\circ}$ á dos columnas, de 1.600 y 1.606 de estas, que son las que están numeradas.

Treinta y tres son los autores citados en la portada. Se refieren á la Agricultura los tratados de los números 64 al 79. Registramos en el segundo grupo los que se ocupan de Arboricultura, Desmonles y Desagiles.

271. Instruccion para los guardas de caminos, paseos y arbolados, y distribucion de estos en 37 cuarteles. Aprobada por el Excmo. Ayuntamiento Constitucional de esta M. H. Villa en $1 .^{\circ}$ del corriente, y por el Excmo. Sr. Jefe Político de la Provincia en 8 del mismo.

Fechada en Madrid á 20 de Abril de 1845 . Consta de quince artículos, en los que se determinan los deberes, dependencia, uniforme que deben usar dichos funcionarios, herramientas de que deben estar provistos y otros pormenores.

No aparece registrado este folleto en el Diccionario de bibliografía agronómica del Sr. Anton Ramirez.

272. Instruccion para los pretendientes de plazas de alumnos internos y externos en la Escuela de Ingenieros de Montes, aprobada por Real órden de esta fecha. $-4 .^{\circ}$, sin pié de imprenta. Hoja de 4 págs.

Suscrita en Madrid á 11 de Setiembre de 1847, por el Director D. Bernardo de la Torre Rojas. Consta de diez artículos y una disposicion transitoria. Al final acompaña los formularios de solicitud de ingreso en la Eseuela y de escritura de obligacion para el pago de las cuotas ó pensiones semestrales.

273. INSTRUCCION PARA PASTOBES Y GANADEROS, escrita en francés jor el C. Daubenton, profesor de Historia natural en el Museo de París. Traducida de órden del Rey y adicionada por D. Francisco Gonzalez, Maestro de la Real escuela de Veterinaria de Madrid.Con superior permiso. Madrid, en la Imprenta Real, por D. Pedro Pereira, impresor de cámara de S. M.—Año de 1798.-8. 335 páginas con dos estados de estadística pecuaria y dos láminas sobre tipos de raza ovina.

Contiene al final un vocabulario pastoril. Trata de los deberes de los pastores; de las razas de ganado; de los sistemas y práctica del pastoreo; de los pastos, ramon y demás alimentos; perros, alimañas y cuanto concierne á la 
ganadería, con aplicacion á los usos y métodos empleados en España por la asociacion de la Mesta.

274. Instruccion pRÁctica para las cortas y entresacas de los montes de pino albar, arreglada á las observaciones hechas en la sierra de Guadarrama.-Por A. P.-Madrid, 1847: imprenta del Colegio de Sordo-mudos. - Fólio, 8 págs. á dos columnas.

Contiene doce artículos, y sirven de complemento varias tablas, tarifas y formularios para gobierno de los dependientes forestales del Real Patrimonio. El autor del Diccionario de bibliografía agronónica, D. Braulio Anlon Ramirez, de quien tomamos csta nota, añade que cpor la materia, las iniciales y la costumbre de ocultar su nombre, principalmente en documentos escritos sin pretensiones, se deduce que la Instruccion es debida á la pluma de D. Agustin Pascual (hijo), digno jefe superior del cuerpo de Ingenieros de montes é inspector de los reales bosques del Real Patrimonio."

275. Instruccion sobre el cultivo Del Argan. (Argania Sideroxylon. R. et S.) por D. Est'́ban Boutelou.-Santa Cruz de Tenerife.-Imprenta, librería y encuadernacion de J. Benitez y compaกิ́́a. $1870 .-80^{\circ}, 19$ págs.

Contiene además de lo que indica su titulo, algunas consideraciones sobre la agricultura de Canarias. La Sociedad económica de dicha. provincia, parece que confirmó las buenas cualidades atribuidas al aceite extraido del fruto de aquel árbol con destino al alumbrado, y apoyó la idea emitida por el autor acerca de la introduccion del cultivo del árbol en cuestion, en las Islas y especialmente en las cercanías de Santa Cruz de Tenerife.

276. Instruccros sobre el modo mas seguro y ecoúnímico de trasportar plantas vivas por mar y tierra á los paises mas distantes, ilustrada con láminas. Añádese el modo de desecar las plantas para formar herbarios. Dispuesta de órden del Rey, por el doctor D. Casimiro Gomez Ortega, primer catedrático del Real jardin Botánico y de las Reales Academias Médica, de la Historia, etc.-Madrid, 1779, por J. Ibarra.-4., 70 págs. y dos láminás.

Explica el modo de arrancar con césped los arbolitos, arbustos, matas, y demás plantas perennes, y la forma y tamaño de los cajones para el trasporte. Slgue la indicacion de las plantas que con preferencia deberian traerse á España, y termina con otra sobre el modu de recoger, secar y disponer las de un herbario.

277. Isstruccion sobre la organizacion provisional del servicio que deben desempeñar los funcionarios subalternos del distrito forestal de Teruel. - 28 de Febrero de 1867.-Teruel, Imprenta de Francisco Baquedano, 1867;-4. ${ }^{\circ}, 66$ págs.

Autoriza la Instruccion el Ingeniero jefe, D. H. Ruiz Amado. Contiene disposiciones sobre inventarios, documentacion, demarcaciones, estadistica, mejoras, guardería local, aprovechamientos, denuncias, policía, productos 
fraudulentos, ganados, vedas, marcaciones y ofros particulares propios del servicio. Sigue un Estracto de la legislacion penal vigente por abusos de montes y termina presentando modelos para expedientes de inventario, relaciones estadísticas, incendios, marcacion de árboles, libro diario, partes mensuales de operaciones, estados mensuales de denuncias, y pliegos de condiciones para subastas de productos, de árboles destinados á usos vecinales y de leñas y pastos de igual clase.

278. Instrucciones aprobadas por S. M. en Real órden de 16 de Marzo de 1859 para el reconocimiento, recibo y clasificacion en los arsenales de las maderas de roble aplicables á la construccion naval.-Madrid, imprenta nacional, 1859.-Fólio, 6 págs. sin numerar.

Constan de diez y seis articulos que versan principalmente sobre las cualidades y dimensiones de las maderas. Fechadas en Madrid á 24 de Mrarzo de 1859.-Mac-Crohon.

Este folleto no figura en el Diccionario de bibliografia agronomica del Sr. Anton Ramirez.

279. Instrucciones para liL SERvicio de la guardería Forestal y RURAL (de la provincia de Huesca).-Huesca, 1859, por Jacobo Muría Perez.-4. ${ }^{\circ}, 20$ págs.

Están fechadas en Huesca á 30 de Diciembre de 1859 y suscritas por el Gobernador. Constan de noventa artículos, y establecen las obligaciones de los guardas respecto á los aprovechamientos de los montes públicos y de partículares, asi como en los casos de incendios y de cortas y rozas fraudulentas. Refunden en una, para los efectos de las instrucciones, la guardería forestal y rural, haciéndola dependiente del distrito forestal, observándose las prescripciones del reglamento de 8 de Noviembre de 1849, dictado para los guardas de campo municipales y particulares.

280. Instrucctones para regularizar el servicio de los guarDAS Y POLICíA DE LOS MONTES PúBliCOS. - Sevilla. Imp. de La Andalucia.-4. ${ }^{\circ}, 14$ pág:s. y 2 sin numerar de un Apéndice.

Las autoriza en Sevilla á 15 de Marzo de 1866, el Ingeniero jefe, Luis Bravo.

Son reproduccion de la circular del Gobernador de la provincia, fecha 25 de Febrero de 1866, inserta en el Boletin oficial núm. 675. Se dirige á los Alcaldes, vecinos de los pueblos, funcionarios del ramo y cuantos tienen que intervenir en cuestiones de montes, recordándoles bajo forma preceptiva, por articulos, los deberes respectivos, estractando al efecto las disposiciones vigentes en materia de aprovechamientos, denuncias, desamortizacion, servicio general, incendios, etc. El A péndice, reproduce los artículos de la parte penal de las Ordenanzas de 1833 que han quedado vigentes á consecuencia del Real Decreto de 17 de Mayo de 1865 y otras disposiciones.

281. InTROdUCCION $\AA$ LA IIISTORIa Natural Y g EOGRA Fía FísiCa DE 
ESPAÑA, por D. Guillermo Bowles.-Madrid.-Imprenta Real, 1775. -4. ${ }^{\circ}, 529$ págs.; segunda edic., idem, 1782; terc. edic., idem, 1789; traduccion francesa, París, 17\%6; traduccion italiana, Parma, 1783.

Contiene: Plantas de España, desde la pág. 218 á la 237 inclusives, en que se ocupa el autor de las que ha visto en el reino, citando sus nombres vulgares y científicos y sus propiedades. Del lentisco dice, que es el olíbano de Levante, y la cornicabra, una especie de terebinto de Alepo.

- Bosques y árboles huecos de Vizcaya y Guipúzcoa, desde la pág. 354 á la 359 inclusive. Divide los montes en tres clases, á saber: expontánzos ó naturales; buecos ó arboledas de castaños y de robles albares; y sebes óbosques tallares cercados. Atribuye la extincion de los bosques bravos al carbon que requieren las ferrerías, y describe la plantacion de sebes de roble y castaño, los trasplantes y el aprovechamiento de leña.

- Motivo por qué los robles y otros árboles son huecos en unos paises y sólidos en otros, desde la pág. 365 á la 374 inclusives. Hace consistir la diferencia en los divẻrsos modos de ejecutar la poda, conduciéndole estas consideraciones á combatir la Ordenanza de montes de 1748. El cortar las ramas ó guía principal es causa de que se pudra ó debilite el trunco, en opinion de] autor, de donde se sigue el ahuecamiento, como pasa con las moreras de Valencia y Murcia en contraposicion de lo que sucede con las de Granada, sujetas á mejor tratamiento.

282. INVESTIGACIONES PARA ENRIQUECER LAS FINCAS DEL REAL PATRIMONio con nuevos plantíos, arbolados y razas útiles de animales domésticos, hechas en el extranjero, por D. Ramon de la Sagra.Madrid, 1841. Imprenta del Colegio de Sordo-mudos.-4. $.^{\circ}, 10$ páginas.

El autor adquirió y remesó desde el extranjero para las posesiones del Real Patrimonio, 2400 piés de árboles, arbustos y plartas para vergeles, jardines y bosques, y 300 especies y variedades de plantas de adorno, hortalizas, forrajes, etc.

283. INVESTigaciones SObRe LA ANTIquísima MAdERA, conocida en Sevilla con el nombre de Alerce, por D. Miguel Colmeiro.Sevilla, 185̌2. Imprenta de El Conciliador.—4. ${ }^{\circ}, 8$ págs.

Se publicó en $E l$ Conciliador del 17 de Marzo de 1852; en el Boletin ofcial del ministerio de Fomento, tomo II, Madrid, 18522, y en la Gaceta y otros periódicos.

De las investigaciones resulta, que la madera de que se trata corresponde al Callitris quadrivalvis. Vent., sinónimo de Thuya articulata. Desj., y que el nombre de alerce, segun el articulista, puede provenir del de erez, ciprés en árabe, cuyo vocablo puede leerse el arz ó el erez, y de aqui alerce. En el Diccionario de bibliografia agronómica del Sr. Anlon Ramirez no se lıabla de este opúsculo.

284. Investigaciones sobre la nonterí. y los demás ejercicios 
del cazador, por D. Miguel Lafuente Alcántara.-Madrid, 1849, por

L. García. - 12. ${ }^{\circ}, 160$ págs.

Entre otros puntos, explana el relativo al ejercicio de la caza en las repúblicas de Grecia y Roma; las escenas ó cacerias durante el imperio; la caza entre los godos y el origen de la cetrería, refiriendo la tradicion sobre los monteros de Espinosa; relata los reyes, príncipes y caballeros que han sido insignes cazadores; reseña la memorable cacería de los Reyes católicos, segun el cronista Bernaldez, y por último, inserta una curiosa noticia crítica de los libros de caza compuestos en España desde la formacion del lenguaje castellano.

285. Itinerario DesCriptivo de las provincias de España, de sus islas y posesiones en el mediterráneo; con una sucinta idea de su situacion geográfica, poblacion, historia civil y natural, agricultura, comercio, industria, hombres célebres, carácter y costumbres de sus habitantes, y otras noticias que amenizan su lectura.-Traduccion libre del que publicó en francés Mr. Alexandre Laborde en 1809. Acompaña un atlas de 29 mapas.-Valencia: En la imprenta de Ildefonso Mompié, 1816.-4. ${ }^{\circ}, 482$ págs. con 16 de prólogo, 14 de apéndice y 20 de índices.

Indica muy lijeramente las principales especies arbóreas que dominan en los montes de las antiguas provincias.

\section{J.}

286. Junta GENERAL DE estadística.-BOSQUEJO DASOGRÁFiCO DE LA PRovincia DE oviedo, por D. Francisco García Martino.-Ha servido de base el mapa geográfico de D. Guillermo Schulz.-1862.Escala de 1/250.000.-Madrid, litografía de J. Aragon.-Francisco Vega, litógrafo.

Lo forma una hoja cromolitografiada, en la que figuran catálogos sistemáticos de las especies botánicas que constituyen la flora forestal, agrícola y pratense, consignándose además la distribucion de la superficie bajo estos conceptos y la extension y produccion de los montes.

287. Junta GENERAL DE ESTAdístiCA - - BOSQUEJO DASOGRÁfico DE LA Provincia de Santander, por D. Francisco García Martino, 1862. Ha servido de base el mapa geográfico publicado por D. Francisco Coello.-Escala de 1/2:0000 .-Madrid, litografía de Bachiller.

Lo forma una hoja cromolitografiada, en la que figuran catálogos sistemácos de las especies botánicas que constituyen la flora forestal, agrícola y pratense, consignándose ade:nás la distribucion de la superficie bajo estos conceptos y la extension y produccion de los montes. 
288. Junta General de estadístTCA. - Ensayo dE DEsCripcion GEOGNósTiCA DE LA PROVINCIA DE TERUEL, en sus relaciones con la agricultura de la misma, por D. Juan Vilanova y Piera, doctor en ciencias naturales, catedrático de geología en la universidad central, é indivíduo de varias sociedades científicas nacionales y extranjeras.-Escudo de armas de España.-Madrid, imprenta nacional, 1863.-Fólio, 312 págs. con 45 grabados intercalados en el texto, representando vistas, cortes y otros detalles de los terrenos, y 10 láminas con dibujos de fósiles.

El capítulo $\nabla$ trata del Cultioo agrario y forestal de la provincia, incluyendo un catálogo de las principales plantas expontáneas de la misma. El artículo 11 del mencionado capítulo, págs. 283 á 286, está destinado exclusivamente al $C$ ultivo forestal, y trata de la distribucion de los montes y de las especies leñosas que los constituyen.

289. Junta general de estadística.-Plano de rodales deL MoNTE La Garganta, DE LOs PRopios DEL espiNAR, por D. A. Anton Villacampa y D. A. Romero Lopez. Año de 1863. - Escala de 1/20.000 A. Hernandez.-Litografía de F. Kraus.-Madrid.

Lo forma una hoja cromolitografiada en la que figura el Apeo de rodales; la Tabla de superficies por clases de edad, la Tabla de superficies por clases de edad y calidades, y la Tabla de existencias de los rodales por clases de edad.

290. Junta PúbliCA DE LA REAL SOCIEDAd valenciana, celebrada el 9 de Diciembre de 1800.-Valencia, 1801, por B. Monfort. $-4 .^{\circ}$, 408 págs.

Comprende la Memoria premiada que contiene la indicacion de los montes de Valencia, etc., de que damos cuenta en el lugar respectivo.

\section{L.}

291. LABRADOR VASCONGADO, (EL), $b$ antiguo agricultor español. Demostracion de las mejoras de que es susceptible la agricultura en las provincias Vascongadas, y de las grandes ventajas que se podrian lograr en todo el reino, observando las reglas de la antigua labranza. Por D. Antonio de San Martin y Burgos, presbítero beueficiado de la villa de Ondarroa, en el señorío de Vizcaya, etcétera.-Madrid, 1791, por B. Cano.-8. ${ }^{\circ}$, xvi.—280 págs.

Aboga por la plantacion de montes en los terrenos vacíos. Se contesta en esta obrita á las dos cartas que, sobre el estado de la agricultura, industria y comercio de Guipúzcoa, se insertaron en el periódico: Espiritiu de los mejores diarios, números 185 y 194 del año 1789. 
292. Lecciones de administracion norestal. Apuntes de la clase.-Véase: Escuela especial del cuerpo de Ingenieros de montes.

293. Lecciones De agricultura, explicadas en la cátedra del Real jardin Botánico de Madrid el año de 1815, por el profesor Don Antonio Sandalio de Árias y Costa, indivíduo de mérito de la Real Sociedad Económica Matritense, secretario de su clase de agricultura y sócio correspondiente de la de Valladolid.-Madrid, 1816, por Fuentenebro.-Dos tomos, $4 .^{\circ}$, xxxvir.-164 y.400 págs.

Se lizo en la misma imprenta una nueva edicion corregida y aumentada por el autor, en 1818, constando de dos tomos, $4 .^{\circ}$, de xxxvı.-282 y 451 páginas.

De los prados naturales y artificiales así como del cultivo de plantas de adorno, árboles y jardines ingleses, se ocupa en el tomo Il, insertando un extenso catálogo de plantas pratenses.

294. Legislacion forestal novísima, que contiene la ley: de montes, el reglamento para su ejecucion y el del cuerpo de Ingenieros del ramo.-Madrid, Imprenta de R. Labajos.-1865.-8. . 134 págs.

Comprende: $1^{\circ}$ un lijero prólogo sobre la necesidad de coleccionar y anotar la legislacion.

2. ${ }^{\circ}$ La ley de montes de 24 de Mayo de 1863 y su Reglamento de 17 de Mayo del mismo año, subdividido en titulos como sigue: I. De la clasificacion de los montes públicos. II. Deslinde de los montes priblicos. III. Adquisicion de montes por el Estado, permutas con los pueblos o particulares y plantacion de terrenos yermos. IV. Refundicion de dominios. V. Servidumbres sobre los montes públicos y aprovechamientos vecinales. VI. Administracion de los montes públicos. VII. De los aprovech amientos de montes. VIII. De los gastos de mejora y conservacion de los monles. IX. Policia de los monles públicos. X. De los montes particulares. Disposicion general.

3. Instruccion para la ejecucion de las ordenaciones.

4. Id. para llevar a efecto la ordenacion defnitiva de los montes públicos. Hay un modelo de la Memoria de reconocimiento.

5. Id. para la formacion de los planes provisionales de aprovechamiento, conforme á lo dispuesto en el articulo 86 del Reglamento para la ejecucion de la Ley de 24 de Mayo de 1863.

Todas las instrucciones lievan la fecha del Reglamento de la Ley de montes públicos.

6. Reglamento orgánico del cuerpo de Ingenieros de montes, aprobado por Real decreto de 23 de Junio de 1865. Abraza los puntos siguientes: Objeto, atribuciones y dependencia del cuerpo de Ingenieros de montes; clases, ingreso en el cuerpo y nombramiento de los Ingenieros: Derechos, honores y consideraciones de los Ingenieros: De las diversas situaciones en que podrán hallarse los Ingenieros dentro del cuerpo, y de las causas por las que dejaran de pertenecer á él: De la Junta consultioa: De la Escuela especial del cuerpo: De la distribucion general de los Ingenieros y del modo de ejercer sus funciones y servi- 
cio, desde los Inspectores de primera y segunda clase hasta los aspirantes: De las disposiciones relativas al servicio comunes á todas las clases de Ingenieros: De la disciplina interior del cuerpo; y disposiciones transitorias y generales.

7. A péndice. -Titulos $\mathrm{m}, \mathrm{\nabla}$ y vi de las Ordenanzas generales de montes que tratan de la policía comun á todos los montes del reino; de la particular de los montes dependientes de la Direccion, y de las penas por daños causados en los montes.

8. Escalafon del cuerpo de Ingenieros de montes en 16 de Enero de 1865.

295. Legislacion y JuRisprudencia forestal, ordenada y comentada, etc.- -Véase: Boletin de la Revisla forestal, económica y agricola.

296. Ley, Reglanento y Cartilla de la Guardia rural.-Depósito de la Guerra.- Madrid, Imprenta y litografía del Depósito de la Guerra, 1868. -8. ${ }^{\circ}, 210$ págs. con cinco modelos de documentacion oficial.

La ley es de 31 de Enero de 1868; el reglamento está aprobado por Real decreto de 20 de Febrero del mismo año y la cartilla por Real órden de $1 .^{\circ}$ de Marzo siguiente. Consta la primera de 11 artículos sobre la creacion, organizacion y servicio; el segundo de 125 artículos relativos al personal de jefes, oficiales y guardias, haberes, ascensos, servicio ordinario y en sus relaciones con los guardias particulares, armamento, uniforme, y equipo; y por último la cartilla se ocupa en 121 artículos de la distribucion y modo de llevar á cabo su cometido cada una de las clases, comprendiendo lo rclativo al ramo de montes en el título vi1. En la tercera parte se especifican los deberes del soldado y el cabo en 66 artículos, destinándose la cuarta á la exposicion del sistema métrico, y la quinta á formularios y tratamientos.

297. Ley votada en córtes para el establecimiento de la Guardia rural, y reglamento aprobado por S. M., comentado por un jurisconsulto de esta córte.-Madrid, Imprenta de D. J. Morales y Rodriguez, 1868.-8. ${ }^{\circ}, 44$ págs.

Véase: Ley, reglamento y cartilla de la Guardia rural. Los comentarios:son once y versan sobre cuestion de creacion, organizacion, haberes y recompensas del personal, guardas particulares y otros puntos de menor interés.

298. LEY Y REgLAMENTo DE GUARDERía RURAL.-Escudo de armas de España.-Madrid, Imprenta del Colegio de Sordo-mudos y de Ciegos, 1866.-4. $.^{\circ}, 16$ págs.

La ley consta de nueve artículos y el reglamento de cincuenta y siete. Entrambas disposiciones están expedidas con fecha 3 de Agosto de 1866. Tratan del servicio de Guardería rural, encomendado á la Guardia ci ril; del servicio de este cuerpo en sus relaciones con los guardas particulares, conductores de ganados, regantes y empleados de montes, $y$ del personal y material de la Guardia civil necesario para el completo servicio de la rural.

299. LeYes, REglaMientos Y CIRCULARES SOBRE yontes, PLANTíos Y CAMinos vecinales de NatarRa. - Escudo de armas de la provin- 
cia.-Pamplona: Imprenta de Francisco Erasun y Rada, 1851.$4 .{ }^{\circ}, 30$ págs.

Contiene la ley 26. de las Córtes de Navarra de los años de 1828 y 29 , compuesta de sesenta y ocho artículos que versan sobre creacion y conservacion de montes, arbolados y plantíos, prohibicion de roturaciones, entrada de ganados, extraccion de leñas y raices, cortezas ó taño, etc., con todo lo relati vo á guardería y policia forestal; la circular de $10^{\circ}$ de Agosto de 1850, sobre formacion de juntas de montes y extraccion de taño; la de 9 de Setiembre del mismo año, sobre libertad de contribuciones de los nuevos plantios; el Reglamento de 30 de Enero de 1851, sobre montes, y el de igual fecha sobre caminos vecinales.

En el Diccionario de bibliografia agronómica del Sr. Anton Ramirez, no se cita esta publicacion.

300. Libro DE AGRicultúra. Su autor el doctor excelente Abu Zacaria Iahia Aben Mohamed Ben Ahmed Ebn el Awam, sevillano. Traducido al castellano y anotado por D. Josef Antonio Banqueri, prior claustral de la catedral de Tortosa, indivíduo de la Real Biblioteca de S. M. y académico de número de la Real Academia de la Historia.-Madrid, 1802, Imprenta Real._Dos tomos en fólio, á dos columnas, 698 y 756 págs.; la columna izquierda contiene el texto en castellano y la derecha en árabe.

En el primer tomo, capítulos v, vi, vıl y vilı, págs. 155 á 499, trata de todo lo relativo á plantaciones é ingertos, ocupándose entre otros vegetales, del laurel, mirto, madroño, castaño, encina, pino, ciprés, serbal, almez, cinamomo, . palma, avellano, fresno, plátano, adelfa y sauce. El capitulo xi describe la corta y limpia, págs. 500 á 509 ; el vı, págs. 544 á 569 está destInado á los riegos, y en el XV. pág. 656, describe “una operacion para el naranjo, el arrayan, el ciprés, el pino y otros semejantes árboles, que sostenidos de un tronco, son de graciosa vista y de verdor y frondosidad permanente."

En el tomo segundo, capítulo xxx, pág. 389, se ocupa de la eleccion de la mejor madera para construccion y de la época de su corta.

301. Libro dE la CAZA. Por Luis Sanz, natural de la ciudad de Valencia. Año de 1600.

Citado en el tomo I, pág. 268 de la obra de D. Vicente Gimeno, titulada: Escritores del reino de Valencia.

302. Libro DE LA MONTERía que mandó escribir el muy alto y muy poderoso rey D. Alfonso de Castilla y de Leon, último de este nombre. Acrecentado por Gonzalo Argote de Molina. Dirigido á la S. C. R. M. del rey D. Felipe Segundo, nuestro señor.-Sevilla, 1582, por Andrés Pescioni. Fólio xxv. -91 págs. á dos columnas.

Refiere la historia de los monteros de Espinosa, habla del oficio del montero mayor y de los subalternos; de la montería de jabalies, gamos, osos, cabras, lobos, zorras, gatos monteses, tejones, leones, etc., y termina con 
una égloga pastoril del granadino D. Gomez de Tapia, en la cual se describe el bosque de Aranjuez.

La obra está dividida en tres libros: el primero trata de los monteros de á pié y de á caballo, y de las reglas y cuidados que deben observarse en la caza del venado y de los osos, y de la cria de los perros de caza; en el segundo, estudia los métodos de cura de las heridas de los canes, quebrantaduras ó rábia; y en el tercero, de los montes de Castilla, de Leon y de Andalucía, y de lo que sucedió al rey en el monte.

En la pág. 91, dice asi: “La primera vez que corri este monte, maté en él un oso de los grandes que nunca ví, é fué el primero que maté en tierra de Algecira."

303. Libro verde (EL). Manual para empleados de montes. Grandes verdades sobre agricultura, selvicultura, arboricultura prácticas y sobre el estado actual del ramo. Primera edicion por D: José García Sanz, comisario.-Teruel: Año de 1855.-Imprenta de A. Zarzoso.-8. ${ }^{\circ}, 176$ págs.

Es un conjunto de noticias, bajo forma de diảlogo, relativas á la cria, cultivo y aprovechamiento de los productos de los montes, policía y prácticas administrativas. Al final hay unas tablas de correspondencia para el conocimiento del sistema métrico.

\section{M.}

304. Maderas di las islas de cuba y Santo domingo. Expresiones experimentales de sus resistencias en todos sentidos, por D. Nicolás Valdés, Coronel de Ingenieros.-Madrid: Imprenta del Memorial de Ingenieros, 1866.-4. ${ }^{\circ}, 131$ págs. con una lámina.

Contiene los nombres vulgares de ciento veinticinco clases de madera de la isla de Cuba y ciento de las de Santo Domingo, expresando para cada una el peso especifico, la resistencia á la presion y á la tension, la elasticidad, la carga correspondiente á esta, el coeficiente ó módulo de elasticidad y el coeficiente de fractura respecto á la torsion, su fuerza absoluta y en las aplicaciones.

Clasifica despues las indicadas maderas por örden de preferencia respecto á sus resistencias á la presion paralela ó perpendicular á las fibras, tension y torsion, y con respecto á la elasticidad.

Sigue una descripcion de las especies de donde proceden aquellas, indicando los nombres científicos y dando noticias de los caractéres de las plantas y de sus aplicaciones.

305. Manual completo De Jardinería, arreglado conforme á las mas modernas publicaciones, y dispuesto para uso de los españoles, tanto peninsulares como americanos, por D. Miguel Colmeiro, doç- 
tor en ciencias, Catedrático de Organografía y fisiologia vegetal en el Jardin Botánico de Madrid, etc.-Madrid, 1859, por C. Lopez.Tres tomos en $8 .^{\circ}$, de 591, 360 y 343 págs.

Dedica una parte de la obra á tratar de los ingertos, podas, plantaciones, y cultivo especial de muchas especies completamente forestales.

306. Manual de agricultura dedicado al hijo del cultivador, por D. José García Sanz, Comisario de montes, cesante por supresion, y autor de la guia de labradores y de otros tratados.-Madrid: Imprenta de D. José Cuesta, 1861.-8. , 472 págs. y dos láminas.

Ocupa desde la pág. 121 á la 203 , la parte que el autor dedica á la selvicultura, defectos de las maderas, señales de las que son buenas, establecimiento de montes, dehesas, sotos, brozales y alamedas, ganados y pastorías, segun clasificacion establecida por el mismo.

30\%. MANUAL DE BOTÁNICA aplicada á la agricultura y ála industria, por D. Miguel Bosch, Ingeniero jefe del cuerpo de Montes, exVicedirector y Profesor de la Escuela del mismo ramo, de la Academia de ciencias naturales y Artes de Barcelona, de la Sociedad Filomática de la misma ciudad, de las Sociedades Económicas de Amigos del Pais de Madrid y de Tortosa, Caballero de la Real y distinguida Orden Española de Cárlos III, etc.—Obra publicada á expensas del Ministerio de Fomento á propuesta del Real Consejo de Agricultura, Industria y Comercio.-Madrid: Imprenta del Colegio de Sordo-Mudos y de Ciegos, 1858. -8. ${ }^{\circ}, 207$ págs. y xxm de índices.

Expone, pág. 202 y siguientes, las clasificaciones prácticas del arbolado lineal y de las principales especies leñosas de los montes de España, añadiendo una lista de las que, por su aplicacion especial, no tienen cabida en aquellos grupos, como el regaliz, esparto, palmito, etc.

308. Manua de la provincia de madrid, con un plano de la capital y un mapa de la provincia, por D. Juan Cotarelo.-Madrid: Establecimiento tipográfico de A. Lopez.-1849.-12. , 214 páginas.

Bajo el enunciado Bosques, trata, desde la pág. 36, de la historia de los montes de la provincia, indicando la agrupacion establecida para el servicio, el número de los montes y árboles que estos contienen, especies dominantes y rendimientos anuales.

309. Manual de la tasacion de Montes y bosqule, por D. José María Paniagua.-Madrid, 1847, por Manuel Alvarez.-4. ${ }^{\circ}, 129$ páginas.

Es un resúmen de la obra publicada en francés por Mr. Noirot-Bonnet sobre esta materia. El asunto de los ocho capítulos, en que se divide la obra del Sr. Paniagua, es el siguiente: $1 .^{\circ}$ tasacion de los bosques, con diversas tablas para su evaluacion bajo diferentes aspeclos; $2 .{ }^{\circ}$ tablas de cubaje; $3 .^{\circ} \mathrm{cre-}$ 


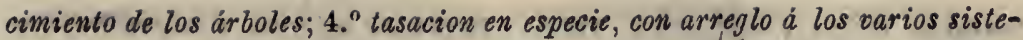
mas de aprovechamiento;.$^{\circ}$ de la posibilidad en general (relativamente á la extension y volúmen); $6 .^{\circ}$ de la cantidad comparada de los productos materiales; 7. ${ }^{\circ}$ ie la renta en $i d$. id.; $y$ 8. ${ }^{\circ}$ de los productos sometidos á los aprovechamientos por entresaca y á matarrasa.

310. Manual DE Legislacion Y administracion forestal, por D. H. Ruiz Amado, Ingeniero de montes.-Gerona, Imprenta de F. Dorca, sucesor de J. Grases, 1859.-En 4. ${ }^{\circ}, 502$ págs.

Se divide en cuatro libros: el primero se refiere á la teoría de la legislacion forestal vigente; el segundo contiene el índicc croinológico de las disposiciones dictadas sobre el ramo, desde el Fuero Juzgo hasta el año de 1857; el tercero es un formulario para la instruccion de expedientes; y el cuarto trala de la importanicia de los montes bajo los puntos de vista de la cosmología, economia y moral de los pueblos.

Es la primera obra de su clase, que se ha publicado en España.

311. Manual de Piscicultura, incubacion y fecundacion artificial, segun los últimos adelantos, por D. José García Sanz.-Madrid, 1863. Imprenta de la Viuda é hijos de D. J. Cuesta.-8. , 102 pág's.

Es obra muy elemental y de escasa novedad.

312. MANUAL DE RIEGos y aplicacion de las aguas de aluvion al cultivo de las tierras. Establecimiento de los prados naturales y artificiales, por D. José de Hidalgo Tablada.-Madrid, 1851: Imprenta del Colegio de Sordo-mudos.-4. ${ }^{\circ}, 436$ págs. y cuatro grandes láminas litografiadas.

En la parte relativa á prados manifiesta las propiedades de muchis plantas. Las láminas representan noventa especies forrageras de España.

313. Manual de selvicultura practica, ó escuela para el arbolista, jardinero, propietarios y guardas de montes, por D. José Garcla Sanz.-Madrid, 1863: Imprenta de la Viuda é hijos de D. Juan Cuesta.-8. $.^{\circ}, 159$ págs.

Se ocupa de siembras, plantaciones, poda, y todo lo concernicnte al cul . tivo de varias especies forestales, recoleccion de semillas, enfermedades, etc.

314. Manual del agricultor asturiano, por D. Luis Percz Minguez, de la facultad de ciencias, catedrático de Historia natural y sócio de la económica de amigos del País, en Oviedo.-Oviedo. Imprenta de D. Rafael Cornelio Fernandez y compañía, 1864.-8. ${ }^{\circ}$, 196 págs.

Se ocupa del cultivo del haya, roble, castaño, nogal, pinos, fresno y otras especies forestales.

315. Manual del Jardinero, por D. José García Sanz, comisario y autor de varios tratados que ha distinguido el público cultivador. 
Primera edicion.-Madrid, 1865.-Establecimiento tipográfico de Eduardo Cuesta.-8., 224 págs.

Abraza las operaciones generales y propías del cultiro de los árboles y arbustos, bajo el punto de vista de la ornamentacion.

316. ManUal DEL JaRdinfro y ARBolista, ó sea arte de componer, dirigir y adornar toda clase de jardines, de cultivar y de propagar las flores, las hortálizas y las frutas; de podar y de ingertar los árboles frutales, formar espalderas, y aclimatar las especies exóticas en la América española. Por Julio Rossignon, ex-catedrático de ciencias naturales de las Universidades de París, Guatemala y San Salyador, miembro de la Sociedad de horticultura de París, etc. Con láminas.-Poissy, 1859, Imprenta de Arbieu: Paris, 1859, librería de Rosa y Bouret. $-8 .^{\circ}$, Iv. -320 págs.

Indica el cultivo de los árboles resinosos.

317. Manual DEL podador ó del gobierno de los árboles silvestres en montes, jardines y plantaciones, por D. José María Paniagua, individuo correspondiente de la Academia de Ciencias naturales de Madrid, antiguo Catedrático de Agricultura, miembro de varias sociedades.-Madrid, 1845, por Suarez.-4. ${ }^{\circ}, 62$ páginas.

Dá cuenta de los fenómenos fisiológicos que es necesario conocer para poder con inteligencia exponer la utilidad de la poda, y describe esta operacion en todas las edades y en un gran número de especies, recopilando los preceptos de varios autores franceses. Entre otras prácticas detalla la del recepado, la poda de los árboles cabezudos, que son sus expresiones, y la poda on los montes, dando á conocer los instrumentos y époeas propias para eje. cutar dicha operacion.

318. Manual para gobierno de los ayuntamientos de Navarra, por D. José Yanguas y Miranda. - Pamplona, imprenta de Francisco Erascum.-1846.-4. . 83 páginas.

Contiene en primer término la ley sobre conservacion y propagacion de los montes, arbolados y viveros, $\delta$ sea la $26 .^{\mathrm{a}}$ de las Córtes de Navarra de lo años 1828 y 1829, que dejamos registrada bajo el título de Leyes, reglamentos y circulares sobre monles, plantios y caminos vecinales de Nuoarra.

319. ManUal para la administracion MUNiCipal DE LOS PUEblos DE la PRovincia de NavarRa, aprobado, impreso y mandado publicar y ejecutar por la Excma. Diputacion foral y provincial de $\mathrm{Na}$ varra. - Pamplona. - Imprenta provincial, bajo la direccion de J. F. Cancela.-1867.-Fólio, 294 páginas.

En este manual aparece en primer lugar la ley sobre conservacion y propagacion de los montes, arbolados y viveros, que es la ley 26." de las Córtes de Navarra de los años 1828 y 1829 , de la cual damos cuenta, bajo cl título de Leyes, reglamentos y circulares sobre montes, plantios y caminos vecinales die Navarra. 
320. Manual práctico de agricultura y economía rural, escrito en francés por un labrador hacendado del departamento de la alta . Garona, traducido al español por D. S. J. T. y S.-Barcelona, 1822, por José Torner.-8. $.^{\circ}, 236$ páginas.

Dá cabida á un sucinto tratado de bosques y baldios.

321. Manual práctico de Piscicultura ó Prontuario para servir de guía al piscicultor en España, y á los empleados de la administracion pública en nuestras aguas dulces y saladas, escrito y publicado de órden de S. M. el Rey, por el Ilmo. Sr. D. Mariano de la Paz Graells, Comendador de la Real órden de Cárlos III, (siguen los titulos.)-Escudo de armas de España.-Madrid, por D. E. Aguado, impresor de Cámara de S. M. y de su Real casa.-1864.-4. ${ }^{\circ}$ mayor, 264 páginas.

Explica todo lo concerniente á la reproduccion y cría de peces de las especies más conocidas y estimadas, en mares, lagos, rios, estanques, albuferas, etc., comprendiendo tambien la cria de moluscos. La tercera parte de la obra es una recopilacion de todas las disposiciones dictadlas sobre pesca, desde el Fuero Juzgo hasta el reglamento para la pesca del Bidasoa, de $1 .^{\circ}$ de Junio de 1859.

322. MáquiNas hidráulicas de molinos y herrerías, y gobierno de los árboles y montes de Vizcaya, por D. Pedro Bernardo VillaReal de Berriz, Caballero del órden de Santiago.-Dedicado á los amigos Caballeros y propietarios del Infanzonado del muy Noble y muy Leal Señorío de Vizcaya, y muy Noble, y muy Leal Proviucia de Guipúzcoa.-Con privilegio.-En Madrid en la oficina de Antunio Marin, rño de $1736 .-8 .^{\circ}, 168$ páginas, con 30 de principios y 2 láminas.

En el libro III se ocupa del modo de plantar y adelantar los montes, $y$ criar viveros de robles, encinas, hayas, etc.

323. Maravillas (Las) y las riquezas de la tierra, por don D. de M.-Obrita instructiva, moral y recreativa, seguida de una reseña histórica sobre el orígen, progresos y vicisitudes del hombre y de las sociedades.-Lérida, 1859: Imprenta barcelonesa de A. García. $-8 .^{\circ}, 128$ páginas.

Destina una parte del librito á los árboles silvestres.

324. Medidas adoptadas por la Diputacion general de Alava SOBRE PLANTACION DE ÁRBOLES EN LOS MONTES COMUNES.-Hoja sin pie de imprenta ni fecha.

Expedidas en Vitoria á 11 de Enero de 1845, por el Diputajo general don Francisco Urquijo de Irabien.

Contiene cuatro medidas, en las que se dispone que cada vecino plante en terrenos comunales, egidos ó tierras propias, cuatro árboles jóvenes de la 
calidad que la tierra permita, y cuatro frutales, tomándose al efento disposiciones para asegurar el cumplimiento de estos preceptos.

325. Memoria aCERCa de la aClimatacion de plantas exóticas, por D. Pablo Boutelou, director de los jardines del Real Alcázar, suplente, por su señor padre, en el desempeño de los destinos de catedrático de Botánica y de director de los paseos públicos de Sevilla, indivíduo de la Sociedad Económica y de la Academia de bue11as letras de la misma ciudad, etc.-Sevilla, 1842: Imprenta de $E l$ Sevillano.-4. ${ }^{\circ}, 53$ págæs.

Discurre sobre los climas, trasplantes, aclimatacion, etc. En u110 de los capítulos inserta una lista de las plantas que, en su opinion, convendria introlucir en España, indicando su origen y propiedades.

326. MEMORIA ACERCA DEL PLAN DE UNA OBRA DE ARQUITECTURA DE JARDINES, utilidad de esta ciencia y consideraciones sobre la histoI'ia, y las diferentes escuelas de jardinería, por D. Meliton Atienza y Sirvent, Médico-Veterinario de primera clase, sócio fundador de honor y mérito del Museo Popular, Catedrático y Vice-Presidente de su seccion de agricultura, indivíduo de la Academia Médico-Veterinaria matritense, Catedrático y director que fué de la Escuela agronómica de Nogales.-Madrid: Imprenta á cargo de Joaquin René, 1855.-4. ${ }^{\circ}, 56$ págs.

En la cubierta se indica este opúsculo con el título de Hisloria de la arquitectura de jardines. El lema adoptado por el autor es el de Magnificentia placet, Varietas delectat. El Sr. Anton Ramirez, Diccionario de bibliografia agronómica, pág, 240, apunta la idea de haberse hecho éste trabajo sobre el (le igual clase de Mr. Gabriel Thouin, primo del celebrado Andrés Thouin, profesor y director que fué largo tiempo del jardin de plantas de Paris. Trata el Sr. Atienza de la utilidad de la arquitectura de jardines, del bosquejo del plan de una obra que de esto trate y de !a historia del indicado ramo, en el cual admite tres escuelas: la oriental, la greco-romana y la moderna.

327. MEMoria de LA SOCIEDAD ECONÓMICA MATRITENSE DE AMigos DEL PAís, proponiendo al Gobierno las bases para una ley de montes, redactada con arreglo á las discusiones y acuerdos de la Sociedad, por su secretario D. Juan Antonio Seoane.-Madrid, 1840: Imprenta Nacional.-4. 24 págs.

Va dirigida al Exemo. Sr. Ministro de la Gobernacion de la Península. tiene la fecha de 20 de Abril de 1810, y la suscriben D. Eusebio María del Valle como director de la Sociedad, y el referido secretario.

Juzga el resultado obtenido con la aplicacion de la ordenanza de 1784; recuerda las ordenanzas de 1792 que no llegaron á aplicarse; cita el decreto Ie las Córtes de 1812 y se queja de los males que predujo la legislacion subsiguiente hasta que se organizó mejor el ramo con las ordenanzas de 1833.

Se lamenta y atribuye la decadencia del arbolado á las estafas, dilapidaciones é incendios voluntarios, causas por las cuales apenas existe una octa- 
va parte de terreno cubierta de monte, cuando por las necesidades del pais sería preciso del quinto al tercio.

Recomienda urıa prudente intervencion del Gobierno en los montes de corporaciones, define la palabra monte, y clasifica las fincas forestales en cuatro grupos á saber: montes del Estado, de Propios, comunes y de estableciuvientos públicos; del Patrimonio Real y de particulares; y los que están pro-indiviso.

El proyecto de ley consta de doce bases, con observaciones. Los principa . lis títulos son: De los montes.-Division de los mismos.-Régimen en general.-Gobierno de los montes.-De la administracion.-Inspeccion.-Parte económica.-Parte judicial.

328. Memoria dB RECONOCIMIENTO dE LA SIERRA DE GUAdarRama, bajo el punto de vista de la repoblacion de sus montes, por D. Máximo Laguna y Villanueva, Jefe de segunda clase del cuerpo de Ingenieros de montes, vocal de la Junta facultativa, y Profesor de la Fiscuela especial del ramo.-Impresa por cuenta del Estado en virtud de lo dispuesto por Real órden de 16 de Noviembre de 1864. liscudo de armas de España.-Madrid: Imprenta Nacional, 1864.Folleto en $4 .^{\circ}$ de 47 páginas y un Croquis de las principales masas de pinar de la sierra de Guadarrama en cromolitografía, con distincion de los montes de pino piñorero y negral; negral, púdio y silvestre; pino silvestre, y hayal, desde los pueblos de Riaza y Riofrio hasta los de Pelayos y San Martin.

Describe la orografia y geología, extendiéndose mucho en la reseña bolánico-forestal de la zona; trata luego muy particularınente del estado del lıayal ó lıayedo de Riofrio de Riaza, de las masas de pino silvestre, piñonero y negral, de los melojares y de los rasos, estudiando los medios mas fáciles lte repoblacion, que propone se ejecute por el Estado ó los pueblos, así como que aquel adquiera el pinar de Navafría y los demás de pino silvestre, por la iulluencia que tienen en las condiciones climatológicas de la comarca y en la sujecion de los terrenos.

329. Memoria de varios actos administrativos justificada con documentos oficiales, que revela el deplorable estado del ramo de montes, confiado en esta provincia al Sr. D. José Rodriguez de los Rios, jefe de la seccion de la misma. Escrita por D. Pedro Miró, abogado y propietario de Lérida.-Lérida: Imprenta de D. José Rauret, 1865.-4. $.^{\circ}, 36$ págs.

Está autorizada por el autor, y fechada en Lérida á $10^{\circ}$ de Noviembre le 1865. Tiene por objeto combatir las providencias administrativas en virtud de las cuales se sujetó á las reglas vigentes para los montes públicos, el monte de Cuberes, 'sito en términos del pueblo de Bahent en la provincia de Lérida, vendido por el Estado con arreglo á las leyes de desamortizacion, por la cantidad de 961.000 reales, con la servidumbre de maderar á favor de los vecinos del pueblo. 
330. Memoria descriptiva y tasacion pericial de la Baronía de Gurrea y sus agregados, de la propiedad del Excmo. Sr. Conde de Parcent.-Zaragoza, 1869.-Eistablecimiento tipográfico de Calisto Ariño. $-4 .^{\circ} 32$ págs.

Comprende este trabajo, que fechan en Zaragoza á 11 de Setiembre de 1869 los agrimensores D. Alberto Salinas y D. José Valier y Escartin, la reseñ: uatural del prédio, así como la forestal y agrícola, terminando con la tasacion de su valor, que se hace ascender á 19.786.000 reales vellon. La mencionada reseña forestal contiene noticias de produecion, rodales, beneficio, operaciones, servidumbres, daños, renta, pastos, ramon, cortezas, frutos, plantas menudas, caza, pesca, siembras y plantaciones, mercados y comunicaciones. Las especies forestales mas importantes son el pino blanco ó soro, (Pinushalepensis), la encina (Quercus ilex), la coscoja (Q. coccifera), el lentisco(Pistacia lentiscus), el romero (Rosmarinus officinalis), la sabina (Juniperus phoenicea), el encbro (Juniperus communis), el esparto (Macrochloa tenacissima) y otras igualmente individualizadas en el opúsculo.

331. Memoria elevada al exCMo. SR. Ministro de Fomento por la Direccion general de Agricultura, Industria y Comercio sobre el estado de los ramos dependientes de la misma en Octubre de 1861. Escudo de armas de España:-Madrid: Imprenta Nacional, 1861.Fólio, 471 págs.

En el capítulo III, dedicado al ramo de montes, págs. 113 á 153, hace una reseña histórica de la legislacion, y examina todo lo referente á desamortizacion, proyectos de ley de montes, estadística, organizacion administrativa, coucesiones de aprovechamientos, prórogas, incendios y reformas preparadas. El apéndice al capítulo indicado comprende, desde la pág. 281 á la 326, treiuta y siete estados dedicados á la estadistica territorial forestal, a la de gastos é ingresos, á la de consumo, y á la de personal, presentando variadas combinaciones que exponen perfectamente el conjunto numérico de todos los elementos de este ramo de la riqueza pública.

332. Memonia en defensa de la necesidad de revocar la parte dispositiva de los nuevos aranceles que permite la exportacion del corcho en rama de la provincia de Gerona á 6 rs. por quintal. Por D. J. B. Guardiola y D. A. Vidal.-1842.

Este folleto, del cual no hemos podido ver ningun ejemplar á pesar de las repetidas diligencias que al efecto hemos practicado, aparece citado bajo lit precedente indicacion en los Estudios forestales de D. H. Ruiz Amado, tomo I, pág. 669, en la cual se dice, reproduciendo noticias de la cuestionada Memoria, que en 1841 existian en la provincia de Gerona, cuatrocientas treinta y ocho fábricas de tapones repartidas en veintiocho pueblos con un capital circulante de 12.490.834 rs. , consumiendo doscientos ochenta mil docenas de panas, que daban veintiunmil quinientas balas de tapones de toda* clases.

333. Memoria akognóstico-Agrícola sobre la provincia de CASTELLON, premiada por la Real Academia de Ciencias en concurso 
público, con arreglo al programa presentado por la misma para el año de 1858. Por D. Juan Vilanova y Piera, catedrático de Geología y Palanteología en la Universidad central, indivíduo de la Sociedad geológica y de la Imperial zoológica de aclimatacion de Francia, etc.-Madrid, 1859, por E. $\Lambda$ guado.—Folio, 229 págs. y seis láminas, que representan las islas Columbretes y el bosquejo geológico de la provincia y varios fósiles.

En la parte cuarta trata de las plantas de toda clase que existen en la provincia, y del cultivo del alga rrobo, almendro, naranjo, nogal, pinos, tejo, boj, haya, encina, roble, alcornoque, avellano y castaño.

Esta Memoria forma parte de la coleccion de las Memorias de la Real Academia de Ciencias, y figura en el tomo IV, desde la pág. 575 á la 800.

334. Mrmoria geognóstico-agrícola sobre la provincia de poNTEVHDRA, premiada por la Real Academia de ciencias en concurso público con arreglo al programa presentado por la misma para el año de 1855, por D. Antonio de Valenzuela y Ozores, Catedrático de Historia natural, Física y Química en el Instituto provincial de segunda enseñanza de Pontevedra.- Madrid, 1856. Imprenta, fundicion y librería de D. Eusebio Aguado.-Fólio, 114 págs. y dos láminas en negro que representan el enlace $\mathrm{y}$ altura de los principales montes de la provincia de Ponteredra, y varios cortes de terrenos de la misma.

Estudia la aplicacion (pág. 87 y siguientes) de los conocimientos físicogeognósticos locales al cultivo en general y particularmente á la cria de árboles; divide la provincia en tres zonas de temperatura; reseña las especies forestales que constituyen los montes, y recomienda su fomento y propagacion considerándolos como un poderoso elemento de riqueza.

Esta Memoria se insertó en el tomo IV de las Memorias de la Real Academia de Ciencias.--Tercera série.-Ciencias naturales.-Tomo II.-Parte 1. pảgs. 1 á 114 .

335. Memoria presentada al Excmo. Ayuntamiento constitucional de Madrid por el Director de paseos y arbolados, en 1855. Comprende la relacion de las operaciones ejecutadas en el ramo desde la presentacion de la última Memoria, varias observaciones acerca del presupuesto, y algunas además sobre las condiciones físicas del suelo y de la atmósfera en que vegetan los árboles para estar frondosos, comparadas estas con las que rodean á los de los paseos, calles y plazas de la corte.-Madrid: Imprenta y Estereotípia de M. Rivadeneyra, 1855.—4 $4^{\circ}, 32$ págs.

Suscrita en Madrid á 25 de Marzo de 1855, por el director D. Lucas de Tornos. Da cuenta del número de árboles existentes, de los introducidos por plantacion, de los riegos, poda y demás operaciones de cria y cultivo, del presupuesto de gastos, del estado general de la vegetacion, de la calidad de las tierras y de la influencia de la atmósfera en los árboles. 
Segun el Sr. Anton Ramirez, en su Diccionario de bibliografia agronómica, pág. 280, las Memorias publicadas sobre el arbolado de Madrid y debid 's á D. Lủcas de Tornos, son ocho. Nosotros no hemos encontrado mas que las seis de que damos cuenta, á pesar de haber recorrido detenidamente la bien ordenada biblioteca del Excmo. Ayuntamiento de esta capital. El autor, á quien hemos acudido, tampoco nos ha facilitado mas que los seis folletos en cuestion.

336. Memoria presentada al Excmo. Sr. Alcalde Corregidor, por la Direccion del arbolado, en 1850, comprensiva de las operaciones y economías verificadas en el ramo; de la clase y número de árboles que comprende; y de una analisis razonada de los -riegos actuales, de su escasez y de los medios de aumentarlos; con una propuesta sobre la traida de aguas rodadas para la poblacion.-Madrid, 1850: Imprenta de D. José C. de la Peña.-4. $.^{\circ}, 40$ págs. y cuatro cuadros sinópticos.

Suscrita en Madrid à 24 de Abril de 1850, por el director D. Lúcas de Tornos. Da cueuta de la reposicion de árboles, de las nuevas plantaciones, de las operaciones de cria y cultivo, del estado de los riegos y de las ohras necesarias para fomentarlos, cuyo asunto constituye casi completamente la materia, objeto de la Memoria.

337. Memoria presentada al Excmo. Sr. Alcalde Corregidor por la Direccion del arbolado, en 1852, comprensiva de las operaciones y economías verificadas en el presente año, de la clase y número de árboles que comprende y de las enfermedades que estos padecen, igualmente que de los remedios que les sean aplicables, en algunas observaciones acerca de las vegetaciones indígenas.-Madrid: Imprenta y Estereotipia de M. Rivadeneyra, 1852.-4. ${ }^{\circ}, 36$ págs. y tres cuadros sinópticos.

Suscrita en Madrid á 13 de Agosto de 1852, por el director D. Lúcas de Tornos. Da cuenta de las operaciones de cultivo y conservacion practicadas en los arbolados, del número de especies vegetales existentes, de los gastos y de las mejoras introducidas, exponiendo despues las principales enfermedades que sufren los árboles y los medios de combatirlas. Termina dando una idea de la conveniencia de propagar las plantas arbóreas y leñosas indígenas.

Se publicó tambien en el tomo V, págs. 573 y 604, y tomo VII, píg. 403 del Boletin oficial del Ministerio de Fomento.

338. Mrmonia presentada al Excmo. Sr. Alcalde Corregidor por la Direccion del arbolado, en 1853, siendo regidor comisario del ramo el Excmo. Sr. D. José Cassani, gentilhombre de S. M.; comprensiva de las economías y uperaciones ejecutadas en el presente año, y de algunas observaciones acerca de la poda de los árboles de sombra.-Madrid: Imprenta y Estereotipia de M. Rivadeneyra, 1853. 4., 24 págs. y tres cuadros sinópticos.

Suscrita en Madrid á 20 de Julio de 1853, por el director D. Lúcas de 
Tornos. Da cuenta del número de árboles existentes, de los que han sido objeto de plantacion, de las bajas ocurridas, de los riegos, de las lluvias, del personal de guardería, de los abonos, del mantillo y de la poda, acerca de cuyo punto se extiende en minuciosas consideraciones teóricas y prácticas.

339. Memoria presentada en 1851 al Excmo. Sr. Alcalde Corregidor de Madrid, por la Direccion del ramo de paseos y arbolados, en la que se da cuenta de las operasiones ejecutadas en el año agrícola, que acaba de espirar en fin de Julio, con algunas observaciones acerca de la manera con que obran en la vegetacion las tierras agrarias y el calor.-Madrid, 1851.-Imprenta de D. José C. de la Peña.-4. ${ }^{\circ}, 35$ págs. y tres cuadros sinópticos.

Suscrita en Madrid à $10^{\circ}$ de Setiembre de 185̄l, por el director D. Lúcas de Tornos. Da cuenta de las operaciones de poda, roza y repoblacion de los árboles plantados, de los jardines hechos, de los daños causados á las plantas, de los riegos, y de la falta de tierra vegetal que consilera como una de las principales causas que se oponen al desarrollo de la vegetacion de Madrid.

340. Memonia presentada por la Direccion del arbolado al Excmo. Sr. Alcalde Corregidor de Madrid, comprensiva de los trabajos y operaciones practicadas en el presente año agrícola de 1848 á 1849, y de algunas observaciones acerca de las varias clases de árboles que comprende este ramo.-Madrid, Junio 1849.-Imprenta de D. José C. de la Peña. - 4. ${ }^{\circ}, 31$ págs. y cinco cuadros.

Suscrita en Madrid á 14 de Junio de 1849, por el director D. Lúcas de Tornos. Da cuenta del número de árboles existentes en los paseos y viveros, de los trasplantes ejecutados, de las bajas habidas, de las operaciones de cria, cultivo y poda, de los riegos, de los daños, de las mejoras introducidas, de las condiciones de vegetacion, cuidados y daños por los insectos que sutre el olmo, y de diferentes especies arbóreas y arbustivas que se han introducido en los paseos y jardines.

341. Memoria publicada por la Comision de la provincia de Gerona y distrito judicial de Arenys de Mar, á fin de acreditar que la ley prohibitiva de extraer el corcho en pana, ha hecho y está haciendo la felicidad del país, y que el libre comercio de este artículo arruinaria á un tiempo la industria y la agricultura, destruyendo completamente su estado de prosperidad.-Por D. Ramon de Cabrela, D. Narciso Fonolleras y D. Andrés Guri.-Madrid: Imprenta del

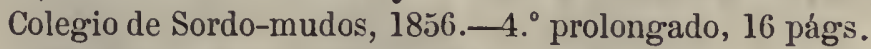

Esta memoria está fechada en Madrid á 25 de Febrero de 1856. En ella se asegura que no se conoce corcho de mejor calidad que el que se cosecha en las provincias de Gerona y Barcelona, que casi todo se exporta al extranjero, y que no puede ser suplido por el de otra procedencia porque este suele tener mal olor comunicándolo á los vinos embotellados, ó carece de la conveniente elasticidad, lo que no sucede con los tapones de corcho catalán. Termina con una demostracion que evidencia las ventajas de la ley prohibiti. 
va y graves perjuicios de la libre extraccion, como consecuencia de los antecedentes y noticias que constituyen el cuerpo del trabajo. En él se hace constar tambien la importancia de la industria taponera en España, que puede dar trabajo á treinta y cuatro mil setecientos obreros, produciendo un ingreso anual, segun la balanza mercantil, de 100.500 .000 reales, derivados de una riqueza imponible que, solo en patentes de fábricas, puede dar al Erario público mas de 487.500 reales. Recuerda la comision que todas las naciones que consumen tapones desean establecer fábricas para dar á sus obreros el trabajo de que son tributarias á España, y por esto dan libre entrada al corcho en panas y cargan crecidos derechos á los tapones, llegando á ser de 8 libras esterlinas en Inglaterra y de 65 francos 12 céntimos en Francia para el quintal métrico. Considerando, pues, el número de brazos que esta industria sostiene, la riqueza que desarrolla, y la conducta que siguen las demás naciones que la ejercen, la comision pide que subsista la prohibicion de exportar el corcho en panas, $\delta$ que al menos se imponga á este artículo un derecho protector que equilibre al que paga el corcho elaborado en tapones á su entrada en Inglaterra y Francia, á menos que estos paises dejen libre y franca la entrada, en cuyo caso pudiera admitirse el libre comercio.

Sin duda porque el carácter de este trabajo, es mas industrial y económico que agrícola, no lo incluyó el Sr. Anton Ramirez en su Diccionario de bibliografia agronómica.

342. Memoria que dirige al Excmo. Sr. Ministro de Fomento el Grobernador de la provincia de Guadalajara, sobre el estado, progresos y necesidades de los servicios dependientes del citado departamento, en el año próximo pasado de 1863. Redactada por D. Manuel Risueño, jefe de la Seccion del ramo en la misma provincia.Guadalajara, 1864: Imprenta de D. Elias Ruiz.-4. , 68 págs.

Autorizada en Guadalajara á 23 de Marzo de 1864, por el Gobernador D. Vicente Lozana. Da cuenta de los expedientes cursados en el año último y detalla el concepto de cada uno de ellos; irata del personal y formula un estado de la produccion.

343. Memoria suble hit modo mas aceitiado de remediar los males inherentes á la extremada subdivision de la propiedad territorial de Galicia, premiada por la Sociedad Económica de Santiago. Su autor, el doctor D. Manuel Colmeiro, sócio de mérito de la misma, y exprofesor de Economía política en esta Universidad literaria.Santiago, 1843, por la viuda é hijos de Compañel.-4. $.^{\circ}, 68$ págs.

Uno de los medios propuestos, estriba en la concesion de terrenos incultos. Laméntase el autor de la disininucion del arbolado, atacado por los fabricantes de curtidos y los leñadores. Estimula á los labradores para que hagan nuevos plantíos de robles é introduzcan el zumaque, á fin de que no sea tan codiciada la corteza de aquel árbol.

344. Mlimoria sobre la inundacion deL Júcar en 1864, presentada al Ministerio de Fomento por D. Miguel Bosch y Juliá, inspec 
tor general de segunda clase del Cuerpo de Ingenieros de montes, jefe de la comision nombrada para estudiar los desbordamienlos de aquel rio.-Impresa de Real órden.-Escudo de armas de España. Madrid: Imprenta Nacional, 1866.-4. ${ }^{\circ}$ mayor, 424 págs. y tres lá minas, las dos últimas en colores.-Representa la primera varias recciones trasversales del Júcar y sus afluentes; la segunda el bosquejo agrícola-forestal de la cuenca del Júcar; y la tercera el bosquejo oro-hidrográfico de la misma cuenca con cl de los terrenos inundados.

Firına la Memoria D. Miguel Bosch en Madrid á 23 de Noviembre de 1865. Despues de insertar las órdenes expedidas para la ejecucion de los trabajo:, hace una reseña de los mismos, y entra en materia estudiando los puntos siguientes: Reseña de la cuenca hidrológica del Jucar dentro de la provincia de Valencia; Reseñu orográfica bajo el punto de vista de las inundaciones; Reseña geognóstica bajo el mismo concepto; Reseña meteorológica; Reseña hidrológica; Reseña agricola; Reseña forestal; Reseña de los principales daños causados por la inundacion; y Medios que deberian emplearse contra las inundaciones del Júcar y de sus afluentes en la provincia de Valencia.

El Sr. Bosch fué auxiliado en este trabajo por el Ingeniero jefe del cuerpo. Sr. D. Andres Anton Villacampa.

345. MeMoria solire La parte forestal DE LA EXPosicion DF Lóndres de 1862, por D. Miguel Bosch y Juliá, jefe de primera clase del Cuerpo de Ingenieros de montes, vocal de la junta facultativa del ramo, etc., etc. Inipresa por cuenta del Estado, en virtud de lo dispuesto por Real órden de 2 de Agosto de 1863.-Escudo de armas de España.-Madrid: Imprenta nacional, 1863.-4. , 335 págs.

Está fechada en Madrid á 20 de Junio de 1863. En la Iniroduccion se ocupa de las colecciones forestales en conjunto y discurre sobre el progreso dil . sonómico que representan. Divile luego el trabajo en cinco partes que tratan respectivamente de los productos de los montes de Europa, Asia, Africa, América y Oceanía, y concluye con algunas consideraciones sobre las prácticas científicas de la dasonomia, la riqueza forestal de la Gran Bretaña, las exposiciones iorestales de todos los paises, la necesidad de crear en España un museo forestal que serviria de escuela práctica y exposicion permanente, el porvenir de la dasonomia en las diversas regiones del globo y el interés de que España dé á conocer en la primera ocasion que se presente los recursos de sus montes y los frutos de la ciencia que de ellos se ocupa.

346. Memoria sobre la pertenencia, extenston, calidad de tierras, poblacion y administracion de los montes de Toledo, por el Ayuntamiento de esta ciudad, y sobre el sistema que deberá adoptarse en su reparticion y enagenacion, presentada á las Córtes generales por los ciudadanos Julian Antonio Lopez, labrador y agrimensor de la provincia, y Francisco Antonio Martinez Robles, miliciano nacional voluntario de caballería, y catedrático de. agricultu- 
ra de Toledo.-Madrid, 1821: Imprenta de la calle de la Greda.-8. 55 págs.

Segun se lee en el periódico titulado El Universal, número correspondiente al 3 de Noviembre de 1820, la mayor parte de los materiales para escribir esta Memoria ó Exposicion los procuró el agrimensor Lopez: Martinez Robles no hizo mas que coordinarlos y redactar el escrito. Se hace una reseña de la pertenencia y vicisitudes de dichos montes, á partir desde el año 1243; se enumeran sus clases, la calidad de los terrenos, los diez y seis pueblos comprendidos en ellos, la extension y uso que se hacia de los pastos, y se pronone, en tin, la enagenacion á censo de esta riqueza pública, despues de satisfacer ciertas obligaciones que se indican. Hay noticias relativas á los minerales y vegetales mas importantes de dichos montes y de las cercanias de Toledo.

No será del todo importuna para el que fije su atencion en el asunto de esta Memoria, la noticia de que en la Biblioteca Nacional (registrada D. d. 114) existe una copia, sacada por el P. Burriel, de la carta de venta hecha á To ledo de todos sus montes por el rey Fernando III, en la cantidad de 45.000 maravedis alfonsis. El original está fechado en Jaen, á 2 de Enero de 1246. era 1248; se hallaba en el archivo secreto de Toledo, extendido en un pergamino de media vara en cuadro, y cumienza así: "Conoscida cosa sea á todos Ios que esta carta vieren, como Yo, D. Fernando, por la gracia de Dios, rey de Castilla, et de Toledo, etc., con placer et con otorgamiento de la reina doña Berenguela mi madre, en uno con la reina doña Juana mi muger, et con mios fijos, etc., etc."

La autorizacion de la copia dice asi: "Cotejé esta copia con su original en dicho Archivo, á 17 de Mayo de 1753.-Andrés Burriel."

347. Memoria sobie la utilidad de los montes y neCESidad de atenner Á su Conservacion, escrita por D. Pedro Sainz Gutierrez, catedrático de la facultad de ciencias de esta Universidad de Granada, indivíduo de varias corporaciones científicas y literarias, y vicecensor de la Real Sociedad Económica de Amigos del País de esta provincia.-Granada.-Imprenta de D. Francisco Ventura y Sabatel, 1862.-4. ${ }^{\circ}, 55$ págs.

Esta Memoria fué premiada por la Sociedad en sesion de 8 de Julio de 1861, y presentada por el autor en 30 de Octubre de 1860, adjudicándosele título de Sócio de mérito, y acordándose la impresion de la indicada Memoria á expensas de la corporacion. El tema oflcial sobre que fué escrito es el siguiente: “Si es perjudicial á la salud pública y á la agricultura, la destruccion ó corta de montes, y en caso de deber conservarse estos, qué arbnlado será el mas á propósito en nuestra provincia, para la Armada, cria del ganado y carboneo, y si será mas conveniente para la pública prosperidad, el que los montes se hallen en poder del Estado ó de los particulares."

Reconociendo en los montes gran influencia cosmológica y valor econıınico, despues de reseñar el estado de esta riqueza en la provincia, recomienda la repoblacion mas eficaz, enumerando varias especies arbóreas útiles para el caso, é indicando el sistema de introducir antes el matorral como 
medio preparatorio, para asegurar la tierra vegetal y facilitar el asiento de la vegetacinn arbórea. Concluye aceptando decididamente el principio de que el Estado debe poseer el monte alto. El autor aduce textos de Arago, Humbold, Bousingault, Hericat de Tunry, Raspail y Vacherot en apoyo de sus opiniones.

Sigue despues el informe de la Comision nombrada por la Sociedad para juzgar la Memoria, en el que se consigna que el autor wha bebido en buenas fuentes, y que su escrilo èstá en consonancia con las mejores obras alemanas que en el dia nos dán la pauta y la enseñanza en todos los ramos de agricultura;" recuerda los principios sustentados en la materia por Müller y Grinose, y particularizanio algunos puntos del opúsculo, propone la adjudicacion del premio al autor de él.

348. Memoria sobre las CaUsas de la SEQUia de las provincias de Almería y Murcia, y de los medios de atenuar sus efectos, escrita con arreglo al programa del Real decreto de 30 de Marzo de 1850. Premiada con el accesit por la Real Academia de ciencias. Su autor, D. José de Echegaray.-Madrid, 1851: Imprenta del Ministerio de Comercio, Instruccion y Obras públicas. -4. , 125 pág`s.

Aconseja, entre otros medios encaminados á remediar las sequias, la plantacion de montes y el fomento del cultivo de las leguminosas, barrilleras, tornasol, nopal, pita, alcaparra, olivo, vid, almendro, higuera, granado, morera y algarrobo.

349. Memoria sobre las Causas metereológico-Físicas que pioducen las constantes sequías de Murcia y Almería, señalando los medios de atenuar sus efectos: premiada por el Ministerio de Comercio, Instruccion y Obras públicas, á juicio de la Real Acarlemia de ciencias, en el certámen abierto por Real decreto de 30 de Marzo de 1850. Su autor, D. Manuel Rico y Sinobas.-Madrid, 1851, por s. Compagni. $-4 .^{\circ}, 391$ págs. y varios planos.

Habla extensamente de la vegetacion que en el siglo XI constituia la flora arbórea de Murcia, Cartagena y Sierra Segura; de la época de los antiguos iberos y wisigodos, agrícolamente considerada; de los sistemas de riego, y de si será ó no oportuno establecer la selviculiura en algunos puntos del S. E. de España, ó fomentar solamente el cultivo de la vegetacion arbórea como riqueza mercantil.

350. Memoria sobre laAs plantas barrilleras de españa.-Por D. Mariano Ia Gasca.-Madrid: Imprenta Real, 1817.-4. , 84 páginas con diez de principios y un prólogo.

Se publicó tambien como Adicion, exceptuando el prólogo, en la Agricultxy a general de Gabriel Alonso de Herrera.

En el Diccionario de bibliografia agronómica del Sr. Anton Ramirez, no se menciona esta Memoria.

351. Mrmorta sobre los Árboles de MoNTE ó BOSQJE, premiarla por la Sociedad económica en sesion de 5 de Diciembre, de acuerdo 
con el favorable dictámen de la comision de agricultura, su autor D. Vicente Tortosa y Cerdá, súcio de número y mérito.-La sociedad ofrece el premio de sócio de mérito «al autor de la mejor Memoria sobre la siembra, plantacion, cultivo y aprovechamiento de los árboles de monte $\sigma$ bosque, clima, exposicion y terrenos que conviene a cada clase de los mismos, y método mas ventajoso de reponer los montes y aprovechar las tierras en que no pueden criarse olivos, algarrobos, almendros y otros frutales.»-Escudo de lu. Sociedad económica de amigos del país de Valencia.-Valencia, 1859.-Imprenta de José Rius. $4 .^{\circ}, 39$ págs.

Esta Memoria se insertó en gran parte, antes de imprimirse, en las $\mathrm{Ga}$ cetas de Agosto del año anterior, 1858. En el ejemplar que tenemos á la vista que obra en la biblioteca de la Junta consultiva del Cuerpo de Ingenieros de inontes, hay una advertencia firmada por el autor, en la que expresa que la Memoria fué premiada en 5 de Diciembre de 1849, é impresa, por 10 tantG, diez años despues.

Clama contra la restriccion de las pragmáticas de los radios de marina, á las cuales atribuye una perniciosa influencia sobre el progreso del arbolado. Se concreta la Memoria á las provincias de Valencia y Alicante, describiendo la siembra, cuidados, poda y otras operaciones de beneficio en los pinos y las encinas; da cuenta de muchas siembras y plantaciones de especies forestales hechas por el autor. Lamentando despues el mal estado de los montes, expone el método mas ventajoso de reponerlos y aprovechar las tierras que no pueden producir ó criar frutales, fiando el éxito de las siembras, al mayor cuidado de los particulares, á quienes debería obligarse á repoblar los terreıos comunales ó de realengo que al cfecto se les cediese por el Gobierno.

352. Memoria sobre los grandes montes y demás riquezas de la Liébana.-Por D. Matías de La-Madrid y Manriqize de la Vega, súcio corresponsal de la Real Sociedad Económica Cantábrica de Amigos del país. Publicada por acuerdo de la misma.-Búrgos, 1836, por J. Arnaiz.-4. ${ }^{\circ}, 139$ págs.

Describe la riqueza del arbolado y hace algunas consideraciones económicas acerca de la utilidad de las maderas para la marina, abogando por la apertura de comunicaciones para la extraccion.

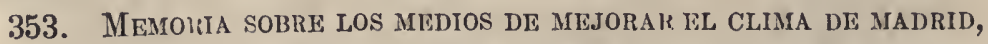
restablecer su salubridad y fertilidad.-Por el licenciado D. Blas Llanos, indivíduo del Real Colegio de médicos de Madrid, y de número en su Real Academia médica, etc.-Madrid, 1825: Imprenta que fué de Fuentenebro. $-4 .^{\circ}$, virı,-60 págs.

Explana sus opiniones, despues de recomendar la plantacion de árboles, en los capítulos siguientes: $10^{\circ}$ Idea general de la antigua poblacion de $\mathrm{Ma}$ drid, de sus dehesas, monles y alamedas, etc. $-2 .^{\circ}$ Epocu en que comenzó la curta y tala del arbolado, y a sentirse, por consiguiente, destemple en. los aires reinanles, escasez de agua inferlilidad é insalubridad.-3.' Refexiones 
sobre lo urgente que es atender á varias necesidades si ha de evitarse la despoblacion de la villa y córte. $-4 .^{\circ}$ Ventajas y propiedades de los árboles en general. $-5 .^{\circ}$ Consideraciones sobre estos vegetales como medio de mejorar el clima y restablecer la salubridad y fertilidad.-6..$^{\circ}$ Utilidades que de las medidas anteriormente propuestas deben esperarse, con pariicularidad en el aumento de frutos, por el beneficio del riego, y en. la ocupacion de los braceros.

354. Memoria sobre los productos de la agricultura españoLA, reunidos en la Exposicion general de 1857, presentada al Excmo. Sr. Ministro de Fomento por la Junta directiva de aquel concurso. Madrid, Imprenta Nacional.-1859-1861._Fólio, 1128 págs. y CXLviI de índices á dos columnas, ciento cuarenta grabados en el texto, cuarenta y cinco láminas y cuatro estados.

Tiene la fecha de 31 de Diciembre de 1858; la suscriben el almirante duque de Veragua, como presidente, y D. Braulio Anton Ramirez, como secretario. Las 146 páginas primeras comprenden los documentos oficiales, invi . taciones, circulares, discursos de inauguracion, personas y corporacione: coadyuvantes, listas de expositores premiados, destino de los productos cedidos por los expositores, etc., etc. La Mexnoria sigue luego comprendiendo el catálogo de productos exhibidos y el juicio crítico de los objetos y ganados; despues vienen los índices por materias, nombres de personas, nombres vulgares de objetos, nombres sistemáticos, y de láminas,

Este trabajo, fué ejecutado por el Excmo. Sr. D. Agustin Fascual en vista de los datos reunidos por la Secretaría y de los informes de las Secciones.

Las materias de utilidad forestal son las siguientes:

Plantas, alzados y cortes del Castillo-Palacio de Villaviciosa de Odon. Págs. 211 á 223. Se ncupa de la enseñanza dasonónica en su conjunto histórico y en su estado presente.

Croquis, reconocimientos forestales, planos, detalles de inventarios de montes, de sus ordenamientos y de sus aprovechamientos generales. Págs. 237 a 260.

Dibujos de plantas y animales. Paigs. 264 y 265.

Máquinas, aparatos, herramientas, aperos, etc. Págs. 268 y 269.

Maderas y leñas. Págs. 343 á 478, con extensas noticias de las cualidades. usos, precios y otras condiciones de la madera y leña de las principales especies arbóreas y leñosas.

Cortezas. Págs. 479 á 488 .

Frutos, extracto de regaliz, cenizas, barrillas, gomas, resinas, breas, aguarrás, liga, carbones y ciscos. Págs. 488, 1102, 1104, 1111 y 1114.

355. Mrmoria y reclayaciones al Excmo. Sr. Ministro de Hacienda, por G. Baudoux, Director de la Sociedad civil belga de los pinares del Paular, residente en Madrid.-Madrid, 1869.-Imprenta de Manuel Alvarez. -4. $.^{\circ}, 52$ págs.

Fechada en Madrid á 20 de Mayo de 1869, y suscrita por el director.

La sociedad poseedora del pinar y monte del Paular, sito en el tèrınino municipal de Rascafria, acude al ministro suplicando que no se le perturbe en el ejercicio del derecho de propiedad, ni en el modo de aprovechar el pi-. 
uar, en atencion á los ataques que sufre la finca por parte de los vecinos itel sesuo de Lozoya respecto al disfrute y aprovechamiento de madera y leñas muertas en el prédio mencionado, llamado pinar de Cabeza de Hierro.

356. Memorial ajustado, hecho en virtud de decreto del Consejo, del expediente consultivo, que pende en él, en fuerza de R'al órden, comunicada por la Secretaría de Estado, y del Despacho Universal de Hacienda, con fecha en San Ildefonso, de 20 de Julio del año 1764, entre D. Vicente Paino y Hurtado, como Diputado de las ciudades de Voto en Córtes, Badajoz, Mérida, Trujillo y su Sexmo, Llerena, el Estado de Medellin, y Villa de Alcántara, por sí, y toda la provincia de Extremadura; y el nonrado Consejo de la Mesta greneral de estos Reynos: en que intervienen los señores fiscales drl Consejo, y D. Pedro Manuel Saenz de Pedroso y Ximeno, Procurador General del Reyno. Sobre que se pongan en práctica, los diez y sicte capítulos, ó medios, que en representacion, puesta en las Reales manos de S. M. propone el Diputado de las Ciudades, y Provincia de Extremadura, para fornentar en ella la Agricultura, y cria de Ganados, y corregir los abusos de los Ganaderos trashumantes. Fólio, pergamino, 291 págs. una parte y 144 otra.

Aunque versa sobre cuestiones de derecho, contiene noticias sobre dehesas, montes y sistemas de aprovechamiento de pastos, de verdadero interés forestal.

357. Memorial Literario instructivo y curioso de la corte de Madrid.-Madrid, 1784-1808. En la Imprenta Real, desde 1784 á 1790, veintiun tomos; y desde 1793 á 1797, diez y ocho; en las de García y Vega, desde 1801 á 1804, siete tomos, y en la de Repullés, desde 1805 á 1808 , siete tomos, en $8 .^{\circ}$; cincuenta y tres tomos en junto, de á 300, 500 y 600 págs.

Encontramos en este periódico los artículos siguientes: Tomo X, 1787, págs. 216, 366 y 501; Tomo XI, pág 52 y Tomo XXI, pág. 119: De las orugas; varios articulos, en el primero de los cuales se insertan las observaciones que hizo un párroco en un monte de Camarena, donde habian causado grandes destrozos; se habla de la semejanza de estos insectos con los gusanos de seda, y de la posibilidad de hilar su capullo.-Tomo XX, 1790, pág. 401.-Real cédula de S. M. y señores del Consejo, dada en Aranjuez á 27 de Mayo de 1790, en la que, para eoitar los daños que causa el ganado cabrio al fomento de los arbolados, se manda guardar lo prevenido en el capitulo XVI, art. 1. ' litulo $V I I$, lib. VII de la Novisima Recopilacion, y en el XXI de la Ordenanza de Montes.

De la Real cédula de S. M. fecha 27 de Enero de 1788, sobre el exteruinio de aninales dañinos, damos cuenta en el lugar correspondiente, asi como de los articulos titulados: Descripcion topográfica de la Albufera; Carla sobre los hongos; y Noticia de haber existido el árbol llamado Garoe. 
358. Menorias de agricultura y artes.-Barcelona, 1815-1821. Doce tomos en $4 .^{\circ}$

Los artículos titulados, Observaciones sobre el cultivo de la encina, etc.; y el que se ocupa de la Idea del alto grado de opulencia á que puede ascender. Uataluña, etc., los registramos en el lugar correspondiente.

359. Memorias de LA REAL ACAdEMia de Ciencias.-Madrid, 18501863. - Por Aguado, Impresor de Cámara de S. M. y de su Real casa. - Seis tomos, folio, con láminas.

En el tomo I se halla la Memoria geognóstico-agricola sobre la provincia de Asturias; y en el tomo III, las correspondientes á las provincias de Ponlevedra, Castellon y Vircaya, si bien esta última lleva el título de Suelo, clima, cultivo agrario y forestal de la provincia de Vizcaya. Todas están anotadas en el lugar que les corresponde, así como el Catálogo de las aves que frecuentan las inmediaciones de la ciudad de Santiago y otros puntos de Gali. cia, el de las aves de la Albu fera, el metódico de las aves observadas en una gran parle de la provincia de Murcia, la Erpetología hispalensis, la Memoria premiada con el accessit... sobre la distribucion geográfica de las familias de las plantas crucíferas, leguminosas, rosáceas, salsoláceas, amentáceas, coniferas y gramineas de la peninsula ibérica, y un Discurso sobre la necesidad de una descripcion completa de la cordillesa de Sierra-Morena con relacion á los tres reinos de la historia natural.

360. Memorias de la RIAal sociedad económica mallorquina DE AMIGOS DEL PAIS. Primera parte.-Palma de Mallorca, 1784, por D. Ignacio Sarra y Frau.-4. 279 págs.

Contiene una memoria sobre la formacion de viveros y plantios comunes de donde se faciliten los árboles gratuitamente á los vecinos para sus haciendas.

"Creemos, dice el Sr. Anton Ramirez en su Diccionario de Bibliografí agronómica, que no llegó á publicarse ningun otro volúmen que este, aun cuando lleva el título de primera parte."

361. Memorias de la sociedad económica (de Madrid). Madrid. 1780-1787, por A. Sancha é Imprenta Nacional.-Seis tomos en 4 mayor de 400 á 600 págs. cada uno.

El tomo I contiene un Extracto de la Memoria del Sr. D. Vicente Calvo :i Julian, Canónigo de la cathedral de Tarazona, conforme al acuerdo de la clase de agricultura en las Juntas de 1 y 3 de Abril de 1777.

De ella damos cuenta en el lugar que le corresponde, así como del Informe sobre las gomas, resinas y gomo-resinas, y de la Memoria sobre mejor ejecucion y fomento de arbolados, entrambos trabajos insertos en el tomo III.

362. Memorias instructivas y curiosas sobre Agricultura, Comercio, Industria, Economía, Química, Botánica, Historia natural, etc., sacadas de las obras que hasta hoy han publicado varios autores extranjeros, y señaladamente las Reales Academias y Sociedildes de Francia, Inglaterra, Alemañia, Prusia y Suecia.-Por D. Mi- 
guel Gerónimo Suarez.-Madrid, por D. Pedro Marin.-1778-1791. Doce tomos $4 .^{\circ}$ de 400 págss. próximamente, con cincuenta y una láminas.

Damos cuenta en el lugar opor/uno de la memoria titulada: Instrucciones necesarias para el conocimiento de diversas plantas del pais, cuyo uso puede servir para ahorrar las encinas, etc. que está inserta en el tomo IV.

Contiene además, Tono II. Memoria 20: Métodos difercntes de mulitiplicar el trigo y demás semillas, plantas, árboles, etc.-Tomo VI. Memorias 66 y 67: Cultivo de todo género de ärboles puesto por órden alfabético, sacado del manuscrito sobre agricultura práctica que dejo D. Cosme Martin de Fuentidueña, jardinero y arbolista mayor de los Sres. Reyes D. Cárlos II y l). Felipe $V$ en el Real sitio del Buen-Retiro y sus agregados.-Tomo X. Vemoria 96: Ensayo sobre esta cuestion: ¿Cuál es el mejor método de establscer y mantener los prados naturales y artificiales, relativamente a las plantas que los compo. nen? ¿y cuáles son los medios de destruir las planlas, insectos y demás animales que los perjudican?

363. Memorias sobre el partido Judicial de segura de la sierIeA, escritas por D. Juan de la Cruz Martinez.-Baeza, 1842, por F. Moreno. $-4 .^{\circ}, 181$ págs.

Despues de algunas escursiones históricas acerca de la ve getacion de toda clase, sobre todo de la forestal, reseña la marcha administrativa desde 1214 á 1778 , desde este último año al de 1836, y por fin hasta 1842 en que el autor escribió las Memorias. Al final hace un cálculo de lo que, en su concepto, debe producir á la nacion el ramo de montes.

364. Mentor de las familias (EL).-Periódico de instruccion popular.-Madrid, 1849-1851. - Tres tomos en 4. ${ }^{\circ}$

Registramos en el sitio que le corresponde, el artículo denominado, Arboricultura; consideraciones generales sobre los árboles, etc.

365. Metalurgia del Hierro.-Ferrerías al carbon vegetal. Notas sobre la situacion de las ferrerías primitivas en España, y sobre los bosques que les suministran combustible, por D. Eugenio Karr, Caballero de la Legion de Honor, Ingeniero y Director de Ferrerías.-Zaragoza: Imprenta y librería de Roque Gallifa, 1862.-4. , 124 págs.

Expresa el gasto de carbon vegetal en las ferrerías, calcula el que se consume en España en este ramo de la industria, enumera las especies vegetales cuyo carbon es aplicable á la elaboracion del hierro, da cuenta de los terrenos y aprovechamientos convenientes para determinadas especies y del modo de cuidar los tallares, y ejecutar las cortas y rozas de leñas destinadas al carboneo, ocupándose despues con la mayor minuciosidad del modo de formar los hornos para carbon, y de la manera de dirigir y cuidar la carbouizacion, así como del modo de desmoutar los hornos y trasporlar y almacenar los carbones. 
366. Mr aficion al isstudio.....-Por D. Alfredo de Luis. Hoja de tres páginas en fólio sin pié de imprenta.

Lleva la fecha de Noviembre de 1873, y está escrita en forma de carta dirigida al que entónces era ministro de Fomento, Excmo. Sr. D. José Ecbegaray. Es ya público que el nombre de Alfredo de Luis es un seudónimo. El autor combate el proyecto de ley de montes presentado á las Córtes por el indicado ministro, afirmando que por él se creará el socialismo que el proyecto se propnne destruir, que se venderán muchos montes de verdadera iafluencia cosmológica, que se aprobarán los planes de aprovechamiento bechos por los Ayuntamientos, en mengua y daño de los funcionarios facultativos y de los montes, y que la distribucion del personal que de los mismos ha de cuidar, debe hacerse segun la indole, el estado y las condiciones de los prédios.

Esta carta es la primera de las tres que escribió el autor sobre la cuestion. Quedan regisiradas las dos restantes con las indicaciones siguientes: Algunos de los que han criticado.....-Si creyese que $V$. $E$.....-Pueden verse en la Revista forestal, económica y agrícola. Tomo VI, pág. 49, en donde fueron copiadas.

367. Milicia y descripcion IiE LAS Indias.-Por Bernardo Vargas Machuca.-Madrid, por Madrigal, 1599.-4.

Habla de muchas plantas útiles, enumerando particularmente los árboles, que divide en fructíferos llevados de España, cultivados (indigenas de América), fructiferos silvestres, y silvestres sin fruto, es decir, que no lo dan bueno, añadiendo, finalmente, los árboles aromáticos.

De esta obra, indicada por el Sr. Colmeiro en La Bolánica y los Botánicos, nada dice el Diccionario de bibliografia agronómica del Sr. Anton Ramirez.

368. Ministerio de Fomento.-Agricultura, industria Y C0MERCIO.—Moxtes.-Real decreto de 18 de Mayo de 1862, aprobando el Reglamento, que á continuacion se inserta, para la Escuela especial de ingenieros de Montes.-Véase: Reglamento parci la Escuela especial de Ingenieros de montes.

369. Mrscelanta instructiva, curiosa y agradable, ó Anales, etc.-Alcalá, 1796. - Siete tomos en $8 .^{\circ}$

Contiene una Noticia histórica del Bohon-Upas $\beta$ árbol venenoso, de que damos cuenta en el lugar correspondiente.

370. Modelo DE UNirolime.-Divisas de las diferentes clases y graduacíones (de los indivíduos del cuerpo de Ingenieros de montes).-Hoja grande dibujada y litografiada en negro por Kraus.

Completa el diseño otra hoja iluminada, del mismo dibujante y litógrafo, que representa el Modelo de la espada. 
371. Monogralía das̃ográfica del haya.-Por D. Cárlos Castel y Clemente, ingeniero de montes.-Madrid: Imprenta de El Debale. á cargo de J. M. Luengo, 1873.—4. ${ }^{\circ}, 99$ pág.s. y 3 de índice.

En esta monografía, que es una de las mas completas que se lian publicado en España, se estudian, con relacion á aquella especie, los nombres, distribucion, suelo, germinacion, raiz, tallo, corteza, ramas, yemas, hojas, inflorescencia, fruto, potencia invasora y sociabilidad, intermitercia on los años de cosecha, recoleccion de los frutos, conservacion de las semillas, prueba de las mismas, estacion mas ventajosa para efectuar la siembra, cantidad de semillas, preparacion del terreno para la siembra y su ejecucion, formacion de viveros, plantaciones, métodos de beneficio en monte alto y bajo, cualidarles de la madera, usos de la misma, de la leña y de los frutos con la preparacion del aceite de hayuco, y por último, los enemigos y enfermedades que sufre la planta.

Se ha liecho una corta tirada de este folleto, del cual no se ha puesto á la venta ningun ejemplar. Diclıo trabajo se publicó eu el mismo año en la $R \ell-$ vista forestal, económica y agrícola, tomo VI, págs. 82, 123, 173. 327 y 364, con el título de Arboricultura-El Haya.

372. Montes.-Cinco artículos publicados en La América acerca de este importante ramo, por A. B.-Pamplona: Imprenta de la Union artistica, 1862.-Fólio, 38 págs.

Sus títulos son: Desamortizacion, fecha 24 de Mayo de 1860; Réplica á la hoja forestal, 24 de Julio de 1860; Continuacion de la réplica, 8 de Agosto de 1860; La propiedad forestal, 24 de Agosto de 1860; y Sobre la legislacion de montes, 8 de Octubre de 1860.

Aboga por la general desamortizacion si bien enagenando las fincas prévia tasacion científica y como tal exacta. Combate el principio de que sien la produccion forestal, á medida que aumenta la renta en esplecie decrece la renta en dinero\%, niega la existencia de los bienes de aprovéchamiento comun, rechazando los disfrutes vecinales y censura las Ordenanzas de montes de 1833 y legislacion posterior considerándola ineficaz para el buen ré- . gimen de los montes públicos.

373. Montes de las minas de Rrotinto.-Véase: Tasacion de los montes y terrenos anejos (de las minas de Riotinto) con su Memoria y Estado.

374. Montes españoles (Los), bajo el punto de vista de su desamortizacion y adłninistracion, por un máscara sin careta.-Gerona: Imprenta de Dorca sucesor de Grases, 1862._4. ${ }^{\circ}, 127$ págss. y cinco estados que expresan por provincias los montes exceptuados de la desamortizacion en 1859, y los que son enagenables en 1862, conteniendo 1.090 ú más liectárcas de superficie.

La obra se propone combatir el Real decreto de 22 de Enero de 1862 , por el que se dió inayor amplitud á la desamórtizacion forestal. El anónimo autor critica dicho decreto, hace lo mismo con el proyécto de ley de montes pre- 
sentado al Miuisterio de Fomento en 27 de Febrero de 1861 por la Comision al efesto nombrada, y termina presentando un Bosquejo del proyecto de ley que á su entender convendria presentar á las Córtes, ilustrado con uotas y un juicio justificalivo en forma de preámbulo.

375. Montes (Los), y el cuerpo de ingenieros en las Córtes Constituyentes, por D. Francisco García Martino, indivíduo del expresado cuerpo.-Madrid; establecimiento tipográfico de Manuel Minuesa, $1871 .-4 .{ }^{\circ}, 454$ págæs.

El autor, reproduciendo la discusion parlamentaria habida en las Córtes Constituyentes con motivo de la aprobacion de los presupuestos gencrales del Estado, ciñéndose particularmente al de Fomento en el ramo de montes, impugna las ideas vertidas por el ministro y diputados que combatierou el Cuerpo, la escuela especial del ramo y las doctrinas forestales más aceptadas por la ciencia, patentizando los errores en que aquellos incurrieron, exponicndo los procedimientos más adecuados para fomentar la riqueza forestal, y rectificando cuantos conceptos equivocados se vertieron en contra del Cuerpo de que forma parte.

Este trabajo comenzó á publicarse en la Revisla forestal, economica $y$ agricola, Tomo III, ṕgs. 163 y 224 , resolviéndose luego formar con él un libro especial en atencion á la importancia del asunto, y en vista de la extension que alcanzaba.

\section{IN.}

376. Norte de Castilla (EL).-Diario de Valladolid.-Véase: Fomen lo del arbolado.

377. Noticia DE LA ACADRM:A DF CIENCIAS, RELLAS LETRAS Y NOBLES ARTES DE LA CIEDAD DE CóRDOBA, que comprende el resúmen de sus tareas, desde el 16 de Noviembre de 1813, hasta el 31 de Diciembre de 1846.-Córdoba, 1847, por Juan Manté.-4. , 31 pág.

Fn la segunda porlada solo se lee: Resimen de las tareas de la Academia cordcbesa.

Se cita en esta Nolicia una Ḿemoria de autor anórimo, del año 1816, sobre el modo de extracr la resina de los pinos, y otra sobre las utilijades del arbolado y medios de presentarlo, escrita por D. Francisco de Borja Pavon (censor de la Academia) en la cual, su autor, eon variedad de razones sacadas de las ciencias físicas, deduce la necesidail de conservar y fomentar los plantíos con respecto á España, y muy particularmente con aplicacion á la provincia de Córdoba.

378. Noticia sobre EL Árbol Del azuCAR, descubierto en 1807 por D. Rodrigo Armesto, recorriendo los montes de Návia en la 
provincia de Orense.-Madrid, 1811, por Alban y Delcasse.-4. ${ }^{\circ}$, 16 páginas.

Se alude al madroño, refiriendo el autor su agradable sorpresa al encontrarse en aquel país multitud de dichos árboles. Infiere de sus observaciones, que puede extraerse azúcar creando asi un nuevo ramo de riqueza, á semejanza de los indicados entónces por Mr. Archand y por Mr. Proust.

379. Novedades (Las).-Periódico político de Madrid.-Véase: Costumbres inglesas. - Estudios históricos sobre los giros y pastos comunes de Jerez de los Gaballeros.

380. Novísima guia de labradores.-Véase: Curso de agricultura práctica, conforme à los últimos adelantamientos, etc.

381. Novísnia recopilacion de las leyes de España. Dividida en XII libros, en que se reforma la Recopilacion publicada por el Señor Don Felipe II en el año de 156\%, reimpresa últimamente en el de 1775 . Y se incorporan las pragmáticas, cédulas, decretos, órdenes y resoluciones Reales, y otras providencias no recopiladas, y expedidas hasta el de 1804. Mandada formar por el Señor Don Cárlos IV. Escudo de armas de España.-Impresa en Madrid, año 1805.Folio, seis tomos de $338,492,729,400,530$ y 662 páginas.

El último tomo está compuesto de los tres indices generales por órden alfabético, y del suplemento correspondiente á los años 1805 y 1806.

En el tomo II trata: De las casas, sitios y bosques Reales y de sus primitivas jurisdicciones, pág. 57.-En el tomo III De los despoblados y su repobla. cion, pág. 486.-De los terrenos baldios, solares y edificios yermos, pág. 506. De los montes y plantios, su conservacion y aumento, pág. 510.-De las dehesas y pastos, pág. 556.-Del Consejo de la Mesta, etc., pág. 575.-De la caza y pesca, pág. 639.-Y en el tomo VI. Apéndice; De losmontes y plantios, su conservacion y aumento. - De las dehesas y pastos y de la extincion de animales nocivos.

382. Nueva clasificacion de las tierras de labor y de sus diferentes abonos. Tratado teórico-práctico escrito por Don Lúcas de Tornos, profesor de fisiografía agrícola en la escuela central de agricultura.-Obra publicada bajo la proteccion del Gobierno de S. M. á propuesta del Real Consejo de Agricultura, Industria y Comercio.-Madrid: Imprenta Nacional 1862.-4. ${ }^{\circ}$, xCvi, 296 páginas.

Presenta el resultado de los análisis hechos por Pelouze, Fremy, Baer y Regnault, de maderas y cortezas de ébano, haya, encina, pino, abedul, temblon, sauce, aliso, chopo, tilo, bonctero, nogal, fresno, acácia, olmo, abeto, cedro, alcornoque y alguna otra especie.

383. Nueva leiy agrairia (La).-Por D. Diego Gonzalez Alonso. Madrid, 1840. Istablecimiento tipográfico. -8. ${ }^{\circ}, 295$ páginas.

Contiene un proyecto de ley proponiendo la prohibicion de toda comu- 
nidad en pastos y montes, baldíos, comunes ó de Propios. Los prédios de esta naturaleza opina el autor que se vendan por juro de heredad, ó que se adjudiquen á los vecinos con las cualidades y condiciones que expresa detalladamente.

Esta Memoria obturo el accesit en el concurso abierto por la Sociedad Económica el año 1840.

384. Nuevas investigaCiones SObRe LOS AlerCes que por tradicion se supone haber existido antiguamente en los alrededores de Sevilla y Córdoba, é instrucciones para verificar la siembra del araar, llamado alerce africano, cuya semilla acaba de recibirse. Por D. Miguel Colmeiro, catedrático de botánica en la universidad de Sevilla.-Sevilla, 1852, imprenta de El Diario.-8. mayor, 14 páginas.

Resulta de las investigaciones, que la especie á que corresponde la madera de algunas construcciones de aquellas ciudades, denominada alerce, es el Callitris quadrivalois. Vent, proveniente de Africa.

Este trabajo vió la luz pública en $E l$ Diario de Sevilla y en el Boletin oficial del ministerio de Fomento, tomos V y XII, años 1853 y 1851; la segunda vez con adiciones. No se menciona en el Diccionario de bibliografia agronómica del Sr. Anton Ramirez.

385. NuEvo PROYECTO DE HACIENDA por el cual se proporcionan al Gobierno recursos permanentes con que poder ocurrir á todas sus dificultades y déficit actual, por D. Manuel Perez Gutierrez, abogado, comisario de montes que ha sido en varias provincias, y últimamente oficial cesante por supresion de la secretaría de la Junta general de beneficencia del reino.-Madrid, imprenta de D. José C. de la Peña, 1855.-4. ${ }^{\circ}, 67$ páginas.

Entre otros medios para conseguir el fin que se propone el autor, figura el arrendamiento por suerte, de terrenos baldios, á los precios de 10,7 y 5 rs. fanega los de $1 .^{\mathrm{a}}, 2 .^{\mathrm{a}}$ y $3 .^{\mathrm{a}}$ calidad respectivamente de los que supone que hay mas de ochenta millones de fanegas en España, considerando como cultivables las tres cuartas partes. La propuesta comprende el acotamiento de treinta millones del indicado terreno.

\section{O.}

386. Obras publicadas É inéditas de D. Gaspar Melchor de Joveldanns.-Coleccion hecha é ilustrada por D. Cándido Nocedal. Madrid, 1859, imprenta de MI. Rivadeneyra.-Tomo II. $4 .^{\circ}$ mayor, XXvi, 684 páginas. 
Corresponde á la Biblioleca de autores españoles desde la formacion del lenguaje hasta nuestros dias. Tomo L. Comprende la Represenlacion de la villa de Gijon para que se prorogue el arbitrio de vino y sidra para fuentes, calles y plantios que registramos en el segundo grupo de este libro.

38\%. Onsenvaciones á la mocion presentada á la Junta de Agricultura, Industria y Comercio de la provincia de Almería, por su Vicepresidente de la seccion de Industria el Sr. D. Ignacio Gomez de Salazar. - Almería, 1863, imprenta de D. Mariano Alvarez y Robles. $-4 .^{\circ}, 20$ páginas.

Estas observaciones, suscritas en Almeria á 25 de Abril de 1863, por don Ramon Orozco, D. Felipe Barron y D. Antonio Hernandez, se insertaron en el Boletin oficial de aquella provincia del 18 del indicado mes y año. Precede en el folleto, la mocion del Sr. Gomez de Salazar de la que se hacen cargo los autores expresados, combatiendo sus fundamentos y estableciendo que el aprovechamiento del esparto, objeto de estos escritos, debe ajustarse á las disposiciones de la circular de 21 de Junio de 1862 , respetando la propiedad legitima de los pueblos y particulares, sin adoptar medidas que lastimen derechos reconocidos, ni produzcan monopolio á favor de determinadas clases 6 personas.

388. Onservaciones sobre la Historia natural, geografía, agricultura, poblacion y frutós del reino de Valencia, por D. Antonio Joséf Cavanilles. - De órden superior. - En Madrid, en la Imprenta Real.-Año 1795-1797. -Dos tomos; gran fólio, de 236 y 338 pági nas, con láminas.

En el pié de imprenta del segundo tomo se añade: «siendo regente D. Pedro Julian Pereyra, impresor de Cámara de S. M.»

Describe los términos de todos los pueblos del reino de Valeneia, indicando lijeramente, por lo que hace á los mortes, las especies que los constituyen, el aspecto y extension de las masas arboladas, y la aplicacion de los productos forestales.

389. Opinion (LA).-Periódico de Valencia.-Véase: ¿Pueden evitarse para lo sucesivo las inundaciones en la cuenca del Jucar y sus afiuentes?

390. Opúsculo SOBRE la desamortizaCion DE LOS TERRENOS COMUNEs de Navarra, por D. Florencio Sanz y Baeza.-Madrid, 1861.Imprenta de N. Matute y B. Compagni. -4. $.^{\circ}, 30$ páginas.

Analiza y compara el autor, las leyes y dccrelos sobre desamortizacion, con las leyes especiales de Navarra, en cuanto se refieren á los terrenos y bienes ccmunes de los pueblos. Para acreditar el carácter especial y la antigüedad de los bienes comunes en Navarra, da cuenta de las diferentes donaciones hechas por los reyes, y las disposiciones que el reino se dió, citando particularmente la ley de 1828 en la que se consigna que uen atencion á que los efectos puramente vecinales son un caudal y hacienda de propiedad de los vo- 
cinos y habitantes de los pueblos, puedan disponer de sus productos y ventas, del modo que mejor les pareciese en objetos ú obras de utilidad pública, y tambien podrán cargarlos para los mismos objetos con censos ú otros gravámenes, etc." "Al amparo de éste precepto, dice el Sr. Sanz, sucede que el vecino mantiene sus vacas y ganados que emrlea en las faenas y trabajos de su oficio; recoge la hoja y el helecho secos con que hace el estiercol ó abono para sus heredades; toma la píedra y la leña con que hace cal para los campos; con ellos, en fin, toma el maderamen que necesita para las obras y mueblaje de su casa, para los aperos de labranza, para cerrar sus campos y el combustible para su cocina. Pero todo esto ni le basta ni ocurre más que á una parte de las necesidades interiores del hogar doméstico; le rodean otras exteriores á que es preciso ocurrir con metálico, pues que son del interés público, y para esto van á los montes ccmunes á trabajar en la fabricacion de mil objetos, como son: carretones, mesas, catres, sillas, palas, duelas, remos, aros, cellos, cestas, comportas, terreras, cucharas, pinas, rayos, cubos, carros, yugos, arados, dentales, estevas, arneros, etc., que luego venden en los pueblos comarcanos."

391. Ordexanza de la Real casa y patrimonio, expedida en 23 de Marzo de 1848. - Escudo de armas de España.-Madrid.-Por Aguado, impresor de cámara de S. M. y de su Real casa._1848._ $4 .^{\circ}$ mayor, 77 páginas.

En los títulos III y IV, páginas 32,33 y 34 , trata de la Inspeccion de Monles y Bosques, y de la Direccion de jardines y arbolados, artículos 103 á 110 , determinando el número, clase, atribuciones y deberes generales de los indivíduos afectos á los cargos respectivos.

392. Ordenanza de la Real casa y patrimonio, 9 Noviembre 1872.-Madrid, por Quirós, impresor de Cámara.-1872.-Folio, 32 páginas.

En el tít. X que versa sobre la Direccion del Patrimonio, pág. 24, art.66, determina el personal que ha de ocuparse en el fomento, cuidado y aprovechamiento de los montes, bosques, jardines y arbjlados.

393. Ordenanza de los bosques reales, aprobada por S. M. en 31 de Julio de 1848.-Madrid, 1818, por A guado.

Está dividida en tres títulos: el primero trata de la organizacion del personal; el segundo del aprovechamiento de los bosques, y el tercero de la conservacion. Acompañan quince modelos relativos á los partes semanales, al modo de hacer las denuncias, las so'icitudes y el reconocimiento de las licencias de caza, etc., etc.

394. Ordenanzas de la Real Sociedad de Agricultura, creadaen la villa de Pareja y sus aldeas el año de 1816. - Madrid, imprenta de Lopez y hermano. Con superior permiso, 1817.-4. ${ }^{\circ}, 42$ páginas.

A probadas por Real carla de 28 de Marzo de 1817. Al final tiene el discurso de instalacion pronunciado por el presidente D. Dionisio de Benito y 
Hermosilla, y despues la lista de toda clase de sócios. De este opúsculo, nada dice el Diccionario de bibliografía agronómica del Sr. Anton Ramirez. Entre las atribuciones y deberes señalados á la sociedad en el capitulo $2 .^{\circ}$, están los de procurar la repoblacion de las riberas con árboles y arbustos, y los de acrecentar la plantacion de especies ya experimentadas en el término ú otros puntos, como los castaños, avellanos, carrascas de buena-bellota y demás útiles para cultivar terrenos eriales.

395. Ordenanzas de los bosques Reales. - P. Cervantes. - Madrid, 168\%. $-4 .^{\circ}$ pergamino.

Así indicada en el Catálogo de los libros que se hallan de venta en la libreria D. B. J. Hernandez, en las Cuatro-Calles de Toledo. Madrid, imprenta de Espinosa y compañía, 1850 -4. 4. 80 páginas.

Bajo esta designacion al ménos, no figura en el Diccionario de bibliografia agronómica del Sr. Anton Ramirez.

396. Ordenanzas Generales de Montes.-Madrid, 1833.-Imprenta Real. $-4 .^{\circ}, 81$ páginas.

Están aprobadas por Reat decreto de 22 de Diciembre de 1833 . Constan de 236 artíeulos agrupados en diez títulos, cuyo enunciado es el siguiente: $D i s-$ posiciones generales. - De los montes puestos bajo la guarda y régimen de la Direccion general. - Policia comun á todos los montes del reino.-Policia parlicular de los montes dependientes de la Direccion.-Procesos por delitos y contravenciones de las ordenanzas. - Penas. - Ejecucion de las sentencias.Aplicaciones de los tres titulos anteriores á los montes de dominio parlicular. Disposiciones excepcionales. - Disposiciones para la ejecucion de estas ordenanzas.

997. Ordenanzas para el BUen réGimen y gobierno de la muy noble, muy leal é imperial ciudad de Toledo.-Toledo: Imprenta de D. José de Céa. 1858. - Fólio, 272 páginas.

Es publicacion costeada por el Ayuntamiento. Tienen interés forestal los puntos siguientes: Título 73. De los guardas de la legua, pág. 117.-Título 75. De los guardas de los montes, pág. 118. -Título 85. De la legua y sus ordenanzas, pág. 137. -Título 87. De la leña, pág. 147.-Título 88. De la madera, pág. 148. -Título 102. De los montes de Toledo, pág. 160.-Título 108. Del pacer de los ganados, pág. 163.-Título 115. De los prados, pág. 170.

398. Ordenańzas para el gobierno del Real sitio de Aranjuez. Madrid, 1795, Imprenta Real. $-4 .^{\circ}, 272$ páginas y un Apéndice con 275 .

Contienen estas Ordenanzas muchas disposiciones sobre caza, hurto de leñas, entrada de ganados, quemas y otros puntos de policía y conservacion, determinándose las multas en que incurren los infractores.

399. Ordenanzas que el Rey nuestro señor munda se observen para la conservacion de los paseos de las Delicias y camino de Santa María de la Cabeza, desde la puerta de Atocha al canal de Man- 
zanares y Caminos imperiales.-Hoja de doble fólio sin pié de imprenta.

Consta de siete artículos, por los que se pena la entrada de ganadoz y carruajes en dichos paseos, asi como toda clase de daño inferido á los árboles.

Nada se dice en el Diccionario de bibliografia agronómica del Sr. Anton Ramirez, de estas Ordenanzas.

400. ORIGEN é historia DE LOS BIENES DE PROPIOS, y consideraciones sobre su porvenir. Memoria presentada á lá Sociedad Económica Matritense de Amigos del País.-Por D. Julian Saiz Milanés, sócio de la misina, secretario honorario de S. M., Caballero de la Real órden americana de Isabel la Católica, y de la militar de San Juan.-Madrid, 1853.-4. ${ }^{\circ}, 32$ páginas.

Se insertó en los Anales de la Sociedad Económica matritense de Amigos del pais. Tomo II de la 2." série, 1853. Páginas 177 á 210.

Trata con gran extension y copia de datos del Origen de los bienes de Propios y su aplicacion; de los servicios hechos al pais por los bienes de Propios de lospueblos; datos estadisticos de los bienes de Propios; razones de conveniencia pública contra la venta en general de los bienes de Propios; y mejoras que pudieran hacerse en favor de los Propios de los pueblos y. fincas que debieran enagenarse á venta real con destino á levantar una linea general de camino de hierro.

Encareciendo la importancia de las dehesas de Propios por los recursos que facilitan á los Ayuntamientos, á los vecinos y á la ganadería, propone que las fincas rústicas no se enagenen, reservándose á los pueblos para atender con sus rendimientos al servicio doméstico interior de los mismos y levantar sus cargas concegiles.

401. ORíGEN y diGnidad DE LA CAZA, por Juan Mateos, ballestero mayor de S. M.-Madrid, 1634.-4. ${ }^{\circ}$

Es un libro de montería que trata de la caza del venado, del jabalí, y del lobo, y refiere curijsas batidas dadas en los bosques del Pardo, Balsain, Aranjuez y el Escorial, con los lances ocurridos en ellas a los príncipes de la casa de Austria y otros personajes de la córte.

\section{$\mathbf{P}$}

402. Pedacto Dtoscóntdes anazarbeo, acerca de la materia me-dicinal y de los venenos mortíferos, traduzido de lengua griega en la vulgar castellana, etc., ilustrado con claras y substanciales annotationes, y con las figuras de inmensas plantas exquisitas y raras, por el Doctor Andrés de Laguna, Iédico de Iulio III, Pont. Max. 
Añadióse una tabla para hallar remedio de todo género de enfermedades y otras cosas curiosas, nunca ántes impresas. Divo Philippo, divi Caroli V Aug. filio horedi opt. Max. Dicatum.-Amberes, 1555; Salamanca, 1570, por Mathias Gast.-Fólio. xxvin, 616 págs. y xxvir de tablas al fin.

En el libro primero trata de los avellanos, cap. CXLII, y del madroño, cap. CXXXVIII.

403. Peirsanientos políticos r económicos dirigidos á promover en España la Agricultura y demás ramos de industria, á extinguir la ociosidad, y dar ocupacion útil y honesta á todos los brazos. $\mathrm{Su}$ autor D. Múiguel Ignacio Perez Quintero, de la Real Academia de la Historia y de la de Buenas Letras de Sevilla, sócio de número correspondiente de las Económicas de Madrid, Sevilla, etc., Madrid. Imprenta de D. Benito García de Lastra y compañía.-Año 1798.8., 276 págs.

Determina los cuidados que las sociedades municipales agronómicas, cuya creacion propone, deberín tener con los arbolados de toda clase, dirigiendo los plantíos y cortas de maderas para construccion de bajeles y armaduras de edificios, disponiendo las talas, limpias y entresacos, y cuidando de que en los montes de particulares se ejecuten bien estas operaciones haciendo desaparecer los desórdenes que se notan en las cortas de los montes altos. Mas adelante trata de las condiciones que deherian reunir los delineadores y guardas de montes de las provincias de Marina. Ilace algunas indicaciones sobre la conveniencia de los cerramientos para facilitar la multiplicacion de los árboles. Y por último, se ocupa de los baldíos y montes bajos en el concepto de que estos pueden surtir de leñas á los hogares y establecimientos industriales, asi como proporcionar abrigo á los ganados y pasto de hoja y pimpollos de arbustos.

404. Physica DE los Árboles, en la cual se trata de la anatomía de las plantas y de la economía vegetal, ó sea introduccion al tratado general de bosques y montes, con una disertacion sobre la utilidad de los métodos botánicos; escrita en francés por el célebre Mr. Duhamel du Monceau, y traducida al castellano, con varias notas por el doctor D. Casimiro Ortega, primer catedrático del Real Jardin botánico, é indivíduo de la Real Academia de la Historia, de la Real de Medicina de Madrid y de la Sociedad botánica de Florencia.-Madrid, 1772, por Joachin Ibarra, impresor de Cámara de S. M. A expensas de la Real compañía de impresores y libreros del reino. -Dos tomos en $4 .^{\circ}$, xCı. - 304 págs. el primero y 371 el segundo. Con varias y excelentes láminas.

Trata de la anatomía, organografia, crecimiento, fructificacion, germinacion, ingertos, enfermedades y otros puntos propios de la materia objeto de la obra. 
405. Plan de Código rural, proyectado por Ia Sociedad Económica matritense, á cuyo exámen y remision de noticias invita á las demás sociedades, autoridades y ciudadanos ilustrados para lograr su perfeccion y presentarlo á las Córtes y al Gobierno.-Escudo de la Sociedad económica matritense.-Madrid: Imprenta y librería de D. Ignacio Boix, 1844.-Fólio, 14 págs.

Se publicó tambien en El Amigo del Pais, lomo II, pág. 1.

Expuesto extensamente el plan se desarrolla prévias unas consideraciones generales, indicando los puntos que debería abrazar el Código respecto á la condicion general de los agriculıores, los capitales, los convenios, las penas y la intervencion de la autoridad. En la segunda parte titulada, Capitales, comprende la propiedad general inmueble de los Nunicipios y del Estado, la especial de pastos, yerbas, montes y plantíos, la superficial de caza y pesca y las servidumbres de caminos, acotamientos, mancomunidad de pastos, tránsito, etc. Las Penas, comprenden á su vez las correspondientes á los daños en arbolados y montes, caza, pesca, etc., y en la Intervencion de la autoridad se ajusta la parte relativa á guardas rurales.

406. Plan de nueva ordenanza de montes, memoria compufsta de órden de la sociedad patriótica de Sevilla por su sócio de número el Padre Manuel Gil, de los clérigos menores de la casa del Fspíritu Santo de la misma ciudad. Madrid, 1794, imprenta de Sancha.8. " mayor, 94 págミ.

407. Plano de rodales del monte La Garganta, de los Propios del Espinar.-Véase: Junta general de Estadistica.

408. Plano Del yonte De irati. Sin nombre de autor, fecha ni lugar de publicacion.

Escala de 1]59701,48 de metro. Expresa las variaciones sufridas en el perímetro y superficie en virtud de lo resuelto con arreglo al Tratado de limites entre Francia y Éspaña de 2 de Diciembre de 1856. Demarca los montes del Estado cedidos por el valle de Aezcoa, el monte de la comunidad rle Cisa y San Juan de Pié de Puerto, el monte de la Cuestion, la porcion del monte Iratí perteneciente al valle de Salazar, y las Algas, en el valle de Sols, $\delta$ sea una de las dos porciones cedidas á Francia en cambio del monte de la Cuestion.

A esie plano acompañó una hoja impresa en $4 .{ }^{\circ}$, de 3 págs. que reproduce textualmente la parte que sirve para ilustrar la cuestion de límites, elı el Acta de deslinde y faceria celebrada en 1507 entre Salazar por un lado y Cisa y San Juan de Pié de Puerto por el otro; la del Acla de deslinde celebrada en 1556 entre Aezcoa y Cisa y San Juan de Pié de Puerı; la del Acta de reconocimiento y reposicion de mojones celebrada entre Salazar y Aezcoa en 1S15; la de la Informacion de testigos y escrito de bien probado presentado por Salazar ante el Tribunal de la Cámara de Comptos; y la Respuesia de agravios presentada por Salazar ante el Consejo de Nacarra. 
409. Plantas DE esPaN̄a.-Véase: Introduccion à la Historía natural, etc.

410. Prensa. (La) Periódico político de Madrid.-Véase: Ley de montes.

411. Presente y porvenir de la agricultura española y procedimiento breve, fácil, y económico, para destruir la causa principal que se opone á su desarrollo, por A. Cañas, Ayudante de Obras públicas.-Valladolid: Imprenta de los hijos de Rodriguez, 1868.-8. 205 pág:s. y láminas.

Discurriendo bajo la base de constituirse el coto redondo, enumera las ventajas físicas y económicas que reportaria la multiplicacion del arbolado en él, é indica los principales productos que podrian obtenerse de la vegetacion forestal, pág. 181.

412. Problema De los Bosques, (EL) bajo el doble punto de vista físico y social. Memoria leida en la Sociedad imperial y central de Agricultura de París, en sesion del dia 17 de Mayo de 1854, por D. Ramon de La Sagra._Madrid, 1854, por S. Compagni.-4. $.^{\circ}, 15$ páginas.

Se propone hacer cesar la alarma producida por la carestia de maderas, haciendo resaltar el empleo que, en su sustitucion se hace, del hierro y del carbon de piedra. Concede sin embargo à los bosques una gran influencia climatológica y agrícola y recomienda un gran estudio natural y estadístico de los montes de los paises más civilizados, para que conociendo to que es la riqueza forestal, se deduzca de ahí lo que debe ser, ó lo que es lo mismo, conocida la cuestion de hecho, se derive de la misma la resolucion de los problemas de derecho que han de servir de base para formular la legislacion á que deban sujetarse los montes.

Se publicó tambien en el Boletin ofcial del Ministerio de Fomento, 1854. Tomo XII, pág. 398.

413. Profesiones libres (LAS) y las carreras del Estado.-Apuntes sobre el deslinde de atribuciones mandado hacer por Real órden de 25 de Febrero de 1863 entre los arquitectos é ingenieros de varias clases.-Madrid: Imprenta de la Viuda de D. J. C. de la Peña, 1864.-4. ${ }^{\circ}, 41$ págs.

Aunque el trabajo versa principalmente sobre los ingenieros de caminos; comprende en algunos puntos cuanto atañe á los de minas y montes. El anómino autor del folleto defiende la libertad del trabajo en lo que se refiere á los ser vicios que puede reclamar de los indivíduos adornados de un título profesional, la industria privada; y en lo tocante á la prestacion de servicios al Estado, opina que el único principio racional de deslinde es el interés de la administracion y del público á quien sirve, de donde se deriva la cónstitucion de ramos administrativos especiales. Este trabajo se afribuye al ingeniero de caminos D. Gabriel Rodriguez. 
414. Programa de las materias de que han de ser examinados los indivíduos que en el mes de Setiembre del presente año aspiren á ingresar de alumnos en esta Escuela (la especial del Cuerpo de Ingenieros de montes). - Hoja de 4 planas en folio, sin piś de imprenta.

Suscrita en Villaviciosa de Odon á 22 de Febrero de 1861, por el Director, por delegacion D. Indalecio Mateo.

415. Progreso. (EL)-Periódico de Jeréz.-Véase: Algunas palabras sobre la importancia de los nontes y arbolados.

416. Prólogo del tomo XIII del viaje de España, que su autor D. Antonio Ponz ha hecho ímprimir separadamente. Se contienen en él varias reglas fáciles y prácticas para la siembra, plantío y multiplicacion de árboles que pueden criarse con abundancia en las provincias del reino.-Madrid, 1785, por J. Ibarra.-8..$^{\circ} 86$ páginas con diez de principios.

Explica el modo más fácil de sembrar, plantar y multiplicar el olmo, el á'amo negro ó negrillo y el álamo blanco, y sucesivamente los almendros, olivos, encinas, robles, pinos, castaños, nogales, fresnos, alisos, morales, moreras, árbol del amor y cipreses.

417. Prontuario ó tarifa por sucesiva progresion de dimensiones de las piezas de madera de construccion de baxales y edificios, y su respectivo producto en codos y partes cúbicas: y otra para la cubicacion de maderas redondas: que sirva de gobierno y direccion á los facultativos en la construccion empleados en los montes, depósitos y riberos: escritas de órden superior, por D. Antonio de Arizmendi, contramaestre de construccion, graduado de alférez de fragata de la Real Armada.-Escudo de armas de España.-Madrid.En la Imprenta Real, 1789.-Fólio, 491 págs.

Las tablas comienzan para las maderas de 1 pulgada de grueso, y continúan aumentando de $1 / 4$ en $1 / 4$ de pulgada, hasta las maderas que tienen 24 , comprendiendo, respecto á longitudes, desde $1_{\mid} 2$ pié á 56 piés. Siguen luego otras referentes á maderas redondas ó curvas que determinan los volúmenes de las de 2 hasta 40 pulgadas de diámetro, creciendo de $l_{l} 2$ en $l_{l} 2$ pulgada, siendo las longitudes desde $1_{1} 2$ pié hasta 96 piés.

No se menciona este libro en el Diccionario de bibliografia agronómica del Sr. Anton Ramirez.

418. Prontuario para los guardas de montes de la provincia de Huelra, aprobado por el Sr. Gobernador civil de la misma.-Comisaría de montes de la provincia de Huel ra.-El presente prontuario y libro de denuncias impreso de órden del Sr. Gobernador de esta provincia con fecha 13 de Febrero del pasado año de 1856 , para que sirva de guia á los guardas de montes de ella en el inejor des- 
empeño de su cargo, es á los mismos obligatoria su adquisicion.Los guardas mayores serán responsables á esta Comisaría, cada cual en su respectiva comarca, de las faltas que aquellos subalternos cometan por la carencia de dicho prontuario.-Huelva $1 .^{\circ}$ de Agosto de 1857.-Manuel Montilla.-Huelva año de 1857: Imprenta de D. F. de Galvez y Palacios.-Cuaderno sin numeracion en las páginas.

Contiene: de las Ordenanzas generales de montes de 22 de Diciembre de 1833, título III, artículos 145 á 15I; título IV, artículos 152 á 162 y título VI, artículos 186 á 198 todos inclusives; del Reglamento de 24 de Marzo de 1846 el título IV, artículos 34 á 57 inclusives, que tratan de los guardas de montes; y luego varias advertencias de la Comisaria respecto á guias, denuncias, procedimientos, disciplina, operaciones, obligaciones de los guardas, etc., con modelos para los partes sobre incendios, resultado de subastas, avisos de denuncias, y cuenta de productos de los montes bajo diversos conceptos.

En el Diccionario de bibliografia agronomica del Sr. Anton Ramirez, no se hace mencion de este Prontuario.

419. Providenciar la libre extraccion del Corcho en panas, seria destruir un ramo importante de riqueza y arruinar el país. Por D. Narciso Fonolleras.-Barcelona: Imprenta de A. Brusi, 1856.8. ${ }^{\circ}, 4$ pág̊s.

Este breve opúsculo, del cual no se dá noticia en el Diccionario de bibliografíu agronómica del $\mathrm{Sr}$. Anton Ramirez, viene á ser un estracto del folleto publicado en el mismo año por el Sr. Fonolloras, en union de los señores D. Ramon Cabrera y D. Andrés Guri, del que hemos dado cuenta con el título de Memoria publicada por la Comision de la prooincia de Gerona y distrito judicial de Arenys de Mar, etc.

420. Provincia DE GrRona. (LA) Datos estadísticos sobre su territorio, poblacion, beneficencia, baños y aguas minerales, instruccion pública, monumentos históricos y artísticos, diversiones y espectáculos, criminalidad, contribuciones, aduanas, rentas estancadas, desamortizacion, prestaciones personales, industrias minera, forestal, pesquera y de caza, agricultura, ganadería, industria fabril y comercial, medios de comunicacion, etc.

Contiene además esta obra los totales de la mayor parte de dichos datos respecto á España y á las provincias de mayor y menor importancia, y un nomenclator por órden alfabético de todos los pueblos y principales cascríos de esta provincia, con expresion del Ayuntamiento, partido judicial y diócesi á que corresponden; de la distancia á la capital del partido y de la provincia; del número de sus casas, indicando las que están agrupadas y discminadas; y del número de vecinos y habitantes de cada pueblo, por D. Pedro Mar- 
tinez Quintanilla, jefe que ha sido de primera clase de seccion de cstadística y actualmente secretario del gobierno de dicha provincia. Gerona: Imprenta de F. Dorca, sucesor de J. Grases, 1865.-4. ${ }^{\circ}$ mayor, 403 págs.

El título expresa perfectamente el contenido de la obra. Respecto á mon tes públicos indica el número, extension, pertenencia, principales especics dominantes y subordinadas, situacion y rençimientos, manifestando que estos podrian aumentarse mucho si las filcns se cuidasen y aprovechasen con arreglo á ciencia. Por lo que hace á montes particulares considera las principales especies que los pueblan uno á uno, indicando su localidad y los usos á que se pueden ciestinar. Las especies á que se contrae son, pino con inclusion del pinabete, haya, roble, encina, alcornoque, çstaño, a vellano, almez, boj, brezo, madroño, y retama, con sus correspondientes productos de maderas, leñas, carbones y cortezas curtientes. Dedica algunas páginas al aprovechamiento, elaboracion, producto, y fabricacion del corchn, y á la madera de roble destinada á duelas y aros. Acerca de estos dos puntos consigna datos estadísticos numerosos é interesantes.

421. Provincia. (La)-Periódico de Huesca.-Véase: Desamortizacion (La) de nuestra riqueza forestal .

422. Provincias. (Las)-Diario de Valencia._Véase: Montes. priblicos (Los) y la Diputacion provincial.-Inundacion del Júcar (La) en 1864.-Maderada del Turia. (La)-Venta de los montes del. Estado.-Condiciones de existencia de los montes. - Productos forestales (Los) en la Exposicion regional. - Sobre las cartas contra los montes.-Contestacion à un articulo de «El Imparcial».-Observaciones sobre un articulo de "La Epoca».-Desamortizacion completa é inmediata de la propiedad forestal. - Estudios sobrc la imundacion del Jucar. - Inundaciones (Las) y «El Pensamiento español». - Extension del arbolado y repoblacion de los bosques por medio del E'ucalyptus. - Mas sobre el Eucalyptus.

423, Proyecto de arreglo jel ministelio de fonento, presentado al Excmo. Sr. Ministro del ramo, por D. Julian Pellon y Rodriguez, caballero de la Real y distinguida órden americana de Isabel la Católica, profesor de ciencias físicas y naturales, escritor público, alumno de economía politica, miembro de varias Academias científicas y de varias sociedades económicas, ex-catedrático de física experimental y de química industrial en el Anfiteatro politécnico de Sevilla, ex-catedrático de geologia aplicadá á la agricultura y á la minería, director de varios establecimientos industriales, etc. etc.-Madrid, 1855: Imprenta del Agente industrial minero, à carg’o de D. Vicente Maldonado.-4.", 16 pág’s.

Suscrito por el autor, en Madrid á 17 de Agosto de $185 ̃$.

Eutre otras direcciones proposte la organizacion de la de Agricultura. 
con tres secciones, forestal, agronómica y veterinaria, correspondiendo á la primera el personal y Escuelas de ingenieros de montes y riegos, así como con otros asuntos, el de la construccion de pantanos, canales y acéquias de riego, servicios que siempre han correspondido al ramo de obras públicas.

A causa de esta novedad, que no deja de ofrecer interés, damos cuenta del proyecto, del cual nada dice el Sr. Anton Ramirez en su Diccionario de bibliografía agronómica.

424. Proyecto de código rural Francés, ó coleccion metódica de las leyes civiles, administrativas, de montes, de pesca, de procedimiento y de policía rural; publicado por la Academia de la industria agrícola, manufacturera y comercial, redactado por una comision especial de su seno. Traducido para la comision de código rural de la Sociedad Económica Matritense, con referencia á la tabla de materias aprobada por la Seccion de Agricultura, por D. Juan Antonio Seoane.-Madrid: 1845. Imprenta del Colegio de Sordomudos.-4. ${ }^{\circ}$ marquilla, 52 págs. á dos columnas y dicha tabla ó cuadro sinóptico.

La primera parte se reflere á la propiedad rural; la segunda, álas atribuciones y competencia administrativa y civil y policia vural; y la tercera á las penas, formando en junto una série de 563 articulos.

La tabla citada, que vá al final, referente al Código ó leyes rurales de España, establece cinco divisiones; primera, condicion social de los agricultores; segunda, capitales agricolas; tercera, contratos ó relaciones; cuarta, penas; y quinta, intervencion de la autoridad.

425. Proyecto de ley de montes presentado al Ministerio de Fomento en 27 de Febrero de 1861 , por la comision creada con encargo de redactarlo, en Real decreto de 22 de Octubre de 1860.-Escudo de armas de España._Madrid: Imprenta nacional, 1861.-4. 17 págss.

En el preámbulo se traza á grandes rasgos la historia de la legislacion forestal y los motivos que justifican el proyecto. Este propone la exclusion de la venta de los montes exceptuados por el artículo $10^{\circ}$ de la ley de $10^{\circ}$ de Mayo de 1855, declarando enagenables los demás á condicion de que los adquirentes no puedan roturarlos sin permiso del Gobierno. Se exceptuan veinte fincas para dehesas yeguares y potriles, y se autoriza al Estado para adquirir los montes públicos de la clase de exceptuados por la especie arbórca, fijándose reglas para la tasacion y pago del valor de los mismos. Siguen otras disposiciones relativas á servidumbres y policía. Autorizan el dictámen los individuos de la Comision, que indicamos por el órden con que figuran sus firmas; á saher: Manuel Alonso Martinez.-Cirilo Al rarez.-José Caveda.-Francisco Tames Hevia.-José Joaquin Matcos.-Antonio Cánovas del Castillo.-Aguslin Pascual.-Pedro N. Aurioles.-Fernando Cos-Gayon.

426. Proyecto de reglamento para la ejccucion de la ley de 24 de Mayo de $1863 .-4 .^{\circ}$ mayor, 50 pág̊s. 
Carece de fecha, piẻ de imprenta é indicacion de autor, pero se reconoce su procedencia oficial. Circularia impreso para facilitar su estudio. Le precede una minuciosa exposicion de motivos, siguiendo la parte dispositiva que se compone de 139 artículos agrupados en diez títulos que tratan de la clasificacion y deslinde de los montes públicos, de la adquisicion de montes por el Estado, de la refundicion de dominios, de las servidumbres y aprovechamientos vecinales, de la administracion, de los aprovechamientos, de los gastos de mejora y conservacion y de la policía de los montes públicos, y, por fin, de los montes particulares.

42\%. Proyecto de una lex agraria ó Código rural. Publicado de acuerdo de la Sociedad Económica Matritense, por D. Juan Alvarez Guerra.-Madrid, 1841, por MI. de Búrgos.-4. $.^{\circ}, 285$ págs. en junto.

Se publicó en tres cuadernos ó libros, que son las divisiones de la obra; el primero trata de las relaciones mútuas entre la nacion, las provincias y los pueblos, con la agricultura y los agricultores; de los bienes y mejoras públicas en general, y de las provincias y del comun: el segundo, de las relaciones mútuas,entre los labradores, examinándolas bajo el aspecto de la propiedad rural y del condómino ó particionero; de los usufructuarios y enfiteutas, censualistas y foreros, arrendatarios y arrendadores, asalariados y salärios: y en el tercero, de las relaciones entre los labradores y las demás clases de la sociedad, hablándose con extension de la policía de los pueblos y de los campos, de las hipotecas generales y de las especiales.

428. Proyecto para la organizacion de la guarda rural, por D. Vicente Lassala y Palomares, publicado por la Diputacion provincial de Valencia.-Valencia, 1864. Imprenta de La Opinion á cargo de José Domenech.—4. ${ }^{\circ}, 55$ págs.

Fechado en Valencia á 16 de Julio de 1864. El plan consiste en que bajo un sistema general, organice y administre por si cada provincia la fuerza de guardia rural que necesite, procediendo del ejército las clases de jefes y oflciales, siendo voluntarios los indivíduos, y pudiendo, por relaciones mútuss entre el Estado y las provincias, ser declarada la Guardia rural en cuerpo franco, en caso de guerra extranjera interior. Presenta el proyecto con las bases formuladas, en número de quince; y expone las relativas á los jefes y oficiales, clases, indivíduos; obligaciones mútuas entre el Estado y la provincia; disposiciones generales para el reglamento de la Guardia rural, y obligaciones del inspector, ayudante, jefe y ayudante de canton, celador rural, cabo de ronda y guarda. Tambien se ocupa de la parte de aplicacion, detallando lo relativo á armamento, uniformes, sueldos y gratificaciones.

Sigue el acuerdo de la Sociedad para que se eleve el proyecto á las Córtes, la exposicion con que se hizo y unas Reflexiones del autor sobre la misrna materia, expuestas á la indicada Sociedad en 31 de Marzo de 1864.

De este trabajo no se hace mencion en el Diccionario de bibliografia agronómica del Sr. Anton Ramirez.

429. Proxecto que D. Andrés Martí, capitan de galeota, pone á 
los piés de Vuestra Majestad, sobre la limpieza de las calles de Madrid, construccion de jardines, huertas y arboledas en sus cercanías, y considerables utilidades que de todo resultan á favor de la Real Hacienda de Vuestra Majestad, vi'la y córte y arzobispado de Toledo, bien comun y particular; y se satifface á algunos reparos pue: tos á este proyecto.-Madrid.-Sin año; es del 1737.

Asi se indica esta publicacion en el Diccionario de bibliografía agronómi$c a$ del $\mathrm{Sr}$. Anton Ramirez, el cual añade: «Se dá razon de este impreso en el número 31 del Mercurio español, correspondiente al 1. ${ }^{\circ}$ de Julio de 1814; y D. Félix Torres Amat, sin añadir nada á las noticias del libro ni del autor, le comprende en la pág. 380 de sus Memorias para ayudar á formar un Diccionario critico de los escritores catalanes."

430. Puente de alcolea. (EL)-Periódico político de Madrid.Véase: Proyecto de ley de montes (El).-Ramo de desamortizacion (El) y el de montes.

\section{Q.}

431. Quinta de la Esperanza.-Véase: Catálogo del establecimiento de floricultura.... etc.

\section{R.}

432. Raincal asturiano (EL).-Periódico de Oviedo.-Véase: Disfrule y aprovechamiento de los montes municipales.

433. RAPPoRT SUR L'ÉtAT, L'ORGANISATION ET LE PROGRÉS DE LA STATISTIQUE EX ESPAGNE, presenté á la huitiéme session du congrés international de statistique.-Madrid: Imprimerie de T. Fortanet, 1872.-Folleto en $4 .^{\circ}$ de 64 págs.

- El trabajo está redactado en francés y fechado en Madrid á 6 de Agosto de 1872, firmándolo, como delegado oficial de Bspaña, D. Agustin Pascual.

Es de interés forestal la parte relativa á los trabajos de la Flora y el Mapa forestal de España, de que se hace mérilo con elogio, en las págs. 11, 12, 13 y 14, reseñando la historia de las respectivas Comisiones, todo bajo el siguiente enunciado: Application des sciencés naturelles á la statistique.

434. Real cÉnula, Instruccion y Ordenanzas que Su Majestad (Dios le guarde) manda observar para la custodia, adninistracion, 
conservacion y cria de los Reales Pinares y Matas de Robledales de Valsain,-Piron y Rio-frio, desde quince de Octubre de mil setecientos sesenta y uno en que se incorporaron en la Corona.-Escudo de armas reales, con el lema: Carolus III D. G. Hispaniarum et Indiarum Rex.-Madrid. De órden de Su Majestad.-En la Imprenta de Juan de San Martin. Año de 1761.-Fólio, 25 páginas numeradas.

Comienza recordando que por Real decreto expedido á 28 de Junio de 1861, mandó el Rey otorgar escritura de cornpra con incorporacion á la Corona de aquellas fincas que pertenecieron á la ciudad de Segovia, su Noble Junta de Linages, al Comun y al de su Tierra. Dicha escritura se ctorgó el dia 4 de Octubre del indicado año. Proponíase el Rey conseguir el restablecimiento, conservacion, aumento y cria de los Pinares y Matas.

La Instruccion y Ordenanza, formada por D. Andrés de Valcárcel, ministro del Real Consejo, fué expedida por el Rey en el Real Sitio de San Lorenzo á 15 de Octubre de 1761 . Compónese de 50 capitulos cuyas disposiciones más importantes versan sobre los puntos siguientes: nombramientos de intendente, subdelegado, escribano actuario para las causas por daños ó delitos cometidos en los montes, contador, secretario de la intendencia, guarda mayor, teniente de guarda mayor, y guardas de á pié (catorce), además de los destinados exclusivamente á la custodia y fomento de la caza; armamento y distintivo de los guardas; obligaciones del reconocedor y apreciador para designar el tiempo, modo y forma de hacer las cortas de maderas y leñay para establecer siembras; contabilidad; derecho de la ciudad de Segovia y consortes al goce y aprovechamiento de los pastos de invierno y verano para sus ganados, disfrutando las aguas corrientes, estantes y manantes y las las ñas muertas y secas de solo los pinares, entendiéndose que por cada rebaño de mil cabezas de merinas solo se han de incluir treinta y cinco cabras, concediéndose asímismo la entrada al pasto de las yeguas, mulas, pollinos y vacas, respetando los sembrados y tallares en los seis primeros años las vacas y en los cuatro primeros el resto del ganado, para evitar los daños de la huella; designacion de pasos y cañadas; goce, por parte de los vecinos de la ciudad y tierra de Segovia, de las leñas inútiles de jabinos, cambroños, retamas, piornos y tomillos; extraccion de teas; corta de latas secas para las funciones que hacen las parroquias con el nombre de Catorcena, obtencion de ramas de acebo para las funciones del domingo de Ramos respetando las guias ó cogotas, y labra y escava de canales, cubos y saetines, para las Comunidades; composicion de caceras dentro de los pinares y matas; corta de cambroños para la conservacion de los ventisqueros y nieve de la sierra; prohibicion de cortar pinos para Mayos; penas en que incurren los que corten leña verde; prohibicion de sacar leña seca de más de seis piés de largo, así como la de usar carretas para la extraccion; veda de todos los montes al ganado cabrío á excepcion del número de cabezas por rebaño lanar de que habla el capítulo 19; prohibicion de quemar en los pueblos circunvecinos, los pastos secos, á fin de evitar los incendios; veda absoluta para el ganado de cerda; precauciones para encender fuego en el monte; marqueo de las 
maderas; prohibiclon de sacar tierra y piedra; sobre regular la leña por carreta de dos bueyes; denuncias contra los pastores de ganados propios de eclesiásticos que disfrutan inmunidad; corla de pinos dejando solo un tocon de dos piés, y labrando todo el tallo sin reservar tronco ni camajon; resistencia á los guardas; derogacion de todo fuero; forma de distribuir el fondo de multas; auxilio de las justicias á los guardas; y provision de las vacantes de guarda mayor y reconocedor.

sigue despues, manuscrita, una Adicion aprobada por el Rey en Aranjuez á 20 de Abril de 1782, que consta de nueve capítulos sobre prohibicion de entrar en los montes con hacha de viento ó tea encendida, y los gabarreros durante la noche; que no puedan aquellos hacer más que un viaje al dia ni llevar más de tres caballerías menores y cinco mayores; que se respete la leña destinada á las Reales fábricas; que los padres ó amos de los dañadores están obligados á presentar á estos en la cárcel ó á pagar las multas correspondientes; y que los guardas respeten á sus superiores y no abandonen su puesto, prohibiéndoseles el einparentar ni admitir agasajo de los gabarreros.

Son dignos de estudiarse por las buenas prácticas selvícolas que su mandato entraña, el capítulo $6 .^{\circ}$, sobre siembras; el $8 .^{\circ}$ que fija las rozas del robledal en los meses de Noviembre, Diciembre, Enero y Febrero; el $14 .^{\circ}$ que recomienda la ejecucion de la corta y derribo sin daño de las pimpolladas prohibiendo se corlen en pieza los maderos de á seis, ocho y diez, por ser perjudicial á los pinares; el $16 .^{\circ}$ que manda ejecutar claras dando la preferencia á las latas que estuviesen á medío derribar ó sean torcidas; y el $24 .^{\circ}$ que ciñe el disfrute de teas á los tocones de los pinos cortados, sin que se puedan arrancar aquellos, y sí solo cortar á flor de tierra, previniendo además que la operacion se haga de dia, y nunca en los meses de Julio, Agosto y Setiembre, para evitar los incendios (a).

La coleccion completa de las Ordenanzas especiales dictadas para el régimen de los montes de las antiguas Comunidades, seria tan curiosa como instructiva, pudiéndose considerar como indispensable para conocer con toda exactitud el perfeccionamiento que ha tenido la selvicultura en estos últimos tiempos. Desgraciadamente, las Ordenanzas en cuestion no se encuentran recopiladas en parte alguna, y es menester mucho tiempo y mucha diligencia para reunir todas las que existen; relegadas hoy á los archivos de las municipalidades de su referencia.

Las de Coca en la provincia de Segovia, las de Pareja, en la de Guadala-

(a) La coloccion completa de las Ordenanzas especiales dictadas para el régimen de los montes de las antiguas Comunidudes, seria tan curiosa como instructiva, pudiéndose considerar como indispensable para conocer con toda exactitud el perfeccionamiento que ha tenido la selvicultura en estos últimos tiempos. Desgraciadamente, las Ordenanzas on cuestion no se encuentran recopiladas en parte alguna, y es menester mucho tiempo y mucha diligencia para reunir todas las que existen, relegadas hoy á los archivos de las municipalidades de su referencia.

Las de Coca, en la provincia de Segovia, las de Pareja, en la de Guadalajara, las de la Comunidad de algunos puebios del partido de Daroca, on la de Zaragoza, y otras muchas, cuyos originales no hemos podido consultar, merecen ciertamente los honores de una nueva publicidad, 
jara, las de la Comunidad de algunos pueblos del partido de Daroca en la de Zaragoza, y otras muchas, cuyos originales no hemos podido consultar, merecen ciertamente los honores de una nueva publicidad.

435. REAL DECRETo DE 6 DE JULIO DE 1845, en que se determinan las disposiciones generales para el arreglo y servicio del ramo de montes.-Madrid: Imprenta nacional, 1846.-4. , 40 págs.

Acompaña a! Real decreto, el Reglamento para su ejecucion, fecha 24 de Marzo de 1816 , así como la Instruccion de $10^{\circ}$ de Abril del mismo año, aprobada por S. M. para proceder al deslinde y amojonamiento de los montes del Estado, de los Propios y comunes de los pueblos y de los eslablecimientos publicos.

436. ReAl DECRETo de 26 de Octubre de 1855, para la ejecucion de la ley de 1. de Mayo del mismo año en la parte rélatira á la desamortizacion de los montes, y el informe emitido con este objeto por la Junta facultativa del cuerpo de Ingenieros del ramo.-Escudo de armas de España.-Madrid: Imprenta del Colegio de Sordomudos, 185̌ว̆.-Folleto en $4 .^{\circ}$ de 104 págrs.

El espiritu del decreto es exceptuar de la venta por la influencia que ejercen sobre el clima, el terreno y la distribucion de las aguas, los montes de las regiones altas, compuestos de pinabetes, pinsapos, pinos, enebros, sabinas, tejos, h๘yas, castaños, avellanos, abedules, alisos, acebos, robles, rebollos, quejigos y piornos, declarando enagenables los demás, á excepcion de los alcornocales, encirares, mestizales y coscojales cuya enagenacion ó reserva debe determinarse prévio reconocimiento especial y en vista de la importancia cosmológica de la finca en cada caso. Se dictan reglas para la clasificacion de los montes.

El Informe, abraza los puntos siguientes: Funciones de los montes en la fisica del globo; constitucion economica de la produccion forestal y del monte maderable en particular; la mayor produccion en especie da la menor renta en el beneficio de los;montes; montes españoles; introduccion; infuencia de la pendiente; infuencia de la naluraleza del suelo; zonas forestales; extension de los montes; estado de los montes; bases de desamortizacion forestal; montes que no pueden pasar al dominio de los particulares sin comprometer la salubridad del pais, la fertilidad del suelo y la defensa del territorio; montes que no pueden enagenarse sin préoio reconocimiento; monles cuya venta puede declararse desde iuego oportuna sin necesidad de reconocimiento prévio; conclusion.

437. REAL ÓRDEN de 30 de Abril de 1857, sobre el modo de formar las colecciones forestales que deban figurar en la Exposicion agrícola, y catálogo general de los productos forestales redactado por la Junta facultativa del cuerpo de Ingenieros de montes.-Escudo de armas de España.-Madrid, 185\%: Imprenta del Colegio de Sordo-mudos y de cieg’os.-Fólio, 19 págs. sin numerar.

Se determinan las clases, dimensiones, forma, etc., que deben tener los productos, y el modo de remitirlos los distritos forestales á la junta faculta- 
tiva. El catálogo expresa los nombres científicos, los vulgares y las localidades de donde deben enviarse los ejemplares de las maderas, carbones, ciscos, cenizas, corchos, cortezas, productos resinosos y frutos. Autorizan el catálogo, fechado en Madrid á 2 de Mayo de 1857, D. Agustin Pascual, D. Indalecio Mateo, D. Miguel Bosch y Juliá y D. Pedro Bravo como secretário.

438. Real ordenanza para el gobierno de los montes y arbolados de ia jurisdiccion de Marina.-Madrid, 1803: Imprenta Real.$4 .^{\circ}, 265$ págs. y ocho modelos de estados estadísticos.

Aprobada por S. M., en San Ildefonso, á 27 de Agosto de 1803; fué propuesta por el principe de la Paz, generalísimo de mar y tierra. Comprende algunas disposiciones relativas á los montes y arbolados de dominio particular; á los terrenos baldios, realengos y de Propios; al personal de conservadores, celadores y guardas, y á la jurisdiccion contenciosa, entendiéndose afectos á la de Marina los montes altos y bajos, comprendidos en el espacio de 25 leguas desde las costas.

439. Real provision expedida por S. M. y señores del Consejo, para que en el ramo de arbolados de los paseos de esta villa se observe el Reglamento aprobado por S. M.-Escudo de armas de España.-Madrid en la Imprenta Real: Año de 1831.-Fólio, 16 páginas.

Lleva la fecha de 15 de Octubre de 1831 y consta de 51 artículos que tratan de la dircccion gubernativa y económica; del director facultativo, sus obligaciones y fa_ultades; del ayudante, del director facultativo y sus obligaciones; del modo de formar y rendir las cuentas pertenecientes al ramo de arbolados y paseos públicos; de la provision de las plazas de director, ayudante y guardas; de algunas operaciores facultativas que no podrá dejar de observar el director de arbolados; y de la repoblacion de arbolados. En el párrafo I, se declara el Rey protector especial del ramo en ía villa de Madrid.

No se menciona esta Real provision en el Diccionario de bibliografia agronómica del Sr. Anton Ramirez.

440. Real resolucion y documentos importantes del expediente de concurso administrativo de los acreedores censualistas sobre los Propios de esta ciudad de Toledo. Año de 185\%.-Toledo: Imprenta de Severiano Lopez Fando, 1857.-4. , 72 págs.

Comprende los dosumentos oficiales relativos á esta cuestion, que afecta directamente á lns importantes montes da Propios de aquella ciudad.

Nada dice el Sr. Anton Ramirez en su Diccionario de bibliografia agronomica, de esta publicacion.

441. Reales Decrizos sobre la exposicion de los productos agrí-1 colas de la península, islas adyacentes y posesiones ultramarinas, que ha de celebrarse en Madrid desde el 24 de Setiembre al 4 de Octubre de 1857.-Escudo de armas de España.-Madrid: Imprenta Nacional, $1857.4 .^{\circ}, 16$ págs. 
Contiene el Real decreto de 11 de Marzo relativo á la organizacion de la Exposicion; el de igual fecha que trata de los productos admisibles en la Exposicion agricola, de los expositores y sus obligaciones, de la Junta directiva y comisiones de provincia, y de las disposiciones generales. Comprende en sus secciones correspondientes, la indicacion de los productos forestales que pueden concurrir al certamen, en clase de planos y dibujos, maderas, leñas, cortezas, frutos, resinas, carbones, etc.

Este folleto no está indicado en el Diccionario de bibliografía agronómica del Sr. Auton Ramirez.

442. Recopilacton de las reales ordenanzas y cédulas de los bosques Reales del Pardo, Aranjuez, Escorial, Balsain y otros. Glosas y comentos á ellas. De la jurisdiccion privativa de la Real y Suprema Junta de obras y bosques. Y de la del Consejo de Cámara de Castilla, interpretacion á la ley II, título IV, del libro II de la Nueva Recopilacion. Del fuero privilegiado de los ministros y oficiales de los alcázares, casas y bosques Reales, y exenciones de los de la Real montería y volatería. Y de la práctica y forma judicial en las causas y denunciaciones de estos Reales bosques. Dedicado al rey D. Cárlos II nuestro señor. Por mano del Excmo. Sr. conde de Oropesa, presidente de su Consejo. Autores: el licenciado D. Pedro de Cerbantes, que lo empezó, y D. Manuel Antonio de Cerbantes, su sobrino, alcalde de la Casa y Córte de su Majestad, y jueces de sus Reales obras y bosques, que lo continuó y concluyó de órden y mandado de dicha Real y suprema Junta.-Madrid, 1867, por Melchor Alvarez.-Fólio xxxı, 803 págs. comenzando el índice en la 749 .

Precede la provision general y ordenanzas del Real bosque del Pardo, dada en Madrid, por Felipe II, el 23 de Julio de 1572, en la cual se citan cartas y provisiones de los Reyes Católicos y de Cárlos I. Despues se divide la obra en siete partes: la primera se refiere á la caza; $\mathrm{v}$ tiene 41 glosas: la segunila sobre la pesca, y contiene 6 glosas; la tercera sobre los árboles, leña y bellota, acompañada de 13 glosas; la cuarta de los pastos y yerbas con 4 glosas; la quinta, de los fuegos (prohibiendo que se enciendan en las cercanías de los montes y mandaudo que los concejos comarcanos acudan á apagarlos), tiene 2 glosas: la sesta, del oficio y potestad del alcalde del Pardo y de su teniente, guardas y oficiales, á lo cual se agregan 19 glosas; y la sétima, de la jurisdiccion del alcalde, juez de bosques, y de la forma judicial ęn todas instancias, completándola 21 glosas.

443. Recuerdos de un viaje á marruecos, por D. Fernando Amor, catedrático de Historia natural del Instituto de Córdoba.Sevilla, 1859: Imprenta de La Andalucia.-4. ${ }^{\circ}, 118$ págs.

Aun cuando esta obra no tiene exclusivo carácter forestal, merece citarse por las curiosas indicaciones de este género que en la misrna se hacen. Los 
asuntos más interesantes versan sobre la vegetacion siguiente: adelfas, palmitos, (pág. 35), fresnos, sauces, (pág. 36), tarayes, (pág. 40), bosques de alerce africano, (pógs. 76 y 77), montes de acebuches, lentiscos, sanguinos, algarrobọs, filireas, espinos y encinas, (págs. 84 y 85), montes de acebuches y lentiscos gigantescos de Siachem (págs. 111 y 112), y monte de brezos, majoletos, alcornoques, coscojas, jaras y arrayanes de Bubana (pág. 113).

444. Reriexiones sobre la ley agraria de que se está tratando en el Consejo. Carta' escrita al Sr. D. Manuel Sisternes y Feliu, fiscal que fué del mismo Consejo y de la Real Cámara, por D. Luis Marcelino Pereira, del Colegio de abogados de Madrid.-Madrid, 1788: $8 .^{\circ}$

El Sr. Colmeiro (D. Manuel) de cuya Biblioteca de los economistas españoles de los siglos $X V I, X V I I$ y $X \nabla I I I$, tomamos la indicacion de esta obra, la juzga de este modo: “Cuerda y prudente doctrina. El autor espera con razon el fomento de la agricultura de España de la fidelidad á los principios de propiedad y libertad."

El autor propone entre otras cosas, la division de los terrenos rcalengos y concejiles, y "la supresion absoluta de los privilegios de la IIarina en los montes y bosques particulares, fiando la multiplicacion de los plantios al interés individual, y al comercio el surtido de las maderas necesarias á los arsenales." No se habla de esta publicacion en el Diccionario de bibliografia agronómica del Sr. Anton Ramirez.

445. Reflexiones sobre los montes de Segura de la Sierra, y sobre las ventajas que resultarán al Estado de convertirlos en propiedades particulares. Informe dado al Excmo. Sr. D. Josef de Mazarredo, Ministro de Marina, por D. Martin Fernandez de Navarrete, Ministro y Fiscal que fué del extinguido Consejo Supremo de Marina.-Madrid, 1811, por Ibarra.-4. ${ }^{\circ}, 40$ pág:s.

Atribuye el mal estado de los montes, á la ineficacia de las disposiciones administrativas, y fundado en el iuterés particular, pide el autor la inmediata division de los montes en suertes, y su enagenacion, suponieudo que esto sería un ensayo felíz para hacer lo mismo con las tierras comunales.

Este interesante informe se reprodujo el año de 1825 , en un opúsculo que lleva por titulo: Expedienle sobre el régimen y administracion de los montes de Segura de la Sierra y de su provincia, reseĩado en el lugar correspondiente. Es preferible consultar en esta edicion el trabajo del Sr. Navarrete, porque en ella se comprenden todos los antecedentes que tuvo á la vista para redactarlo.

446. Reiutacion á las breves observaciones que sobre la memoria, Sueto, clima, cullivo agravio y forestal de la provincia de Vizcaya, ha publicado D. Fernando Mieg. Por D. Lúcas de Olazabal, autor de la expresada Memoria.-Bilbao: Imprenta y litografía de D. Juan E. Delmás, 1858. $-80^{\circ}, 45$ págs. 
Versa sobre si hay ó nó identidad entre la Memoria y los trabajos hechos por Mr. Collete en 1848, asentando el autor que solo hay alguna coincidencia de noticias. Rectifica lo expuesto por el Sr. Mieg sobre varios puntos climatológicos, geognósticos, agronómicos y forestales.

Véase: Suelo, clima, cultioo, etc.

447. RegldMento de arbolados y paseos de esta M. H. villa.Madrid, 1851: Imprenta de A. Espinosa y compañía.-8. $0^{\circ}$ mayor, 14 págs.

En el Diccionario de bibliografía agronómica del Sr. Anton Ramirez, no se menciona este Reglamento que determina los deberes y atribuciones del personal de direccion y guardería.

448. Reglaniento de asociacion para casos de enfermedades graves y defunciones en el Cuerpo de Ingenieros de montes.Madrid, 1863.--Imprenta del Colegio de Sordo-mudos y de Ciegos. $4 .^{\circ}, 4$ págs. sin numerar.

Consta de 16 artículos y está fechado en Madrid el 1. ${ }^{\circ}$ de Enero de 1863.

449. Reglamento de la asociacion de la Revista forestal.-Madrid: Imprenta del Clamor, á cargo de D. D. Navarro, 1866.-4. ${ }^{\circ}$, 8 págss.

Consta de 20 artículos en los que domina el plan de que la Revista forestal se publique con el apoyo moral, cientíltco y económico de los Ingenieros de montes españoles y demás perscnas que hayan hecho estudios especiales en el pais ó en el extranjero.

450. Reglamento de la Escuela agronómica de Nogales, fundada por D. José de Hidalgo Tablada y D. Eugenio García y Gutierrez.-Madrid, 1852.-Imprenta de Luis Garcia.-4. ', 24 págs.

Segun este reglamento, debia correr á eargo de un Ingeniero de montes, la enseñanza de la botánica, montes, geometría, agrimensura y nivelacion, estudiándose en la asignatura especial de montes, todo lo concerniente á la dasotomia y selvicultura, con arreglo al programa cuyo pormenor contiene el reglamento indicado.

El Sr. Anton Ramirez no cila este Reglamento en su Diccionario de bibliografia agronómica.

451. Reglanexto de maderas necesarias para la fábrica de los baxeles del Rey y demás atenciones de sus arsenales y departamentos: formado por D. Joseph Romero Fernandez de Landa, de la órden de Santiago, brigadier de la Real armada, é Ingeniero Director de ella. Aprobado por S. M.-Madrid, 1784, por D. Joachin Ibarra.-Fólio, Xxıv-77 págss. y 77 láminas, con un modelo al principio del pié de Búrgos.

Establece reglas para la presentacion de las piezas de maderas por los asentistas. Previene que al tiempo de labrarse la madera en el monte se le 
deje la demasia de grueso que se juzgue necesaria para resistir el desbaste del arrastre, é igualmente el exceso en el largo para resistir las rajaduras de cabeza. Se dice tambien que las piezas se han de marcar precisamente en el monte con el número correspondiente á su destino; se advierte que cuando se sustituyan con piezas de pino las significadas de roble, ha de aumentarse al grueso y ancho la quinta parte, y si de cedro, la cuarta.

Sigue una Tabla que manifiesja los largos, gruesos y anchos de las maderas de roble y pino, correspondientes á los navios de 100 cañones para arriba, de 74, y de 64: Fragatas de 34 cañones para arriba: Fragatas menores, Paquebotes, ó sus semejantes; y demás ocurrencias de los Departamentos; con una sexta clase de maderas para Lanchones, Lanchas, Botes, Picaderos, Masieleros para Planchas, Travesaños, Escoras, Espeques, piezas para Motoneria, Tamboretes, Cepos de Anclas, piezas para Cureñas, y para edificios; y un Reglamento de Perchas de pino para Arboladuras, Tosas, y Tablazones para cubiertas, obras muertas, Remos, y otros fines del servicio.

Las láminas indican la forma y dimensiones de las piezas de construccion naval, explicándose minuciosamente cada una de ellas por medio de tablas adjuntas.

Este libro es notable por su perfeccion y belleza artística.

452. Rhigamento del ramo de arbolados y paseos de esta M. $\mathbf{H}$. villa de Madrid.-Madrid: en la imprenta de Yenes, 1841._8. . 31 págs.

Consta de seis capítulos subdivididos en varios artículos, y trata de la direccion, economía y gobierno del arbolado y paseos, de las obligaciones del director, de las del interventor, de las del ayudante, de las de los guardas, y de la provision y nombramiento del direclor, interventor y ayudante.

En el Diccionario de bibliografía agronómica del Sr. Anton Ramirez, no se menciona este Reglamento.

453. Reglamento del servicio del personal subalterno del ramo de montes de la provincia de Segovia, aprobado con fecha 30 de Mayo por el señor Gobernador.-Segovia, 1858: Imprenta de Alba. $4 .^{\circ}, 15$ págs. en las que se comprenden cuatro modelos de documentacion oficial.

Lo autoriza en Segovia á 18 de Mayo de 1858, el Ingenicro jefe, Manuel Fernandez Monjardin.

Determina los deberes de los auxiliares, agrimensores, guardas mayores, sobreguardas y guardas, así como las faltas que pueden cometerse y las correcciones aplicables al caso. Los modelos se refieren al libro Diario, Libro registro de concesiones, Parte quincenal o semanal de operaciones, y Cuaderno de denuncias.

No se registra este Reglamento en el Diccionario de bibliografia agronómica, del Sr. Anton Ramirez.

454. Reglamento general, y demás disposiciones para la conservacion de montes y plantíos de la provincia de Alara.-Vituria, 1845, por la viuda de Manteli é hijos.-4. ${ }^{\circ}, 42$ págs. 
Es una recopilacion de las Reales provisiones circulares de la Diputacion general, y de otras providencias sobre dicho asunto, hasta el Reglamento que, para los celadores, inspectores de montes, fué aprobado por la Junta general de la provincia el 7 de Mayo de 1845.

455. REGLAMENTO ORGÁNICO para el buen gobierno y aprorechamiento de los bosques Reales; aprobado por S. M. en Real decreto autógrafo de 19 de Enero de 1817. Precédele una exposicion del Excelentísimo Sr. D. Pedro de Egaĩa, intendente general de la Real Casa y Patrimonio.-Madrid, 18t7: Imprenta Nacional.-Fólio, 9 páginas.

Contiene 45 articulos, agrupados en esios cuatro títulos:-Bases generales.-Apeo.-Plan de aprovechamiento.-Conservacion.

"En la comunicacion que precede al Reglamento, se menciona honrosamente, al inspector de bosques Reales, D. Agustin Pascual, dice el Sr. Ramirez, á cuyo distinguido agrónomo atribuimos, añade, una inteligente cooperacion en el trabajo."

En la exposicion se dice que así como en los antiguos tiempos no se consideraban los montes sino como un medio para obtener el fin de la caza, ahora tienen toda la importancia que les dan los progresos de la ciencia forestal.

456. Reglamentò orgánico para la Escuela especial de Ingenieros de montes, creada por Real decreto de 18 de Noviembre de 1816.-Sin pié de imprenta.

Es edicion oficial, que consta de 14 páginas en fólio, sin numerar. Está expedido el reglamento en Madrid á 17 de Agosto de 1847, por el Ministro de la Gobernacion del reino, D. Antonio Benavides. Consta de cuatro títulos que iratan de la organizacion de la Escuela, de la junta consultiva, del director, del vicedirector, de los profesores, de los vigilantes, de los alumnos, del conserge y mayordomo, de la enseñanza, de las asignaturas y sus profesores, de la bibliotaca y colecciones del establecimie.ıto, de la administracion y contabilidad, y de los ingenieros de montes y plantíos. Sigue la Instruccion para los pretendientes de plazas de alumnos inlernos y externos en la Escuela de Ingenieros de montes aprobada por Real órden de 11 de Setiembre de 1847, autorizada por el director, el Excmo. é llmo, Sr. D. Bernardo de la Torre Rojas, y concluye con los formularios de solicitud de ingresu y escritura de obligacion para el abono de las pensiones que deben satisfacer los alumnos.

En el Diccionario de bibliografia agronómica del Sr. Anton Ramirez, no se habla de este Reglamento. Hay olra edicion de 9 páginas en fólio que no conliene más que el Reglamento, careciendo de la Instruccion para los pretendientes, etc,

45\%. Reglayento para el personal subalterno del distrito de Guadalajara. Aprobado por el Sr. Gobernador civil en 15 de Marzo de 1866. 
Sin pié de imprenta, ni año de edicion.-4. ${ }^{\circ}, 8$ págs. y dos modelos de documentacion oficial.

Lo autoriza en Guadalajara á 10 de Marzo de 1866, el Ingeniero jefe del distrito forestal, D. Roque Leon del Rivero. Determina los deberes de los auxiliares, guardas mayores, cabos de guardas ó de peloton, y guardas locales, así como las penas en que pueden incurrir por determinadas faltas. El modelo $1.0^{\circ}$, es del libro Diario; el $2 .^{\circ}$, de estados de Concesiones de aprnvechamientos, y el $3 .^{\circ}$ y $4 .^{\circ}$, de Partes quincenales de deauncias y loda clase de novedades.

458. Reglamento para el servicio de la direccion general del Real Patrimonio y tesorería de la Real Casa, é Instruccion provisional para la administracion y conservacion de las Reales Posesiones. Madrid: Imprenta de Quirós, 1871.-4. ${ }^{\circ}, 63$ págs.

En el capítulo VIl, págs. 25 y 26, trata de la Inspeccion de bosques y arbolados, artículos $79,80,81$ y 82 , en los que se determina el número, clase, atribuciones y deberes generales de los indivíduos dedicados al servicio indicado.

459. Ruglamento para el servicio de la Real montería, ballestería y armería.-Madrid: Imprenta de Quirós, 1871.-4. , 24 páginas.

Fechado en Palacio á 2 de Octubre de 18\%1, y autorizado por el primer montero y ballestero, Baron de Benifayó.

Tratan los capítulos IV, V, VI y VII, págs. 10 á 2I, artículos 32 á 87 inclusives, de los deberes yobligaciones que corresponden al inspector general de caza y guardas, y á los sobreguardas generales, cazadores de S. M., celadores, mozo encargado de los perros, y guardas.

460. Reglamento para la Escuela especial de Ingenieros de montes. Aprobado por decreto de S. A. el Regente del Reino en 24 de Octubre de 1870.-Madrid: Imprenta del Colegio nacional de Sordo-mudos y de Ciegos, 1870.-4. ․, 36 págrs.

Se divide en seis títulos que tratan del objeto de la escuela y de la enseñanza; del personal y material; de la junta de profesores; de las obligaciones, atribuciones y'derechos del personal de la Escuela; del director; de los pro fesores; de los ayudantes; del secretario y empleados de la secretaría; del bibliotecario y empleados de la biblioteca; del contador deposiiario; del jefe del campo forestal; del recolector, preparador y conservador de objelos de historia natural; del conserge, sobrestante del campo forestal, porteros y mozos; de la enseñanza libre; de la admision de alumnos internos; de las obligaciones de los mismos; del régimen de la enseñanza y de los derechos de los alumnos internos; y disposiciones generales y transitorias. Es disposicion vigente.

461. Reglanento para la Escuela especial de Ingenieros de montes:-Sin pié de imprenta, año de edicion, sin numeracion. $-4 .{ }^{\circ}$, 26 págs. 
Aprobado por Real decreto de 18 de Mayo de 1862, cuyo contenido se inserta. El Reglamento se divide en títulos y capítulos, abrazando los puntos siguientes: Del objelo de la Escuela y de la enseñanza que ha de darse en ella; duracion y método de los estudios; asignaturas; gobierno de la Escuela; organizacion; director, profesores; ayudantes; junta de profesores; secretario; deposiario; dependientes; aluinnos; admision y obligaciones de los mismos; derechos; correcciones; castigos; exámenes, oyentes, y disposiciones transitorias.

462. Reglamento para la organizacion, servicio y disciplina del personal subalterno de montes.-Madrid, 1869.-Imprenta de La Monarquia democrática. $-4 .^{\circ}$ menor, 25 págs.

Expedido por el ministro de Fomento en 28 de Agosto de 1869. Determina las condiciones de nombramiento y los deberes del personal subalterno del ramo, en lo relativo á disciplina, aprovechamientos, deslindes, policía, guardería, etc. Está dividido en cuatro capítulos, el $1 .^{\circ}$ trata de las Disposiciones comunes á todos los emp.leados; el $2 .^{\circ}$, De los ayudantes; el $3 .^{\circ}$ De los sobreguardas; y el $4 .^{\circ}$ De los guardas.

Es disposicion vigente.

463. Reglamento para los guardas municipales y particulares del campo. Aprobado por S. M. la Reina (q. D. g.), en 8 de Noviembre de 1849.-Madrid, 1853, por S. Compagni.-4. ${ }^{\circ}, 20$ págs.

Hay otra edicion de 1849. Se dictó por el ministerio de Fomento, de acuerdo con el de Gobernacion. Consta de 46 artículos, reunidos en seis títulos, que son: De la propuesta, nombramiento, distintivo y armas de los guardas municipales. - De sus obligaciones. - De los guardas particulares del campo no jurados - De los guardas particulares del campo jurados. - De las peras en que incurren los guardas municipales y los particulares jurados. $-D e$ las hojas de servicio de los mismos.

464. REglas que deberán tener presentes los guardas mayores. sobreguardas y guardas locales, para llenar el servicio que les está encomendado. - Imprenía de Alba.—-8. 7 págs.

No tiene portada. Autoriza dichas Reglas, en Segovia á 31 de Mayo de 1864, el ingeniero jefe D. Roque Leon del Rivero.

Se entiende que se trata del personal de guardería dependiente del distrito forestal de aquella provincia. Se previene en 17 artículos, el modo y forma de proceder, respecto á la custodia de los montes públicos, denuncias, vigilancia, libro diario de operaciones, conducta, disciplina, etc.

465. Reixo. (EL)-Periódico pulítico de Madrid. - Véase: Desamortizacion forestal. Juicio critico... etc. - LA EPOCA, sale en defensa... etc. $-A l$ hacer la reseña... etc. - Al presentar el señor marqués de la Vega de Armijo el proycclo de ley de montes... etc.La sesion que turo lugar en el Congreso... etc.-Solo el cumplimiento de la palabra... etc.-En los últimos dias... etc.-Despues de desechada la enmienda... etc. 
466. RELACion General de los premios propuestos por el Jurado de la Exposicion de agricultura de $185 \%$ - Aprobada por Real decreto de 3 de Marzo de 1858.-Escudo de armas de España.-Madrid: Imprenta Nacional, 1858.-F́́lio, 48 págs.

Figuran entre otros, los premios concedidos al Cuerpo de ingenieros de montes y á la escuela del raino, por planos y croquis forestales, coleccion de herramientas del pais y del extranjero, maderas, resinas, breas, aguarrás, cortezas, carbones, ciscos y cenizas.

Esta Relacion no está registrada en el Diccionario de bibliografía agronómica del Sr. Anton Ramirez.

46\%. Representacion de los reinos de Castilla, Leon y Aragon, para la enagrenacion de los baldíos y realengos, y respuesta fiscal á este asunto.-1739.-(Anónimo.)

El Sr. Colmeiro (D. Mánuel) que cita esta publicacion en su Biblioteca de los economistas españoles de los siglos $X V I, X V I I$ y $X V I I I$, dice, á propósito de ella, que su doctrina está ajustada á los principios de la ciencia económica.

No se menciona en el Diccionario de bibliografía agronómica del Sr. Anton Ramirez.

468. República ibírica. (LA)-Periódico de Madrid.-Véase: Escándalo en Huesca.

469. Reseña geOGRÁfico-estadística de españa, por el Excelentísimo señor D. Fermin Caballero.-Segunda edicion.-Madrid: Imprenta y Estereotipia de M. Rivadeneyra, 1868.-4..$^{\circ}$ menor, 126 páginas.

Ocúpase sucintamente de la superficie, productos y propiedad de los montes, en las págs. 69 y 70 .

470. RESEÑAS geográfica, g’eológica y agrícola de España, l’edactadas por D. Francisco Coello, D. Francisco de Luxán y D. Agustin Pascual, y publicadas por la Comision de Estadística greneral del reino en el Anuario correspondiente á 1858. - Escudo de armas de España.-Madrid: Imprenta Nacional, 1859.-4. ${ }^{\circ}$ mayor, 176 páginas.

La Reseña agricola, escrita por D. Agustin Pascual, comprende desde la pág. 93 á la 161. Se describen aunadamente los caractéres agrícolas y forestales, con bastante extension, y presenta los hechos siguientes: Posicion geográfica de las principales capitales; Resimen de las observaciones meteorologicas hechas en el Observatorio de Madrid y en los de las provincias, desde 1838 en el primero y el año 1858 en los demás; Zonas de temperatura; Clasificacion hidrometeórica; Zonas de vegetacion y regiones en que estas se subdividen, determinadas por los caractéres de la vegetacion, altitud, temperatura y fructificacion de los cereales y la vid. Concluye con un Bosquejo dc bibliografia 
agricola, desde la pág. 162 á la 169, que enumera 707 publicaciones, de las cuales la edicion más antigua data del año 1499 y la más moderna llega al de 1859 .

471. Resúnen de las tareas de la Academia cordubesa.-Véase: Noticia de la Academia de ciencias, bellas letras y nobles artes de la ciudad de Cordoba.

472. Revista científica del Ministerio de Fomento.-Véase: Boletin oficial del Ministerio de Comercio, Instruccion y Obras picblicas.

473. Revista DE Administracion, (antes de Gobernacion).-Periódico semanal. - Tres tomos en $4 .^{\circ}$, el primero con el título de Revista de Gobernacion.-Madrid, 1871-1873: Imprenta de M. Minuesa.

El tomo IiI de la Revista de Administracion, IV de la coleccion está publicándose.

En el lugar que les corresponde dejamos registrados los siguientes artículos: Disfrute y aprovechamiento de los montes municipales. -Guarderia rural. Memoria y proyecio para establecer, etc.-Administracion püblica (La) en sus relaciones con la propiedad particular.-Montes.

474. Revista de agricultura práctica, economía rural, horticultura y jardinería. Publicada por el Instituto agrícola catalan de San Isidro. Bajo la direccion del sócio D. Isidoro de Angulo.-Barcelona, 1853-1873. - Imprenta de D. Antonio Brusi y en la del Diario de Barcelona á cargo de Francisco Gabañach, desde el tomo VII.Veintiun tomos en $4 .^{\circ}$ á dos columnas de 300 á 400 págss., excepto el $\mathrm{V}$ que contiene la mitad por corresponder á un'solo semestre.

Dejó de estar la direccion á cargo del Sr. Angulo á la publicacion del tomo IV, con motivo de su fallecimiento. En 1865, cambió el título por el de Revista de agricultura del instituto agrícola catalan de San Isidro, y desde 1869 se denominó Revista del instituto agricola catalan de San Isidro, con cuyo título continua publicándose.

Damos cuenta en el lugar correspondiente de los siguientes artículos: Cultivo é ingerto del Alcornoque.-Palologia vegetal.-Selvicultura.-Arboricullura. - Sucinta descripcion de los árboles más propios, etc.-Máquina para la trasplantacion de los árboles.-Estraccion del corcho en panas. - A rbolado de Barcelona.-Ingertos. - Noticias botánico-agricolas solre los pinos de Cataluña.-Utilidad de los árboles,-Libre entrada $(\mathrm{La})$ de los corchos, etc.-Rejoblacion del arbolado en el A mpurdan.- - ZHay solaridad entre los campos $y$ los montes etc.?-iEs posible ó convenienie la reunion de todos 0 parte de los establecimientos, etc.?-A vellano $(E l)$. - Apunles sobre el modo de conservar los Iosques. - Eucalyptus globulus.-Bosques (Los).-De las causas que pueden "Troducir las enfermedades en los cultivos arbóreos. - La riqueza forestal, etc. nforme sobre la galeruca, etc. - Selvicultura. Metodos de beneficio.-Confe- 
rencias agricolas, etc.-Proyecto de ley de montes. - Exposicion elevada por el Instituto, etc.

475. Revista DE Caminos vecinales, canales de riegroy construcciones civiles.-Véase: Causas que producen la postracion de la agricultura.

476. Revista DE ESPAÑA.-Madrid, 1868-1873: Imprenta de José Noguera.-XXXI tomos en $4 .^{\circ}$ de 600 págs. próximamente.

Esta Revista continua publicándose. Damos cuenta en el lugar corres pondiente, de los articulos que siguen: Desoinculacion $(L a)$ y la desamortizacion de la propiedad civil en Inglaterra y Francia.-Economia rural.

477. Revista DE Gal.icia.-Santiago, por Rey Romero, 1850.

Se publicaron tan solo algunas entregas de este periódico. Lo menciona el Sr. Colmeiro en La Botánica y los Botánicos con el número 929, y dice: "Contiene artículos de agricultura y arboricultura (árboles resinosos), no destituidos de interés, y debidos á José Naría Gil, cuya temprana muerte privó á Galicia de un apasionado al estudio de su Flora."

478. Revista de Instruccion pública.-Véase: Sobre los trasplantos.

479. Revista de Los PRogresos de las ciencias exactas, físicas y naturales.-Madrid, 1850-1867.-Diez y siete tomos en $4 .^{\circ}$

Registramos en el lugar correspondiente los artículos denominados Arboles; de su cultivo, etc.-Anatomia vegctal; Estracto de una Memoria sobre la corteza de los dicoliledones, y especialmente sobre el suber.-Estudios acerca de la especie, con motivo de una revision de la familia de las cupuliferas. Naturalizacion del alerce africano, llamado A rar en Marruecos.-Catálogo de las aves observadas en Andalucia.-Cabálogo metódico de las aves observadas en las Islas Balearés.

480. Revista DE obras públicas.-Véase: Arbolado en las carreteras (Del).-Inundaciones.

481. Revista ECoNóMiCA.-Periódico agrícola, artístico y comercial de la Sociedad de amigos del país de Santiago.-Santiago: Imprenta de Manuel Mirás: 1859 y 1864.-Cinco tomos en fólio de 550 págs. próximamente.

Damos cuenta en el lugar correspondiente de los siguientes artículos: Agricultura práctica del castaño.-Legislacion de montes.-Arbolado. Recientes medidas dictadas, etc.-Fomento del arbolado.-Desamortizacion de los montes del Estado.-Gas de leña.-Ferrerias. - Industria fabril de las tenerias.-Agricultura forestal.-Plantas forestales. - Sobre las ventajas del ar. bolado.

482. Revista económica.-Semanario agrícola, comercial é industrial, publicado en union con el periódico político La Epoca.Madrid: 1872-1873.-Imprenta de La Epoca.-Fólio. 
Continúa la publicacion. Véanse en el segundo grupo los artículos siguientes: Ley de montes. -Fomento del arbolado.-Proyeclo de presupuesios.

483. Révista Forestal, ECoNómica y agrícola.-Redactada bajo la direccion de D. Francisco García Martino, Ingeniero de montes. Van publicados 5 tomos en $4 .^{\circ}-\mathrm{I}$. Madrid, 1868: imprenta de La América, á cargo de José C. Conde: 740 págs., y tres láminas en negro.-II. Madrid, 1869: imprenta y librería unicersal de los señores Crespo, Martin y Compañía: 768 págs. - III. Madrid: Imprenta de la Sociedad española de crédito comercial, 18\%0: $5 \% 2$ páginas.-IV. Madrid: Establecimientos tipugráficos de Manuel Minuesa, 1871: 702 págs.-V.'Madrid: Establecimientos tipográficos de M. Minuesa, 1872: 624 págs.-VI (en publicacion). Madrid: Imprenta de El Debate, á cargo de J. M. Luengro, 1873.

Esta Revista, sostenida en su mayor parte por Ingenieros del Cuerpo de montes, se publica mensualmente en cuadernos de 61 págs., que forman un tomo al fin de cada año. Son redactores de la misma los señores D. Andrés Anton Villacampa (a), D. Pablo Gonzalez de la Peña y D. Francisco de Paula Arrillaga, secretario de la redaccion.

(a) Siete meses habian trascurrido tan sólo desde que comenzó la publicacion de estos pobres A puntes, cuando este distinguido Ingeniero, jefe de primera clase del Cuerpo, entregó su alma al Criador en Madrid, víctima de una afeccion pulmonar contraida en el penoso ejercicio de su profesion, al que se entregaba con un ardor y un celo extraordinarios. Cinco años de continucs padecimicntos, no fueron bastantes á moderar el febril entusiasmo con que se dedicaba slempre á los estudios y trabajos forestales. Quince dias antes de su muerte, acaecida el 2 de Enero de 1874, se ocupaba aún en la preparacion de una série de articulos sobre operaciones prácticas en los montes, que déstinaba á la Revista forestal, publicacion de la que fué fundador y á la cual enalteció tanto con sus escritos.

Villacampa, modeslo hasta el excesn, como sucede á todos los hombres de mérito, dio á la imprenta muchos trabajos bajo el velo del anónimo ó del pseudónimo.

Además de los que en este libro aparecen con su firma, se le deben los titulados: Correspondencia, Remitido, Desamortizacion civil $(L a)$ en sus relaciones con los monbes, Un proyecto de ley de montes, Venta de los montes del Estado, Dunas (Las) de la ciudad de San Sebastian, Excursion forestal al nacimiento del Ason, y monie 1 risasi $(\boldsymbol{E} l)$, todos publicados en la Revista forestal, economica y agricola y extractados en el lugar respectivo.

En 1862 tomó una parte muy activa en la discusion que sostuvo la prensa de Madri acerca del Real decreto de 22 de Enero de aquel año relatıvo á la dessmortizacios de los montes públicos. Con este motivo escribió Villacampa, sin firmarios, varios articulos en El Reino y La España, que llamaron mucho la atencion de las personas entendidas en la materia.

Celoso siempre de la suerte futura de los montes, y asaz competente en materias de legislacion forestal, terció tambien en las discusiones que los periódicos de Madrid, principalnuente, entablaron con motivo deI proyecto de ley de montes que en 1872 presentó á las Córtes el Ministro de Fomèn to D. Jusé Echegaray. Encerrado en su casa hacia ya tiempo y en los umbrales de la muerte, que tan poco tardó en arrebatarlo, nadie pudo imaginar que fuesen de Villacampa los artículos que sobre aquella contienda vieron la luz en $\boldsymbol{L} a \boldsymbol{T r}$ ibuna y $\boldsymbol{L} a$ Prensa, ni mucho ménos el graciosisimo y atildado romance que sobre el mismo asunto, y atribuido por su belleza literaria á uno de nuestros mejores poe tas, compuso y fstampó en $\boldsymbol{L} \boldsymbol{a}$ Independencia kspañula con el titulo de Carla de Cachano Tejas á su primo Lúcas Gomez, cediendo con esto al decidido gusto que tenia por la poe- 
Fn el lugar correspond ente hemos extractado la mayor parte de los articulos que contiene, circunscribiéndonos á los de verdadero interés forestal. Son los siguientes: Abetos y pinsapos.-Arboricultura. Ideas generales.Alcornoque (El).-Avellano (El).-Haya $(E l)$.-Olmo $(E l)$. - Palmito $(E l)$. Regaliz ( $E$ Z ).-Acacia blanca (La).-Encina (La). -Robles (Los).-Pino silvestre.-Bibliografia.-Breves indicaciones sobre el pino negro de la provincia de Lérida. CConceptos equivocados del señor D. Pedro Perez de la Sala, profesor de la escuela especial de ingenieros de caminos, canales y puertos en materia de montes $i$ inundaciones. - Conservacion de las simientes y preparacion de las mismas para la siembra.-Consideraciones económicas sobre la propiedad forestal. - Consideraciones generales sobre la historia y la literatura de la ciencia forestal en Alemania.-Correspondencia.-Cortabilidad.-Costumbres cubanas. - Cultivo de arenas voladoras por medio de navazos.- ¿Deben venderse los montes del Estado? - Influencia (De la) que los humos de las fábricas de fundicion de sulfuro de plomo, ejercen en la vegetacion.-Proteccion de las riquezas naturales (De la)._Argan (Del).-Conocimiento (Del) y castigo de los delitos y contravenciones de las ordenanzas vigentes en maleria de montes publicos. - Pretendido monopolio (Del) de los ingenieros de montes.Demostracion analitica de una importante ley foresial. - Desamortizacion forestal. - A gua atmosférica (El) y su influencia en la agricultura.-Alcornoque de Occidente $(E l)$.-Humus $(E l)$.-Individuo vegetal $(E l)$ y su duracion.Monte Irisasi (El).-Pinsapar de Ponda (El)._Progreso forestal de los Rusos $(E l)$.-Ensayo critico sobre algunos articulos persales de las ordenanzas generales de montes de 22 de Diciembre de 1833.-Excursion forestal al nacimiento del A son.-Estádística foresial, España, Francia, Prusia.-Estado del servicio püblico forestal. - Bstudios forestales sobre el reino de Prusia.Exposicion agricola celebrada en Barcelona en 1872.-Forma de los árboles que viven en espesura y nuevo método de cubicacion.-Formacion de las resinas en los vegetales. - Fórmula para la interpolacion de términos en la série del crecimiento leñoso.-Infuencia de ta luz en la vegetacion.-Agricultura (La)

sia que cuitivó con fruto, si bien limitando la publicidad al reducidó circulo de sus amigos.

Colaboró Villacampa aportando á ellos los mejores materiales, en los libros de los inspectores del Cuerpo de montes Excmo. Sr. D. Miguel Bosch é Ilmo. Sr. D. Francisco García Martino, titulados Memoria sobre la inundacion del Jucar de 1864, del primero, y Los montes yel Cuerpo de ingenieros en las Córtes Constituyentes, del segundo.

En el profesorado, en los distritos forestales, en la Junta consultiva del Cuerpo, en la de Estadistica y en las diversas comisiones que ha desempeñado, ha dejado muchos y ricos trabajos, informes y memorias que atestiguan su extraordinaria laboriosidad y sus vastos conocimientus.

No sabemos si cuando la imprenta se encargue de dar publicidad á estas líneas, habrá cuidado el Cuerpo de Ingenieros de montes de dar á luz la biografia de este aventajado compañero, victima de su celo por el servicio de los montes en los mejores años de su vida.

Su mérito le hacia muy acreedor á esta distincion.

De todos modos, sirvan estos renglones como testimonio del gran cariũo que le profesaba el humilde autor de estos Apuntes, el cual perdió con Vlllacampa ipérdida irreparable! el mejor compañero de sus campañas forestales, su mejor maestro en cuestiones cleutificas, y su mojor amigo en la sociedad. Dios habrá premiado ya sus sacrificios y virtudes. 
y los montes. - Desamortizacion civil (La) en sus relaciones con los montes.Provision de los empleos $(\mathrm{La})$. - Reforma de las escuelas especiales de ingenieros.-Dunas de la ciudad de San Sebastian (Las), su repoblacion y cultioo.Nubes de la ciencia. (Las)-Ingenieros (Los).-Montes de los Estados-Unidos (Los).-Montes (Los) y la administracion forestal en el parlamento de la Alemania del Norte.-Montes (Los) y las minas.-Noticia sobre los incendios de los pinares de la ciudad y tierra de Soria.-Nuevo sistema de fabricacion de duelas y coronas para barriles. -Obseroaciones sobre la administracion fores tal de España.-Obsercaciones sobre la discusion de la ley municipal en las Córtes Constituyentes, con relacion á los montes.-Observaciones sobre las tem. peraturas minimas que pueden soportar los vegetales.-Parte forestal de la última exposicion de Paris. - Pasta de madera.-Patología vegetal: El mohoblanco de las plantas.-Pinos.-Producoion de cortezas curtientes en España.Rápida ojeada sobre el estado de los monles de Canarias, Puerto-Rico, Cuba y Filipinas.-Remitido.-Repoblacion de las montañas.-Siembras y plantaciones por E. Burkhardt.-Sistemas forestales.-Sobre el vocablo: Forestal.Sobre la rentabilidad del mélodo de beneficio de monte alto.-Sobre las cartas, sobre los montes. - Trasportes, fuviales. - Un incidente sobre desamorlizacion forestal en las Córtes Constituyentes.-Un pedazo de Sierra-Morena.-Un problema de la ciencia de montes.-Un proyecto de ley de montes. - Venta de los montes del Estado.

481. Revista GeNeral DE EstadístiCa.-Madrid, 1862-1865.Cuatro tomos en $4 .^{\circ}$ de $608,740,764$ y 764 págs.

Damos cuenta en el lugar correspondiente de los articulos siguientes: Datos forestales.-Consideraciones económicas sobre la propiedad forestal.

485. Revista senanal (y mensual) de Agricultura, periódico de intereses materiales.-Madrid, 1850-185̃3.-Seis tomos en $4 .^{\circ}$

Contiene los articulos titulados: Arboles, su estructura, etc.; Plantios, forma que se les debe dar, etc.; Montes; informe sobre los wiedios de proveer á la conservacion, etc.; y Montes; noticia sobre el eslado de la agricultura, etc., de que damos cuenta en el lugar correspondiente.

486. Revolucion ininanciera de España.-Teoría del impuesto. Formas suyas; bases de imposicion. Sistemas que han tratado de explicarlo. Aplicacion de la teoría á la práctica. Exámen de los presupuestos de Francia, Bélgica, Inglaterra, Suiza, Estados-Unidos, Prusia, etc. Presupuestos españoles. Reformas radicales. Economías verdaderas. Los principios de la revolucion de Setiembre se armonizan con las buenas ideas financieras. Supresiones de Ministerios y oficinas. Presupuesto revolucionario. Por el doctor M. de Miranda y Eguia.-Madrid: Imprenta y librería de Pardo y Juste, 1869.4. ${ }^{\circ}$ menor, vir.-260 págs. y 6 de indice.

Al tratar del presupuesto del ministorio de Fomento, el autor hace algun estudio acerca de la produccion de los montes públicos, de sus condiciones para la enagenacion y de los razonamientos aducidos por la escuela indivi - 
dualista de un lado, y de otro por la que defiende la necesidad de que el Estado posea el monte alto, concluyendo, despues de condensar con alguna inexactitud los argumentos en que la última se apoya y admitir como ciertos hechos absurdos asentados por la individualista, que los montes de los pueblos deben entregarse á la libre disposicion de los Municipios y al interés particular los del Estado.

487. Rosa Agrícola (LA).-Coleccion de tratados sobre alimentacion y produccion, por D. Lorenzo de Merlo y Merlo, labrador y abogado.-Madrid: Imprenta de José Noguera, 1868.-4. ${ }^{\circ}$ menor, 88 págss.

Ocúpase ligeramente como sustancias alimenticias para el ganado y dando algunas noticias descriptivas del regaliz, roijo (así llaman los ganaderos, segun dice el autor, á todos los arbustos que come el ganado), palmilla y árboles.

488. S. IsIdori Hispalensis, episcopi, hispaniarum, doctoris opera omnia de novo correcta et aucta recensente Faustino drévalo qui Isidoriana pramisit variorum prafationes, notas, collationes, qua editas qua nunc primum editiones et codices. SS. romanos conlulit. Auctoritate et impensa Eminentiss. Principis D. Domini Fracisci Lorenzana, S. R. E. Presbyteri Cardinalis, Tit. SS. XII Apostolorum.-Romœ, 181)1, Apud Antonium Fulgonium.-Siete tomos en fólio.

Las Etimologias del mismo autor se hallan comprendidas en el tomo IV de la expresada cdicion. El capítulo VI trata de los árboles, etimología de su nombre, principales clases en que se dividen, ideas de su organizacion y del ingerto. En el VII, de los nombres propios de los árboles, etimología de las palmas, laurel, granado y de otros muchos; y en el VliI, de los árboles aromáticos, comenzando por la etimología de la palabra aroma, y hablando despues del árbol del ińcienso, del de la mirra, estoraque, resina, pimienta, áloe, cinamomo, canela, caña aromática y bálsamo.

489. Santiago y á ellos.-Periódico de Santander.

Ha publicado varios artículos de interés forestal y entre ellos algunos contra el proyecto de ley de montes que en 1872 presentó á las Córtes el ministro de Fomento D. José Echegaray.

490. Secjion de Fomento de la provincia de Madrid.-MemoRIA REFERENTE Á LOS ASUNTOS EN QUE SE HA OCUPADO DURANTE EL AÑo 1861.-Escudo de armas de España.-Madrid: Imprenta Nacional.-1862.-4. $.^{\circ}, 113$ págs. y 31 estados.

Dirigida al Excmo. Sr. Duque de Sexto, Gobernador de la provincia de Madrid, por el jefe de la seccion, D. J. Nicolás de Salas, que lo firma en la inảicada villa á 15 de Enero de 1862. 
De los asuntos de montes dá cuenta desde la pág. 22 á la 33 ambas inclusives, mencionando el número de expedientes tramitados, la superficie de las fincas desamortizadas, las de las que podrian enagenarse en lo sucesivo, el importe de los daños causados por los incendios en los montes públicos, y el número de individuos de que consta el personal subalierno con indicacion de los sueldos que disfrutan. Dá á conocer las ventajas que reporta la administracion forestal del plan provisional de aprovechamientos puesto en práctica en el distrito, y despues de examicar las condiciones y móviles á que obedecen los autores de los daños que más trecuentemente tienen lugar en la propiedad forestal, expone extensamente un plan de una nueva organizacion de la guardería bajo la base de depender de las provincias ó del Estado y estar mandada por jefes militares.

491. Seccion de Fomento de La provincia de Madrid. -MemoRIA REFERENTE Á LOS ASUNTOS EN QUE SE HA OCUPADo HaSta FIN DE Diciembìne De 1860.-Escudo de armas de España. - Madrid, Imprenta Nacioral.-1861.-4. ${ }^{\circ}, 66$ págs. y un estado.

Dirigida al Excmo. Sr. Marqués de la Vega de Armijo, Gobernador de la provincia.

Dá cuenta de los asuntos de montes, desde la pág. 19 hasta la 31 inclusives, enumerando los productos forestales, primarios y secundarios, mejoras introducidas en los aprovechamientos, trabajos de deslindes y repoblacion, daños de toda clase, correcciones, produccion, condiciones del personal subalterno, con un informe bastante extenso sobre el modo de organizar un cuerpo de guardería planteado por vía de ensayo en la provincia de Madrid, a cerca del cual entra en pormenores de toda clase.

492. Seccion de Fomento de la provincta de Toledo.-MenoRIA REFERENTE Á LOS ASUNTOS EN QUE SE HA OCUPADO DURANTE EL AÑo DE 1861.-Toledo: 1862.-Imprenta de José de Cea.-4. ${ }^{\circ}, 43$ páginas y 11 estados.

Autorizada en Toledo á $1 .^{\circ}$ de Mayo de 1862 por el jefe de la Seccion doı: Manuel de Ojeda y Siles.

Se ocupa de los productos, aprovechamiento, daños, repoblaciones y personal del ramo de montes, indicando las mejoras que convendria introducir para fomentar el arbolado y procurar su más eficaz custodia.

493. Seccion de Fomento de la provincia de Toledo.-MEMORIA REFERENTE Á LOS ASUNTOS EN QUE SE HA OCUPADO DURANTE ILL AÑo DE 1862.-Toledo: 1863.-Imprenta de José de Cea.-4. ${ }^{\circ}, 43$ pá ginas y 5 estados.

Autorizada en Toledo á $1 .^{\circ}$ de Mayo de 1863 por el jefe de la Seccion don Manuel de Ojeda y Siles.

Expone los resultados de la aplicacion del Real decreto de 22 de Enero de 1862 sobre desamortizacion forestal, y se ocupa del personal subalterno del ramo, de los incendios, aprovechamientos, roturaciones, labores, $\mathrm{y}$ asuntos relativos á montes enagenables. 
494. Semanario de Agricultura.-Véase Montes. - dnarquía forestal.

495. Semanario de Agricultura y Artes, dirigido á los párrocos.-Madrid, 1797-1808, por Villalpando. - Veintitres tomos en $4 .^{\circ}$, de á 400 págs. próximamente y 25 láminas.

Registra entre otros muchos articulos de interés agrícola los forestales siguientes:

Aclimatacion y expatriacion de los vegetales; de la aclimatacion de varios árboles de la América septentrional en los bosques de Francia y en Aranjuez. Arboles frutales $y$ de sombra; del cultivo, poda, ingertos y precauciones que necesitan.-A rbustos. - Bosques con relacion á Inglaterra y Suecia._Castaños. de Indias y de los de España; insecto que más daño les causa._Encinas; sus utilidades y uso de los diferentes productos. -Ganados en general; daños que causan en las dehesas y plantios, necesidad de plantios, etc. -Jardineria; orientacion de los árboles, tiempo de trasplantarlos, cultivo y demás labores.-Montes; modo de conservarlos en Venecia y el de repoblarlos; sobre que no deben repoblarse con las mismas especies; formacion y aprovechamiento de los tallares en Guipúzcoa.-Pinos; de los de Escocia ó alerces; terrenos adecuados; su madera es perjudicial para los enseres en que se fabrican quesos; sus ramitas extinguen el tizon; modo de sacar la resina; quema de los pinares.-Plantios; silios en que se deben hacer; leyes protectoras que rigen en Sajonia, etc.

Se encuentran además los siguientes artículos: Carta sobre las orugas; Causas de la sequia y medios de precaverla, etc.; Especies y variedades de pinos que se crian en la Sierra de Cuenca; y Memoria histórica y descriptiva de las agallas, etc., que registramos en el lugar que les coresponde.

496. Semanario de Agricultura y artes.-Impreso y publicado por D. M. Calero y Portocarrero.-Lóndres, Sevilla y Madrid, 1829-1833. - Dos tomos en fólio; el primero de 508 págs. y xıv de índice, con algunos grabados, y el segundo de 420 págrs.

Pueden leerse en él los siguientes artículos: Aprovechamiento y sultico de los baldios.-Crecimiento de los árboles y arbustos. - Enfermedades más comunes de id. id. - Necesidad y utilidad de los árboles. - Semilleros de id.

Tambien contiene los titulados Bosques, montes y terrenos propios para ellos; y otro con el epígrafe de Lobos, que registramos en el iugar correspondiente.

497. Semanario econónlco, compuesto de noticias prácticas, curiosas y eruditas de todas ciencias, artes y oficios; traducidas y extractadas de las Memorias de las ciencias de París, de las de Trexoux y de muchos otros libros de fama franceses, ingleses, italianos, alemanes, etc., por D. Pedro Araus y D. Juan Bicen.-Madrid, 1765, 66, 67 y 1778, por Andrés Ramirez los tres primeros tomos, y por Pantaleon A\%nar el cuarto.-Cuatro tomos en $4 .^{\circ} ; 304$, 308, 468 y 296 págs. 
En el tomo Il pág. 341, trata de los daños que causan al ganado los botones ó renuevos de la encina; y en el tomo I, pág. 22, y IV. págs. 214, 246 y 253, de los medios de atraer los peces, conservarlos en los estanques durante el invierno, y cogerlos pór medios bastante raros.

El articulo sobre Arboricultura; varios modos de sembrar y plantar, etc., del III tomo, queda reseñado en el lugar correspondiente.

498. ShManario erudito que comprende varias obras inéditas, críticas, morales, instructivas, políticas, históricas, satíricas y jocosas, de nuestros mejores autores antiguos y modernos. Dálas á lu\% D. Antonio Valladares de Sotomayor.-Madrid, 1788-1791, por Blas Roman.-Treinta y cuatro tomos, $4 .^{\circ}$; 280 págs. próximamente cada uno.

Véase en el lugar correspondiente la Carta al Duque de Medina Sidonia, etcétera.

499. Semanario industrial. - Madrid, 1840-1841.-Dos tomos en $4 .^{\circ}$

Registramos en el lugar correspondiente los artículos que siguen: Destruccion de algunos animales dañinos; Arboles; su utilidad; ejemplo de proteccion, etc.; Resina del pino; modo de extraerla, etc.; Conservacion y coloracion de las maderas, etc.; Cocotero; de su origen, plantacion, etc., y Rompimiento de terrenos, etc.

500. Semanario pintoresco español. - Lectura de las fainilias.-Enciclopedia popular.-Madrid, 1836-1857, por Omaña, viuda de Jordan, F. Juarez, V. Lalama, B. Gonzalez, G. Alhambra, J. René y M. Gomez.-Veintidos tomos, á dos columuas, de 300 páginas el primero y variando los demás entre 412 y 424 págs., con profusion de grabados en el texto.

Se ocupa en el tomo II, pág. 76, del banano, de sus utilidades como frutal, para forrajes, tejidos, etc., en la India, Anlillas y Africa, y en la página 309, del árbol, del pan que existe en las islas Marianas, del fruto del mismo, que cocido es semejante al pan, y de la tentativa de su propagacion.

En el tomo VI, pág 369, describe el gran castaño del Etna, decano de los árboles de Europa.

El artículo Longevidad de los árboles, del tomo II, pág. 94, lo registramos en el lugar correspondiente.

501. Señor Director del periódico... etc.-Carta en fólio de 3 págs.

Suscrita en Castellon á 20 de Junio de 1869, por los Ingenieros del distrito forestal de dicha provincia, D. H. Ruiz Amado, D. Domingo Vidal y Soler, D. Manuel Gimenez y Lluesmas y D. Felipe Esteller y Forés. Está dirigida al diputado á Córtes D. Juan Andrés Bueno, con motivo de la proposicion presentada por este, sobre repartir á censo reservativo entre los indivíduos de la clase necesitada todos los bienes que de los pueblos existen sin enagenar. 
Se extienden los comunicantes en consideraciones técnicas y económicas para probar que esta medida produciria la inmediata desaparicion de todos los montes y la combaten en sentido de los perjuicios generales que sufriria con ella el clima y la agricultura patria.

502. Si CReyese que V. E...-Por D. Alfredo de Luis.-Hoja de 3 páginas en fólio, sin pié de imprenta.

El autor, que emplea evidentemente un pseudónimo, dirige su escrito en forma de carta, con fecha de Noviembre de 1872, al Excmo, Sr. D. José Echegaray, por entonces ininistro de Fomento y autor del proyectode ley de mones que presentó á las Cortes en 5 del indicado mes. Censurando este proyecto, rechaza la enagenacien de los montes de pino, roble y haya, que de su aplicacion como ley ha de segurse, la abolicion del"congoce comunal, el reparto de suertes y la localizacion absoluta de las cortas. Juzga haber probado, y con esto termina la crítica, que el mencionado proyecto representa un despojo, la negacion de los bienes físicos que los montes reporlan, la inconsiderada reduccion de la zona forestal necesaria, la muerte de pequeñas industrias, el fomento de la miseria, el ensanche rápido y funesto de la zon: de cultivo, la acumulacion de la propiedad, u'a descentralizacion absurda y el desconocimiento de la materia propia de la ley.

Esta carta es la tercera y última de las que escribió el autor sobre el asunto. Las dos precedentes quedan registradas bajo las indicaciones siguientes: Mi aficion al estudio.....-Algunos de los que han criticado.... Fueron copiadas en la Revista forestal, eeonómica y agricola, tomo VI, pági . nas 46 y 49.

503. Siglo (EL).-Periódico de Lérida.-Véase Roturaciones (Las) en la alta'montaña.

504. Silva venatoria. - Modo de cazar todo género de aves $y$ animales, su naturaleza, virtudes y noticias de los temporales. Su autor D. Agustin Calvo Pinto y Velarde, montero de á caballo de S. M. - Dedícase á la Excma. Sra. Doña María Francisca Theresa Alphonsa de Silva, Hurtado y Mendoza, Rios y '/apata, Haro, Guzman, Sandoval, Cerda, de la Vega y Luna, duquesa del Infantado.-Madrid, 1754, por los herederos de D. Agustin de Gordejuela. $-8^{\circ}, \operatorname{xxx} . \cdots 303$ pág’s.

Explica la caza de las ares, y la del ciervo ó venado, gamo, corzo, jabalí, lobo, tejon, oso, liebres y conejos.

505. Selvicultura ó tratado de plantíos y arbolados de bosque, por el teniente coronel D. José María Paniagua, catedrático de agricultura en la provincia de Logroño, é individuo de varias Sociedades económicas y literarias.-Logroño, 1841, por Domingo Ruiz. - 8. ${ }^{\circ}, 328$ págs. y vil de índice.

Deplora el lamentable estado de los montes de España y encarece la propagacion de los conocimientos facultativos, advirtiendo que en el extranjero 
se exigen tres años de estudios para ejercer el cargo de guarda, $\mathrm{J}$ "algunos más en Francia, dice, para ser guardas generales de bosques."

Dá algunas nociones de organografía y fisiologia vegetal, y describe los semilleros, las clases de terrenos, árboles que les convienen, plantaciones de montes y arbolados, cultivo y gobierno de los bosques, explotacion, productos, conservacion y defensa de los mismos.

506. Sistena de podas de arbolado, con notas, por D. Antonio Campuzano, ingeniero de montes. - Madrid: Imprenta de R. Anoz, 1864. -4. $.^{\circ}, 11$ págs. con una lámina.

Tratado sucinto que se ocupa de los sistemas de podas, origen, conveniencias, y condiciones de dicha operacion. describiéndose además los instrumentos necesarios para ejecutarla.

Hay otra edicion de 1871, exenta de muchas crratas de imprenta que tiene la primera.

50\%. Sobre el Real decreto de dar licencias para romper DEHESAS Y Baldíos.-Por D. Francisco Amaya.-Granada, 1633.Zamorano.-Un tomo en fólio.

Citado de este modo en el Bosquejo de bibliografia agricola de D. Agustin Pascual. No se encuentra en el Diccionario de libliografia agronómica, del Sr. Anton Ramirez.

508. Suelo, Clina, Cultrio agrario y Forestal de la trovincia de Vizcaya.-Memoria premiada por la Real Academia de Ciencias en concurso público con arreglo al programa presentado por la misma para el año de 1856, por D. Lucas de Olazabal, ingeniero de montes, etc.-Madrid, imprenta, fundicion y librería de D. Eusebio Aguado, 1857.-Fólio, 114 págs., con un cuadro de las rocas de la provincia, y dos láminas en negro, una que representa la distribucion de gramíneas, leguminosas y crucíferas en las inmediaciones de Durango y Bermeo, y otra que representa la carta g'eológica de la provincia de Vizcaya.

Reseñada la geognosia, el clima y tierra vegetal y el cultivo agrario, dedica el autor al Arbolado la seccion II del capítulo IIl, describiendo el estado presente de los montes de Vizcaya, el sistema de aprovechamiento, las regiones dendrológicas, las necesidades que se manifiestan, los medios de fomentar dichos montes, la introduccion de especies arbóreas nuevas, y otros particulares.

Esta Memoria se insertó en el tomo IV de las Memorias de la Real Academia de Ciencias, $3 .^{a}$ série.-Ciencias naturales.-Tomo 11.-Parte 2. ${ }^{a}$, páginas 211 á 324, y se insertó tambien en las Gacetas de Enero de 185\%. E1 profesor de Historia natural del Instituto de Bilbao D. Fernando Mieg, la impugnó en unas Breves observaciones, contestadas con una Refutacion del Sr. Olazabal, y esta á su vez fue contradicha por el primero en un folleto que se titula Dos palabras más sobre la Memoria; Suelo, clima, etc. 


\section{$\mathbf{T}$}

509. TARIFAS aprobadas por S. M..en Real órden de 16 de Marzo de 1859 para el recibo y clasificacion en los arsenales de las maderas de roble aplicables á la construccion naval.-Madrid: Imprenta nacional, 1859.-Folio: 6 páginas sin numerar.

Suscritas en Madrid con la fecha indicada por el Ministro de Marina MacCrohon. Comprenden la madera recta y curva con sus dimensiones y flecha, y la de la clase de tablones de roble, álamo negro y haya, con análogas indicaciones.

Este folleto no se menciona en el Diccionario de bibliografia agronómica del Sr. Anton Ramirez.

510. TaRifas é instrucciones aprobadas por Real órden de 6 de Mayo de 1860, para el reconocimiento, recibo y clasificacion en los ar:enales de las perchas para arboladura, y demás madera de pino empleada en la construccion naval.-Madrid: Imprenta nacional, 1860.-Folio: 21 págiras sin numerar.

Autorizadas en Madrid con la fecha indicada por el Ministro de Marina Mac-Crohon. Determinan las tarifas las dimensiones míni nas que habrán de tener las perchas regulares para ser recibidas, su clisificacion, segun el empleo, los precios á que deberán pagarse los excesos de àiámetro major y rnenor en las perchas, perchas de pequeñas dimensiones $\mathrm{y}$ arbolillos, los precios en iguales ciases por excesos en la longitud, la tarifa para los baos de pino de superior calidad, y la general para las maderas de pino de igual clase. Las instrucciones constan de diez y nueve artículos, en los que se expresa el modo de proceder á los reconocimientos, los defectos de que deben estar exentas las maderas, y el modo de hacer las clasificaciones.

En el Diccionario de bibliografía agronómica del Sr. Anton Ramirez, no se hace mencion de estas Tarifas.

511. Tarifas í instrucciones aprobadas por S. M. en Real órden de 31 de Enero de 1865, para el recibo y clasificacion en los arsenales de las maderas de roble aplicables á la construccion naval. Madrid: litografía alemana de.G. Pfeiffer.-Folio: 15 páginas sin numerar.

Expedidas en Madrid á 31 de Enero de 1865 por el Ministro de Marina Armero. Están arregladas al sistema métrico, diferenciándose en esto de las de 1859. Distingue la tarifa $10^{a}$ las maderas rectas de las curvas, y contiene ocho advertencias respecto de las mismas. La tarifa $2 .^{a}$ está destinada á los tablones de roble, álamo negro, har a y otras maderas. Siguen las instruccio nes, que constan de quince artículos referentes al modo y forma de hacer el reconocimiento y cualidades que deben reunir las maderas frara ser admitidas ó desechadas.

512. TASACION DE LOS MONTES Y TERRENOS ANEJOS Á LAS MINAS 
Nactonales de Rio-Tinto.-Plano número 1.-Año 1871. Ejecutado en escala de $1 / 10000$.

No se ind́ca el dibujante ni el litógrafo que hizo la estampacion, pero consta que fué ejecutado con los demás de la coleccion en el establecimiento litográficn que tiene en Madrid el artista Sr. Cuaranta. Este plano, que tiene por objeto describir el término municipal de las minas, es simplemente geométrico, representándose en él el relieve del terreno por medio de curvas de nivel á la distancia de diez en diez metros.

513. TASACION DE LOS MONTES Y TERRENOS ANEJOS Á LAS MINAS nacionales de Rio-Tinto.-Plano núvero 2. - Año 1871. Ejecutado en la escala de $1 / 10000$.

No se indica el dibujante ni el litógrafo que hizo la estampacion, pero consta que fue ejecutado con los demás de la coleccion en el establecimiento litográfico que tiene en Madrid el artista Sr. Cuaranta. Este plano representa pur medio de tintas convencionales la distribucion de la vegetacion arborea y arbústiva, constituyendo un verdaủero plano de rodales.

514. TASACION DE LOS MoNTES Y TERRENOS ANEJOS Á LAS MINAS nacionales de Rio-Tinto.-Plaño número 3.-Año 1871. Ejecutado en escala de $1 / 10000$.

No se indica el dibujante ni el litógrafo que hizo la estampacion, pero consta que fué ejecutado con los demás de la coleccion en el establecimiento litográfico que tiene en Madrid el artista Sr. Cuaranta. Represeńta este plano la distribucion de la superficie total de los montes y terrenos anejos á las minas, distinguiendo la parte que puede enagenarse, de la que es necesario conservar unida al establecimiento para la produccion de las maderas y leñas que en él se consumen. La vegetacion está expresada por rodales, representándose las especies arhóreas, las leñosas y el erial con diferentes tintas.

515. Tasacion de los Montes y terrenos anejos (de las minas de Rio-Tinto) con su Memoria y Estado.

Este trabajo, que llevó á cabo el ingeniero jefe del Cuerpo de montes D. Luis Satorras, fechándolo en Madrid á 15 de Marzo de 1861, constituye el documento num. 4 de los que formaron el expediente general para la venta de aquellas minas, con arreglo á lo dispuesto en la ley de 25 de Junio de 1870. Todo él, encabezado con el anuncio para la enagenacion, se publicó en el Boletin general de ventas de Bienes nacionales. - Suplemento especial á la Gaceta, núm. 71 duplicado, del 11 de Mayo de 1871.-Imprenta nacional, fólio, 79 páginas.

Comprende el trabajo del Sr. Satorras la descripcion del término muni.cipal de las minas; la de la extension de la parte de los montes y terrenus del térnino municipal pertenecientes al Estado, necesario para la explotacion y beneficio de los minerales, su actual distribucion y la determinacion de sus existencias leñosas; y por últirno, la valoracion de la parte de los montes y terrenos pertenecientes al Estado, necesaria para aquellas opera- 
ciones. Van al final tres estados: el primero expresa las clases de productos leñosos que se consumen en la explotacion y benéficio de las minas; el segundo determina el consumo anual de productos leñosos en las operaciones indicadas, y el tercero dá á conocer la especie y cantidad de existencias leñosas que vegetan en los montes y terrenos anejos á las minas.

Acompañó el autor, para ilustrar más su trahajo, un plano del térmico municipal, otro de la extension necesaria para la explotacion y beneficio, y otro expresivo del estado del vuelo como base de la valoracion.

Como estos planos no corren unidos al expediente ni á la Memoria, á pe . sar de haberse estampado, damos cuenta de ellos en el lúgar que les corresponden con arreglo á sus enunciados.

516. Teoría (LA) y la práctiga de la Resinacion, por D. Ramon de Xérica, jefe de primera clase del Cuerpo de Ingenieros de montes.-Madrid: Imprenta del Universal, 1£69.-4. ${ }^{\circ}, 158$ páginas y tres láminas en negro que representan aparatos, herramientas, etc.

Estudia con todo detenimiento las gomo-resinas, bálsamos y resinas; los depósitos resiniferos de los pinos; las especies de pinos más á propósito para la produccion de resinas; los procedimientos de extraccion, examinando los puntos relativos á las claras, edad en que los pinos deben someterse á la resinacion; descortezamientos; entalladuras; recipientes; recoleccion de los productos; rendimientos; métodos de resinacion en los alerces y pinabetes; instrumentos para la resinacion; fabricacion; recepcion de la miera; trementina purificada; esencia de trementina; colofania; resina opaca ; pez negra; aceite pirogeuado; brea; aceile de brea; pez comun y negro de humo; concluyendo con varias consideraciones acerca de la extension de la industria resinera en España y con unos apuntes bibliográficos. Siguen despues dos detallados índices de materias y alfabético, y las lá minas.

Este trabajo se publicó antes en la Revista forestal, económica y agrico $l a$, tomo I.

517. Tertulia de Alicante (LA).-Diario progresista-democrático.-Véase Venta de montes.

518. Tesoro DE LA escopeta y demás pertrechos del cazador, ú arte de tirar á toda clase de caza, y guia práctica y segura pari obtener grandes resultados; añadido con la higiene y medicina del cazador, y las precauciones que debe observar para evitar las desgracias que suelen ocurrir con la escopeta. Obra recopilada por una sociedad de cazadores.-Madrid, 1858: Imprenta de D. Ramon Campuzano. $-8 .^{\circ}, 72$ páginas con grabados intercalados en el texto.

El título dá una idea bastante clara del contenido del libro, cuyas materias están tratadas en once capítulos.

519. Tesoro de LA monTería, ó arte de buscar, perseguir y matar la caza mayor. Reglas y curiosidades para el perfecto conocimiento de este ejercicio. Obra recopilada por una sociedad de ca\%i- 
dores.-Madrid, 1858, por R. Campuzano.-En 8. 132 páginas. con grabados en madera.

Divide la caza en mayor y menor, incluyendo en la primera la cabra montesa, el corzo, el ciervo, el venado, el jabalí, el labo y el oso, y en la segunda la liebre, conejo y otros animales pequeños. En la segunda parte trata de la persecucion y extincion de los animales dañinos, como los lobos, zorras, osos, comadrejas, patialbillos, gardunas, turones, tejones, gatos monteses, cervales y nútrias.

520. TESORO DE LOS PERROS DE CAZA, ó sea arte de conocer las razas de los perros, eleccion de los de caza, modo de criarlos, enseñarlos, adiestrarlos y curar sus enfermedades, con los secretos $\mathrm{y}$ recetas para el pronto alivio de sus inales. Obra recopilada por una sociedad de cazadores. - Madrid, 1858: Imprenta de Ramon Campuzano. - 8. ${ }^{\circ}, 80$ páginas, con grabados intercalados en el texto.

Las razas de que se ocupa, son: perdiguero, pachon, podenco, de barbas ó lanudo, galgo, sabueso, zarcero, lebrel, mastin, alano ó de presa, quitador y zorrero ó alimañero. En la tercera parte se dán á conocer las cualidades y cuidados que requieren los eaballos que se destinen á la caza.

521. Tesoro del pajarero, ó arte de cazar con toda clase de redes, liga, reclamos, lazos y demás armadijos, seguido del modo de criar, enseñar y curar á las aves menores de pajarera ó canto. Obra recopilada por una sociedad de cazadores._Madrid, 1858: Imprenta de Ramon Campuzano. $-8 .^{\circ}, 128$ páginas, con grabados intercalados en el texto.

Precede á la indicacion de los puntos que comprende el título una reseña de la parte práctica de las disposiciones vigentes sobre el ramo, relativa á los sitios, épocas y clases de ares que pueden cazarse.

522. Tratado de Caza, escrito por los aficionados á ella D. Cárlos Hidalgo y D. Antonio Gutierrez Gonzalez.-Madrid, 1845, por II. Alvarez. $-8 .^{\circ}, 188$ páginas con cuatro láminas.

Juzga contraria al fomento de la caza la ley de 3 de Mayo de 1834, y excita al Gobierno y á las Córtes para que dén cima á los trabajos más perfectos que sobre el particular se prepararon en 1837.

Se ocupa despues de todo lo concerniente al cazador, útiles de caza, perros, y caceria de aves, comunes y de rapiña, así como de la caza de pelo y alimañas.

523. TRatado de la CAZA de las peirdices con los reclamos macho y hembra, por D. Ramon Mauri y Puig.-Madrid, 1848, por A. Vicente. $-8 .^{\circ}, \mathrm{IV}-156$ páginas y una lámina.

Desarrollado el asunto principal, añade algunas prevenciones generales para conservar la caza muerta, concluyendo con un vocabulario para la in teligencia de los idiotismos que en el tratado se emplean.

524. Tratado de la Caza de lobos y zorras, y medios más se- 
guros de exterminarlos.-Madrid, 1829, por M. de Búrgos.-8.', 45 páginas y una lámina.

Explica los instintos y costumbres de dichos animales. La lámina contiene seis figuras que representan los-artificois más á propósito para cogerlos.

525. Tratado de la caza del vuelo, escrito por D. Fernando Tamariz de la Escalera, capitan de caballos corazas. Al muy ilustre Sr. D. Ivan de Guzman, señor de Carrascosa, cavallero de la órden de Alcántara y mi señor.-Madrid, 1654, por Diego Diaz.-8. , v. 31 hojas.

Explica el manejo de las armas y la cria de perros, con otros puntos de general aplicacion á la caza.

526. Tratado de las plantas tintóreas, de la barrilla, y otras plantas que dan sosa, y del tabaco. Escrito segun los adelantos del dia y conforme á la práctica de los mas célebres agricultores.-Madrid, 1844: Imprenta de D. Manuel Romeral. -8. $.^{\circ}, 90$ páginas.

Describe el clima, terreno, siembra, cuidados, recoleccion y preparacion industrial que requieren las plantas de que se ocupa, y sus productos. Cómprende las barrillas borde, pinchuda, carambollo, sisallo, salada, tamojo, zagua y escobilla, àsi como el salicor, salicornia, garbancillo, polluelo y sapina.

527. Tratado de las plantas venenosas y sospechosas. - Obia en la cual se hace conocer todas las plantas que su uso puede llegar á hacer el orígen de algunos accidentes más ó ménos graves; tambien se indica las señales que caracterizan las varias suertes de envenenamiento, y los medios más prontos y más eficaces para remediar los accidentes causados por los venenos vegetales, tanto en lo interior como en lo exterior. Escrito por el célebre botánico monsieur Bulliard. Traducido de la última edicion por el doctor don Antonio Lavedan, Profesor de Medicina, etc. (Siguen los títulos).Con licencia en Madrid.-Imprenta de D. Francisco de la Parte, 1817. $-4 .^{\circ}, 305$ páginas .

Se ocupa, entre otras' muchas plautas, describiendo sus cualidades, del bonetero ginesta ó esparlo ágrio,"enebro, sabina, laurel-cerezo, zumaque, tejo, almendro, boj, colutea arborescente, citiso de los Alpes, fresno, nogal, cerezo de aves y espino cervino.

528. Tratado de las siemras y plantíos de árboles, y' dé su cultivo, ó medios de multiplicar y criar árboles, de plantarlos en espesillos y alamedas; de formar montes y bosques, y de con'servarlos y restablecer los que estén deteriorados; lo cual constituye una parte del tratado completo de montes y bosques. Escrito en firancés por el célebre Mr. Duhamel du Monceau, y tradúcido al castelláno, con 
varias notas, por el doctor D. Casimiro Ortega, primer catedrático del Real Jardin botánico, y académico de las Reales academias de la Historia y Médica de Madrid, y de la Sociedad botánica de Florencia.-Madrid, 1773, por J. Ibarra _-4..$^{\circ}$ mayor, Lxxı.-363 páginas y 16 láminas.

Explica en el prólogo algunas disposiciones dictadas para fomentar el arbolado, como las cédulas de 14 de Noviembre de 1553, y 26 de Abril del siguiente año, é indica las causas que se han opuesto á su conservacion y desarrollo. Comprende en seis libros todo lo relativo al terreno, exposicion, eleccion de especies, medios de multiplicacion, cultivo de arbolillos nuevos, piantacion de los criados en planteles, bosques de grande extension, conservacion de los mismos, y restablecimiento de los deteriorados.

529. Tratado de los prados Naturales y artificjales, y su mejora en España, por D. José de Hidalgo Tablada.-Segunda edicion, corregida y mejorada con nuevos datos. - Madrid, establecimiento tipográfico de Eduardo Cuesta, 1872. -4. ${ }^{\circ}$ menor .—283 páginas, con diez grabados y tres láminas que representan máquinas, aperos y plantas pratenses.

La primera edicion se publicó en 1851 , comprendiendo la parte relativa á riegos.

Se describen en la presente numerosas plantas para prados, estudiándose en el capítulo xv los nalurales, asi como el clima, suelo y regiones propias de esta produccion.

530. Tratado del arbolista teórico y práctico, que comprende la anatomía, fisiología, y patología regetales; formacion y conservacion de los viveros, y una relacion por órden alfabético de las plantas arbóreas que más abundan en los cultivos europeos y en nuestra Península.-Obra dedicada á S. M. el Rey, y compuesta por D. Ramon Romualdo Aguado, agrimensor y aforador de S. M., jardinero mayor en su Real sitio del Buen Retiro, individuo de la Sociedad Económica Matritense, y de la Imperial y Central de Horticultura de Francia, etc., etc.-Madrid, librería de D. Leocadio Lopez, editor, 1864.-Imprenta de M. Rivadeneira. -4. ${ }^{\circ}-487$ páginas y seis láminas.

Encarece la inportancia de los arbolados y montes respecto al clima, á la salubridad y á la defensa del territorio en unas consideraciones generales. Describe los principales insectos que atacan á los árboles, y explica todo lo concerniente á la plantacion, incluyendo un catálogo de las plantas arbóreas que más abundan en los parques y jardines europeos, y varias tablas que expresan, para las diferentes especies, la época de recoleccion de la semilla, método de reproduccion más adecuado, persistencia de las hojas y las plantas sarmentosas, trepadoras y rastreras. 
531. Tratado Del CUIDAdO y aprovechamiento de LOS MoNTES Y bosques, corta, poda, beneficio y uso de sus maderas y leñas, escrito en francés por el célebre Mr. Duhamel du Monzeau, y traducido al castellano con varias notas, por el doctor D. Casimiro Gomez do Ortega, primer Catedrático del Real Jardin botánico, é individuo de las Reales academias de la Historia y Médica de Madrid, y de la Sociedad botánica de Florencia.-Madrid, 1773-1774, por J. Ibarra. Dos tomos en $4^{\circ}$ mayor, $\mathrm{Lx}-427$ páginas y 13 láminas el primero, y 311 páginas y 23 láminas el segundo.

Se ocupa de las cortas, tallares, bosques bravos, valuacion, árboles para construccion naval, épocas de corta, beneficio de bosques bravos y maderas cuadradas, con un sistema de medicion. Al final hay un vocabulario de los términos botánicos, ayronómicos y forestales más en uso, y un índice de los árboles, arbustos, matas y yerbas de que se hace mencion en esta y domás obras análogas del aútor.

532. Tratado DEL ESTABLECIMIENTo, gobierno y aprovechamiento de los prados naturales y artificiales, con aplicacion al clima de España. Obra útil á los agricultores, propietarios de pastos y dehesas, arrendadores de yerbas y criadores de ganados, por D. José María Paniagua, indivíduo correspondiente de la Academia de ciencias naturales de Madrid, antiguo profesor de Agricultura, é indivíduo de varias sociedades.-Madrid, 1843: Imprenta de la Carrera de San Gerónimo, núm. 43.-4. ㅇ, 134 páginas.

Estudia los prados naturales, artificiales, permanentes, temporales, secos, bajos, pantanosus, anuales, bisanuales y viraces, y la repoblacion, conservacion, riegos, saneamiento, abono y cerramiento de los mismos.

533. Tratado del ingerto, en que se explica todo lo correspondiente al arte de ingertar, por D. Cláudio Boutelou, director y profesor de agricultura y botánica del jardin y estudio, que con la soberana aprobacion de S. M., se ha establecido en Alicante por el Real Consulado; acadéinico de las Reales Academias médica matritense, etc.-Madrid, 1817, por F. M. Dávila.-4..$^{\circ}$, con una lámina.

Escrito en cumplimiento de un mandato de S. M. el Rey, quien por Real decreto de 17 de Noviembre de 1816, le ordenó compusiera un Manual de jardinería para la enseñanza de los acogidos en los hospicios del reino.

534. Tratado del marco valenciano de las maderas, con su equivalencia del sistema métrico, al alcance de todos, y aranceles á razon de 70, 75, 80, 85, 90, 95 y 100 pesos la carga. Es de suma utilidad para los arquitectos, maestros de obras, carpinteros y particulares que construyan abras: por D. Alejändro Lopez.-Valen- 
cia, 1871.-Imprenta de José Domenech. -8. ${ }^{\circ}, 99$ páginas, con un patron del marco con sus dimensiones naturales.

Describe el marco, sus grados y mejorías, y los casos que ocurren en su aplicacion, determinan lo el modo de medir la mädera. Añade numerosas tablas de dimensiones, reducciones y valoracion.

535. Tratados de rstadística general y nociones preliminares para su formacion. Por el brigadier de caballería y diputado á Córtes D. Antonio Ramirez Arcas.-Madrid, 1856. - Imprenta de Manuel Minuesa.-Fólio.

La obra habia de constar de cuatro volúmenes denominados libros. El que registramos es el segundo, y consta de 245 páginas con varios estaros. Se ocupa en la página 99 y siguientes de la caza y pesca, con relacion á las épocas en que pueden ejercitarse: leyes, costumbres de los pueblos, sitios, gastos, etc., y de los montes, desde la página 200 hasta la página 218, tratando de su estado, situacion, cualidades, cantidad, uso y cultivo, estima, produccion leñosa, norma para la apreciacion, influencia de la especie y la edaci sobre el valor de los bosques, y normas relativas al valor de las cortas anuales $g$ al de las cortas futuras.

536. Tratados sobre ta Física del Clero, y otros puntos útiles y provechosos de las ciencias naturales, impresos en el Memorial literario de Madrid de 1787, 1789, 1790 y 1793. Reimprímense ahora, añadido un discurso sobre la Historia natural con respecto á Cataluña, con permiso de su autor el Excmo. é Ilmo. Señor D. Pedro Diaz de Valdés, caballero Gran cruz de la Real y distinguida órden española de Cárlos III, del Consejo de S. M. y obispo de Barcelona, etc.-Con las licencias necesarias.-Barcelona: en la oficina de Manuel Texéro.-dño de MDcccvi:-4. ${ }^{\circ}, 218$ págs.

Este libro que no está regisirado en el Diccionario de bibliografía agronómica del Sr. Anton Ramirez, sir duda porque sus principales discursos se publicaron en el Memorial literario del cual se ocupa extensamente, ccnsta de los estudios siguientes: I. -Sobre la Historia natural con respecto á Catataluña. II. Sobre la necesidad de una Fisica provechosa con que el Clero, y parlicularmente los curas párrocos harán un gran bien á la Nacion. - III.Sobre los Hongos, y remedio de los veneivos os; y sobre dos especies de aceytes que pueden suplir el de aceytunas para alumbrar. $-1 \mathrm{~V}$. - Sobre algunas raras petrificaciones, y sobre la imporlancia de la Historia nalural; y V.-Sobre si la Escabiosa es un especifico para curar la mordedura de la vibora; y sobre algunos remedios contra su veneno.

Nos ocupamos en el lugar correspondiente del tema III, registrado bajo la indicacion de Carta sobre los hongos, etc., cuyo trabajo firmó el autor, así cumo otros de aquel tiempo, con el anagrama Zaldidalvés.

Nos ha comunicado bastantes ant scedentes acerca de esta publicacion, el Ingenieró de montes D. José Diaz Laviada, que cuenta entre sus ascendiendientes, á aquel sabio gijonés. 
537. Trrbuna (La). Periódico político de Madrid.-Véase: Pro. yeclo de ley de montes (ET).

538. Tricnfo de la sávia ce los árbolls (El), ó sea ensayo sobre la posibilidad de construir un buque grande de madera en una sola pieza. Lo publica en la ciudad de Barcelona á 25 de Diciembre del año 1838, D. Juan Migụel Vidal y Mascaró. (Il vaut mieux forger son esprit, que le meubler des pensées d'autrui.) Barcelona, 1839 , por Brusi. $-4 .^{\circ}, 16$ páginas.

Cree el autor que prestándose la sávia de los vegetales á tan admirables combinaciones, si se plantasen en un terreno férlil, a orillas del mar 6 rios caudálosos, artolitos de mas de doce pulgadas de diámetro, criados dé antemano en un semillero que forinasen una especie de $Y$, que puestos en línea se ingerlaran por aproximacion, y en seguida se culocase un simple molde de tab'as apoyado sobre diez y seis columuas, se lograrian una ó dos sólidas embarcaciones, y añade que aplicando este sistema á otras cosas, es decir, subordinando la sávia á las necesidades ó caprichos del hombre, se obtendrian acueductos, lindes para los prélios rústicos, invernáculos y muchas cosas mas.

Defiende la grande utilidad de los bosques, reseñando los beneficios que de elios reportan los paises donde se protegen, y los desastrosos efectos que se experimentan donde se abandonan y extinguen.

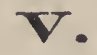

539. Valunciano (E:). Periódico de Valencia.-Véase: Idea sobre el modo de evitar los desbordamientos... etc.

540. Variedades de ciencias, literatura y aiktes. Obra periódica.-Madrid, 1803-180כ, por Benito García y Compañía.-Ocho volúmenes en $80^{\circ}$ de 380 páginas próximamente.

En el volúmen vuı hay un arículo sobre el ınodo de preservar los árboles del cáncer, y de cura:los si lo padecen, por Forsyth, jardinero del rey de Inglaterra, contenido en su Tralado del cultivo de los árboles frutales.

Ei artículo del tomo vil, hllulado Proyecto para la exlincion de los lobos, queda registrado en el lugar correspondiente.

54l. Venta de maderas para la construccion civil y la naval, traviesas de ferro-carriles, postes telegráficos, etc., etc.-Sin pié de imprenta.-Fílio mayor, 3 páginas y un mapa litografiado que representa la situacion del monte respecto de los principales centros de consumo.

Es una noticia econónira del Coto de Morilla, lérmino juristiccional de Segura de la Sierra, en la proviucia de Jien, para la venta de ina lera de pino, cuya especie es la dominante en la expresil la finca, propiedad del señor Marquas de Torreorgaz. Se indicı la cabida, la especie, calldad, uúmero y 
dimensiones de los árboles y los melins de explotacion y de extraccion, enumerando los mercados mas importantes para la venta.

512. Verdad y la Justicia (LA).-Memoria con documentos para la cuestion administrativa entre el ijustrísimo ayuntamien to de Toledo y los dueños pro-indiviso del terreno que en la particion de los montes de la ciıdad fué adjudicado en censo enfitéutico, á los vecinos del lugar de Yébenes en el año 1832, sobre una tercera remedicion del mismo, dispuesta por Real órden de 27 de Agosto de 1860. Escrita por los administradores de la propiedad de dicho terreno, para uso de sus poderdantes, y demostracion de sus derechos. Toledo, imprenta de José de Cea, 1862.-Fólio.-75 páginas de texto y xuI de Apéndice, con un plano, cuya escala es de 1.000 es tadales de once pies, representando el término antiguo y el modernamente señalado al lugar de Yébenes, lerantado en el año 1829 por la Comision régia divisora de los montes de Toledo.

Hace la historia del asunto, examinando minuciosamente todos los trámites y resoluciones dictadas sobre estacuestion. Demuestra que el lugar de Yébenes no perdió por la emancipacion de Toledo los derechos á los disfrutes de la coinunidad, y que hay necesidad de llevar á cabo la cuarta medicion de los terrenos, que estaba pendiente de ejecucion. 


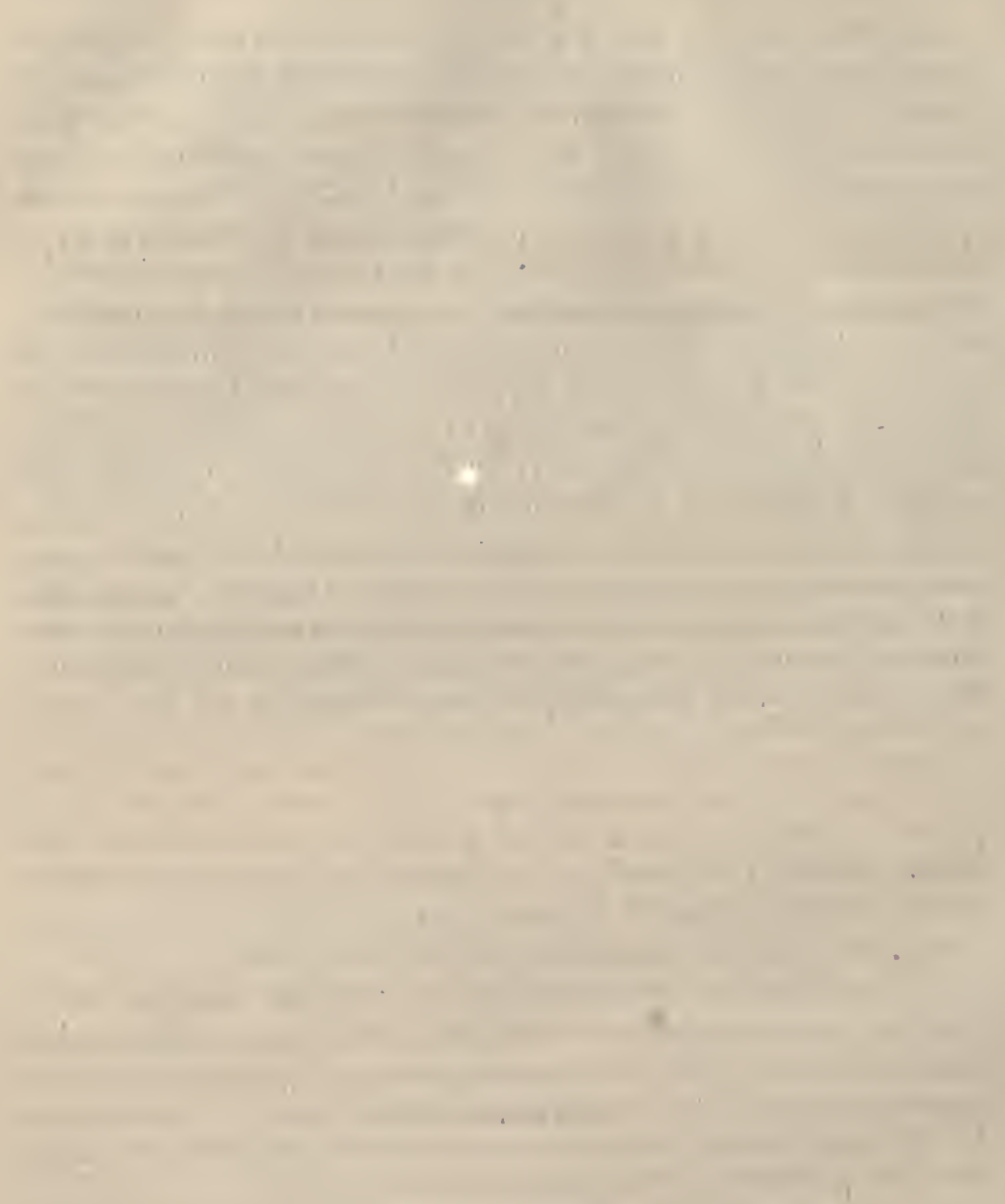




\section{SEGUNDO GRUPO.}

\section{MEMORIAS, ARTÍCULOS Y OTROS TRABAJOS}

CONTENIDOS EN LOS PERIódICOS Y OBRAS DE MATERIAS DIVERSAS.

\section{A.}

543. A La España.-Cuestion de montes.

La Epoca.-Periódico político.—8 de Noviembre de 1859.

En contestacion á lo expuesto por La España en contra de la desamortizacion de muchos montes, cuya venta consideraba perjudicial al pais, trascribe La Epoca los discursos pronunciados por entonces en el Senado por el señor marqués de Molins, interpelante, y el señor Ministro de Fomento, marqués de Corbera. Nutridas entrambas peroraciones de luminosos datos, y exponiéudose en ellas los fundamentos críticos más importantes de la cuestion de montes, los indicados senadores convinieron en la necesidad de excluir de la desamortizacion los montes que ejercen influencia directa sobre el clima, terreno, salubridad, etc., y sobre las condiciones de subsistencia de una parte de la poblacion española.

544. A laS POCAS hORAS DE HARER LEIDO.... elc.

El Constitucional.-Periódico político.-17 de Mayo de 1862.

Sale á la defensa del proyecto de ley de montes, haciendo comparaciones numéricas, de las que deduce que con la aplicacion de aquella, sólo se entregarán á la venta 217.510 bectáreas de monte. Aboga por la conservacion del monte alto en manos del Estado y pueblos ricos, y del monte medio y bajo en poder de pueblos pobres y de particulares.

545. Abetos y pinsapos.-A puntes.-Por D. M. Laguna.

Revista forestal, económica y agricola.-Tomo II, pág. 614.

Es un estudio botánico-geogrático del pinsapo, del abeto, abete ó pinabete y del abeto rojo ó del Norte, con respecto á España.

546. Acacia blanca (LA).-Por D. R. Jordana.

Revista forestal, económica y agricola.-Tomo IV, páginas 31, 77,172 y 247.

Monografía que comprende los nombres, descripcion, distribucion geográfica, métodos de beneficio en monte alto, bajo y medio, escamonda y des- 
cabezamiento, productibilidad, cultivos, cuali!ades y aplicaciones de los productos, y enemigos y enferrredades.

547. Administracion pública (LA) en sUS rej.aciones CON LA PROPIEDAD PARTICULAR.

Revista de Administracion.-Tomo I, año II, 2. "época, páginas $385,417,449,532,566$ y 622 .

Despues de tratir en los dos primeros númerosdel dominio de las aguas, dedica el resto del extenso artículo que registramus, des.le la página 449 en adelante, á la cuestion de montes, estudiando detenidamente l. legislacion derogada y la vigente en sus relaciones con la propieslanl particular, y deleniéudose mucho en lo conceruieute á deslindes, roluraciones, condominios, mancomutudades, servidumbres y desaınortızacion.

548. Agricultura forestal.-Por D. José Planellas.

Revista económica.-Tomo IV, pág. 261.

Enaltece las ventajas físicas y económicas que reporta el arbolado, y aconseja su plantacion en las montaũas, brezales y márgenes de los campos gallegos.

549. Agricultura (La) y Los Montes.

Diario de Tarragona.-22 y 24 de Marzo de 1868.

Se extiende en notables consideraciones acerca de la importancia física y económica de los arbolados.

550. Agricultura (LA) y los Montes. - Por D. R. Jordana.

Revista forestal, económica y agricola.-Tomo IV, pág. $65 \%$.

Encaminado á demostrur que solo con el desarrollo y prosperidad de los montes se puede conseguir el fornento de la agricultura.

551. Agricultura Práctica del Castaño.-Por D. Dionisio R. Cousillas.

Revista económica.-Tomo I, páginas 104, 152 y 217.

Se ocupa del cultivo de este árbol, de su utilidad como frutal y como ma dera de construccion, procedimieuto de siemb'a, trasplante, ingerto, labores, plantacion de asiento, poda y recoleccion de la castaña.

552. Agricultura.-Véase: Fomento del arbolado.

553. AGUa ATMOSFÉriCa (EL) Y SU INFLUENCIA EN LA AGRICULTURA.

Revista forestal, económica y agricola.-Tomo V, páginas 490 y 605 .

Estudio del capitan de Ingenicros D. Antonio Almeyda, publicado en la Revisla de obras puiblicas y minas de Porlugal. De sus conclusiones resulta que el arbolado es necesario en las alturas para evitar la rápida denudacion de los montes.

554. Al esclchar el incesante clamgr..... etc.

La Iberia.-Diario liberal._-17 de Abril de 1862. 
Comienza de este modo un artículo cuyo objeto es denunciar la infraccion de las leyes vigentes, que se cornete eutregando á la venta varios montes que debian exceptuarse de la desamortizacion por ser de aprovechamiento comun, ó debian destinarse á dehesas para pasto del ganado de labor.

555. Al HACER LA RESEÑa..... etc.

El Reino.-Periódico político. - 7 de Mayo de 1862.

En contestacion á un artículo de La Epoca, acerca de la sesion del Senado celebra 'a el dia $2 b^{\circ}$ de A bril último. exıone la opinion de varios súbios acerca de la relacion que en todo pais debe haber entre la superficie forestal y la io'al; hace luego un minucieso recuento del área total de los inontes que se reservar de la venta por el heal decreto de 22 de Enero de aquel año, y deduce ds ahí, la exigüidad del terreno forestal que se excluye de la desarnortizacion.

556. Al presentar el seÑor Marquís de la Vega de Armijo EL PROYECTO DE LEY DE MONTES..... etC.

El Reino._Periódico político. -10 de Mayo de 1862.

Se ocupa del proyecto de ley de montes presentado á las Córtes por el Ministro de Fomento. Lo censura por haber contradiccion entre el preámbulo y el articulado, lastimándose de que se entreguen á la venta los terrenos que no contengan pino, robie ó haya, si despues se han de adquirir para repoblarlos. La única razon, que á jùicio del arliculista, ha habido para formular el proyecio, ha sido la de vender lo más posible en el menor tierrpo posible.

557. Álamos negros (Los) en esta córte.-Por D. Estanislao Malingre.

La Epoca.-Periódico político.-27 de Abril de 1871.

Atribuye á las podas mal ejecutadas y á los daños de los inseclos, especialmente cle los scolytos, el estado lamentable de las plantas de aquella especie. Reseña ligeramente la vida y costumbres de los insectos citados.

558. Alcornoque de Occidente (EL).'-Por D. R. de Xérica.

Revista forestal, económica y agricola. -Tomo V, pás. 94.

Estudio botánico de la indicada especie, que el autor considera, fundado en la propia observacion y en testinonios muy respetables, ser la misma que la del $Q$. suber, sin más diferencia que presentar la mualuracion del fruto bienal.

559. ALCORNOQUe.-De su cultivo é ingerto.-Por D. Miguel de Foxá.

La Granja.-1852.-Año III, pág. 241; y en la Revista de agricultura práctica, publicada por el Instituto agrícola catalán de San Isidro, de Barcelona.

Describe el clima y terreno que conviene á este árbol, así como las operaciones de siembra y trasplante. Respecto del ingerto dice que antes de los 
experimentos de Mr. Rourdo Torrens, se ccnocia y practicaba el ingerto del alcornoque sobre la encin» comun en el Ampurdan.

560. Alcornoque (EL).-Por D. Ramon Jordana.

Revista forestal, económica y agricola.-Tomo V, págs. 125, 161, 242, 284, 326 y 384 .

Monografía que comprende los nombres, descripcion, distribucion geográfica, métodos de beneficio, determinacien de la posibilidad, turno de aprovechamiento del corcho, cortabilidad, plan de aprovechamiento, descortezamiento, siembras, plantaciones, ingerto, cualidades y aplicaciones de los productos en corcho, leñas, fruto y carbon, y enemigos y enfermedades.

Se reprodujo en la Revista del Instituto agricola catalán de San Isidro. 1872-73. ToMros XX1 y XXI1.

561. Algunas Palabras SOBRE La IMPORTANCia DE LOŞ MONTES Y Arbolados. - Por D. A. Parada.

El Progreso.-Periódico político de Jerez. - 13 y 22 de Noviembre, 5, 13 y 28 de Diciembre de 1872; y El Guadalete, periódico político y literario de Jerez.-28 de Enero y 19 de Marzo de 1873.

El autor examina en siete artículos la importancia é influencia que los montes ejercen en el clima, terreno, indusiria y defensa del territorio; se hace cargo despues de los males que acarrea su destruccion, y por medio de razonamientos matemáticos, dasonómicos y económicos, deduce que el interés privado no puede conservar el monte alto, y que por el contrario responde á sus fines particulares la destruccion, de donde se sigue la necesidad de que el Estado posea aquella riqueza.

El artículo VI estudia la estadística furestal de España en sus relaciones con la de otros países, bajo el título de Estadistica de los montes españoles; su esiado y administracion; y el VII, que se titula Desamortizacion forestal, examina las condiciones naturales de la region propiamente forestal, las necesidades á que los montes de esta region satisfacen, y las superficies entregadas á la venta en las épocas desamortizadoras de 1859 y 1862 , así como las condiciones en que dicha enagenacion ha tenido lugar.

562. Almez.-De la utilidad de su cultivo y de sus aplicaciones.

El Cultivador.-185̃.-Tomo IV, pág. 438.

Se recomienda este árbol para bosques artiticiales con destino sus produclos á la carpintería. A este fin se le debe criar en terrenos húmedos y muy ventilados, reservándole las inmediaciones de las corrièntes de agua, donde retoña con facilidad, cuando se destine la madera á cercos de toneles $\boldsymbol{b}$ cosas semejantes. Puede suplir, por el pulimento que admite, á la madera de América; cortado en sazon se rompe difícilmente, y despues de la del èbano y del boj, es la más tersa, fuerte y dura y ménos expuesta á la carcoma. Así lo dice el articulista.

563. Alternativa de cosechas.-Por E. A. 
Boletin oficial del Ministerio de Comercio, Instruccion y Obras públicas.-1848.-Tomo I, pág. 136.

Expone algunos bechos esperimentales que demuestran ser reemplazadas unas plantas por otras en la naturaleza, sin que se conozca con exactitud la verdadera causa de este fenómeno. Cita las observaciones de Mr. Thiebault en algunos monteś de Francia, en donde despues de un incendio, ó con posterlori dad á determinadas explotaciones, el haya fué sustituida por el roble. Asímismo recuerda haber visto Mr. Michaud en la América septentrional el reemplazo expontáneo de árboles de hojas caducas, por coníferas.

564. Anatovía vejetal.-Extracto de una Memoria sobre la corteza de los dicotiledones, y especialmente sobre el suber; por Mr. Them. Lestiboudois. (Comptes rendús, 31 de Diciembre de 1860.)

Revista de los progresos de las ciencias, etc.-Tomo XI, página 115.

Segun el autor, es preciso llamar liber á la parte viva de la corteza, y suber ó corcho á la parte exterior que carece de aclividad vital y suele estar desecada. Despues de examinar las trasformaciones de los troncos y sus órganos especiales, concluye, apoyado en varios experimentos, alìrmando que el suber esti formado por las capas del liber, y que por lo tanto las diversas zonas de la corteza se vuelven corcho.

565. Animales dañinos.-Apuntes relativoș á su aparicion y extension en las provincias del reiuo, con varias observaciones acerca de la legislacion vigente sobre la materia.

Boletin oficial del Ministerio de Fomento.-1861.-Tomo XXXVII, pág. 57.-Reproducido en La Agricultura Española.-Tomo IV, pág. 91, 123, 154, 201, 218, 234 y 264.

Se dá cuenta, provincia por provincia, del aumento ó disminucion que han tenido las alimañas en el último quinquenio; de los métodos observados para la persecucion, de las opiniones de corporaciones y personas competentes acerca de las reformas que conviene introducir en el Real decreto de 3 de Mayo de 1834, de las cantidades invertidas en la persecucion, y del número y clase de animales exterminados.

566. Aplicacion te las yaderas para empedrados Y PaviMENTOS.

Bolelin enciclopédico de la Sociedad económica dé amigos del pais de Valencia.-Tomo I, pág. 263.

Traduccion de un artículo publicado en $L$ 'A sociation brilanique de sciences. Dá cuenta de los trabajos de esta clase, hechos por Mr. Hasokins, en las calles de más tránsito de Lóndres, Viena y Nueva-York. Cree el autor, que empedradas todas las calles con cuñas de madera, se podria formar un camino en donde los caballos se fatigarian ménos que en los ordinarios, y por doude podrian circular con seguridad y rapidez las máquinas de vapor. 
Considera preferible para esta aplicacion la madera de los árboles resinosos, y especialmente la del alerce, debiemilo aprovecharse tan sólo en este caso el duramen, y darse á las cuñıs una forma exagonal, con una altura mitad mayor que su ancho.

567. Aprovilchamentos Comunales De pastos en faror DE LA GANADERÍA.

El Consultor de los Ayuntamientos.-Tomo XIX.-1871.-Página 132.

Censura las dispnsiciones rontenidas en la rirculár del gnbernador civil de la provincia de Zarag za, fecha $1 t$ de Uiciembre útimo, respecto a excluir del disfrute gratıitu de los pavos comulia'es á toula elase de ganados exreplo los de labor y los de abastos de carues, únicos que aquella di-posícion cousidera con dererho al di-frute libre sin pago de cuota alguria. El Consultor entiende que deben considerarse de igual elase, para los efectos de la exeucion del pago, los rebaños y piaras de los ganaderos vecinos del pueblo, mientras haya yerbas sobrantes.

568. Aprovechamientos comunales. - Del cumplimiento del art. 70 de la ley municipal, y R. 0. de 8 de Mayo, publicada en 27 de Octubre de 1871.

El Consultor de los Ayuntamientos.-Tomo XX, 1872, pág. 237.

Expone las dificultades del cumplimiento de aquella disposicion y los perjuicios que se han de seguir a los ganaderos, considerando ruinosa para esta industria la medida en cuestion.

569. Aprovechamientos comunes.-Sobre si deben ó no admitirse gratuitamente los rebaños ó piaras de los ganaderos propiamente dichos, distinguiéndolos de los recriadores, iratantes ó negociantes.

El Consultor de los Ayuntamientos.-Tomo XIX, 1871, página 228.

Sostiene, ell contra de lo expuesto por D. José Bragat en un comunicado que insertó este periódico en la pág. 212, que los ganaderos propiamenta dichos tienen derecho al disfrute gratuito de pastos, cuando haya sobrantes en los montes de donde sean vecinos.

570. Aprovechamientos FORESTALES.

E'l Eco de Aragon.-Periódico político de Zaragoza.-24 de Febrero de 1872 .

Tiene por objeto aclarar la circular del Goblerno civil de la provincia, feoha 17 del mismo mes y año, relativa á los aprovechainientos que los pueblos intenten realizar en sus montes en el próximo año forestal. Dicha cir cular se estaınpó en el miswo número del periodico. Examina éste las disposiciones que aquella comprende relativas á disfrutes conunales de leñas, pastos, etc., recomendando la conservacion de los montes por los produc- 
tos de toda clase que de ellos se obtienen cu beneficio de los pueblos propielarios de las finces.

571. Apuntaciones sobre los montes de Galicia y Asturias.

Continuacion del Almacen de frutos literarios.-Tomo IV, página 88 .

En este extenso trabajo se estudia la situacion de los montes de entrambas provincias, indirandu las especies q te los pupblan. la cali lad de los arboles y del terreno, ! las romlicione- cconómicas de exurtaci-n. Drspues se examinan las causasde la decadenci, inrestal on las provincias indicalas, que atribuye a los incendius y quemas, il la arlutraria lirencia de los asentistas, a la mala voluntad de los labradores, a la equivoca in eligencia de la ejecucion de los plantís que previenen la ordenanza y mevos proyectos, y aldesorden en las coitas para las fabricas de curtedos y herros. Desarro la todos estos puntus con previs is descripciones, y despues pasa á exponer las mejıras más urgentes para regenerar la poblaci n forestal, á cuyo tin propone lus medios de reenplazar los plantios existentes, la iutruduccion de pinos y pinabetes, los plantios populares y la reforma del personal encargado de la custudia y direccion de los montes.

5\%2. APUNTES SOBRE EL MODO DE. CONSERVAR LOS BOSQUES.Por P. C.

Revista de Agricultura del Instituto, etc.-1866.-Tomo XV, pág. 27.

Di.ta regias para las limpias y las podas; recomienda la conservacion de las brozas para que se forme mantil!o; exınina las condiciones que deben reunir las semillas para la siembra; lamenta los daños que causan los ganados en los enciuares jóvenes, y hice algunas consider rciones re-pecto á los perjuicios que se seguirian de la desapsricion de los encinares.

573. ARBOL DFL SEBO (EL).

Revista cientifica del Ministerio de Fomento.-1863.-Tomo II, pág. 148.

Se ocupa del Croton sebiferum, Stillingia sebifera, cuya aclimatacion en Hamma (Argelia), asegura huberse lón:ado con el mejor éxito. Considera al indicado árbol cumo poco delicado y bueno para paseos porque re zuiere poco riego. Las hojas so:ı cumo las del Pópulus tremula. Indica ser muy comun en China, y describe el modo de extraer el sebo, asegurando que un árbol de 10 años dá dos kilógramus de sebu al año, y tres ó cuatro, uno de 25.

574. AkBolado dE BARCEIoNa.-Por D. An'onio C. Costa.

Revista de Agricultura práclica.-1856.-Tomo V, página 33.

Enumera las especies de los $\mathrm{p}$ sseus de aquella ciudad, manifestando que sólo deben respetarse los plátanos, hacieudo desaparecer los ciuamomos, moreras, japones, alanios blancus (atacados por el cusus ligniperda y séssia apifor'mis), los olıos (perseguidos por el liparis dispar, galeruca calmariensis, bomiyx neustria, acroenite aceris), los falsos harnices, de poca sombra, y las falsas acácias, sustıtuyéndoios por el castaño de Indi.ıs, arce de hoja pe- 
renne, acácia saparera (A julibrizin), sicomoro, parasol chino, tilo, pacano (Juglans nigra), sófora, etc. Describe las almácigas y las operaciones de siembra, plantacion y poda.

575. Arbolado de la Córte (EL).-Por D. José Jordana.

El Argos.-Nium. 14.-18 de Setiembre de 1871.

El autor se ocupa del estudio hecho por D. Estanislio Malingre acerca del arbolado de Madrid, entendiendo que son muy aceptables las mejoras que éste propone en el cultivo, introduccion de especies nuevas y creacion de jardines, parques, etc.

576. Arbolado de Madrid (EL).

El Argos.-Núm. 33.-10 de Octubre de 1871.

Se ocupa de los defectos que se notan en la direccion y ejecucion de las operaciones propias del ramo de arbolados, en lo referente al cultivo, poda, siernbra, plantacion, jardines, viveros, etc.

577. Arbolado en España (EL).-Por D. Estanislao Malingre.

La Epoca.-Periódico político. -7 de Febrero de 1867.

Carta acerca de la conveniencia de propagar el Eucalyptus para repoblar muchos terrenos y contribuir de este modo á la aminoracion de los es tragos que causan las aguas fluviales. Contiene una noticia de la procedencia de aquel árbol, de las condiciones de su madera, de su crecimiento, cultivo, etc. Reprodujo esta carta el diario de Valencia, Las Provincias, en el número del 22 del indicado mes y año, bajo el epigrafe Extension del arbolado y repoblacion de los bosques por medio del Eucalyptus.

578. Arbolado en España (EL).-Por D. Estanislao Malingre.

La Epoca.-Periódico político.-20 de Febrero de $186 \%$.

Es una nueva carta que se relaciona con la del mismo autor publicada en el número del 7 de aquel mes y año. En esta ccmpletı las noticias relativas al Eucalyptus, en lo que se refière á sụ introduccion en Europa, naciones en donde se ha ensayado su aclimatacion, cultivo, crecimiento y otros pormenores. Reprodujo este escrito bajo el título de Más sobre el Eucalyptus, Las Provincias, diario de Valencia, en el numero del 23 de aquel mes y año, añadiendo otra tarta publicada en Los Sucesos, en la que su autor, D. Manuel A. García Ochoa, que la fecha en Mascaraque (Toledo) á 15 de Febrero de 1867, dá cuenta de unas plantaciones de Eucalyptus y de un caso de oidium sobre un árbol de la indicada especie.

579. Arbolado en las carreteras (Dei). - Por D. Ramon Llorente Lázaro.

Revista de Obras públicas.-Tomo 1, 1853, páginas 15, 44, 153, 180 y 210 , y tomo II, 1854, páginas 11 y 175.

Son seis artículos q'ie tratan brevomente de los viveros, 'siembras, plantaciones, podas, plantacion definitiva, ingerto de aproximacion, trasplantes, tierra, suelo, subsuelo, aire, laz y temperatura. 
580. ARBolado.-Recientes medidas dictadas sobre este ramo en la provincia de la Coruña.-Por D. J. S. V.

Revista económica. -Tomo II, pág. 144.

Haciéndose cargo de la circular del Gobierno civil de la provincia fecha 25 de Enero de 1861, relativa al fomento del arbolado, opina que los Ayuntamientos no cumplirán la obligacion que se les impone de hacer plantaciones y vireros, estimando más conducente el sistema de premios y el establecimiento de una buena guardería.

Hace algunas ligeras consideraciones acerca del consumo de la corteza para las tenerías de la provincia, en las que, segun los últimos datos estadísticos, se preparan 30.881 pieles.

581. Arbolado. - Sobre la necesidad de él y sobre las talas de los montes del Pirineo.

El Alto Aragon.-Periódico de Huesca.-1. ${ }^{\circ}$ de Junio de 1871.

Recuerda la influencia climatológica de los montes y su importancia económica, lamentándose de las asoladoras talas que se estaban llevando á ca bo en los mejores montes del Pirineo de aquella provincia.

582. ARbolado.-Su poda, replantacion y fomento.

El Consultor de los Ayuntamientos. -Tomo XV, 1867, pág. 43; tomo XVI, 1868, pág. 62, y tomo XVII, 1869, pág. 44.

Tiene por objeto recomendar á los Ayuntamientos el fomento de las plantaciones, la recompensa hácia los que se distingan en favor del indicado ramo, las buenas medidas de policía rural y el castigo de los dañadores.

583. Arboles.-De su cultivo. - Noticia de una interesante Memoria que en 13 de Agosto de 1849 presentó Mr. Enfantin, miembro de la Comision científica de Argel, á la Academia de ciencias de París.

Revista de los progresos de las ciencias.-1850.-Tomo I, pág. 40.

Tiene mayor aplicacion al cultivo de frutales.

584. Arboles en España (Los).-Por D. Fernando Fulgosio.

La Ilustracion española y americana.-15 de Marzo de 1871.

Aboga por la conservacion de los montes y arbolados, haciendo ver la influencia de las costumbres en ellos y la que á su vez ejercen aquellos en la vida y organizacion de los pueblos.

585. ARBoles.

Extraclos de las juntas generales celebradas por la Real Sociedad Bascongada de los Amigos del Pais en la ciudad de Vitoria, por Setiembre de 1777.-Pág. 12.

Es un catálngo de las especies leñosas que vegetan en la provincia de Alava, de las cuales formó la Sociedad una coleccion de maderas. Comprende 33 especies, desiga adas con sus nombres vulgares y cón el caracter de wus hojas. 
586. Arboles. - Por D. Agustin de Colosia.

Extractos de las Juntıs generales celebradas por la Real Sociedad Bascongada de los Amigos del Pais, en la ciudad de Vitnria, por Setiembre de 1771. - P'́g. 25.

Noticia de una Memoria del indicado aut^r, en la cual se trata de los estrogos que hace cn los árboles cierto inseclo que se cria en ellos, cuyo nombre no dice. Hace la historia de su origen, figura, propiedades y daños que ocasiona; expone las pruebas llevadas á cabo para destruirlo, concislentes en introducir las maderas en agua salada, y reromienda el descortezamiento de prinavera para evitar los ataques del referido insecto y para endurecer las fibras de los árboles.

587. Arboles resinosos.-Por D. José María Gil.

El Eco de la Ganaderír.-Tomo VII, páginas 55 y 72.

Encarece la importancia física y económica de los montes, invitando á ios propietarios á la plantacion de bosques de coníferas. Pasa revista á los Pinus, Abies, Larix, etc., que podrian cultivarse explicando los inedios de siembra y conservacion, así como los procedimientos por medio de plantas protectoras para asegurar el repoblado.

588. Arboles. - Su extructura ú organizacion, su nacimiento y nutrivion, su desarrollo y crecimiento y su multiplicacion.

Revista semanal de agricultura.-1825.-Tomo IV, págs. 7 á 14.

Se juzga más cunveuiente lo multiplicacion por sessilla que por yema. Contiene grabados.

589. Arbolrs.-Su utilidad.-Ejemplo de proteccion y estímulo para fomentar los plantíos.

Semanario industrial.-1810. - Tomo I, páginas 217 y 253.

Recuerda la influencia del arbolado en la atmósfera y la humedad, y los productos en frutos, hojas, yomas y ınaderas que rinde. Hace mérito de las industrias creadas en las landas de Francia, y enumerando las circunstan. cias favorables ne las corcanias de Madrid $\mathrm{y}$ de las margones del Henares hasta Guala'ajara, esti.nula la plantacion de nogales, almendros, avellanos, etcétera. Recuerda la ley de Sajonia, qque no permile el matrinonio sin que preceda la plantacion de seis árloles frutales y otrus tactos robles $\delta$ la yas, y la que orilena que tolo comprator le un terrens ha de plantar cada añn, en las lindes, varios írholes lo stu furinar unn cerca. Tres co:is, ana le, aludiendud un filósofo, debe el hombie a la sociedad: un hijo, un cisa y un árbol.

590 ARBoles y anbistos. - Razon de las espacics raras que se cultivan al aire libre en lo $₹$ jardines de Arimjue\% y el método de propigarlo־, pror D. Clíludio y D. L'téban Boutelou.

Anales de ciencius naturales.-1779-1804.-Tomo IV, pág. 233.

Descrilie las especies y Ins aprovechamienlos de que son susceptibles, comenzando por el arce é indicando las cualidades de la matlera. 
591. Arboles y plantas funerarias.

Gaceta de Madrid. - 15 de Marzo de 1846.

Brevisima indicacion, en la que se agrupan los árboles por la disposicion de su raı́je, en dos clases, á saber: de ramas culgantes y de ramas levantadas; cumprendiendo en la primera el sáuce de Babilonia y el cazarino de las islas del mar del Sur, y en la segunda el ciprés, el álamo de Italia y el abeto del Norte.

592. Arboricultura. - Consideraciones generales sobre los árboles y sobre la destruccion de los bosques.

El Mentor de las familias.-1851.-Tomo III, páginas 241, 275 y 334 .

Se encarecen las ventajas del arbolado y se enumeran los árboles verdes que wás convienen para los terrenos áridos, como los abedules, cerezo de Iahoma ó de monte, y pino marítimo; para los pantanos recomienda el ciprés de Luisiana, los sáuces, el álamo blanco y negro y el aliso. Tráta por último, de las plantaciones de árboles de hosque, indicando las especies màs propias para las pendientes rápidas, para los bordes de las zanjas y para la defensa de lus corrales del ganado.

593. Arboricultura.-Ideas generales.-Por D. A. A. Villacampa.

Revista forestal, econónica y agricola.-Tomo I, pág. 252.

Dá á conocer la distribucion general de lis plantas leñosis de España haciendo consideraciones acerca de su importancia climatulogica y geogénica. Traza despues el plan que el autor se proponia seguir en ia publicacion de una série de Monografias de las especies leñosas más importanles.

594. Anboricelturia - Ligera idea de los progresos realizados en el departamento de las landas francesas por medio del cultivo del pino marítimo, por D. Diego Pequeño.

El Eco de la Ganaderia.-Tomo VIII, pág. 201.-Se publicó tambien en La Reforma Agricola.

Traza la historia del cultivo de las landis de Burdeos y deduce la conveniencia de funentar y explotar en España la producciun resinera.

595. Armoricultura.-Por D. Miguel de Foxá.

Revista d: Agricultura práctica.-18j2.-Tomo I, págs. 196, 221, 241, 280.-T'umo II, pág. 15.

Consilera en la introluscion ta importancia del arbolado, su accion sobre el clina é hidrometroros, los usosá que so destina y las ventajis ile su fomento. Recuerila las sequias que expri nenta la i,ld de Mallorca, cuyos piuares fueron destrui los por la codicia de un lucro det momentn. Comienza despues el articuln $1 .^{\circ}$, que trata de los moutes nqueilales y árboles indigeuas ó exólicos de que pue len forınarse, enumerando las signientés fspecies, de las que lí noticias a serca de la germiıtacion, reproducinn, uacimiento vida, enfermedades y aprovechamiento: “P, larix: P. abies: P. pinea: P. fo- 
liis geminis tenuisimis: P. silvestris: P. tæda: P. silvestris maritimus: Quercus alba: Q. rubra: Fagus: Taxus baccata: Tilia europæa: Acer campestris: Betula populi folia: Carpinus betulus: Ilex aquifolium: Fagus castanea: Ramnus alaternus: Fraxinus excelsior: alsina: Quercus suber: Ulmus campestris. Populus alba: P. nigra: Celtis australis: salix y Juglans regia." De la corta de maderas y leñas promete tratar más extensamente, trabajo que, segun parece, no llevó á cabo el autor.

596. Arbonicultura.-Tratado especial, traducido y arreglado por D. Augusto de Búrgos.

Instruccion para el pueblo._1851.—Tomo II, págs. 2433 á 2464.Tratado núm. 77.

Este tratado es uno de los ciento que comprende la publicacion. Se ocupa de los ingertos, plantaciones, explotacion de los plantíos y de los bosques, ilustrado todo con trece grabados.

597. Arboricultura. - Varios modos de sembrar y plantar árboles de rama, estaca y barbados. El de cavarlos, podarlos y limpiarlos.-De los castaños, encinas, fresnos, algarrobos, bojes, álamos negros, pinos, cipreses, enebros, higueras, laureles, morales y moreras, nogales y membrillos.-Cultivo del roble.

Semanario económico.-1767-1778. -Tomo III, págs. 27\%, 285, 293, 301, 309, 317, 325, 333, 341, 349, 365, 373, 381, 389, 397, 405, 413, 421, 429, 437, 445, 453, 461.-Tomo IV, págs. 225, 233, 241, 249 y $25 \%$.

Recomienda la plantacion de castaños, alınendros, a vellanos, pinos, encinas, olivos, etc., y describe el terreno propio de cada especie, la época de las labores en creciente ó en menguante, los medios de multiplicacion y las mejoras que deben intentarse por medio del ingerto. Este trabajo se debe á D. Pedro Araus. El que versa sobre el cultivo del roble para la produccion de maderas para la marina lo escribió D. Juan Bicen, continuador del Sema_ nario, diez años despues del fallecimiento de aquel.

598. Anboricultura.-Véase: Acacia blanca (La).

599. Arboricultura.-Véase: Alcornoque (El).

600. Akвoricultura.-Véase: Avellano (El).

601. Arboricultura.-Véase: Éncina (La).

602. Arboricultura.-Véase: $\operatorname{Haya}(E l)$.

603. Arboricultura.-Véase: Olmo (El).-(Ulmus campestris.)

604. Arroricultura. - Véase: Palmito (El).

605. Arboricultura.-Véase: Pino silvestre.

606. Arboricultura. -Véase: Regaliz (El).

607. Arboricultura.-Véase: Robles (Los).-(Género Quercus.)

608. Argan (DrL).-(Argania sideroxylon. $R$. et, $S$.)-Por don Estéban Boutelou.

Revista forestal, económica y agricola.-Tomo I, pág. 480 . 
Describe la planta, las localidades africanas donde se encuentra formando bosques, las condiciones y aplicaciones del fruto y la madera, y el cultivo por siembra y plantacion.

609. Arroyo Butarque. - Informe dado al Excmo. Sr. Ministro de Comercio, Instruccion y Obras públicas por la Junta de Agricultura de Madrid, sobre un proyecto presentado por el señor Blazquez Prieto con objeto de hacer plantíos de árboles en las márgenes del citado arroyo y sus afluentes.

Boletin oficial del Ministerio de Fomento.-1853.-Tomo VIII, pág. 508.

Defiende la conveniencia de los montes, lamenta su destruccion, presagia los daños que esta traerá consi@o, entiende que por el sistema de premics no se conseguirá el fomento del arbolado, $y$ aconseja la plantacion por medio de la accion administrativa. Sigue otro iniorme en igual sentido del comisnrio régio de agricultura $\mathbf{D}$. Luis Piernas.

610. Arte de dirigir la sávia.

Boletin oficial del Ministerio de Fomento.-1847.-Tomo XXIII, pág. 58 š.

Es un articulo tomado de la Revista de Agricultura. Para dirigir la sávia cual conviene al objeto que se desee, refićrense las precauciones que dehen observarse, ya para aumentarla, ya para disminuirla, prodigando á las planlas cuidados semejantes á los que se prestan á los animales.

611. Avllaga.

Gaceta de Madrid.-30 de Octubre de 1862.

Dá cuenta de varias especies de aulagas y de su cultivo y aplicacion como alimento para los ganados. Es reproduccion de La Agricultura española.

612. Aun Cuando nos habíanos propuesto..... etc.

La España._Periódico político._-16 de Abril de 1862.

Comienza así un artículn de controversia con La Epoca á propósito del Real decreto de 22 de Enero de arquel año. Se funda principalmente en la excesiva restriccion establecida respecto á las especies arbóreas que ha de servir para determinar si los montes deben ó no venderse, quejándose de que así se enajenarán terrenos torrenciales y mucha superficie forestal que interesa al pais' conservar.

613. Aunque Fuera del sitio destinado..... etc.

La Epoca.-Periódico político.-22 de Abril de 1862.

Es un extenso artículo de polémica con La España y El Reino, en el que se trata de probar que la venta de los nontes, consecuencia de aque! $\left|i_{i}, i\right|$ decreto, obedece á un criterio cientifico, y no desmembra el área forestal que debe reservarse para satisfacer las necesidades más importantes que los montes deben llenar en el país.

614. Avellano (EL),-Por D. Antonio Magriñá. 
Revista de Agricultura del Instituto, etc.-1865.-Tomo XIV, pág. 201.

Fechado en Tarragona en Marzo de 1865. Es una descripcion de la planta, seguida del estudio de sus variedades, zona, clima, terreno, plantacion, cultivo, recoleccion del fruto, accidentes y enemigos.

615. Avellano (EL).-Por D. R. Jordana.

Revista forestal, económica y agricola.-Tomo III, págs. 131 y 183.

Monografía que comprende los nombres, descripcion, distribucion geográfica, condiciones de existencia, productibilidad, cultivos, cualidades y aplicaciones de los productos y los enemigos y enfermedades.

\section{B.}

616. Bibliografía.-Véase: Siembras y plantaciones, por E. Burkhavdt.

617. Bienes de CokPoraciones.-Por D. J. J.

El Éco de la ley y la España juridica.-Núm. 41: 15 de Octubre.-Núm. 49:22 de Diciembre de 1860.-Núm. 56: 15 de Febrero de 1861 .

Examina en tres artículos si el Estado debe ejercer patrocinio sobre los indicados bienes; si puede llegar hasta invadir el derecho de libre administracion de que al parecer gozan aquellas; y si el tributo que grava á las fincas puede considerarse como un impuesto fijo ó como una remuneracion equitativa por los cuidados anexos á la lutela.

6]8. Bienes de propios y conunes. Consideraciones sobre la proposicion de ley presentada á las Córtes para su reparto á censo entre los vecinos.

El Consultor de los Ayuntamientos:-Tomo XVII, 1869, página 111 .

Examina detenidamente la proposicion de ley indicada, exponiendo que deberia modificarse bajo lá base de reservar los terrenos de pastos necesarios para el ganado de labor, repartir las superficies susceptibles de cultivo agrario y entregar á la venta las restantes que no reuniesen estas circunstancias. Pide tambien la legitimacion de las roluraciones arbitrarias ejecutadas hasta el dia. Desarrolla este proyecto en una série concordada de catorce artículos ó bases, cuya aceptacion recomienda á los Ayuntamienlos, á tin de que eleven à las Córtes exposiciones en igual sentido.

619. Bosqurs.-De los que existen en parajes elevados: de su utilirlad y benéfica influencia, por N. Cook.

El Europeo, periódico.-1824.-Número $5 .{ }^{\circ}: 7$ de lebrero: página 133.

Hablando de la suma utilidad de los bosques que coronan las cumbres 
de los montes y visten sus faldas, dice el autor que atraen las nubes, y que despojándolas de una gran eantidad de calórico, estas se disuelven en lluvias, proveyéndonos de innumerables fuentes y arroyos permanentes que bañan las llənuras, $y$ son, por lo mismo, el manantial de la fertilidad. Son tambien los directores de la electricidad, ó la conducen y distribuyen directamente, ó forman una de las principales causas de sus modificaciones en los generales fenómenos de la naturaleza; interceptan los vientos, disminuyen su ímpetu, purifican el aire, etc.

Recuerda los desastres que en otros paises ocasiona la destruccion de los bosques, particularmente la del que atraviesa toda la Garnia hasta la Croacia turca, y con propósito de que se imite el ejemplo, cita las medidas que, para conservacion y fomento de esta riqueza, han adoptado Francia, Inglaterra, Alemania y Suiza.

620. Bosques,-De su cultivo, combinado con el de los cereales y forrajes.

El Cultivador - -1850.-Tomo III, pág. 317 á 323.

Parece sustentar el nuevo sistema de economia rural con relacion á los bosques, de Mr. Noirot, del cual se ocupó Cotta. Comprende la selvicultura y la agricultura; el objeto es trazar el modo de hacer extensos plantíos de árboles, disponiéndolos para el cultivo de cereales y forrajes. Desarrolla las reglas, preceptos y ejemplos conducentes al objeto, refutando algunas objeciones.

621. Bosques (Los).-Por P. C.

Revista de Agricultura del Instituto, etc.-1867.-Tomo XVI, página 129.

Encarece la necesidad de los bosques, aconseja la repoblacion de los terrenos que á este objeto se han destinado siempre, lamenta los daños causados en los encinares de Cataluña por el ganado cabrío, y excita el celo de los agricultores para que los eviten.

622. BOSQUES, MONTES Y TERRENOS PROPIOS PARA ELLOS.

Semanario de agricultura y artes.-Por D. M. C. Portocarrero. -1832.-Tomo II, págs. 205 y 213.

Dá el nombre de monte, bos que y tallar á la reunion de árboles y arbustos de todas especies y magnitudes en cierta y determinada extension. Encarece las utilidades que reportan y dá reglas para la plantacion y explotaeion. La fecundidad de la tierra, añade, depende en gran parte de los árholes, supuesto que ellos conservan la humedad de los terrenos, multiplican las fuentes, los arrovos y los estanques, y con los restos de sus hojas bonifican la tierra. La abundancia de los bosques ó de los árboles, además, arregla el imperio de la atmósfera, sirre para establecer la circulacion del flúido eléctrico, y asi se comprende que un solo árbol, próximo á una cabaña, puede preservarla del rayo. Des rribe luego los terrenos más propios para la plantacion de montes y bosques, con destino á la produccion de inaderas, y habla de siembra, plantacion y época de corta de los árboles, remi- 
tiendo al lector, para sus ampliaciones, á la excelente obra de Mr. Duhamel, traducida al español por D. Casimiro Gomez de Ortega.

623. BREVES INDICACIONES SOBLE EL PINO NEGRO DE LA PROVINCIA IE LÉRIDA.-Por D. R. Jordana.

Revista foreslal, económica y agricola.-Tomo II, pág. 158.

Se refiere al Pinus uncinata. D. G., ó sea el Pinus montana Duroi. Describe la localidades de la provincia en donde se encuentra, el estado de los montes, el aprovechamięnto de șus prorluctos y los sitios donde convẹndria propagarlo,

\section{C.}

624. Capullos y ORUGas DE los Pinos; POSIBILIDAD de Utilizar LOS CAPULLOS PAKA EL HILADO.

Boletin enciclopédico de la sociedad cconómica de Amigos del Pais de Valencia.--Tomo V, pág. 147.

Este artículo está tomado de la Enciclografia de industria. Su autor llama la atencion acerca del inmenso número de capullos de distinto tamaño que existen en los pinares. Expone sus observaciones respecto de las épocás y duracion de las melamórfosis que sufren los insectos que fabrican dichos capullos, y su modo de alimentarse. Se hace cargo, muy particularmeute, de la utilidad que podia obtenerse de dichos capullos ensayando el hilado. Al efecto asegura que cuatro de estos producen media onza de hilo muy propio para prendas de abrigo.

625. Carcona - - Insecto que se agarra á los árboles y los hace perecer.-Medios de destruccion.

Gaceta de Madvid, 10 de Abril de 1828.

Es un articulo tomalo del periódico francés Biblioteque physico-economique.

Expone que la careoma ataca al olmo y al sáuce y rara vez al chopo y al rob!le; que por espacio de cerca de tres años se mantiene de la segunda cor'eza y de la albura de los árboles, mudando la piel muchas veces; que suĺre una metamórfosis, y no sale de dicho sitio sino de noche, bajo la forma de gusanó ó mariposa; que aparece'en Julio y Agosto, y que en su priInera edad es una especie de serrin que puede secarse ó aplastarse con una brocha fuerte. Propone tambien el medio de extraerla con un hierro puntiagulo y cortante, levantando la corteza lel á bol, cuya herida ó cortadura se debe cubrir con tierra cernida, desleida y mezclada con estiércul de vaca, composicion llamada por los franceses ungilento de Saint-Fiacre.

626. Carta al duque de Mridna Sidonia sobre la etimología del nombre Aranjuez, árbol Gerion y la Cetreria.-Por Martin Sarmiento.

Semanario erudilo de Valladares. -Tomo VI.-Madrid, por Roman, 1787, págs. 208-215. 
El árbol Gerion es, en concepto del autor, el Dragon ó Drago de Africa, Canarias y Cádiz, Dracena Draco. L. La carta fué escrita en 1754 desde Pontevedra,

627. Carta de Cachano Tejas á.su phimo lucas Gomez.

La Independencia Española.--30 de Noriembre de 1873.

Romance festivo en el que se dán á conocer los vicios y defectos de que adolece el proyecto de ley de montes presentado á las Córtes por el Ministro de Fomento señor Echegaray, en la parte relativa al reparto vecinal de las suertes en que deberán dividirse ciertos montes con arreglo al proyecto indicado.

628. Carta sobre las orugas.-Por D. Antonio de Aguilera y Aguilera .

Semanario de Agricultura y Artes, dirigido á los párrocos, 1803. -Tomo XIV, pág. 401.

Trata especialmente de las orugas que más atacan al olivo, á la vid y á la eutcina. Se ocupa ligeramente de las que darian á esta última, aconsejando, para combatirlas, la poila cada tres años y quemar hasta la más pequeña boja, como se practica en Andalucía respecto de los olivos.

629. Carta sobre los hongos, y remedio de los venenosas; y sobre dos especies de aceytes que pueden suplir el de aceytunas para alümbrar - - Por D. Pedın Zaldidalvés. (Anágrama de Diaz Valdés).

Tratados sobre la fisica del Clero, pág. 133 á la 169, y Memovial literario, 1789.-T'omo XVII, págs. 199 y 273.

Resume cuanto sobre los hongos han diclıo los autores más notables de lodos los tiempos, y dá reglas para aminorar ó neutralizar los efectos del veneno que contienen algunas especies, añadiendo la indicacion de los caractéres que sirven para distinguirlos de los inofensivos.

En cuanto á las plantas de cuyas semillas ó frutos se puede extraer aceite, cita el onopordon ó cardo borriquero (Onopordon acanthium L.), y el cornejo. (Cornus sanguinea. L.)

630. Castaño; de su utilidád y cultivo.

El Cultivador, 1849.-Tomo II, pág. 78.

A segura ser la madera de castaño la mejor para pipería. Recuerda los seculares bosques de castaños a cuya sombra entonaban los druidas sus sagrados limnos Cita el castaño del monte Etna, cerca de la ciudad de Así, de 150 pies de circunferencia, y en cuyo tronco, que esta hueco, se alberga un pastor con todo su rebaño. Despues se ocupa del clima, terreno, siembra, plantacion y cuanto hace referencia al cultivo del indicado árbol.

631. Castã̃o (El).

Gaceta de Madrid.-24 de Diciembre de 1857.

Artículo reproducido de El Fénix, en el que con bastante extension se describe el árbol y los procedimieutos de siembra, plantacion, poda y labores de conservacion, así como se dá noticia de las condiciones de la madera y fruto, indicando la aplicacion que tienen estos productos. 
632. Castaño (El). Por L. B.

La Agricultura valenciana.-Tomo II, pág. 430.

Describe el árbol, indica las localidades españolas donde podria cultivarse, el método de cultivo y la aplicacion y consumo de sus frutos.

633. Castaños, Robles, encinas, hayas, nogalis y Fresnos.

Gaceta de Madrid.-28 de Diciembre de 1857.

Este artículo está tomado de $E l$ Faro Asturiano. Despues de encarecer las excelencias del arbolado, se ocupa de la formacion de los viveros y plantaciones de asiento, indicando el número de plantas que deben dejarse en cada unidad superficial, y el procedimiento de poda con destino los produclos á la carbonizacion.

634. Catálogo de lás aves de jaA Alburetia, por D. Ignacio Vidal, ccrresponsal de la Real Academia de Ciencias en Valencia.

Memorias de la Real Academia de Ciencias de Madrid.-Tomo I, 2." parte, pág. 167; y Tomo IV, 2. " parte, pág. 401.

Ofrece interes por designar las especies que son objeto de caza.

635. Catálogo de las aves observadas en Andalucía, por Don Victor Lopez Seoane y Pardo Montenegro.

Revista de los progresos de las ciencias exactas, fisicas y naturales.-Tomo XI, pág. 326.

En las curiosas noticias que contiene acerca de la habitacion y régimen de muchas aves, se encuentran indicaciones útiles para la ornitologia forestal.

636. CatÁlogo de las aves que frecuentan las inmediaciones de la ciudad de Santiago y otros puntos de Galicia, por D. Francisco de los Rios Naceyro, corresponsal de la Academia de Santiago.

Memorias de la Real Academia de Ciencias de Madrid.-Tomo I, 1. ${ }^{2}$ Parte, pág. 93.

Comprende indistintamente las aves que pueden ser objeto de caza, y las que ofrecen interés forestal, por los lugares que habitan ó frecuentan.

637. Catálogo METódico de LAS aves observadas en las Islas Baleares, por D. Francisco Barceló y Combés, licenciado en medicina y cirujía, catedrático de física del Instituto de segunda ensenanza de las Baleares, ex-catedrático de historia natural del mismo establecimiento.

Revista de los progresos de las ciencias exactas, fisicas y naturales.-Tomo XVI, págs. 45 y 103.

Indica, respecto de muchas especies, la habitacion, distinguiendo las que suelen encontrarse en los montes. Acerca del Lóxia curvirostra. Lin. Trenca-piñons, que se alimenta de piñones, hace un ligero estudio taxonó mico, para determinar si debe elevarse al rango de especie la variedad $b a-$ beárica. 
638. Catálogo metónico de las aves obserradas en una gran parte de la provincia de Murcia, por D. Angel Guirao, sócio corresponsal de la Real Academia de Ciencias de Madrid.

Memorias de la Real Academia de Ciencias de Madrid.-Tomo IV, 3. Parte, pág. 511.

Consigna noticias interesantes acerca del régimen y costumbres de muchas aves,

639. Causas de helarse los árboles en los rigorosos inviemos, y medios que propone el Sr. Stromer, profesor de la Universidad de Upsal, para preservarlos de este accidente.

Discursos mercuriales.-Números 20, 21 de Julio de 1756, página 1057.

Opina que los árboles, especialmente los que pierden los hojas en otoño, chupan en el verano gran cantidad de agua, la cual se evapora despues, y que los vasos de los ramillos más tiernos, son más anchos y capaces que los del tronco. Los árboles que conservan las liojas en invierno, dice que se ven más fácilmente asaltados por el frio, y de tales consideraciones deduce que antes que llegue el invierno, deben desnudarse los árboles imitando á la naturaleza, esto es, quitando las hojas de poco en poco y cuidando de no arrancar las ycmas.

640. Causas de la sequía y medio de precaverla con la conservacion y aumento del arbolado.

Semanario de agricultura y artes, dirigido á los párrocos. -1800 . - Tomo VIII, pág. 193.

Es un extracto de las observaciones comunicadas á la Sociedad de Agricultura del Sena por Cadet de Vaux. Tratábase en Francia de enajenar ó destruir los montes de la nacion, $y$ habiéndose publicado las observaciones de aquel escritor sobre la disminucion progiresiva de las aguas, sé alarmaron tanto los representantes del país, que desistieron desde luego de su propósito. Describe la influencia directa de los bosques sobre las agnas corrientes y manantiales, cuya evaporacion favorece el arbolado haciendo saludable el aire. Un bosque, dice, es un depósito del calor solar y del que irradia de la capa de restos orgánicos que cubre el suelo.

Aboga por la plantacion de árboles en los caminos, heredades, cementerios, cumbres, etc.

A continuacion de este escrito se inserta una carla sobre el mismo tema de un eclesiástico de Castilla (C. F. D. C.) En Agreda, segun el autor, no se admite vecino que no plante un nogal en la dehesa; asi se ha formado un bosque de nogales con el cual cubria el pueblo sus contribuciones. En Narros, tres leguas de Soria, pertenecen á cada vecino los árboles que planta á las orillas de un arroyo; así obtiene cada cual la leña que necesita para el consumo de su casa.

641. Causas (De Las) QUe pueden prodecir las eNferyeidadis EN LOS CULTIYOS ARBÓREOS,-POr A. Ch. 
Rerista de Agricultura del Instituto, etc.-1867.-Tomo XVI página 167.

Reseña los principales productns de toda clase que dan los árboies, y examina las causas de las enfermedades que sufren, que hace derivar en la mayor parte de los casos, de la continuacion de un mismo cultivo, y de siembras de especies á quieres no convenga el clima, situacion y exposicion; de la propagaeion por division; le la mala calidad de algunas semillas; de la mucha espesura; de los cambios de temperatura; de las malas podas; de los a taques de los insectos, etc.

Este artículo está basado sobre los trabijos siguientes: Sobre los medios de regenerar la agricultura en Francia y principalmente en el Mediodia.Marsella.-1820.-Por Mr. Lardier; y Memoria dirigida á la Sociedad de aclimatacion de Francia sobre el cultioo forzado; por Mr. Henrictte, cónsul rancés en el Cabo de Buena Esperanza.

642. Causas que Producen la postracion de la agricultura.Por D. F. Zabala.

Revista de caminos vecinales, canales de viogo y construcciones civiles.-1870. - Tomo VIII, páginas 153 y 177, y 1871, tomo IX, páginas 18,67 y 84 .

El autor atribuye á tres causas principales la decalencia agricola de nuestro país: á saber: la tala de los montes, la excesiva extension del cultivo y la mala calidad de los abusos. De la destruccion de los montes ha venido, segun el artículo, la escasez de lluvias, y la esterilidad del suelo.

643. Cocotero.-De su orígen, plantacion y aprovechamientos de su fruto y madera.-Por D. Lorenzo de Allo.

Semanario industrial.-1841. -Tomo II, pág. 181.

A unque exótico y propio de climas cálidos, cree que puede aclimatarse en los templados como el dátil y el naranjo. Describe los terreuos que le convienen y la siembra: puede ó debe sembrarse en el centro de los plantíos para resguardarlos del sol ó de los vientos. La madera es dura, filamentcsa y veteada; admite pulimento como el ébano, y sirve para marcos, bastones, muebles pequeños y shapas; en Cieilan hasta se hacen barcas con ella.

644. Código rural español.

El Amigo del Pais.-Tomo VIII, núm. 13, miércoles 3 de Abril de 1850 .

Contiene las priccipaies disposiciones de la legislacion rural española lesde el Fuero-Juzgo hasta 1850, relativas á baldios, dehesas y pastos, arbolados y plantios, caza y pesca, delitos y penas, y guardas y otros empleados.

645. Conunicado. - Por D. Mariano de la Paz Graells.

La Oorrespondencia.-Diario de noticias. -22 de Mayo de 1862.

Haciéndose cargo de las censuras hechas por varios periódicos y en particular La Esperanza conla el director del jardin Botanico de Madrid, que 
lo era entonces el comunicante, cen motivo de la poda practicada en el arbolado, sale á la defensa de esta operacion exponiendo el criterio científico que ha presidido á la poda, y manilestando las razones que hacen conveniente la renovacion de los árboles.

Este comunicado, lo dirigió el autor á la vez á La Esperanza y El Contemporáneo.

646. Conchptos equivoca uos, del Sr. D. Pedro Perez de la Sala, profesor de la Escuela especial de Ingenieros de caminos, canales y pliertos, en materia de montes é innundaciones.-Por D. Andrés Llauradó.

Revista forestal, económica y agricola.-Tomo IV, páginas $25 \%$, $321,485,549,618$ y $67 \%$.

En una série de seis extensos arlículos, rebate el Sr. Llauradó las opiniones emitilas por el Sr. de la Sala, en los que con el título de Inundaciones publicó en la Revisla de ouras públicas de aquel año, en co:itra de la inlluencia benéflca de los montes sobre las cresidas de los rios. Esta refutacion no ha sido contestada.

647. Condiciones de existencia de los montes.-Pol D. J. N.R. Las Provincias.-Diario de Valencia.-25 de $\Lambda$ bril y 2, 5 y 9 de Mayo 1867.

En los indicados numeros, se insertaron con aquel título, seis artículoy de'D. Juan Navarro Reverter, en los cuales, rebatiendo las icheas emitidas por D. Niguel Amat y Maestre en el mismo perióti:o, números del 7 de Febrero y 17 de Abril de ayuel año, sobre alribuir á la intervencion del Estado la decadencia de los montes, pidiendo en su virtud 'a desanortizacion absoluta de dicha riqueza, el atitor expone los fundamentos de la ciencia forestal, exaınina las relaciones economicas de los montes, estudia el espíritu y la aplicacion de las leyes desamorlizadoras y administrativas, y concluye de todo que al interés particular, inducido por el noovil de la especulacion, no le conviene tener montes altos, por cuyo molivo es menester que el Es ' tado se encargue de la conservacion y fomento de la indicada riqueza.

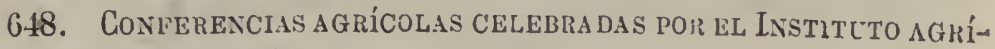
COLA CATALÁN EN 1872.

Revista del Instituto, etc.-1872.-Tomo XXi, pág’inas, 55, 94 y 121 .

En estas conferencias se puso á discusion el siguiente tema: "Es conveniente fomentar eı las cuatro provincias catalanas ó en parte de ellas la riqueza forestal? ¿Qué interés tiene en ello la agricultura? ¿Conviene verificar algunos repoblados? ¿Por qué inedios?", el cual formuló al socio D. José M. de Fivalier, iniciando la discusion, duranle la cual hicieron uso de la palaura, los sres. D. José Jordana, D. Luis Justo Villanueva, D. Francisco Lopez de Sincho, D. Andrés ferran y el seiior presidente D. Cárlos de Fontcuberta, conviuiendo todos en la importancia de los inontes, así fisica como económica, y en la necesidad de repoblar los terrenos yermus y torrenciales; 
á cuyo fin se propus la concesion de primas á otros medios de estímulo á los repobladores de los montes, y el elevar al Gobierno una exposicion pidiendo que proteja la riqueza forestal y modifique, si es preciso, la legislacion vigente, para conseguir este fin.

649.- Congreso agrícola en Buuselas el año de 1848. - Su programa; su primera sesion.

El A migo del Pais.-1848.-Tomo VI, pág. 248.-Boletin oficial del ministerio de Comercio.-1848.-Tomo IV, páginas 310 y 369 .

Entre los varios temas que se sujetaron á discusion, figuró el siguiente: "Influjo de la tala de los montes, y medidas sobre su plantio."

650. - CoNocimiento (Del) DE los Deittos y faltas POR INFraCCIONES DE LAS ORDENANZAS GENERALES DE LOS MONTES PÚILICOS.

El Consultor de los Ayuntamientos.-Tomo XIX.-1871._Página 42.

Pasa revisla á las disposiciones vigentes sobre la materia, determinando los casos en que el conocimiento corresponde á los Juzgados de partido, al municipal, al Gobernador de la provincia ó al alcalde en cuyo término haya tenido lugar la infraccion ó falta.

651. Conocimiento (DEL) y Castigo de los delitos y contravenciones de las ordenanzas vigentes en materia de montes públicos.Por D. J. Jordana.

Revista forestal, económica y agricola.-Tomo V, pág. 44.

Deduce de diversas consideraciones comparativas, la necesidad de una re. forma racional y ajustada á las prácticas y sistemas forestales de hoy en la legislacion penal del ramo, así como la urgencia de determinar con claridad la autoridad ó poder que ha de aplicarla.

652. Conservacion de las maderas.

Boletin enciclopédico de la Sociedad económica de Amigos del Pais de Valencia.-1841.-Tomo 1, pág. 240.

Este artículo está tomado del Bulletin de la Societé d'encouragement. Se indica en él que las alteraciones de las maderas provienen de reacciones expontáneas y de los ataques de los insectos, originándose grandes perjuicios á las construcciones, por lo cual seria de mucha utilidad conocer exactamente las alteraciones llamadas podredumb:e seca y hümeda, calentamiento, carcoma, etc. Enumera los esperimentos hechos por los señores Paýen y Arosa, para encontrar una sustancia preservadora.

653. Conservacion de las simientes y preparacion de las mismas para la siembra.-Por D. E. Boutelou.

Revista forestal, cconómica y agricola.-Tomo II, pág. 625.

Resúmen ó compendio de lo más principal que se ha publicado sobre la materia. 
65̃4. Conservacion y Coloracion de las maderas y de los cáñamos y linos.

Semanario industrial.-1841.-Tomo II, pág. 105.

Se refiere el autor al procedimiento de inyectar las maderas sumergiéndolas por el extremo del córte en una cubeta que contenga el líquido inyectante. Para aumentar la dureza recomienda el pirolignito de hierro; para la incombustibilidad, los cloruros y varias sustancias solas ú combinadas para la coloracion. Atribuye estos procedimientos al médico de Burdeos Mr. Boucherie.

655. Consideraciones económicas sobre la propiedad forestal.Por D. Francisco García Martino.

Revista forestal, económica y agricola. -Tomo II, págs. 27, 79, $129,193,257,321,385$ y 449.

En una série de cíez artículos, y apoyado en razonamientos así maternáticos, como fisicos y econiomicos, concluye el autor demostrando que la posesion de los montes por el Estado es conveniente, legítima y ajustada al camun sentir, respondiendo rle esta manera á la ley económica, á la ley jurídica y á la ley moral.

Estos artículos, algun tanto ampliados en la Revista forestal, se publicaron en la Revista general de Estadistica, tomo II, 1863, pág. 617; tomo III, 1864, págs. 11 y y 611 , y tomo IV, 1865, págs. 321, 335, 476 y 513.

656. Consideraciones generales sobre la historia Y la liteRatura de la ciencia forestal en Alemania.-Por D. F. G. Martino.

Revista forestal, económica y agricola.-Tomo I, págs. 19\%, 383, 514 y 612 .

Analiza el progreso de la ciencia dasonúmica y las vicisitudes de la propiedad en todos los periodos históricos, dando á conocer los fundamentos de las teorias y las combinaciones de los métodos que han traido á la ciencia forestal al grado de desarrollo que hoy tione.

65\%. Contestacion a un artícijlo de «El Iimarcial.»-Por Don I. A. y M.

Las Provincias, diario de Valencia.-13 y 14 de Marzo de 1868.

Dos artículos, en que su autor D. Higuel Amat y IIrestre, haciénúose cargo de otro publicado por $E l$ Imparcial, en el que pide la desamortizacion de los montés con ciertas precauciones, defiende la inmediata enagenacion de esta riqueza, suponiendo que si se hacen las tasaciones debidamente, y se venden las fincas por su justo valor, el interés particular será bastante para que no se talen ó arrasen, siempre que radiquen aquellos en la verdadera zona forestal.

658. Conimúa «El Reino»atacando al Ministerio di Fomento EN LAS CUESTIONES DE MONTES..... ETC.

La Epoca.-Periódico político.-18 de Mayo de 1862. 
Como lo indica el comienzo del articulo que dejamos copiado, La Epoca reclifica varios conceptos de su cólega respecto á la superficie forestal de España, á la clasificacion por métodos de beneficio, á las ventas de montes hechas por el Ministerio de Hacienda, y á los asertos atribuidos á los autores más autorizados que han tratado de la materia, confirmándose en la opinion ya emitida un otros artículos, de que las disposiciones del Real Decreto de 22 de Enero último, están en arınonia cou el parecer de la Junta facultativa del ramo, y responden perfectamente á las necusilades del país y á los principios desamortizadores.

659. CorRespondencia.-Por D. J. Navarro Reverter.

Revista forestal, económica y agricola.-Tomo I, págs. 342 y 423.

Dos cartas dirigidas al director del periódico, en las que el señor Navarro Reverter, profesor de la Escuela especial de Ingenieros de inontes, dá cuenta de la excursion verificada en compañia de los alumnos de la Escuela, á los montes de las sierras dé Cazorla y segura, en la provincia de Jaen, con cuyo motivo describe ligeramente el estado de aquellos montes, y hace algunas consideraciones económico cientiticas del mayor interès. Estas cartas fueron reproducidas por La América.

660. Correspondencia.-Por un suscritor.

Revista forestal, económica y agricola.-Tomo V, págs. 539.y 591 .

Es una reseña histórica, geográfica y natural de los valles de Neez y Ossau (Francia), y otra especial, con caracter dasonómico, del monte de pinabete y haya de Laruns, con una descripcion minuciosa de los caminos de arrastre (schlitte) del monte de aquella villa, denominado Bitet.

661. Contabilidad.-Por D. H. Ruiz Amado.

Revista forestal, económica y agricola.-Tomo II, págs. 65 y 283.

Desarrollia la teoría de la cortabilidad, encareciendo esle estudio por su roce con la economía política y con la cuestion relativa á las diferencias que lay entre los eampos y los montes. Estudia la cortabilidad física, la absoluta y la relativa á los productos más útiles, á la mayor venta y al mayor interés, así como la llamada compuesta ó sea la que abraza el mayor interés y los productos más considerables en un tiempo dado.

662. Costumbris cubanas.-Por D. J. Emilio de Santos.

Revisla forestal, económica y agricola.-Tomo IV, págs. 522, 581,645 y 646 .

Se ocupa de la vejetacion leñosa y maderable de la isla de Cuba, facilitando minuciosos datos acerca de la densidad y resistencia de las principales maderas.

Añade un catálogo de los vejelales que producen resinas, gomo-resinas y sustancias uleaginosas.

663. Costumbres inglesas. - Los jardines de Kew。 
Las Novedades.-Periúdico político . -8 de Marzo de 1854.

Estensa descripcion en la que se dá cabida á la de las especies arlóreas más notables que se encuentran en aquellos jardines.

664. Criaderos ó planteles de Árboles.-Por D. Nicolás Casas.

El Amigo del Pais, 1846.-Tomo IV, págొ. 49.

Describe todas las operaciones propias de los semilieros y arborelos en el primer artículo. Iil segundo versa sobre los planteles de árboles de bosque y monte, el cuarto sobre los árboles dé adorno y sombra, y el quinto sobre los verdes ó resinosos, entendiendo por tales los pinos, abetos, pinabetes, cipreses, cedros, tuyas, enebros, tejos, etc. Los ảemás árboles que conservan sus hojas durante el invierno. los coloca en el grupo de los de adorno y sombra.

665. Cultivo de arenas voladoras por Medio de Natazos.-Por D. Salvador Ceron.

Revista forestal, económica y agricola. -Tomo V, pág. 321 .

Describe la formacion y cultivo de los navazos formados en los arenales ó dunas de Sanlúcar, Chipiona y Rota, y las repoblaciones de pino piñonero extendidas desde la márgen izquierda del Guadalquivir, laasta cl lérmino de Trebugena.

666. Cultivo de los rinos (DEL).-Por D. José Loño.

El Eco de la Ganaderia.-Tomo VII, pág. 180.

Trata del cultivo del pinus pinea, sylvestris y maritima, con especial aplicacion á Galicia, indicando despues los productos que se ob!ienen de dichos árboles, particularmente los resinosos, acerca de los cuales extier,de más las noticias.

667. Cultivo del exebro.

Extractos de las Juntrs generales celebradas por la Real Sociedad bascongada de los Amigos del Pais en la villa de Vergara por Setiembre de 1776.-Pág. 16.

Noticia de un escrito sobre el cu'tivo del enebro, y en particular del que hay en las islas Bermudas, con el fin de desarrollar las varias inclustrias á que puede aplicarse su madera, goma, aceite y boyas.

668. Cultivo del piño Marítino EN Sologne.

Gaceta de Madrid. -8 de Noviembre de 1847.

Lleva este artículo al pié esta indicacion: (A del P) Tiene por objeto dar á conocer los métodns de siembra del pino marítimo pue se usan en Sologne, y al efecto dá cuenta de las labores preparatorias, de la cantidad de semilla, del modo de ejecutar la siembra, y de los cuidados que se prodican á las plantas jóvenes. Cita ejemplos de siembras hechas en diversas localidades dando prrmenores numrosos de ellas y de la proporcion en que se mezcla la semilla del pino marítimo con la del silvestre. y li de encina, y aun algunas veces con la del castaño, procedimiento que parece estar bastante gene ralizado en aquel pais. 
669. Cultivo É InJerto del AlCoRnoque (Alsina surera).-Por Miguel de Foxá.

Revista de Agricultura práctica.-1852.-Tomo I, pág. 127.

Describe lijeramente la especie y la siembra y trasplante, tratardo del injerto sobre la carrasca para facilitar el crecimiento. Se ocupa de los de coronilla y hendidura, recomendando este procedimiento para lograr que se puedan hacer los descorches antes de que el árbol tenga treinta años. Excita á los agricultores para que extiendan el cullivo de esta especie.

670. Cultivo y aprovechamento de la barrilla, salicor, algazul, sosa y otras plantas saladas.-Por D. Mariano Lagasca.

Agricultura general de G. A. de Herrera, edicion de 1816 y 1819.-Adiciones al libro I, tomo I, pág. 228 á 311.

Describe el terreno propio para las referidas plantas, el modo de llevar á cabo el cultivo, el tratamiento contra ciertas enfermedades, y los métodos de elaboracion de la barrilla.

671. Cumpliendo nuestro empeño.... ETC.

La España.-Periódico político.-27 de Abril de 1862.

Enumera, contestando á La Epoca, los defectos de que adolece el Real Decreto de 22 de Enero último, encontrando, especialmente en los artícu$\operatorname{los} 3 .^{\circ}, 4 .^{\circ}$ y $5 .^{\circ}$, faltas graves que pueden ser causa de que se vendan terrenos cubiertos de arbolado cuya conservacion interesa, y que no se mejoren ni repueblen por falta de recursos propios otros montes cuyo estado de decadencia es notorio.

\section{D.}

672. Datos Forestales. - Por Isaac Glastupun.

Revista general de Estadistica.-'Tomo I.-Mayo, 1862, página 129.

No es difícil reconstruir cơn la corrbinacion anagramática que autoriza el artículo, el nombre de uno de nuestros más insignes y esclarecidos forestales, propagador infatigable de la dasonomia en España.

Los datos forestales constituyen un estudio crítico y filosófico del desarrollo de la dasanomia á través de los tiempos, confirmando el discurso variados datos estadísticos relativos á los montes de Altenburgo, Anlralt Bernburgo, Anhal-Dessan-Köthen, Austria, Baden, Baviera, Bélgica, Gran Bretaña, Brunswick, Coburgo, Dinamarca y Francfort del Mein.

673. De DONde ulínos SE PIENSA.... etc.

La Epoca.-Periódico político._-13 de Noviembre de 1872.

Recuerda al Imparcial, con quien debate acerca del proyecto de ley de montes presentado á las Córtes por el miusistro de Fomento Sr. Echegaray, que la ley municipal vigente y la Real órdeu de 29 de Julio último en las que el colega encueutra peligros para la conservacion de los monles, fueron hechas precisainentt" por el Sr. Rivero y el mismo Sr. Echegaray, autor del 
proyecto que defiende aquel periódico. Añade La Epoca que el Sr. Ruiz Zorrilla sostuvo en el Congreso, en el año $18 j 2$, doct rinas contrarias á las que contiene el proyecto en cuestion, relativas a la clase de montes y á la superficie de los que debian entregarse á la venta.

Reproducido en la Revista foresial, económica y agricola. -Tomo VI, página 140.

674. Débeuos expresivas GRaCias..... etc.

La Epoca.-Periódico político.—7 de Febrero de $186 \%$.

Trasmite las nolicias que acerca del Eucalyplus le comunica D. Estanislao Malingre, recomendando el indicado árbol para la repoblacion de nuestras montañas y comarcas desarboladas, á cuyo efecto excita el celo del Gobierno para que destine á esta atencion el 20 por 100 de las cortas de los montes, y estimula á los particulares para que organicen sociedades de aclimatacion y agricultura.

675. ¿DEBEN VENDERSE LOS MONTES DEL ESTADO?-Por D. José María de Fivaller.

Revista forestal, económica y agricola. -Tomo I, pág. 234.

Aboga por la propiedad nacional de los montes en atenciou á que satisfacein necesidades públicas y generales, referentes á la salubridad, defensa del suelo, modificacion del clima y otras acciones de conservacion, negando. con el testimonio de distinguióos economistas, que el interés yarticular sea bastante para conservar los montes y aumentar su produccion.

676. DEL PROYeCTO DE LEY dE MoNTES..... etc.

La Epoca.-Periódico político.--7 de Noviembre de 1872.

Artículo çue censura principalmente el espíritu desamortizador, el reparto de terrenos y otros puntos culminantes del proyecto de ley de montes presentado á las Córtes por el ministro de Fomento Sr. Echegaray.

Reproducido en la Revista forestal, económica y agricola. -Tomo VI, página 134.

67\%. Demóstracion aNalítica DE UNA IMPORTANTE LEY FORESTAL. -Por D. Alberto Bosch.

Revisla forestal, ecowómica y agricola.-Tomo III, pág. 505.

Carta del autor en la que por medio del cálculo a nalítico demuestra la generalidad de la förmula deducida en los artículos que publicú la Revista, con el título de Considerariones económicas sobre la propiedad forestal, aplicable á la demostracion de que la renta en especie de los montes, disminuye á medida que se eleva el turno.

678. Desayortizacion Civil (LA), en sus relaciones con los montes.-Por D. A. A. y V.

Revista forestal, económica y agricola.-Tomo I, pág. 81 .

Artículo dedicalo al exámen del informe emitido por Jovellanos en el célebre expediente sobre el proyecto de ley agraria, en lo que se relaciona con los montes, deduciendo que el iuterés particular, al cual fiaba el porvenir de la riqueza forestal aquel ilustre patricio, no ha respondido como se 
prometiera al fin del fomento del monte alto, perseverando aquel, por el coutrario, en su conducta de destruecion.

679. Desamortizagion COMPLETa É inMediata de la propiedad TORESTAL.-POR D. M. A. y M.

Las Provincias._Diario de Valencia._27 de Noviembre de 1868.

Encareco el autor, D. Miguel A nat y Maestre, la conveniencia de desamortizar todos los montes públicos, para que se dediquen al cultivo agrario permanente los que sean á propósito para ello, y para que se inejoren y repueblen los que se encuentren en la verdadera zona forestal, con el estímulo y la eficacia del interés particular.

680. Desamortizacion de los montes del Estado.-P. J. S. V. Revista económica.-Tomo III, pág. 193.

Reconociendo la influencia climatolóoica del arbolado de las montañas, se congratula, sin embarẹo, de que se entreguen á la desamortizacion, segun el Real decreto de 22 de Enero de 1862, la mayor parte de los montes de Galicia.

681. Di:Sayortizacion f0anstal. - Juicio crítico de la sesion del Senado correspondiente al 26 de Abril.

El Reino.-Periódico político.-5 de Mayo de 1862.

Comenta la interpelacion dirigida al Gobierno por el señor marqués de Corbera, á propósito del Real decreto de 22 de Enero último, manifestando que por la indicada disposicion se enajenan ter renos elevados, pendientes é impropios para la agricultura, reduciendo el área forestal necesaria para el equilibrio climatológico y ecorómico de la nacion. Hace resaltar la diferencia de apreciacion entre el Ministro de Fomento y el de Hacienda respecto de los montes que habian de ser enajenados.

682. DesayortizaCion Forestal. - Juicio crítico de las sesiones del Congreso de los Diputados en los dias 8, 10 y 11 de Marzo.

El Reino.-Periódico político.-11, 12 y 14 de Abril de 1862.

El tema se desarrolla en tres articulos, teniendo por objeto combatir las disposiciones del Real decreto de 22 de Enero del mismo año. Quéjase $E l$ Reino de que no se haya oido á la Junta facultativa de montes; de que se saquen à la renta, sin una clasificacion especial prévia, montes que ocupan regiones montañosas y torrenciales; de que sỏlo se exceptien de la desamortizacion las fincas de pino, rohle ó haya; de que se deja reducida el área forestal del país a $1 / 15$ del área lotal del territorio, entrando en otras extensas consideraciones accrea de las nesesidades generales de la nacion en sus reJaciones con los montes, de las que se deduce que el decreto objeto de la discusion ha de causar qrandes males por la excesiva latitud que dá á la desàmortizacion forestal.

683. Desamortizacjon yorestal (La).

Diario de Barcelona.-19 de Noviembre de 1868 .

Expone las principales condiciones económicas, físicas y sociales que reunen los montes, y la especial tendencia del particular á destruir esta ri- 
queza, citando las leyes $\mathrm{y}$ disposiciones amortizadoras de más importancia de Francia y los Estados-Unidos, y las cantudades destinadas á la repoblacion. Termina pidiendo que se reserven de la venta aquellos montes que por su situacion y condiciones especiales sean considerados como de interés general, idea admitida en la enmienda del artículo 11 de la ley de presupuestos del ejercicio económico corriente.

684. Desamortizacton Forestal.-Por D. J. Jordana.

Revista forestal, económica y agricola.-Tomo III, pág. 256.

Tiene por objeto encarecer la importancia y la necesidad de los montes, así como establecer el principio de que deben exceptuarse de la venta, los que estén situados en donde no quepa establecer un cultivo agrario permanente.

685. Desamortizacion Forestal.-Por D. José Jordana.

El Eco de la ley y la Espaĩa juridica.-Núm. 15, 22 de Marzo de 1860.

Examina las disposiciones vigentes sobre la materia y defiende la amortizacion del monte alto, en virtud de la influencia física y económica que ejerce sobre el pais.

686. Desamortizacion forestal. - Véase: Algunas palabras sobre la importancia de los montes y arbolados.

687. Desamortizacion (LA) DE NUEstra RIQUEza FOREstal.Por D. José Bragat.

La Provincia. Periódico de Huesca.-Núm. 37.-20 de Marzo de: 1869 .

Examina la influencia de los montes sobre las aguas corrientes, terreno, vientos, lluvias, etc., citando hechos concretos acaecidos en algunos pueblos de la provincia, y termina recomendando que la cuestion de la venta de los montes se estudie con detenimiento, excluyendo de ella aquellus cuya conservacion sea necesaria por exigirlo el interés general, que debe estar siempre sobre el interés privado.

688. Descripcion de la isla DE Pinos, hecha por el capitan de fragata de la marina Real, D. Juan Tirry y Lacy, comisionado para examinar si los pinos de que está poblada y los betunes que estos producen podian ser útiles para el uso de los bajeles de la Armada; exornada con varias noticias sobre sus producciones, situacion de sus costas y rentajas que pueden prometer.

Continuacion del Almacen de frutos literarios.-Tomo III, página 97 .

Ofrecen abundantes noticias forestales los párrafos en que se trata de la calidad de las tierras de la isla y de sus producciones naturales, de la salubridad del clima, aires y aguas, uso y utilidades que se han sacado ó podrán esperarse de los bosques, calidal de los pinos, inconvenientes para que se crien robustos é inutilidad de estos árboles para arboladuras.

Esla descripcion está flrmada por su autor á 10 de Diciembre de 1797. 
689. Descripcion topografica de la Albufera, ó famoso lago que.se halla en las inmediaciones de la ciudad de Valencia; noticia de sus producciones y de las aves y pescados que en él se crian, etc. Por D. Miguel Serrano Belezar.

Memorial literario, 1788.-Tomo XV, páginas 12 á 30 .

Explica las derivaciones de la albufera por manantiales propios y por la concurrencia de las principales acequias, expresando la infinita va riedad de aves que allí se encuentran.

690. Desuontes. -Desagües. - Trabajos usuales.-Instrumentos de labranza. - Tratado especial traducido y arreglado por D. Augusto de Búrgos.

Instruccion para el pueblo, 1851.-Tomo II, páginas 2049 á 2080. Tratado número 65.

Describe é ilustra con diez y ocho grabados las operaciones de los desmontes de los bosques y terrenos baldíos; asi como los sistemas de desagüe por derivacion, ascension, salida, infiltracion y elevacion del terreno.

691. Despues de Desechada la enmienda..... etc.

El Reino. Periódico político. -9 de Junio de 1862.

Reseña favorablemente la defensa hecha por el Sr. Ruiz Zorilla en el Congreso, de una enmienda al proyecto de ley de montes, en la que se pedia la excepcion de la venta de los montes de roble, pino y haya, áun cuando tuvieran ménos de cien hectáreas, siempre que el ingeniero de la provincia creyese que debian exceptuarse por cualquier molivo.

692. Destruccion de algunos animales dañinos á la agricultura.

Semanario industrial, 1840.-Tomo I, página 200.

Recomienda el empleo del hidrỏgeno sulfurado para destruir las ratas, topos, zorras y otros animales.

693. Desvinculacion (LA) y la desamortizacion de la propiedad civil en Inglaterra y Francia.-Por D. Francisco de Cárdenas.

Revista de España.-Tercer año.-Tomo XVII, página 321.

Estudia In desamortizacion de la propiedad municipal en Inglaterra, tanto de propios como de comunes, el estado de la de igual clase en Francia antes de la revolucion de 1789 , su desamortizacion y el restablecimiento de la misma desde 1796.

694. DrCtámen de LA COMrsion y voto particular sobre la proposicion dè ley presentada por el Sr. Nuñez Arenas, concediendo una pension al huérfano Rodrigo Lainez, reproducida á peticion de dicho Sr. Nuñez Arenas.

Diario de las Sesiones de Córtes.-Año 1861.

Fechado en el palacio del Congreso á 24 de Enero de 1861, y suscrito por 
D. Bernardino Nuñez Arenas, D. Ramon de Frau, D. Ambrosio Gonzalez, D. Juan J. Cañas y D. Mariano Ballestero.

Se propone la concesion de una pension anual de 3.000 rs. á favor del niño D. Rodrigo Lainez, huérfano del ingeniero primero del Cuerpo de montes D. Antonio Lainez y de Doña Magdalena Martinez Falero, muertos del cólera en Toledo dende se hallaba destinado el ingeniero en cuestion.

El voto particular, contrario á esta concesion, lo formularon en 22 de Febrero de 1861 los diputados D. Ramon Ugarte y D. Agustin Leis.

695. Discurso que D. Antonio Cavanilles leyó en el Real Jardin botánico de esta córte el $10^{\circ}$ de Abril de 1802, sobre la utilidad, multiplicacion y germinacion de las plantas, importancia de los bosques, etc.

Anales de ciencias naturales._-Tomo V, pág. 111.

Laméntase de que se destruyan los bosques y que no se planten, desconociéndose que su disminucion camina al mismo paso que la de las aguas.

696. Discurso SOBRE EL ESTADO Y DECANENCIA DE LOS MONTES Y plantíos, y de su restauracion.-Por el segundo censor (de la Sociedad Económica de Segoria), D. Nicolás Alonso de Miranda.

Actas y Memorias de la Sociedad Económica de Segovia, 1793:Tomo IV, páginas 219 á 268.

Estima como árboles más útiles para el hombre los pinos, encinas, robles, quejigos y fresnos, porque dan maderas, leñas y carbones. Condena la inobservancia de la Ordenanza Real de 1748. Se hace cargo en un extenso capítulo de las causas de la decadencia de los montes, atribuyéndola á los mismos dueños, á los guardas, á los ganaderos y á los leñadores; propone las reglas conducentes á la restauracion de los montes y pinares por medio de visitadores peritos que participen de las inultas, traza los deberes y atribuciones de estos funcionarics y resume las doctrinas de su discurso anticipándose á explicar lo que, á su juicio, puede parecer más censurable ó inconducente.

697. Discurso sobre la necesidad de una descripcion completa de la cordillera de Sierra-Morena, con relacion á los tres reinos de la historia natural, leido por el Sr. D. Felipe Naranjo y Garza en la sesion pública de su recepcion como Académico numerario, celebrada el dia 11 de Enero de $185 \%$.

Memorias de la Real Academia de Ciencias de Madrid.-Tomo IV, 2. " parte, pág. 329.

Hace algunas indicaciones de ias especies zoolngicas y botánicas de aquella localidad, distinguiendo las forestales.

698. Disfrute y aprovechamiento de los Montes Municipales.

Revista de Administracion.-Tomo II, año II, 2. "época, página 502.

Reproduce un artículo de $E l$ Radical Asturiano, que tiene por objeto 
censurar una circular inserta en el Boletin oficial de aquella provincia, relativa al plan de aprovechamientos de los montes públicos de la misma para el año 1872-73. Al efecto, estudia las disposiciones contenidas en los artículos 78 y 79 de la ley municipal y la Real órden del ministro de la Gobernacion, fecha 8 de Mayo de aquel año, encontrándolos en oposicion con lo prevenido en la Real órden emanada del ministerio de Fomento con fecha 21 de Agosto del propio año, concluyendo de todo, que en vista de la falta de conformidad y armonia, deben los Ayuntamientos atenerse á las leyes y disposiciones peculiares ó emanadas del ministerio de la Gobernacion.

699. Dunas de la ciudad de San Sebastian (Las), su repoblacion y cultivo. - Por D. Aniceto Valls d'Amprana.

Revista forestal, económica y agricola.-Tomo III, pág. 89.

Describe las dunas, el método empleado en su repoblacion y el estado del repoblado obtenido por medio de siembra,

\section{W.}

700. Économía RURAL. -Por D. Juan de Revilla Oyuela.

Revista de España.-Tomo XIX, pág. 511.-Tomo XX, página 570. -Tomo XXII, pág. 69 y tomo XXIII, pág. 378.

Se ocupa de los terrenos baldíos, comunes, concejiles, de aprovechamiento comun y de propios, manifestando la conveniencia de desamortizar los terrenos de los municipios, que llama de universidad para favorecer el desarrollo de la agricultura, de cuya medida parece querer excluir á los montes "que la ley (se reflere á la de desamortizacion de 1855) ha declarado previsoramente, dice, exceptuados de la venta."

701. El arbolado del Retiro se pierde.-Véase: Parque, (El) los jardines..... etc.

702. El AUTOR DE LOS ARTículOS SOBRE MONTES..... etc.

El Contemporáneo. Periódico político. -8 de Mayo de 1862.

Contiende con La Epoca manifestando que debe reservarse á la accion del Estado los montes beneficiados á turnos largos y los que no sirvan de un modo permanente para el cultivo agrario. Recorre la legislacion antigua para demostrar que la necesidad de conservar los montes ha sido siempre reconocida, y termina considerando necesaria la ley de montes que se proyecta, si bien cree que su espíritu debe responder al principio de reservar el área ocupada por los montes, cuya influencia físico-económica, no armonizada con el interés particular, exija su perpétua conservacion.

703. EL PROYECTO DE LEY DE MONTES..... etc.

El Constitucional. Periódico político.- $-1 .^{\circ}$ de Abril de 1862.

Considera muy conveniente el proyecto de ley de montes presentado al Congreso de los Diputados por el señor ministro de Fomento, suponiendo que por su medio se conservará la riqueza forestal. 
704. EN LoS Últimos dias..... etc.

El Reino. Periódico político.—5 de Junio de 1862.

Se ocupa de la discusion del articulado del provecto de ley de montes, encontrando fuudada la enmienda que tenia por objeto exseptuar de la venla las fincas pobladas de roble, pino y haya, cuya superficie excediera de cincuenta hectáreas, anulándose para esta cabida las que distaren entre si ménos de dos mil metros.

705. EN NUESTRO ANTERIOR ARTí CUL 0...... etc.

La Epoca. Periódico político.-28 de Abril de 1862.

Entrando en referencias y comparaciones de datos estadísticos abundantes, se propoue demostrar que, llevado á cabo lo que dispone el Real decreto de 22 de Enero último acerca de la venta de montes, no quedará en Espaĩa ménus superficie forestal de la que es necesaria para que exista el equilibrio que debe haber entre la produccion agrícola y la produccion dasonómica.

706. EN UNo DE nUESTRos Últimos n ÚMERos..... etc.

La España. Periódico político._22 de Octubre de 1859.

Dedica un extenso artículo á la cuestion de la venta de los montes, defendiendo por razon es científicas y económicas la posesion de aquella riqueza por el Estado. Da da la clasificacion de aquellas fincas hecha por el Cuerpo de ingenieros de montes, se lamenta de la gran superficie forestal que debe entregarse á la venta y de las malas condiciones on que esta ha de tener lugar.

707. Enagenacion de la dehesa de la Jara (LA).

El Guadalquiviv .Periódico liberal (Córdoba).-Números 115, 6 de Abril.-116, 7 de Abril._138, 3 de Mayo._139, 4 de Mayo._144, 10 de Mayo.-145, 11 de Mayo, y 151, 18 de Mayo de 1866.

El autor de estos artículos es D. Ramon Jordana. Constiluyen dos séries; la primera compuesta de cuatro secciones, liene por objeto demostrar quela enagenacion de la dehesa de la Jara del comun de vecinos de varios pueblos de la provincia de Córdoba, seria más conveniente haciéndo la prévia division en lotes, en el supuesto de haber sido declarada de propios.

A consecuencia de un comunicado inserto en el mismo periódico, núme ro 124, y suscrito por el corresponsal de Pozoblanco, en el que se defiende la venta de la finca en grandes quintos, comenzó de nuevo su trabajo el articulista, exponiendo en cinco artículos la conveniencia, la necesidad y el mayor provecho que habia de obtenerse con vender la finca en lotes pequeños, para dar acceso á todas las fortunas y evitar el monopolio de unos cuantos poderosos, que serian los únicos que tendrian el capital disponible para adquirir la finca integra.

708. Excina.-Descripcion de várias especies nuevas.-Considerables plantaciones de dicho árbol y utilidad de sus aprovechamientos.-Por D. Luis Née.

Anales de ciencias naturales, 1799, 1804.-Tomo III, pág. 260. 
Comienza por la descripcion de nueve especies ya conocidas y presenta la de diez y seis nuevas de América. Reseña los productos de todas clases que se obtienen de dichos árboles y cita plantaciones de 40 y 150.000 pies hechas en su tiempo, lamentándose de que este ejemplo no lenga imitadores.

Segun el Sr. Colmeiro (La botánica y los botánicos), comprende Née como propias de España algunas especies que no lo son.

709. Excina (LA).-Por D. R. Jordana.

Revista forestal, económica y agricola.-Tomo V, páginas 497 y 548.

Monografía que trata de los nombres, descripcion, variedades, distribucion geográfica, condiciones de existencia, método de beneficio en monte medio y bajo, productibilidad, siembra, plantacion, cualidades y aplicaciones de la madera, leña, carbon, fruto y casca, y enemigos y enfermedades.

710. Exsayo crítico sobre algunos artículos penales de las Ordenanzas generales de montes de 22 de Diciembre de 1833.-Pol D. J. Jordana.

Revista forestal, económica y agricola.-Tomo IV, páginas 655 y 679 .

Despues de algunas consideraciones históricas y científicas acerca de la teoría penal en lo relativo á los montes, examina los defectos de que adolecen los artículos 145, 186, 187, 188, 189, 190, 191, 192, 193 y 194 de las Ordenanzas generales del ramo, indicando los conceptos cuya modificacion es necesaria.

711. Entre todas las Fórmulas parlamentarias... etc.

La España.Periódico político. -6 de Noviembre de 1859.

Se ocupa de la interpelacion del Sr. Marqués de Molins en el Senado sobre la venta de montes, y con este molivo discurre con bastante extension acerca de la conveniencia de conservar los montes públicos, exceptuándolos de la desamortizacion, y sobre todo, fijando reglas más severas para determinar los que deban enagenarse.

712. Eirpitologia hispalensis, seu catalugus metodicus reptilium et amphibiorum in provincia hispalensi viventiun, auctore Antonio A. Machado, MUCCCLIX.

Memorias de la Real Academia de Ciencias de Madrid.-Tomo IV, 3. parte: pág. 561.

Indica las localidades forestales en que se encuentran y habilan varias especies de las comprendidas eı el catálogo.

713. ¿Lis POSIBLE Ó CONVENIENTE LA REUNION DE TODOS Ó PATTE DF LOS ESTABLECIMIENTOS QUE SE DEDICAN AL FOMENTO DE LAS PRODUCCIONes forestal, agrícola y animal?-Por D. Miguel Viñas. 
Revista de Agricultura práctica, 1863.-Tomo XII, páginas 97, 169 y 195; y 1864.—Tomo XIII, pág. 165.

Este trabajo tiende á demostrar que hay una relacion intima entre los estudios forestales, agrícolas y veterinarios, y al efecto discurre bajo la base de que la tierra sustenta los vegetales y estos sirven para la alimentacion de los animales. Critica la creacion aislada de las escuelas especiales de aquellos ramos, y expone un plan de enseñanza para una escuela de Bconomía rural, en la que la parte forestal se estudiaria en dos años.

714. Escándalo en Huesca.

La República Ibérica. Periódico de Madrid.-9 de Febrero de 1870.

Denuncia las escandalosas cortas que se ejecutaban en los montes del Pirineo, de las cuales se habia ocupado ya la prensa de aquella provincia.

715. Escandalosas talas del. Pirineo. (Las).

El Alto Aragon, periódico de Huesca.-28 de Junio de 1870.

Censura ágriamente las talas que se ejecutaban en los montes másimportantes del Pirineo de aquella provin sia y reclama la más eficaz actividad por parte de las autoridades para hacerlas cesar y castigar á los dañadores.

716. Escursion forestal al Nacimiento del Ason.-Por $\mathbf{X}$.

Revista forestal, económica y agricola.-Tomo IV, páginas 361 y 598 .

Es una descripcion geográflco-forestal del valle de aquel rio (provincia de Santander), y de sus principales condiciones económico-dasonómicas.

717. Esparto (DeL). - Por D. Cárlos Lasalde.

El Fomento.-Tomo II. 1872. Pág. 326.

Fechado en Yecla á 2 de Junio de 1872. Dá cuenta de la naturaleza, propagacion, terreno que requiere, aplicaciones y cultivo del esparto.

718. Esparto (EL).

Gaceta de Madrid.-30 de Diciembre de 1865.

Tomado de La Agricultura española. Es un extracto del folleto, A puntes sobre el esparto, de que damos cuenta en el lugar correspondiente.

719. EsPeCies arbóREAS QUE deben PROPAGarse bN EsPaña.-Por D. Estanislao Malingre.

Gaceta de Madrid.-11 de Setiembre de $186 \%$.

Con molivo de la coleccion de maderas que Austria envió aquel año á la Exposicion de París, enumera las cualidades de algunas especies del indicado pais, aconsejando su aclimatacion y propagacion en España.

720. Especies y variedades de Pinos que se crian en la sierra de Cuenca.-Por D. Estéban Boutelou.

Semanario de Agricultura y artes.-Tomo XX. Madrid 1806.

Cuenta entre las especies el Pinus Cembra, L, que Palou llamó pino uñal, pero tal especiẹ, dice el Sr. Colmeiro (D. Miguel), es propia de montes más 
elevados, y el indicado nombre vulgar corresponde al pino mollar, que es variedad del Pinus Pinea, L.

721. EstadístiCa de LOS MONTES ESPAÑoles, su Estado y AdMinisTnacion.-Véase: Algunas palabras sobre la importancia de los montes y arbolados.

722. Estadística forestal.-España.-Por D. P. G. de la P.

Revista forestal, económica y agricola. -Tomo 1, pág. 52.

Comprendedatos críticos que expresan el estado en que se encuentran los montes públicos españoles, su extension, pertenencia y productos.

723. Estadística Forestal.-Fraircia-Por D. P. G. de la P.

Revista forestal, cconómica y agricola.-Tomo I, pág. 266.

Despues de una série de datos referentes á la superficie, métodos de beneficio, propiedad, situacion, administracion y personal para el servicio de los montes, deduce que la despoblacion de estos ha sido fatal para el país, y que son laudables los esfuerzos que hace para repoblar las montañas y yermos.

724. Estadística forestal.-Prusia.-Por D. P. G. de la Peña.

Revista forestal, econónica y agricola.-Tomo I, pág. 113.

Relaciones numérico-criticas, acerca de la superficie forestal, propiedad, especies arbóreas dominaıtes, renta, personal, material, ordenacion, cultivo, rescate de servidumbres y otros de gran interés para comprender el grado de desarrollo á que ha llegado en Alemania, la conservacion y explotacion de los montes.

725. Estadística forestal.-Véase: Produccion de cortezas curtientes en España.

726. Estado del SERvicio púBLico Forestal.-Por R.

Revista forestal, económica y agricola.-Tomo V, pág. 481 .

Dá cuenta de los vicios de que adolece el servicio en lo relativo al personal y á las operaciones generales; examinando tambien las disposiciones legislativas que á su juicio, entorpecen la accion administrativa y cientifica.

727. Extension del AJBolado y REPOBLACION DE lOS BOSQUES POI? Medio del eucalyptus. - Véase: El arbolado en España.

728. Estos dias Se ha estado discutienro..... etc.

La Lisperanza. Periódico político. -27 de Mayo de 1862.

Combate el proyecto de ley de montes, presentado á las Córtes por el ministro de Fomento, considerando injusta y perjudicial para el país, la venta de aquellas fincas.

729. Extraccion del Corcho en panas.-Por D. Narciso Fonolleras.

Revista de Agricultura práctica. 1855. -Tomo IV, pág. 215.

Entiende que seria destruir la riqueza del pais, providenciar la libre extraccion del corcho. Con respecto á ta provincia de Gerona, hace notar la 
importancia que en ella tiene el aprovechamiento del corcho, cuyos tapones se consumen en gran cantidad en el extranjero. Se extiende en consideraciones proteccionistas para la industria taponera nacional, aduciendo el ejemplo de lo que bacen los gobiernos de otros paises.

730. Estudios acerca de la especie, con motiro de una revision de la familia de las cupulíferas.-Por Mr. Alf. de Candolle. (Ann. des Sciences natur. t. 17. núms. 1 y 2).

Revista de los progresns de las ciencias. -Tomo XIV, pág. 155 y 236 .

El autor se ocupa extensamente de la agrupacion de las formas de las cupulíferas, y de varias observaciones y conjeturas sobre la historia y origen de aquellas formas, dando cuenta de las especies del género Quercus y concluyendo que en el estado actual de la ciencia es tan dificil definir la especie, como el género ó la familia.

731. Estudios forestales sobre el reino de Prusia.-Por Don F. de P. Arrillaga.

Revista forestal, económica y agricola.-Tomo II, págs. 98, 145, $227,293,474,535$ y 674.

Extracto crítico de la obra Die forstlichen Verhäitnisse Preussens, publica. da en Berlin, por el Director general de montes, Otto de Hagen. Comprende la estadística de los montes en su extension, situacion, suelo, especie, estadoy renta; legislacion y administracion; intervencion del Estado en la administracion de los montes de los pueblos y corporaciones; estado legal de los montes y propiedades del Estado; servicio forestal; principios generales í que se ajusta la administracion, conservacion, a:nojonamiento y medicion de los montes; ordenacion, aprovechamientos, administracion y direccion de turberas, prados, viveros, jardines, flotajes y caza.

732. Estudios sobre la inundacion del Júcar.-Por D. Augusto Belda.

Las Provincias. Diario de Valencia.-2 de Enero de 1867.

En vista de la Memoria sobre la inundacion del Júcar en 1861, escrita por el inspector del cuerpo de Ingenieros de Montes D. Miguel Bosch y Juliá, el $\mathrm{Sr}$. Belda se extiende en consideraciones, atribuyendo gran influencia en el régimen de las aguas al suelo y al arbolado de los montes, pidiendo que se forme un plan general ce defensa del territorio contra los estragos de las aguas, y que se repueblen los terrenos yermos y calvos dé las montañas, para prevenir los daños de las inundaciones y asegurar el cultivo de muchas superficies, hoy indefensas y condenadas á la esterilidad.

733. Estudios sobre la inundacion del Júcar. - Por L. O. de V. Gaceta de Madrid.-23 de Diciembre de 1865.

El autor compendia la Memoria sobre la inundacion del Jícar en 1864, de que damos cuenta en otro lugar, encomiando dicho trabajo y reproduciendo la indicacion de los medios que en el mismo se proponen, como indispensables para evitar aquella calamidad. 
734. Eucalyptus Globulus.-Por D. Joaquin Salarich.

Revista de Agricultura del Instituto, etc., 1866.-Tomo XV, página 80.

Da noticias acerca de este árbol, y contiene algunas instrucciones para el uso de la hoja en in fusiones antitípicas.

735. Exposicion Agrícola celebrada en Barcelona en 1872.-Por D. Eugenio Plá y Rave.

Revista forestal, económica y agricola.-Tomo VI, páginas 65 y 113.

Examina con bastante detencion las diferentes cla ses de productos que concurrieron al certámen, haciendo una his toria de los procedimientos seguidos para organizarlo y de la distribucion del local en donde tuvo lugar. Al tratar de los productos naturales correspondientes á la primera seccion, se hace cargo de las plantas curtientes, maderas, cortezas y demás productos forestales que expusieron D. Juan Dodero, el distrito forestal de Lérida, don Ildefonso de Casanova y D. Francisco Domingo.

736. Exposicion elevada por el Instituto á las Córtes, en solicitud de que se deseche el proyecto de ley de Montes, presentado por el Gobierno.

Revista del Instituto, etc., 1873.-Tomo XXII, pág. 59.

La firman en Barcelona á 12 de Diciembre de 1872, los indivíduos de la junta directiva, de la que es presidente D. Pelayo de Camps y secretario D. Andrés de Ferran.

Examinando el proyecto que presentó á las Córtes en 5 de Noviembre último el ministro de Fomento Sr. Echegaray, entiende el Instituto que el interés de la conservacion del monte alto no reside en el particular, que es injusto el reparto de los terrenos de aprovechamiento comun; que á semejanza de lo que pasa en Francia y otras naciones, es menester cuidar de la repoblacion de nuestros montes; que los planes de aprovechamiento deben hacerse exclusivamente por el personal facultativo, y que la especie arbóren no es carácter bastante para fijar la conveniencia de la conservacion o enagenacion de un monte: de todo lo cual deduce la inconveniencia del proyecto, cuya desaprobacion pide á las Córtes.

737. Extracto de la Memoria del Sr. D. Vicente Calvo y Julian, Canóni go de la catedral de Tarazona, conforme al acuerdo de la clase de agricultura en las Juntas del $10^{\circ}$ y 3 de Abril de 1777.

Memorias de la Sociedad Económica (de Madrid).-Tomo I, página 288.

Esta Memoria fué presentada al concurso abierto por la Sociedad, bajo el tema: Exímen de los medios para que florezca sólidamente la agricultura y se remuevan los obstáculos que puedan impedirla, sin detrimento de la cria de ganados.

El autor encarece la utilidad de los bosques y la repoblacion, recomendando á la vez que se propaguen las buenas prácticas de cultivo y que se 
reformen las leyes penales, aumentando las multas contra los transgresores de cualquiera providencia concerniente á la cria de árboles. Este punto constituye el cuarto medio propuesto por el autor como provechoso al fo. mento de la agricultura, y lo resume bajo el epigrafe de Extension y buena calidad de los plantios.

738. Extracto DE LA OBRA FRANCESA titulada Historia de las encinas de la América septentrional, por el licenciado Andrés Michaux.

Anales de ciencias naturales, 1799, 1804.-Tomo V, pág. 104.

Describe veinte especies, áun cuando Michaux parece que trató de veintinueve.

\section{F.}

739. Ferrerías.-Notas sobre la situacion de las Ferrevias primitivas y actuales del Norte y del Oeste de España, y sobre los bosques que les suministran combustible.-Por D. Eugenio Karr.

Revista económica.-Tomo III, pág. 336.-Es reproduccion de la Gaceta de los caminos de hierro.

Trata de los métodos de fundicion y encarece la necesidad de conservar los hosques. Presenta datos estadísticos del consumo de carbon vegetal é indica las especies que deberian introducirse, como más propias para prodúcir el carbon más estimado en las ferrerías, añadiendo algunas ligerísimas consideraciones acerca del cultivo de las especies aludidas.

740. Filtros naturales.-Por E. M.

La Epoca. Periódico político.-21 de Octubre de 1870.

Es una carta suscrita con las indicadas iniciales y fechadą en Madrid á 14 de Octubre de aquel año, en la cual se propone como medio más eficáz pară que las aguas del Lozoya no se enturbien, la repoblacion de lis montañas cuyas vertientes forman la curnca de aquel rio, á cuyo efecto se extiende en algunas consideraciones respecto á la æccion con que obra sobre las aguas corrientes y subterráneas la vegetacion leñosa de los montes.

741. FoMento dél ARBolado.

El Consultor de Ayuntamientos.-Tomo XI, 1863, pág. 54.

Reproduce la circular del Gobernador de Ciudad-Real, D. Enrique de Cisneros, expedida con fecha 28 de Euero de 1863, en la que se previene á los Ayuntamientos que hagan plantaciones de árboles en los paseos, y entradas y salidas de las poblaciones, así como que exciten el celo de los huerteros para que coloquen alrededor de cada pozo-noria doce árboles por lo ménos, prefiriendo el álamo negro ó la morera. El Consultor aplaude esta determinacion, y encareciendo la utilidad de la multiplicacion del arbolado, recomienda la creacion de viveros provinciales, de donde puedan sacarse las plantas para facilitarlas con equidad á los pueblos y propietarios.

En el tomo XIV, 1866, pág. 28, publica el indicado Consultor, con igual titulo, otro artículo encaminado al mismo firs, entendiendo que la planta- 
cion debe hacerse extensiva á todas las provincias, consignándose en los presupuestos municipales, provinciales y del Estado, las sumas necesarias para la creacion de viveros, y para premiar á los particulares que más se distingan en materia de plantaciones.

742. Fonento deL arbolado.

El Norte de Castilla. Diario de Valladolid.-Núm. 4865 del jueves 13 de Febrero de 1873.

Forma parte este articulo, de una série que tiene por objeto el estudio de los medios para fomentar la riqueza. Habiendo en los anteriores artículos tratado de la conservacion de las carreteras y de los riegos, supone que sigue, por órden de importancia, el ramo de arbolados afirmando la necesidad de mantener el equilibrio entre los terrenos de labor y los montuosos segun el testimonio de la ciencia y la experiencia, y conforme al ejemplo de otros paises. Aconseja el fomento del arbolado en plantaciones lineales á lo largo de las carreleras, ferro-carriles y rios, y establece la conveniencia de que el Estado se apodere de los terrenos forestales, cualquiera que sea su extension.

743. Fonento del arbolado. -Por J. G. H.

Revista económica.-Número 11 del 7 de Enero de 1873.

Considera fuera de duda que debe haber arbolado en todos los silios donde no estorbe á otra produccion, principalmente en las orillas de las carreteras, rios y terrenos estériles, apoderándose de ellos el Estado. Combate el proyecto de ley de montes presentado á las Córtes por el ministro de Fomento Sr. Echegəray, pidiendo una nueva clasificacion de terrenos "que comprenda los desmontables y los no desmontables." Reclama la formacion de viveros municipales proporcionando las semillis el Estado, para cuya atencion supone que bastaria un presupuesto de 100,000 reales al año.

744. Fomento del ARBOLado.

Revista económica.-Tomo II, pág. 353. Es reproduccion de El Crédito.

Encarece la importancia del arbolado, aconsejando la apertura de vias de comunicacion y la concesion de premios á los mejores selvicultores, para fomentar la riqueza forestal.

745. Fonento y mejora de Los montes PÚBLicos.-Por D. R. Egozcue.

El Eco de Aragon.--Periódico político de Zaragoza. --Núm. 2605, del 6 de Abril y 2606, del 7 de Abril de 1872.

Recorre la legislacion antigua y moderna para probar que en todas épocas el Estado ha procurado el fomento y la mejora de los montes, y encareciendo la conveniencia de la repoblacion, pide que se destinen desdo luego á este objeto las sumas descontadas del importe de los aprovechamiontos de montes sujetos á subasta, segun determina la legislacion vigente.

746. Forma de los árboles que viven en espesura, y nuevo método de cubicacion. 
Revista forestal, económica y agricola.-Tomo V, pág. 273.

Es una traduccion del artículo que, scbre este asunto, publicó en la Revue des Eaux el Fórets, M. Reynard.

747. Fornacion de las resinas en los vegetales.-Por D. R. de Xérica.

Revista forestal, económica y agricola.-Tomo V. págs. $15 \mathrm{y}$ 234.

Recopila todo lo que se ha escrito sobre el particular con arreglo á los conocimientos modernos.

748. Fórmüla para la interpolacion de términos en la série del crecimiento leñoso.-Por D. F. de P. Arrillagra.

Revista forestal, económica y agricola.-Tomo V, págs. 6 y 71 .

Explica y desarrolla la fórmula de Breymann para la construccion de tablas de produccion y crecimientos.

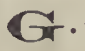

749. GAS DE LEÑ̃ .

Revista económica.-Tomo III, pág. 252.

Se ocupa de la fabricacion de este gas, encareciendo sus buenas cualida des para el alumbrado, de la brea, ácido piroleñoso, etc. Indica las especies más apropósito para la obtencion de estos productos.

750. Guardería rural.

El Eco de Aragon. Periódico político de Zaragoza.-20 de Febrero de 1872 .

Encarece la necesidad de organizar una buena guardería por el abandono en que yace la propiedad rủstica, aceptando el reciente proyecto de $D$. José Galofre, consignado en su Memoria y proyecto para eslablecer una guarderia rural en España.

751. Guardería rural.-Por D. José Jordana.

El Argos.-Núm. 134, 8 de Febrero de 1872.

Tiene por objeto este artículo examinar la Memoria escrita por D. Jose Galotre, con el lítulo de Memoria y proyecto para establecer una nueva guarderia rural en España. Aceptando todos los fundamentos en que esta se apoya, entiende el articulista que es muy recomendable crear una fuerza única para los campos y los montes, inamovible, sujeta á la disciplina militar, conocedora del pais, organizada en cuerpo, é i:upuesta en la legislacion penal, para la custodia de la propiedad territorial.

752. Guardia Rural.-Projecto para establecerla, presentado al Real Consejo de Agricultura, Industria y Comercio por la Comision de su seno, nombrada al efecto.

Boletin oficial del Ministerio de Comercio. 1849.-Tomo V, 
pág. 530.-El Amigo del Pais. 1849.-Tomo VlI, páginas 162 y 169.

En ambas publicaciones se inserta el razonamiento de la Comision antes de proponerse el proyecto, con idea, segun órden de la Direccion general de Agricultura, fecha 19 de Marzo de 1849, de que los Gobernadores, Municipios, Juntas de Agricultura, Sociedades económicas y particulares, ilustrasen la materia con sus observaciones. La Comision tuvo presentes, al formular sus trabajos, un proyecto de la asociacion de propietarios;de Barcelona y otro de los de Estepa, elevado al Gobierno por conduclo del Gobernador de Sevilla. Resultado de estos trabajos preparatorios y de otras informaciones que se reunieron, fué el reglamento de los guardas de campo, aprobado por Real órden de 8 de Novieınbre de 1849 , que aun está vigente.

La Sociedad Económica, en el tomo VII, pág. 172, del periódico El Amigo del País, emitió su opinion en seritido de que la guardia rural dehe ser una institucion nacional, y no municipal; auxiliar y congénere de la civil, en la seguridad de que todos los pueblos de España que pagan con gusto los treinta millones que ésta cuesta, 10 rechazarian el pago de los quince que debe costar la rural.

\section{H.}

753. ¿HAY SOLIDARIDAD ENTRE LOS CAMPOS Y LOS MONTES, ó SON POR El CONTRARIO ANTAGóNicos?-Por D. José Jordana.

Revista de Agricultura práctica. 1863.-Tomo XII, pág. 76.

Describe las principales condiciones que distinguen el cultivo agrario del forestal y enumera los auxilios que el segundo proporciona al primero, deduciendo de ahí la conveniencia de que se conserve siempre cierta extension de superficie destinada à montes.

754. - Haya (EL). - Véase: Monografía dasográfica del Haya.

755. Haya (EL).-EL ROBLe.-Por D. Luis Perez Minguez.

El Eco de la Ganaderia.-Tomo VII, pág. 515.

Se publicó tambien en $L a$ Abeja montañesa. - Trata de la cria y cultivo de dichas especies, con aplicacion al terreno y clima de algunas localidades de España. Llama al roble carbayo, y carbayones á los robledales.

756. Humes (EL).-Por D. F. de P. Arrillaga.

Revista forestal, éconómica y agricola.-Tomo II, pág. 43.

Estudio sobre la composicion, division, propiedades y aplicaciones de aquella sustancia, con arreglo á los últimos adelantos de la química orgánica.

\section{I.}

757. IDEA DEL ALTO GRADo de opulencia á que puede ascender 
Cataluña, con la cosecha de aceites, cuando se cultiven los muchos vegetales olefferos, propios y adoptables á su país, y se beneficien sus frutos, en especial el hayuco ó fruto del haya.-Por D. Francisco Mirambell y Giol, presbítero y socio de la Real Academia de buenas letras y de la de Ciencias naturales y artes de la ciudad de Barcelona, cura párroco de la villa de Prats de Llusanés, corregimiento de Manresa.

Memorias de Agricultura y artes.-1819. Tomo VII, pág. 149 y 195.

Extiéndese en consideraciones' cconómicas sobre la produccion y consumo del aceite, é indica las páginas de dichas Memorias en donde puede consultarse el trabajo de D. Juan Francisco Bahí acerca de las propiedades de los frutos oleaginosos.

758. IDEA SOBRE EL MODO DE EVITAR LOS DESBORDAMIENTOS É INUNDACIONES DEL JÚCAR, Y MEDIOS DE AMINORAR SUS CALAMITOSOS EFECTOS. -Por D. Manuel Beixet.

El Valenciano. Periódico de Valen cia.-22de Noviembre de 1864.

Entre las medidas que el autor propone para evitar las inundaciones, figura el repoblado de los imontes, obligando á cultivar y plantar á los dueños dentro de diez años, todo el erial contenido en las cercanías de los rios principales y sus afluentes. Se da cuenta de este trabajo en la Memoria sobre la inundacion del Júcar en 1864, de D. Miguel Bosch y Juliá.

759. IDEAs GEnerales sobre la conveniencia de la enagenacion, en la provincia de Santander, de los terrenos conocidos con el nombre de Sierras-bajas. - Memoria leida en la Junta de Agricultura, Industria y Comercio, por el vocal nato de la misma D. José Ezquerra (Ingeniero de montes.)

La Abeja montañesa. Periódico de Santander.--1866.

Describe las sierras, (que son los montes calvos ó poblados de especies de poca importancia forestal), encarece la utilidad que podrian reportar des tinadas á prados artificiales, refuta las objeciones que se hacen en contra de la venti y concluye indicando los medios que deberian adoptarse para efectuar la enagenacion que se propone.

760. InCONVENIENTES DE LA DIVISION DE LA PROPIEDAD EN ALGUNos Montes de Extremadura. - Por D. Ramon Jordana.

El Eco de la ley y la España juridica.-Núm. 58, 28 de Febrero y núm. 60, 15 de Marzo de 1861 .

Estudia las consecuencias de la division con respecto á los incendios, censos, talas y roturaciones, haciendo un exámen crítico de la legislacion antigua y moderna, y da á conocer los inconvenientes de la division de dueños por lo que hace al suelo y vuelo. En sentir del autor, la base de la conservacion y futura regeneracion de los encinares extremeños seria la refundicion inmediata de dominios. 
- 761. Individuo vegetal (EL) y su duracion, - Por C. C.

Revista forestal, económica y agricola.-Tomo VI, pág. 5.

Examina las diversas teorias sobre la especie y la longevidad de los vegetales, concluyendo que, dados los conocimientos actuales, la representacion genuina del individuo debe buscarse en el vegetal completo, y que todas las plantas mueren necesariamente de vejez, cuando antes no han sido destruidas por los accidentes ó enfermedades, persistiendo sólo la especie en la sucesion de generaciones.

Este trabajo es debido al ingeniero de montes D. Cárlos Castel.

762. Industria fabril Je LAS TEnerías.-Por J. S. V.

Revista económica.-Tomo III, pág. 409.

Reseña las condiciones económicas de esta industria y presenta al final una lista de plantas forestales con indicacion de las proporciones de tanino que contienen, y químicos que han hecho los análisis.

763. INFLUENCIA DE LA LUZ EN LA VEGETACION.-Por D. Luis de la Escosura.

Revista forestal, económica y agricola.-Tomo V, págs. 139 y 209.

Estudio de los descubrimientos más modernos acerca de la indicada influencia en el órden químico y fisiológico.

764. Influencia (DE LA) QUE LOS hUMOS DE LAS FÁbRicAS DE FUNDICION DE SULFURO DE PLOMO, ejercen en la vegetacion.-Por D. R. de Xérica.

Revista forestal, económica y agricola.-Tomo II, pág. 689.

El título indica claramente el objeto de este trabajo. Se da cuenta en el de curiosos experimentos y análisis de los que se deduce que aquellos humos son notoriamente perjudiciales á la vegetacion arbórea.

765. INFLUENCIA DE LOS BOSQUES EN LA PRODUCCION CEREAL. Por D. José Jordana.

El Eco de la ganaderia.-Tomo XII, pág. 7.

Es un fragmento de una série de artículos que con el título de Desamoriizacion forestal, publicó el autor en la Revista forestal, económica y agrico$l a$, tomo III, 1870. La redaccion del $E c o$ encabezó el fragmento sin conocimiento del Sr. Jordana.

Versa sobre la influencia de los montes en el clima, vientos, aguas y suelo agrario.

766. Informe sobre la galeruCA Ulma Riensis dE la AlHAMbra. -Por D. Benito Ventué.

Revista del Instituto etc. 1872.-Tomo XXI, pág. 304.

Este estudio, en el cual se describe este insecto de la fámilia de los chrysomelinos, su modo de vivir y los medios inás apropiados para destruirlo, se hizo en virtud de la plaga que atacó al arbolado de la Alhambra de Gra- 
nada, mediando al efecto algunas órdenes expedidas por el ministerio de Fomento.

767. INFORME SOBRE LAS GOMAS, RESINAS Y GOMO-RESINAS, principalmente de las Indias Occidentales.-Por el Sr. D. Juan Pablo Canals, Baron de Balroja.-Madrid 28 de Marzo de 1778.

Memorias de la Sociedad Económica de Madrid, 1787.-Tomo III, pág. 84 á 92 .

En virlud de este trabajo que fué recomendado al Gobierno por la Sociedad, se expidió una circular encargando á los vireyes y gobernadores que enviasen muestras y comunicasen noticias acerca de aquellos productos.

768. Ingenteros civiles.-Por D. Manuel de Osquiguilea.

Extractos de las Juntas generales celebradas por la Real Sociedad Bascongada de los Amigos del pais en la villa de Bilbao por Setiembre de 1784.—Pág. 78.

Este trabajo consiste en una carta que el autor, residente en Génova, dirició á la socierad, sometiencio á su exámen dos proyectos, uno proponiendo la creacion de un cuerpo ó gremio de ingenieros civiles, compuesto de profesores hidrostáticos, geómetras, arquitectos civiles y agricultores, y otro, consistente en la formacion de un mapa geográfico de toda precision y exactitud.

Para la clase de agricultores, el autor reclama conocimiento y pericia en el aprecio y valor de las tierras, en su cultivo, en el plantío de arboledas, en el corte de las maderas y en la inspeccion de los bosques.

769. Ingenieros. (Los)-Por D. A. Ximenez.

La Gaceta industrial.-21 y 28 de Diciembre de 1871 y 29 de Febrero de 1872.

Tres artículos de los cuales los dos primeros están dedicados á combalir la organizacion de las escuelas especiales de ingenieros de caminos, minas y montes en España, y el modo de ser de los cuerpos facultativos de estos ramos. Contestados oportunamente en la Revista foresial, económica y agricola por D. Ramon Jordana, dedicó el tercero el Sr. Ximenez á hacerse cargo de los argumentos expuestos por éste. Replicś de nuevo el indicado Jordana, defendiendo la organizacion de las escuelas tal como subsiste hoy, y aceptando tambien la institucion que tienen en el dia los cuerpos facultativos, sin que el articulista de La Gaceta industrial haya tenido por conveniente proseguir la polé:nica.

770. Ingenieros. (Los)-Por D. R. Jordana.

Revisla forestal, económica y agricola.-Tomo V, págs. 97 y 192.

Snn dos artículos'de polémica, con referencia á los publicados por la $G a-$ ceta industrial en los números del 21 y 28 de Diciembre de 1871 y 29 de $\mathrm{Fe}-$ hrero del año 1872 por D. A. Ximenez. Il Sr. Jordana defiende la organizacion de la enseñanza en las Escuelas especiales de ingenieros civiles y la 
de los cuerpos facultativos de los ramos correspondientes. Su contrincante dejó huérfana la contienda como ja se ha dicho.

771. INGerto. (DeL)-Por G. del C.

Gaceta de Madrid. -30 de Mayo de 1847.

Breve indicacion de los procédimientos más usuales para preparar y conservar el ingerto y el patron; y enumeracion de las diferentes clases de ingertos.

772. Ingertos.-Por D. Domingu de Miguel.

Revista de agricultura práctica. 185\%.-Tomo VI, pág. 309 .

Examina las condiciones que deben reunir los vegetales para poder practicar con éxito aquella operacion, y describe los ingerlos más comunes.

773. Instruccion para el servicio público de los montes de la provincia de Ziragoza.

Boletin oficial de la provincia de Zaragoza, núm. 27, martes 16 de Febrero de 1869.

Autorizado por el Gobernador interino D. Gervasio Ucelay, á 15 de Febrero de 1869. Consta la instruccion de 21 articulos relativos á las obligaciones de los Ayuntamientos y del personal de guardería, eı punto á poíicía, conservacion, daños y otros asuntos de interés forestal. Al final se inserta la distribucion por comarcas y cuarleles del personal subalterno de montes destinado á la provincia por decreto del Excmo. Sr. Ministro de Fomento fecha 27 de Diciembre último.

774. InSTRUCCION PRÁCTICA sobre la creacion de prados naturales.-Por Buenaventura Arago.

El Amigo del Pais, 1848 y 1849.-Tomo VI, págs. 356, tomo VII, págs. 12, 21, 24 y 51. dos.

Trata del cultivo en todas sus formas, y de las plantas útiles para pra-

775. INSTRUCCIONES NECESARIAS PARA EL CONOCIMIENTO DE DIVERSAS PLANTAS DEL PAIS, cuyo uso puede servir para ahorrar las encinas y otros vegetales propios ó extranjeros que se emplean en las tenerías para el curtido de las pieles. Por Mr. Gledissch. Memorias de la Real Academia de las Ciencias de Berlin, año 1754.

Inserta en el tomo IV, pág. 117, de las Memorias instructivas y curiosas, sobre Agricultura, Comercio, Industria, Economia, Qutmica, Botánica, Historia natural, etc.

Discurre sobre las plantas de corteza curtiente é inserta una larga lista de las que se ban empleado en ensayos de tenería.

776. INUNDACION DEL JÚCAR (LA) EN 1864.-Por N.

Las Provincias. Diario de Valencia.-20 y 22 de Noviembre de 1866.

Son dos artículos que tienen por objeto dar cuenta de la Memoria sobre 
la inundacion del Júcar en 1864, presentada al Misisterio de Fomento por el inspector del cuerpo de ingenieros de montes, D. Miguel Bosch y Juliá. Se elogia el trabajo, y se reproducen con extension las ideas, conceptos yobservaciones prácticas de más bulto que contiene la Memoria referida. Es ya público que estos notables artículos los escribió el ingeniero de montes Don Juan Na varro Reverter.

777. Inundaciones (LAS).--Por A. R.

Diario de Barcelona.-28, 29 y 31 de Diciembre de 1866.

Se hace cargo con mucha detencion de la Memoria sobre la inundacion del Júcar en 1864, presentada al Minisiro d $=$ Fomento, por D. Miguel Bosch y Juliá, inspector general de segunda clase del cuerpo de ingenieros de montes, dando cuenta detallada de todos los puritoš de que trata, mereciéndole elogios el trabajo y manifestando el deseo de que se difunda y se generalicen las aplicaciones que del mismo se derivan.

778. Inundaciones (Las) y kEl Pensamiento español.»

Las Provincias. Diario de Valencia.-10 y 16 de Enero de 1867.

En controversia con aquel periódico, Las Provincias sale á la defensa de la civilizacion moderna, demostrando que esta se esfuerza en remediar los males que nos han legado los siglos en que dominaba la absorcion absolutista, y al efecto, cita las repoblaciones de las Landas de Burdeos en Francia y las que se hacen en Alemania, para evitar los estragos de las lluvias torrenciales, atribuyendo á los montes la mayor y más benéfica influencia en el régimen hidrológico. Asímismo, defiende la desamortizacion considerando que el interés particular se basta á si mismo para repoblar los terrenos desnudos de vegetacion arbórea.

779. InLNdACIONES. - Por D. P. P. de la S.

Revista de obras públicas.-Tomo XIX, 1871, núm. 3, 1.` de Febrero; núm. 4, 15 de Febrero; núm. 5, 1. ${ }^{\circ}$ de Marzo; núm. 6, 15 de Marzo; y núm. 7, $1 .^{\circ}$ de Abril.

En estos artículos, su autor el Ingeniero de caminos, profesor de la Escuela especial del ramo, D. Fedro Perez de la Sala, se propone probar que la ciencia del Ingeriero es impotente contra aquella calamidad, y al efecto, copiando muchas ideas del ingeniero francés Mr. Vallés, uiega la influencia de los bosques en la aminoracion de aquellos desastres, porque supone que el suelo de los montes es ménos absorbente que el de los terrenos cultivados y que la accion del arbolado para aminorar la cantidad de lluvia, no está bien comprobada.

Contradice algunas aserciones contenidas en la Memoria sobre las inundaciones del Júcar, de D. Miguel Bosch y Juliá, con cuyo motivo, D. Andrés Llauradó salió á la defensa de dicho trabajo, y combatió las erróneas teorías del Sr. de la Sala en una série de artículos publicados en la Revista forestal, económica y agricola de aquel año, con el título de Conceplos equivosados del señor D. Pedro Perez de la Sala, profesor de la Escueia sspecial de ingenieros de caminos, canales y puertos en materia de montes $\dot{e}$ inundaciones. Quedan registrados en el lugar correspondiente. 
780. Invento curioso.

Boletin oficial del Ministerio de Fomento. 1856.-Tomo XIX, pág. 429.

Es una descripcion del procedimiento de Mr. Apelt, profesor sajon, para conservar las maderas. Consiste en poner á estas en contacto con el carbon sulfurado, que pasa á carbon vitriólico. Se extrae la humedad almosférica quedando expuesto á la influencia de la lluvia el sulfato de hierro contenido en el carbon, se disuelve y penetra lenta y gradualmente en la madera, mineralizándola casi completamente.

\section{L.}

781. La Epoca Sale en difensa..... etc.

El Reino. Periódico político.-1. e Mayo de 1862.

Es contestacion á un artículo de aquel periódico, en que defendia el Real decreto de 22 de Enero de aquel año. En este artículo $E l$ Reino demuestra que la ciencia puede resolver el problema de la determinacion local de la influencia cosmológica de los montes; que no hay conformidad entre la opinion de los hombres de ciencia y la doctrina que establece aquel Real decreto, y que este es funesto para el pais por el extraordinario desarrollo que da á la desamortizacion forestal.

782. La FRECUENCiA CON QUE SE REPITEN..... etc.

La Epoca. Periódico político.-3 de Marzo de 1868.

Lamentándose de las sequias que sufre el país, recomienda la propagacion y replantacion de los montes, y estimula al gobierno para que destine á estas operaciones cuanto antes, el 10 por 100 de los productos de los montes públicos.

783. La PREMURa de los trabajos periodísticos..... etc.

La España. Periódico político.-18 de Marzo de 1862.

Se hace cargo de la discusion habida en el Congreso de los Diputados á propósito del Real decreto de 22 de Enero del mismo año, en la parte relativa á la desamortizacion de montes, combatiendo la venta de los terrenos torrenciales y otros, cuya situacion exige que no se entreguen al dominio privado, para que no sean descuajados.

Da cuenta tambien de haber recibido un folleto con el título de Los montes españoles, bajo el punto de vista de su desamortizacion y administracion, cuyo objeto es combatir aquel Real decreto por la excesiva extension que se da á la venta de los montes públicos. La España encuentra interesante, práctico y digno de estudio el folleto en cuestion.

784. La sesion uUe tuvo lulüar en el Congreso..... etc.

El Reino. Periódico político. - 16 de Mayo de 1862.

Se hace cargo de la discusion de la totalidad del proyecto de ley de montes, y elogia el discurso del Sr. Ruiz Zorrilla encaminado á limitar la desamortizacion de los montes, por inconveniente para los intereses agricolas y 
sociales. Con na la clasificacion por especies y propone el sistema de reconocer en cada caso la localidad.

785. Las tardías JeREMIAdas..... etc.

La Epoca. Periódico político.-19 de Marzo de 1862.

En contestacion á un artículo de La España, defiende el Real decrelo de 22 de Enero de aquel año, afirmando que la nueva clasificacion de montes obedece al mismo criterio científico á que se subordinó la de 1855, y que se introducen importantes mejoras en el servicic, para regularizar la marcha de los aprovechamientos, hacer repoblaciores, montar sequerias, preparar !a creacion de un personal subalterno y otras modificaciones importantes.

786. Legislacion de Montes.-Por D. MI. Salvá.

Revista económica.-Tomo I, pág. 209.

Expone el mal estado de los montes en diferentes períodos históricos, y considera como reforma más apremiante la de que se apliquen las doctrinas de la ciencia al cuidado, conservacion y aprovechamiento de los arbolados.

787. Legislacion forestal.-Por D. José Jordana.

El Eco de la ley y la España juridica.-Núm. 7, 22 de Enero de 1860 .

Se ocupa de los defectos de que adolece la legislacion del ramo, y aboga por la promulgacion de una ley, que estando exenta de aquellos vicios, contribuya á mejorar la riqueza forestal.

788. LeY DE MONTES.

La Prensa. Periódico político.-6 de Diciembre de 1872.

Censura el proyecto de ley de montes presentado á las Córtes por el ministro de Fonıento señor Echegaray, concluyendo que de su aplicacion se seguirá la extension del aprovechamiento comun sin mejorar la situacion angustiosa de los pueblos, y perturbaciones graves en el clima y régimen de las aguas por la desaparicion de los montes que se entreguen á la venta.

Reproducido en la Revista forestal, económica y agricola.-Tomo VI, pág. 142.

789. LEY DE MONTES.-Por J. G. H.

Revisla económica.-Núm. 12 del 24 de Diciembre de 1872.

Tiene por objeto examinar el proyecto de ley presentado á las Córtes por el ministro de Fomento en 5 de Noviembre de aquel año. No encuentra claro en él, más que el propósito de llevar la desamortizacion tan lejos como sea posible, cuyo intento combate, afirmando que los montes ejercen una benéfica influencia en el clima, en la agricultura y en la hidrografía. Cita casos prácticos de la accion de las masas de árboles sobre las corrientes torrenciales y sobre la sujecion del terreno, y considerando necesaria en cierta proporcion, la conservacion del arbolado forestal, entiende que debe ponerse limitacion al uso de los montes que se vendan, á fin de asegurar su existencia; que debe atenderse más á la posicion orográflca que á la super- 
ficie en la designacion de los que deban reservarse de la venta, y que es menester establecer los casos y condiciones en que los terrenos que no tengan cierta cantidad de vegetacion, pueda el Estado apropiárselos sin indemnizacion, los casos en que hayan de devolverse estos terrenos á los particulares que los posean mediante indennizacion de gastos, y los casos en que proceda subastarlos al público en beneficio exclusivo del Estado.

790. Libre entrada (LA) De los Corchos en España, arruinaria la propiedad y la industria taponera.-Por D. Narciso Fonolleras.

Revista de Agricultura práctica. 186:. -Tomo XI, pág. 10 כ.

Supone que existe cierto equilib ro entre la produccion del curcho y su consumo por la industria taponera. Recuerda las graudes plantaciones de alcornoque que se lian hecho y pide la prohibicion de la entrada libre de los corchos extranjeros, para no arruinar la propiedad forestal del país.

791. Ligeras CONSIDERaCiones SObRe la FALTA DE Lluvia QUE VENIMOS SINTIENDO KN ESPAÑA.

\section{Diario de Tarragona.-8, 10 y 11 de Marzo de 1868.}

Examinando el autor con bastante extension los efectos que en la marcha de las lluvias producen los arbolados, y considerando bajo este punto de vista como contrarios á las sequías los montes de las regiones montañosas, recomienda eficázmente su conservacion, aduciendo datos estadísticos y ejemplos que confirman sus opinioues.

Creemos que este trabajo debe atribuirse al ingeniero de montes, D. Victoriano Montés.

792. Lовоs. - De sus instintos y modo de cazarlos.

S'emanario de agricultura y artes, publicado por M. C. y Portocarrero.-Sevilla, 1832.-Tomo II, pág.' 217.

Describe minuciosamente las especies, costumbres y modo de destruirlos.

793. LONGEvidad DE LOS ÁrBolrs.

Semanario pintoresco. 1837.-Tomo II, pág. 94.

Describe el crecimiento, fijándose en la enciua, olmo, cedro, álamo, acacia, pino, abelo, enciua y otros. Cita ejemplos de encinas y abetos cuya existeucia parece datar de 6.000 y 12.000 años.

\section{L1.}

794. Llamajos la atencion... etc.

El Alto Aragon. Periódico de Huesca.-11 de Abril de 1871.

A propósito de las talas que se estaban ejecutando en los montes del Pirineo, reproduce to que sobre el particular dijo la Revista forestal, económica y agrícola; llamando la atencion ile la prensa de Madrid, á fin de que ésta reclame justicia contra los autores de aquellos daños, y se procure que cesen cuanto antes. 


\section{M.}

795. Maderada del turia (La).-Por D. J. N. R.

Las Provincias. Diario de Valencia.-10 de Febrero de 1867.

El autor D. Juan Navarro Reverter describe minuciosamente el modo, forma y condiciones de la conduccion de las maderas por el Turia, desde el punto en donde se flotan hasta su llegada á Valencia, dando cuenta de las dificu'tades de la navegacion en muchos puntos, de la organizacion del trabajo por lo que hace á los conductores, de los gaslos de la conduccinn, del valor de las maderas y le otros particulares de murhn interés. Liste artículo, notablemente aumentado, se insertó en la Revisla foréstal, económica y agricola, Tomo V, págs. 86 y 113, con el título de Transportes fluviales.

796. Máquina para la trasplantacion de los Ánboles.-Por D. Antonio Brusi.

Revista de agricultura práctica. 1854.-Tomo III, págs. 205 y 235 .

Enumera las ventajas que se deben obtener con dichas máquinas para la improvisacion de paseos, jardines, etc. Dá noticia de liaberse experimentado una. En la pág. 237, hay un grabado, copia de otro de L'Illustration de Paris, que representa una máquina de esta clase, la de Stewart Mac Glashen, ensayada bajo la direccion de Mr. Mathieu, en Villeneuve, premier étang, cerca de Saint-Cloud.

797. Más sobre el euCalyptus.-Véase: Arbolado en Espa$\tilde{n} a \cdot(E l)$

798. MÉdico DE los Árboles (EL).

Discursos mercuriales.-Núm. 9, 4 de Febrero de 1756, página 232.

Se refiere al procedimiento de Mr. Vitry, jardinero de Paris, que, asemejando los vegetales á los animales, decia que debian curarse aquellos por procedimientos internos, á cuyo efecto inyectaba en ellos ciertas sustancias liquidas, cuya composicion guardó como secreto.

799. Medio de aumentar las lluvias en ueterminado punto, utilizando la influencia eléctrica.-Por D. Eduardo G. Campos.

Diario de Barcelona.-1..$^{\circ}$ de Abril de 1868.

Reconociendo el autor la gran necesidad de favorecer las lluvias en el centro de España y en la costa del Mediterráneo, se propone dernostrar que con el establecimiento de para-rayos se lograria aquel objeto, en cuanto el fluido eléctrico precisa la liuvia, impidiendo que las nubes se alejen, antes de resolverse en agua pluvial. Reconoce que el arbolado del monte alto ejerce mucha influencia en la cantidad de agua que cae sobre una localidad, $y$ que la escasez de lluvias se atribuye justamente en España á la tala ó disminucion de las masas forestales, pero opina asímismo que algunos árboles propios del cultivo agrario como el olivo, almendro y avellano, dan más 
sombra que los de monte y por lo tanto sostienen mejor la humedad del suelo, así como que el medio más ęicáz para obtener las lluvias seria el del establecimiento de los para-rayos ya indicados, ó mejor esferas huecas de metal con más ó ménos puntas agudas y prolongadas, colocadas á la mayor altura posíble y unidas á tierra por un conductor que permitiese quitar ó poner la comunicacion segun fuera conveniente.

800. Menoria DE RECONOCIMIENTo DE LOS MONTES DE SIERRABULlones, PERTENRCIENTES Á ESPAÑa, por los ingenieros de montes D. Máximo Laguna y D. Luis Satorras, cumisionados de Real órden para la práctica de este trabajo.

Boletin oficial del Ministerio de Fomento. 1861.-Tomo XXXVIII, pág. 149 .

Fechada en Villaviciosa de 0 lon á 10 de Febrero de 1861.

Trata detenidamente de la situacion geográflca de los inontes, límites y extension; topografía é hidrografia, composicion geognóstica del terreno; vegetaciou leñosa dominante y dominada, zoografia, clima; determinacion de existencias del alcornocal, que es la parte dominante, del pinar del Acho y del nonte bajo; y por último del proyecto de aprovechamiento futuro bajo una division geotáxica por la que se destina una parte del terreno al monte alto, otra al monte bajo y otra al cultivo agrario, estudiándose minuciosamente el producto en especie y dinero, de las maderas, leñas, y cortezas ó corcho. Acompañan al trabajo, estados que expresan las existencias del alcornocal, del pinar del Acho, del monte bajo y la distribucion general del terreno por superficies.

Se acompañaron asímismo á la Memoria lcs planos de rodales y geotáxico, y un croquis geo'ózico, que, segun tenemos entendido, no se han publicado.

801. Memoria geognóstico-Agrícola sobre la provincia de Asturias, premiada por la Real Academia de Ciencias en concurso público con arreglo al programa presentado por la misma para el año de 1853.-Por D. Pascual Pastor y Lopez, Catedrático que fué de Mineralogía, Zoología y Botánica, en la Universidad de Oviedo, y en la actualidad en la de Valladolid, Doctor en Ciencias naturales, Licenciado en Medicina y Cirujía, etc.

Memorias de la Real Academia de Ciencias.-Tomo I, tercera série, Ciencias naturales.-Tomo I, parte 3."

Comprende 129 págs. de dichó volúmen. La parte tercera, está destinada al arbolado, ocupándose en ella minuciosamente de la extension y sistema de cultivo y de las especies más dignas de cultivarse en Asturias, que son segun el autor, el haya, roble, castaño, nogal, fresno, olmo o negrillo, abedul, aliso, manzano y avellano. Discute si los pinos, alerce, abeto y pinabete deben ó no cultivarse en Asturias y recapitula luego lo expuesto sobre la topografia del arbolado en la provineia objeto de su estudio.

Es exiraño que no se hable de esta Memoria en el Diccionario de bibliografia agronómica dol Sr. Auton Ramirez, siendo así que menciona las cor. 
respondientes á las provincias de Castellon y Pontevedra, publicadas y premiadas, como ésta, por la Real Academia de Ciencias.

802. MEMTRIA HistóniCa y DEsCriptiva de las agallas que cria el ruble comun, y de las especies de insectos que las ocasionan; conforme á las observaciones bechas en los robledades de San Ildefouso y San Lorenzo, en Agosto y Setiembre de 1807. - Por Don P. R. N., abogaulo de los Reales Consejos y aficionado á las ciencias naturales.

Semanario de agricullura y artes, dirigido álos párrocos. 1808. - Tomo XXIII, págss. 33, 54, 73 y 88.

Determina y describe nueve especies de agallas y sus insectos, explicando el modo de formarse estas escrecencias.

803. Mesroria premiada con ei accessit por la Real Academia de Ciencias, en concurso público segun el programa de premios publivados para el año 1860.-Por el śr. D. Mariano del Amo, doctor en farmacia, etc., sobre la distribucion geográfica de las familias de las plantas crucíferas, leguminosas, rosáceas, salsoláceas, amentáceas, coniferas y gramíneas de la península ibérica.

Memorias de la Real Academia de Ciencias de Madrid.-Tomo V. 1." parte, pág. 223.

En eite extenso trabajo, además de figurar curiosas noticias relativas al clima, terreno, temperatura, etc., se hace una descripcion del cultivo y productos de muchas especies arbóreas escncialmente forestales, indicando los terrenos donde podrian propagarse.

804. Memoria premiada que contiene la indicacion de los montes del reino de Valencia: clase, calidad, uso y abundancia ó escasez de sus maderas; rios y carreteras que facilitan su extraccion; causas de la decadencia de los bosques de este reino, medios de evitarla y de asegurar su permanencia, por el sócio numerario D. Joaquin de Lacroix y Vidal.

Junta piblica de la Real Sociedad Valenciana. 1801.-Páginas 163 á 267.

Fué premiada esta Memoria con una medulla de oro en que se grabó el nombr zel autor, entregándosele en junta celebrada el 9 de Diciembre de 1800 . Ei dibujo que representa el premio y su descripcion se encuentra en la pág. 391 del mismo volúmen. El Memorial literario hizo mérito de este trabajo en el tomo III, pág. 201.

En los prelimioares se trascriben estas palabras de la Instruccion que $\mathrm{Fe}-$ lipe II dirigió á D. Diego Cobarrubias: “Temo que los que vinieren despues de nosotros, han de tener mucha queja de que se los dejemos consumidos (los bosques), y plegue á Dios que no lo veamos en nuestros dias."

Hace notar la decadencia de los montes aun á pesar de las Ordenanzas de 1748, que considera perjudiciales. Se lamenta sobre todo de la amovilidad ciel persoual. Atripuye el mal estado de los montes al aumento de la po- 
blacion y del comercio, á las roturaciones, á los incendios, á las cortas indiscretas y empíricas, á las mismas leyes promulgadas para favorecer el arbolado y á otras causas, emiliendo luego su parecer sobre el modo cómo deberian establecerse juntas é inspectores provinciales para la mejor organizacion de este importante servicio.

805. Memorta sobre el estado de los ramos dependientes del Ministerio de Fomento en la provincia de las Islas Baleares al finalizar el año de 1861, escrita por el Jefe de Seccion de la misma, don Galo José de Ponte.

Revista cientifica del Ministerio de Fomento. 1862.-Tomo I.

Despues de hacer resaltar la importancia de los inontes de la provincia cuyo número, nombres, cabidas y linderos presenta en un estado, expone la marcha seguida en los a provechamientos de pastos, frutos y leñas con arreglo al plan aproba:lo por la superioridad, y los esfuerzos liechos cerca de los ayuntamientos para estimularlos á la repoblacion de los calveros, y para evitar los daños que se cometen en aquellas ñncas.

806. Memoria sobre el sistema maś Conveniente de Selvicultura, premiada por la Sociedad Económica Matritense ccn una carta de aprecio y que se imprima en este periódico para que se generalicen las buenas ideas que contiene acerca de la enseñanza de la selvicultura.

\section{El Amigo del Pais. 1846.--Tomo IV, págs. 481 y 536.}

Encarece en el preámbulo la importancia del arbolado y su influencia sobre la salud pública, los vientos, la humedad atmosférica, y otros agentes de la vida. Recuerda los productos maderables, leñosos, tintỏreos, a romáticos y alimenticios que rinden los bosques, y cita, con referencia al duque de Ragusa, el ejemplo de que así como en el Cairo era ráro que lloviese una vez al año, despues de hechas grandes plantaciones de árboles, lo general es que llueva treinta ó cuarenta veces.

Dando por establecida una escuela de ingenieros selvicultores 6 de montes, desarrolla el plan de enseñanza comprendiendo la ciencia de los vegetales, explotacion de bosques, $\mathrm{y}$ beneficio de praderas, pastos, carbon vegetal y turba. En las ciencias auxiliares comprende la fisica, química, geologia, mineralogía, meteorclogía, geodesia y mecánica práctica aplicada. En la segunda parte de la Memoria trata del encurvamiento de las maderas y su reblandecimiento con el agua y rapor, terminando con algunas nociones de administracion, economia y estadística selvicultora.

807. Memoria SOBRE LAS MEJORAS DE QUE ES SUSCEPTIBLE LA PROvinCIA DE JAEN; por el Doctor D. Antonio Romero y Linares, Comendador de la Real y distinguida órden de Cárlos III, etc.

Boletin oficial del Ministerio de Fomento.-1856. Tomo XVIII, págss. 60 á 74.

Recomienda entre otras mejoras la de que se entregue al interés particular la explotacion de los ricos piuares de aquella provincia (Jéca en árabes, 
que significa abundancia), de los cuales, practicándose las operaciones aconsejadas por la ciencia, se obtendria madera blanca y sin veta, mejor que la que se consume en Francia y Holanda.

808. MEMORIA SOBRE LOS BOSQUES Y ARBOLADOS DE ESPAN̄A; escrita por.D. Ramon Justino de Gassó, y premiada por la Sociedad Econúmica Barceloıesa, en sesion del 19 de Noviembre de 1849.

El Cultivador.-1850.-Tomo III, págs. 25, 60, 86, 114, 133, 161 y 185.

Lamenta la decadencia del arbolado y propone que por medio de estimulos y de leyes protectoras se impulse la plantacion de arboes y la perfeccion de las labores, sin temor al escrúpulo de alterar disposiciones existentes por guardar respeto á su antigüedad.

809. MEMORIA SOBRE MEJOR EJECUCION Y FOMENTO DE ARBOLADOS, dirigida á la Real Sociedad Económica Matritense, con fecha 15 de Mayo de 1778, por D. Miguel Gijon y Leon, caballero de la órden de Santiago, vecino de la ciudad de Málaga y hacendado en la villa de Torıx, jurisdiccion de Velez Málaga.

Memorias de dicha Sociedad._-1787. - Tomo III, pág. 70.

Versan las principales observaciones sobre la Real cédula de 12 de Diciembre de 1748 relativa á la conservacion y fomento de montes y arbolados, atribuyendo el exiguo resultado obtenido, de una parte á la falta de viveros por cuya razon se hicieron los plantíos de rama, y por ofra á que siendo tardios los rendimientos, el labrador no halla estimulos. Cree que lo mejor seria hacer viveros acotando con árboles algunos terrenos realengos y comunes.

810. Mumoria sobre QUE EsPEcies de ÁRBOLEs producirá y convendrá mejor plantar en el término de dos leguas al contorno de la ciudad de Segovir, indicando los medios de conseguirlo. - Por don Juan de Zamora y Aguilar.

Actas y Memorias de la Sociedad Económica de Segovia.-1786. —Tomo II, pág. 384.

Obtavo esta Memoria el premio de 1782. Declara que las plantas y pastores de aquella provincia se habian hecho incompatibles. Para la orilla del Eresma, recomienda el álamo blanco, el negro, el aliso, el abedul, el tilo, los cerezos, ciruelas, membrillos, perales, castaños y avellanos; para el secano, los manzanos, moral, nogales y almendros, y para las tierras estériles, la encina, el roble, el haya, el enebro y el pino, estimulando á la Sociedad para que haga ensayos de plautaciones por su cuenta y que se hagan en los camiuos con los fondos de propios.

811. Mejorias sobre el plantío de írboles, y principalmente de las moreras.

Discursos mercuriales.-Junio de 1756._Pág. 1010 á 1022.

Se lamenta de que haya tautos eriales sin plantio de arbolados. Cuando 
el terreno no sirva para moreras, se recomienda la plantacion de pinos por prestarse á útiles aprovechamientos.

812. Método para sembrar y Criar el piNabete, segun se practica en.las montañas de Hartz, pais de Brunswick.

Discursos mercuriales. -Núm. 3, 4 de Noviembre de 1755.

Explicada la preparacion del terreno, dá varios consejos para evilar el daño que pudieran causar á las plantas los ganados. Se inspira el autor en el deseo de que se repueblen de pinos ó pinabetes los terrenos incultos de España.

813. Monte (EL) y los monasterios de SAN JUAN de LA PEÑa.

El Alto Aragon.-Periódico de Huesca.-27 de Octubre de 1869.

Se reflere á la anunciada venta de aquella finca, cuyo intento combate por considerar ilegal la enagenacion y por los desarreglos climatológicos que podria sufrir la comarca caso de que se talase el arbolado, pudiendo llegar las consecuencias hasta el desprendimiento de algunas porciones del terreno que pondriau en peligro el monasterio antiguo, panteon de los Reyes aragoneses. Por cabeza de este artículo se inserta uno del Vizconde de Torres Solanol, sobre $E l$ Monte de San Juan de la Peña ya indicado.

814. Monte IRISASI. (EL)-Por X.

Revista forestal, económica y agricola.-Tomo III, págs. 517 y 564 .

Es una descripcion forestal y legal de este monte de Guipúzcoa, seguida de algunas consideraciones acerca de su importancia económica y de las mejoras de que es susceptible.

815. Monte IRISASI, (EL) su historia y actual estado.-Por don Severo Aguirre Miramon.

Revista forestal, económica y agricola.-Tomo V, págs. 369 y 433 .

A la reseña histórica, acompaña la descripcion geográfica, climatológica, geognóstica, legal y forestal, incluyendo el estado de los límites, el de los rodales y sus existencias y el de las clases de edad.

816. Monte rompesacos (EL) DE la villa de luna.

El Éco de Aragon. -Periódico político de Zaragoza.-23 de Febrero de 1872 .

Hace la historia de la propiedad de dicho monte, para probar que pertenece á la villa de Luna, sin que deba admitirse la reclamacion entablada por dos vecinos de Undués Pintano que pretenden el pleno dominio de la finca, fundados en cierto contrato de venta otorgado en 1812, entre el Ayuntamiento de Luna y D. Pedro Soteras, vicario de la parroquial del Frago.

81\%. Montes.-Anarquia roresíral.-Por el doctor Blanco Fernandez.

Semanario de Agricultura.—29 de Marzo de 1862, pág. 143.

Defiende las bases de desamortizacion forestal adoptadas por el Real de- 
creto de 22 de Enero de 1862, y combate algunos errores del Máscara sin careta (folleto) y del autor de los artículos de La América, que censuraban los principios técnicos y económicos de aquella disposicion.

818. Montes De Cuenca.

La Bolsa.-Periódico político de la tarde, defensor de los contribuyentes.-Madrid, 25 de Marzo de 1866.

Sale á la defensa de los montes de los pueblos, denunciando los abusos cometidos en algunos de ellos por los que se ha despojado al vecindario de una dehesa poblada de pinos que figuraba como de propios, babiendo sido despues repartida ilegalmente en suertes, vendiendo los adquirentes de lds parcelas, los pinos. Reclama pronta y enérgica justicia contra los autores de tamañas ilegalidades.

819. Montes.-De la conservacion de los montes por el Estado en beneficio del clima y de la fertilidad del terreno.-Desamortizacion de los montes.-La cuestion de montes. - A la Gaceta del Comercio de Santander.-Desamortizacion de los montes en la provincia de Santander.

Gaceta del Comercio.-Diario de Santander.-Núms. 760, 15 de Setiembre de 1865-773, 30 Setiembre.-775, 3 Octubre.-776, 4 Octubre.-777, 5 Octubre.-780, 8 0ctubre.-785, 14 Octubre.-795, 26 Octubre.-798, 29 Octubre.—770, 1. * Noviembre.-818, 24 Noviembre.-827, 5 Diciembre y 828, 6 Diciembre.-1866.

Es una variada y curiosa ınlémica entablada por los Sres. D. Francisco Javier Bona y D. Félix Bona, contra D. Prudencio Sañudo, en la que los primeros sostienen la necesidad y la conveniencia de la posesion del inonte alto por el Estado, mientras que su contrincante opina que deben venderse todus los montes, tlando su destino futuro al interés individual. D. José Maria Orense, autor de los dos artículos últimos, aboga tambien por la desamortizacion absoluta.

El debate se inició en virtud de un artículo publicajo en la $R \in$ visia $P e-$ ninsular Ultramarina, cuya doctrina era la que despues sostuvieron en la Gaceta del Comercio los hermanos Bona.

820. MONTES (DE LOS) B AJO SU ASPECTO ECONÓMICO-ADMINISTRATivo.-Por D. M. Salvá.

El E co de la ley y la España juridica.-Núm. 5, 8 Enero 1860.

Encareciendo la importancia y la necesidad de los montes, examina las tendencias de la legislacion adininistrativa respecto de su conservacion y beneficio, y concluye asentando que la indicada riqueza, es lenta en crecer, breve en acabar y de utilidad suma para el Estado.

821. Montes DE LOS EsTados-Unidus. (Los)

Revista forestal, económica y agricola.-Tomo V, pág. 187.

Traduccion de un artículo publicado en la Reoue des caux et fórets por Mr. G. Fabre, en el que se da á conocer el verdadero estado de la riqueza forestal de aquel pais. 
822. Montes del estado.-Por D. J. B. Guardiola.

La Discusion.-Periódico democrático.-Núms. 1206, 15 Diciembre y 1208, 17 Diciembre 1859.

Haciéndose cargo el autor en dos artículos, del informe emitido por la Junta facultativa del cuerpo de ingenieros de montes en 1855 , á propósilo de la desamortizacion forestal, $\boldsymbol{y}$ del Real decreto dictado en presencia del susodicho informe, coinbate la posesion de los montes por el Estado, fundándose en principios exclusivamente económicos.

823. Montes del Estado.-Por D. Leandro Rubio.

El Eco de la ganaderia.-Tomo I, págs. 7, 19, 25, 34, 52, 90 y 98 .

Abcga por la conservacion y propiedad de los montes por el Estado, refutardo lo que en contrario habia escrito el periódico político La Discusion. Determina los límites y funciones del Estado resrecto de los inontes, prueba que la existencia de estos es una nacesidad para las naciones y que su explotacion no puede dejarse á la iniciativa individual. El cuarto artículo de los siete dedicados á esta cuestion, está escrito por el abogado D. Pedro Oller y Cánovas. Los dos últimos reproducen la Hoja foreslal publicada por don José Cortés, que reseñanos en otro lugar, aceptando el sir. Rubio todas sus conclusiones.

824. Montes del pirinio (Los).

El Alto Aragon.-Periódico de Huesea.-3 y 21 Octubre 1869.

En estos artículus se llama la atencion del Gobierno sobre las talas que se estaban ejecutando en los montes de los púeblos de Acumuer, Gabin, Yésero y otros del Pirineo, on la provincia de Huesca.

825. Montes.-Discordancia entre el periódico la Ley y el Dertosense en esta materia.

El Dertosense.-24 Setiembre 1848.

Artículo de discusion en el que se elogia la creacion de la Escuela de ingenieros de montes, se indica la necesidad de los deslindes, y. se recuerdan los trabajos administrativos, hechos por los comisarios de montes; entrando luego en consideraniones tecnológicas acerca del plan de enseñanza que regia en la Escuela forestal de Villaviciosa. Del contenido del artículo se des prende que además de $L a L e y$, se ocupaban por entonces de la cuestion de montes los periódicos siguientes: $\mathrm{El}$ Heraldo, El Clamor Público, La Guía del Comercio y $\mathrm{El}$ Independiente sevillano.

826. Montes espáñoles (Los) Bajo el punto de vista DE SU DESAMORTIZACION Y ADMINISTRACION.

La Epoca.-Periódico político.-25 Marzo 1862.

Rebate los principales razonamientos einpleados por el autor anónimo' de un folleto que lleva aquel título, contra el Real decreto de 22 de Enero de $1 \varepsilon \hat{2} 2$, confirmando que la nueva clasificacion de montes ohedece á un criterio científico y oonveniente, así como que los terrenos que se entregan á la 
venta pueden pasar sin temor alguno á manos de particulares por encontrarse en la zona agrícola.

827. Montes.-Informe sobre los medios de proveer á la conservacion de este precioso ramo de riqueza en la provincia de Lugo, que al Consejo de'Administracion ha presentado el Sr. Castro Bolaño.

Revista semanal de Agricultura.-1851.-Tomo III, págs. 201 ả 204.

Se publicó primero en el Eco de Galicia. Se propone el autor llamar la atencion sobre los aprovechamientos comunes de aquella provincia que consisten en lıelecho, árgoma, aliaga ó tojo, retama, broza y yerbas para los ganados, patentizando las causas de su decadencia, entre las que se cuenta la confusion de la propiedad, su mulliplicada division en suertes y falta de inteligencia. Propone la ejecucion de deslindes, sujetándolo todo á reglas convenientes y respetando las mejoras introducidas por los cultivadores aplicados.

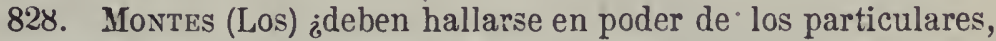
de los pueblos, ó del Estado?_-Por D. Ramon Jordana.

El Eco de la ley y la España juridica.-Núm. 69, 22 Mayo 1861.

Examinando las necesidades que satisfacè los montes, sus condiciones económicas y algunas disposiciones legales acerca de los mismos, deduce que el Estado debe poseerlos porque es el único que liene los medios para administrarlos cientiflcamente y realizar asi su conservacion como su repoblacion.

829. Montes. (Los)-Por D. Antonio Vilamor.

El Eco de la ganaderia.-Tomo V, pág. 385.-La Agricultura valenciana.-Págs. 248 y 264.

Considera los aıntes en sus relaciones con la atmósfera, deduciendo que no son un simple ramo de produccion, sino una condicion de existencia para el hombre en sociedad. Recorre los paises en donde se ha destruido el arbolado dando á conocer las desastrosas consecuencias que de ahi se han seguido, y cita textos de varios sabios para probar la necesidąd que hay de conservar y fomentar la riqueza forestal.

830. Montes. (Los)-Por D. Ramon de Xérica.

La España.-Periódico político.-11 Diciembre 1864.

Este articulo tiene por objeto hacer resaltar la diferencia que existe entre el estado general de los montes de España, y aun entre los que se consideran como bosques virgenes, y los de Alemauia, sujelos á un tratamiento reg'alar, científico y metódiro. Al efecto, describe el autor, el aspecto de nuestros inontes sujetos á talas irregulares y á daños de toda especie, y el que ofrecen los alemanes, deslindados, divididos en distritos y cuarte'es separados por calles, callejones y corta-fuegos, formados por especies homogéneas y rodales de edad gradual, limpios de maraña y maleza, cruz ıdos por caminos forestales y provistos de sierras de agua $\zeta$ rapor, fábricas de car- 
bon, sequerías, almacenes, эrrastraderos, casas de guardas, etc. Termina escitando á la autoridad popular de Alava para que dicte medidas preparatorias que protegiendo la propiedad forestal, faciliten al propio tiempo la constitucion de cotos redondos, evitando el excesivo fíaccionamiento de la propiedad en aquelia provincia.

831. Montes (Los) y La administracion Forestal EN EL Parlamento de la Alemania del norie.-Por D. P. Gonzalez de la Peña. Revista forestal, económica y agricola.-Tomo III, pág. 208.

Da cuenta de los debates habidos en aquel parlamento, haciendo notar la conformidad de pareceres respecto á la necesidad de la existencia de los montes y sobre el deber del gobierno de atender preferentemente á su conservacion y mejora.

832. Montes (Los) y las minas.-Por D. Eugenio Naffei.

Revista forestal, económica y agricola.-Tomo I, págrs. 277 y $700^{\circ}$.

Encarece la necesidad de dictar reglas administrativas que se refieran á la conservacion de los montes, por el auxilio que estos prestan á la industria minera. Examina con sana crítica algunas disposiciones legislativas dictadas sobre el particular.

833. Montes.-Noticia sobre el estado de la agricultura en varios paises de Europa.

Revista semanal de Agricultura.-1852.-Tomo IV, págs. 209 à 214 .

En la Revista se halla propuesto el epigrafe Montes, que anteponemos porque el artículo no se reflere á otra cosa y aun se concreta á los de Francia.

Despues de algunas consideraciones sobre lo que Tácito, Plinio y Julio César escribieron acerca de lo poblado de bosques que se hallaba Euroṕa, se dice que la civilizacion ha hecho perder al suelo de Francia la fisonomía original de sus montes y disminuido la extension de ellos, hasta el punto de calcular algunos ingenieros que en dicho pais solo hay cubiertas las trece centésimas partes de la extension territorial. Descritas las zonas septentrional, media y meridional de Europa. habla de la produccion y consumo de los montes en Francia. La superficie aparece distribuida como sigue:

\begin{tabular}{|c|c|c|c|}
\hline \multirow{3}{*}{ 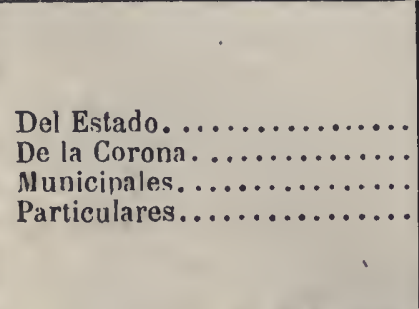 } & Monte alto. & $\begin{array}{c}\text { Monte medio } \\
\text { y bajo. }\end{array}$ & $\begin{array}{l}\text { TOTAL } \\
\text { de hectáreas. }\end{array}$ \\
\hline & $\begin{array}{r}482.640 \\
32.500 \\
447.760 \\
792.390\end{array}$ & $\begin{array}{r}590.616 \\
74.4^{\circ 9} \\
4.376 .073 \\
4.916 .720\end{array}$ & $\begin{array}{r}1.073 .256 \\
106.929 \\
1.823 .833 \\
5.709 .110\end{array}$ \\
\hline & 1.755 .290 & $\begin{array}{ll}6 & 957.838\end{array}$ & 8.713 .128 \\
\hline
\end{tabular}


El producto de estos montes se calcula aproximadamente en 40.589 .537 estéreos, en esta forma:

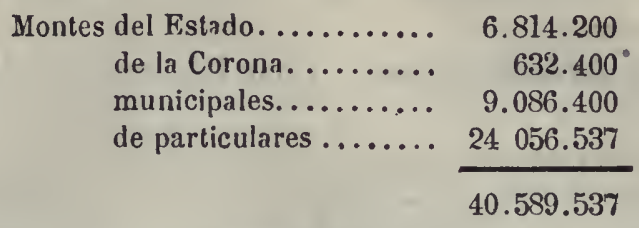

834. Montes.-Observaciones acerca de los de dominio particular y de los de propios y comunes de los pueblos.-Por D. Rafael Monares.

El Consultor de los Ayuntamientos.-Tomo VIII, 1860, página 269.

Este arlículo vió tambien la luz publica en la Revista de legislacion. Estudia los puntos de derecho y las causas originarias que dan lugar á la diferencia de una y otra clase de montes.

835. Montes.-Por E. Ft.

La Agricultura española, y El Imparcial (Diario de Zaragoza). -Núm. 70, 28 Enero.-71, 29 Enero.-72, 30 Enero y 73, 31 Enero 1864.

Glosa con extension los datos de estadistica forestal de España publicados en el Amario estadistico, y muy particularmente los de la provincia de Sevilla, leduciendo en vista de las necesidades que satisfacen los montẹ, la conveniencia de que no se amplie más la desamortizacion de esta riqueza y que se conserve bajo el dominio público.

836. Montes.-Proyecto de ley presentado á las Córtes.

El Consultor de los Ayuntamientos.-Tomo XX.-10 de Noviembre de 1872 .

Se ocupa del proyecto de ley de montes presentado á las Córtes por el ministro de Fomento señor Echegaray, en 5 de aquel mes, deduciendo que su princlpal objeto es ampliar la desamortizacion de los montes públicos vendiendo asimismo fincas de aprovechamiento comun, espíritu que considera contrario al derecho de los pueblos y ruinoso en la práctica, para la riqueza forestal de España.

La Revista forestal, económica y agricola reprodujo este artículo en el tomo VI, pág. 189.

837. Montes públićos (Los) y la Diputacion provincial.

Las Provincias. - 15 de Junio de 1871.

Tiene por objeto dar cuents del acuerdo tomado por la Diputacion provincial de Valencia relativo á la mejora de los montes públicos para cuya afencion se proponc la inclusion en los presupuestos de cinco mil pesetas. El articulista trascribe algunos parrafos del preimbulo de la eumienda presentada por los diputados provinciales que propusieron las mejoras indicadas. En él se hacen razonadas y extensas cunsideraciones climatołógicas, 
económicas y administrativas en favor de la riqueza forestal. Este trabajo fué elogiado por Las Provincias.

838. Montes.

Revista dé Administracion.-Tomı III, año III, 2:" época, página 136.

Es un extracto bastante extenso de la exposicion elevala á las Córtes en 21 de Diciembre de 1872, por la Sociedad Fomento de la produccion nacional de Barcelona, en contra del proyecto de ley de montes que con fecha 5 de Noviembre anterior presentó á las Córtes el vilinistro de Fomento, Sr. Echegaray. Damos cuenta de elıa registrándola con el título: $A$ las Córtes.

839. Montes.-Véase: Aprovechamienlos comunales de pastos en favor de la ganaderia.

840. Montes. - Véase: Conocimiento (Del) de los delitos y faltas por infracciones..... etc.

841. Montes.-Véase: Observaciones acerca del 10 por 100 de sus productos con destino a su replantacion, mejora y fomento.

842. MonTEs.-Véase: Reglamento sobre la organizacion del servicio, etc.

843. MotIVO POR QUÉ LOS RORLES Y OTROS ÁRBOLES SON HUECOS EN uNOS PAISES Y SólIDOS EN OTros. - Véase: Introduccion à la historia natural, etc.

844. Multiplicacion del olmo (ulmus campestris), conocido por nuestros labradores solo con el impropio nombre de álamo negro.

El Agricultor español.-1850.-Págs. 5, 6 y $\%$.

Establecidos los caractéres botánicos que distinguen el olmo del álamo negro, explica el modo de recoger la semilla, su conservacion y las labores que requiere el cultivo. Enumera los productos que rinde y da cuenta de su facilidad para reproducirse por estaca, acodo, division de raices, que es el más generalizado, y siembra, cuyo último método recomienda comoel mejor de todos.

845. Mư Equivocado está El Imparcial..... etc.

La Epoca.-Periódico político.-11 de Noviembre de 1872.

Contestando à la réplica que dió $\mathrm{El} \mathrm{Imparcial,} \mathrm{al} \mathrm{artículo} \mathrm{del} \mathrm{7,} \mathrm{confirma}$ La Epoca las opiniones que habia emitido acerca del proyecto de lej de montes prezentado á las Córtes por el Ministro de Fomento Sr. Echegaray, demostrando que el proyecto referido se ha formulado sin conocimiento de los hechos y del derecho, confundiendo las atribuciones del ministerio, respecto de las del de Hacienda, y eximiéndolo del estudio de las corporaciones que pstaban llamadas á inforınar sobre él.

Reproducido en la Revista forestal, económica y agrícola. Toino VI, página 136. 


\section{N.}

816. Nateralizacion del allerce africano, llamado Arar en Marruecos, por D. Miguel Colmeiro.

Revista de los progresos de las ciencias exactas, fisicas y natuvales.-Tomo VI, Madrid, 1856. - Revista de agricultura prictica, 1854. - Tomo III, pág. 178, con el título de Aclimatacion... etc.

Dicho alerce es el Callitris quadrivalvis. Vent., cuya madera fue usada antiguamente en Córdoba y Sevilla con el nombre de Alerce. Se procuró aclimatar en Europa á principios de este siolo, en las provincias meridionales. A estas noticias añade el autor otras respecto á siembras y plantaciones hechas en el jardin botánico de Sevilla, y recomienda la propagacion de este vegetal por la dureza é incoriuptibilidad de su madera.

847. To queremos deJar pasar... etc.

El Cóntemporáneo. Periódico político.—29 de Abril de 1862.

Toma parte en la polémica entablada entre La Epoca y El Reino acerca del real decreto de 22 de Ésero de aquel año, y dedica á la cuestion un artículo que comienza con las palabras registradas, probando que si se lleva á cabo la venta de los monles á que afecta aquel real decreto, quedará en España muy poca superficie forestal para satisfacer las necesidades cosmológicas y económicas. Al efecto, para fundar su opinion respecto á la posesion de los montes por el Estado, se apoya en las de Bastiat, y en el ejemplo de lo que sucede en las naciones más civilizadas de Europa.

848. Nos place ver á nuestros colegas... etc.

El Constitucional. Periódico político.-16 de Abril de 1862.

Con las antedichas palahras empieza un artículo de este periódico, deslinado á defender el real decreto de 22 de Fnero del mismo año y á refutar lo que sobre la misma cuestion habia ex́puesto $B l$ Reino. Las bases de este escrito se reducen á demostrar que el criterio de las especies como punto de partida para la desamortizacion forestal se adoptó ya en 1855 por la junta facultativa del ramo, y que segun todos los datos estaristicos reunidos quedari todavía mucha superficie de montes en España, despues de verificadas las ventas que se deriven de aquel real decreto.

849. Noticla de haber existido el Árbor llamado Garoe en la isla de Fero ó del Hierro, al norte de las Canarias, llamado árbol de la maravilla, por A. C. B.

Memorial literario, Madrid. -Setiembre de 1806.

Se trata de la Oreodaphne faetens, Nees, que corresponde á los laureles $y$ cuyas emanaciones acuosas, se han exagerado tanto.

850. Noticia histókICA DEL BOHON-UPAs, Á BBol víninoso de la isla* de Java, tomada de la obra publicada en Inglaterra, por el Dr. Darwin, con el título de Botanic Garden, tomo II, dada á luz por pri- 
mera vez en holandés por N.P. Foersch, é inserta en francés en la Biblioteca Británica.

Miscelánea instructiva, 1799.-Núm. 26, pág. $15 \%$.

Existe una copia manuscrita en la Bıblioteca agronómica del jardin Botánico de Madrid.

El relato se debe á un cirujano que estaba en 1774 , al servicio de la com pañía holandesa de la India. De este árbol sc recogia el veneno que se inoculaba con lanceta en el cuerpo de los condenados á riuerte. Crecia á la orilla de un arroyo, era de mediana altura y le rodeaban cinco o seis árboles nuevos de su especie.

Reseña, asimismo, varios experimentos hechos con la goma del bohonupas.

851. Noticias botánico-agrícolas sobre los pinos de Cataluña, por D. Antonio C. Costa.

Revista de agricultura práctica, 1857.-Tomo VI, pág. 38.

Recuerda la benéfica accion de los árboles en las cumbres de las montañas, respecto á la sujecion de la tierra vegetal, arenas voladoras, modiflcacion de la temperatura, regularizacion de las lluvias, etc. Recomienda al Estado la conservacion de los montes y la repoblacion de los que ya están talados, para obtener maderas y restablecer el equilibrio casmológico de la península. Para estos fines recomienda los pinos, enumerando las cualidades de las especies siguientes: $P$. syloestris, $(L)-$.$P . uncinata, ($ Ram. $)-P$. laricio, (Poiret.)-P. pyrenaica, (Lap.)-P. halepensis, (Mill.)-P.pinea, (L.)P. pinaster, (Sol.)-P. canariensis, (Smith.)

852. Noticias sobre los incendios de los pinares de la ciudad y tierra de Soria, por D. R. Breñosa.

Revista forestal, económica y agricola.-Tomo II, pág. 168.

Investiga el origen de los incendios, y las causas que favorecen su rápida propagacion, dando cuenta de las medidas adoptadas para disminuir los estragos del fuego, é indicando las medidas preventivas que deben adoptarse en adelante. Termina expresando la superficie Incendiada, el número de árboles destruidos por el fuego, y la tasacion de los daños, en los montes de los partidos judiciales de Almazan, Burgo de Osma y Soria.

853. Noticias y observaciones sobre la isla de Ceylan, remitidas por el vicecónsul de Ėspaña.

Gacela de Madrid.-2 y 3 de Enero de 1869.

Estudio geográfico y estadístico que entre otros puntos comprende el de los reinos animal y vegetal.

En este último da cuenta de las maderas de construccion más estimadas y de los precios y cantidades exportadas, incluyendo un catálogo con los nombres sistemáticos de ciento oclienta y ocho especies.

854. Nubes de la CIEncia, (LAS) por D. J. Navarro Reverter. Revista forestal, económica y agricola.-Tomo II, pág. 427.

Versa sobre la temperatura del aire dentro y fuera de los montes con re- 
lacion á los trabajos practicados por Bećquerel y su hijo, y sobre la influencia de los prédios arbolados en la lluvia.

855. Nueva LEY DE MONTES. (LA)

El Fomento. Periódico de Badajoz.-1. ${ }^{\circ}$ de Diciembre de 1872.

Juzgando, con aplicacion ả la provincia de Badajoz el proyecto de ley de montes presentado á las Córtes en 5 del mes anterior por el ministro de Fomento señor Echegaray, encuentra que es excesiva la superficie forestal que debe entregarse á la venta, y se lamenta de los males que puede acarrear esta medida, provinientes de los trastornos que pueden sufrir con el desmonte, el clima, las aguas corrientes y el suelo.

Copió este artículo la Revista forestal económica y agricola, insertándolo en el tomo VI, pág. 194.

856. Nuevo sistema de fabricacion de duelas y coronas para barriles, por D. R. Breñosa.

Revista forestal, económica y agricola.-Tomo I, pág. 567.

Es una descripcion de la fábrica que los señores Fagoaga y compañía tienen establecida en Navarra para la preparacion de duelas y coronas de haya.

Hace una reseña del modo cómo funciona y del resultado que con ellá se obtiene.

\section{O.}

857. OBSERVACIONES ACERCA DEL CARBON vegETAL, vena de hierro, y fábrica de anclas del país Bascongrdo, hechas por el teniente de navío D. Gerónimo Tabern, indivíduo de la Sociedad, y comunicadas por él mismo en sus juntas generales.

Extractos de las juntas generales celebradas por la Real sociedad Bascongada de los Amigos del Pais, en la ciudad de Vitoria por Agosto de 1789. -Pág. 15.

Da una idea del consumo de carbon vegetal empleado en las ferrerías de Guipúzco3, de las existencias provinientes de las de Alava y Navarra, y de los defectos de que adolece la elaboracion del indicado producto.

858. Observaciones acerca del 10 por 100 de sus productos, (de los montes) con destino á su replantacion, mejora y fomento.

El Consultor de los Ayuntamientos.-Tomo XVI, 1868.-Página 6.-Tomo XVIII, 1870.-Pág. 398. y Tomo XXI, 1873.—Página 14.

Se hace cargo de lo dispuesto sobre la materia en los artículos 116 y siguientes hasta el 120, del reglamento de 17 de Mayo de 1865 dictado para la ejecucion y cumplimiento de la ley de 24 del propio mes del año de 1863 , deduciendo que ha caducado el prévio depósito del 10 por 100 y que solo debe estarse por los Ayuntamientos, al plan anual que se publique en los Boletines de provincias, para incluir en sus presupuestos las sumas que se 
les marquen cen destino á la mejora y fomeuto de sus montes. Hace observaciones semejantes respecto al descuento del 5 por 100, desitinando á igual ohjeto, aconsejando á los ayuntamientos que soliciten la devolucion de las sumas deposit adas y descontadas hasta la fecha, que no se hayan invertido en mejoras de sus montes.

859. Observaciones atmosféricas, é influencia qne ejercen en los montes, por D. R. Beaumont.

La Crónica. Periódico de Badajoz.-Núm. 582, del 13 de Febrero de 1872.

Da cuenta de la marcha general de los vientos y lluvias, atribuyendo á los montes gran influencia sobre estos meteoros así como sobre la temperalura, de donde deduce la necesidad de que las masas de arbolado forestal estén convenientemente distribuidas, atajando las roturaciones. Examina el resultado de la desamortizacion de los montes en la provincia y se lamenta del gran núınero de fincas de esta clase que se han entregado al dominio particular, privando á los pueblos de los valiosos recursos que de las mismas obtenian.

860. Observaciones Sobre el Ccltivo de la encina Y PlantaCION de los Bosques, por el Dr. D. Juan Francisco Bahí.

Memorias de agricullura y artes, 1816.-Tomo III, páginas 52 у 97.

Recomienda la plantącion de árboles especialmente en la Mancha. Allmite que la encina tiene un siglo para crecer, otro para mantenerse ccn vigor y otro para decaer; explica la clase de terreno que le conviene, la siembra y la trasplantacion.

"Si el fondo es arcilloso, dice, el terreno será conveniente para la encina, ojaranzo, avellano y arce; si es cretáceo ó guijarroso, le convendrá el haya, el sicomoro y la acacia; si es fresco, húmedo y acuático, el aliso, álamo blanco, chopo y fresno, y si arenoso y seco, el abedul, el castaño y el pino."

861. OBSERVACIONES SOBRE LA ADMINISTRACION FORESTAL DE ESPA$\tilde{\mathrm{N}}$, por D. R. Jordana.

Revista forcstal, económica y agricola.-Tomo II, pág. 271.

Hace la historia de la Escuela de Ingenieros de montes y del cuerpo facultativo del ramo, reseñando las vicisitudes del servicio forestal, y los obstáculos que se oponen á la marcha de la administracion, invocando la proteccion del gobierno á favor de los montes.

862. OBSERVACIONES SOBRE LA DISCUSION DE LA LEY MUNICIPAL EN las Córtes Constituyentes, con relacion á los montes, por D. P. Gonzalez de la Peña.

Revista forestal, económica y agricola.-Tomo III, pág. 270 .

Defiende el proyecto de la comision del Congreso, en contra de lo que sobre el mismo expusieron los diputados republicanos señores Castelar y Pi y Margall, demostrando que la absoluta autonomia que estos pretenden 
conceder al municipio, seria causa de la inmediata desaparicion de los montes.

863. Observaciones sobre las temperaturas mínimas que pueden soportar los vegetales, por D. M. Laguna.

Revista forestal, económica y agricola.-Tomo V, pág. 577.

Da cuenta de los trabajos de Goeppert acerca de la cuestion, cuyos resultados generales establecen las temperaturas más bajas que ban resistido las plantas, concluyendo que la cubierta de nieve no permite desarrollo alguno á los vegetales helados bajo de ella; que la vegetacion depende de la atmósfera, y que la especie de rigidez d́ que en los grandes frios se acostumbran algunas plantas, no las defiende de la fatal influencia de las temperaturas extremas.

864. ObSeRvacrones sobre un artículo de $L a$ Epoca, por Don M. A. y M.

Las Provincias. Diario de Valencia. -18 de Marzo de 1868.

Haciéndose cargo de un artículo de $L a E p o c a$, en el que eśte ilustrado periódico, recomendaba al Estado la inmediata repoblacion de las montañas y mesetas del centro de España, el autor de las Observaciones, D. Miguel Amat y Maestre, combate esla doctrina, manifestando que el Estado es impotente para conseguir aqueı fin, y que debe flarse esta mejora al interés particular, enagenando todos los montes.

865. OLMo. (EL)-(Ulmus campestris), por D. R. Jordana.

Revista forestal, económica y agricola.-Tomo III, págs. 281, 322 y 408.

Monografía que comprende los nombres, descripcion, distribucion geográfica, condiciones de existencia, método de beneficio en monte alto, bajo y medio, cultivos, enemigos y enfermedades y cualidades y aplicaciones de los productos.

\section{P.}

866. Palmito, (EL) por D. R. Jordana.

Revista forestal, económica y agricola.-Tomo V, pág. 457.

Noticias sobre los nombres, descripcion, condiciones de existencia, distribucion geográfica, cultivo, y cualidades y aplicaciones de los productos.

867. Parque, (EL) los jardines y paseos públicos de Madrid, por D. Estanislao Malingre.

La Época. Periódico político.-2, 8, 9 y 14 de Agrosto de 1871.

Cuatro artículos en los que con bastante extension trata el autor de demostrar que el arbolado y fincas anexas no corresponden á los gastos que ocasionan; de los principios que deben presidir á la formacion y conservacion de los arbolados y jardines; de las especies cultivadas y de los daños á que están sujetas, y por último, del atraso en que está el cultivo lo mismo respecto á lo concerniente á los vegetales como en lo que se reflere al suelo y abonos. 
Con mayor ó menor extension; y aceptando sus conclusiones, dieron cuenta de estos artículos El Popular, 25 de Agosto de 1871, con el tílu'o de $E l$ ramo de arbolado en Madrid; Las Novedades, 20 de igual mes y año, con el epigrafe de $E l$ Retiro, y $E l$ Tiempo, 23 del mes y año repetido, con el enunciado de $E l$ arbolado del Reliro se pierde.

868. Parte forestal de la última exposicion de París, por don I. Bosch.

Revista forestal, económica y agrícota.-Tomo II, págs. 340, 404, 460, 524, 590, 651 y 718 .

Comprende el estudio analítico y critico de los productos forestales correspondientes á España, Portugal, Francia, Italia, Prusia y otros eślados alemanes, Austria, Rusia, Peninsula escandinava, Gran Bretaña, Grande archipiélago asiático, Argel, Isla de la Madera, Fernando Póo, Canadá, Brasil, Nueva Gales del Sud, Queensland, Victoria, Tasmania y Nueva Caledonia.

869. Paseos y arbolados de Madrid.

El Constitucional. Periódico político.-28 y 30 de \ayo, y 4 y 6 de Julio de 1862.

Cuatro artículos destinados á demostrar la conveniencia y ventajas del arbolado; á describir las condiciones y estado de los jardines, paseos y plantaciones lineales de Madrid para probar que no satisfacen á las necesidades de la poblacion; á reseñar las causas que han retrasado el fomento de los paseos públicos; y á estudiar hasta qué punto ha influido en el deplorable estado del ramo la direccion facultativa del mismo.

870. Paseos y arbolados de Madrid, por D. José M. de Garay.

El Constitucional. Periódico político.-10 de Julio de 1862.

El autor contesta por medio de un comunicado á los cuatro artículos que publicé sobre la materia $E l$ Constilucional, defendiendo la direccion y ejecucion de los trabajos liechos ell el ramo de arbolados de Madrid, del cual era Comisario municipal.

871. Pascos y arbolados de Madrid.

El Constitucional. Feriódico político. -19 de Agrosto de 1862.

Es contestacion á un comunicado que con el mismo título y suscrito por el comisario de arbolados de Madrid D. José M. de Garay, publicó el periódico expresado en su número del 10 de Julio anterior. En la presente contestacion se hace constar que la censura no iba ençminada al comisario y sí á la direccion facultativa del ramo. Confirmase ia exactilud de las apreciaciones y noticias que habian servido de fundamento a la crítica y se liacen comparaciones minuciosas entre el arbolado de Madrid y el de París, para comprobar el atraso en que se encuentra este servicio en la primera de dichas poblaciones.

872. Pasos CABAÑales.

El Éco de Aragon. Periódico político de Zaragoza.-20 de Marzo de 1872 . 
Recuerda la conveniell cia de proceder á un deslinde general de los pasos, cañadas, abrevaderos y descansaderos de la provincia, en virtud de las usurpaciones y roturaciones de que han sido objeto estas vias pastoriles. Al efecto indica el procedimiento administrativo y técuico que debiera seguirse, que no es otro que el determinado en el Real decreto de 4 de Dicienbre de 1871 .

873. Pasta de madera, por D. Andrés Llauradó.

Revista forestal, económica y agricola.-Tomo III, pág. 368.

Describe la fábrica de pasta de madera establecida á orillas del Ter, junto á Gerona. Se o :upa tambien de las ventajas de dicha pasta empieada en la elaboracion del papel, de su blanqueo y de los caractéres con que puede reconocerse el papel de esta clase.

874. Patologia vegetal.-El moho blanco de las plantas, por D. R. de Xérica.

Revista forestal, económica y agricola.-Tomo II, jáginas 347 y 417.

Este trabajo fué publicado en íos números 42 al 46 del Eco de la Ganaderia, año 1863, con ménos extension de la que tiene en la Revisla. Estudia los hongos en gemeral, las observaciones de G. Hartig sobre el moho blanco, el blanco seco ó molıo blanco de orígeu vegetal, el blanco-dulce ó moho blanco de origen animal, el inoho blanco formado de larvas del género Anguillula, de los daños que acompañan al moho blanco en las plantas y de los inedios para combatir estos daños.

875. Patologia vegetal, por Erasmo de Janer.

Revista de agricultura práctica, 1852.-Tomo I, pảg. 130.

Indica las precaliciones que deben tomarse en la poda, para no producir enfermedades ó la muerte de los árboles; da noticias acerca de la espesura en que aquellos deben vivir, y recomienda la podis y la limpieza de la corteza para preservar á los árboles de los daños que les causan varios inseclos.

876. Pino silvestre, por D. A. A. Villacampa.

Revista forestal, económica y agricola.-T'ouı I, págs. 414, 547, 640 y 717; y Tomo II, págs.s. 56, 114, 370, 501 y 561.

Es una extensa monografia que comprende los puntos siguientes: nombres; descripcion; distribucion geogrática; condiciones de existencia; iocalid:des que habita en Españia; cultivo y daños.

877. Pino.-Sobre sus utilidades.-Memoria aue remitió á la Sociedad D. Pedro Ucero, boticario de la villa de Cuellar.

Actás y Memorias de la Sociedad Económica de Valencia, 1786. —Tomo II, págrs. 358 á 383 .

Enumera las ventajas económicas que se obtienen de su raiz y de su tallo. y las que ofrecen para la medicina las demás partes del árbol.

878. Pinos, por D. MI. Laguna.

Revista forestal, económica y agricola.-Tomo III, pág. 359. 
Estudio de las especies del género Pinus, con indicaciones de sus cualidades, distribucion, regiones y caractéres peculiares de las principales.

879. Pinsapar un Rond ; (El) por D. M. Laguna.

Revista forestal, económica y agricola.-Tomo I, pág. 96.

Descripcion botánico-forestal de aquel célebre monte, con indicaciones de la naturaleza del suelo y otras circunstancias cuyo conocimiento interesa bajo el punto de vista dasonómico.

880. Plantacion de Árboles.

Ensayo de la sociedad Bascongada de los Amigos del Pais.Año 1766.-Pág. 94.

Este trabajo está fechado en Vitoria á 19 de Abril de $170^{\circ} 6$ Versa sobre los modos de plantíos, formacion de viveros, tiempo de sembrar, sitio para vivero, advertencias para las plantaciones de viveros, trasplantacion, métodos de Mr. Liger, Hall, Dupuy y Duhamel, diferencia de estos mélodos con el del país, método de Duhamel para anticipar la vegetacion de los árboles, observaciones sobre este método, del suelo para la plantacion, suelo para el castaño, roble, haya, fresno y nogal, del modo de plantar, advertencia sobre la inutilizacion de la guia de la raiz, tiempo de trasplantar, observacion sobre el trasplantar en otoño, precauciones en el trasporte de los plantíos, método de Duhamel para el trasporte, la distancia en la trasplantacion, rescyurdo y cultivo de los árboles, de la poda, intervalo de las cortas, árboles bravas y modo de guiarlos. "Los árboles se guian de tres modos, dice; en bravos. en jaros y trasmochaderos. El primero sirve para los que se reservan para las fábrivas y edificios; y los otros dos para los que se destinan para leña y carbon." Opina que la palabra "chirpia es corruplela de chirivia por la semejanza que tiene la raiz de este nombre, con el plantío recien nacido de la semilla y que no ha silo trasp'antido al sitio del vivero."

881. Plantacion de Árboles.-Extracto de un tratado práctico. sobre la plantacion, presentado á la Sociedad por el Marqués de San Lorenzo.

Extractos de las juntas generales celebradas por la Real Sociedad Bascongada de los Amigos del Pais en la Villa de Bilbao por Setiembre de 1775.-Pág. 18.

Se ocupa de la preparacion del suelo para la siembra de bellotas y de la haya; de los clareos segun la tierra y la espeoie; de las labores segun la clase de tierras; de la roza y hormigueros; del tiempo de plantar la chirpia; del cultivo de las plantas; del rozado de las plantas de roble y castaño; de la porla de la chirpia y modo de dar los cortes; edad de la chirpia para trasplantar; distancia á que deben plantarse los árboles; grueso de lus árboles para trasplantarlos teniendo muchas raices capilares; de la extraccion de los árboles del vivero; de la preparacion de las plantas arrancadas antes de trasplantarlas; cuidalos en los trasportes; modo do plantar y cuidarlos y labores á las plantaciones.

Sigue el dictámen de la comịsion que nombró la Sociedad para informar sobre este tratado. 
882. Plantacion de Árboles silvestres.

Discursos mercuriales, 1755.-Núm. 5, 3 de Diciembre, página 35.

Da reglas para la recoleccion y conservacion de la bellota y semilla de pinabete, y recomienda que el trasplante no se haga en niugun tiempo respecto del haya y del álamo blanco.

883. Planiaciones.

Extractos de las juntas generales celebradas por la Real siociedad Bascongada de los Amigos del Pais en la villa de Vergara por Setiembre de 1779._Pág. 12.

Trata de los diferentes viveros de árboles que sostenia la Sociedad en los huertos de Vitoria con el fin de reparlir las plantas entre las diferentes comarcas de la provincia de Alava.

884. Plantas forestales, por D. José Planellas.

Revista económica.-Tomo IV, pág. 290.

Es una monografía selvícola de la acacia blanca.

885. Plantios.-Forma que se les debe dar; preparacion del suelo; eleccion de árboles; desplantacion; plantacion propiamente dicha; poda ó entresaca, y explotacion de los bosques.

Revista semanal de agricultura, 1851. - 'lomo II, páginas 3, 19 y 34.

Da reglas generales acerca de las operaciones propias de la plantacion y las sucesivas.

Añade algunas noticias sobre exp'otacion de bosques, distinguiendo el monte alto ú oquedal, del bajo ó tallar.

886. Poda en General.

El Agricultor español.-Tomo único, pág. 225.

No se dan realmente reglas concretas, hablándose tan solo de la conveniencia de la poda. Combate la doctrina de Cadet de Vaux, que recomienda la torsion de las ramas, cual si esto no equivalie:a á la poda.

887. Prenio nuevo.

Extractos de las juntas generales celebradas por la Real Socicdad Bascongada de los Amigos del Pais, en la ciudad de Vitoria, por Julio de 1792.-Pág. 11.

Figura entre otros, el ofrecimiento de un premio de mil reales vellon á la persona de la provincia de Alava que en las juntas generales que habian de celebrarse en 1795, acreditase haber dispuesto el vivero más extendido y de mejores circunslancias, entre las cuales se alenderia especialıneste á la variedad y utilidad de las plantas, conveniente distancia entre ellas y buen cultivo. La exiension debia ser la necesaria para contener á lo ménos dos inil plantas en vivero, y el aspirante al premio debia justificar que todos los árboles contenilos en su vivero habian sido criados por él ó de semilla, ó de estaca pequieña. 
,Para señalar este premio se tuvo presente que las repetidas órdenes de Rey á eonsulta de su Consejo relativas al aumento de árboles no habian logrado en aquella provincia el efecto que se deseaba.

888. Puetrindido Monopolio (DeL) De los ingenieros DE Montes, por D. F. de P. Arrillaga.

Revista forestal, económica y agricola.-Tomo I, páginas 585 y 689 .

Da cuenta de la organizacion de los cuerpos de ingenieros civiles desde su fundacion, de la indole de sus servicios, de las condiciones cion que sus individuos sirven al Estado, y de las propias de otras carreras, deduciendo de todo, que los ingenieros no solo no gozan de privilegio alguno, sino que son los únicos para quienses está planteada la libertad de profesion.

Encarece al final, lo mismo que al principio, la necesidad de fomentar los montes entregíndolos de lleno á la gestion científica, con la dotacion de recursos necesarios para ello.

889. Priviligios.

El Debate. -26 de Setiembre de 1871.

Se demuestra en este artículo, que los ingenieros de caminos, minas y montes, estáı sujetos á una organizacion para la cual se necesita pasar por esfudios dificiles y aprovechaniento probado, no disfrutando del monopolio que existe á favor de los que obtienen otros titulos profesionales, dado que. por lo que á estos toca, no puede nadie ejercer las funciones de la facultad de que se trate, sin que tenga el título propio de la misma, mientras que no hay tal prohibicion para todo el que se dedique á trabajos propios de la carrera de los ingenieros antedichos.

890. Phoduccion d́ Cortezas curtientes en españa, por don L. de la E.

Revista forestal, económica y agricola.-Tomo II, pág. 121.

Trata de la composicion química del tanino, de las especies de corteza curtiente, del aprovechamiento de la casca y de la produccion de cortezas en los montes españoles, incluyendo un Eslado general de la produccion, consumo, y valor de corlezas y plantas curtientes en España.

El autor de este trabajo es el ingeniero de montes D. Luis de la Escosura.

891. Productos Forestales (Los) en la EXPOSiCion REgional.

Las Provincias.-Diario de Valencia.-30 de Mayo de 1867.

Pasa revista á los trabajos y productos forestales presentados en la exposicion q̨ue tuvo lugar el año de la fecha en Valesıcia, haciendo particular elogio de los bosquejos dasográficos de las provincias de Oviedo y Santander, del plano de rodales del monte La Garganta de los propios del Espinar; de los planos levantados por la comision del cuerpo de ingenieros de montes que esludió las inundaciones del Jucar en 1864; de la coleccion de madera, frutos y carbones, presentadla por el ingeniero de montes D. Juan Navarro IReverter, de la de carbones y espartos de Murcia, y de otras varias extendldas hasta los artefactos más varialos cuya primera materia procede de los montes. 
892. Programa de los Premios que la Sociedad Económica de Amigos del país de Astúrias, ofrece y adjudicará iá los labradores y ganaderos), en 19 de Noviembre de 1856.

Buletin oficial del Ministerio de Fomento, 1856.-Tomo XVIII, página 78.

Los principales premios se destinaron al que acreditase haber sembrado un bo:que con determinadas circunstanciss.

893. Progreso forestal de los irusos, (El) por D. Agustin Pascual.

Revista forestal, económica y agricola.-Tomo V, pág. 529.

Presenta variados datos estadísticos de la produccion territorial y comercial, describiendo muy particularmente la carta que representa el movimiento de las mercaderías entre San Petersburg o y Astracan por la vía navegable del Volga, y la carta de las producciones naturales, que comprende toda el arca forestal subdividida segun el caricter de su poblacion botánica.

- 894. Propiedad RuRal.-Expedientes de roturaciones arbitrarias.

Ell Consultor de los Ayuntamientos.-Tomo XX, 1872.-Número 43.

Censura la Real órden de 19 de Octubre de aquel año por la que se dispone que sean remitidos á la aprobacion del Gobierno, todos los expedien. tes de reconocimiento de la propiedad de las roturaciones arbitrarias, considerando esta resolucion como contrarid á las disposiciones vigentes, que atribuian á las Diputaciones provinciales !a exclusiva competeucia eı la materia.

895. Proteccion de las riquezas naturales, (De la) por don F. de P. A.

Revista forestal, económica y agricola-Tomo III, págs. 60, 307 y 466 .

Despues de reproducir dos articulos de Madame Clemence Royer, publicados en el Journal des economistes, en los que esta combate la libertad absoluła pretendida por la escuela individualista en lo referente á las producciones naturales, controvierte el articulista, D. Francisco de Paula Arrillaga, las tendencias de las escuelas economistas que pretenden anular las atribuciones del Estado, y defiende el iuterés colectivo, en coutraposiciou al individual absoluto por que abogan los partidarios del laisser faire.

896. Provision de los expleos, (LA) por D. J. J.

Revista forestal, económica y agricola.-Tomo IV, pág. 83.

Contestocion al Imparcial sobre el mismo tema, abogando por que los servicios púb'icos se eutreguen á uii personal de aptitud probada y sujeto á inamovilidad, como sucede en los cuerpos de ingenieros civiles.

897. PRoYecto DE LEY dE MoNTES. (EL)

Diario de Barcelona. -23 de Noviembre de 1872. 
Se hace cargo del proyecto de ley de nontes presentado à las Córtes, en 5 de aquel mes por el ministro de Fomento señor Echegaray, y despues de censurar algunas opiniones generales consignadas en el preambulo del proyecto, analiza sus disposiciones, juzgando muy perjuclicial á los intereses generales y licales de la nacion, la mayor amplitud que se quiere dar á la desamortizacion forestal, ln intentada abolicion del aprovechamiento comun, y el reparto entre los recinos de las suertes en que se dividan los montes.

La Revista forestal, económica y agricola copió este crticulo, que puede verse eu el tomo Vl, pág. 191.

898. Proyecto de Ley de montes. (EL)

El Debate - Periódico político.-12, 18, 19, 20, 22 y 23 de Noviembre, 3, 10 y 27 de Diciembre de 1873.

Es una série de nueve artículos dectinados á combatir el proyecto de ley de montes presentado á läs Córtes por el Ministro de Foinento señor L̇chegaray en 5 ile Novieıbre de ałucl año. El procedimiento adoptadó por el crítico es el de seguir pasn á paso los puntos mis nutables del preámbulo del. proyecto continuardo despues con el articulado del mismo. En la imposibilidad de dar cuenta detallada de los argumentos empleados por el articulista, porque esto seria úna tarea muy larga, uos limitaremos á decir que á su juicio, el proyecto representa la destruccion de los montes más importantes, la reduccion del área dasonómica, un ataque al derecho legitimo de los pueblos, la condenacion de los aprovezhamienlos comunales, y un pobre auxiliọ prestado á la Hacienda.

La Revista forestal, económica y agricola copió estos articulos, insertándolos en la pág. 23 y siguientes del tomo VI.

\section{PROYECTO DE LEY DE MoNTES.}

Fomento de la produccion nacional.-Periódico de Barcelona.21 y 28 de Diciembre de 1872.

Dedica este periódico dos artículos, á combatir el proyecto de ley ie montes presentado á las Córtes en 5 de Noviembre último, por el Vinistro de Fomento señor Echegaray, censurando el espiritu desamortizador, el intelıto de repartir los terrenos, la abolicion del aprovechamiento comun y otros puntos que comprende el proyecto cuestionado.

Reproducidos en la Revista forestal, económica y agricola.-Tomo VI, página 195 .

900. Proyecto De LeY De MONTES.

La Iberia:-Periódico político. - 20, 21 y 22 de Noviembre y.5 de Diciembre 1872.

Es'e periódicn, combate en cuntro artículns el provecto de ley de montes presentado á las Córtes por el Ninistro de Fomento señor Kchegaray. considerando perjulicialá los intereses del pais y á los foresta'es la mayor amplitud que se quiere dar á la desamortizacion de los montes, el reparto i) concesion à los vecinos de las parcelas en que aquellos pueden dividi'se, Ir abolicion defaprovecha miento conuual y ctrós varios puitos eseru iales del proyecto de que se ocupa. 
Reproducidos en la Revisla forestal, económica y agricola.-Tomo Vl, página 92.

901. Proyecto DE LEY DE MONTES.

El Imparcial.-Periódico liberal de Madriḍ.-14, 16, 19 y 27 de Noviembre de 1872.

Habiendo censurado La Epoca y El Debale el proyecto de ley de montes presentado á las córtes por el Ministro de Fomento señor Echegaray en 5 de aquel mes, $E l$ Imparcial dedica cuatro artículos á la defensa de dicho proyecto, combatiendo principalmente lo expuesto por el primero de aquellos dos periódicos. En el primer artículo, cuyo epigrafe es, El proyecto sobre montes, recuerda la necesidad que habia de armonizar la legislacion del rawo coula luneva ley municipal, asentando que el proyecto puede muy bien parangonarse con cuanto se ha hecho en la materia hasta el dia; en el segundo expone los principios fundamentales del proyecto repetido respecto a la couservacion del monte alto por medio de la abolicion de las prácticas convecinales, en to que atañe a la desamortizacion y en cuanto hace referencia con el aprovechamiento comun; en el tercero se ocupa de la mayor concentracion de fuerzas que, sobre los montes adquirirá el Estado, precisando wás las condiciones dasonómicas que reunan lor que deban exceptuarse de la venta y amenguando los efectos del aprovechamiento comunal cuya descripcion hace con referencia al provecho que de él reportan las clases pobres; y en el cuarto deflende la abolicion del congoce vecinal bajo el aspecto económico y jurídico, entendiendo que así caerán los montes reservados á la intervencion del Ministerio de Fomento, en las monos que mejor pueden conservarlos y mejorarlos.

Reproducidos en !a Reoista forestal, económica y agricola.-Tomo Vl, página 245.

902. Proyecto de Ley de Montes (EL).

La Tribuna.-Periódico político. -4 de Diciembre de 1872.

Juzgaudo el proyecto de ley le mortes presentado á las Córtes por el Ministro de Fomento señor Echegarny, afirma que queda reducido á una autorizacion para vender mayor número de fincas, y á la abolicion del aprovechamiento comun tan necesario para los pueblos. A juicio del articulista bastaria el exacto cumplimiento de las leyes vigentes y un buen cuerpo de guardería forestal para fomentar los montes.

Reproducido en la Revista forestal, económica y agricola.-Tomo VI, piigina 144.

903. Proyecto De Ley de yonths, (EL) por D. José María Ruiz.

El Puente de Alcolea.-Periódico político.-3 y 4 de Diciembre de 1872 .

Examina el autor, en dos artículos, el proyecto de ley de montes presentado á las Córtes en 5 le Noviembre de aquel año por el Ministro de Fomento señor Echegaray, censurando las principales disposiciones del mismo, especialmente las relativas á la desamortizacion que juzg pocu eficaces para 
facilitar la accion administrativa y la venta de los prédios que deban enagenarse.

- Estos artículos fueron copiados en la Revista foresial, económica y agricola.-Tomo VI, págs. 147 y 185.

904. Proyecto DE LEY DE Montes, por R. Jordana.

Revista del Instituto agricola catalan de San Isidro, 1873.Tomo XXII, pág. 14.

Tiene por ohjeto combatir el proyecto de ley de montes presentado á las Córtes por el Ministro de Fomento Sr. Echegaray á últimos del año anterior. Fúndase principalmente en que dicho proyecto se encamina á entregar á la desamortizacion y al reparto vecinal, mucha superficie arbolada, necesaria para conservar el equilibrio físico del país.

905. Proyecto de presupuestos, por J. G. H.

Revista económica.-Núm. 21, del 27 de Febrero de 1873.

En su seccion Impuesto terrilorial, estudia las bases à que este debe sujelarse, consistiendo la segunda en el sapoderamiento temporal del Estado para la formacion de montes, de todo el terreno que no pague el impuesto en el grado mínimo." Cálcula en 5.000 .000 de hectáreas la superficie que ocupa en España el monte alto y bajo, para el cual propone un impuesto de 2 reales por hectárea, que justifica, por si pareciese excesivo, suponiendo que por este medio, los particulares se limitarian al disfrute razonado de los terrenos bien poblados y productivos, abandonando los calvos y estéri'es, que á su vez serian repoblados por el Estado, cumpliendo este, dice, su mision de formar moute alto en los terrenos que vengan á su poder.

906. Proyecto para la extincion de los lobos.

Variedades de ciencias, literatura y artes, 1805.-Tomo VII, página 167.

Propone un impuesto de cuatro mara vedises por cada cabeza menor de ganado y ocho por cada mayer, lo cual calcula que producirá cuatro millones de reales àl año, y que esta suma se reparta en premios de 3000 rcales el primer año por cada lobo que se cace, pudiéndose exlinguir así 1.300 lobos sin perjuicio de aumentar en los años sucesivos el precio ell razon de aumentar la dificultad de cazarlos.

907. Pudiéra yos deCir que en la Curstion de Montes... etc.

El C'onstitucional.-Periódico político.-1. - de Mayo de 1862.

En este artículo de polémica con $E l$ Contemporáneo, se defiende la venta de los montes con arreglo á las disposiciones del real decreto de $2:$ de Enero de aquel año, fundándose en la escasa imporiancia que tientn los que están poblados de deferminadas cspecies y en que por la initicada mediúa, se asegura la posesion del monte alto por instituciones perpétuas.

908. ¿Pueden evitarse para lo scclestyo las inundaciones lin LA CUENCA DEL JÚCAR Y SU'S AYLuentes,? por D. Felicísimo Llorente.

La Opinion.-Periódico de Valencia.-20 de Noviembre de 1864. 
Describe la última inundacion producida por las avenidas de aquel rio, fijándose en la gran cantidad de agua de lluvia que cayó. Considera ineficaces para evitar las crecidas los sistemas de acequias, ramales y pozos absorbentes, y el de reforzamiento de las márgenes. A juicio del articulista el único medio que se puede emplear con éxilo contra las inundaciones, es la repoblacion de las montañas.

\section{R.}

909. Ramo de arbolado (EL) en madrid.-Véase: Parque, (El) los jardines... etc.

910. RaMo DE DESAMortizacion (EI) Y EL DE MonTEs, por D. José María Ruiz.

El Puente de Alcotea.-Periódico político.-8, 9 y 11 de Enero de 1873.

- Se propone demostrar el autor la conveniencia de la desamortizacion general, y al efecto estudia en dos artículos la historia de sus vicisitudes y efectos, así como los producidos por la legislacion relativa al fomento, mejora y conservacion de los predios forestales de carácter público.

911. Rápıda ojEAda sobre el estado de los montes de Canarias, Puerto-Rico, Cuba y Filipinas, por D. Miguel Bosch.

Revista forestal, económica y agricola.-Tomo I, págs. 169, 329, 396 y 465.

Demuestra la necesidad de los montes en aquellas provincias, describe las vicisitudes por que estos han pasado, y las especies arbóreas que en los mismos se encuentran; condena, como contrarias á la conservacion, varias prácticas viciosas, determina las cuestiones de preferente atencion para beneficiar y mejorar los mantes que quedan, y analiza muy detenidamente el proyecto de Ordenanzas de montes para Ultramar de que se estaba ocupando el gobierno.

912. Real CÉdula DE S. M. y señores del Consejo, dada en el Pardo, á 27 de Enero de 1788, en que se manda guardar el Reglamento inserto, formado para el exterminio de lobos, zorros y otros animales dañinos.

Memorial literario, 1788.-Tomo XIII, pág. 210.

Consta el Reglamento de quince capitulos. Se dispuso que dos veces al año, en Enero y Octubre, se hicieran batidas en todos los lugares de un partido en el mismo dia y hora. Se estableceu algunas reglas, acerca del modo de echar cebos y de los premios que habian de darse por los animales muertos fuera de las batidas. El rey se reservó el cuidało de avisar los montes y puntos en que era preciso el auxilio de los pueblos por ser suficientes las cacerías que él emprendia.

913. RECOLECCION Y CONSERVACION DE LOS PRODUCTOS. 
Boletin oficial del Ministerio de Fomento, 185\%.-Tomo XXIV, pág. 322.-Se publicó tambien en El Mallorquin.

Se ocupa de las semillas, frutos y otros productos. Respecto de las maderas estudia las capas leñosas recomendando como medio de conservacion la pintura, $\mathrm{y}$ las Inyecciones de acetato de hierro. Indica tambien la época más conveniente para efectuar las cortas y las precauciones que haý que tomar con la madera cortada.

914. Reforma (LA) DE LAS ESCUElas especiales DE INGenieros, por D. F. G. Martino.

Revista forestal, económica y agricola.-Tomo I, pág. 661.

Demuestra la necesidad de los servicios públicos que desempeñan los ingenieros del Estado y deflende despues la reforma introducida en las escuelas especiales por el decreto de 23 de Octubre de 1868, en contra de los que pretendian la libertad absoluta de enseñanza, encontrando muy conveniente que se dè en ellas la enseñanza profesional por un lado y la especial para el servicio del Estado, por otro.

915. ReForma (LA) DE LOS CUERPOS DE INGENIEROS CIVILES.

El Argos.-Núm. 34, 11 Octubre.-35, 12 Octubre.-37, 14 Octubre. $-40,18$ Octubre. $-46,24$ Octubre. $-50,28$ 0ctubre; y 61, 13 de Noviembre de 1871.

Siete artículos de los cuales el $1 .^{\circ}, 2 .^{\circ}, 50^{\circ}$ y $6 .^{\circ}$ son de D. José Jordana. Tiene por objeto el trabajo combatir la reforma introducida en la organiza cion de los Cuerpos de ingenieros civiles por los decretos de 12 de Agosto y $1 .^{\circ}$ de Setiembre de aquel año, fundándose la censura en que la supresion de personal es injustificada dadas las necesidades del servicio, en que se atacan derechos adquiridos $y$ en otras varias razones de equidad, conveniencia y justicia.

916. Regaliz, (EL) por D. J. Jordana.

Revista forestal, económica y agricola.-Tomo II, páginas 303 y 361 .

Apuntes monográficos de dicha planta, que comprenden los nombres, descripcion, distribucion, clima, situacion, exposicion; terreno, reproduccion, crecimiento; a provechamiento, produccion, cultivo, composicion, propiedades y usos.

917. Reglamento sobre la organizacion del servicio que deben prestar los empleados y la cooperacion eficáz de las autoridades locales para la prosperidad de los montes de la provincia de Jaen.

Boletin oficial de la provincia de Jaen.-Núms. 48 y 49 del viernes 23 y lunes 26 de Abril de 1852. -4 pliegros en fólio, con 7 páginas de estampacion.

Expedido con fecha 27 de Abril de 1852, por el Gobernador civil de la provincia D. Félix Sanchez Fano. Va precedido de una circular de igual fe. cha, en la que se dictan reglas para evitar $y$ apagar los incendios, para per- 
seguir las roturaciones, y para denunciar las cortas fraudulentas é impedir que tengan lugar, todo comprendido en 28 artículos. El reglamento consta de 37 , subdiviendo la materia segun los deberes propios de los alcaldes y ayuntamientos, de los peritos agrónomos, de los guardas mayores montados, de los guardamontes del Estado, y de los guardamontes locales, en lo concerniente á la custodia, aprovechamiento y mejora de la riqueza forestal. Sigue un estado que expresa la residencia en la provincia de los distintos empleados del ramo, y añade, por conclusion, los artículos de la ordenanza de montes, citados en las disposiciones anteriores.

918. Remitido.-Caparroso (Navarra) $10^{\circ}$ de Noviembre de 1868, por D. Juan Yanguas.

Revista forestal, económica y agricola.-Tomo II, pág. 177.

Discurriendo sobre las sequís, enfermedades y alteraciones del clima que se observan en aquella parte de Navarra, lo atribuye á la despoblacion forestal, y propone la prohibicion de las roturaciones y la plantacion de árboles en las lindes de las fincas agrícolas.

919. Resirtido.-Por un suscritor.

Revista foreslal, económica y agricola.--Tomo IV, pág. 145.

Es un estudio detallado de las opiniones sustentadas en la época presente en las Córtes españolas, con motivo de la desamortizacion forestal. Pasa revista á los defectos prácticos de la dezamortizacion y despues de encarecer la necesidad de un buen servicio facultativo y administrativo para el ramo, establece las bazes principales para una buena ley de montes, encaminadas á la conservacion y fomento de aquella riqueza.

920. ReMTido.-Por un suscritor.

Revista forestal, económica y agricola.-Tomo IV, pảg. 301.

Se ocupa de las últimas disposiciones sobre desamortizacion forestal, especialmente del decreto de 14 de Febrero de aquel año, reorganizando la Direccion de Propiedades y derechos del Estado, y de la circular del ministro de Fomento fecha 28 de Marzo siguiente, recomendando que no se entreguen á la venta más montes que los determinados por la ley de 24 de Mayo de 1863. A este propósilo el articulista hace notar las irregularidades y fallas cometidas por aquel centro de llacienda, en la materia cuestionada.

921. Reponlacion de las montañas.-Por D. L. Bengoechea.

Revista forestal, económica y agricola.-Tomo II, pág. 357, 438 y 495.

Artículo que reproduce el informe de la Seccion de Selvicultura de la Sociedad de Agricultores de Francia, redactado por Mr. Grye, y en el cual se da cuenta de los beneficios que respecto al clima y á las inundaciones produce el repoblado de los montes, de lo que puede esperarse de las disposiciones administrativas dirigidas á aquel objeto, y de los hechos y.observaciones repetidamente comprobadas, que vienen á evitar los daños sufridos en los últimos tiempos por los arrastres y aguas torrenciales. 
922. Repoblacion del arbolado en el Ampurdan.-Por D. José Vergés y Almar.

Revista de Agricultura práctica.-1863. Tomo XII, pág. 197.

Describe en estilo muy levantado las ventajas del arbolado y su benéflca influencia, los usos de que es susceptible, los productos que proporcionan los árboles, elc. Aconseja al final que se pucblen de alerce los montes elevados y de pino de Burdeos las partes bajas hasta las orillas del mar.

923. Repoblacion del aRbolado.-Necesidad de atender á este importante ramo de la riqueza pública.-Idea laudable.

El Consultor de los Ayuntamientos.-Tomo VIII, 1860, pág. 75. -Véase: Sobre la repoblacion del arbolado en la provincia de Búrgos.

924. RepresentaGion de LA vilLa DE GiJon para que se prorogue el arbitrio de vino y sidra para fuentes, calles y plantíos.

Obras publicadas é inéditas de D. Gaspar Melchor de Jovellanos. -Tomo II, pág. 517.

Este trabajo debido aI ilustre autor del Informe sobre la ley agraria es, á pesar de su modesta apariencia, uno de los más importantes para determinar las verdaderas opiniones de aquel esclarecido patricio acerca de la naturaleza, conveniencia, utilidad y posesion de los montes públicos, sobre cuya materia, y ajusando tal vez de la concision con que la trató en el $I n$ forme arriba citado, creen muchos, bien equivocadamente por cierto, que encarecia en absoluto la desamortizacion completa de la propiedad forestal. Del texto de la Representacion no se desprende esto al ménos, y antes al contrario, se conceden á los montes públicos ventajas y utilidades de verdadero carácter social, imposible de obtener con solo el estimulo del interés particular.

He aquí los párrafos más notables de la Representacion: "No es ménos cierta la necesidad de bacer á la entrada de esta villa un plantío de pinos en el vasto arenal que la rodea por el Oriente y Sur, cuyas arenas, movidas continuamente por los vientos, entran en las calles, y amontonadas en ellas, obstruyen y embarazan el paso público, con gran perjuicio de los traginantes y notable molestia de los vecinos.

Es verdad que para remediar este mal se han tomado otras precauciones sobre las cuales representará esta villa separadamente á vuestra alteza; pero la más principal seria hacer el plantío de pinos que va indicado y que produciria desde luego dos grandes utilidades, una la de cortar y quebrantar el fuerte soplo de los vientos, y otra, agramar y solidar el terreno, librando para siempre á esta hermosa poblacion de un enemigo que la ha destruido varias veces, y proporcionando la abundancia de maderas, tan necesaria á la boca de un puerto que tiene su pequeño astillero, dondo se construyen continuamente barcos, pinazas, pataches y otras embarcaciones de pesca y comercio.

Tambien desea esta villa aumentar otros, plantios en sus inmediaciones, para lo cual tiene el terreno más extendido y proporcionado que puede ima- 
ginarse, ya guarneciendo las orillas de la nueva carretera, que se está construyendo de órden de S. M., ya poblando las del nuevo paseo y zanjas del Humedal, hechos con permiso de V. A., y ya coronando de árboles el monte de Santa Catalina, que defiende esta poblacion del mar por la parte del Norte.

Todos estos plantíos y otros muchos que pueden hacerse en las inmediaciones de esta villa, fueron propuestos á su ayuntamiento por nuestro compatricio D. Gaspar Melchor de Jovellanos."

925. Resind Del pino. - Modo de extraerla y de fabricar la brea. Sumario industrial, 1841.-Tomo II, pág. 66.

Considera al pino en disposicion de producir resina á los 28 ó 30 años, explicando la época y el modo de extraerlo. La primera labor preparatoria la indica para Enero ó Febrero, comenzando la incision de labor definitiva desde mediados de Marzo á principios de Mayo. Detalla el modo de ejecutar el trabajo, los productos que se obtienen y las operaciones sucesivas para la elaboracion de los que se derivan de la resina.

926. Reiriro (EL). - Véase Parque (El), los jardines, etc.

927. ReVista FOREstaL.

Boletin oficial del Ministerio de Fomento.-Tomo XVIII, página 270 .

Esta Revista, que corresponde á los meses de Enero á Abril del año de 1856 , así como las dos siguientes, deben atribuirse al actual inspector de primera clase del Cuerpo de Ingenieros de montes, D. Agustin Pascual. Se reprodujo este trabajo en la Gaceta de Madrid, número del 10 de Mayo, y en El Agente industrial minero. núm. 345 y 346 del mes de Junio.

Dá cuenta con bastante extension de la obra Anleitung zur Waliverthsberechnug. - Viena, 192 pág., publicada por el profesor H. K. Breimann, catedrático de la escuela de Mariabrunn, sobre la valoracion de los montes, echando de ménos en ella las teorías del valor del suelo, del vuelo y del monte; y el que tampoco se trate de la influencia de los métodos de beneflcio, ni se discuta la relacion de los precios y la determinacion ảel rédito.

Recuerda los ensayos hechos con la máquina de descuajar llamada Waldteufel; los trabajos de selvicultura ejecutados en Francia; los reconocimientos hechos en Españd, en las zonas forestales de las provincias de Soria, Segovia, Avila, Valladolid, Búroos, Cáceres, Salamanca, Teruel, Huesca, Navarra, Santander, La Coruña y Jaen; los trabajos de ordenacion en la Real dehesa de la Albufera, montes de las minas de Riotinto, dehesa de Castelserás y mesa Real de Urbasa; los trabajos de siembra, plantacion y aclimatacion ejecutados en el arboreto de la Escuela especial de Ingenieros de montes, en la huerta de San Gerónimo de Madrid, en la Casa de Campo, en el Escorial y en el Real Soto del Lomc de Grullo; el plan de cultivos para el campo experimental de Estepas en la huerta de secano del Real Sitio de Aranjuez, y por último, el informe sobre desamortizacion forestal, evacuado por la Junta consultiva del ramo, y alguna otra publicacion española dada á luz por aquel tiempo. 
928. Revista Forestal.

Boletin oficial del Ministerio de Fomento. -Tomo XVIII, página 500.

Corresponde esta Revista al mes de Mayo del año de 1856. El Agente $n$ dustrial minero la reprodujo en los números de los dias 17,18 y 19 de Junio.

Entre otras publicaciones, dá cllenta de las que acababan de ver la luz relativas á literalura, geonomia, xilometria, tecnolegia, dosocracia y dasótica forestal debilos á Laurop, Krutsch, Pressler, stahl, stoecthardt, Schober, Colta (Augusto), Peruitzsch, Cari, Papius, Keltrek, Uxkull, Gillenband, Beil, Fintelmann y Richl. Dá una idea del opúsculo titulado Ensayo aritmélico sobre el valor de los plantios que atribuye á D. Alejo de Molina y Saurin, Vizconde de Huerta, del de D. Juan de la Cruz Martinez, Estudios sobre el ramo de montes y arbolados de España, y de la notable obra de los Sres. Lorentz y Parade, directores de la escuela imperial de montes de Nancy (Francia), que se titula Cours elementaire de culture des bois, de la que hace elogios, si bien encuentra en ella materias que corresponden á los tratados especiales de meteorologia, geonomia y botánica. En punto á trabajos esteparios dá á conocer los que se han hecho en los terrenos de Aranjuez que rodean al mar de Ontígola y en la huerta de los Diques, de la administracion patrimonial de la Real acequia del Jarama.

No se dá cuenta de esta Revista en el Diccionario de bibliografia agronómica del Sr. Anton Ramirez.

929. Ruvista FORESTAL.

Boleitin oficial del Ministerio de Fomento.-Tomo XIX, página 375 .

Esta Revista corresponde al mes de Junio del año de 1856. En ella se dá cuenta de los trabajcs de T. Hartig y Oetzel sobre valoracion; de las tablas de cubicacion del lugeniero Braun; de la obra de G. Heyer sobre el cálculo de probabilidades en la graduacion de las penas por faltas y delitos en materias de montes; de los comentarios de Brater á la ley forestal de Baviera; del proyecto del profesor do Eldena H. Trommer, sobre los establecimientos de agricultura práctica y de las actas de la Sociedad forestal de Austria. Añade otras varias nolicias forestales sobre publicaciones francesas y sobre la Exposicion universal de Paris. Dá cuenta de haber terminado sus estudios en la Academia de montes de Tharand, los Ingenieros españoles Sres. Madaringa, Laguna y Bengoechea.

No hace mencion de esta Revista el Sr. Anton Ramirez, en su Diccionario de bibliografía agronómica.

930. Riqueza forestal de España (La) y los bosquis de CastaÑo y de a vellano en el Monseny.-Por D. Manuel E. de Casanova. Revista del Instituto, etc. 1869.-Tomo XVIII, pág . 332.

Reconoce la accion benéica de los montes y se lamenta del atraso de la dasonomia en España, á cuyo efecto recuerda que en Alomania hay más de 40 escuelas forestales mientras que en nuestro pais solo existe una. Hace com- 
paraciones estadísticas sobre superficie y produccion, lamentándose del mal servicio de guarderia y de la falta de repoblaciones. Respecto al Monseny, maniflesta que sus montes ocupan 2.500 hectáreas pobladas en $4 / 5$ de castaก̃ก y $1 / 5$ de avellano cuidadosamente explotados y rindiendo pingües productos, por cuyo motivo desea que se repueblen muchos terrenos incultos del pais.

931. Robles (Los).-(GÉnero Quercus).-Por D. R. Jordana. Revista forestal, económica y agricola.-Tomo V. pág. 22.

Comprende noticias historicas, descripcion y estudio de las especies.

932. ROGaMos Á Ja DIRECCION GENERAL DE AGRICtLTERA... ETC.

La Epoca.-Periódico político.-12 de Noviembre de 1872.

En este artículo se llama la atencion acerca de los publicados por $E l E C$ de Galicia, sobre el proyecto de ley de montes, presentado á las Córtes por el ministro de Fomento señor Echegaray, en los cuales se demuestra que los. montes comunes de las parroquias constituyen una propiedad de estas que no les puede ser arrebatada, como sucederia si aquel proyecto llegase á ser ley.

Reproducido en la Revista forestal, económica y agricola. Tomo VI, página 139.

933. RoMpiniento de TERRENOS Y SU PREPARACION.

Sumario industrial, 1841.-Tomo II, pág. 241.

Recomienda que solo se roturen los terrenos llanos, respetando las lomas, cerros y collados cubiertos de árbolado espontáneo, porque este abriga el país, evita la sequía y proporciona abonos que son arrastrados por las aguas á los sitios inferiores.

934. Roturaciones (Las) en la alta montaña.

El Siglo, Periódico de Lérida.-Núm. 17, 9 de Julio de 1868.

Aun cuando no está firmado, nos consta que el autor de este articulo es D. Ramon Jordana.

Expone las consecuencias económicas y físicas de la roturacion de los montes en las localidades montañosas, y aconseja el respeto á la integridad del área forestal, como medida necesaria para evilar los arrastres é inundaciones, así como para mantener en pié los elementos de las industrias que se derivan de los montes.

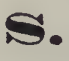

935. Selvicultura. - Métodos de Beneficio.-Por D. José M. de Fivaller.

Revista del Instituto, etc., 1872. tomo XXI, págs. 77, 112, 142 y 179.

Hace atinadas reflexiones sobre la importancia que se ha atribuido á los montes en todos tiempos, define y determina los montes alto, medio y bajo y estudia los métodos de cortas á clareos sucesiros, el establecimiento de sé- 
ries de cortas, las de fajas alternas, las practicadas á matarrasa, las írregulares, las claras, las limpias, la cortabilidad y sus divisiones, la posibilidad, el turno y todo lo concerniente al monte alto, medio y bajo, con inclusion de lo referente al número, clase y edad de los resalvos.

936. Selvicultura.-Por D. Francisco de Brichfeus.

Revisıa de agricultura práctica.-1852.-Tomo I, pág. 148.

Enumera los grandes perjuicios que ocasinna la roluracion de los montes situados en la region montuosa, y aconseja $<u$ conservacion. Juzga que al aumentarse las vías de comunicacion disminuirá el precio de los cereales aumentando el de las maderas, leñas y carbones.

93\%. Selvicultura.-Por N. C.

Gaceta de Madrid. -7 de Abril, 3 de Junio, 7 de Julio y 8 de Setiembre de 1849:

Extenso artículo en el que se trata con amplitud de la recoleccion y empleo de la semilla, método de siembra, labores, cuidado de los planteles y , cuanto concierue á este ramo del cultivo forestal, dividiendo la materia en cuatro partes, indicadas con los enunciados siguientes: Plantel para los árboles de bosque y monte.-Plantel para los árboles frutales.-Plantel de los árboles de adorno y de sombra.-Plantel de árboles verdes ó resinosos.

938. Segquía (LA) y los ARBoles. - Por D. José Galofre. Eco de la Ganaderia.-Tomo XII, pág. 69.

Reseña los accidentes de varias sequías memorables y recomienda las plantaciones.

939. Si PRUeba Negesitásemos DE QUE LA LeY DE MoNTES..... etc. El Contemporíneo.-Periódico político.-24 de Mayo de 1862.

Comenta la sesion celebrada en el Congreso de los diputados el dia 12 de aquel mes, en la que se disculió la totalidad del proyecto de ley de montes, ponièndose del lado del Sr. Ruiz Zorrilla, que lo impugnó, por aceptar la base de las especies para la clasificacion, y porque se entregarian impremeditadamente á la venta muchos millares de hectáreas de terreno forestal, para tenerlas que adquirir para la repoblacion ya descepadas. Refuta el discurso del $\mathrm{Sr}$. Ardanaz en lo relativo á las propiedades fisicas de los montes, á las zonas agronómicas y otros puntos objeto de la peroracion de aquel. Condensa el fin del proyecto en el deseo de vender rápidamente muchos montes.

940. Sicomoro (DeL).-Por D. José Antonio Valcárcel.

El Eco de la Ganadería.-Tomo IV, pág. 92.

Describe el árbol y todas las operaciones de cultivo, indicando despues las aplicaciones más comunes de sus productos.

941. Siembras DE PIÑones.

Extractos de las Juntas generales celebradas por la Real Sociedad Bascongada de los Amigos del Pais, en la villa de Bilbao, por Setiembre de 1775. 
Es una nola en que se dá cuenta del éxito que tuvo una sieınbra de piñon hecha de órden de la Sociedad. Asimismo se dá á conocer el resultado que tuvo una plantacion de pita, y el reparto que se hizo de varios árboles frutales para conocer las localidades del país que más les convinieran.

942. Siembras y plantacionfis, por E. Burkhardt.-Por D. M. L. Revista forestal, económica y agricola.-Tomo IV, pág. 129.

Noticia de la obra del título indicarlo, en la cual se trata del cuitivo de las principales especies forestales, estudiando las siembras, plantaciones, cria y méludos de beneficio. El articulista, D. Máximo Laguna, recumienda este libro á sus compatriolas españoles como verdaderamente útil y práctico.

943. Sistemas forestales.-Por D. A. Pascual.

Revista forestal, económica y agricola.-Tomo III, págs. 49, 97, 145, 193, 241, 289, 337, 385, 433 y 529.-Tomo IV, págs. 4, 97, 282 y 351 .

Despues de dar á conocer en la introduccion las nociones del capital dasonómico, y los elementos que influyen en la regularidad dasocrálica, examina y expone los sistemas de ordenacion, conocidos con el nombre de distribucion ó pragmáticos, subdivididos á su vez con los de distribucion de árboles, distribucion de áreas, distribucion de las clases de edad y distribucion de cuotas de productos.

944. Sobre el vocablo: forestal.-Por D. A. Pascual.

Revista forestal, economica y agricola.-Tomo I , págs. 17, 65, $306,538,631$ y 709.

Constituye un detenido estudio lexicográfico de aquella palabra, por cuyo medio el autor reseña las vicisitudes económicas y científicas de la riqueza forestal á través de los tiempos históricos.

945. SOBRe La RENTABILIDAD DEL MÉTOdo DE BENEFICIO DE MONTE ALTO.-Por D. R. Jordana.

Revista forestal, económica y ayricola.-Tomo III, pág. 111.

Constituye un extrзcto crítico de un trabajo del doctor Th. Hartig, publicado en el periódico Allgemeine Fors-und Jagd.Zeitung, del que resulta, despues de una série de calculos matemáticos aplicados á los elementos que entran en la formacion del problema, que en los montes, á modida que crece el turno, aumenta la produccion absoluta y disminuye el interés del capital representado por las existencias.

946. Sobre LA REPOBlaCion dEL ARBolado EN LA PROVINCIA DE Búrgos.-Por Manuel de la Fuente Andrés.

El Fomento.-Periódico de Búrgos.

Fechado y firmado por el autor en Aranda de Duero á 3 de Diciembre de 1859. Dió cuenta de este trabajo, haciendo de él un gran elogio, El Consultor de los Ayuntamientos.-Tomo VIII.-1860.-Pág. 75.

Se lamenta de la decadencia del arbolado particular y público; recuerda los tiempos de prosperidad forestal en la provincia y recomienda el fomento de las plantaciones mediante creacion de un vivero provincial, exhortaciones 
técnicas, y vigilancia y custodia de los plantíos. Para dar el ejemplo, el autor ofrece de su cuenta un premio de 500 rs. vn. al terrateniente de los pueblos de Aranda, Fuentespina ó Fresnillo de las Dueñas, que acredite haber p!antado en aquel invierno mayor número de árboles frutales de todas ó de varias especies, no bajando el número de 200 ; otro de 300 al que con iguales condiciones presente un semillero ó almáciga de árboles frutales de hueso ó pepita, cuyo número sea por lo ménos de 1.000 plantas, y un accesit de 200 reales al propietario que más se acerque á cualquiera de los que obtengan uno de los dos premios anteriores.

947. So 3RE LA SIEMBRA DE LAS YeMas de árboles y arbustos como medio de obtener plantas fuertes y robustas, y sobre tudo, que sean de la misma casta y más tempranas en producir frutos, por D. Lúcas de Tornos.

La Concordia. -6 de Diciembre de 1863, pág. 486.

Estudia organográfica y fisiológicamente la reproduccion por yema en todos los casos, indicando las precauciones que hay que tomar en los semilleros y viveros para el mejor éxito de la multiplicacion.

948. Sobre las cartas contia cos montes, por D. J. Navarro Reverter.

Revista forestal, economica y agricola.-Tomo I, págs. 486, 572, 655 y $728 ;$ y Tomo II, pág. 240.

Despues de liaber contestado el autor á las dos cartas que en 7 Febrero y 17 Abril de 1867, habia dirigido al periódico de Valencia Las Provincias, D. Miguel Amat y Maestre proponiendo la desamortizacion absoluta de los montes, volvió este á su tema en una série de caturce cartas, fundándose en que la Administracion no habia podido conseguir el fomento de los montes. Esto dió lugar à otra série de seis artículos del Sr. Navarro Reverter, que son los que aqui indicamos. Se publicaron primero en Las $P$ rovincias números 25 Abril, 10 y 15 Hayo, 6 Junio 1868 y 24 Febrero 1869, y los reprodujo despues la Revista. En ellos demuestra la legitimidad de la dasonomia y que solo poseyendo los montes el Estado se les puede hacer prosperar; explica las causas de la decadencia ó mal estado de algumos; dá á conocer el espiritu de las leyes desanortizadoras y desvanece las apreciaciones erróneas de su contrincante acerca de la naturaleza de la propiedad forestal en Alemania.

949. Sobre las ventajas del arbolado.

Revista económica.-Tomo IV, pág. 508.-Es reproduccion de La A beja montañesa.

Considera lọs montes bajo el aspecto climatológico, agricola, industrial é higiénico, recomendando su conservacion y fomento.

950. Sobre las ventajas del arbolado, por D. Lúcas de Tornos.

La España, periódico político.-30 de Octubre de 1863.—La Concordia.-25 de Octubre de 1863, pág. 390.

Expone las ventajas del arbolado con relacion á sus productos, y al cli- 
ma, higiene, y economia social, recomendando la adopcion de un buen sistema de repoblaciones y cultivo, asi como la plantacion de los terrenos desnudos de vejetacion.

951. SOBRE LOS TRASPLANTOS.

Gaceta de Madrid.-17 de Noviembre de 1858.

Artículo reproducido de la Revista de Instruccion puiblica, en el que se estudian los fenómenos fisiológicos de los árboles en la que se llama vegetacion de invierno, primavera, verano y otoño, cilando experinentos de muchos bo. tánicos distinguidos. Indica las precauciones que exige el trasplante y expone las razones fisióógicas en que estas se fundan.

952. Sobre Montes, por Colibrí.

Diario de arisos de Zaragoza.-Núm. 9, 11 de Enero de 1872.

Manifiesta las necesidades á que subvienen los montes, especialmente los de la provincia, presentando la estadistica de su produccion, la de los daños, expedientes, etc., concluyendo de ahí la necesidad de aumentar el personal destinado al servicio del ramo y emplear en la conservacion y fomento de los montes, las sumas aplicables á este objeto segun la legislacion vigente.

953. Solo el CUMPLimiento de LA PALABli... etc.

El Reino, periódico político. -31 de Mayo de 1862.

Es contestacion á un arículo de $L a$ Epoca del dia 18 de aquel mes. Confirma su opinion respecto á las malas condiciones del proyecto de ley de montes sugelo á discusion en las Córtes, apoyándola en las enıniendas presentadas y aceptadas. Insiste en que no fué oida la Junta consultiva del cuerpo de ingenieros de montes acerca del real decreto de 22 de Enero último, y en que el Estado debe posecr no solo los montes, sino los terrenos que el interés particular no esté en condiciones de conservar.

Rectifica algunos conceptos equivocados respecto á opiniones de algunos sábios que se han ocupado de la cuestion foreslal y echa en cara al colega la falta de opinion propia en el asunto debatido.

954. Sucinta descripcion de los árboles más propios para los paseos, alamedas y plazas públicas, leida en la Academia de Marsella por el Direćtor del Jardin botánico Mr. Salze.

Revista de agricultura práctica, 1854.-Tomo III, pág. 78.

Es una monografía, ó descripcion del cultivo de las especies siguientes: Sophora japónica.-Tilia microphyla.-T. platyphyla.-T. argentea.-Acer neapolitanum.-A. psendo-platanus. - Fraxinus lentiscifolia.-Alamo blanco.-Alamo negro. - Alamo del Canadá (Populus monilifera).-Populus virginiana. - Celtis australis. - Li. occidentalis. - Olmo de hojas anchas.-Olmo de hojas anchisimas. -Olmo de hojas anchas y frutos prolongados ú olmo de Irianon.

\section{$\boldsymbol{T}$.}

955. Trasplantacion de los árboles crecidos.

Gaceta de Madrid.-25 de Octubre de 1858. 
Es un breve artículo que tiene por objeto indicar el procedimiento de trasplante de lós árboles de grandes dimensiones, consistente en abrir á su alrededor una zanja cortando todas las raices y llenando de mantillo el foso circular ó cuadrado que queda, despues de lo cual y pasados dos años, se saca la planta con todo el cepellon en la época de la paralizacion de la savia.

956. Traspontes fluviales, por D. J. Navarro Reverter.

Revista forestal, económica y agricola.-Tomo V, páginas 86 y 113.

Se ocupa de las condiciones generales de los trasportes por agua, y de los métodos usados para flotar y ennducir las maderadas por el rio Turia, con indicacion de los gastos de trasporte.

95\%. Tronco (EL) DE un Árbol es SU Árbol Genealógico; por E. Adolfo Rossmaessler, Véase: La Abeja. Revista científica, etc.

\section{$\mathbf{U}$.}

958. Ultimo atentado CONTRA NUESTRA RIQUEZA FORESTAL.

Diario de Cádiz.-3 de Diciembre de 1870.

Creyendo amenazada la existencia de los montes públicos en virtud de un supuesto empréstito proyectado con el producto de los arbolados exceptuados de la desamortizacion, medida que se atribuia al ministro de Hacienda en union con el de Fomento, expone las razones más culminantes en pró de la conservacion de los montes públicos, y reseña brevemente las importantes funciones que estos ejercen, física y económicamente considerados.

959. Un INCIDENTE SOBRE DESAMORTIZACion Foliestal, en las Córtes constituyentes.-Por la Redaccion.

Revista forestal, económica y agricola.-Tomo III, pág. 25.

Ocupándose de la parte relativa á los montes, con motivo de la discusion habida en el Congreso de los diputados el dia 29 de Noviembre de 1869, á propósito del proyecto de ley sobre desvinculacion y venta de los bienes del patrimonio que fué de la Corona, combate la Revista las opiniones de los diputados, señores Moret, Rodriguez y Figuerola, corroborando la comun verdad de la importancia de aquellos prédios arbolados y la necesidad de que el Estacio los posea ó los intervenga para asegurar su conservacion y fomento.

960. Un pedazo de Sierra-Morena.-Por D. M. Laguna.

Revista forestal, económica y agricola.-Tomo I, pág. 437.

Es un estudio de la vegetacion leñosa del trozo de Sierra-Morena que enlaza las provincias de Córdoba y Jaen con la de Ciudad-Real, ó sea el terrilorio comprendido entre Despeñaperros y el extremo occidental del valle de Alcudia.

961. UN PROBlema dE LA ciencia de Montes,-Por D. F, G. Martino. 
Revista forestal, económica y agricola.-Tomo II, págș. 5ỉ3, 577,641 y 705.

Es traduccion de un artículo del profesor Doctor A. Clebsch, de Gottingen, en el que desarrolla la teoría general de los principios en que se apoya la ciencia dasonómica, por medio de cálculos matemálicos del órden más elevado.

962. Un Problema Sobre Montes. - Por D. Rafael Breñosa.

La Crónica.-Periódico de Badajoz.-Febrero de 1870.

El autor plantea y resuelve en estos arlículos la cuestion de la rotacion selvicola ó sea la sustitucion de especies para sostener el vigor de la produccion. Al efecto estudia las condiciones de alimentacion de los árboles, citando los anàlisis de Berthier, Werneck y Chevandier de Valdrome, de los cuales se concluye que los vegetales leñosos asimilan distintos principios fijos y en proporciones distintas, así como que existen sustancias minerales preferidas por cada especie. Decide el autor la cuestion á favor de la rolacion, fijando la amplitud del cielo en que esta debe verificarse, con arreglo á los plazos inherentes á los turnos adoptados en el cultivo y ordenacion de los montes.

963. UN PROYECTO DE LEY DE MONTES.

Revista forestal, económica y agricola.-Tomo IV o pág. 706.

Trascribe la proposicion de ley sobre montes y plantios, presentada al Congreso por el diputado señor Barrio y Mier, en 22 de Junio de 1871. En la imposibilidad de poder ocuparse de los 64 artículos que comprende, el anónimo articulista lo lace por grupos, concluyendo de su critica que el proyecto en ruestion produciria la ruina de los montes.

\section{Un tRiste vaticinio.-Por D. Mauricio Zornoza. \\ La Epoca.-Periódico político.-7 de Julio de 1870.}

Describe la perturbacion que en nuestras provincias meridionales ha causado la despoblacion de los montes, fijándose en las sequias, arramblamientos pedregosos de los rios, terrenos agostados y pérdidas de la tierra vegetal.

965. Una acLaracion.

El Alto Aragon.-Periódico de Huesca.-30 de Mayo de 1871 .

Amplia las noticias que ya habia publicado sobre las talas de los montes del partido judicial de Boltaña, y dirige cargos á la Administracion porque no secunda los esfuerzos que hace el personal del rano de montes, para que concluyan de una vez aquellos daños.

966. Utilidad de los Árboles.-PorD. Alejandro Olivan.

El Eco de la Ganaderia.-Tomo II, pág. 67, y Tomo III, pág. 467.

Enumera las circunstancias recomendables de las arbolados física y eco: nómicamente considerados, é indica algunas localidades españolas donde convendria introducirlo o favorecer el desarrollo del existente, examinado las condiciones de las especies árboreas de monte que más útiles puedan ser. 


\section{$\mathbf{V}$.}

967. Venta DE Los Montes DEL estado.-Por D. A. A. V.

Revisla forestal, económica y agricola.-Tomo I, pág. 189.

Este artículo resume la discusion habida en el Congreso de los diputados sobre las autorizaciones pedidas á las Córtes por el ministro de Hacienda Sr. Barzanallana, en el proyecto de ley de Presupuestos correspondientes al año económico de 1868 á 1869. Por el art. 11 de dicho proyecto el Gobierno debia quedar autorizado para la venta de los montes del Estado exceptuados de la desamortizacion liasta entonces por razones forestales, reservando solo los de reconocida ámportancia, prévia declaracion hesha por el ministerio de Hacienda de acuerdo con los de Marina y Fomento. El Sr. Fivaller, saliendo á la defensa de los montes, propuso una enmienda por la cual la declaracion de reservables debia hacerse facultativamente por el ministerio de Fomento, de acuerdo con los otros dos. Fué combatida la autorizacion por el Sr. Nougués que consideraba muy exigua la superficie forestal de España y muy necesaria la conservacion del arbolado.

968. Venta de Los Montes del estado --Por D. M. A. y M.

Las Provincias.-Diario de Valencia.-7 7 de Febrero, 17 de Abril 22 y 28 de Junio, 24 y 25 de Julio, 21, 22 y 23 de Agosto, 15, 19, 23 y 26 de Setiembre, 1, 7 y 17 de Diciembre de 1867, 24 de Enero y 8 , 12, 14 y 20 de Febrero de 1868.

Todos estos trabajos de D. Miguel Amat y Maestre, constituyen: $1 .^{\circ}$, dos cartas á que contestó en el mismo periódico el ingeniero de montes D. Juan Navarro Reverter con unos artículos titulados Condiciones de existencia de los montes, de que damos cuenta en el lugar correspondiente; $2 .^{\circ}$ catorce cartas, que se insertaron además en la Gaceta economista, y $3 .^{\circ}$, cuatro artículos, cuya doctrina así como la de las catorce cartas anteriores, rehatió tambien el Sr. Navarro Reverter en el mismo periódico y en la Revista forestal, económica y agricola en otros artículos titulados Sobre las cartas contra los montes de que igualmente nos ocupamos en el lugar que les corresponde. Todos los estudios del Sr. Amat se encaminan al objeto de demostrar la conveniencia de desamortizar todos los montes públicos, basando principalmente sus argumentos en razones simplemente económicas.

969. Venta de Montes.

La Tertulia de Alicante.-25 de Febrero de 1872.

Censura los defectos de las ventas de montes, principalmente en lo relativo á la inexactitud de las tasaciones, á la mala designacion de las cabidas y á la falta de amojonamierilo, citando casos ocurridos en la provincia. Reclama la inmediata correccion de estos vicios, á fin de que los compradores no se vean perturbados por cuestiones litigiosas, cuyo orígen está en las faltas cometidas por la $\Lambda$ dministracion al enajenar las fincas.

970. VENTAJAS DE USA'r EL CARBON DE CHOPO EN LAS FERRERIAS.Por D. José Villota. 
Extractos de las Juntas generales celebradas por la Real Sociedad Bascongada de los Amigos del Pais en la ciudad de Viloria por Setiembre de 1777.

En una nota relativa á las observaciones hechas con aquel objeto, por D. José Villota (a) del valle de Guriezo.

971. Ventas de Valsain (Las).

El Argos.-Núm. 86, 13 de Diciembre.-88, 15 de Diciernbre.95, 23 de Diciembre.-96, 24 de Diciembre.-100, 29 de Diciembre de 1871.-109, 9 de Enero.-110, 10 de Enero.-113, 13 de Enero. -114, 15 de Enero.-115, 16 de Enero - - 127, 30 de Enero._128, 31 de Eenero.-133, 7 de Febrero.-134, 8 de Febrero.-140, 16 de Febrero.-141, 17 de Febrero.-143, 20 de Febrero._-145, 22 de Febrero y 146, 23 de Febrero de 1872.

Revista forestal, económica y agricola.-Tomo V, págs. 252, $298,340,400$ y 462 .

Son diez y seis artículos en los que se estudia la cuestion de las ventas de Valsain, desde su urígen hasta la época en que por el ministerio de Hacienda se mandó comprobar sobre el terreno el grado de exactitud de las denuncias que se habian presentado contra los compradores de las fincas en concepto de causantes de varios daños, cortas, usurpacion de terzenos, etc. 'Dichos artículos demuestran las infracciones de ley y reglamentarias que se cometieron, declarando vendibles las fincas y despues de vendidas, asi como la exactitud de los extremos que comprendian las denuncias comparadas con los trabajos de comprobacion que se llevaron á cabo oficialmente.

972. Vicisitudes dE LA PROPiedad FOnEstal.-Por D. José Jordana.

El Eco de la ley y la España juridica.-Núm. 18, 22 de Abril de 1860.

Examina el espfritu y el resultado obtenido con la aplicacion de las leyes dictadas en materia forestal desde muy antiguo hasta el dia, concluyendo con la determinacion de tres periodos, significado el último, por el reconocimiento de la influencia cosmológica de los montes.

973. Viveros.-Por D. Gerónimo Tabern.

Extractos de las Juntas generales celebradas por la Real Sociedad Bascongada de los amigos del Pais; en la villa de Vergara, por Julio de 1788.-Página 21.

(a) Descendia de esta famila el distinguido y jóven ingeniero de montes D. Juan Villota y Urroz arrebatado ála ciencia, que cultivó con gran fruto, tras de penosas tareas que dieron lugar á la enfermedad que causó su premalura muerte acaecida en 1867.

Juntos cursamos las aulas de Villaviciosa de Odon, y más de una vez tuvimos el placer de apreciar la dulzura de su carácter, la privilegiada intellgencia que le distinguia y la extraordinaria aplicacion con que se dedicaba á los estudios forestales.

Sirva este pequeño desahogo de nuestro corazon como testimonio de la profunda pena que nos ha causado la pérdida de tan esclarecido amigo y compañero. 


\section{4}

Este escrito tiene por objeto describir el modo de formar los viveros y fomentar por este medio la poblacion de árboles en los montes de las provincias de España, particularmenle en las inmediaciones del mar Océano desde el Pirineo hasta Galicia. Trata de los puntos siguientes: Formacion de viveros; trasplantacion; enfermedades de las plantas; costo de las plantas; necesidad de los viveros; ventajas que hacen los viveros al métndo de las demás provincias; premio que dá la provincia de Guipuzcoa, vida del roble bravo ó trasmocho; defectos de los trasmochos; de las hayas; del nogal, álamo, castaño, encina y fresno; de los jarales (a) y de los pinos y pinatetes.

(a) El autor aplica el nombre de jarales á una especie de montes, dice, que hay en Gui púzcoa, Vizcaya y algunas partes de Navarra y de las montañas de Santander, que consisten en unas cepas bajas de dos á cuatro piés de altura, cuyas ramas sirven útilmente para leña y carbon. 


\title{
TERCER GRUPO.
}

\section{MANUSCRITOS Y TRABAJOS GRÁFICOS.}

\author{
INÉDITOS.
}

\begin{abstract}
A.
974. Arbol azederach, llamado inícuamente Cinamomo.-Un pliego escrito en 1756, copiado en el tomo XI de los manuscritos de su autor Martin Sarmiento.
\end{abstract}

Segun el Sr. Colmeiro (D. Miguel), es probable que el Marqués de Villafranca posea una copia de dicha coleccion de manuscritos.

975. Arbol Bétula, llamado en gallego Bideyro y en castellano Abedul; cuatro pliegos, de Martin Sarmiento, copiados en el tomo XI de sủs manuscritos.

Trabajo redactado en 1759, dice el Sr. Colmeiro (D. Miguel), y que tambien existe manuscrito en la Biblioteca Nacional.

\section{B.}

976. Breve Noticia de algunas particularidades que pueden dar cabal idea del clima y del terieno de las zonas forestales y desarrollo del arbolado en la provincia de Lérida, segun las observaciones hechas por D. Juan Andrieu, çomisario de montes de la misma.Tremp., 1857.--Fólio, 18 págs.

Manuscrito del Archivo del Ministerio de Fomento.

Atribuye el mal estado del arbolado, á los incendios, roturaciones, y á que en diversas épocas han servilo los montes para aliviar las cargas de liss pueblos hasta el punto de ser muy corriente el mayor recargo de irnpuestos sobre aquellos términos municipales en que existen bosques, pernicioso abuso que se ha ido desterrando por el mayor rigor de la legislacion, que tiende, neturalmente, á la conservacion y prosperidad de esta riqueza. 
97\%. Bheve trasunto saCado de los oniginales libros que los SEÑORES REIES DE ARAGON THNIAN PARA EL CONOCIMIENTO DE LAS AVES DE CAÇA Y DE TODA NATURALEZA DE haLCONEs. Con una breve práctica de sitreria ( $(\mathrm{ic}$ ) para curar las enfermedades y dolencias que acaecen. Compuesto por el muy reverendo y muy ilustre canónigo D. Mathias Mercader, arcediano de la Santa Iglesia Metropolitana de la ciudad de Valencia, á peticion del invictísimo Sr. D. Fernando de Aragon, Rey de Nápoles, Sicilia y Ungría, y tambien del generoso y virtuoso canónigo Pedro Lopez de Ayala. Dirigido al ilustrísimo y reverendísimo señor obispo de Búrgos D. Gonzalo de Mena. Con las anotaciones del emperador Federico II y del Rey Manfredo, su hijo. El cual sirve para el excelentísimo señor Conde de Concentaina, virey y capitan general en este reino de Nápoles. -Un tomo en $4 .^{\circ}$ de 28 hojas con las capitales y el frontis rudamente iluminadas.

Es del siglo XVII. Existe en la Biblioteca del Ministerio de Fomenlo. Es traruccion del que el mismo autor escribió en latin y dedicó al rey D. Fernando I de Nápoles en 146弓, con el título de Tractalus de re accipitraria, seu de medendis accipitrum morbis que existe en la Biblioteca del Escorial. Evte libro se tradujo igualmente al italiano por un anónimo que le añadió al fin un recetario para los halcones.

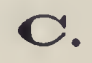

978. Coleccion de disertaeiones sobre varios puntos de agricultura, leidas por los discípulos de la cátedra del Real jardin Botánico de Madrid, á cargo de D. Antonio Sandalio de Arias.-Aùos 1815 y 1818.

Manuscrito de la Biblioteca agronómica del jardin Botánico de Madrid.Tomo $\mathrm{V}$ de papeles varios.

Se encuentran entre otras, las siguientes:

III.-Diserlacion sobre la necesidad de los bosques, arbolados y plantios para el mejoramiento de la agricultura, por D. José María de Nieva.

IV. - Disertacion sobre el cultivo y direccion de los árboles en general, por D. José de Aguirre.

XIII.-Disertacion sobre los prados naturales y artificiales de Es $s_{l} a \tilde{n} a$, por D. Pedro Toribio Conde.

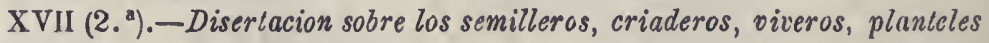
ó almácigas, por D. Gabriel Ortiz.

Todas ellas se mencionan en el lugar que les corresponde. La de D. José María de Nieva, se dió á la imprenta en 18:22 y se incluyó en el tomo II, de la Casa rústica de 1840, segun decimos en su correspondiente articulo. 
979. Conocimiento de LAS CATORCE Aves Menores de JaUla, su cria, canto, instinto y naturaleza, tiempo y modo de cogerlas, de hacer las pajareras y jaulas y el de alimentarlas en ellas. Varias enfermedades que padecen y remedios para su curacion. Por D. Franci-co Saura, presbítero beneficiado de la villa de Fresneda.

Segun Latassa, Biblioteca nueva de los escritores aragoneses, tomo Vi, página 318, este trabajo constaba de dos tomos inéditos, de los cuales uno se perdió, y el otro obraba, hácia 1802, en poder de D Joaquin Fernandez Garay, vecino de Allora. Advierte el referido Latassa que no debe confundirse esta obra con la que hacia pocos años se habia impreso con un título muy parecido. Debe ser esta, en npinion del Sr. Aaton Ramirez, Diccionario de bibliografía agronómica, la de Juan Baptista Xamarro, de que ya hemos dado cuenta.

\section{D.}

980. DFseripcion de los principales productos Vegrtales de la ISLA-DE Cuba para el fomento de su poblacion blanca y de su industria agrícola y forestera.-Por Tito Visino.-Habana, 1856.-Fólio, 810 págs.

Manuscrito del Archivo del Ministerio de Fomento.

Contiene muchos dibujos de plantas y frutos, y planos topográficos. Se presentó á la Exposicion general de agricultura, celebrada en Madrid el año de 1857. El autor fué distinguido con una medalla de oro.

Se habla del plátano, del árbol del pan, del boniato, de la yuca, y de otras muchas plantas de más interés agricola que forestal, dando noticias de l"s nombres científicos, historia, aplicaciozes, cultivo, cuidados, recoleccion de los frutos y fabricacion de papel con el tejido de los tallos del plátano.

La parte relativa á este ảrbol, al llamado del pan, y á la yuca, ñame y boniat), se publicó en el Boletin ofcial del Ministerio de Fomento, 1861.-Tomo XXXVIII, pág. 38 y tcmo XXXIX, pág. 327.

981. Descripcion de un Carro proplo para trasplantar ghanDES ARBOLES.

Manuscrito de la Biblioteca agronónica del jardin Botánico de Madrid.

Se trata de una sencilla combinacion de un juego de ruedas avantren y otro juego mayor, unidos por dos varas. Se describen las operaciones del descepe, y precauciones sucesivas.

982. Diálogos DE Lã Monteá́a; sigglo X.VI.-Fólio.

Manuserito de la Biblioteca de la A cademia de la Historia.

Es tenido por el tralado general de caza más perfecto que se ha escrito, entre los publicados é inéditos. Explica las reglas de la montería, la éducacion de los perros y la caza menor, ó sea de liebres, conejos y perdices. 
983. Diccionario de las ordenanzas del Ministerio de Marina, de Escribanos y Maestres, de Arsenales, del Almirantazgo, de Montes, y Matrícula con sus adiciones. - Fólio, 168 págs. sin numerar.

Manuscrito de la Biolioteca del Ministerio de Marina.

Parece que fué escrito de puño y letra de D. Fernaudo de Senra, pues al dorso de la página sexta aparece su apellido y rúbrica de igual curácter caligráfico que el resto del manuscrito.

Comienza indicando las disposiciones oficiales á que se contrae el libro, que es, en lo relativo á montes, la Ordenanza de 31 de Enero de 1748. Dá principio el diccionario con la palabra Almirantazgo y concluye con la de Fiveros, careciendo de toda indicacion que exprese quedar terminada la obra. Los artículos de interés forestal, aunque breves, se encuentran registrados en las voces; Alquitran, Arboles, Guarda celador de Montes, Hayas, Madera, Montes, Pesca, Pindales, Pinos, Plantios, Podas, Robles, Visita de Montes, $y$ Viveros.

No se hace indicacion alguna de este manuscrito en el Diccionario de bibliografía agronómica del Sr. Anton Ramirez.

984. DiCtámen y PROYeCto DE LEY sobre la direccion, fomento y repoblacion de los montes y arbolados públicos y particulares, formados de órden del Gobierno por la comision de agricultura establecida por S. M., y presentados al mismo en 23 de Febrero de 1822.

Manuscrito del Archivo del Ministerio de Fomento, Legajo número 13 de los de montes.

Aparecen firmados dichos trabajos por los indivíduos de la comision, Lagasca, Sandalio de Arias, D. Donato García, D. Tomás Villanova y D. Antonio Felipe de Salas, secretario. El proyecto de ley, que como tal fué presentado á las Córtes el 18 de Diciembre de 1822, va seguido de una instruccion práctica para la repoblacion, conservacion y fomento de los montes, plantíos y arbolados, formando todo ello doce títulos ó divisiones en los términos siguientes: jurisdiccion económica y gubernativa de los montes; visitas à los mismos; comisarios de montes; guardas; secretarios del ramo; fondo y aprovechamiento; siembras y plantios para la repoblacion; entresacas; podas y ol.ras operaciones; corlas, incendios, montes y plantios particulares; penas á los infractores.

Este trabajo se redactó en vista de muchos expedientes que radicaban en diversas dependencias del Estado y oyeudo el parecer de funcionarios públicos particulares y aun teniendo presentes ordenanzas de muchos pueblos. Entre los informes, merece especial mencion una nolicia histórica acerca de la subdelegacion general de montes, con los motivos de su creacion, suscrita el 12 de Junio de 1820, por D. Estéban de Izcaray, siendo Superintendente del ramo.

985. Discurso sobre la conservacion de los montes del Principado de Asturias y algunos de Galicia, motivos de su decadencia y los 
medios de fomentarlos, por D. Luis García de Longoria y Flores, oficial 2. ${ }^{\circ}$ del Ministerio de Marina, Ministro interventor y Tesorero de Real Hacienda en el acopio de maderas de los montes Pirineos y bosque Irati de Navarra. $-4 .^{\circ}, 148$ págs.

Manuscrito que existe en la Biblioteca de la Junta consubtiva del Cuerpo de Ingenieros de montes, y del cual nada se dice en el Diccionario de bibliografia agronómica del Sr. Anton Ramirez.

Hay tambien un ejemplar en la biblioteca de la Escuela especial de Ingenieros de Caminos, Canales y Puertos.

Fechado en Pamplona á 2 de Febrero de 1798 y dirigido al Capitan general de la Real Armada, D. Antonio Valdés y Bazan, caballero de la insigne órden del Toison de Oro, etc., cuyo escudo de armas está dibujado en el reverso de la portada. Sigue despues la introduccion al discurso, con este encabezamiento: Fomento y conservacion de montes del Principado de Asturias y algunos de Galicia, antes que lleguen al estado de su total ruina, á quẹ ya están muy inmediatos: utilidades que resultarán á S. M., como tambien á todos aquellos vasallos y labradores.

Se ocupa primero de los montes de Asturias, cuya decadencia atribuye á los asientos de maderas, á las quemas, á las fábricas de curtido, hierro y cortas del vasallo, y á la mala ejecucion en los plantíos, explicando las prácticas viciosas y proponiendo reglas para evitar dichos defectos. Sobre los montes de Galicia se extiende en iguales ó semejantes consideraciones, detallando las localidades á propósito para la creacion de dehesas.

986. Discerso sobre la UTILIDAd de las trampas para CAZar animales dañınos.-Por D. Vicente Franco; año de 1779.

Manuscrito del Archivo de la Sociedad económica de Valencia, segun sus catálogos.

987. Disculiso sobre las CAUSAs físicas de la MUltipliCACion DE LOS INSECTOS DAÑOSOS Á LOS ÁRBOL.eS y plantas fructíferas, y los medios más experimentádos y ménos costosos para extinguirlos ỏ precaver el perjuicio que causaron.-Por D. Vicente Vicien y $\mathrm{Mu}-$ ñoz: año 1779.-4. ${ }^{\circ}, 72$ págs.

Manuscrito del Archivo de la Sociedad económica Aragonesa, segun Latassa, en su Biblioteca nueva.-Tomo V, pág. 311.

Escrito dicho discurso para optar al premio de cincuenta pesos, que la Sociedad ofreció en 1779 , tuvo la fortuna de alcanzarle, segun acuerdo de la Junta de 16 de Junio de 1780, publicado en la Gaceta de Zaragoza del Mlártes 4 de Julio.

988. Disertacion optaisdo al premio (que ganó) ofrecido por la Sociedad económica de Valencia, sobre las reglas que deben observarse en el tiempo y modo de cojer el esparto que se cria en el reino de Valencia, á fin de que no se deteriore la produccion de este 
género, y en lo posible se asegure y aumente.-Por D. José Antonio Valcárcel: 22 de Octubré de 1783.

Manuscrito del Archivo de la Socielad económica de Valencia, segun sus catálogos.

989. Disertacion sobre el Cultivo y DiReccion de los Árboles EN GENElial, y descendiendo á un objeto particular, se habla del modo de restablecer un monte deteriorado.-Por D. José de Aguirrè.-Leida el 31 de Agosto de 1818.—4. ${ }^{\circ}, 19$ págs.

Manuscrito de la Biblioteca agronómica del jardin Botánico de Madrid.

"Los árboles, dice, adornan las poblaciones, purifican los aires, templan la estacion extremada, fertilizan el terreno que ocupan, con la descomposicion de sus hojas y frutos; con su absorcion atraen los beneficios de la lluvia, detienden las vegas y las tierras de las a venidas, hacen producir pastos a las arenas más estériles y áridas, con sus maderas prepara el labrador la tierra que cultiva, sin ellas careceriamos de materiales para nuestras casas, de combustible en el rigor del frio y de sabrosos frutos para nuestro sustento, etc."

Estas consideraciones sirven de fundamento al aut or para clamar por el estimulo y proteccion á favor de los plantios. Despues pasa á tratar de la siembra, labores, poda, enfermedades y modo de combatirlas.

990. Dinertacion sorre los montes de Asturias y Galicia.Por el Lic. D. Antonio Linares de Montefrio.-4. ${ }^{\circ}, 172$ págs.

Manuscrito de la Biblioteca agronómica del jardin Botánico de Madrid.Tomo XXXIV de papeles varios.

Contiene un prólogo, un discurso basado en la ley 15, tít, VIII, lib. VII de la Novísima Recopilacion, que dispone la conservacion y mejora de aquellos, y por último, la disertacion en que se describen ios montes de Asturias y de Galicia, marifestándose las causas de su decadencia.

991. Disertacion sobre los prados natulales y artificiales DE España.-Por D. Pedro Toribio Conde, jardinero de primera clase en el Botánico de Madrid.-Leida en el mismo el dia 14 de Octubre de $1815 .-4 .^{\circ}, 39$ págs.

Manuscrito de la Biblioleca agranómica del jardin Bolánico de Madrid.Tomo $\mathrm{V}$ de papeles varios.

Encarece la importancia de los pastos, hace su division en naturales y artificiales, é indica con nounbres científicos, por lo general, las plınlas convenientes para el cultivo pratense.

992. Disertacion sobre los semilleros, Criaderos, viveros, Plantlilis ó almácigas.-Por D. Gabriel Ortiz: 21 de Octubre de $1815 .-4{ }^{\circ}, 28$ págs.

Manuscrito de la Biblioleca agronónica del jardin Bolánico de Madrid. El aulur se lamenta de la decadencia del arbolado, y despues de recowen- 
dar la creacion de planteles, aconseja que se prohiba el que los ganados'se acerquen á ménos de un cuarto de legua de donde haya arbolado. y de que penetren en los sembrados.

\section{E.}

993. En la Junta de sociedad patriótica de 24 de Noviembre de 1796, se leyó un oficio de la clase de agricultura, remitiendo el informe pedido á D. J. Ricardo O-Farril sobre las'ideas que en la Memoria de la conservacion de los montes del Padre Manuel Gil halle adaptables á este país.-Por.D. Joseph Ricardo O-Farril.

En $4 .^{\circ}, 24$ págs. Al fin de la última página está la firma del autor con la fecha, en la Habana, de 22 de Octubre de 1796.

Este trabajo, que suponemos manuscrito toda vez que no se indica la imprenta, y las pocas noticias que acerca de él consignamos, están reproducidas de la relacion que con el número 1.306 se hace en la Biblioteca america$n a$ de $C h$. Leclerc, Paris, 1867.-4. ${ }^{\circ}, 407$ páğs. No hay indicacion alguna en el Diccionario de bibliografía agronómica del Sr. Anton Ramirez.

994. Ensayo de la historia natural y Médica de España, por D. Francisco Fernandez de Navarrete:

Grueso manuscrito en fólio dè la Academia de la Historia, escrito á mediados del siglo XVIII.

Consta de cinco discursos, á saber: $10^{\circ}$ Cielo propio de España; $2 .^{\circ}$ De las aguas de España; $3 .^{\circ}$ Del terreno de España; $40^{\circ}$ De las plantas de España; y $5 .^{\circ}$ De los animales de España. Con respecto á la vegetacion forestal, cuya nomenclatura ofrece el autor bajo indicaciones muy contrarias á lo que la ciencia reconoce $\delta$ admite en el dia, merecen leerse los capítulos que tratan: De los árboles silvestres de los bosques y selvas; de los de márgenes y sitios húmedos; de las malezas y arbolillos mayores y menores; de las praderas y pasladeros y de los herbazales.

Tal vez no se hace mencion de este manuscrito en el Diccionario de bibliografia agronómica del Sr. Anton Ramirez, porque no contiene doctrina especialmente aplicada al cultivo de la tierra.

995. ENSAYO PARA LA DESCRIPCION geográfica, physica y civil del Corregimiento de Calatayud, por D. Miguel Monterde Lopez de Ansó.-4. ${ }^{\circ}, 168$ fólios.

Este manuscrito escrito á fines del siglo pasado, existe en la Academia de la Historia. Al final tiene un Discurso sobre el cáñamo y su cultivo en Calata yud. Dá noticias acerca de las especies y estado de los montes de los diferentes pueblos del Corregimiento. "Los carboniles, dice que cuando se cortaban á tajo raso se criaban pronto y se poblaban de nuevo, están perdidos sin remedio si no se acude á los sementeros de bellota." "Los olmos, en muchos 
pueblos se aprovechan de la hoja inutilizando la madera; con todo prestan para el surtido de cercillos de cubas, utensilios de molinos y para reparar las azudes de los rios."

Fl. Sr. Anton Ramirez no dá cuenta de este trabajo en su Diccionorio de bibliografia agronómica.

\section{H.}

'996. Historia de plantas. - Por el licenciado Bernardo de Cienfuegos.

Manuscrito que consta de siete tomos en fólio, encuadernados en tafilete. Uno de ellos no contiene más que dibujos iluminados de plantas, si bien en los demás los hay tambien abundantes. Se conserva en la Biblioteca Nacional. La introduccion ó prefacio está en el tomo II, firmándole el autor en Madrid á $1 .^{\circ}$ de Noviembre de 1627 . Tienen interés forestal las noticias del tomo IV, acerca del regaliz; las del VI referentes al esparto; y las del VII sobre el tratamiento de los lodoñales (almeces) de Tarazona y la aplicacion de sus productos.

No se menciona en el Diccionario de bibliografia agronómica del Sr. Anton Ramirez.

997. Historia general y natural de Cataluña.-Por el Padre Mateo Aymerich, de la Compañía de Jesús.-1766.-Un tomo en 4. de 408 págs. la segunda parte.

Manuscrito dividido en tres partes que tratan, la primera del reino fósil ó cavcble; la segunda del reino vegetable; y la tercera del reino animal. En la Biblioteca del Palacio Real está el manuscrito de la primera parte, en el que figura una certificacion original de la licencia de imprimir el libro con el litulo de Historia general y natural de Cataluña, expedida en Madrid á 5 de Setiembre de 1766.

La segunda parte, que obra en la Biblioteca de la Academia de la Historia, trata entre otros puntos, de los árboles frutales é infructiferos de Cataluña, del álamo, olmo, nogal, roble, encina, alcornoque, haya, abetos, melis, pino, ciprés, box, castaño, texo, fresno, almez, alinendro, acebo y otras plantas forestales, dalldo noticias de sus nombres, cualidades, productos y usos. Se ocupa asimismo de la utilidad de la madera para los barcos grandes y pequeños y de las resinas, pez, alquitran y liga.

El Sr. Anton Ramirez nada dice de este manuscrito en su Diccionario de bibliografia agronómica, y el Șr. Colmeiro lo da a conocer en La Bolánica y los Botánicos, con el título de Historia natural de Cataluña, sin dar noticia de la parte de la obra que se conserva en la Biblioteca del Palacio Real, como hemos diclio.

998. Histohia gegoráfica y natural del principado de CataLũ̃a.-Véase: Historia general y natural de Cataluña. 


\section{$\mathbf{I}$}

999. IdEA SENCILLA Y RÁPIDA DEL ESTAdO DEL ARBOLADO en la Real Casa de Campo y medios de mejorarlo y aprovecharlo.-Presentada de Real órden por D. Francisco Sangüesa en 31 de Enero de 1834.Fólio, 13 págs.

Manuscrito de la Biblioteca particular de D. Agustin Pascual (hijo), segun el Sr. Anton Ramirez.

1000. Informe á la Real Sociedad Econónica de Valencia, extendido por D. José Antonio Valcảrcel, sobre la repoblacion, aumellto y conservacion de los montes de este reino, para evacuar el que se ie habia pedido por el Ministerio de Marina para la nueva Ordenanza de montes; 26 de Abril de 1794.

Manuscrito del Archivo de la Sociedad Económica de Valeneia, segun sus catílogos.

1001. Informe de la Real Sociedad Económica de Válencia, extendido por D. José Antonio Valcárcel, y elevado al Real y Supremo Consejo, sobre la conservacion y uso de la planta de esparto en el reino de Valencia: Diciembre de 1783.

Manuscrito del Archivo de la Sociedad Económica de Valencia, segun sus catálogos.

1002. INFORME EXTENSO SOBRE L I REPOBLACION, AUMENTO Y CONSERVACION DE LOS yonTus del reino de Valencia: año de 1794.

Manu‘crito del Archivo de la Sociedad Económica de Valencia, segun sus calàlogos.

1003. InstrucCion té́rico-práctica para la conservacion, repoblacion, fomento, multiplicacion y aprovechamiento de los montes, arreglada á lo que se previene en el proyecto de ley formado por la Direccion del ramo, presentado al Excmo. Sr. Secretario de Estado y del despacho de la Gobernacion de la Penínsila.-Por D. Antonio Sandalio de Arias: Madrid, 1839.-4. ․, 225 págs.

Manuscritu que estaba en poder de los herederos del autor, en 1861, segun el Sr. Anton Rawirez.

El original ó copia obra en la Real Academia de ciencias exactas, físicas y naturales. Contiene seis capitulos que trataı: $1 .^{\circ}$, de la extension aproximada de los montes de la Península española, que se aprecia en 23.362.250 fanegas de las de 400 estadales, entre montes, bosques, debesas y sotos; $2 .^{\circ}$, de su clasificacion, segun las especies de árboles que en ellos se crian; 
$3 .^{\circ}$, de los medios que conviene emplear para su direccion y conservacion; $4 .^{\circ}$, division de los montes segun las diversas edades de los árboles; $5 .^{\circ}$, de las cortas propiamente dichas; y $6 .^{\circ}$, necesidad de repoblar y aumentar los montes por medio de siembras y plantios y modo de verificarlo.

Obraba asimismo en poder de los herederos del Sr. Arias, segun se lee en el Boletin biblioǵráfico español, tomo I, pág. 11, un Informe á la Sociedad Económica de Amigos del País sobre la materia anterior, que comprendia 53 plieguecillos, y otro manuscrilo sobre el mismo asunto, dirigido al Ministro de la Gobernacion, extendido en 225 cuartitlas.

\section{L.}

1004. Libro de Acetrería, compuesto por Mossen Juan Vallés', thesorero general y del Consejo de S. M. en el reino de Navarra y añadido al cavo el de montería, dirigido al serenísimo príncipe don Cárlos, príncine de las Españas y de las Sicilias, y de Flandes y de todas las Indias del mar Océano, etc., nuestro Señor.-Con privilegio, año de 1556.-Fólio, 228 hojas, una más de distinta letra, al parecer del siglo XVII, y otras 14 hojas de principios.

Manuscrito de la Biblioteca Nacional. L. 89.

Hay otros varios códices de la misma obra. La dedicacion, en que se ensalzan las bellezas de la acetreria, está fechada en Pamplona, á $10^{\circ}$ de Agosto de 1556.

Está dividido en cinco libroś ó tratados, de los cuales los cuatru primeros tratan exclusivamente de la caza con azores, $\delta$ gavilunes y el último de rrontería :

1005. Libro de CAzA de halcones, hecho por Alonso Velazquez de Tovar.

Nada se sabe de su autor que parece habər florecido en la última mitad del siglo XV. Este tratado de cetrería, se conserva en la Biblioteca de la Academia de la Historia, y hay de él una copia en la Nacional, señalada con la L. 117.

1006. Libro de Cetrería, por I). Luis Zapata, señor del Cehel.Al Ilustrísimo Sr. D. Diego de Córdova, en Madrid, siglo XVI.-En fólio, 145 hojas, en $4 .^{\circ} 314$ y en $4 .^{\circ} 365$.

Biblioteca Nacional de Madrid. L. 88, L. 174 y T. 296.

Son tres códices copias unos de otros. A excepcion del prólogo y una tabla, todo lo demás está ell verso.

1007. Libro dE CETrería que hizo Evangelista corriendo fortuna por el golfo de Leon.-A Dios misericordioso por no estar ucioso, y trata de las aves de rapiña, de los talles y plumas y propiedades de 
cada una, y de los gobiernos y curas para sus dolencias, como adelante oireis. -En $4 .^{\circ}$, siglo XVI.

Biblioteca Nacional de Madrid.-Q. 224.

Comprende tan solo unas 10 hojas.

1008. Libro DE CAZA.-Por el príncipe D. Juan Manuel, Infante de España.-Siglo XIV.-En fólio, 222 hojas á dos columnas.

Biblioleca Nacional de Madrid.-S. 34.

Tratd de azores y halcones y de los lugares mís propios para lacelrería.

1009. LiBRo de LAS AVES dE CAÇA ó regla de cómo sepueden regir y gobernar los falcones, açores é gavilanes:-Por Johan de Sant Fagund.

De este libro que el autor escribió en el siglo XIV hay una copia en la Biblioteca Nacional de Madrid, hecha á fines del siglo XVI, constituyendo un toıno en $4 .^{\circ}$ mayor de 230 hojas, señalado con la L. 86.

1010. Libro de J.os HalCones.-Letra del siglo XVIII.-En fólio 110 hojas.

Biblioleca Nacional de Madrid. L. 117.

En la portada dice: Libro de los halcones, en el lomo, Libro curioso de cetreria, y en los indises de la Biblioteca, Libro anónimo de halcones y olras aoes, incompleto, y asi es en efecto porque no tiene principio ni fin. En la parte que se conserva traia de los azores y de las mejores tierras de donde proceden.

1011. Libro ne montería, compuesto por Don Pedrode Pedraza Gastan, que trata de cómo se ha de seguir el monte con el arcabuz y sabueso.-Dirigido á la Majestad del rey D. Felipe IV.

Manuscrito de la Biblioteca del Excmo. Sr. D. Luis Mayans, segun don Mignel Lafueute Alcántara, en sus, Investigaciones sobre la monteria.

1012 Libro ne montería.-Compvesto por D. Hernando de Hojeda. Qve trata como sea de seguir el Monte con el Arcabuz y Sa bueso. Dirigido á la Majestad del Rey D. Felipe IIII.

Este manuscrito, segun leemos en el Cabálogo de la Biblioteca de Saloá, tomo II, pág. 380, número 2.631, es original é inédito, y está ejecutado con suma nitidez y lujo como destinado al uso de Felipe IV. La encuadernacion en tafilete verde es le aquella época, y lleva á ambos lados las armas reales. "Nicolás Antonio, dice la nota de Salvá, no tuvo noticia de Hernando de Hojeda, que era Juez de los reales bosques, como lo asegura el mismo en la Dedicatoria al rei."

El Sr. Anton Ramirez no menciona este manuscrito en su Diccionario de bibliografía agronómica.

1013. LIBRo QLE TRATA DEL MODO QUE SE HA DE TENER EN GURAR HALCONES, AZORES Y GAVILANES.-En $4 .^{\circ}$ 
Biblioteca Nacional de Madrid. C. 141.

Añádese por nota que es de D. Alfonso Tostado, pero el Sr. Anton Ramirez, Dic. de bibliog. agron. no lo considerá como tal.

\section{M.}

1014. Maderas finas del Reino.-Por D. Antonio Sandalio de Arias.

Manuscrito que reseña las propiedades del tejo, acacia, morera, moral, nogal, encina, castaño de Indias, aliso, copudo, liła, azufáifo, boj, amargoso, abedul, cerezo, naranjo, olivo, negrillo, almendro, acebo, roble albar, roble comun ó negro, tilo, sauco, plátano, laurel, albaricoque, mostajo y ciprés.

Los herederos dél autor poseian este manuscrito en 1861, segun se lee en el Boletin bibliográfico español, tomo I, pág. 11. El Sr. Anton Ramirez en su Diccionario de bibliografía agronómica, añade que en la Real Academia de ciencias exactas, físicas y naturales de Madrid hay una carpeta que contiene entre otras cosas, unos fragmentos de este trabajo.

1015. Manual forestal. Contiene las principales Leyes, Reglamentos é instrucciones concernientes al ramo de Montes, y reglas para el mejor servicio del personal subalterno del mismo, con formularios de toda clase, la division forestal Peninsular, prescripciones á que está sujeta la propiedad forestal y la confinante con los montes públicos, breves nociones de geometría, y explicacion del nuevo sistema métrico decimal de pesas y medidas con las equivalencias más usuales sobre uno y otro sistema, y por último un tratado de Selvicultura con las operaciones más importantes de cultivos, métodos de beneficio y de cortas, principales industrias forestales, cultivos, mejoras, marqueos, etc., seguido de unas tablas de cubicacion de maderas, leñas y ramaje.-Es útil además para los Ayuntamientos, propietarios, guardi-montes de los pueblos y particulares, y contratistas de productos forestales.-Por Ricardo Beaumont de Miras Peralta, jefe de Seccion facultativo que ha sido en varias líneas de ferro-carriles en construccion, antiguo auxiliar de obras públicas y ayudante del Cuerpo de Montes.-Badajoz.-1870.-4..$^{\circ}$ mayor, 360 fólios.

El autor escribió este Manual, destinado principalmente al personal subalterno del ramo de montes, en 1870 , sometiéndolo á la aprobacion de la Direccion general de Agricultura, Industria y Comercio en 21 de Junio de aquel año. Prévio informe de una comision facultativa que al efecto se nombró, el indicado centro aprobó el trabajo declarándolo de utilidad para los funcionarios del ramo y prometiendo recomendarlo cuando se publicase. 
Encarecia, además, el celo y conocimiento del autor, y le facultaba para encabezar el Manual con la comunicacion en que se indicaba lo expuesto.

A poco tiempo se habló de estarse preparando una nueva ley de montes, y temeroso el autor, de que esta apareciera inutilizando en parte su trabajo que se fundaba en la legislacion entonces vigente, suspendió la publicacion de su libro sin que haya tenillo lugar posteriormente, por causas cuya indicacion no es de este lugar.

Creemos que un libro de esta clase hace falta en España, en donde no se ha publicado aun ninguno que entrañe iguales fines, doliéndonos de que el $\mathrm{Sr}$. Beaumont no haya realízado su digno é ilustrado propósito.

En cuanto á las materias que comprende el Manual, no hay más que repasar la portada, para convencerse de su utılidad y de su importancia.

1016. Mapa de la provincia de Marina de Segura de la SierRA, dedicado al Excmo. Sr. B. ${ }^{\circ}$ Fr. D. Antonio Valdés y Bazan, cavro. del Orn. de Sn. Juan i Screto. de Estado y. del Despacho universal de Yarina.

Este curioso plano inédito perteneciỏ á la coleccion de D. Felipe Bauzá, pasando despues al miristerio de Fomento. Está toscamente trazado é iluminado. La red hidrográfica está representada por líneas negras. La vegetacion arbórea, indicada por a edio de árboles sueltos en proyeccion vertical, no representa más que los pinares y encinas con tinta verde de diferente intensidad y los sabinares con tinta parda. Fajas de diversos colores inarcan los límites jurisdiccionales de los pueblos sujetos al ministerio, y de las subdelegaciones de Alcaráz, Santistéban, Villanueva del Arzobispo y Cazorla. Los límites de los departamentos están expresados por medio de líneas de color punteadas.

La escala es de leguas de una hora y cuarto de camino, de donde se puede inferir la antigüedad del dibujo. Hay una pequeña rosa náutica. El escudo rotulatorio, cuyo centro está en blanco, vả acompañado à la derecha de una figura en actitud de barrenar un cubo de rueda yaciendo á sus piés una azuela y una hacha, y á la izquierda de otra figura que está labrando una pina, poco distante de un trípode del que cuelga un caltero alrededor del cual se vé la ropa de los obreros y un perro acostadojunto á la misma.

1017. Memoria aCerCa de la Galeruca que deshoja á los olmos en las orillas del Manzanares; acompañada de algunas observaciones sobre la naturaleza de este arbol, que no halla las condiciones convenientes de existencia en el Real sitio de la Florida: y sobre los medios de perseguir al insecto que le priva de la verdor y hermosura y prevenir sus extragos.-Por D. L. de T.-1859.-4. ${ }^{\circ}, 43$ páginas sin numerar.

Este manuscrito que obra en poder de su autor D. Luis de Tornos, está fechado en Madrid á 1. ${ }^{\circ}$ de Agosto de 1859. Recuerda algunas condicione: vegetativas, nosológicas y económicas del olmo enumerando los principales insectos que lo atacan; describe despues la Galeruca calmariensis, objeto 
principal de la Memoria, especificardo su vida y costumbres y los medios de preservar los árboles de sus daños, así como los de destruirlo en sus estados de huevecillo, larva, ninfa é insecto perfecto.

No se registra este trabajo en el Diccionario de bibliografia ogronómica del Sr. Auton Ramirez.

1018. Memorta de RECONOCIMIENTO DE LAS CUENCAS DE LOS bIOS Lozoya y Guadalix para la repoblacion forestal de los terrenos en que se extienden las obras del canal de Isabel II._Por D. Francisco García Martino.

Se conserva en la hiblioteca de la Junta consultiva del Cuerpo de Inge nicros de montes. Eslá fechada en Madrid á 3 de Julio de 186\%. Comienza describiendo los caractéres de la zona obielo del rstudio, así físicos, como geológicos y botánicos, y despues describe particularmente bajo igual concepto, la parte correspondiente á la cuenca del Lozoya, ladera de Patones, cuenca del Guadalix y linea del Canal, presentando la propuesta detallada de repoblacion para cada una de estas localidades, á cnyo fin indica las especies que debièran ser objeto de la repoblacion, el mélodo que conventria seguir, la superticie que se habria de repohlar y los gastos que ocasionaria esta mejora. Al final aparecen tres croquis forestales de la cuenca del Lozoya, de la ladera de Patones y de la cuenca del Gundalix ejecutadoz en escala métrica de $\frac{1}{10000}$.

1019. Memoria descriptiva del honte de Urbasa, en la provincia de Navarra, partido judicial de Estella.-Por D. José Diaz Laviada, ingeniero de montes; año de 185\%.-Folio, 42 hojas.

Manuscrito del Archivo del Minislerio dè Fomenlo.

Corresponde á los documentos presentalos á la Exposicion general de Agricultura de 1857.

La superficie del monte es da 11.994 hectáreas y 86 áreas. Predomina despues del haya que es la especie principal, el endrino, el brezo, el encbro, el fresno y el alamo. Describe las vicisitudes de la propiedad, citando el acuerdo de las Córtes de Olite de 1688, en las que el Rey cedió el aprovechamiento dol monte á aquellos pueblos en recómpensa de los 30.000 durados con que contribuyeron para las fortificaciones de Pamplona, y sigue hahlando de los productos primarios y secundarios, proporiendo un sistema de ordenacion.

1020. Memoria que presenta D. Juan Guinart, fabricante de tapones de corcho, á la Exposicion general de Agricultura de 185.7, sobre el arbolado del alcornoque y grandes producciones que dá.

\section{Manuscrito del Archivo del Minislerio de Fomento.}

Opina que el alcornoque se dá bien en lodos los climas y terrenos, que vive de cinco à seis siglos, que á los seis años de racido principia á dar hellotas, y que á los doce ya se puede exiraer el corcho. Habla tambien de las unuchas aplicaciones de este producto. 
1021. MeMoria sobre El MÉtodo y PROPOSICION DE LA PropagaCion de los Arboles.-Por D. Roque Miguel del Rivero.

Manuscrito de nueve hojas en folio, ezerito el año 1772. Lo posee el distinguido ingeniero de montes D. Roque Leon del Rivero, biznieio del aulor, el cual era conserva lor de montes de la provincia maritima de Santander. Parece que en esta ciudad se dió á la estampa por entonees la inidicada meınoria, tirindose un corto número de ejemplares, muy difiéiles de encontrar hoy. No hemos visto ninguno y por esta razon no hemos registrallo este trabajo en la primera parte de este libro.

En la portida del inanuscrito, despues del lítulo, se lee: "La dá á luz don Roque Viguel del Rivero, para instruccion de su lijo, explayando en ellas las observaciones que le facilito en su vida el génio investigador que le caracterizaba. Descanse en pa\%."

Despues de una breve introduccion, se desarrolla la niateria en seis capítulos que tratan, de los semilleros, de los viveros, del trasplanto desde el viveroal monte, de la eleccion de terrenos, del método con los árboles segun su destino, y de varias reflexiones sobre los aprooechamientos y destino de los arboles. Las indicaciones culturales se refieren al roble, castaño, encina, nogal, haya, fresno y álamo negro. Concluye con una discusion acerca de la conveniencia de la poda:

Llaman la atencion en este trabajo, que no registra el Diccionario de bibliografía agronómica del Sr. Anlon Ramirez, algunos vocablos tésnicos, que están fuera del uso corriente.

1022. Memoria sObRe LA DEstruCCION DE LOS ESCOLItos DE LOS ouros, por D. Ramon Romualdo Aguado.

Consigna el $\mathrm{Sr}$. Aguado en este trabajo, que no es de gran extension y ha sido formulado en el año 1873 , el resultado de los experimentos que ha hecho para destruir el barrenillo del olmo, que tantos estragos causa ell el arbolado lineal de Madrid. Sepun asegura el dicho Sr. Aguado, antigno jardinero mayor del Retiro que ha sido, el único medio eficaz, para destruir aquella plaga, consiste en bañar con petríleo el tallo de los olmos atacados. Las especies que viven sobre el árbol en cucstion son dos: el Scalytus destructor y el $S$. pygmeus.

El autor ha presentado esta Memoria en la Exposicion nacional que ha tenido lugar en Madrid á últimos del pasado año de 1873.

1023. Mejoria sobre los productos de la Liébana, presentada por la Sociedad Económica de aquel país á la Exposicion general de Agricultura -OPotes, 3 de Setiembre de 185\%.-Folio, 7 págs.

Manuscrito del Archivo del Ministerio de Fimento.

Está suserita por el director D. Matías de la Mallrid y Manrique y D. Anselmo Marin. Indica la importaneia del rob'e, encina, nogal y tilo de los montes; lamenta la destruccion de los mismos y abega por la amorlizacion de los montes inaderables por el Estado, nero no por los pueblos.

1024. Mrmorial ajustádo del expediente que pendia en el Con- 
sejo Real por los años de 1783, sobre arreglar una ordenanza gene ral para la conservacion y aumento de todos los montes del reino, su gobierno y direccion.

Manuscrito del Archivo del Minisierio de Fomento.-Legajo número 5 de los de montes.

Abraza los tres, objetos siguientes: atender á la provision de maderas para los arsenales; atender asimismo á los aprovechamientos de los vecindarios y lueños de mon'es; y evitar competencias entre las justicias ordinarias y miuistros de Marina, reuniendo en dicha ordenanza general todas las insirucciones reglamentarias y providencias dispersas.

1025. Movtés. Documentos relativos á la comision de reforma creada en 1846.

Manuscrito del Archivo del Minislerio de Fomento, año de 1849.

Lns documentos más dignios de mencion son seis: $1 .^{\circ}$, consu'ta elevada a! Gobierno en 30 ỏe Abril de 1841 por la Direccion general de Montes, estando al frente de la misma D. Cenon Asuero; en ella se hace una reseña del deplorable estado de la riqueza forestal, $y$ se propnnen bases para una nueva ordenanza; $2 .^{\circ}$, proyecto de decreto que en 14 de Abril de 1842 formuló Don Agustin Alvarer Sutomayor, siendo jefe político de Jaen, sobre la averioua cion y deslinde de ciertos montes; son notables las observaciones que le preceden; $3 .^{\circ}$, proyecto de decrelo suscrito en 15 de Febrero de 1814 , por Don Pe Iro Saiuz de Andino; se hacen interesantes observaciones sobre la legislacion que ha regido en España desde los tiemnos más remotos ; $4 .^{\circ}$, escrito de D. José Ca veda, fechado en Madrid á 9 de Marzo de 1846; contiene diversas reglas que pueden considerarse como ntras tantas bases para la formacion de una ordenanza forestal; se divide en cuatro partes, que son: legislacion vigente sobre el ramo de montes; régimen administrativo; medios de ejecuciou; ; legislacion contencirsa y criminal; $5 .^{\circ}$, voto particular, suscrito en 31 de Diciembre de 1818 por el vocal de la comisicn, D. Jorge Perez Lasso de la Vega, proponiendo para la marina una intervencion más éficaz en la administracion de los montes; $6^{\circ}$, proyecto de ley de la aludida comision (fe cha 21 de Enero de 1849), compuesta de los Sres. D. Diego Me Jrano, presidente, D. Manuel Perez Seoane, D. Félix José Bejarano, D. Jorge Lasso de la Vega, y D. Franciseo Caveda, secretario.

1026. Mostajo en Castei.lano, Mostayo ex Leon, Asturias Y Bienzo; tres pliegos, de Martin Sarmiento, copiados en el tomo XI de sus manuscritos. Véase: Arbol Acbderach.

Segun el Sr. Colmeiro (D. Miguel) este trabajo fué redactado en $1757 \mathrm{y}$ versa sobre el Pyrus Aria. Ehrh.

\section{N.}

102\% Nomenciatura de los Árboles, de los ingertos y de todas las producciones en agricuitura.-4. ${ }^{\circ}, 32$ págs. 
Manuscrito de la Biblioteca agronómica del Jardin Botárico de Madrid.Tomo I de papeles varios.

Divide el arbolado en montes, bosques, sotos, alamedas y plantíos, sisuiendo la minuciosa nomenclatura de cada clase; los ingertos en los de pua ó de yema, y en los de escudete ó peto.

1028. Noticia PUNTUAL DE LOS Montes comprendidos en la extension del departamento de marina de Cartagena, con separacion de provincias y subdelegaciones, pueblos respectivos de cada una, calidades de árboles que producen, distancias á los embarcaderos, disposicion de caminos, etc.-Formada en virtud de $\mathrm{R}^{1}$. órn. de 16 de Septiembre de 1777.-Por D. Alfonso Alburquerque.-Folio, 492 págss. y 25 de índice.

Manuscrito de excelentes formas caligráficas que obra en la Biblioteca del Ministerio de Marina.

Está suscrito por el autor en Cartagena á 16 de Diciembre de 1777. Dá una breve noticia de las especies arbóreas que pueblan los montes de eada pueblo, del estado de los misinos, del de los caminos y de las distancias á los embarcaderos. Comprende todas las poblaciones de las antiguas provincias marítimas de Cartagena, Vera, Alicante, Valencia, Tortosa, Tarragona, Barcelona, Mataró, San Feliú y Mallorca. Respecto de esta última provincia no se expresan más que los nombres de los pueblos que comprende. El índice alfabético se contrae á las poblaciones.

No se menciona este manuscrito en el Diccionario de bibliografia agronomica del Sr. Anton Rawirez.

\section{P:}

1029. Parte de las plantas que pacen en Suecia los caballos y algunas de ellas los bueyes, que nacen expontáneas en Aragon.

Es un catálogo de plantas, sin indicacion de autor, que existe en el archivo de la Sociedad económica de amigos del país de Zaragoza. Comprende 175 especies expontáneas distinguiendo las que comen el caballo y el buey, las que no comen, y las que unas veces pacen y otras las desechan. Se supone que en Aragon serán cuando ménos otras tantas las especies que se crian en su territorio propias para el pasto del ganado caballar.

Nada se dice de este trabajo en el Diccionario de bibliografia agronómica del Sr. Anton Ramirez.

1030. Pragmáticas de don cárlos y sobre la pesca de los rios, cabos ponzoñosos, cestos, redes y tiempos de pescar, y sobre los tiempos de caza y modo de ello; año de 1552. - Fólio.

Manuscrito de la Biblioteca Nacional.-Fólios 147 y 151 del volúmen Dd 137. 
Tienen respectivamente la fecha de 21 y 22 de Marzo de 1552 . Se prohibe el uso de jerga, lienzos, sábanas, cestos y otros que se marcan, asi como sacar de madre á los rios para dejarlos en seco. Determina las multas enque incurrian los infractores. En cuarto á la caza, condena el uso de cepos, armadijos y perros no chorniegos, estableciendo la veda, para favorecer la cria desde Marzo á Mayo, sin perjuicio de que las justicias formen sus ordenanzas especiales á tenor de la pragmática.

1031. Principios fundanentales sobre.la explotacion de los bosques, por D. Antonio Sandalio de Arias.

Manuscrito que en $186 \mathrm{l}$ obraba en poder de los herederos del autor, segun se dice en el Boletin bibliográfico español, tomo I, pág. 11.

1032. Proyecto De Reglamento para una escuela especial de INGENieros DE Bosques, por D. Antonio Sandalio de Arias; año de 1835.

Manuscrito del Archivo del Ministerio de Fomento.—Legajo número 16 de los de montes.

Tiene la fecha de 26 de Junio de dicho año, y le preceden algunas consideraciones sobie la conveniencia de crear esta carrera en España para la conservacion y fomento de la riqueza forestal. En el mismolegajo se encuentran unos apuntes, fechados el 29 de Mayo de 1837. que contienen noticias sobre los daños causados en los montes y un cálculo aproximado de los gastos y productos de su administracion: la direccion del ramo se hallaba entonces á cargo del referido Arias. Reprodijo literalmente este proyecto, que consta de 20 artículos, D. Juan de la Cruz Martinez, en sus Estudios sobre el ramo de montes arbolados de España, de que hemos dado cuenta oportunamente.

\section{R.}

1033. RELACron del estado aCtual de la vilia de CASPE, en el reino de Aragon, en cuanto al cultivo y ganudería, por D. Antonio Polo; año de 1815.

Manuscrito de la Biblioteca agronómica del jardin Botánico de Madrid.Tomo IV de papeles varios.

Tiene la fecha de 30 de Diciembre de 1815. Lamenta la falta de lluvias que ocasiona la de cosechas, solo completas de cinco en cinco años, y se queja de las talas é incendios que tienen lugar en los inontes y bosques.

1034. Relacion individual de Los Árboles útiles que se encuentran en el partido de Coamo, por D. Tiburcio Rodriguez.

Manuscrito del año 1790, de 4 hojas, fólio, conservado en poder de D. Miguel Colmeiro, segun indica este autor en la Botánica y los Botánicos, donde 
añade que hay algunas figuras luechas con pluma, y que los árboles se designan con los nombres vulgares, perteneciendo todos á la isla de Puerto-Rico.

1035. Sobre el plantío de los Árboles.--Por el Dr. D. Manuel Barba y Roca.

Al hablar de las obras de este escritor catalán, dice el Sr. Torres Amat, en sus Memorias para ayudar á formar un diccionario crilico de los escrilores catalanes, pág. 90, que en 1789 en vió Barba á la Academia de Ciencias y artes de Barcelona, una disertacion con el título registrado.

No se hace mencion de este trabajo en el Diccionario de bibliografia agronómica, del Sr. Anton Ramirez.

1036. Sobre la Planta UVA-UISI, QUE dá las GayUbas; un pliego de Martin Sarmiento, copiado en el tomo XI de sus manuscritos. -Véase: Arbol Azederach.

Escrito en 1758, segun el Sr. Colmeiro (D. Miguel).

1037. Sobre LOS VEgETABles KALI, SOSA Y BARRILLA, Y SI XACEN eN Galicia; 26 pliegos, escritos en 1756, copiados en el tomo XI de la coleccion de manuscritos de Martin Sarmiento.

Existe en poder del Marqués de Villafranca, probablemente, una copia do dicha coleccion, segun el Sr. Colmeiro (D. Miguel) el cual añade que del trabajo que aquí registramos hay un manuscrito en la Universidad de Santiago, con título poco diferente. El Pais, periódico de Pontevedra, lo publicó.

\section{$\mathbf{T}$}

1038. Tabla de Resistencia y PESO oE Las Maderas de Filipivas. - Contiene 17 provincias.-Por el coronel de Ingenieros D. Tomás Cortés.

Este manuscrito, es una copia del trabajo que en 1828 hizo el Sr. Corlés. Existe en la biblioteca de la Escuela especial de ingenieros de montes á cuyo establecimiento lo regaló el Inspector del Cuerpo de Minas, D. Isidro Sainz de Baranda.

Figura al principio una tabla comparativa del peso y resistencia de algunas maderas de Europa y Bengala con las de su especie en Filipinas, y siguen luego los estados por provincias, que comprenden el número de órden de las maderas, nombres vulgares, aplicacion que de ellas se hace, elasticidad (en límeas por un peso de $121_{1} 2$ libras), peso que produjo la ruptura, peso al aire, peso específico (estos dos por pulgada cúbica), y caractéres fisicos exteriores. 
De estos estudios del Sr. Cortés nada se dice en el Diccionario de bibliografia agronómica del Sr. Anton Ramirez. El distinguido ingeniero de montes D. Sebastian Vidal y Soler, los ha reproducido metódicamente en su folleto titulado; Breve descripcion de algunas de las maderas más importantes y mejor conocidas de las Islas Filipinas, del que damos cuenta en el Apéndice.

1039. Tratado sucinto sobre el cultivo de varios árboles Exóticos:-4. $.^{\circ}, 170$ páginas.

Manuscrito de la Biblioteca agronómica del jardin Botánico de Madrid.Tomo VI de papeles varios.

Versa sobre el cultivo, naturaléza y propiedades del cedro, de la caoba de Cuba y las Indias Occidentales, de la morera, palo campeche, etc. Hay una tabla alfabética de los árboles de que se trata, con los nombres castellanos, latinos y catalanes. Se hace cargo de la horrorosa actividad del veneno que contiene el Bohon-upas, (en malayo) y de su empleo en los sacrificios humanos. 


\title{
APÉNDICE (a).
}

\author{
PRIMER GRUPO.
}

\section{. \\ PUBLICACIONES DE TODAS CLASES.}

\section{A.}

1040. Abeja montañesa (La).-Periódico de intereses morales y materiales, publicado en Santander.

Publicó en forma de artículos los trabajos que dejamos registrados en los números 269 (31 de Mayo, 14 y 22 de Junio de 1865), 372, (22, 23, 24 y 25 de Junio de 1868, reproduciendo tan solo el articulo cuarto que trata de la propiedad forestal), 572 ( 17 de Abril de 1866), 652 (11 y 12 de Diciembre de 1867 y 666 (11 de Abril de 1866 con el título de Los Pinares, que tambien vió lá luz en el periódico El Miño).

Contiene además varios trabajos de los cuales damos cuenta más adelante bajo los enunciados siguientes: Arboles (Los).-Arboricultura.-Infiuencia del cultivo sobre el clima de un lugar.-Los recientes decretos..., etc.-Proyecto para establecer una casa modelo de enseñanza, elc.

(a) La imprevista lentitud con que ha tenido lugar la publicacion de estos $\$$ Apunces, cuyo primer pliego salió á luz en Abril de 1873, ba permitido recoger á su autor varias noticias de publicaciones y trabajos anteriores que no le babia sido dado encontrar hasta entonces.

Con esto y con las publicaciones que desde aquella fecha han venido á enriquecer la bibliografia forestal, ó sea hasta el dıa en que cierra la ultima nota de este libro, se ha formado el presente $A$ pendice en el que como es natural, se ha adoptado 10 misma clasificacion que on el texto que le precede.

Sabido es que estas adiciones, en libros de bibliografia, constituyen un defecto poco disimulable, porque hacen más penoso el exámen de los unismos á la vez que son ocasion de error por cuanto muchos de los que los manejun no suelen fijarse en sí contionen o no apéndices, limitándose á registrar el cuerpo principal do la obra. Pero comprendieudo asimismo que, aunque sea con mayor trabajo, vale más encontrar la indicacion que se busca en un solo libro, que hacer por si mismn cada investigador los rebuscos parciales á que de etro modo tendrian estos que entregarse, se decide el autor por 1 a publicacion de este Apendice, por no sacrificar á una mera cuestion de forma, otra de fondo bastante más mportante. 
1041. Amenidades naturales de las Españas ó bien disertacíones varias sobre las Producciones Naturales Espontáneas, ó Conaturalizadas en los Dominios Españoles. Por D. Mariano La Gasca, profesor de Botánica aplicada á la Medicina del Real Jardin Botánico de Madrid, encargado por S. M. de viajar por la Península para escribir la Flora Española, y Médico de número de los Reales Exércitos de S. M. C. con destino al tercer Exército.-Impreso en Orihuela.En la imprenta de la muy Ilustre Junta. Año de 1811.-Cuaderno en $4 .^{\circ}$ de 44 págs.

F.n las páginas 19,20 y 21 , figura una lista de plantas de la China, del Japon, Amboyna, Malabar y Filipinas conaturalizadas en España, Ó cultivadas al raso en sus jardines, que comprende cuarenta y tres especies de árboles y arbustos indicados por sus nombres sistemáticos y vulgares.

1042. América (LA).-Crónica hispano-americana.-Véase: Industria y Comercio. Maderas, sus cualidades, aplicaciones y precios.

1043. AnUario forestal DE España, para 1874.-Publicado por la redaccion de la Revista forestal, económica y agricola.-Madrid, Establecimientos tipográficos de M. Minuesa, 1874.-4..$^{\circ}$ I90 páginas.

Es el primer libro de su clase que se ha publicado en España. Contiene amplias y curiosas noticias del ramo de montes, referentes á presupuestos: rendimientos de los montes públicos, escuela especial de ingenieros, servicio administrativo y facultativo del Ministerio de Fomento, distritos, comisiones especiales y junta consultiva, indicándose el personal que lo presta, desde los ingenieros hasta los guardas; extension y poblacion de las provincias, posiciones gengráficas de sus capitales y altitudes de los puntos más notables de la orografía española; tablas de medidas métricas usuales, así del pais como extranjeras con las correspondencias respectivas; medidas forestales y marcos de maderas, tablas de cubicacion de árboles $\mathrm{y}$ de cálculo de multas; clasificacion de tierras, usos, deusidad y resistencia de las maderas; legislacion forestal vigente y anuncios. Comprende asímismo, la indicacion de los rendimientos de los montes públicos de Filipinas, el personal facultativo que de ellos cuida, y la legislacion forestal de dichas islas.

1044. Asociacion agrícola (LA) por la iniciativa privada.-Revista quincenal de agricultura de Valladolid.-Véase: Cuatro palabras sobre montes.

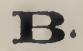

1045. Biblioteca de autores españoles desde la formacion del lenguaje hasta nuestros dias.-Historiadores primitiros de Indias.Coleccion dirigida é ilustrada por D. Enrique de Vedia.-Madrid, 
imprenta y estereotipia de M. Rivadeneyra.-1852,-Tomo I, ó sea el 22 de la coleccion, fólio, 599 págss.

Contiene el Sumario de la natural historia de las Indias de D. Gonzalo Fernandez de Oviedo, de que damos cuenta en la seccion correspondiente.

\section{Boletin oficial del Ministerio de Ultramar.}

Su publicacion comenzó el 12 de Noviembre de 1873. - Aparece drs veces al mes en cuadernos en $4 .^{\circ}$ mayor de 32 páginas, de las cuales se destinan á legislacion más de la mitad. Se estampa en lá Imprenta nacional. En los números $2,3,4$ y 5 de los dias 27 de Noviembre, 12 y 27 de Diciembre de 1873, y 12 de Enero de 1874, se publicó la Memoria sobre la produccion de los montes públicos de Filipinas en el año económieo de 1871-72, presentada por el Ingeoiero Inspector D. Ramon Jordana, de la que se dá noticia más adelante, así como de la Memoria descriptiva é histórica de las isias Marianas, escrita por D. Felipe de la Córte Ruano Calderon, que tambien se insertó en el mencionado Boletin.

1047. BREve DESCRIPCion de algunas de las maderas más importantes y mejor conocidas de las Isias Filipinas, por el ingeniers de montes D. Sebastian Vidal y Soler, jefe de primera clase en Ultramar, profesor que fué de la escuela especial del ramo.-Madrid, establecimientos tipográficos de $\mathbf{M}$. Minuesa, 1874. - Folleto en $4 .^{\circ}$ de 35 páginas.

Este apreciable trabajo comprende 70 especies maderables dispuestas por órden alfabético de sus nombres, de las que se indica la elasticidad, resistencia á la carga, peso en el aire, peso específico y aplicaciones más comunes. Al final están agrupadas las especies segun sus propiedades físicas y con arreglo al uso que reciben en la construccion naval y civil, ebanisteria, carpintería, elc. El autor además de las experiencias que por sí mismo ha practicado, ha tenido á la vista el trabajo de igual índole del Sr. Valdés, y ha utilizado las noticias que el coronel de ingenieros D. Tomás Cortés reunió en unas tablas inéditas, de las cuales hay una copia en la biblioteca de la Escuela especial de ingenieros de montes.

La Revista forestal, económica y agricola publicó este trabajo del Sr. Vidal y Soler, en los números de Abril y Mayo del año 1874.

\section{D.}

1048. Diario de Manila (EL). - Véase: Legislacion de inontes.

1049. Dićcionario GEŐ́GRÁfico, estadístico, histó́rico de LAS Islas Filipinas, dedicado à S. M. el Rey por los MM. RR. PP. Misioneros Agustinos Calzados Fr. Manuel Buceta, actual comisario y procurador general de las misiones de Asia en esta corte, y Fr. Felipe Bravo, rector del colegio de Valladulid.-Madrid, 1850.-Imprenta de D. José C. de la Peña. -2 tomos en $4 .^{\circ}$ mayor de 567 y 
478 páginas con 18 de apéndice, varios estados y un plano de la ciudad de Manila.

Uno de los puntos objeto del estudio general de Filipinas que precede al tcxto sujeto á la forma de diccionacio, es el referente á la vegetacion arbórea, págs. 34 á 37 , bajo el punto de vista de sus productos así unaderables como ind ustriales, alimenticios, medicinales, etc. Se citan las especies más notablos, se indica el número de las que viven en cada provincia, se enumeran los artículos de comercio que producen, la variedad de frutos comestibles que dan y otros particulares que no debe pasar por alto todo el que desee conocer á grandes rasgos la fisonomía dasonómica de aquel arclipiélago.

1050. Discvrsos de las cosas Aromaticas, árboles y Frutales Y DE OTRAS MUCHAS MEDIGINAS SIMPLES QUE SE TRAEN DE LA INDIA Oriental, y sirven al uso de medicina.-Avtor el licenciado Iuan Fragoso médico y cirujano de su Mag.-Con privilegio,-Impresso en Madrid en casa de Francisco Sanchez, año 1572.-Un tomo en 8. menor de 211 págs. y 29 de Tabla sin numerar.

Aunque dando la preferencia á la indicacion de los caractéres que distinguen las partes medicinales de las plantas (flores, frutos, cortezas, raices, etc.,) reseña algunos organográticos generales dę ciertos árboles, como el árbol triste de Malaca, anacari de Malabar, Bdelio ó Ulolochil, palmito del Perú, ber ó bor ó Vidaras de Malaca, camphora, caña olorosa, caña fislola, coco indico, carambola de Goa, Carandas, guayacan, cyrifole ó marmelo de Bengala, dorion de Malaca, areca, árbol iaca, iangoma, lacca, manga, myrobalano, musa, tune ó higuera indica, tamarindo y alguna otra.

Esta obra no esta indicada en el Diccionario de bibliografia agronómica del Sr. Anton Ramirez, en donde tal vez hubiera podido tener cabida ensanchando un poco los límites de la especialidad á que dicho libro esta dedicado.

\section{E.}

1051. Elementos de aGricultura x zootechia, escritos expresamente para las Bibliotecas Parroquiales de ia plovincia de Santander, for D. Augusto Lecanda Chaves, ingeniero ag'rícola de la escuela de Gembloux (Bélgica).—santander, 1873. - Inprenta de salvador Atienza.-Un tomo en $4 .^{\circ}$ de 552 pág's., con 34 laminas.

Aunque de carácter esencialmenle agrícola, en esta obra puede consultarse sin embargo la parte reiativa a prados naturales y plantaciones propias tambieu de la selvicultura en sus reglas generales. La materia esta iratada con mucha coucision.

1052. Epoca (LA).-Periódico politico de Madrid.-Véase: $A r^{-}$ ticulos de LA PRENSA sobre lasituacion de las Islas Filipinas(Los).- 
Influencia de las mareas en la vegetacion. - Influencia de los montes sobre el clima, las fuentes y aguas corrientes de un pais.-Traviesas de ferro-carril.

1053. EstadO DE LAS ISLAS Filipinas EN 1810, brevemente descrito por Tomás de Comyn.-Con permiso del Supremo Consejo de Indias.-Madrid, Imprenta de Repullés.-1820.-4. ${ }^{\circ}, 190$ págs. y II estados.

Las páginas 20 y 21 del capítulo II, están destinadas al estudio de las maderas con aplicacion á Ia construceion naval. Indica tambien las especies que son objeto de mayor exportacion. La brevedad de las noticias da poco interés á esta seccion del capítulo.

1054. Estado GEOGRÁfico, TOPOGRÁFICO ESTAdístico, HistóricoRELIGIOSO DE LA SANTA Y APOSTóliCa PROVINCIA DE SAN Gregorio MaGNo, de religiosos menores descalzos de la regular y más estrecha observancia de N. S.P. S. Francisco en las islas Filipinas. Comprende el número de religiosos, conventos, pueblos, situacion de estos, años de su fundacion, tributos, almas, producciones, industria, cosas y casos especiales de su administracion espiritual en el archipiélago filipino desde su fundacion en el año de 1577 hasta el de 1853.-Compuesto por el R. P. Fr. Felix de Huerta, predicador, lector de sagrada teología, examinador sinodal del Arzobispado de Manila, y guardian en el convento de San Francisco de dicha capital.-Mandado dar á luz en noinbre de esta santa Provincia, por el M. R.P. Ministro Provincial de la misma.-Con las licencias necesarias.-Nanila, 185̌5.-Imprenta de los Amigos del Pais, á cargo de D.M. Sanchez.-Un tomo en $4 .^{\circ}$, de 439 págs. y un estado.

En la descripcion de lọs términos de los pueblos, se enumeran las prin¿ipales especies arbóreas'que regetan en los montes.

1055. Estudios sobre las inundaciones, por el Ingeniero D. Pedro Perez de la Sala.-Madrid, imprenta y estereotipia de M. Rivadeneyra.-1871.-Fólio mayor, 24 págs. á dos columnas.

Liste folleto está formado con los artículos que bajo el título de Inundaciones, publicó el autor en la Revisla de Obras príblicas. De su contenidohemos dado cuenta en el segundo grupo.

\section{F.}

1056. Folleto SOBRe los BIENes de Propios, en la parte relativa á su enagenacion.-Por D. Eugenio de Gregorio.-Madrid, imprenta del Colegio de sordo-mudos.-1851.-4. ${ }^{\circ}, 15$ págrs.

Estudia la historia y procedencia de dichos bienes desde la época ro- 
mana y discute la conveniencia, forma y manera de la enagenacion, á la cual no se muestra propicio, estimando mejor la purificacion de las administraciones, y la repoblacion de los montes yermos ó maltratados. Se pronuncia deci lidamente en contra de la venta de las dehesas boyales y potriles, exidos, albuheras y otros prédios de uso comunal.

A pesar de su corta extensín este trabajo es uno de los mejores que se han escrito sobre la materia. No se menciona en el Diccionario de bibliografia agronómica, del Sr. Anton Kamirez, como ya hemos dicho en el número 230 en Joude no se dió cuenta del contenido porque aun no habia llegado entonces á nuestras aıanos ningun ejemplar.

\section{I.}

1057. IgUaldad (La). - Periódico político de Madrid.-Véase: $\mathrm{Ni}$ individualismo puro ni colectivismo exclusivo.

1058. Imparcial (EL).-Periódico político de Madrid.-Véase: Apuntes sobrela India.-Arboricultura. Los paseos y jardines publicos de Madrid.-Riqueza forestal ( $L a)$. - Un paseopor elbuen Retiro.

1059. Informe SOBRE EL ESTADO DE LAS IsLAS Filipinas EN 1842.Escrito por el autor del Aristodemo del sistema musical de la lenga castellana, etc.-Madrid.-Enero de 1843.-Dos tomos en $4 .^{\circ}$ menor, de 483 págs. el primero y 397 el segundo.

Esta obra fué escrita por D. Sinibaldo de Más. Tienen paginacion distinta las diferentes partes enque se halla dividida, relativas á historia, estadistica, corrercio, agricultura, etc. En la seccion destinada á los Vegetales, da noticias de las principales especies arbóreas del archipiélago, productos que de ellas se obtienen, aplicacion de los mismos y otros datos que no debe desconocer el que se dedique á estudios forestales.

Como complemento del Informe, el autor publicó además un estudio sobre Politica interior, constituyendo un volúmen en $4 .^{\circ}$, de 121 páginas de texto y 22 de notas. Se tiraron muy pocos ejemplares que con el carácter de reservados y bajo numeracion correlativa, regaló á los Ministros, señores del Consejo de Gobierno y otras personas influyentes en los negocios de la Nacion, rogándoles que no lo circulasen ni permitiesen sacar copia de él. Advierte el autor por medio de apostilla, que toda reimpresion ilegal del libro será reconocida fácilmente por medio de un reactivo. Semejante deseo de evitar la circulacion de la obra se explica por la conclusion de la misma, en la que defiende el publicista la opınion tel abandono de las islas. Por 10 demás nada hay en este volúinen que merezca leerse respecto á cuestiones forestales. El ingeniero jefe del Cuerpo de montes, D. Sebastian Vidal y Soler, posee un ejemplar de dicho volúmen.

1060. Instruccion para el régimen y gobierno de la Direccion general del Patrimonio que se reservó al último monarca y sus dependencias.-Madrid, Por Quirós. -4. ${ }^{\circ}$ menor, 39 págs. 
Expedida en Madrid á 4 de Abril de 187t, y autorizada por el ministro de Hacienda. Consta de 94 artículos distribuilos en XXI capítulos. De estos el XVI, determina los deberes y atribuciones del Inspector facultativo de monles, bosques y jardines, relatiras á apeos, planes do aprovechamiento, redaccion de ordenanzas y reglamentos, distribucion de peones, traslacion de guardas, y fomento, conservacion, explotacion y régimen de aquellas fincas. L\&s obligaciones de loz guardas mayores, veedores, celadores y guardas, referentes á la ejecucion de las operaciones de explotacion, beneficio, custodia, conservacion y policía, se determinau en los artículos 71, 72, 73 y 74, comprendidos en el capítulo XVIII.

1061. Instruccion Para El SERvicio forestal de LAS ISLAS FiLIPINAS.-Por el Ingeniero inspector D. Ramon Jordana.-Manila, 1873.

No hemos tenido á la vista ningun ejemplar de esta publicacion, por cuyo motivo no nos es posible hacer constar la imprenta, el tamaño, ni el número de páginas. Sabemos sin embbargo, que esta Instruccion se ha dado á la imprenta á últimos de 1873, y q'ie en ella se prescribe el modo cómo han de llevar la documentacion y desempeñar el servicio de campo, los suardas ó monteros del Estado para cuyos funcionarios se ha redactado.

En la primera parte se explica el modo de llevar el libro inventario, el diario $\mathrm{y}$ el de partes quincenales, la manera de instruir y clasificar los expe. dientes, y los procedimientos que han de emplearse para hacer las tasaciones de productos.

En la segunda parte se indica cómo se han de hacer los reconocimientos, y operaciones que han de ejecularse en los aprovechamientos efectuados, revision y tasacion de los cargumentos ob balsas de madera, denuncias, multas, incendios y policia. Concluye con algunas instrucciones generales y con la designacion de los derechos y deberes de los monteros.

A esta Instruccion van unidas unas tablas para la cubicacion de maderas en rollo ó labradas, aplicables á la designacion del adeudo de las mismas.

1062. Instreccion SOBRe El CUltivo de ALGunas semillas, dedicada á la Junta de Agricultura, Industria y Comercio de Santander, por D. Manuel de Revilla y Oyuela, abogado del ilustre colegio de Valladolid.-Santander, 1865.-Imprenta de La Abeja montanesa.-Folleto de 12 págs. en $40^{\circ}$ menor.

Se publicó tambien en' el folletin de La Abejamontañesa. Trata de la naturaleza del terreno, mé todo de cultivo y produccion de las semillas, comprendiendo las de monte, y tambien de los procedimientos culturales apropiados á la cria de la alfalfa, trébol, remolacha, nabo vacuno y zanahoria.

1063. Instruccion SOBkF el Cultivo del Argan. (Argania sideroxylon. R. et S.) Por D. Estéban Boutelou.-Sevilla, Imprenta de Gironés y Orduña, 1871.-4. ${ }^{\circ}, 14$ págs.

Es el mismo trabajo de que se ha dado cuenta en el número 275. Se trata 
tan solo aqui, de una nueva edicion, no indicada en aquel lugar por no haber tenido entonces conocimiento de ella.

1064. InstrucCiones de Servicio para EL CUerpo de Ingenieros DE MONTES Y sUS DEPENDENCIAS._Madrid, Imprenta Nacional, 1874.4. ${ }^{\circ}$ menor, 37 págss.

Es publicacion dispuesta por el Ministerio de Fomentn. Contiene el decreto de 11 de Julio de 1874, por el que se reorganiza la Junta consultiva de montes, se crean inspecciones, y se determina la clase, distribucion y relaciones que deben existir entre los Inspectores, Ingenieros jefes, Ingenieros subalternos, Ayudantes y Guardas. Siguen despues las Instrucciones aprobadas por decreto de 11 de Setiembre del mismo año, en las que se señalan más detalladamente las obligaciones y facultades de la Junta consultiva y personal del ramo, desde la clase de Inspectores hasta la de Guardas, completado todo con diez modelos que tratan: $1 .^{\circ}$ De la Memoria que han de redactar los Inspectores relativa á los planes generales de aprovechamiento. $2 .^{\circ} \mathrm{Me}-$ moria general sobre el estado del servicio en la Inspeccion de... $3 .^{\circ}$ Parte de los trabajos verificados y de las novedades öcurridas en la... Inspeccion de... en los meses de... 4. ${ }^{\circ}$ Registro de aprovechamiento... $5 .^{\circ}$ Modelo de inventario... $6 .^{\circ}$ Cróquis del monte... 7. Hoja de los aprovechamientos anuales. $8 .^{\circ}$ Libro diario... (para los Sobreguardas). 9. ${ }^{\circ}$ Parte semanal del Sobreguarda... $y$ $100^{\circ}$ Cróquis de la Inspeccion.

\section{L.}

1065. Libro DE CETRERIA DE CACGA DE AZor, en el qual, por diferente stilo del que tienen los antiguos que están hechos, verán los que á esta caça fueren afficionados, el arte que se ha de tener en el conoscimiento y caça destas aves, y sus curas y remedios, en el cual allí mesmo habla algunas cosas de halcones y de todas aves de rapina, y cómo se han de curar y preservar para que no cayan en dolencias. Por D. Fadrique de Zúñiga y Sotomayor.-En Salamanca. En casa de Juan de Canoua. Año MDLXV. - Un tomo en $4 .^{\circ}$, de 126 hojas, con números romanos y además otras seis de preliminares y tabla.

Está dividido en dos libros, de los cuales el primero habla de las diferentes aves útiles para la caza de altanería, y el segundo de las enfermedades que padecen y modo de curarlas.

1066. Libro de las aves de CAÇA, del Canciller Pero Lopez de Ayala, con las glosas del Dúque de Alburquerque.-(Publícalo la sociedad de bibliótilos).-Madrid, MDCCCLXIX, Imprenta de M. Galiano.-Un tomo en $4 .^{\circ}$, xxvirr.-224 págs., con tres láminas ilıminaulas que representan tipos de rapaces nobles.

En esta muy excelente edicion tipográfica se reproduce el libro que Pero 
Lopez de Ayala escribió á fines del siglo XIV con el título de Libro de las aves de caca, é de sus plumajes é dolencias é melecinamientos, al cual siguen las glosas del Duque de Alburquerque, un indice alfabético de nombres propios y geográficos citados en el libro, y las glosas y un glosario de voces antiguas, cuyo Irabajo se debe al entendido bibliófilo D. Pascual de Gayangos.

\section{M.}

1067. Maderas de Construccion Naval, por D. Eugenio Plá y Rave, Ingeniero segundo del Cuerpo Nacional de montes, Ayudante de la Escuela especial del ramo, Licenciado en Ciencias exactas, Correspondiente de la Real Academia de ciencias de Barcelona, sócio de número de la Española de Historia natural. (No se ha puesto á la venta ningun ejemplar). - Mradrid, Establecimientos tipográficos de Manuel Minuesa, 1874._4. ${ }^{\circ}, 186$ págs.

Se ocupa de las materias siguientes: principios constitutivos de las maderas, extructura anatómica, propiedades físicas, noticias dasotómicas sobre la cria y aprovechamiento de árboles maderables, conservacion de las maderas, enfermedades y defectos, maderas y piezas usadas en la construccion naval, reseña de los astilleros y de la industria naval de España, precios y mercados. Sigue un apéndice que contiene: $10^{\circ} \mathrm{Un}$ modelo del pliego de condiciones para la contrata de la corta, labra, desmonte $\mathrm{y}$ conduccion al puerto de las maderas de construccion naval destinadas á los astilleros de Estado, pliego que rije en la provincia de Santander. $2 .{ }^{\circ}$ Las Tarifas é instrucciones legales vigentes para el reconocimiento, recibo y clasificacion en los arsenales del Estado de las maderas destinadas á la construccion de buques; y 3. ${ }^{\circ}$ Un índice bibliográfico de las principales obras que el autor ha consultado para su trabajo.

Este estudio se publicó tambien en el tomo sétimo de la Revista forestal, económica y agrícola (año 1874) páginas 309, 389, 461, 490, 533, 587 y 631.

Reune este libro lo más moderno que se ha publicado sobre la materia, presentando agrupadas las noticias con buen método y órden.

1068. Mandal Completo del Cazador $\delta$ arte completo de toda clase de caza.-Traduccion de R. Villalta, aficionado con 30 años de ejercicio en caza mayor y menor.-Barcelona, Manuel Sauri, editor. - 1874. - Un tomo en $8 .^{\circ}$ mayor.

1069. MANCAL DeL CAZAdoR DE PERdices con los reclamos, con un apéndice sobre el puesto portátil y los reclamos artificiales y una lámina para dar á conocer estos medios de cazar, por D. J. Jacobo de Escalante y Moreno, precedido de un prólogo por D. Enrique Perez Escrich.-Madrid, Imprenta y Librería de Miguel Guijarro.1874. -8. ${ }^{\circ}$ menor, xxxıx.-167 páginas con una lámina.

1070. MEdIOS QUE EL GobIERNO Y LA SOCIEDAD ECONÓMICA DE AMIgoS DEL PAÍs DE Filipinas pueden emplear para obtener el desarrollo de la agricultura del país.-Memoria para optar al premio 
ofrecido por la sociedad segun el programa publicado por la secretaría de la misma en 31 de Agosto último, seguida de un índice general de la legislacion que en relacion á la agricultura se ha expedido desde el año 1513 á $186 \%$, distinguida por la corporacion con el primer premio, consistente en una medalla de oro, su autor, D. Antonio de Keyser y Muñoz. - Manila, establecimiento tipográ-

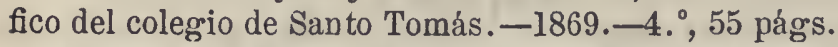

Fechada en Manila, á 30 de Noviembre de 1868.-El índice comprende ciento cincuenta y tres disposiciones, entre las que figuran algunas forestales relativas á envio de semílas á la península, denuncia y concesion de baldios y realengos, enseñanza de botánica y agricultura por los ingenieros de montes, tramitacion de expedientes de concesion de terrenos, cortas de madera, roturaciones, aprovechamiento de resinas y otros jugos, ejecucion de deslindes y acotamiento de los montes del Estado.

1071. - Memoria sobre el RAMo de Montes en las islas Filipinas, presentada al Excmo. Señor Ministro de Ultramar por el Ingeniero de montes D. Sebastian Vidal y Soler, jefe de primera clase de Ultramar, profesor que ha sido de la Escuela especial del ramo.--Publicada con autorizacion superior suprimiendo la parte concreta de organizacion del servicio.-Madrid. Imprenta estereotipia y galvanoplastia de Aribau y Compañía; (sucesores de Rivadeneyra).1874.-Un volúmen en $4 .^{\circ}$ mayor, 456 págs., y una lámina que representa un monte de la cuenca del rio Grande de Mindanao.

En la portada exterior dice: $S$. Vidal y Soler.-Memoria sobre los montes de Filipinas. Estudia la produccion, consumo y administracion de los montes públicos, hacierido resaltar la importancia económica y cosmológica de los mismos. Da cuenta de la produccion de maderas del Archipiélago comparada con la de los países vecinos, insulares y continentales. Discurre sobre la constitucion de la propiedad, sobre la desamortizacion de los montes, sobre el estudio de la vegetacion leñosa de los mismos y sobre los productos que el Estado podria obtener de la enajenacion de los prédios desamortizables, concluyendo de todo la necesidad de crear una comision de Ingenie. ros que estudie la flora forestal Filipina y que recoja datos estadisticos relativos á superficies, formas del terreno, geognosia, geonomia, y cuantos sean útiles para preparar el inventario de aquella riqueza. Siguen á la memoria, tres apéndices; uno que describe las maderas más importantes y mejor conocidas del Archipiélago Filipino, de cuyo trabajo habia ya hecho el autor una publicacion aparte, con el título de Breve descripcion de algunas de las maderas, elc., registrado por nosotros con el número 1047, otro apéndice dedicado á la isla de Minlanao, en el cual el Sr. Vidal presenta las noticias por él recogidas dırante un viaje que hizo á dichas islas, ciñend ose principalmente á las geográflcas y naturales; y por último, sigue á los dos anteriores. otro apéndice, que contiene una lista de ubras y artículos importantes, referentes á los paises del extremo Oriente. Se registran en ella 1523 publicaciones agrupadas como sigue: 
I. Obras generales de colonizacion y viajos.

II. Islas Filipinas.

III. Archipiélago malayo: Java, Sumatra, Borneo, Timor, Molucas y Célebes.

IV. India inglesa; Indostan, Ceylan, Birmania, Malacca .

V. China y Japon, $\mathbf{y}$ -

VI. Cochinchina, Cambodga, Anam, Sian.

Concluye el libro con unas adiciones y correcciones que tienen por objeto dar á conocer el Quercus (Cyclobalanus) Woodh, indicado últimamente como existente en las islas; Ics Pinus IIerkusil. Jungh et de Vriese, y P. insularis Endl, que es muy probable se encuentren en las islas, y los datos más recientes respecto á la superficie de todo el Archipiélago.

1072. MEMORIA SOBRE LA PRODUCCION DE LOS MONTES PÚBLICOS DE Filipinas en el año económico de 1871-72, elevada al Excmo. señor Ministro de Ultramar por el Ingeniero Inspector del ramo en aquellas islas, D. Ramon Jordana y Morera, jefe de Administracion de segunda clase y jefe de primera del Cuerpo de Ingenieros de Montes.-(Este trabajo ha sido publicado en el Boletin oficial del Ministerio de Ultramar de órden del Excmo. Sr. Ministro, prévio el favorable informe de la Junta consultiva del Cuerpo).-Madrid, establecimientos tipográficos de Manuel Minuesa, 1874.-Folleto en $4 .^{\circ}$ de 58 páginas.

Fechada en Manila á 30 de Junio de 1872 . Contiene un A péndice por órden alfabético de los nombres científicos y vulgares de las plantas que se citan en el texlo. Su principal iuterés consiste en los datos estadísticosde produccion expresados por provincias y meses, asi como en la designacion de las masas de monte más importantes, en la reseña de las especies arbóreas que las pueblan y en varias noticias naturales y económicas de carácter forestal, constituyendo el primer bosquejo de inventario dasonómico de aquellas islas que se ha publicado hasta el dia.

Se insertó en el Boletin oficial del Ministerio de Clliramar, números 2, 3, 4 y 5 , correspoudientes á los dias 27 de Noviembre, 12 y 27 de Diciembre de 1873 y 12 de Enero de 1874, así como en la Revista robestal, económica $\mathbf{Y}$ Agrícola, números de Enero, Febrero, Marzo y Abril de 1874, y en El Porvenir Filipino, periódico de Manila.

Se han tirado un corto número de ejemplares de esta Memoria, que no se ha puesto a la venta.

1073. MEMORIA SOBRE LA PRODUCCION DE LOS MONTES PÚBLICOS DE Filipinas en el año económico de 1872-73, elevada al Excmo. señor Ministro de Ultramar por el Ingeniero Inspector del ramo en aqueJlas islas, D. Ramon Jordana y Morera, jefe de Administracion de segunda clase y jefe de primera del Cuerpo de Ingenieros de Montes.-Impresa por cuenta del Ministerio de Ultramar en virtud de lo dispuesto en órden de 26 de Noviembre de 1874. - Madrid, estable- 
cimientos tipográficos de Manuel Minuesa, 1874.-Folleto en $4 .^{\circ}$ de 58 páginas.

Fechada en Manila á 27 de Octubre de 1873. Contiene un Apéndice que enumera por sus nombres científicos y vulgares, agrupándolas por familias naturales, las especies arbóreas acerca de las cuales se dan en el texto noticias relativas á las cualidades y usos de sus maderas respectivas. Expresa la produccion en dinero de los montes, por provincias y meses, y añade numerosas noticias respecto á las propiedades y empleo de las maderas más comunes y útiles. Precede un juicio crítiso de las vicisitudes por que ha pasado el servicio del ramo en el archipiélago, desde su creacion.

De la comparacion de los datos de esta Memoria con los análogos de lu del año anterior, resul ta que los ingresos aumentan notablemente.

La Junta facultativa de Montes elogió el trabajo de que aquí se trata, recomendando su publieacion.

\section{N.}

1074. Nveva filosofía DE LA NATURALEZA DEL HOMbre, no conocida ni alcançada de los grandes filósofos antiguos, la qual mejora la vida y salud humana: las addiciones de la segunda impressiô y (en esta tercera) expurgada. Composta por Doña Oliva Sabuco.Dirigido no I. S. D. Loño Lobo Barao D'albito, etc.-Impresso e Praga, co as liceças necessarias por Fructtooso Loureço de Basto, año MDCXXII.-8. ${ }^{\circ}$ pergamino, 347 fojas y una tabla de 12.

En la Biblioteca Nacional, además de esta edicion, existe la de 1728, hecha en Madrid por Domingo Fernandez, constituyendo un pergamino en 4 . de 412 páginas. Se han hecho otras ediciones, siendo la más antigua de las que conocemos la de 1588, que tambien se imprimió en Madrid, por Pedro Madrigal. En la de 1728 se añade en la portada el segundo apellido de la 2utora, que es de Nantes.

En todas ellas aparece un capítulo (en la edicion que registramos es el Titulo $X$, folio 157 vuelto), titulado: Mejorias con el agua y plantas, en el que se indican sumarísimamente las precauciones que requieren los trasplantes, recomendándose la aclimatacion de árboles exóticos, oriundos de las Indias. Como la obra no es especial de agricultura, nada tiene de particular que no esté registrada en el Diccionario de bibliografía agronómica de D. Braulio Anton Ramirez.

\section{O.}

1075. Obras del Doctor D. Diego de Torres Villarroel de el Gremio y Claustro de la Universidad de Salamanca y su cathedrático de Mathemáticas, jubilado por el Rei nuestro señor.-Salamanca: impreso por Pedro Ortiz Gomez, año de 1752. - 13 tomos en $4 .^{\circ}$ mayor de unas 130 páginas. 
Hay otra edicion, que es la que hemos consultado, hecha en Madrid por los años 1794-99 en la imprenta de la viuda de Ibarra, compuesta de 15 tomos en $8 .^{\circ}$ de unas 300 páginas cada uño.

El tomo VI comprende entre otras materias la Cartilla rústica de que damos cuenta en el lugar que le corresponde y de la cual no se dice nada en el Diccionario de bibliografía agronómica del Sr. Anton Ramirez.

1076. Orígen é historia del Jardin Botánico Y dE LA Escuela de Agricultula de Filipinas, por D. Rafael García Lopez, Alcalde mayor que fué de varias provincias en aquellas islas y Autor de otras obras en Cánones, Legislacion, Moral, Agricultura y Administracion civil: con un Apéndice ó diccionario botánico-farmacéutico y artístico, correspondiente al reino vegetal, y tecnicismo indigena de Filipinas: útil para el progreso de las ciencias naturales, médico-quirúrgicas, artes y oficios.-Madrid, imprenta á cargo de Juan Iniesta, 1872. - Folleto en $4 .^{\circ}$ de 60 páginas.

En el Apéndice da una noticia por órden alfabético de nombres vulgares, - de las propiedades y usos de la madera, corteza, frutos, jugos y ctros productos de muchos árboles y arbustos forestales, cuyos datos se observa desde luego que han sido tomados en su mayor parte del Informe sobre el esiado de las islas Filipinas en 1842, de que damos cuenta en el lugar respectivo.

\section{P.}

1077. Plantas industriales (Las).-Tratado curioso del cultivo y aprovechamiento de las plantas téstiler, oleaginosas, tintóreas y otras que son objeto de la industria, por varios agrónomos. Obra de sumo interés para los tejedores, estampadores, tintoreros y pintores; para los fabricantes de aceite, vinos, ag*uardientes, licol'es, sidras, y en fin, para los cosecheros ó cultivadores de dichas plantas.Barcelona, Manuel Sauri, editor.-1874.-8. ${ }^{\circ}, 296$ páginas.

Da algunas sumarísimas noticias de plantas forestales, tales como el esparto, a vellano y alcornoque.

1078. Ponvevik (Ec).- -Revista salmantina. - Véase: Costumbres salmantinas. El merodeador de los montes. - Valle de Batuecas $(E l)$.

1079. Programa del Ayuntamiento del valle de Cabuérniga (Santanrler) para el mejoramiento de su adrainistracion, por D. Gervasio G. de Linares, Alcalde accidental del mismo y Comisario de Agricultura de la provincia.-Madrid, 1873.- Imprenta de Aribau y compañía.-Folleto en $4 .^{\circ}$ mayor de 32 páginas.

Dedica un ar ticulo á la desamortizacion de terrenos comunes y otro á los montes. En el primero propone la desamortizaciou gradual de aquellas fin- 
cas, y en el segundo expone la opinion de que por ahora continúen los montes administra tos por los pueblos y dirigidos por los Ingenieros. Recomienda el mayor desarrollo en la guarderia rural y propone otras medidas administrativas, concluyendo pordemostrar que la inicialiva privada no responde al interés de las buenas explotaciones forestales, por lo cual es de parecer que la venta de estos prédios no daria otro resultado que su tala llevada á cabo inmediatamente por los particulares que los adquiriesen.

\section{R.}

1080. Recuerdos de Rusia. Por D. Agustin Pascual, caballero gran cruz de la órden civil de María Victoria; gran cordon de primera clase de la órden rusa de San Estanislao y de otras nacionales y extranjeras; Presidente de la Junta consultiva del Cuerpo de Ingenieros de Montes; Académico electo de la Española; Director de la Sociedad económica Matritense; Delegado oficial de España en los congresos estadísticos de Berlin y San Petersburgo, etc.-Madrid, imprenta de Pedro Nuñez.-1873.-Un tómo en 8. de 243 páginas.

Consigna curiosas noticias forestales de Rusia en la parte de la obra destinada al Reino vegetal, desde la páoina 88 hasta la 102, ambas inclusive, con motivo de los productos de montes que el imperió exhibió en la exposicion politécnica de Moscow de 1872, de los cuales apunta la importancia y la índole. Trascribe notas estadísticas de áreas forestales, comunicaciones, movimiento comercial de los productos de los montes, presupuestos del ramo, ganadería, poblacion y otros.

Muchas de estas relaciones forman parte del artículo titulado Progreso forestal de los rusos (El), que el autor publicó en la Revista rorestal, EcoNómica y AGrícola, tomo $V$, página 529 , de que ya hemos dado cuenta.

1081. Revista del Instituto agrícola Catalan de San Isidio.Periódico de Barcelona.-Véase: Los montes considerados como fuente de riqueza.-Un recuerdo. Un aprovechamiento de los bosques.

1082. Revista Forestal, ECONóMica Y Agrícola.-Tomo VII.Madrid, establecimientos tipográficos de Manuel Minuesa, 1874.4. ${ }^{\circ}, 704$ páginas.

Desde el mes de Octubre de 1873, dejó de estar dirigida esta revista por D. Francisco García Martino, continuando á cargo de los demás redactores. En el tomo aquí registrado pueden consultarse, y de ellos damos cuenta más adelante, los artículos siguientes: Clave sencilla para la determinacion de las coniferas expontaneas en los montes de España.-Consumo de combustible vejelal y madera en Madrid. - Daños y perjuicios.-Escursion foresial por Catalwx̄a.-Bistadistica forestal del reino de Italia. - Gas de madera para el 
alumbrado.-Industria foresial.-Montes del valle de Andorra (Los). - Noticias físico-naturales de la seccion $N$. $O$. de la provincia de Guadalajara.Pabellon (El) del Minisierio de Agricultura austriaco en la exposicion de Viena.-Primer congreso internacional de Agricultores y Forestales en Viena $(E l)$. - Ramo de montes (El) en la exposicion nacional de Madrid de 1873.Señor Director de la Revista Forestal Estrasburgo.., etc.-Una coleccion do coniferas.

1083. Revista general DE Legislacion y JuRISPRUdencia.-Periódico de Madrid.-Véase: Infracciones de montes públicos.-Montes. ¿Cuál es la penalidad.... etc.?-Montes. Informe de la Audiencia de Cáceres..., etc.

\section{T.}

1084. Tabla`Para hallar la CUbicacion de los Árboleś EN ROLLo, por un método sencillo puesto al alcance de todas las personas que solo sepan la numeracion y la simple operacion de sumar números enteros, por D. Fulgencio Montoya, profesor de instruccion primaria.

En estos términos está concebido el anuncio de esta obrita, (que no hemos leido) en el Boletin oficial de la provincia de Santander, número correspondiente al dia 15 de Mayo de 1874. 



\section{SEGUNDO GRUPO.}

\section{MEMORIAS, ARTICULOS Y OTROS TRABAJOS}

CONTENIDOS EN LOS PERIÓDICOS Y OBRAS DE MATEIIAS DIVERSAS.

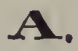

1085. Apuntes sobre la India.-Por D. Eduardo Lopez Bago.

El Imparcial.-Periódico político.-19 de Octubre y 2 de Noviembre de 1874.

Contienen esios dos artículos algunas noticias acerca de la especies arbóreas dominantes en los montes de la India inglesa, y sudistribucion. Señalan las principales reglas á que están sujetas las explotaciones de árboles bajo el punto de vista dasocrático y los medios de extraccion de que se valen los maderistas.

Aun cuando el autor no lo dice, el trabajo es simplemente un extracto é imperfecta traduccion del artículo que con el tílulo de "L. Exploitalion de forets de l' Indies" publicó en el número del 15 de Abril de 1867, en la Reoue des deux Mondes Mr. Jules Clavé, donde puede verse en el tomo 68, págınas e848 á 873 . .

Obsérvanse entre otras faltas cometidas por el traductor la de confundir el cocotero con el árbol del cacao, y el cedro de Deórara con el del Líbano. Omite la indicacion del abedul y del aliso como especies que viven en las últimas regiones forestales de las montuñas indianas. Al señ lar las dimensiones de algunos troncos de arboles de teca, cita las de 8 a 9 var. s de circunferencia y 30 á 40 de altura, siendo asi aue estas medidas estan expresadas por 2 y 20 metros respectivamente en el articulo de $\mathrm{Mr}$. Clavé.

Hay otras inexactitudes cuya indicicion omilımos en gracia á la brevedad. Los curiosos obrarán cuerdamente estudıando en el trabajo original del autor francés.

1086. Arboles (Los).-Por D. N. Prieto y Prieto.

La Abeja montañesa, periódico de Santander, 25 y 26 de Mayo de 1868.

Consta el trabajo de dos artículos que segun parece fueron publicados an- 
tes ell el periódico Los Sucesos. Defiende el autor en el primero la utilidad de los bosques para la salubridad del pais, y en el segundo encarece la necesidad del arbolado y de los montes para la vida animal y social. Estos artículos están escritos en vista del proyecto de ley que sobre arbolados presentó á las Córtes por entonces el señor marqués de Rogaraya.

1087. ArBoricultura. - Los paseos y jardines públicos de $M a-$ drid.-Por D. Sebastian Vidal.

El Imparcial.-Periódico político.-1.` de Junio de 1874.

Da á conocer entre otras las plantas leñosas de adorno y sombra que predomizan y dan carácter á los paseos y jardines de la capital indicada.

1088. Arboricultura.-Por D. Agustin de Bendito.

La, Abeja montañesa.-Periódico de Santander.-23 de Mayo de 1868.

Encarece las ventajas que la labranza reportaria si se asociase convenientemente á la arboricultura. A propósito de la falta de árboles que se nota en Castilla atribuye el mal á que los criados los destruyen, á que el pais no se esfuerza en criarlos y á otras causas tan ciẹrtas como evidentes.

1089. Artíçulos de la Prensa sobre la situagion de las Islas Filipinas (Los).-Por J.

La Epoca.-Periódico político.-25 de Marzo de 1874.

Refutando á La Prensa sobre varias de las cuestiones económicas, sociales y de administracion que sobre aquellas islas, expuso en una série de cinco articuloś publicados pocos dias antes, La Epoca sale á la defensa de la admi nistracion forestal facultativa demostrando la necesidad de un cuerpo de ingenieros que, á semejanza del inglés en la India, cuide del buen aprovechamiento de los bosques, de las repoblaciones, y donde sea conveniente, de señalar las zonas cuya roturacion convenga así como de dirigir los desmontes.

Para probar la inexactitud cometida por La Prensa en cuanto á sustituir . se naturalmente el arbolado eı dos años allí donde se corta el existente, cita varias localidades en donde a pesar de los muchos años trascurridos, no se han reproducido las especies maderables de más valia que antes las poblaban.

\section{O.}

1090. Cartilla rústica, lecciones pastoriles y juicios de Agricultura para hacer docto al Labrador.-Dedicada á la Excma. Señora Doña María Teresa Giron y Pacheco, etc., Condesa de Miranda, etc.

Obras de D, Diego de Torres,Villarroel.-Tomo. VI, pág..151.

Ocúpase brevemente de las operaciones de siembra, plantacion, poda y otras de cultivo, respecto de jvarias especies forestales, como sauces, olmos, etc., en la indicacion de las Obras del Campo por los meses del año. 
1091. Clave sencilla para la determinacion de las confferas expontáneas en los montes de España.-Por D. Máximo Laguna.

Revista forestal, económica y agricola.-Tomo VII. pág. 530.

Está dividida en dos grupos, uno para los géneros y otro para las especies. Basándose la clasificacion en los caractéres de los frutos, hojas, corteza y otros apreciables á simple vista ofrece una gran sencillez para la determinacion, siendo además el primer cuadro completo de las coníferas expontáneas españolas presentado hasta el dia, exento de los errores y confusion que se notan en las obras taxonómicas y descriptivas que de estas especies forestales se ocupan.

1092. Consumo de Combustible vegetal y Madera en Madrid.Por D. Pablo Gonzalez de la Peña.

Revista forestal, económica y agricola.-Tomo VII, pág. 79.

Comprende los datos estadísticos de consumo, y valor, segun las distintas especies de combustible y madera durante al decenio de 1858 á 1867. Examina despues la superficie de monte que se necesita para tener asegurada la produccion leĩosa que exige el vecindario de Madrid, y entra en curiosas comparaciones respecto al consumo de carbon mineral y al de leñas de varias especies que se gastan así en el hogar doméstico como en las fábricas de distintas clases.

1093. Costumbres Salmantinas.-El merodeador de los montes. Por D. Antonio García Maceira.

El Porvenir. - Revista salmantina.-14 de Abril de 1872.

Cuadrode costumbres que puntualiza los daños que causan á los montes los paleros, banasteros y otros matuteros forestales, en algunas comarcas de la provincia de Salamanca. Para contener estos daiios', quisiera el articulista que se aumentasen lis penas que la legislacion vigente señala en lo que hace referıncia á los in ontes públicos.

\section{Cuatro palabras sobre Montes.-Por D. Francisco Javier} Hoceja.

La Asociacion agricola.-Periódico de Valladolid.-Tomo 1.', números 4 y 9 del 16 de $\mathbf{A}$ ayo, y 1. ${ }^{\circ}$ de Agrosto de 1869: y tomo 2. números 1 y 9 del 1. de Abril, y 1." de Agosto de 1870.

Son cuatro artículos de los cuales el primero está dedicado á recordar la importancia de los inontes y las causas fue contribuyeron á su engrandecimiento antes y á su decadencia despues. Recuerda asímismo, en el segundo artículo, la influencia que lo; bos ques ejercen en las lluvias y clima de un país, elennentos esenciales de la agricultura, de cuyo ramo, lejos de ser enemigos son coastantes protectorss. El artículo tercero determına el modo cómo los montes iulluyen en la distribucion de las azuas s ibterráneas y superticiales aumentando las pri neras, y en sauzando las segunlas; y por último en el artículo cuarto, describe la accion de las masıs de arbolado en los vientos, y en la sujecion de los terrenos sueltos, ofreciendo a esto pro- 
pósito como notable ejemplo, lo que en el dia sucede con las arenas movedizas que invaden gran parte de los partidos de Olmedo y Medina de aquella provincia. Termina exponiendo el modo cómolos inontes influyen en la temperatura y salub.idad del país mạejorándola eficazmente.

\section{D.}

1095. Daños Y penjuicios. -Por D. Antonio García Maceira. Revista forestal, económica y agricola.-Tomo VII, pág. 673.

Fistudia el autor el concepto comun y jurídico le aquellas palabras, exponiendo algunos ejemplos para esclarecer los casos en que los hechos deban considerarse como correspondientes á una ú otra clase de los dos examinados. Hace tambien la debida aplicacion á la parte penai de lıз Ordenanzas de montes.

\section{4.}

1096. Encursion forestal poir Cataluña.-Pasta de madera de papel -Los alcornocales.-Industria taponera.-Por D. J. S. de Baranda.

Revista forestal, económica y agricola.-Tomo VII, págs. 207 y 241 .

Son noticias recogidas en 1870 en la provincia de Gerona. Contiene abundantes y muy útiles datos sobre los diversos puntos que indica el epígrafe del artículo, sobre todo, acerca de la distribucion, estado, aprovechamiento y bereficio de los alcornocales y del corcho, datos que son de gran interés para el que desee conocer debidamente este ramo de la produccion é industria forestal.

1097. Estadística rorestal del Reino de Italia.-Por D. Pablo Gonzalez de la Peña.

Revista forestal, económica y agricola.-Tomo VII, pág. 21.

lixpone la organizacion del servicio forestal detallando el número, clàse y haberes del personal facultativo y de guardería, á cuyo cargo está la direccion y administracion de los montes públicos del reino. Despues de algunas - noticias orográficas, estudia la distribucion superticial de las especies arbóreas dominantes y dominadas que constituyen los montes de los Alpes, Apeninos, Sicilia'y Cerdeña, haciendo comparaciones bajo el punto de vista de la propiedad, poblacion, especies, método de beneficio y producto por hectárea. Apunta los caractéres más culminantes del clima, estudia el consumo y las necesidades de la poblavion respecto á los productos de los montes, y discute los resultados esenciales de todos los datos estadísticos, deduciendo la conveniencia de que se conserven y mejoren las masas forestales̃ de las montañas, cuya existencia proteje á las comarnas agricolas que radican en los valles, 


\section{G.}

1098. «Garganta» DEL EsprNar (L:).-Noticias relativas al pinar de este nombre, recogidas durante los años 1861-1862.-Por D. José Jordana.

Revista forestal, económica y agricola.-Tomo VI, págiuas 257, 305,353 y 404.

Las noticias, desarrolladas en la fnrma propia de un trabajo de reconocimiento, versan sobre los puntos siguientes: posicion geográfica; confines y área; posicion orográfi za y topográfica; hidrografía; clima; terreno; vegetacion; aprovechamiento; servidumbres; daños; carbones; pastos; plantas menudas; caza; pesca; tierras y canteras; siembras y plantaciones; inercados y trasportes; comunicaciones y personal. Hay datos sobre las existencias leñosas y sobre los productos en especie y dinero obtenidos desde 1790 á 1861 .

1099. Gas de madera para el alumbrado.-Por J. S. de B. Revista forestal, económica y agricola.-Tomo VII, pág. 363.

Traduccion hecha por D. José Sainz de Baranda, del artículo de monsieur B. de la Grye, publicado por aquel entonces en la Reoue des eaux et forets.

Da cuenta bastante detallada del procedimiento que debe seguirse para obtener el gas, añadiendo varios datos de costo, volúmen de leñas, gas obtenido y otros, que comparados con los relativus á la producciou del gas por medio de la hulla, demuestran que Ja elaboracion del primero es más económica que la del segundo.

\section{$\mathbf{I}$.}

1100. Industria forestal.-Produccion, extraccion y fabricacion de la brea.-Por D. Ramon de Xérica.

Revista forestal, económica y agricola.-Tomo VII, pág. 110.

Describe minuciosamente, cou arreglo á los últimos conocimientos, los productos de la destilacion de la madera. Este articulo está sacado de los materiales que el autor ha reunido para hacer una segunda edicion de su obrita: La teoría y la práctica de la resinacion que publicó en 1869 y de la cual ya nos heinos ocupado en este libro.

1101. Industria y COMERCio.-Maderas, sus cualidades, aplicaciones y precios, por D. F. J. P.

La América, crónica hispano-americana.-28 de Octubre de 1874.

Indica la procedencia, caractéres físicos, aplicacion industrial, formas del consumo, precio y otras noticias relativas á las maderas de varias especies de pino, roble, olmo, fresno, cedro, caoba, nogal y alguna otra. 
1102. Influencia de LAS MAREAS EN LA Vegetacton.-Por don Luis Alvarez Alvistur.

La Epoca.-Periódico político.-12 de Mayo de 1874.

Da cuenta de los experimentos hechos por un hacendado de Lorca, de los que parece deducirse, que haciendo la poda durante el reflujo, los árboles no enferman de caries así como no son atacadas por los insectos las maderas cortadas en dicho período.

1103. INFLUENCIA DE LOS MONTES SOBRE EL CLIMA, LAS FUENTES $\mathbf{Y}$ aguas Corrientes de un País. - Por el Doctor Negro. (D. Juan.)

La Epoca._Periódico político de Madrid.-3 de Julio de 1874.

Tiene por objeto este artículo, recomendar la conservacion y buena explotacion de los inontes de España por la influencia que ejercen en el clima, hidrología y riqueza pública.

Lil razonaıniento se apoya sobre los estudios hechos por Mr. Becquerel, y expuestos por él mismo á la Academia de ciencias de París en 1865, de los cuales se deduce que los desmontes disminuyen las aguas corrientes, así como las aumentan y regularizan los busques, influyendo estos ademas muy provechosamente sobre otros elementos del clima y de la produccion.

1104. INFLUeNCIA DEL CULTIVO SOBRE EL CLIMA DE UN LUGAR.

La Äbeja montañesa, periódico de Santander.-17 de Julio de 1867.

Está tomado de La Voz del Progreso de Tarragona. Razona bajo la base de atribuir grande y favorable influencia en el clima, á las localidades culแvadas.

1105. Infracciones en MoNTES públicos.-Dictámen del fiscal de la Audiencia de Valencia, D. Ricardo Diaz de Rueda, en causa promovida por hacer en monte público una carga de rámaje de pino, valuadia en tres reales.

Reoista general de Legislacion y Jurisprudencia.-Tomo XXXVI. -1870.-Pág. 126.

El fundamento de este dictámen está en hacer constar que en el tít. $6 .^{\circ}$ de las Ordenanzas de montes no se castigan más que hurtos y daños de arbolindo, y que por lo tanto, esos hurtos y daños en inontes públicos no son delilos de la misma clase comprendidos en el código penal, sino contravenciones que deben corregirse gubernativamente.

\section{I.}

1106. Legislacion de MONTES. El Diario de Manila.-4, 9 y 11 de Enero de 1874.

Se ocupa del Reglamento' de 8 de Febréro del año anterior, cuýo plan- 
leamiento acababa de ordenarse en, Filipinas, por el Gabierno superior civil. Encuentra muy acertadas las disposiciones generales que comprende y reconoce la influencia física de los montes, haciendo derivar de ahí la determinacioul de las masas arbóreas que conviene beneficiar y conservar en poder del Estado. Combate por su vaguedad y por el entorpecimiento que puede causar á la creacion de uuevos cultivos agrarios, la limitacion de los terz̧enos de aprovechamiento comun que el Reglamento manda señalar y designa con el nombre de leguas comunales. Examinada en conjunto y en sus detalles la disposicion objeto de los articulos del Diario, deduce que otorga al, interés privado, en clase de aprovechamientos forestales, más libertad de accion, de la que antes gozaba.

1107. LOS RECIENTES DECRETOS SOBRB SERviCIO FORESTAL...

La Abeja montañesa, periódico de Santander.-18 de Junio de 1868.

Se ocupa de los decretos de 10 de Junio de 1868, por los que se reorganizó el personal subalterno del ramo de montes, y se creó una comision encargada de formar el maja forestal de España, y de estudiar un proyecto general de repoblacion. El articulista encuentra muy convenientes estas medidas y se felicita de que, atendiendo el Gobierno á los verdaderos intereses del pais, muestre predileccion por la conservacion de los montes, dando preferencia al sistema aleman ó sajon, opuesto á la desamortizacion de dicha riqueza.

\section{IM.}

1108. Memoria descriptiva É hustókica de las Islas Marianas y otras que las rodean en relacion con ellas y de su organizacion actual, con estudio analítico de todos sus elementos físicos, morales y pulíticos, y propuesta de su reforma en todos los ramos, para elevarlos al grado de prosperidad que le corresponde, escrita por el teniente coronel D. Felipe de la Córte y Ruano Calderon, del Cuerpo de Ingenieros del Ejéreito, Gobernador de dichas Islas, como resultado de la comision que se le confirió por el Superior Gobierno de Filipinas, en decreto de 8 de Junio de 1868, y aprobada por Real orden de 26 de Noviembre del mismo. - Islas Marianas._-1865.

Boletin oficial del Ministerio de Ultramar.-Números del 27 de Marzo, 12 y 27 de Abril, 12 y 27 de Mayo, 12 y 27 de Junio, 12 de Julio, 12 y 27 de Agosto, 12 y 27 de Setiembre, 12 y 27 de Octubre y 12 de Noviembre de 1874.

Describe las maderas más comunes que producen las islas, apuntando sus cualidades características y las aplicaciones que reciben. Indica asimisıno la for na y caractéres principales de los árboles de que se obtienen, señalando sus nombres vulgares, condiciones de regetacion, propiedades de los frutos, cortezas, etc., con otras noticias de verdadero interés forestal, 
1109. Montes. - ¿Cuál es la penalidad vigente en el dia para castigar las infracciones, daños y otros delitos que se cometen en materia de montes?-Por D. Francisco Salvá.

Revista general de Legislacion y Jurisprudencia. - Tomo XXXVI.-1870.-Pág. 167.

En este trabajo, que es el más extenso y luminoso de los que sobre la materia se han escrito, analiza el autor todas las disposiciones penales del ramo, lasórdenes aclaratorias dictadas en distintas épocas, los dictámenes y opinio nes del Consejo de Estado, Tribunales y autoridades administrativas, concluyendo de todo, eitre otros extreınos, que “los daños é infracciones que hayan sido el inedio de perpetrar delitos (excluyendo los de daño mayor de 1.000 escudos), se considera que forman con estos un hecho complejo y se castigan conjuntamente y con la pena que a dichos delitos corresponde por los Tribunales ordinarios y con arreglo á las penas que establece el Código," correspondiendo á las autoridades administrativas, ó sea á los Gobernadores ó Alcaldes, segun el importe de la multa, las correcciones de los demás hechos punibles por las Ordenanzas, ley y reglamento de montes vigentes.

De este artículo se formó un folleto, del cual sólo se tiraron unos 50 ejemplares, estampados en la imprenta de la Revista.

1110. Montes del Valle de Andorra (Los).-Por D. José Jordana.

Revista forestal, económica y agricola. -Tomo VII, pág. 64.

Breve artículo que da una idea del estado, distribucion y aprovechamien. to de los montes andorranos y de las especies arbóreas que los pueblan.

1111. Montes.-Informe de la Audiencia de Cáceres.

Revista general de Legislacion y Jurisprudencia. - Tomo XXXVIII.-1871.-Pág". 186.

Este informe fué emitido para ilustrar el expediente instruido por el Gobierno, acerca de la penalidad aplicable á los „delitos cometidos en los wontes.

Hecha la histcria crítica de todas las disposiciones penales del ramo y las doctrinas sustentadas por el Consejo de Estado, asienta que la sustraccion de árboles, por estar penada en las Ordenanzas, no debe considerarse como delito de hurto, traíándose de montes públicos, para los efectos de entender en el asunto los tribunales de justicia, correspondiendo á estos el sustanciar las causas correspondientes, sólo cuando el importe de los daños causados llegue ó exceda de 1.000 escudos.

1112. Montes (Los) Considerados Como FUente de RIQUeZa.Cartas de un labriego.

Revista del Instituto, etc.-Tomo XXIII.-Pág. 125.

No tienen más firma que la de un labriego, pero se descubre desde luego en ella la mano inteligente de alguna persona versada en la ciencia dasonómica. 
En la primera carta, á pretexto de lamentar el mal estado de los montes de Horta, en la provincia de Tarragona, expone las consecuencias de los malos tratamientos dasotómicos.

\section{N.}

1113. NI INDIVIDUALISMO PURO, NI COLEGTIVISMO EXCLUSIVO.

La Igualdad.-Periódico político de Madrid.-1..$^{\circ}$ de Junio de 1873.

Es un estudio de las reformas más urgentes y capitales que, en opinion del publicista, deben llevarse á cabo en la manera de ser de la propiedad territorial, de las que se desprende, que las dehesas comunales deben ser aumentadas reglamentando su aprovechamiento y administracion, y que debe hacerse lo mismo con la propiedad del Estato nacional, conservando este el pleno dominio de los bosques ó plantaciones, cuya desaparicion pudiera alterar de una manera notable las condiciones climatológicas ó higiénicas de una comarca.

1114. Noticias físico-Naturales DE LA SECCION N. O. DE LA PROvincia de Guadalajara. - Por D. C. Castel.

Revista forestal, económica y agricola.-Tomo VII, págs. 216 y 254 .

Despues de bosquejar el aspecto orográfico, hidrológico y geológico de la seccion sometıda á estudio, da á conocer la vegetacion leñosa expontánea de la misma, la distribucion de los montes, el estado de los rodales y las espe. cies arbóreas que los forman, añadiendo algunas indicaciones acerca de la produccion agrícola de aquella parte de la provincia.

\section{P.}

1115. Pabellon (El) del Ministerio de Agricultura austriaco EN La Exposicion de Vifna.-Por D. Francisco de P. Arrillaga.

Revista forestal, económica y agricola.-Tomo VII, páginas 11 y 71 .

- Este trabajo contiene útiles y curiosos datos acerca de los productos de las minas, de los montes y de la agricultura que Austria presentó en la exposicion. Las noticias referentes á las estaciones de investigacion agricola ofrecen el cuadro de una série de experimentaciones de química y fisiologia aplicadas, dignas de estudio por el marcado adelanto que revelan en los análisis de interés agronómico. Se dán á conocer las estaciones forestales bajo el punto de vista de la investigacion climatológica, y en cuanto á la produccion dasonómica, se presentan dalos estadísticos de los montes, así territoriales como de vegetacion y localidad, muy provechosos para el conocimiento cientifico de la riqueza forestal del imperio, fjándose metódicamente en al- 
gunos casos la renta en especie segun las diversas formas con que los productos se presentan al mercado.

1116. Primer congréso internacional de Agricultores y FoRestales en Viena (EL). - Por D. F. de P. Arrillaga.

Revista forestal, económica y agrícola.-Tomo VII, páginas 97, 145 y 195.

Hace la historia del congreso que con motivo de la exposicion universal de Viena, celebraron en dicha ciudad en Setiembre de aquel año (1863) los forestales y agricultores de las naciones más importantes de Europa y América. Reseña la discusion de los diversos temas que fueron objeto de controversia y reproduce las conclusiones $\delta$ acuerdos que en la reunion se adoptaran, recordando despues la excursion llevada á cabo por casi todos los miembros del congreso á los montes de Viena. Los punlos de mayor interés que constituyeron las principales resoluciones, se refieren á la creacion de estaciones forestales sujetas á un sistema internacional de observacion, y al concierto de todas las naciones para evitar la devastacion de sus respectivos montes, resolviéndose que para el mejor éxito de estos propósitos se celebrasen desde 1874 en adelante en períodos fijos, congresós forestales internacionales, de los que se reuniria el primero en Berna el año entrante.

1117. Proyecto para establecer una casa modelo de enseñanza teórica y práctica que promueva el desarrollo de la Agricultura en la provincia de Santander.-Por D. G. G. de L.

La Abeja montañesa, periódico de Santander.-18, 19, 21 y 22 de Mayo de 1866.

El autor de este trabajo que parece se publicó además en forma de opúsculo, debe ser D. Gervasio G. de Linares.

Para la conservacion de los montes cree que debe fijarse una junta á la que pertenezca un ingeniero del ramo, cuidando los pueblos de administrar aquellas fincas con más conocimiento y celo. Aconseja que se establezca en la escuela una cátedra de arboricultura, que se creen viveros y que se repueblen los montes altos con robles, hayas $y$ encinas, propagando el manzano en los valles, en los terrenos llanos el castaño y avellano, en los suelos arenosos de poco fondo el nogal y en los húmedos y arcillosos el álamo, sauce y aliso, reservando el pino para los suelos areniscos profundos. Insistiendo en la conveniencia de fomentar la riqueza forestal, recomienda la creacion de la escuela, en cuanto contribuiria á la consecucion de este resultado, propagando buenas doctrinas selvícolas.

\section{Re.}

1118. Ramo de montes (Ec) en la exposicion nacional de Madrid de 1873.-Por W.

Revista forestal, económica y agricola.-Tomo VII, pág. 116.

Enuncia y juzga los productos y trabajos que concurrieron al certámen, 
entre los que figuraron la obra del Sr. Ruiz Amado, Estudios forestales, una memoria inédita sobre la destruccion del barrenillo del olmo, escrita por el señor Aguado, la coleccion de maderas del Instituto industrial de Madrid, otra del director de arbolados del Canal Imperial de Aragon, los productos resinosos procedentes del pinar de las Navas del Marqués, propiedad de la Excma. señora Duquesa de Medinaceli, los de igual clase de La Resinera se. goviana, espartos del levante de España, regaliz, cascas y otros ménos importantes.

\section{Riqueza forestal (La). Por D. Enrique del Campo.}

El Imparcial. - Periódico político de Madrid. - 22 de Junio de 1874.

Ocúpase con bastante extension de los productos de los montes públicos españoles durante el decenio de $1861-70$ y encarece la conveniencia de aumentar el personal facultativo y de guardería, de reprimir los daños, de regularizar la produccion y de extender el área forestal hasta un quinto de la total del territorio. Respecto á la desamortizacion desea que se lleve á cabo bajo la base de excluir de la veuta los terrenos impropios para el cultivo agricola permanente. Recuerda los beneficios que los montes reportan respecto al clima, agricultura, y sondiciones económicas del mercado en lo relativo á los productos que se obtienen ó se derivan de los montes.

1120. SEÑOR DIRECTOR DE LA «REvista FORESTAL.»-Estrasburgo 19 de Marzo de 1874.-Muy señor mio y querido amigo y compañęo: Hace poco más de dos años... etc.-Por B.

Revista forestal, económica y agricola.-Tomo VII, pág. 321.

Bajo la forma epistolar el autor expone con mucha claridad los trabajos de ordenacion que en el monte de Haguenau, incorporado á Alemania con motivo de la anexion de la Alsacia y la Lorena, ha llevado á cabo la administracion forestal prusiana. La enunciacion es tan instructiva que puede muy bien disculpar la indiscrecion de decir que la carta se debe al Ingeniero Jefe de montes, profesor que ha sido de la Escuela especial del ramo, Don José Sainz de Baranda.

1121. Sumario de la natural historia de las Indias, por Don Gonzalo Fernandez de Oviedo, alias de Valdés.

Biblioteca de aulores españoles.-Tomo XXII, desde la página 473 á la 515.

Se ocupa en varios capítulos, del mamey, guanábano, guayaba, coco, palmas, pinos, encinas, parras silvestres, higuero, membrillo, peral, palo santo ó guayacan, xagua y otros árboles de Tierra-firme, describiendo en unos las cualidades y caractéres de sus frutos y en otros las propiedades físicas que los hacen apreciables bajo el punto de vista industrial. En capítulo a parte, da cuenta de los varios árboles de extraordinarias dimensiones 
que vió en aquellos paises, y de ciertas particularidades que ofrece la madera de algunas especies.

El carácter histórico de la obra justifica hasta cierto punto el no aparecer entre las que registra el Diccionario de bibliografia agronómica del señor Anton Ramirez.

\section{$\mathbf{T}$.}

1122. Traviesas de Ferro-Carril.-Por J. G. H.

La Epoca.-Periódico político de Madrid.-2 de Agosto de 1873.

Estndia el consumo de traviesas para el establecimiento de las líneas nuevas y para la conservacion de las construidas, aconsejando, dada la carestía del pino, roble y otras especies, que se dedique á este uso el Eucaliptus globulus, por la rapidez de su crecimiento, á cuyo fin hace algunas indicaciones sobre los rendimientos que podrian obtenerse de las plantaciones en gran escala.

\section{U.}

1123. Un PASeO POR el Buen Retiro.-Por D. Sebastian Vidal. El Imparcial.-Periódico político.-15 de Junio de 1874.

Despues de escudrin̄ar los orígenes filológicos de la palabra parque, nombre con que se designa actualmente aquella finca de Madrid, enumera las principales especies arbóreas y arbustivas que la adornan, indicando los caractéres que las hacen más apreciables.

1124. Un RECUERDo.-Un aprovechamiento de los bosques.-Por D. Luis Justo y Villanueva.

Revista del Instituto, etc.-Tomo XXII.-1873.-Pág. 313 y tomo XXIII.-1874.-Páginas 9 y 67.

Pasa revista á las especies arbóreas que son objeto de carboneo en Éspaña, indicando el proçedimiento que para ello se sigue y comparándolo con las prácticas que están en uso en Inglaterray Francia; indica las reformas que podrian introducirse para aumentar el producto en carbon; describe un aparato económico para obtener el ácido piroleñoso y se ocupa de la resinacion de los pinos.

1125. Una COLECCION DE Coníferas.-Por D. Máximo Laguna. Revista forestal, económica y agricola. -Tomo VII, pág. 3.

En este curioso articulo se da cuenta del herbario de coniferas puesto á la venta en casa de Alberto Moser de Tübingen, formado por Guillermo Hochstetter, director del Jardin Botánico de la Universidad de aquella poblacion. Da noticia de las formas de los ejemplares y hace comparaciones entre las especies de pinos que en dicha coleccion figuran, y las que vegetan en los montes españoles, aduciendo datos para tijar definitivamente la clasificacion de las indicadas especies. 


\section{V.}

1126. Valle de Batuecas (EL).-Por D. Antonio Garcia Maceira. El Porvenir.-Revista salmantina.-24 de Diciembre de 1871 y 2 de Enero de 1872 .

Contiene la indicacion de la vegetacion forestal que se encuentra en el valle y alguna noticia acerca del aprovechamiento industrial del corcho, por los monges de la extinguida comunidad cuyo convènto se conserva todavía en aquel sitio. 



\section{OBSERVACION.}

Concluye este libro con la indicacion de las publicaciones que se han dado á luz hasta el $10^{\circ}$ de Diciembre de 1874. 



\section{INDICE GENERAL}

DE

\section{AUTORES Y TRADUCTORES.}

(Los guarismos indican el nimero de órden de las publicaciones

ó trabajos de que se dá cuenta en el texto.)

NOMBRES.

Nưmeros

orden.

\section{A.}

Abad, V. Mas y, Celestino.

Abella, Fermin............................. 124

Abellan, $V$. Cubillos, Francisco.

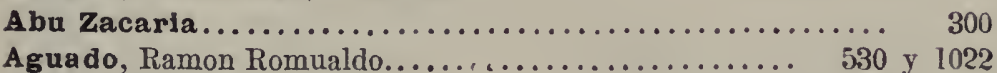

Aguilar, V. Zamora y, Juan.

Aguilera y Aguilera, Antonio de.................. 628

Aguirre, José de............................ 978 y 989

Aguirre Miramon, Severo,...................... 815

Alburquerque, Alfonso......................... 1028

Alburquerque, Duque de..................... 1066

Alcántara, $V$. Lafuente, Miguel.

Alcubilla, V. Martinez, Marcelo.

Alfaro, Agustin............................ 162

Almar, $\nabla$. Vergés $\mathbf{y}$, José.

Almeyda, Antonio......................... 553

Alonso de Herrera, Gabriel.................... 10 y 136

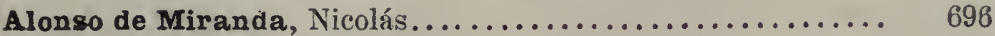

Alonso Martinez, Manuel..... ................... 425

Alonso, $V$. Gonzalez, Diego.

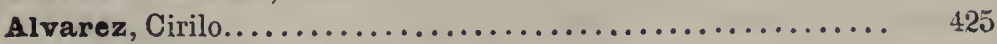

Alvarez de Quíndós y Baeua, Juan Antonio............. 151

Alvarez de Sotomayor y Rublo, Juan María............. 179 
Alvarez Guerra, Juan

Alvarez Sotomayor, Agustin.................... 1025

Alvistur, V. Alvarez, Luis.

Alo, Lorenzo de.

Amado, V. Ruiz, Hilarion.

Amat y Maestre, Miguel.............. 657, 679, 864 y 968

Amaya, Francisco............................ 507

Amo, Mariano del............................ 803

Amor y Mayor, Fernando.................... 208 y 443

Amprana, $V$. Valls de, Aniceto.

Arazarbeo, $V$. Pedacio Dloscorides.

Andino, V. Diez de, Julian.

Andino, V. Sainz de, Pedro.

Andrés, $V$. Fuente, Manuel de la.

Ardricu, Juan..............................

Angulo, Isidoro de............................. 474

Anso, $V$. Monterde Lopez de, Miguel.

Antoine................................... 5l

Anton Villacampa, Andrés........ 289, 483, 593, 678, 876 y 967

Anton y Sayas, Gerónimo........................ 6

Apelt..................................... $\quad 780$

Arago, Buenaventura.......................... 774

Araus, Pedro........................... $\quad 997$ у 597

Arcas, V. Ramirez, Antonio.

Arce y Cortaz 3 , Saturnino..................... 81 y 194

Arellano, Juan Manuel.......................

Arenas, $V$. Nunez, Bernardino.

Argote de Molina, Gonzalo...................... 302

Artas y Costa, Antonio Sandalio de... 10, 81, 293, 978, 984,

Aribau.................................... $\quad 214$

Arizmendi, Antonio de........................ 417

Armero.................................... 511

Armesto, Rodrigo........................... $3 \mathbf{3}$

Arrillaga, Francisco de Paula... 116, 483, 731, 748, 756, 888,

................................ $\$ 95,1115$ y 1.16

Asso, Ignacio de......................... 26 у 250

Asuero, Cenon............................... 1015

Atiouza y Sirvent, Meliton...................... 326

Aurioles, Pedro N............................ 425

A vendaño, $V$. Nuñez de, Pero.

Ayala, V. Lopez de, Pero.

Aymerich, Mateo............................... 997

Azara, Félix de............................. $\quad \$ 49$ 
zara, Ma rqués de Nibbiano, Agustin de

\section{E.}

Baena, V. Alvarez de Qulndós §, Juan Antonio.

B ieza, V. Sanz y, Florencio.

Bago, V. Lopez, Eduardo.

Bahi, Juan Francisco.............................. 860

Ballestero, Mariano............................ 694

Banquer1, Joseph Antonio..................... 300

Baranda, $\nabla$. sainz de, José.

Barba y Roca, Manuel........................... 1035

Barca, V. Calderon de la, Joseph María.

Barceló y Corntés, Francisco...................... 637

Baron de Balroja, V. Canals, Juan Pablo.

Barron, Felipe.................. 15, 16, 17, 128 у 357

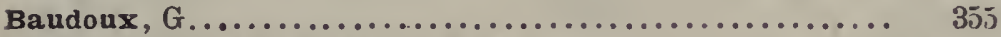

Beaumont de Miras Peralta, Ricardo............ 859 y 1015

Beizet, Manuel............................... 758

Bejarano, Félix José............................ 1025

Belda, Augusto.................................... 732

Belezar, V. Serrano, Miguel.

Benavide , Antonio .......................... 456

Beadito, Agustin de.......................... 10,8

Bengoechea, Luis............................. 921

Benifayo, Bron de........................... 459

Bevito y Hermosilla, Dionisio...................... 394

Bergnes de las Casas, Antonio ................... 2

Berneza, V. Azedo de la, Gabriel.

Berriz, V. Vil a-Real de, Pedró Bernardo.

Biceu, Junn........................... 497 у $5 ? 7$

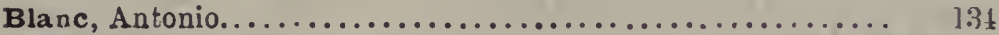

Blanco Fernandez, Antonio................ 43, 192 y 817

Blazquez Prieto............................ 609

Boedo y Cardois, Manuel....................... 186

Bolaño, V. Castro.

Bona, Félix.................................. 819

Bona, Francisco Javieér de.................... 29 y 819

Busch, Alberto..................................

Busch y Juliá, Miguel......... 16?, 307, 344, 34., 437, 8€8 y 911

Bosch y Labrux, P............................. 1

Boutelou, Claudio...................... 10,533 y 590

Boutelou, Eśtéban........ 26, 215, 275, 590; 603, 653, 720 y 1063 
Boutelou, Pablo.

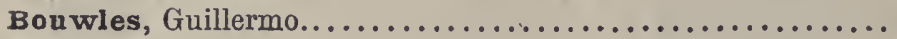

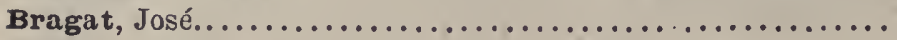

Bravo, Felipe..................................... 1049

Bravo, Luis.................................. 280

Bravo, Pedro.............................. 54 y 437

Breñosa, Rafael.................... 18, 852, 856 y 962

Brichfeus, Francise de......................... 936

Brusi, Antonio.................................. $\quad{ }_{796}$

Buceta, Manuel................................. 1049

Buch, V. Guitart y, Miguel.

Bujanda, Gaspar de............................. $\quad 115$

Bulliard .................................... 527

Burgoa, V. San Martin y, Antonio de.

Burgos, Augusto de............... 8, 53, 76, 162, 596 y 690

Burkhardt, E................................

\section{a.}

Caballero, Fermin ............................. 469

Cabrera, Ramon de................................ 341

Cadet de Vaux................................. $\quad 640$

Galderon de la Barca, Joseph María................. 185

Calderon, V. Corte y Ruano, Felipe de la.

Calero y Portocarrero, M........................... 496

Calvo Pinto y Velarde, Agustin..................... 504

Calvo y Julian, Vicente...................... 170 y 737

Campo, Enrique del.............................. 1119

Campos, Eduardo G............................. $\quad 799$

Camps, Pelayo de.............................. 736

Campuzano, Antonio ............................. 506

Canals, Baron de Balroja, Juan Pablo............... 767

Canals, V. Medina y, Antonio de.

Candalija, Antonio.............................. 240

Candolle, Alfonso de............................ $\quad 730$

Cánovas del Gastlllo, Antonio...................... $\quad 425$

Gánovas del Castillo, Emilio.......................... 163

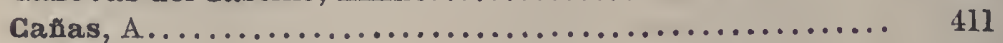

Cañas, Juan J................................... 694

Cañaveras, R. M............................... 40

Caral, Delmiro del................................ 1

Carballo y Sampayo, Diego......................... 185

Cardenal, J.................................. 207 
Cárdenas, Franciseo de.

Cardois, V. Boedo y, Manuel:

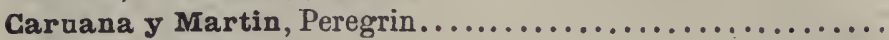

Casanova, Manuel E. de........................ $\quad 930$

Casanova, Ramon de.......................... 78

Casas, $V$. Bergnes de las, Antonio.

Casas y Mendoza, Nicolás...................... 162 y 664

Castel y Clemente, Cárlos................. 371, 761 y 1114

Castellanos de Losada, Basilio Sebastian............... • 149

Castilla y Quirós, Rafael de...................... 201

Castillo, V. Cánovas del, Antonio.

Castillo, V. Cánovas del, Emilio.

Castrillon, Hernando.......................... 254

Castro Bolaño.............................. 827

Cavanilles, Antonio José ó Joseph............. 26, 388 y 695

Caveda, Francisco............................. 1025

Caveda, José ............................ 425 y 1025

Cayo Plinio Segundo......................... 252

Cerbantes, Manuel Antonio de..................... 442

Cerbantes, Pedro de........................... 442

Cerdá, $V$. Tortosa y, Vicente.

Ceron, Salvador............................. 665

Cervantes, P................................. 395

Cervantes, Vicente............................ 26

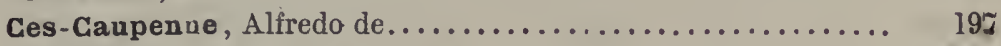

Cienfuegos, Bernardo de........................ 996

Cisneros, Enrique de.......................... $\quad 741$

Clemente, $\nabla$. Castel y, Cárlos.

Clemente, $\nabla$. Rojas, Simon de.

Coello, Francisco............................. $\quad 470$

Colibri..................................... 952

Colmeiro, Manuel............................ 343

Colmeiro, Miguel................ 215, 283, 305, 384 y 846

Colosia, Agustin de........................ $\quad 586$

Columela, $\nabla$. Lucio Junio Moderato.

Collantes, Agustin Estéban..................... 162

Combis, V. Barceló y, Francisco.

Combis, V. Quintana $\mathbf{y}$, Alberto de.

Comendador, $\nabla$. Sanchez, Antonio.

Comision de Estadistica general del reino........... 30 y 31

Comision del Real Consejo de Agricultura, Industria y Comercio................................... ${ }_{752}$

Comision régia de España......................... 94

Comyn, Tomás de............................ 1053 
Conde, Pedro Toribio....................... 978 yे

Cook, N................................ 214 y 619

Corbera, Marqués de.......................... $\quad 513$

Corcuera, Juan Antonio.......................... 141

Cornide, Joseph................................. 191

Cortazar, V. Arce y, Saturnino.

Gorte y Ruano Calderon, Felipe de la................ 1108

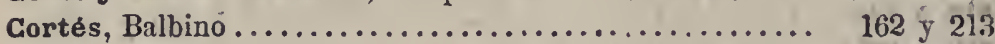

Cortés, José.......................... 25. у 256

Cortés, Tomás............................ ${ }_{1038}$

Cortés, V. Marazuela, G.

Cos-Gayon, Fernando..................... 163 y 425

Costa, Antonio Cipriano.................... 574 y 851

Costa, V. Arias y, Antonio Sandalio de.

Cotarelo, Juan............................... 308

Cousillas, Dionisio R............................ 551

Cubillos Abellan, Francisco.................. 87 y 102

Cuerpo de Ingenieros de montes.......... 97, 105, 132 y 133

\section{CII.}

Chavarri, Basilio de.......................... 209

Chaves, V. Lecanda, Augusto.

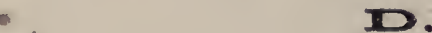

Daukenton, C........................................

Dlaz de Rueda, Ricardo......................... 1105

Diaz de Valdés, Pedro............................ 536

Di z Laviada, José........................... 1019

Dizz de Andin

Dioscorides Anazarbeo, V. Pedacio.

Direccion general de Agricultura, Industria $\dot{y}$ Comer-

cio........................... 167, 168, 213 y 331

Direccion general de Estadistica.................... 32

Direcclon general de Estadistica, Agricultira, Industriá

y Comercio.............................. 44 y 169

Duhamel du Monceau.................. 117, 404, 528 y 537

Dupuy...................................... ii

Ei.

Echegaray, José........................... 162 y 349

Egrafla, Pedro de................................. 
Eguia, V. Miranda $\mathbf{y}, \mathrm{M}$.

Elizondo, José............................. 10

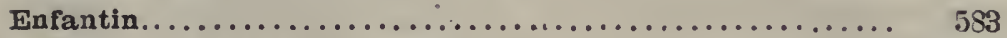

Escalante y Morevo, J. Jacobo................... 1069

Escalera, V..Tamariz de la, Fernando.

Escartin, $V$. Valier §, José.

Escosura, Luis de la....................... 763 y 890

Espejo, Zoilo.............................. $\quad 79$

Espinar, V. Martinez de, Alonso.

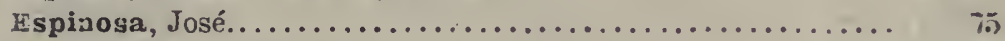

Espinоза, P. C............................. 212

Esteller y Forés, Felipe......................... 501

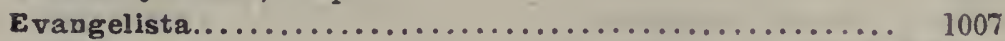

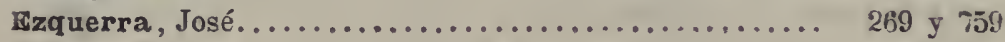

\section{E.}

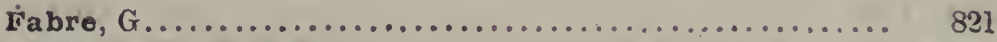

Fages de Romá, Narciso...................... 220

Fagund, V. Sant, Johan de.

Fano, V. Sanchez, Félix.

Feijóo y Montenegro, Benito Gerónimo..............

Feliu, V. Sisternes y, Manuel.

Fernandez de Landa, V. Romero, Joseph.

Fernandez de los Rios, Angel................. 8 y 260

Fernandez de Moratin, Nicolás.................. 155

Fernandez de Navarrete, Francisco................. 99

Fernandez de $\mathrm{N}$ avarrete, Martin............... 217 y 415

Fernandez Monjardin, Manuel..................... $4 ; 3$

Fermandez de Oviecio de Valdés, Gonzalo ........ 1045 y 1121

Fernandez, V. Blanco, Antonio.

Fernandez, $V$. Garcia, Domingo.

Fernandez y Perez, Juan Zoilo..................... $\quad 99$

Ferrản, Andrés de............................ 736

Fica, $V$. Rementeria y, Juan Mnriano de.
Fivaller de Ve'az, Joś́ Naría de ............. 109, 675 y 935

Flores, V. Garcia de Longoria y, Luis.

Fonolleras, Narciso................. 341, 419,729 у 790

Font y Guitart, Juan........................... $\quad 2$

Fontcuberta, Cárlos de........................ 648

Fontes, $V$. Musso y, José.

Forés, V. Esteller y, Felipe.

Foxa, Miguel de. 
Fragoso, Juan.

Franco, Vicente................................ 986

Frau, Ramon de............................... 694

Fuente Andrés, Manuel de la........................ 946

Fulgosio, Fernando........................... 584

\section{G.}

G. de Linares, Gervasio.................. 1079 y 1117

Galofre, José............................. 246 y 938

Galli...................................... 214

Garay, José María de......................... $\quad 870$

Garcia de Gregorio, Eugenio................ 230 y 1056

Garcia de Longoria y Flores, Luis.................. 985

Garcia, Donato............................... 984

Garcia Fernandez, Domingo...................... $\quad 26$

Garcia Gomez, Félix......................... 203

Garcia Lopez, Rafael......................... 1076

Garcia Maceira, Antonio.............. 12, 1093, 1095 y 1126

Garcia Martino, Francisco. 286, 287, 375, 483, 655, 656, 914, 961 y 1018

Garcia Sanz, José................ 303, 306, 311,313 y 315

Garza, $V$. Naranjo y, Felipe.

Gassó, Ramon Justino de...................... 808

Gastan, V. Pedraza, Pedro.

Gijon y Leon, Miguel......................... 809

Gil, José María.......................... 477 у 587

Gil, Manuel .................................. 406

Gil y Montaña, José.......................... 68

Gimenez y Lluesmas, Manuel.................... 501

Giol, $\nabla$. Mirambell y, Francisco.

Glastupun, Isaac.............................. 672

Gledisch .................................. 775

Golobardas, Juan Bautista...................... 118

Gomez de Salazar, Ignacio .............. 15, 17, 227 y 153

Gomez Ortega, Casimiro.......... 117, 2Ł3, 276, 4.04, 528 y 531

Gomez, V. Garcia, Félix.

Gonzalez Alonso, Diego........................ 383

Gonzalez, Ambrosio.......................... 694

Gonzalez de la Pex̃a, Pablo. 169, 483, 722, 723, 724, 831, 862,

Gonzalez, Francisco.......................... 278

Gonzalez, $V$. Gutierrez, Antonio.

Grael, Juan Enrique de........................ $\quad 174$ 
Graells, Mariano de la Paz..

130,321 y 645 Gregorio, V. Garcia de, Eugenio.

Guardiola, Juan Bautista.................... 332 y 822

Guerra, V. Alvarez, Juan.

Guinart, Juan............................. 1020

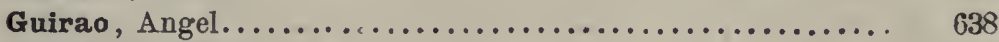

Guitart, $V$. Font y, Juan.

Guitart \$ Buch, Miguel.......................... 2

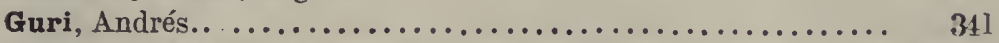

Gutierrez Gonzalez, Antonio.................... 522

Gutierrez, V. Perez, Manuel.

Gutierrez, V. Sainz, Pedro.

Gutierrez, V. Sainz y, Luis.

\section{E.}

Hermosilla, V. Benito y, Dionisio.

Hernandez, Antonio................ 15, 16, 17, 128 y 387

Herrera, V. Alonso de, Gabriel.

Herreros, Manuel María........................ $\quad$ i14

Herrgen, Cristiano.......................... ${ }_{26}$

Hévia, V. Tames, Francisco.

Heyer, Gustavo............................... 116

Hidalgo, Cárlos............................... 522

Hidalgo Tablada, José de.............. 9, 162, 312 y 529

Hoceja, Francisco Javier......................... 1094

Hojeda, Hernando de.......................... 1012

Huerta, Félix de................................ 1054

Huerta, Gerónimo de........................ 252

Huerta, V. Molina y Saurin, Vizconde de, Alejo.

Infante de España, V. Juan Manuel.

Iraben, $\nabla$. Urquijo de, Francisco.

Isidori Hispalensis, San...................... 488

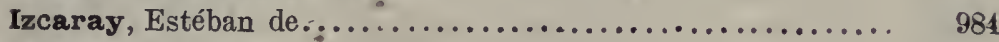

Izquierdo, Alejandro .......................... 18

\section{$\boldsymbol{J}$}

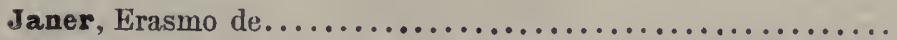


Jordana, Ramon.. $\quad 516,550,560,615,623,707,709,760,770$,

....... $828,861,865,866,904,931,934,945,1061,1072$ y 1073

Jousselin, P............................. 212

Jovellanos, Melchor Gaspar de............. 265, 386 y 924

Juliá, $V$. Bosch y, Miguel.

Juan Manuel, Infante de España.................. 1008

Julian, $V$. Calvo y, Vicente.

Junio Moderato Columela, $V$. Lúcio.

Junta de Agricultura de Madrid................... 608

Junta directiva de la Exposicion de 1857............. 354

Junta direcliva del Fomento de la Produccion nacional........ I I

Junta facultativa del Cuerpo de Ingenieros de montes.... 436

Junta general de Estadistica........... 33, 34, 62,63 y. 189

Justo y villanueva, Luis........................ 1124

\section{IE.}

Karr, Eugenio......................... 365 у. 739.

Keyser y Munoz, Antonio de................. 648 y 1070

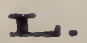

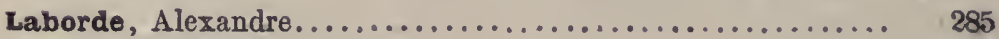

Labrús, $\nabla$. Bosch.y, P.

Lacroix $\boldsymbol{y}$ Vidal, Joaquin........................... 804

Lacy, V. Tirry y, Juan.

Lafuente Alcántara, Miguel................... 284

Lagasca, Mariano................ 10, 350, 670, 984 y. 1041

Laguna, Andrés............................. 402

Laguna y Villanueva, Máximo. $112,113,216,328,545,800$, $863,878,879,942,960,1091$ y 1125

Landa, V. Romero Fernandez de, Joseph.

Lasalde, Cárlos........................... 717

Lassala y Palomares, Vicente.................... 428

Lasso de la Vega, V. Perez, Jorge.

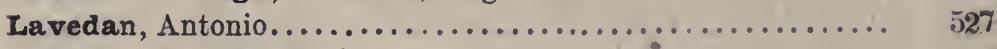

Laviada, V. Diaz, José.

Láza ro, V. Llorente, Ramon.

Lecanda Chaves, Augusto ..................... 1051

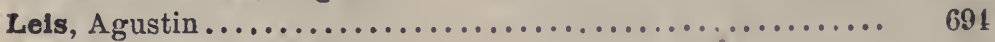

Leon, $V$. Gijon y, Miguel.

Lestiboudois, Them ........................ 564

Linares de Montefrio, Antonio.................... $\$ 90$

Linares, V. G. de, Gervasio. 


\section{INDICA OEXRAAL.}

Linares, V. Romero y, Antonio.

Lorgorla y Flores, V. Garcia de, Luis.

Loto, Jose

Lopez, Alejandro.

Lopez Bago, Eduardo.

Lopez de Ansó,. V. Monterde, Miguel.

Lopez de Ayala, Pero........................... $106 b^{\circ}$

Lopez de Sancho, Francisco.......................... 648

Lopez, Julian Antonio......................... 346

Lopez Seoane, Víctor. ...........................

Lopez Soler............................... 214

Lopez, V. Garcia, Rafael.

Lopez, V. Pistor.y, Pascual.

Lopez, V. Romero, Agustin.

Losada, $\nabla$. Castellanos de, Basilio Sebastian.

Lozano, Pedro..................................... 249

Lúcio Junio Moderato Columela................... 179

Luils, Alfredo de....................... 19, 366 y, 502

Luxán, Francisco de.......................... 4 \%

\section{I.}

Llanos, Blas.................................. 35

Llansó, Jaime........................... $98, \mathbf{Y} 135$

Llauradó, Andrés........................ 646 y. 873

Llorente, Felicísimo.............................. 908

Llorente Lázaro, Ramon........................ 579 ,

Lluesmas, $\nabla$. Gimenez y, Manuel.

\section{IM.}

Mac-Grohon.

278,509 y 510

Macoira, V. Garcia, Antonio.

Máchado y Nunez, Antonio............... 89, 95, y 712

Machuca, V. Vargas, Bernardo.

Madrid y Manrique de la Vega, Matías de la........ 352 y 1023 Maestre, V. Amat y, Miguel.

Máffe1, Eugenio............................. 832

Magrina, Antonio............................. 614 .

Malingre, Estanislao........... 557, 577, 578, 674, 719 y 867

Málo, Nicolás.............................. 210

Manrique de la Vega, V. Madrid y, Matías de la.

Marazuela Gortés, G......................... 122

Margall, V. Pi y, Francisco. 
Marin, Anselmo.

Mármol, Luis del.............................. 150

Marti, Andrés................................ 429

Marti, Francisco de Paula........................... 10

Martin; V. Caruana y, Peregrin.

Martinez Alcubilla, Marcelo...................... 124

Martinez de Espinar, Alonso...................... 46

Martinez, Juan de la Cruz..................... 211 y 363

Martinez Quintanilla, Pedro..................... 420

Martinez Robles, Francisco Antonio.............. 10 y 346

Martinez, V. Alonso, Manuel.

Martino, V. Garcia, Francisco.

Mas, Sinibaldo de............................ 1059

Mas y Abad, Celestino......................... 124

Mascaró, $\nabla$. Vidal y, Juan Miguel.

Mateo, Indalecio......................... 414 y 437

Mateos, José Joaquin........................... 425

Mateos, Juan............................... 401

Mauri y Puig, Ramon.......................... 523

Mayor, V. Amor y, Fernando.

Medina y Ganals, Antonio de..................... 264

Medrano, Diego.............................. 1025

Mellado, Francisco de P......................... 187

Mendez de Vigo, Ignacio........................ 241

Mendoza, $\nabla$. Casas y, Nicolás.

Mercader, Matíás.............................. 977

Merlo y Merlo, Lorenzo de....................... 487

Michaux, Andrés............................ 26 y '738

Mieg, Fernando.......................... 66 y 180

Miguel, Domingo de......................... $7_{772}$

Milanés, $\nabla$. sainz, Julian.

Minguez, $\nabla$. Perez, Luis.

Ministerio de Gomercio, Instruccion y Obras publicas.... $\quad 59$ Ministerio de Fomento................. 59, 60, 107, 108 y 368

Mirambell y Giol, Francisco..................... 757

Miramon, $\nabla$. Aguirre, Severo.

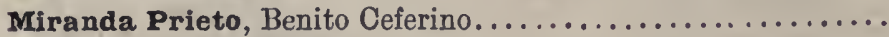

Miranda, $\nabla$. Alonso de, Nicolás.

Miranda, $\nabla$. Yanguas y, José.

Miranda y Eguia, M.

Miras Peralta, V. Beaumont de, Ricardo.

Miró, Pedro................................. 329

Moderato Columela, V. Lúcio Junio.

Molina, V. Argote de, Gonzalo. 
Molina y Saurin, Vizconde de Huerta, Alejo............

Monceaux, V. Duhainel.

Monjardin, $\nabla$. Fernandez, Manuel.

Montaña, $V$. Gil y, José.

Montefrio, $V$. Linares de, Antonio.

Monteggia, I

Montenegro, V. Feijóo y, Benito Gerónimo.

Montenegro, V. Pardo.

Monterde Lopez de Ansó, Miguel. .................. 995

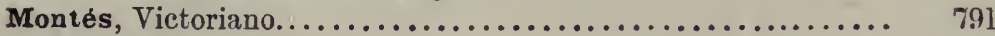

Montilla, Manuel............................. 418

Montoya, Fulgencio......................... 1084

Moratin, V. Fernandez de, Nicolás.

Moreno, $V$. Escalante $\mathbf{y}$, J. Jacobo.

Moreno, V. Pardo y, Eduardo.

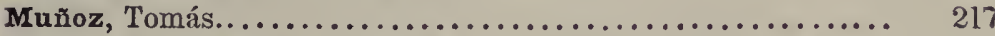

Muñoz, $V$. Keyser $\mathbf{y}$, Antonio de.

Munoz, $V$. Vicien $\mathbf{y}$, Vicente.

Murciano, $V$. Royo $\mathbf{z}$, José María.

Musso $\mathbf{8}$ Fontes, José.......................... 20

Musso y Valiente, José......................... 20

\section{IN.}

Naceyro, V. Rios, Francisco de los.

Naranjo y Garza, Felipe.

Navarrete, $\nabla$. Fernandez de, Francisco.

Navarrete, $\nabla$. Fernandez de, Martin.

Navarro Reverter, Juan...... 6 617, 659, 776, 795, 854, 948 y 9.56

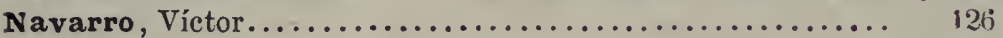

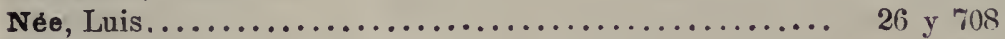

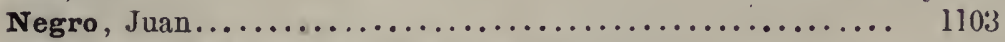

Nibbiano, V. Azara, Marqués de, Agustin de.

Nieva, José Maria de................... 86, 176 y 978

Nunez de Arenas, Bernardino................... 74 y 694

Nuñez de Avendaño, Pero...................... 48

Nuñez, V. Machado y, Antonio.

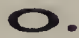

O-Farill, J. Ricardo........................ 993 
Ojeda y Siles, Manuel.

Orellana, Márcos Antonio.................... 88 y 96

Orense, José María........................... 819

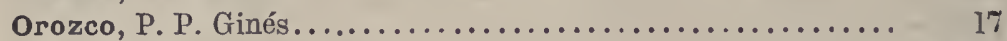

Orozco, Ramon................. 15, 16, 17, 128 у 387

Ortega, V. Gomez, Casimiro.

Ortiz, Gabriel............................ 978 у 992

Ortir, V. Vega y, Domingo de la.

Osquiguilea, Manuel de......................... ${ }^{-6} 68$

Oviedo de Valdés, $V$. Fernandez de, Gonzalo.

Oyuela, $V$. Revilla, Juan de.

Oyuela, $\nabla$. Revilla y, Manuel de.

Ozores, $V$. Valenzuela y, Antonio de.

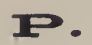

Palomares, $\nabla$. Lassala y, Vicente.

Paniagua, José María.............. 70, 309, 317, 505 y 532

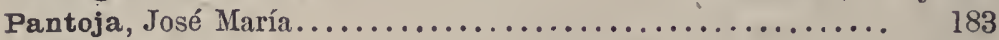

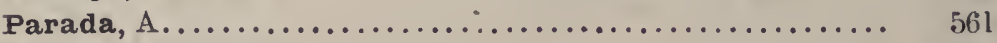

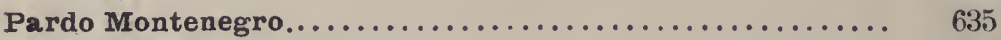

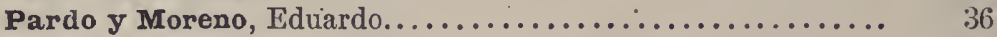

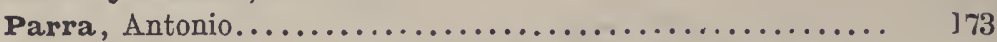

Pascual, Agustin.. $10,162,205,274,425,354,433,437,470$,

pa....... 893,927,928,929,943, 944 у 1080

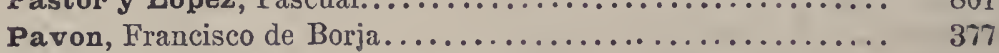

Paz, Principe de la............................. 438

Pedacio Dioscórides Anazarbeu.................. 402

Pedraza Gastan, Pedro de....................... 1011

Pellon y Rodriguez, Julian.................... 423

Peña, . Gonzalez de la, Pablo.

Pequeño, Diego.............................. 594

Peralta, $V$. Beaumont de Miras, Ricardo.

Perez de la Sala, Pedro.................... 779 y 1055

Perez Gutierrez, Manuel. ..................... 385

Perez Lasso de la Vega, Jorge.................... 1025

Perez Minguez, Luis....................... 314 y 755

Perez Quintero, Miguel Ignacio.................... 403

Perez Seoane, Manuel........................... 1025

Perez, $\nabla$. Fernandez y, Juan Zoilo. 
Perez Villaamil, Juan

Plera, $V$. Vilanova y, Juan,

Pinto y Velarde, V. Galvo, Agustin.

Plá y Ráve, Eugenio........................ 735 y 1067

Planellas, José........................ 548 y 881

Plinio Segundo, V. Gayo.

Pluche..................................... 198

Poio, Antonio............................... 1033

Ponte, Galo José de........................... 80.. 80.

Ponz, Antonio.........................

Portocarrero, V. Calero y, M.

Prieto, V. Blazquez.

Prieto, V. Miranda, Benito Ceferino.

Prieto s Prieto, N.......................... 1086

Puig, V. Mauri y, Ramon.

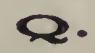

Quindós y·Baena, V. Alvarez de, Juan Antonio.

Quintana y Combis, Alberto de.................... 171

Quintanilla, V. Martinez, Pedro.

Quintero, V. Perez, Miguel Ignacio.

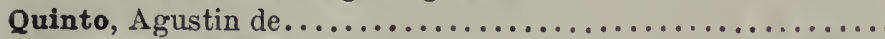

Quirós, V. Castilla y, Rafael.

\section{R.}

Ramirez Arcas, Antonio..................... 53 5.

Ramirez, Francisco.......................... 54

Ransault, $V$. Raul y de, Conde de.

Raul y de Ramsault, Conde de.................. \&

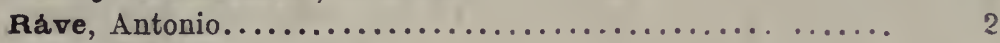

Ráve, V. Plá y, Eugenio.

Reche, Joaquin............................ 221

Redaccion de la Revista forestal, económica y agricola... 959 y 1043

Reguart, V. Sañez, Antonio.

Rementeria y Fica, Juan Mariano de................. 51

Reverter, $V$. Navarro, Juan.

Revilla Oyuela, Juan de....................... 700

Revilla y Oyuela, Manuel de...................... 1062

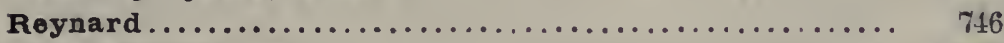

Rico y Sinobas, Manuel... ................... 349 
Rios Naceyro, Francisco de los

Rios, V. Fernandez de los, Angel.

Risueño, Manuel............................ 342

Rivero, Roque Leon del.................... 457 y 464

Rivero, Roque Miguel del....................... 1021

Robledo, V. Montejo y, Telesforo.

Robles, V. Martinez, Francisco Antonio.

Robles, $V$. Vila y, José María.

Roca, $V$. Barba y, Manuel.

Rodriguez, Gabriel.

Rodriguez, Tiburcio........................... 1034

Rodriguez, V. Pellon y, Julian.

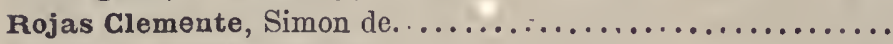

Rojas, $V$. Torre, Bernardo de la.

Romá, V. Fáges de, Narciso.

Romero Fernandez de Landa, Joseph.................

Romero Lopez, Agustin....................... $\quad 289$

Romero y Linares, Antonio....................... 807

Ronqulllo, José Oriol:......................... 164

Rossignon,.Julio.............................. $\quad 316$

Rossmaessler, E. Adolfo.......................... 2

Royo у Murciano, José María....................... 3

Rozier.................................... 138

Ruano Calderon, $\nabla$. Corte, Felipe de la.

Rubio, Leandro............................. 823

Rubio, V. Alvarez de Sotomayor y, Juan María.

Rueda, V. Diaz de, Ricardo.

Ruiz Amado, Hilarion............. 206, 277, 310, 501 у 661

Ruiz, José María......................... 903 y 910

Sabuco, Oliva................................ 1074

Sagra, Ramon de la.................... 251, 282 y 412

Sainz de Andino, Pedro....................... 1025

Sainz de Baranda, José................. 1096, 1099 y 1120

Sainz Gutierrez, Pedro........................ 347

Sainz Milanés, Julian...................... 27 у 400

Sainz y Gutierrez, Luis......................... 114

Sala, V. Perez de la, Pedro.

Salarich, Joaquin........................ 85 y $7: 34$

Salas, Antonio Felipe de....................... 984

Salas, J. Nicolás de............................ $\quad 490$

Salazar, V. Gomez de, Ignacio. 
Salinas, Alberto.............................. $\quad 330$

Salvá, Francisco............................. 1109

Salvà, M.............................. 786 у 820

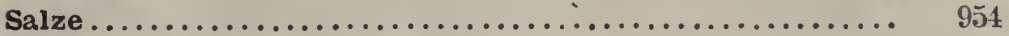

Sampayo, V. Carballo y, Diego.

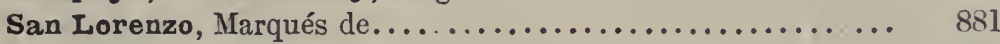

San Martin y Burgoa, Antonio de.................. 291

Sanchez Comendador, Antonio..................... 2

Sanchez Fano, Félix......................... 917

Sanchez Olmo, Diego........................... 134

Sancho, $\nabla$. Lopez de, Francisco.

Sangüesa, Francisco.......................... 999

Sangüesa, Mariano.............................. 225

Sans, Juan.................................. 217

Sant Fagund, Johan de........................ 1009

Santos, J. Emilio de............................ 662

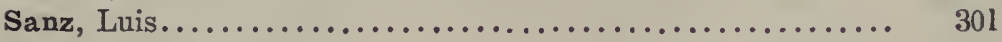

Sanz, $\nabla$. Garcia, José.

Sanz y Baeza, Florencio......................... $\quad 390$

Sañez Reguart, Antonio.......................... 165

Sañudo, Prudencio.......................... $819^{*}$

Sarmiento, Martin............ 626, 974, 975, 1026, 1036 у 1037

Satorras, Luis............................. 515 y 800

Saura, Francisco........................... $\quad 979$

Saurin, Vizconde de Huerta, V. Molina y, Alejo.

Sayas, V. Anton y, Gerónimo.

Scheidnagel, Leopoldo....................... 38 у 39

Segundo, $\nabla$. Cayo Plinio.

Senrra, Fernando de.......................... 983

Seoane, Juan Antonio........................ 327 у 424'

Seoane, V. Lopez, Víctor.

Seoane, V. Perez, Manuel.

Serna, Fernando de la.......................... 177

Serrano Belezar, Miguel......................... 689

Siles, V. Ojeda y, Manuel.

Sinobas, $\nabla$. Rico y, Manuel.

Sirvent, $\nabla$. Atienza y, Meliton.

Sisternes y Feliu, Manuel..................... 258 y 444

Sociedad académica y recreativa de Figueras.......... 52

Sociedad bascongada de los Amigos del País........ 190 y 226

Sociedad económica de Segovia.................... 5

Sociedad económica mallorquina ................. $\quad 360$

Sociedad económica matritense........ 24, 27, 361, 405 y 806

Sociedad económica valenciana............. 55,266 y 290 
Sociedad valenciana de Agricultura............... 13

Solans, Manuel.................................. 18

Soler, Julio................................ 219

Soler, V. Lopez.

Soler, $V$. Vidal y, Domingo.

Soler, $V$. Vidal y, Sebastian.

Sotomayor, $V$. Alvarez, Agustin.

Sotomayor, V. Valladares de, Antonio.

Sotnmayor, V. Zúniga y, Fadrique de.

Sotomayor y Rubio, $\nabla$. Alvarez de, Juan María.

Stromer.................................... $\quad 639$

Suarez, Miguel Gerónimo...................... 36.

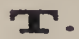

Tabern, Gerónimo........................ 857 у 973

Tablada, V. Hidalgo, José de.

Tamariz de $1 \star$ Escalera, Fernando.................. 525

Tames Hevia, Francisco. ...................... 425

Tenorio, José María............................ 49

Tirry y Lacy, Juan........................... 688

Tito Visino................................. 980

Tornos, Lucas de.. 335, 336, 337, 338, 339, 340, 382, 947, 950 y 1017

Torre kojas, Bernardo de la............ 267, 268, 272 y 456

Torres, Diego................................ $\quad 119$

Torres Solanot, Vizconde de..................... " 813

Torres Villarroel, Diego de................. 1075 y 1090

Tortosa y Gerdá, Vicente..................... 351

Tostado, Alfonso............................. 1013

Tovar, V. Velazquez de, Alonso.

Troche y Zúniga, Froilan..................... 100

\section{U.}

Ucelay, Gervasio.............................. 773

Ucero, Pedro................................. 877

Ugarte, Ramon................................ 694

Urquljo de Iraben, Francisco................. 50 y 324

\section{W.}

Valcárcel, Andrés de.......................... 434 Valcårcel, Joseph Antonio........... 11,940, 988, 1000 y 1001

Valdecebro................................ $\quad 242$ 
Valdés, Nicolás

Valdés, $\nabla$. Diaz de, Pedro.

Valdés, $V$. Fernandez de Oviedo de, Gonzalo.

Valenzuela y Ozores, Antonio de

Valiente, $\nabla$. Musso y, José.

Valier y Escartin, José.

Valladares de Sotomayor, Antonio

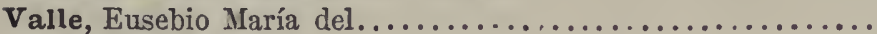

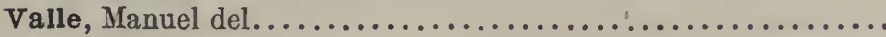

Vallejo, Eugenio................................ 134

Valles, Juan.................................. 1004

Valls d'Amprana, Aniceto....................... 699

Vargas Machuca, Bernardo....................... 367

Vaux, $V$. Gadet de.

Vega, $\nabla$. Madrid y Manrique de, Matías de la.

Vega, $\nabla$. Perez Lasso de la, Jorge.

Vega y Ortiz, Domingo de la................... 21 y 69

Velarde, $\nabla$. Calvo Pinto y, Agustin.

Velaz, $\nabla$. Fivaller de, José María de.

Velazquez de Tovar, Alonso...................... 1005

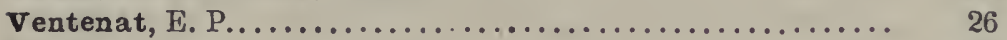

Ventué, Benito................................. 7606

Vergés y Almar, José.......................... 922

Vicien y Muñoz, Vicente........................ 987

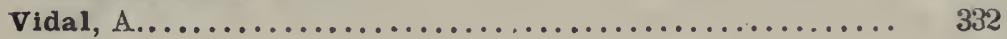

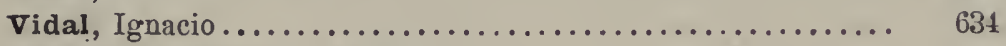

Vidal, $V$. Lacroix y, Joaquin.

Vidal y Mascaró, Juan Miguel..................... 538

Vidal y Soler, Domingo......................... 501

Vidal y Soler, Sebastian.............. 1017, 1071, 1087 y 1123

Vigo, $V$. Mendez de, Ignacio.

Vila y Robles, José M........................ 184

Vilamor, Antonio............................ 829

Vilanova y Plera, Juan.................... 288 y 333

Villaamil, V. Perez, Juan.

Villacampa, $\nabla$. Anton, Andrés.

Villalta, R................................ 1068

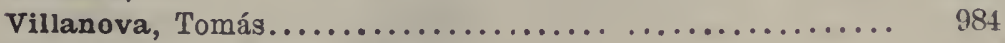

Villanueva, $\nabla$. Justo y, Luis.

Villanueva, $\nabla$. Laguna §, Máximo.

Villa-Real de Berriz, Pedro Bernardo................ 322

Villarroel, $V$. Torres, Diego de.

villota, Isidro de................................ 222

Villota, José..................................... 970 


\section{NOMBRES.}

Villota, Pablo de.................................. 222

Vifias, Miguel.............................. $\quad 713$

Visino, V. Tito.

\section{X.}

Xamarrs, Juan Bautista........................ 121

Xérica, Ramon de...........516, 558, 747, 764, 830, 874 y 1100

Ximenez, A................................ $\quad 769$

\section{$\mathbf{Y}$}

Yanguas, Juan................................ 918

Yanguas y Miranda, José....................... $\quad 318$

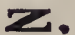

Zabala, F.................................. 642

Zacaria, V. Ahu.

Zaldidalvés, Pedro.............................. 629

Zamora y Aguilar, Juan......................... $\quad 810$

Zapata, Luis................................ 1606

Zornoza, Mauricio............................. 964

Zúniga, V. Troche y, Froilan.

Zúñiga y Sotomayor, Fadrique de................. 1065 


\section{INDICE DE MATERIAS.}

Páginas.

AdVERTENCha PREliminar............................ I

Primer grupo. - Publicaciones de todas clases................ 1

Segundo Grupo.-Memorias, arliculos y otros trabajos contenidos en

los periódicos y obras de materias diversas................ 153

TERCER GRUPO.-Manuscritos y trabajos gráficos inéditos......... 245

APÉNDICE.-Primer GruPo.-Publicaciones de todas clases....... 265

SEGUNDO GRUPO.-Memorias, articulos y otros trabajos contenidos en

los periódicos y obras de materias diversas................ 281

Observacion................................... 295

INDICE GENERAL de autores y traductores................... 297 



\section{ERRATAS.}

\begin{tabular}{|c|c|c|c|}
\hline Página. & Linea. & DICE. & DEBE DECIR. \\
\hline 1 & 23 & Roszmaeszler & Rossmaessler \\
\hline 5 & 7 & -4. & $1872 .-4 .^{\circ}$ \\
\hline 6 & 41 & de país & del pais \\
\hline 9 & 1 & gardines & jardines \\
\hline 29 & 42 & Marzo de 1859 & Marzo de 1859 al \\
\hline 30 & 38 & que llega & que llegan \\
\hline 32 & 8 & $-4 .^{\circ}$ & $1872 .-40^{\circ}$ \\
\hline 35 & 26 & ninchones & pinchones \\
\hline 38 & 2 & troductos & productos \\
\hline 40 & 37 & Conder & Couder. \\
\hline 42 & 7 & estas & estos \\
\hline 43 & 39 & GENERAES & GENERALES \\
\hline 48 & Rneaberamionto & DESERTACION. & DISERTACION. \\
\hline 52 & 36 & Otra & Obra \\
\hline 55 & 19 & Exposicion & Esposictor \\
\hline » & 40 & Extracto & Estracto \\
\hline 56 & 26 & debidos y & debidos á \\
\hline 63 & 3 & UNIVRSAL & UNIVERSAL \\
\hline * & 11 & Vascongada & Bascongada \\
\hline 65 & 19 & trasplantes & trasplantos \\
\hline 66 & 25 & GUARDIA & GUARDERIA \\
\hline 72 & 3 & Tiene & Se publicó en 1865. Tiene \\
\hline 77 & 32 & Burgos & Burgoa \\
\hline 80 & 34 & 1600. & $1600 ?$ \\
\hline 84 & 29 & Erascum & Erasum \\
\hline 8.j & 40 & Irabien & Iraben \\
\hline $90^{\circ}$ & 20 & aplicables, en & aplicables, con \\
\hline 94 & 37 & escrito & escrita \\
\hline 119 & 9 & 1861 & 1761 \\
\hline$"$ & 26 y 27 & las ñas & leñas \\
\hline 123 & 24 & 1867 & 1687 \\
\hline 131 & 42 & droducir & producir \\
\hline
\end{tabular}




\begin{tabular}{|c|c|c|c|}
\hline Página. & Lines. & DICE. & DEBE DECIR. \\
\hline 138 & 40 & Bicen & Biceu \\
\hline 164 & 29 & Bicen & Biceu \\
\hline 172 & 22 & abusos & abonos \\
\hline 177 & 32 & boyas & bayas \\
\hline 178 & 32 & dasanomia. & dasonomia \\
\hline 185 & 6 & anulándose & acumulándose \\
\hline 196 & 40 y 41 & chrysomeliuos & crisomelinos \\
\hline 206 & 44 & árabes, & árabe \\
\hline 207 & 22 y 23 & tardío & tardios \\
\hline 208 & 1 & moreras, se recomienda & moreras, recomienda \\
\hline 210 & 6 & en & con \\
\hline$\gg$ & 36 & Comercio, El Independiente & Comercio y El Independiente \\
\hline 212 & 24 & propuesto & pospuesto \\
\hline 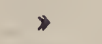 & 38 & $4.376,073$ & 1.376 .073 \\
\hline 224 & 1 & de & del \\
\hline$\gg$ & 41 & madera & maderas \\
\hline 225 & 15 & arca & área \\
\hline $229^{\circ}$ & 3 & absorben & absorven \\
\hline 237 & 18 & vez con & vez en \\
\hline 243 & 4 & En una & Es una \\
\hline 247 & 36 & MONTEAIA & MONTERÍA \\
\hline 248 & 5 & Senra & Senrra \\
\hline 261 & 36 & CÁRLOS Y & CÁRLOS V \\
\hline
\end{tabular}







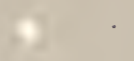





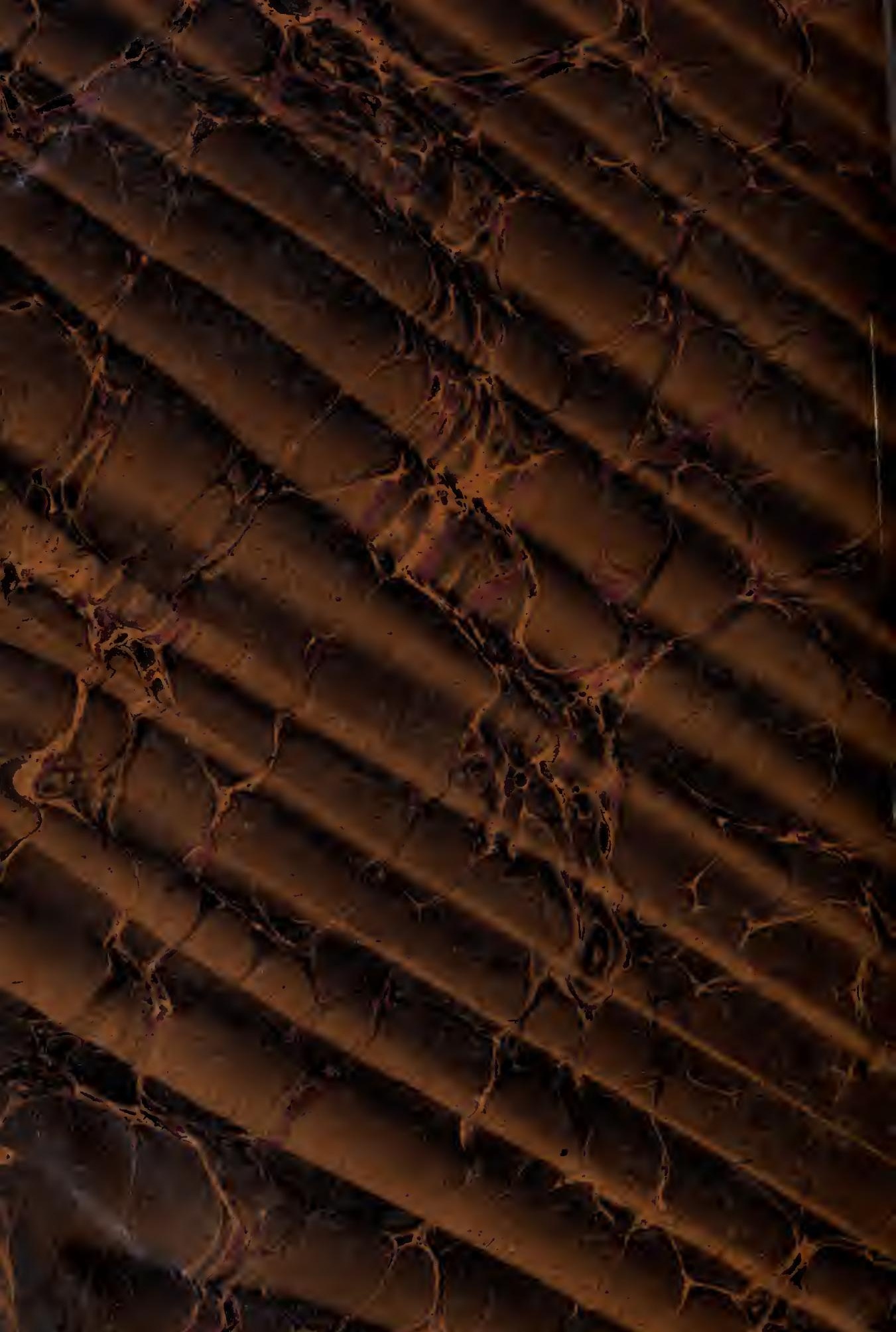


Jordana y Morera; José 5991 Apuntes bibliograficoJ74 forestales

PLEASE DO NOT REMOVE CARDS OR SLIPS FROM THIS POCKET UNIVERSITY OF TORONTO LIBRARY 
